\title{
EUBIN 2017
}

Congreso Internacional BIM / $6^{\circ}$ Encuentro de Usuarios BIM BIM INTERNATIONAL CONFERENCE

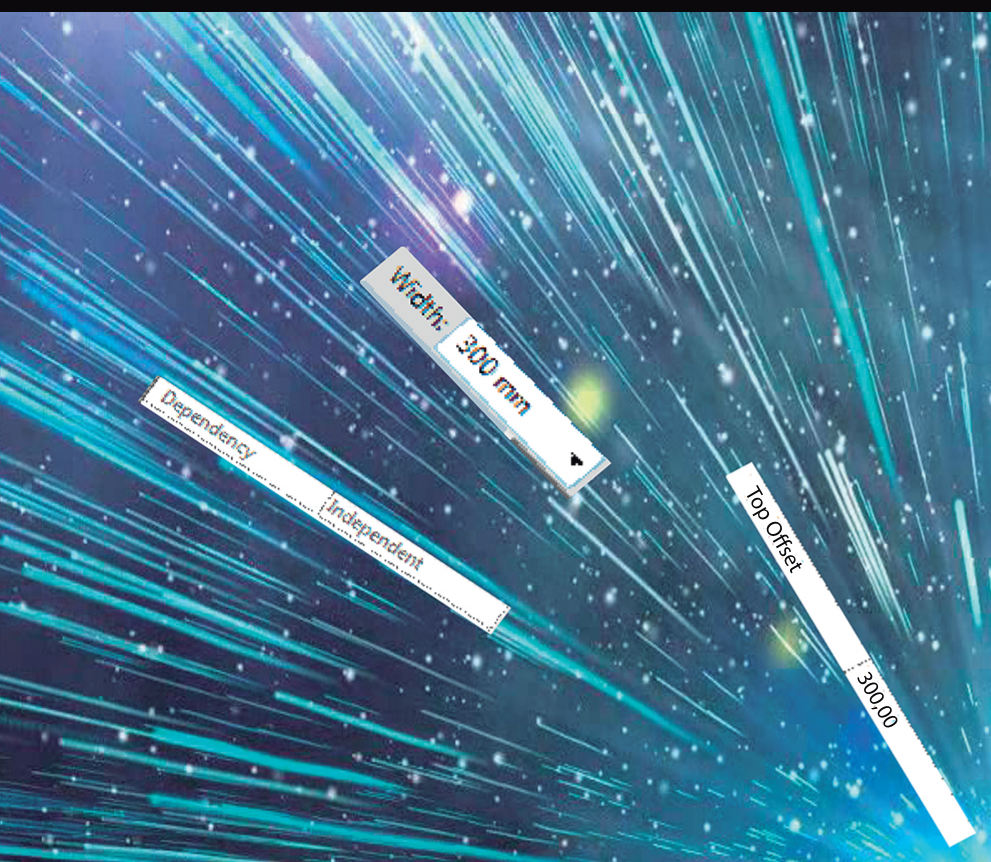

View Scale

$1: 50$
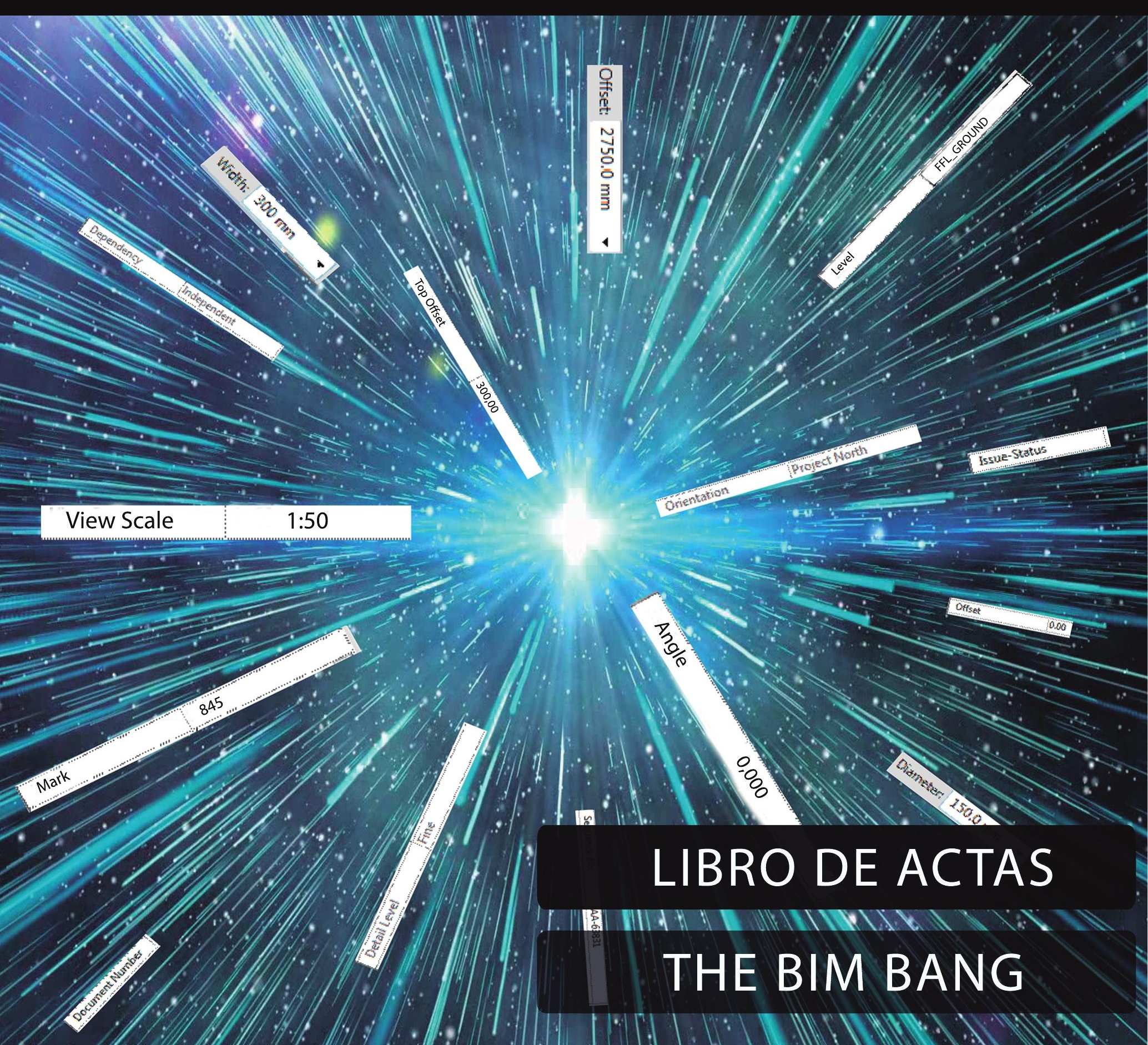

Organizadores:

Entidades Participantes:

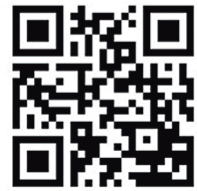

www.EUBIM.com

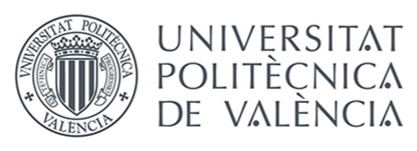

Congreso Patrocinado por:

\section{GURV}

(A) D'EDIFICACIO

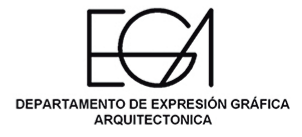

DEPARTAMENTO DE CONSTRUCCIONES ARQUITECTÓNICAS 



\section{EUBIM 2017}

\section{Congreso internacional BIM $6^{\circ}$ Encuentro de usuarios BIM}

Valencia, 19 y 20 de mayo de 2017 


\title{
Congresos UPV
}

EUBIM 2017. Congreso Internacional BIM / $6^{\circ}$ Encuentro de Usuarios BIM

Los contenidos de esta publicación han sido evaluados por el Comité Científico que en ella se relaciona y según el procedimiento que se recoge en http:///www.eubim.com

\section{Editoras científicas}

Inmaculada Oliver Faubel

Begoña Fuentes Giner

\section{Comité Editorial}

\author{
Manuela Alarcón Moret \\ Alberto Cerdán Castillo \\ Amparo Ferrer Coll \\ David Martínez Gómez \\ Lorena Soria Zurdo \\ José Suay Orenga \\ David Torromé Belda
}

Sergio Vidal Santi-Andreu

\section{Editorial}

Editorial Universitat Politècnica de València

www.lalibreria.upv.es / Ref.: 6404_01_01_01

DOI: https://dx.doi.org/10.4995/EUBIM2017.2017.11808

ISBN: 978-84-9048-623-8

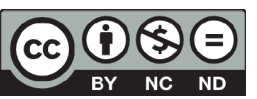

EUBIM 2017. Congreso Internacional BIM / $6^{\circ}$ Encuentro de Usuarios BIM.

Se distribuye bajo una licencia de Creative Commons Reconocimiento-NoComercial-SinObraDerivada 4.0 Internacional.

Basada en una obra en http://ocs.editorial.upv.es/index.php/EUBIM/EUBIM2017 


\title{
PRESENTACIÓN
}

\section{EUBIM 2017: THE BIM BANG}

\author{
"Toda tecnología tiende a crear un nuevo entorno humano... Los entornos \\ tecnológicos no son meramente pasivos recipientes de personas, son procesos \\ activos que reconfiguran a personas y a otras tecnologías similares" \\ Marshall McLuhan (1911-1980) Filósofo, erudito y profesor canadiense
}

Building Information Modeling (BIM) no es el fin último. Es el medio por el que (ipor fin!) el sector de la construcción entrará en el s. XXI y tendrá su particular revolución industrial/digital.

BIM es una necesidad, una demanda, un anhelo de todos los que hemos desarrollado nuestra actividad profesional en el ámbito de la construcción. Resulta insufrible que el proceso diseño-licitación-construcción-explotación constructivo sea tan impreciso, tan sensible a cualquier variación de las condiciones intrínsecas y extrínsecas del propio proceso, tan sujeto a criterios arbitrarios cambiantes a lo largo de su desarrollo, tan poco eficaz y eficiente en sí mismo y en sus resultados...

Podría llamarse BIM o de cualquier otra forma, pero la mejora cualitativa que aporta a nuestra industria era necesaria. Nos proporciona orden, coherencia, confianza en la información. Pone a nuestra disposición un conjunto de herramientas que añaden valor y validan nuestro conocimiento y saber hacer como agentes del proceso constructivo. Aporta base objetiva para la toma de decisiones y discusiones sobre la mejora del proceso y del producto final resultante. $Y$ algo hasta ahora poco habitual en nuestro entorno: aporta precisión, exactitud, fiabilidad en todo el ciclo de vida.

Pero como dice la cita que hemos querido que encabece esta presentación, la tecnología tiende a crear un nuevo entorno humano. Y la tecnología BIM ha facilitado un nuevo salto cualitativo hacia nuestra particular revolución industrial/digital: la colaboración y el trabajo cooperativo. Por primera vez tenemos la oportunidad de no trocear y repartir el proyecto (y sus consecuentes responsabilidades) entre los agentes participantes, sino que todos trabajamos en conjunto, con el mismo objetivo, al unísono, consiguiendo que el resultado obtenido sea mejor que la suma de las partes intervinientes. El desarrollo horizontal y transversal del proyecto constructivo es uno de los grandes cambios de paradigma que proporciona el actual estatus tecnológico.

Como en toda comunidad de nueva formación alrededor de la posibilidad de hacer las cosas de forma diferente, nos descubrimos necesitando reconfigurar el idioma (nosotros diríamos los distintos idiomas) que hemos venido utilizando hasta ahora, necesitamos igualmente reconfigurar de nuevo los roles, funciones, responsabilidades, metodologías y flujos de trabajo y de comunicación, necesidades, requisitos y objetivos que hemos heredado del modelo tradicional y perpetuado hasta nuestros días. Hemos de dotarnos de un nuevo orden, de un nuevo diccionario para el idioma común, de unos nuevos estándares sobre los que hacer posible nuestro trabajo colaborativo y cooperativo. No es tarea fácil. Llevamos en nuestro ADN el modelo y los procedimientos tradicionales de trabajar. Necesitamos ejercitarnos en el cambio de mentalidad y, lo más importante, no tener miedo a equivocarnos. Los errores que podamos cometer apuntalarán nuestro camino hacia la era digital.

La transición en la que nos encontramos ahora mismo es un camino plagado de peligros, equívocos, indeterminación de algunos y búsqueda del beneficio rápido de otros. Corremos el riesgo de desvirtuar el fin último de esta revolución; de que los árboles no nos dejen ver el 
bosque y (añadimos) el horizonte que hay detrás y al que debemos luchar por llegar. Dicen en Star Wars: Rogue One que "las revoluciones se basan en la esperanza". Nuestra esperanza es que todo este ingente esfuerzo que estamos realizando entre todos nos lleve a una mejor reconfiguración del proceso constructivo, más acorde a los tiempos que vivimos y venideros, un proceso orientado a dar respuesta adecuada a las exigencias que la sociedad (clientes, usuarios y ciudadanos pagadores de impuestos) nos demandan de nuestro noble oficio de construir.

Seguimos creyendo que la esperanza y los fieles guardianes de esta revolución son los Grupos de Usuarios BIM que han ido surgiendo a lo largo y ancho de nuestro país. Los que están (estamos) en el día a día dando sentido y dirección al proceso de cambio. Y esa es la esencia de EUBIM. Somos fieles a los principios con los que nació este proyecto: difusión de BIM en todas sus dimensiones (tecnológica, de procesos y metodológica), saber qué están haciendo las empresas y profesionales del sector que trabajan dentro de este nuevo paradigma. Darles la voz y el protagonismo que merecen. Este es un congreso donde tienen la palabra los verdaderos artífices de la revolución. Da lo mismo si el procedimiento es bottom-up o top-down. EUBIM es el espacio de encuentro de los usuarios BIM, de los auténticos conocedores de los retos y dificultades que esta revolución conlleva. Y, como siempre, desde el voluntariado, sin afán de negocio o lucro. Todos los años nos enfrentamos al mismo reto de ofertar un pack completo de networking, difusión y aprendizaje BIM a precio de coste.

En esta edición de 2017 abrimos un nuevo espacio a los ya tradicionales de nuestro congreso: una exposición donde cualquier profesional o empresa puede exponer y dar a conocer sus trabajos desarrollados en BIM. Deseamos que esta nueva opción de difusión crezca y se consolide en las futuras ediciones.

Nos sentimos orgullosos de trabajar para que EUBIM siga siendo el lugar de encuentro BIM más abierto, horizontal, democrático, transversal y enriquecedor del panorama nacional y europeo. Nuestro esfuerzo como Comité Organizador siempre va encaminado en este sentido. Y el rigor y calidad de la que nos nutrimos viene generosamente aportado por todos sus participantes y por el trabajo que realiza nuestro Comité Científico. Y todo ello no sería posible sin la aportación de nuestros patrocinadores, que son los que finalmente facilitan que podamos realizar una nueva edición de nuestro (vuestro) congreso.

También estamos convencidos de que debemos de someter a la opinión de nuestros participantes nuestra labor organizativa, pidiéndoles que, tras cada edición, nos evalúen, nos pongan nota, nos digan qué aspectos mejorar y hacia dónde deberíamos trabajar. Y recogemos todas sus opiniones y las intentamos plasmar en la siguiente edición.

En resumidas cuentas, nos sentimos orgullosos de "hacer BIM" también en la organización de EUBIM. Y nos emociona detectar el mismo orgullo en vosotros, nuestros compañeros y compañeras de revolución. Ser EUBIM es una actitud, un posicionamiento en este proceso de cambio. Frente al postureo, el arribismo y el oportunismo, ser EUBIM es formar parte de la Alianza, la que está propiciando y haciendo realidad el BIM Bang. Habrá otros eventos BIM, pero ninguno es EUBIM.

Bienvenido, bienvenida, a tu congreso BIM, a tu lugar de compartición, disfrute y encuentro con tus iguales.

Esto es EUBIM 2017.

El Comité Organizador de EUBIM 2017 


\section{COMITÉ INSTITUCIONAL}

- Rector Magnífico de la Universitat Politècnica de València, D. Francisco J. Mora Mas.

- Presidente del Grupo de Usuarios Revit Valencia (GURV), D. Alberto Cerdán Castillo.

- Director de la ETSIE UPV, D. Francisco Javier Medina Ramón.

- Director de la ETS de Arquitectura UPV, D. Iván Cabrera i Fausto.

- Director del Departamento de Constr. Arquitectónicas UPV, D. José Ma Fran Bretones.

- Director del Dep. de Expresión Gráfica Arquitectónica, D. Pablo Navarro Esteve.

\section{COMITÉ CIENTÍFICO}

- Francisco Ballester Muñoz (Universidad de Cantabria)

- Alberto Cerdán Castillo (Consultor BIM)

- Eloi Coloma Picó (Universitat Politècnica de Catalunya)

- Ernesto Faubel Cubells (Universitat Politècnica de València)

- Ángel José Fernández Álvarez (Universidade da Coruña)

- Begoña Fuentes Giner (Universitat Politècnica de València)

- Jaume Gimeno Serrano (Universitat Politècnica de Catalunya)

- Francisco Hidalgo Delgado (Universitat Politècnica de València)

- Óscar Liébana Carrasco (Universidad Europea de Madrid)

- Vicente Olcina Ferrándiz (Universitat Politècnica de València)

- Inmaculada Oliver Faubel (Universitat Politècnica de València)

- Miguel Rodríguez Niedenführ (Universitat Politècnica de Catalunya)

- Rafael Sánchez Grandía (Universitat Politècnica de València)

- José Antonio Vázquez Rodríguez (Universidade da Coruña)

- Augusto Mora Pueyo (Universidad de Zaragoza)

- Juan Luis Pérez Ordoñez (Universidade da Coruña)

- Beatriz Inglés (Universidad Europea de Madrid)

- José Jurado (Universidad Europea de Madrid)

- Jesús Alfaro (Universidad de Castilla -La Mancha)

- Patricia del Solar (Universidad Europea de Madrid; Universidad Politécnica de Madrid)

- Norena Martí Dorta (Universidad de La Laguna) 


\section{TEMAS DEL CONGRESO}

Continuando con las líneas de investigación y divulgación que fueron tratadas durante el Congreso Nacional BIM (EUBIM 2013, 2014, 2015 y 2016), hemos elegido y estamos interesados este año en recibir comunicaciones originales sobre:

\section{BIM EN LA UNIVERSIDAD}

\section{DISEÑO Y CONSTRUCCIÓN CON BIM}

\section{EXPERIENCIAS REALES CON BIM}




\section{BIM EN LA UNIVERSIDAD}

Creemos que la Universidad debe ser un agente de cambio fundamental en la divulgación, formación e investigación de nuevas metodologías de gestión de proyectos de construcción. Los futuros profesionales del sector deberían finalizar sus estudios con un nivel competencial suficiente tanto en el conocimiento de estas metodologías como en el dominio de sus herramientas de aplicación. Del mismo modo, el fomento y obtención de resultados de investigación sobre este campo lo consideramos fundamental para la necesaria evolución de nuestro sector productivo.

\subsection{Investigación}

Comunicaciones originales resultantes de un trabajo de investigación (ya finalizado o en progreso) centrado en BIM o donde la metodología BIM juega un papel fundamental en la investigación.

En este campo están invitados a presentar comunicaciones autores de tesis doctorales, trabajos final de máster, proyectos final de grado y grupos de investigación o investigadores a título individual o colectivo.

\subsection{Formación}

Comunicaciones originales resultantes de la experiencia real de programar e implementar en el currículo de asignaturas regladas de grado y postgrado herramientas BIM: objetivos, posibilidades e inconvenientes, metodología formativa, trayectoria, resultados, futuro.

Comunicaciones originales resultantes de la experiencia real de programar e implementar el aprendizaje de herramientas BIM en formación continua, tanto en cursos específicos como seminarios de naturaleza académica y técnica: objetivos, posibilidades e inconvenientes, metodología formativa, trayectoria, resultados, futuro.

En este campo están invitados a presentar comunicaciones tanto el profesorado universitario como formadores BIM fuera del ámbito universitario que deseen presentar su experiencia docente específica en la formación y el proceso aprendizaje enseñanza de herramientas BIM.

\subsection{Empleabiblidad}

Las salidas profesionales y las nuevas profesiones creadas como consecuencia del empleo de la metodología BIM en la gestión de proyectos de construcción.

Nos gustaría recibir comunicaciones originales sobre las expectativas de empleabilidad que puede tener el dominio de la metodología BIM, los requisitos de formación y capacidades que solicitan los empleadores y casos reales de profesionales que han encontrado empleo gracias a sus conocimientos en BIM: localización de la oferta de empleo, requisitos solicitados, demostración de competencias y capacidades del aspirante durante el proceso de selección, etc. 


\section{DISEÑO Y CONSTRUCCIÓN CON BIM}

Evolución de la edificación y construcción, costes y presupuestos con el diseño en BIM. Algunos de estos aspectos se pueden gestionar con programas BIM, para optimizar los costes y el funcionamiento tanto de los inmuebles como de los servicios.

Las comunicaciones pueden incidir en cómo el BIM puede influir en los procesos de:

\subsection{Costes, mediciones y presupuestos}

En el ámbito del diseño y construcción con BIM destacamos los procesos de costes, mediciones y presupuestos.

\subsection{Gestión de las TI}

El uso del BIM para el mantenimiento de las infraestructuras tecnológicas y gestión de su información incluida su relación con otros elementos del edificio estructurales o no.

\subsection{Gestión de los espacios}

Ejemplo de ello es la necesidad actual de crear completos catálogos que permitan a los usuarios disponer de todos los servicios que pueden ser ofrecidos y soportados por la infraestructura, como la reserva de salas, petición de catering, gestión de plazas de aparcamiento, petición de mudanzas y traslados, gestión de llaves, gestión de visitas y un largo etcétera que varía según las posibilidades de cada organización.

\subsection{El mantenimiento de los activos, mantenimiento preventivo y correctivo}

Para planes de mantenimiento operativo (tareas que permiten mantener un activo funcionando y en un estado óptimo) o mantenimiento basado en el estado ( $y$ no de una periodicidad arbitraria) que permiten alargar los ciclos de vida de los activos, disminuyendo el número y la gravedad de incidencias, y a la larga, reducir los costes derivados de ellos.

\subsection{Aplicaciones de las nubes de puntos}

Escaneado y reproducción de espacios mediante nubes de puntos a aplicaciones BIM y su relación con el Facility Management.

\subsection{Facility Management}

Evolución del Facility Management gracias a la influencia del BIM y sus posibilidades.

\subsection{Metodologías BIM al servicio del FM}

Cómo el uso del BIM se convierte en una ventaja estratégica para la empresa de Facility Management.

\subsection{Propiedad y Legalidad en BIM}

Aspectos legales y de Propiedad Industrial e Intelectual dentro de BIM. 


\subsection{Conexión de programas BIM con bases de datos y BMS}

Posibilidades de conexión y beneficios prácticos que ofrece el uso del software BIM junto con diferentes bases de datos y por otra parte con building management systems 0 sistemas de gestión de edificaciones, domótica y automatización integral de inmuebles con alta tecnología basado en software y hardware de supervisión y control instalado en edificios.

\subsection{El papel del BIM en las smart cities}

Utilidades de la metodología BIM en las futuras Smart cities y el papel que puede desempeñar o cómo puede contribuir a conseguir ciudades súper-eficientes y sostenibles. Todo ello desde el punto de vista de cómo puede contribuir el BIM a una supervisión optimizada del espacio de la ciudad, a la relación interactiva y móvil entre sus habitantes o el desarrollo y promoción de nuevas formas de cooperación entre otros.

\subsection{Normalización}

Cualquier estudio o reflexión sobre aspectos o elementos que deban ser considerados en el desarrollo de los estándares para una implantación del BIM a nivel nacional. Como propuestas de estándares, formatos de intercambio, propuesta de documentos, opciones de digitalización, roles y perfiles profesionales, certificaciones, etc...

\subsection{Programación Visual y Desarrollo de aplicaciones vía API}

Estudios y aplicaciones de programación visual o desarrollo de aplicaciones via API en cualquier plataforma y con cualquier herramienta para BIM que facilite la manipulación de datos, el modelado de geometrías estándar o complejas, explorar opciones de diseño, automatizar procesos, y crear vínculos entre múltiples aplicaciones.

\subsection{Realidad Virtual, Realidad aumentada y Realidad Mixta}

Estudios y usos de la información dentro del modelo BIM para diferentes aplicaciones enfocados a una realidad tridimensional / virtual o real. 


\section{EXPERIENCIAS REALES CON BIM}

Experiencias reales tras la utilización de BIM como metodología de trabajo, control de la información generada en relación a una construcción, durante todo su ciclo de vida. El uso del BIM va asociado a grandes cambios y por lo tanto se suele encontrar resistencia al mismo, y no siempre termina con el final deseado si no se realiza adecuadamente.

Este sería el tema más práctico del congreso y estamos interesados en información sobre:

\subsection{Experiencias reales}

Testimonios de empresas locales que hayan implementado el BIM como metodología de trabajo, incluyendo la descripción del proceso que les ha posibilitado la adopción de esta nueva metodología, los problemas que han tenido que superar y los resultados obtenidos.

\subsection{Casos de éxito}

Redundando sobre el apartado anterior, buscamos información sobre los beneficios obtenidos como consecuencia de esta implementación, sobre todo en el terreno las nuevas oportunidades de negocio aportadas a la empresa como conciencia de la adopción de la metodología BIM como procedimiento de trabajo.

\subsection{Coordinación entre diferentes agentes del proceso constructivo}

Soluciones de coordinación entre los diferentes agentes que intervienen en el proceso constructivo en nuestro país.

\subsection{Procesos}

Nuevos procesos tras la utilización de BIM como metodología de trabajo en una empresa.

\subsection{Adaptación de Flujos de Trabajo}

Adaptación de los flujos de trabajo existentes en una empresa a los nuevos requeridos como consecuencia de la implementación BIM.

\subsection{Generación de documentos de Construcción}

Cambios en la documentación de construcción generada como consecuencia de la inclusión de nuevos métodos de producción de la misma. 


\section{ÍNDICE DE COMUNICACIONES Y PONENCIAS}

\section{BIM EN LA UNIVERSIDAD}

- PONENCIA BIM EN LA UNIVERSIDAD:

BIM GAME - UN ENFOQUE MULTINACIONAL PARA IMPLEMENTAR BIM EN LA FORMACIÓN PROFESIONAL

Autores: Helmus, Manfred; Großer-Arnault, Rasa; Kelm, Agnes; Meins-Becker, Anica; Pütz, Carla; José Antonio Cuba Segura; Christian Heins.

- MODELOS PARA LA DOCENCIA DEL BIM: EL GARAGE CATASÚS, DE JOSÉ ANTONIO CODERCH.

Autores: Valderrama, Fernando; Guadalupe, Rafael; Ramírez, Carolina; Muñoz, Efraín.

- BIM: PAUTAS ESTRATÉGICAS PARA LA REGENERACIÓN DEL MÉTODO DOCENTE EN LAS ESCUELAS DE ARQUITECTURA.

Autores: Aldeanueva-Fernández, Mercedes; García-Marín, Alberto; Barrios-Corpa, Jorge; de la Torre-Fragoso, Ciro.

- MODELADO Y SIMULACIÓN ENERGÉTICA DE EDIFICIOS EN ENTORNO BIM. Autores: Pérez Andreu, Víctor; Castilla Pascual, Francisco Javier.

- PRESENTE Y FUTURO DE LA IMPLANTACIÓN DE LA METODOLOGÍA BIM EN LA ESCUELA TÉCNICA SUPERIOR DE ARQUITECTURA Y EDIFICACIÓN UPCT.

Autores: Pérez Navarro, Julián; Pérez Egea, Adolfo; Vázquez Arenas, Gemma.

- EMPLEO DE METOdOLOGÍAS BIM EN ASIGNATURAS DE CONSTRUCCIÓN DEL GRADO EN ARQUITECTURA TÉCNICA.

Autores: Piedecausa-García, B.; Pérez-Sánchez, V.R.; Mora-García, R.T; Pérez-Sánchez, J.C.

- ANÁLISIS, MODELIZACIÓN Y SEGUIMIENTO DE DEFORMACIONES ESTRUCTURALES MEDIANTE ESCÁNER LÁSER Y SU IMPLEMENTACIÓN BIM.

Autores: Cos-Gayon López, Fernando; Carlos Aleixandre Lluesma; Cordón Llácer, Joan; Anquela Julián, Ana Belén; Ángel Martín Furones.

- APlicación de la metodología bim en un PROYECto final de CARRERA. Autores: Oya Sala, Tania; Torres Marrades, Raquel.

- EXPERIENCIA dOCENTE de INTEgRAción de METOdología biM PARA el CONCURSO BIM VALLADOLID 2016

Autores: Cañizares Montón, Jose Manuel; Alfaro González, Jesús; Valverde Cantero, David; Martínez Carpintero, Jesús Ángel; Pérez González, Pedro Enrique.

- EXPERIENCIA DE IMPLEMENTACIÓN DE LA METODOLOGÍA BIM EN IFRN.

Autores: Giesta Pinto, Josyanne; Menezes Batista de, Gilda.

- implementación de la metodología bim en Educacion superior de AEC. Autora: García Granja, María Jesús.

- ESTUDIO SOBRE EL GRADO DE IMPLANTACIÓN DEL BIM EN LA INGENIERÍA CIVIL EN ESPAÑA.

Autores: Lucio Iglesias, Daniel; Del Solar Serrano, Patricia; Vivas Urías, María Dolores; Vilardaga Rodrigo, Iván; Liébana Carrasco, Óscar. 


\section{DISEÑO Y CONSTRUCCIÓN CON BIM}

- ponencia tema diseño y construcCión CON BIM BIM, PRECURSOR DE UNA GESTIÓN INDUSTRIALIZADA DE LA CONSTRUCCIÓN Ponentes: Carranza, Pablo; Santos, Salazar.

- UtILIZACIÓN DEL ALMACENAMIENTO EXTENSIBLE DE AUTODESK@ REVIT'TM PARA ALMACENAR Y CONSULTAR DOCUMENTACIÓN NO GRÁFICA EN OBJETOS BIM. Autores: Abellán Alemán, José María

- GESTIÓN DE AUSCULTACIÓN Y SEGURIDAD DE PRESAS CON BIM. Autor: Hoppe, Stefan.

- ANÁlisis del CICLO dE VIDA IMPLEMENTADO EN PLATAFORMAS BIM. ÚlTIMOS AVANCES.

Autores: Ruiz Alfonsea, Marta; Gómez de Cózar, Juan Carlos; Llatas Oliver, Carmen; García Martínez, Antonio.

- PROPUESTA METOdOLÓgICA PARA LA IMPLEMENTACIÓN DE LA INFORMACIÓN GEOTÉCNICA EN MODELOS BIM.

Autores: Martínez-lbáñez, Víctor; Pellicer, Eugenio.

- AEROFOTOGRAMETRÍA ESTEREOSCÓPICA: ESTUdIOS TRIDIMENSIONALES Y BUILDING INFORMATION MODELING.

Autores: Carrato Gómez, Alfredo; Carmona Ayuela, Covadonga.

- USO de bIM EN LA FASE PRELIMINAR DEL DISEÑO ARQUITECTONICO. ESTADO DEL ARTE.

Autores: Folgar Erades, Alejandro; Vázquez Vicente, Enrique; Sánchez Sánchez, José.

- REALIDAD VIRTUAL COMO HERRAMIENTA PARA EXPERIENCIAS INMERSIVAS APLICADAS A UNA PLANTA INDUSTRIAL.

Autores: Santamarta Martínez, Jaime; Panadero Jiménez, Álvaro.

- gESTIÓN DE LA INFORMACIÓN A TRAVÉS DE DATOS ENLAZADOS PARA EL REDISEÑO DE UNA ESTACIÓN DE BOMBEO EN HOLANDA.

Autores: Malvar Gómez, Víctor; Moreno Barbero, Patricia; Kuppens, Johan.

- PLANIFICACIÓN BIM 4D EN LA REHABILITACIÓN DEL SALÓN DE REINOS.

Autores: Muñoz Pardo, Efraín; Guadalupe García, Rafael; G. Valderrama, Fernando; Ramírez, Carolina.

- empleo de la metodología bim en pRocesos de inVEntario físico de CENTRALES NUCLEARES.

Autores: de Paz Sierra, Jesús; Ballester Muñoz, Francisco; Rico Arenal, Jokin. 


\section{EXPERIENCIAS REALES CON BIM}

- PONENCIA TEMA EXPERIENCIAS REALES CON BIM: CON BIM DESDE PEQUEÑOS MODELOS HASTA MEGA PROYECTOS Ponente: Janek, Pfeifer.

- GUIAS PROPIAS DE BIM PARA LA GESTIÓN DE PORTFOLIO.

Autores: Di Giuda, Giuseppe Martino; Re Cecconi, Fulvio; Dejaco, Mario Claudio; Villa Valentina; Maltese, Sebastiano.

- FOMENTO ESTRATÉGICO DE CITOPIC A LA METODOLOGÍA BIM.

Autores: Perea Mínguez, Rafael; Dueñas Abellán, Carlos; Bielsa Artero, Alicia María.

- RETOS EN LA IMPLANTACIÓN DE BIM EN LA INGENIERÍA CIVIL Y PROPUESTAS PARA ACELERAR SU APLICACIÓN.

Autores: Martínez-Ibáñez, Víctor; Pellicer, Eugenio; Alcobendas, Julio; Casado, Sergio.

- IMPlementación de Gestión DE PEQUeÑos PROYECTOS DE REFORMA MEDIANTE LA METODOLOGÍA BIM.

Autores; De Frutos Ramírez, Adolfo; Liébana Carrasco, Oscar; Cabrero Seral, Juan Carlos.

- CÓMO ESTABLECER UNA ESTRATEGIA VENCEDORA EN UN PROCESO BIM. Autores: Reina Rojas, Andrea; Sarrocco, Matteo.

- LA CODIFICACIÓN EN EL FLUJO DE TRABAJO: DE LA GESTIÓN AL PARÁMETRO EN LA ESTACIÓN FERROVIARIA DE TELDE.

Autores: Céspedes Sánchez, Susana ; Alonso Guinea, David; Santamarta Martínez, Jaime.

- INVENTORY BIM DE INFRAESTRUCTURAS DE LA UNIVERSIDAD DE SEVILLA Autores: Gómez Rodríguez, Matías; Cortés Albalá, Isidro; Nieto Julián, Enrique. 

EUBIM 2017

Congreso Internacional BIM / $6^{\circ}$ Encuentro de Usuarios BIM

BIM International Conference

EUBIM

Escuela Técnica Superior de Ingeniería de Edificación

Universitat Politècnica de València

Valencia, 19 y 20 de mayo 2017 



\section{THE BIM GAME: DE LAS POLÍTICAS DE INTEGRACIÓN DE BIM A LA FORMACIÓN DE LOS FUTUROS PROFESIONALES DE LA CONSTRUCCIÓN}

\section{PÜTZ, Carla (1); CUBA SEGURA, José Antonio (2); HEINS, Christian (3); HELMUS, Manfred (4); MEINS-BECKER, Anica (5); KELM, Agnes (6); GROßER-ARNAULT, Hasar (7)}

(1) University of Wuppertal - puetz@uni-wuppertal.de

(2) Escuela Nacional Superior de Arquitectura de Lyon - jose.cuba@lyon.archi.fr

(3) Jade Hochschule - christian.heins@jade-hs.de

(4) University of Wuppertal, helmus@uni-wuppertal.de

(5) University of Wuppertal, a.meins-becker@uni-wuppetal.de

(6) University of Wuppertal, kelm@uni-wuppetal.de

(7) University of Wuppertal, großer-arnault@uni-wuppetal.de

\section{RESUMEN}

BIM describe un nuevo método para integrar y conectar todos los datos relevantes relativos a la construcción en un modelo de datos virtual durante todo el ciclo de vida de un edificio. Además de los retos para encontrar soluciones técnicas y definir procesos para la digitalización de los edificios (y de la colaboración entre oficios), un tercer aspecto a considerar es las personas que trabajan con BIM. A diferencia del sector industrial, los hábitos laborales (y su necesaria articulación o convergencia) siguen siendo fundamentales para un proyecto de construcción. Sin involucrar y entrenar a la gente en la progresión del método, no tendrá éxito. Por lo tanto, la cuestión es cómo entrenar a los estudiantes actuales y futuros, así como a los profesionales de manera efectiva.

Como muchos países europeos actualmente implementan el método, el proyecto pretende beneficiarse de la experiencia de los países participantes con BIM y especialmente BIM en el campo de la formación. Con una plataforma en línea que incluye escenarios realistas, se desarrolla una herramienta de aprendizaje práctico. Todas las categorías profesionales involucradas en el proceso de construcción pueden participar en el BIM Game en grupos nacionales o internacionales. El juego se centra en la colaboración de los estudiantes y los anima a interactuar con otros. Esto ayuda a los estudiantes a aceptar y entender los diferentes puntos de vista y métodos de trabajo de los participantes del proyecto de construcción, así como la diversidad cultural de los interesados.

Palabras clave: Building Information Modeling, digitalization, construction, qualification, communication platform

\section{ABSTRACT}

BIM describes a new method to integrate and connect all relevant building related data into a virtual data model across the whole lifecycle of a building. Apart from the challenges of finding technical solutions and defining processes for the digitalization of the building sector, 
a third aspect to contemplate on is the people working with BIM. In constrast to the industrial sector, the human aspect is still fundamental for a construction project. Without involving and training people in the progression of the method, that method will not be successful. Hence, the question arieses how one would train current and future students as well as professionals effectively.

As many European countries currently implement the method, the project aims to benefit from the participant countries experience with BIM and especially BIM in the field of training. With an online platform including realistic scenarios, a practical learning tool is developed. All professional categories which are involved in the building process can take part in the BIM Game in national or international groups. The game focusses on the collaboration of learners and encourages them to interact with one another. This helps learners to accept and understand the different viewpoints and working methods of building project participants as well as different cultures.

Keywords: Building Information Modeling, digitalization, construction, qualification, communication platform

\section{INTRODUCCIÓN}

\section{$1.1 \quad$ El Origen del Proyecto}

El desarrollo del BIM en las diferentes áreas del sector de la construcción es un hecho. A nivel mundial, muchos países desarrollan diferentes políticas de integración del proceso BIM es sus diferentes legislaciones y reglamentos. En Europa, varios países se han lanzado en la integración progresiva de BIM. Finlandia, Noruega y el Reino Unido son siempre son mencionados en el pelotón que encabeza esta integración. Pero en los últimos años, las iniciativas se han multiplicado y países como España, Alemania y Francia se ponen en orden de batalla.

Cada país procede a una integración del BIM de manera diferente. Algunos definen parámetros legislativos, otros establecen reglamentos especializados, otros crean incentivos financieros o sistemas de ayuda para la integración y algunos asisten directamente a los actores del sector de la construcción mediante agencias públicas. Podemos clasificar estas iniciativas en dos grupos, los países que eligen la obligación de la integración del BIM en el sector de la construcción y los países que eligen el incentivo. En esta comunicación, nos interesaremos en los países que eligen el incentivo para la transformación hacia el BIM, y más particularmente en el caso francés.

Para estudiar el caso francés, no haremos una presentación tradicional de como las diferentes autoridades provocan la transformación hacia el BIM. En ese sentido, solo mencionaremos que dos entidades públicas están a la cabeza del desarrollo del BIM el "Plan de Transformación Digital en la Construcción" (PTNB) y el "Centro Científico y Técnico 
de la Construcción" (CSTB). Nuestra comunicación presenta la manera de cómo el sistema de transformación hacia el BIM se "auto" alimenta de los cambios de prácticas técnicas y profesionales de los diferentes actores. Trataremos el ejemplo de un consejo regional, y particularmente de las autoridades y servicios que se encargan de la administración y del funcionamiento de los liceos con una superficie de gestión de más de un millón y medio de metros cuadrados.

Nuestra investigación nos lleva a varios conclusiones, constatamos (1) que la integración del BIM vía incentivos es posible y muestra resultados concretos, (2) que esta vía permite la transformación de área de construcción pero a un ritmo lento o moderado, (3) que la dependencias actual entre los actores de la construcción facilita la transmisión de la práctica "común" del BIM y (4) que las formaciones sobre BIM deben integrar la descripción de la necesidades del cliente al integrar el BIM en su gestión. Esta comunicación tratara únicamente de las dos primeras conclusiones de nuestra investigación.

\subsection{La Estrategia}

Para desplegar el BIM en el sector de la construcción, se deben mover una cantidad muy importante de variables. Estas pueden ser observadas mediante diferentes métodos de investigación. En Francia, el despliegue del BIM se observa a partir la tipología de BIM que se integra en cada proyecto. Pera establecer esta medida, los laboratorios MAP-Macc, LRA y LIST establecieron el sistema BIMetrics [1]. Mediante este sistema, es posible comprender el nivel de desarrollo de BIM en un proyecto concreto y delimitado. Pero este método no permite conocer la integración del BIM a una escala superior. Podríamos simplemente adicionar los proyectos para constatar el nivel de integración del BIM en un espacio territorial más amplio. Pero estaríamos aun limitados por el aspecto metodológico que está ligado a un proyecto. Además, es difícil establecer la cantidad de proyectos en BIM que se desarrollan porque no es una obligación declararlos. Esto es particularmente verdad, en los contratos privados, en los cuales se integra el BIM de manera muy diversa sin hacer pública esta integración.

Para estudiar la integración del BIM a una escala superior, utilizamos entonces un método diferente. Nuestra observación de basa en el "cliente". Es decir que voluntariamente nos delimitamos a segmentar el sector de la construcción et observamos la interacciones desde el punto de vista de un solo actor. Esto nos permite facilitar las observaciones, porque solo necesitamos observar un solo actor. La observación se basa en el relevo de las decisiones y actividades relevantes al BIM en un equipo de administración y gestión técnica de un consejo regional que tiene a su cargo más un millón y medio de metros cuadrados. La observación se llevó a cabo desde el momento en el que el departamento de gestión técnica decide de "saber lo que es el BIM" (es decir que solicita informaciones sobre el BIM al CSTB), hasta la publicación y entrega de los primeros mercados públicos de construcción en los cuales se pide la integración del proceso BIM.

Así, hemos clasificado los diferentes procesos que llevan a la integración del BIM en el sector de la construcción en dos categorías que corresponden a cada uno de nuestros 
capítulos. La primera categoría implica los procesos de integración "política" del BIM. Es decir que trata de las decisiones que son tomadas para la integración del BIM. Esto implica también la decisiones de los tipos de marcados públicos que sera publicados et el nivel "técnico" de solicitud del BIM. La segunda categoría implica la integración del BIM desde un punto de vista "sistémico". Es decir la manera en la cual las decisiones del cliente ejercen una influencia en el desarrollo del BIM en el sector de la construcción.

Esta comunicación se desarrolla unicamente sobre la primera parte de nuestra investigación, es decir los elementos ligados a la integración "política" del BIM en el sector de la construcción. Les elementos ligados a la integración "sistémica" están aun en curso de validación al momento de la redacción de la presente comunicación.

\section{INTEGRACIÓN POLÍTICA DEL BIM}

Lo que llamamos la integración política del BIM se refiere al las decisiones y actividades del cliente que se refieren a desarrollo del BIM en un espacio territorial, a una escala superior a la de un proyecto. La única restricción que definimos, es que la decisiones no deben tocar unicamente a un proyecto de construcción de inmuebles pero a la integración del BIM a una escala superior, como el perímetro de una ciudad, un departamento o una región. Esto nos permite de relevar dos tipos elementos en la integración política del BIM, la publicación de documentos contractuales y la definición del nivel técnico del BIM.

Nuestra investigación muestra claramente como el "cliente", como actor del sector de la construcción estructura los contratos y así interviene en el desarrollo del BIM. En este caso, constatamos que nuestro sujeto toma en cuenta desde el principio las sugerencias del PTNB y del CSTB (organismos públicos encargados de la difusión del BIM). Esto define en gran parte su política de integración del BIM. Particularmente, los documentos difundidos por estos organismos, sobre todo el PTNB [2], a través de sus páginas web.

\subsection{Participación a la publicación de documentos}

La primera acción que realiza la autoridad regional la publicación, en diferentes mercados públicos de construcción, de documentos ligados al BIM. Esta publicación se realiza fuera del contexto contractual y las autoridades precisan que son publicaciones informativas que tienen como objeto comunicar la integración futura del BIM a los actores del sector de la construcción. No se trata de documentos de difusión pedagógica o explicativa del BIM. Los documentos publicados son documentos contractuales que están en redacción o que están terminados pero que no se apliquen a todos los mercado públicos de construcción. Son verdaderos documentos que tarde o temprano se volverán documentos obligatorios.

Lo que es interesante en este tipo de iniciativa es que lo documentos publicados permiten a un gran número de actores de comprender lo que se les viene en los futuros contratos. Lo que provoca dos situaciones. La primera es que la autoridad regional tiene sugerencias y preguntas con respecto a los documentos publicados. Las "sugerencias" son generalmente 
subjetivas y tienden a advertir a la autoridad regional que los documentos van a modificar les prestaciones realizadas. Les "preguntas" son generalmente más objetivas y tocan temas técnicos sobre la manera de cómo se van a verificar les prestaciones, sobre todo cuales son los programas que serán utilizados para esta verificación. La segunda es que los actores de concepción et de construcción comienzan un proceso de formación et de equipamiento que les permita en el futuro responder a mercado en los cuales estos tipos de documentos tengan una aplicación contractual.

Par ejemplo, el primer documento que que fue difundido a comienzos del 2016, fue el "contrato de prestaciones técnicas para un proyecto de construcción en BIM". Este documento explicita la manera de realizar un proyecto en BIM para que la maqueta digital producida pueda ser explotada por el cliente para su gestión técnica et patrimonial en el largo plazo. El documento describe el contenido de la maqueta digital producida primero por los equipos de arquitectura et de ingeniería, luego de las empresas de construcción. Dos elementos interesaron particularmente los prestatarios, los nomenclaturas ligadas a los objetos y los atributos de cada de uno de los objetos y los formatos de los diferentes ficheros que deben ser integrados en los programas de gestión técnica y patrimonial.

\subsection{Definición de los niveles técnicos}

La segunda acción es la definición de un nivel técnico del BIM suficientemente simple para que la mayoría de actores de la construcción puedan transformas sus programas informáticos y sus métodos de gestión de proyectos. Sin entrar en los detalles de como se definen las características técnicas de un proyecto en BIM, podemos tomar en cuanto tres variables que tienen una gran influencia en el nivel de conocimientos et de equipamiento necesario para realizar un proyecto en BIM. Les tres variables mínimas a tomar en cuenta en los proyectos en Francia son (1) los usos que se van a realizar sobre las maquetas digitales (generalmente presentados como BIMUSES), (2) el contenido de la maqueta digital (generalmente presentado pajo la siglas LOD), (3) el nivel de colaboración de los actor des un proyecto (generalmente presentado como nivel de BIM 1, $2 \circ 3$ ). A través de estas tres variables, el cliente está en capacidad de abrir o cerrar el mercado a los actores de la construcción, sobre todo a los actores de la construcción que no estén iniciados al BIM.

Podríamos pensar que el pedido del cliente en un nivel técnico bajo de BIM, le quita al proceso BIM todo su interés. Pero lo que es interesante en este tipo de dispositivo es que el "cliente" no pierde candidatos a su mercado pública y así puede continuar a beneficiar de un nivel competitivo alto. Es decir que los precios ligados a los proyectos de construcción en BIM no se revelan superiores a los proyectos de construcción que no están en BIM. Lo que es una gran diferencia en cuanto a los proyectos BIM que piden un nivel técnico alto que tienen un sobre costo ligado al proceso BIM se sitúa entre uno y tres por ciento del presupuesto total de la operación de la construcción.

Por ejemplo, para el primer mercado publica realizado en BIM la autoridad regional definió como única utilización del BIM la entrega de una maqueta digital BIM que integre la totalidad de documentos gráficos y escritos específicos para cada objeto, en cada objeto respectivo. 
En lo que corresponde al contenido de la maqueta, la única obligación fue la entrega de objetos de base de la súper estructura, como paredes, columnas, vigas, puertas y ventanas. Los objetos solo debían respetar la obligación de ser exportados con la opción de las "cantidades de base" integrada. Finalmente, la autoridad regional dejo la libertad a cada uno de los prestatarios de definir el nivel de BIM que iba a proponer en su mercado.

\section{CONCLUSIONES}

Nuestra investigación permite de identificar un tipo de política de integración del BIM específica al mercado inmobiliario francés. La integración del BIM bajo una política que podríamos definir como política de "difusión completa" debe ser puesta en perspectiva frente a otros tipos de políticas de integración identificadas, y particularmente la política definida como de "organización de mercado". El objetivo no es identificar la mejor de la dos políticas, pero más bien el de comprender la implicaciones de cada una.

Así, en el contexto europeo, hemos identificado dos tipos de política de desarrollo del BIM. Podríamos cualificar estos tipos de política de "organización de mercado" (Reino Unido) y política de "difusión completa" (Francia). Estos dos tipos de políticas tienen mucho en común, por ejemplo la manera de explotar las ventajas competitivas del BIM en área del diseño et de la obra, introduciendo nuevos métodos de control para reducir los costos de maneras diversas.

La política de "organización de mercado" tiene como objetivo el desarrollo del BIM con la perspectiva de crear y fabricar diferentes tipos de servicios que permitan a los actores des mercado, miembros de grupos inmobiliarios o de ingeniería, de ocupar el mercado de los servicios emergentes ligados al digital en la construcción y más precisamente al BIM. Para poder introducir este tipo de política, la promoción de la integración del BIM debe ser muy activa. Al punto de hacer del BIM un requerimiento obligatorio por lo menos para el acceso a una parte del mercado. En el caso del Reino Unido, estos elementos están formalmente delimitados en el "Government Construcion Strategy" [3]. Este documento publicado por el antiguo gobierno de izquierda precisa que la transformación hacia el BIM responde a una política de desarrollo ambiental (construir edificios 20\% más económico, 20\% más rápido y con $20 \%$ menos de energía). Pero detrás de esto, los trabajos del "BIM Task Force", precisan como las empresas de construcción, las oficinas de ingeniería et las actores inmobiliarios en general deben usar el BIM como une ventaja competitiva dentro del mercado global de la construcción largamente desarrollado con metodologías Británicas o Estadounidenses.

La política de "difusión completa" tiene como objetivo el desarrollo del BIM con la perspectiva de integrar el BIM en la práctica común de la totalidad de los actores de la construcción. Es este tipo de política, la creación de servicios y la exportación de prestaciones no es una prioridad. La prioridad es transformar el sector de la construcción con los danos colaterales mínimos. La participación de una gran cantidad de sindicatos en el desarrollo del BIM en Francia ha permitido tomar en cuenta el impacto de la transformación 
hacia el BIM. La política de "difusión completa", permite así de integrar en la transformación hacia el BIM a muchos actores de la construcción. Como lo hemos podido constatar, así sea una política que toma tiempo, esta evita que se rompan los lazos entre los actores, y particularmente entre los actores de empresas pequeñas y medianas. La difusión del proceso BIM es más completa porque abarca la totalidad de los actores. A cambio de esto, el mercado tiende a tomar más tiempo en organizarse.

Cada una de estas políticas de integración tiene ventajas y desventajas. Debemos tomar en cuenta dos cosas. La primera es que el desarrollo del BIM sebe ser adaptado al mercado inmobiliario de cada país y tener así en cuanta les problemáticas de los actores de la construcción. La segunda, es que el desarrollo del BIM debe ser acompañado de "apoderamiento" de todos los actores de la construcción, particularmente para que puedan comprender la política de integración. Para que los actores de la construcción puedan tener el poder de comprender y ser actores de la transformación digital es necesario que se formen al proceso BIM. Y la formaciones deben tomar en cuenta los elementos técnicos, como la producción de maquetas digitales, y los elementos metodológicos y contractuales para poder definir les prestaciones BIM que serán solicitadas en cada uno de los mercados.

Es en esta perspectiva, que los proyectos de formación al BIM a nivel europeo deben tomar en cuanta les problemáticas contractuales. El proyecto de formación BIMgame toma en cuenta este sujeto mediante la creación de juego de roles entre diferentes actores desde el momento de la redacción de los contratos en BIM.

\section{REFERENCIAS}

[1] BIMetrics; http://bimetric.list.lu/

[2] PTNB; http://www.batiment-numerique.fr/

[3] Government Construcion Strategy;

[4] https://www.gov.uk/government/publications/government-construction-strategy

[5] The BIM Game; http://bimgame.eu/ 


\title{
MODELOS PARA LA DOCENCIA DEL BIM: EL GARAJE CATASÚS, DE JOSÉ ANTONIO CODERCH
}

\author{
Valderrama, Fernando (1), Guadalupe, Rafael (2), Ramírez, Carolina (3), \\ Muñoz, Efraín (4)
}

(1) RIB SPAIN SA, fernando.valderrama@rib-software.es

(2) Universidad Politécnica de Madrid, rafael.guadalupe@upm.es

(3) Universidad Politécnica de Madrid, info@carolinaramirez.es

(4) Universidad Politécnica de Madrid, efrainmunoz@yahoo.es

\section{RESUMEN}

La elección de modelos adecuados para la enseñanza de los nuevos medios digitales plantea un interesante reto.

El garaje Catasús, construido por el arquitecto José Antonio Coderch en 1953, es un buen ejemplo, porque sus ocho naves de nueve metros de luz se construyeron mediante una elegante lámina de hormigón, pero también porque en las reseñas publicadas se incluye un diagrama de barras con las fechas reales de la ejecución de las actividades de cada nave y algunos datos sobre los recursos utilizados y los costes.

Los autores han reconstruido el modelo desde los puntos de vista 3D, 4D y 5D, realizando las hipótesis necesarias para completar los datos, y han aplicado distintas técnicas de planificación para analizar la eficacia del proceso realizado y sus posibles alternativas.

En esta comunicación se hace énfasis en las características que deben satisfacer los modelos utilizados en la docencia y se propone un esquema para usar el garaje Catasús como base de una enseñanza BIM integrada, que vaya más allá de lo puramente gráfico, en base a un modelo interesante pero abordable, complejo, pero no complicado, atractivo, pero no famoso, y cercano, pero no fácilmente localizable.

Palabras clave: docencia, modelos, ejemplos, tutoriales

\section{ABSTRACT}

The choice of suitable models for new digital media teaching poses an interesting challenge. The Catasús garage, built by the architect José Antonio Coderch in 1953, is a good example. Its eight nine-meter span naves were built using an elegant concrete slab. The published reviews include a Gantt chart with the actual dates of the activities execution and some information about the implied resources and the costs.

The authors have reconstructed the model from the 3D, 4D and 5D points of view, making the hypotheses needed to complete the data, and have applied different planning techniques to analyze the process efficiency and its possible alternatives. 
This communication focuses on the properties to be met by the models used in teaching and proposes a scheme to use the Catasús garage as the basis of an integrated BIM teaching, going beyond the pure geometry, based on a model Interesting but affordable, complex, but not complicated, attractive, but not famous, and close but not easy to find.

Keywords: teaching, models, examples tutorials

\section{$1 \quad$ INTRODUCCIÓN}

El modelo propuesto consiste en una edificación, el Garaje Catasús, destinada inicialmente a guardar camiones de distribución de combustible y realizada por el arquitecto José Antonio Coderch y construida en Barcelona en 1953 [1].

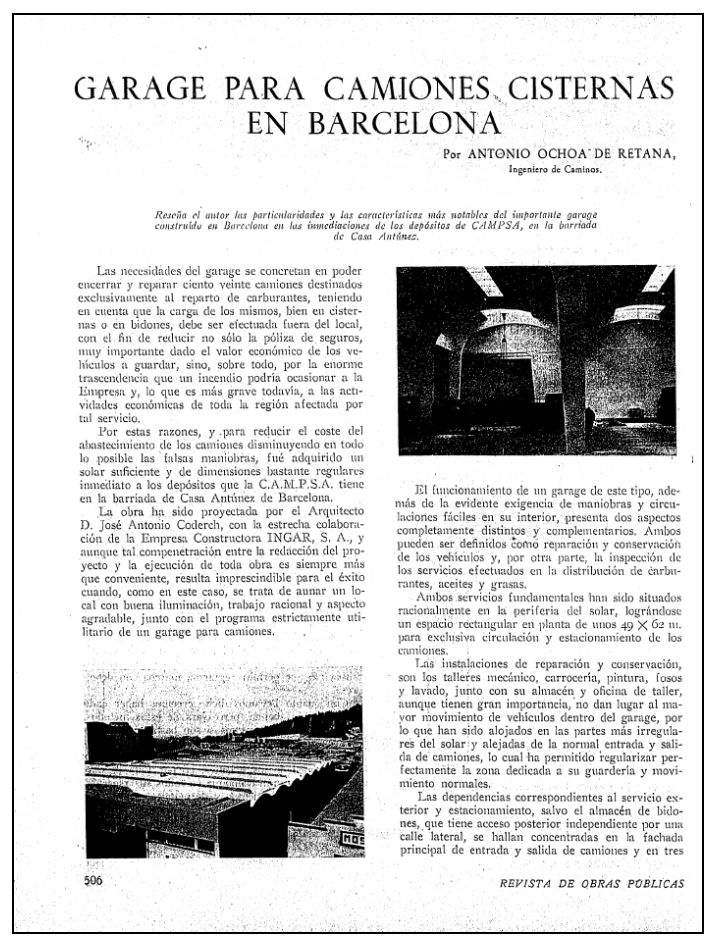

Fig 1. Artículo sobre el Garaje Catasús. 1954. Revista de Obras Públicas

El modelo tiene su origen en un artículo localizado en el Revista de Obras Públicas, ROP [2], por el Doctor Arquitecto Rafael García García, del Departamento de Composición Arquitectónica de la Universidad Politécnica de Madrid, y enviado a los autores. La reseña incluye un diagrama de barras, una información que no suele encontrarse en este tipo de publicaciones, que describen habitualmente las peculiaridades de la construcción, pero no suelen referirse a costes y plazos. Como todos los ejemplares de la ROP, la publicación activa más antigua de España, la reseña está disponible en Internet. Ese artículo es toda la información que han utilizado los autores para realizar esta comunicación y los trabajos que en ella se describen. 
Más adelante se localizó otra reseña [3], publicada en Informes de la Construcción, del Instituto Técnico de la Construcción y del Cemento, ahora "Eduardo Torroja", centrado en la estructura constructiva y en el que se puede apreciar mejor la geometría exacta de la cubierta.

El edificio consta de ocho naves paralelas, del mismo ancho y longitudes similares, realizadas con una lámina de hormigón de patente alemana, de solo $6,50 \mathrm{~cm}$ de espesor. Dispone también de un bloque lateral para oficinas, de cubierta plana.

El diagrama de barras publicado muestra las fechas reales en que se realizaron las principales actividades de cada nave: encofrado, colocación de la armadura, hormigonado y desencofrado. Se observa que se han utilizado tres encofrados o cimbras, de la longitud total de cada nave, que se desplazan alternativamente de nave en nave.

El objetivo inicial al analizar este modelo fue reconstruir la planificación que hubiera dado lugar a este proceso real de ejecución. Conociendo las actividades, se determinarían las duraciones estimadas para cada una y las relaciones entre ellas, tratando de detectar las restricciones aplicadas en el número de equipos y otras condiciones de partida.

Este análisis resultó especialmente interesante y algunos de sus resultados se describen más adelante. Se trataba, sin embargo, de un ejercicio aislado de planificación, sin relación específica con el BIM. Visto el potencial del modelo, se decidió rehacer el trabajo desde el inicio, empezando por el modelado y tratando de resolver la planificación y el presupuesto en un entorno BIM integrado.

Los datos de partida utilizados están disponibles en las reseñas mencionados. Los resultados concretos de cada ejercicio pueden ser diferentes a los obtenidos por nosotros. Lo que se propone en esta comunicación es un conjunto de posibles objetivos didácticos o ejercicios que se pueden realizar en base al mismo.

\section{CONTENIDO}

\section{$2.1 \quad$ Modelado}

La idea de empezar por modelar el edificio en tres dimensiones parece consustancial al BIM. Sin embargo, es importante observar que cuando se trata de aplicar procesos posteriores, como la planificación y la gestión del coste, existen dos alternativas muy diferentes:

- $\quad$ El modelo que se realiza por el mismo equipo que lo utilizará posteriormente, o por equipos que colaboran habitualmente, como podría ocurrir en el interior de la empresa constructora.

- $\quad$ El modelo que es realizado por unos, como el equipo de diseño, y debe ser utilizado por otros que no colaboran ni tienen poder o autoridad sobre los primeros. 
Los dos procesos se pueden simular durante la formación. En el primero, se pueden establecer criterios y buenas prácticas de modelado que tiendan a favorecer la utilización de los datos, y la marcha atrás está permitida. Es posible modificar el modelo una y otra vez hasta que los procesos posteriores resulten totalmente eficientes. En el segundo proceso, por el contrario, el modelador debe trabajar con independencia del resto del equipo y es trampa volver al modelo y cambiarlo si resulta difícil de medir o de planificar. El docente y el alumno deben tener en cuenta que ésta segunda situación va a ser una de las más habituales del mundo BIM, al menos a corto y medio plazo.

En el garaje Catasús parece interesante modelar todo lo que está definido en los planos y al menos lo que aparece en la planificación. No es necesario realizar muchas hipótesis, pero el alumno tendrá que rellenar las lagunas que encuentre sin quedarse parado. La segunda reseña mencionada es muy útil para la definición de la estructura de cubierta.

Realizado el modelo geométrico, en función en las habilidades del alumno y de la formación que haya recibido sobre este aspecto del programa, se identificarán los errores convencionales del alumno. Las dimensiones aparecen en los distintos documentos y debe exigirse un modelo geométricamente y dimensionalmente correcto, además de contrastar los resultados de superficies y volúmenes con los publicados.

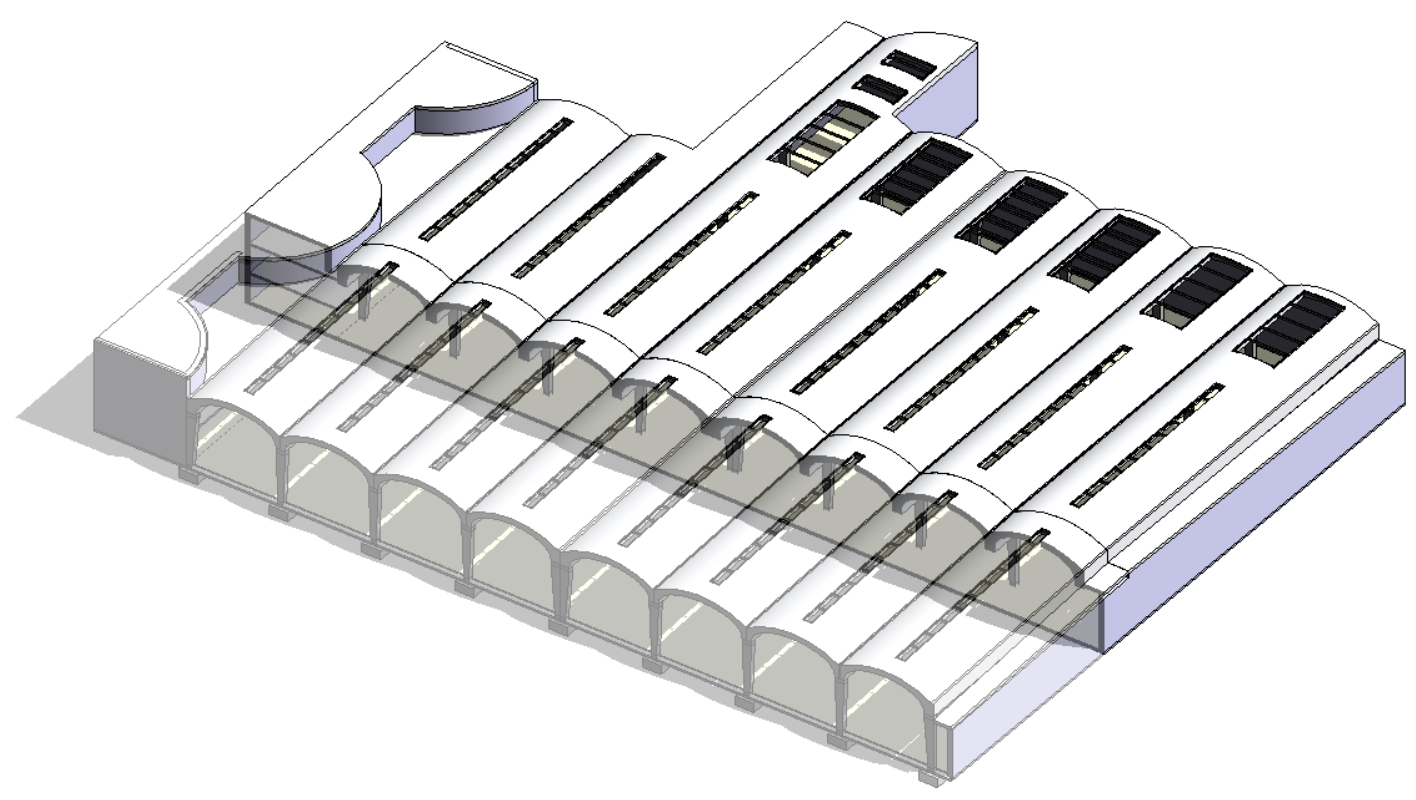

Fig 2. Axonometría del modelo en Revit. 2017. Elaboración propia

El siguiente paso es analizar el resultado en términos del proceso. Se puede revisar el cumplimiento de buenas prácticas, se hayan exigido o no al modelador previamente. La Guía de usuarios uBIM [4] es un buen punto de partida.

¿Se han definido correctamente todos los espacios? ¿Se pueden deducir bien las superficies útiles y construidas y el conjunto es coherente con los datos? ¿Se han creado los objetos con las herramientas apropiadas y se ha insertado información que permita clasificar 
correctamente los distintos tipos? ¿Están rellenos los atributos que permitirán posteriormente clasificar los objetos, medirlos y planificarlos? ¿Se ha dejado a los que vienen detrás alguna explicación de las decisiones, o informe de modelado?

Como se resume en las conclusiones, el alumno se sorprende mucho al descubrir todos estos aspectos, ya que cuando está centrado en modelar se le escapan por completo.

\subsection{Presupuesto}

La generación del presupuesto y la planificación han sido dos aspectos tradicionalmente separados, realizado por equipos distintos y partiendo ambos de los planos. En el entorno BIM es recomendable realizar un enfoque integrado desde el principio, realizando primero el presupuesto, ya que la información, si está correctamente estructurada desde este punto de vista, facilitará mucho el proceso de la planificación.

En cuanto al presupuesto, hay dos tipos de tareas:

- Las que son específicas del entorno BIM, como clasificar y cuantificar los elementos del modelo.

- Las comunes a la generación tradicional del presupuesto, como la descripción detallada de las unidades de obra, añadir las que no están en el modelo, poner precios y, en general, todo lo necesario para obtener un documento que sirva de base para solicitar ofertas.

\begin{tabular}{|c|c|c|c|c|c|c|c|c|}
\hline & Código & NatC & Info & & Resumen & CanPres Ud & Pres & ImpPres \\
\hline - & Revit & $:$ & $\therefore$ & 回 & CODERCH 6 & 1 & 0 & , \\
\hline-1 & 2000160 & (1) & $\therefore$ & & Habitaciones & 1 & 0 & 0 \\
\hline 1.1 & 292951 & 回 & & & OFICINAS 2 & $408,77 \mathrm{~m} 2$ & & 0 \\
\hline 1.2 & 292893 & प & & & GARAGE 1 & $4.422,96 \mathrm{~m} 2$ & & 0 \\
\hline+2 & 2000700 & (1) & $\therefore$ & & Materiales & 1 & 0 & 0 \\
\hline+3 & E02 & (1]) & $\therefore$ & & ACONDICIONAMIENTO DEL TERRENO & 1 & 0 & 0 \\
\hline-4 & E04 & (1) & $\therefore$ & 回 & CIMENTACIONES & 1 & 0 & 0 \\
\hline 4.1 & 291908 & 口 & & 回 & Solera garage & $998,71 \mathrm{m3}$ & & 0 \\
\hline 4.2 & 290156 & प & & 回 & Zapatas & $99,28 \mathrm{m3}$ & & 0 \\
\hline-5 & E05 & [i] & $\therefore$ & 回 & ESTRUCTURAS & 1 & 0 & 0 \\
\hline 5.1 & $B 10$ & 回 & & 回 & Pilares & $74,86 \mathrm{m3}$ & & 0 \\
\hline 5.2 & 264241 & 口 & & & Encofrado & $16,00 u$ & & 0 \\
\hline 5.3 & 273721 & 回 & & & Armadura & $121.687,20 \mathrm{~kg}$ & & 0 \\
\hline 5.4 & $261985 \mathrm{VOL}$ & ㅁ & & & Cubiertas & $3.042,18 \mathrm{m3}$ & & 0 \\
\hline 5.5 & 291908 & 口 & & 回 & Forjado oficinas & $817,54 \mathrm{~m} 2$ & & 0 \\
\hline 5.6 & 223 & 口 & & 回 & Cubierta oficinas & $426,46 \mathrm{~m} 2$ & & 0 \\
\hline-6 & E07 & (7) & $\therefore$ & 目 & CERRAMIENTOS Y DIVISIONES & 1 & 0 & 0 \\
\hline 6.1 & 249 & 回 & & 回 & Muro exterior & $2,309,32 \mathrm{~m} 2$ & & 0 \\
\hline-7 & E11 & (1) & $\therefore$ & 回 & PAVIMENTOS & 1 & 0 & 0 \\
\hline 7.1 & 208786 & ㅁ & & 回 & Pavimento garage & $4.838,22 \mathrm{~m} 2$ & & 0 \\
\hline-8 & E16 & (1) & $\therefore$ & 回 & VIDRIERIA Y TRASLUCIDOS & 1 & 0 & 0 \\
\hline 8.1 & 216688 & प & & 回 & Lucernarios & $688,46 \mathrm{~m} 2$ & & 0 \\
\hline 8.2 & 29425 & 口 & & & Perfilería & $1.266,74 \mathrm{~m}$ & & 0 \\
\hline 8.3 & 289295 & 口 & & 回 & Vidrios & $625,47 \mathrm{~m} 2$ & & 0 \\
\hline
\end{tabular}

Fig 3. Capítulos y partidas en Presto. 2017. Elaboración propia.

Si nos centramos en la parte específica, el alumno debe ser capaz de:

- Identificar todas las unidades de obra presentes en el modelo 
- Elegir la unidad de medida más adecuada a cada una y obtener las cantidades, contrastando el resultado con los datos publicados.

- $\quad$ Proporcionar unas mediciones ordenadas, localizables en el modelo, los planos y el edificio construido, utilizando, si están definidas, las áreas, los espacios y las rejillas.

- $\quad$ Ordenar las unidades de obra en capítulos adecuados a la función del presupuesto.

Al mismo tiempo, debe detectar las diferencias entre lo que se modela y lo que se mide:

- Las mediciones de algunos elementos van a provenir de otros modelos, como las armaduras, cuya cuantía o cantidades exactas serán resultado de un programa de cálculo.

- $\quad$ Otras unidades de obra, sin estar directamente en el modelo, se deducen de las existentes, como el movimiento de tierras o la impermeabilización de las cubiertas.

- $\quad$ Algunos elementos que pueden haber sido modelados o no, como el encofrado, no tienen un coste directo, es decir, no forman parte del presupuesto que realiza el equipo de proyecto, pero puede que tengan que ser calculados por el contratista.

El alumno debe ser capaz de medir también unidades de obra que no sean exactamente áreas totales o volúmenes, como la superficie en verdadera magnitud de la cara superior de las cubiertas.

La formación sobre el presupuesto en entornos BIM puede incluir:

- La realización de un informe a los modeladores, describiendo cómo debería haberse realizado el modelo para facilitar su labor en este caso concreto o, si se desea un mayor alcance, la redacción de una propuesta de buenas prácticas generales.

- $\quad$ El análisis del proceso de gestión del cambio, es decir, cómo se actuaría en caso de que se recibieran nuevas versiones del modelo, según sea la envergadura de los cambios.

En función del escenario elegido, el alumno puede realizar los cambios en el modelo y volver a generar el presupuesto, o terminar el proceso usando el mismo modelo recibido.

\subsection{Planificación}

A su vez, se pueden imaginar dos escenarios:

- Realizar libremente la planificación de la ejecución

- $\quad$ Tratar de reproducir una planificación compatible con la publicada

El primer ejercicio corresponde a una situación real, en la que se dispone del modelo, con el detalle descrito en las referencias, pero sin consultar el diagrama de barras publicado. El alumno tiene toda la libertad para determinar las actividades, las duraciones, la 
secuenciación y las restricciones, pero debe tomar decisiones sobre el número de recursos de cada tipo, que es precisamente el objetivo de la planificación.

Un ejercicio avanzado consistiría en determinar objetivamente la alternativa más económica. Para ello, es necesario estimar unos costes de los medios auxiliares, así como una penalización o ahorro del cliente por el plazo, que no se deducen de la publicación.

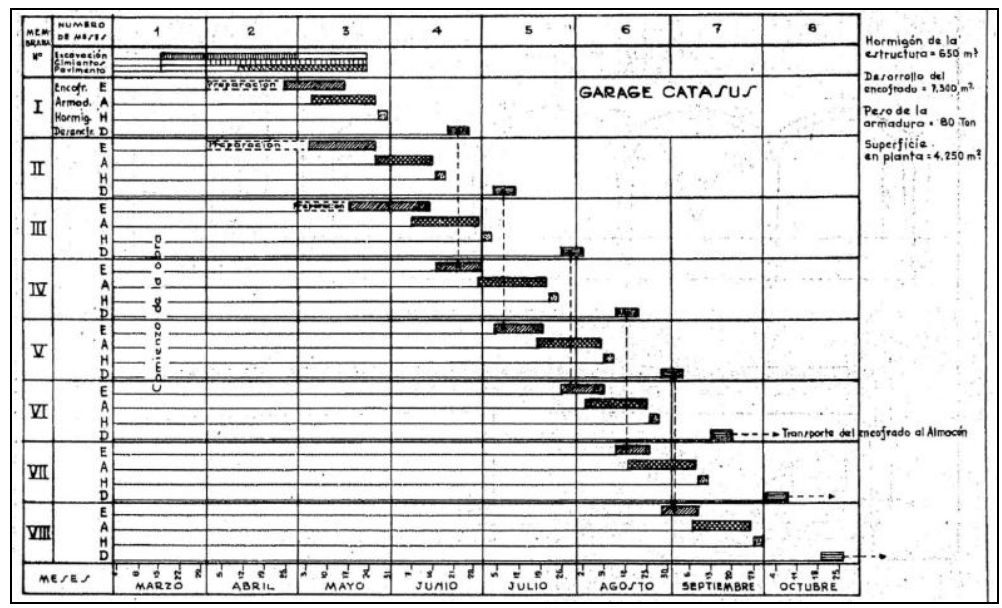

Fig 4. Planificación original. 1954. Revista de Obras Públicas

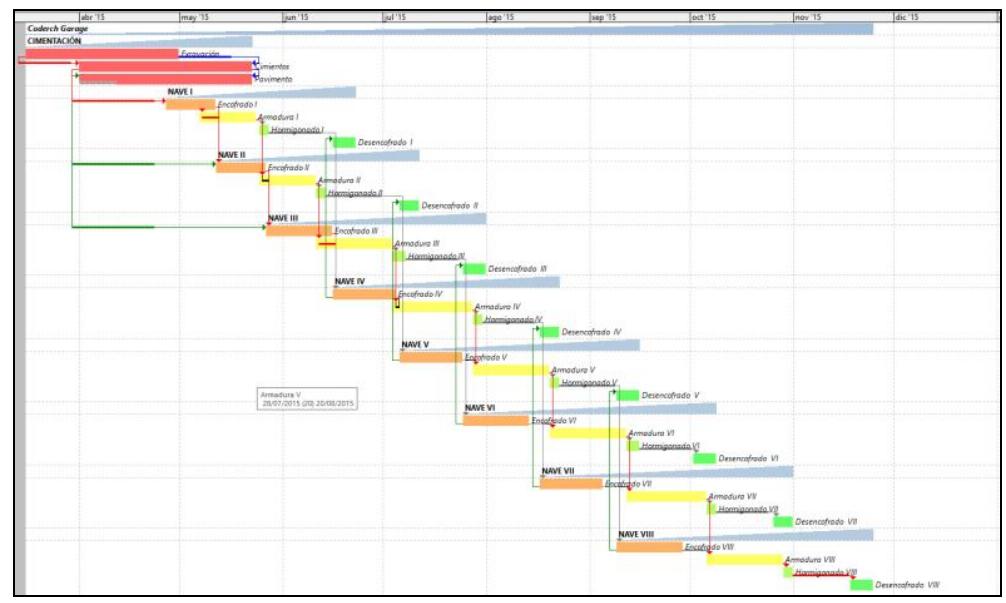

Fig 5. Reconstrucción de la planificación original en Presto. 2017. Elaboración propia.

Este modelo es particularmente interesante para ello porque, a diferencia de la edificación vertical, donde la secuencia de las plantas es fija, las naves en horizontal se pueden ejecutar de muchas formas diferentes, desde avanzar con un sólo equipo linealmente hasta atacar las ocho naves por ambos extremos con todos los equipos necesarios. Es por ello especialmente interesante para una planificación basada en espacios y tiempos y en restricciones de recursos.

La segunda propuesta es de carácter más teórico, ya que consiste en reconstruir una planificación inicial que sea compatible con las fechas reales publicadas de las actividades. Es interesante analizar estos datos y determinar medias y variabilidad de las duraciones, encontrar curvas de aprendizaje y realizar hipótesis sobre las restricciones empleadas. EI 
conocimiento de estos datos reales, poco habitual en tareas repetitivas, permite aplicar técnicas probabilistas, basadas en el método PERT o en análisis de Monte Carlo.

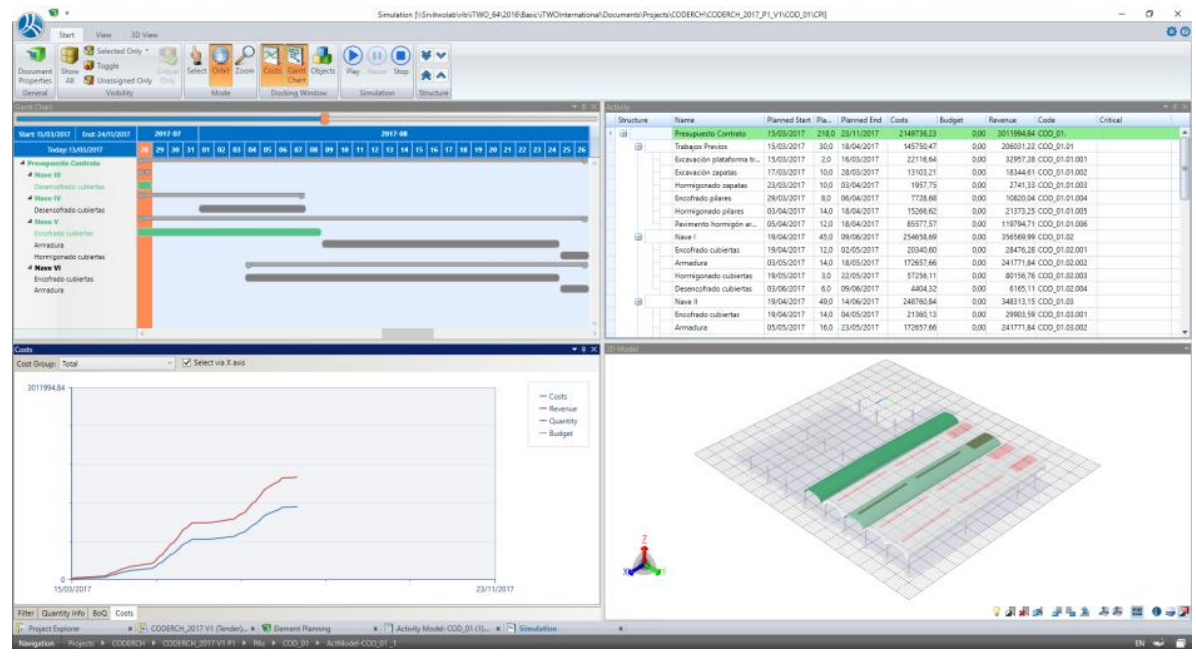

Fig 6. Simulación 4D en iTWO. 2017. Elaboración propia

Como ocurre con la gestión del coste, estas tareas se pueden realizar con independencia de que exista o no un modelo $3 \mathrm{D}$. Por tanto, es conveniente insistir en las posibilidades específicas del BIM:

- Por un lado, realizar las inevitables simulaciones visuales del proceso de la ejecución, que requieren la vinculación del modelo 3D con la planificación

- $\quad$ Por otra parte, generar y mantener los enlaces entre el modelo de coste y el de tiempos, es decir, entre las unidades de obra y las actividades, que en la etapa de ejecución permitirán relacionar los ingresos con los costes, es decir, las certificaciones con el avance de la ejecución.

\subsection{Otros posibles objetivos didácticos}

Muchos especialistas encontrarán en el Garaje Catasús de José Antonio Coderch un buen ejemplo para aplicar su área de conocimiento.

La reconstrucción de la estructura, especialmente de sus armados, y su cálculo con los programas actuales puede ser un interesante reto, teniendo en cuenta las bajísimas cuantías utilizadas y los espesores reales. Hay suficientes datos para contrastar las cantidades totales utilizadas. No hay duda de que las cubiertas se dimensionaron correctamente, puesto que se mantienen en uso, pero es posible que ya no cumplan la normativa y que no pudieran ser construidas nunca más.

El análisis de la luminosidad natural interior es otra posibilidad. En los mismos artículos se comenta este aspecto, como una de las características comprobadas en la realidad. 
El modelo, por su tamaño, su relativa sencillez y su buena definición geométrica, puede utilizarse para casi todas las demás posibilidades de los entornos BIM, como el análisis energético, la generación de imágenes y animaciones o el diseño, introducción y cálculo de unas posibles instalaciones.

\section{CONCLUSIONES}

BIM no es modelado, ni siquiera es modelado enriquecido. BIM es integración de disciplinas, colaboración entre agentes y refinamiento del prototipo. Los ejemplos que utilicemos en la docencia deben insistir en estas características.

En actividades de formación realizadas por los autores con modelos similares a este es sorprendente la reacción de los alumnos cuando se dan cuenta lo que se han esforzado por modelar correctamente desde el punto de vista geométrico, pero no han caído en que el modelo es un medio para realizar otras tareas, no un fin en sí mismo.

El alumno construye el modelo sin darse cuenta de que él mismo va a tener que utilizar sus datos posteriormente para los procesos 4D y 5D. Cuando llega a este punto, se pregunta por qué no se le indicó antes cómo hacerlo correctamente, pero es sólo ahora cuando puede entender bien cómo debería haber procedido, y comprueba las diferencias entre trabajar para uno mismo o pensar en los que vienen después.

De la misma forma, si en cada proceso intervienen equipos distintos, discutirán entre ellos sobre lo que debería o no hacer cada uno, discusión que refleja perfectamente lo que ocurrirá en el mundo real, en el que no existe un modelo perfecto y las personas no colaboran si no tienen un estímulo para hacerlo.

\section{REFERENCIAS}

[1] http://joseantoniocoderch.org/

[2] Antonio Ochoa de Retana (1954). Garage para camiones cisternas en Barcelona. Revista de Obras Públicas, octubre 1954, pp. 506-509.

[3] Garaje Catasús, Barcelona. Arquitecto: José Antonio Coderch. Informes de la Construcción, Madrid: Instituto Eduardo Torroja. (1954), no 65 noviembre, 64-69.

[4] Building Smart (2014). Guía de usuarios BIM. 


\section{BIM: PAUTAS ESTRATÉGICAS PARA LA REGENERACIÓN DEL MÉTODO DOCENTE EN LAS ESCUELAS DE ARQUITECTURA}

\section{Aldeanueva-Fernández, Mercedes (1), García-Marín, Alberto (2), Barrios-Corpa;Jorge (3), de la Torre-Fragoso, Ciro (4)}

(1) Arquitecto BIM en Asenjo y Asociados. Máster BIM en Metodología y Gestión por la Universidad Politécnica de Madrid. mercedes.ald.f@gmail.com

(2) Profesor en Escuela Técnica Superior de Arquitectura de Málaga albertogm@uma.es

(3) Profesor en Escuela Técnica Superior de Arquitectura de Málaga jbarrios@uma.es

(4) Profesor en Escuela Técnica Superior de Arquitectura de Málaga cirtorfra@uma.es

\section{RESUMEN}

Superada la incertidumbre inicial del uso e implantación del método BIM en el mercado laboral, resulta innegociable trasladar al ámbito académico nuevas formas, no sólo de trabajo, sino también de entendimiento de una nueva filosofía del desarrollo profesional del Arquitecto.

La implantación del BIM en las empresas se entiende como un método multidireccional e integracionista y de esa misma forma debe extrapolarse a las escuelas, abordando la complejidad del cambio mediante actuaciones estratégicas de carácter global en los planes de estudio.

Para este fin se propone un modelo de Plan Estratégico que dicte unas pautas generales para el método docente en las Escuelas de Arquitectura, con diferentes grados de actuación BIM dependiendo del carácter de cada uno de los cursos académicos. Se abordarán los temas desde una relación directa con la experiencia real del ámbito laboral: trabajo colaborativo, estandarización, roles, protocolos, etc.

Mediante estas pautas, se pretende esbozar un BAP (Bim Academic Plan) que sirva para, desde la raíz, inculcar a los alumnos una nueva filosofía y método de trabajo, y también abra camino para un planteamiento de más calado en cuanto a la implantación BIM en el ámbito académico y se tomen estrategias conjuntas en la docencia de los futuros profesionales.

Palabras clave: Arquitectura, docencia, filosofía BIM, BAP, pautas estratégicas.

\section{ABSTRACT}

Once the initial BIM implementation and use uncertainty was overcome by labour market, it is non-negotiable to transfer new ways to work and a architect's professional development philosophy to academic environment. 
BIM implementation in companies is an integrationist and multidirectional method, and that is the way to implement it in an academic environment, tackling this complex change through a global action plan across all the programmes.

That is why we propose a Strategic Plan in the Higher Technical School of Architecture of Malaga, which will have different BIM action plans depending on the course, field of study and subject. This action plan will face all the issues from a direct relationship with the work environment, teamwork, standardizing roles and protocols, etc.

This Strategic Plan does not want just to educate and give students the necessary tools either to work in an actual workplace or face a social reality, in addition to that it wants to break all differences between conservative and innovative points of view, and show BIM technology and management do not go against quality and creativity in architecture,

Keywords: Architecture, BAP, philosophy BIM, strategic plan, teaching.

\section{INTRODUCCIÓN}

El método BIM es una realidad en el sector AEC desde que en el año 2015 el gobierno español se involucrara en su implantación determinando que en diciembre del 2018 su uso será obligatorio para las licitaciones públicas de edificación.

En este punto, y al margen de prórrogas, se debe afrontar la tarea de transformar los métodos y herramientas actuales, teniendo en cuenta no sólo la inmediatez del cambio, sino también la necesidad de un entramado con el suficiente calado para que se lleve a cabo de una forma madura y estable a largo plazo.

La madurez en esta transición pasa por no olvidar que existen dos ámbitos a los que prestar atención: el mercado laboral, y el ámbito académico. La metodología BIM ha irrumpido de forma tan inminente que ha dado lugar a una falta importante de profesionales especializados capaces de cumplir con las nuevas exigencias [1], y es por eso que no sólo es importante y necesario migrar hacia el BIM en las empresas sino también en las Escuelas, para formar a alumnos capaces de asumir los nuevos roles que trae consigo dicha metodología.

En países como Reino Unido o Dinamarca, donde el BIM es un requisito legal para las contrataciones públicas, tienen en sus respectivas universidades, Coventry University y VIA University Collegue, planes de estudios que contemplan el BIM desde un punto de vista teórico y práctico [2] abarcando la totalidad del plan. En España debemos asumir la responsabilidad de una docencia eficaz ante la transformación del sector y entender que la metodología BIM necesita de un planteamiento más global en las titulaciones. La premura con la que el mercado laboral demanda profesionales está derivando en iniciativas de implantación complementaria que no son capaces de abarcar por completo el alcance de la transformación en el sector.[3] 
El propósito de esta comunicación es aportar pautas y directrices para la articulación de planes de estudio en las Escuelas de Arquitectura con los que formar en las nuevas competencias BIM.

\section{MÉTODOLOGÍA DOCENTE BIM}

Actualmente en las universidades hay distintos modelos sobresalientes de enseñanza BIM al que puede acceder el alumno: títulos máster para postgraduados, cursos de formación continua o asignaturas de libre elección.

Sin embargo la realidad es que, a pesar de los buenos resultados y la excelente metodología que tienen algunos títulos propios como el impartido por la Politécnica de Madrid, Cataluña o la Coruña, son planteamientos de una formación a posteriori que, aunque tienen en cuenta la necesidad de autoaprendizaje por parte del alumno, requieren un tiempo en formación básica que va en detrimento de una formación más específica de perfiles (BIM Manager, Coordinador BIM, Técnico de soporte BIM, etc.)

Por otro lado, y ante la vorágine BIM, es importante entender que el objetivo de las Escuelas es formar Arquitectos capaces de ejercer su profesión con el total de sus matices, insertos en la filosofía de la metodología BIM, sin que ésta vaya en detrimento de su desarrollo proyectual o su capacidad para controlar su ejecución hasta el final. La especialización del profesional dentro del entorno BIM será posterior y vendrá como consecuencia de su trayectoria y experiencia laboral.

Las soluciones complementarias, tanto en el ámbito laboral como académico, pueden generar una falsa madurez BIM [4], y alargar la duplicidad de los "roles homólogos BIM", cuando "a la larga, el Jefe de Diseño y el BIM Manager se entiende que acabarán fundiéndose en un mismo rol, así que tiene sentido que en un futuro los especialistas del diseño o la construcción tengan un amplio conocimiento en entornos BIM" [5].

A continuación se expone un ejemplo comparativo de dos Escuelas desde el punto de vista de la madurez BIM:

\begin{tabular}{|c|c|}
\hline $\begin{array}{c}\text { ESCUELA - A } \\
\text { Decisión Inicio BIM ascendente } \\
\text { (de abajo a arriba) }\end{array}$ & $\begin{array}{c}\text { Decisión Inicio BIM descendente } \\
\text { (de arriba a arriba) }\end{array}$ \\
\hline Implementación liderada por un individuo & Implementación liderada por la dirección \\
\hline Sin evidencias de estrategia global BIM & La estrategia global precedió la implantación \\
\hline Sin comunicación interna sobre los avances & Comunicación interna del proceso BIM \\
\hline Las normas se desarrollaron y extendieron & Las normas se prepararon antes de la \\
aplicación global
\end{tabular}

Fig.1. - Comparación de dos Escuelas de Arquitectura en base a su grado de Madurez BIM. Elaboración propia adaptada de la Tabla.2 del artículo: Episode 13: the BIM Maturity Index, BIM ThinkSpace. 2017. 
El siguiente Plan de estudios parte entonces de la premisas de una actuación global que permita adquirir a las Escuelas y por ende a sus alumnos, un nivel de Madurez BIM para una adecuada implantación y posterior desarrollo de la metodología en nuestro país.

\subsection{Plan de Actuación en las Escuelas}

El Plan se estructura en tres ámbitos de actuación:

1. Gestión

2. Formación

3. Alcance/Filosofía BIM

1. Gestión

Los proyectos BIM están regulados por un BIM Execution Plan (BEP). Un documento con origen en Pennsylvania (EEUU) [6] que, a pesar de sus múltiples matices según el país, mantiene el objetivo de ser un documento de carácter global fundamental para establecer el alcance y coordinación del trabajo colaborativo en las distintas fases de un proyecto por parte de todos los agentes intervinientes. La normativa británica, que es una de las más utilizadas a nivel internacional, establece en la PAS 1192-2:2013 el contenido mínimo que debe aportar un BEP, incluso en el apartado 6.2 se facilita el acceso a una plantilla precontrato BEP de referencia [7]. De esta forma sintetizamos la información necesaria en los siguientes puntos:

- Información principal del Proyecto Descripción y alcance, integrantes y organigrama del equipo BIM.

- Metas y alcance del Proyecto Los BIM Goals del Proyecto en base a los requerimientos del cliente (Employer Information Requirement. EIR), y los procesos de desarrollo en cada fase.

- Matriz LOD Indicar el nivel de detalle de los elementos del modelo para cada fase teniendo en cuenta a todos los agentes implicados con la intención de planificar los entregables de una forma conjunta.

- Protocolos de colaboración y criterios específicos del modelo Aspectos como la división del modelo y las responsabilidades, el sistema de coordenadas, la utilización de plantillas, nomenclatura de archivos, o la infraestructura para el intercambio de los modelos ( FTP).

- Recursos del Proyecto y requisitos IT [5] La estrategia CDE (entorno de transferencia de datos), software y hardwares necesarios, etc.

- Usos BIM Los usos BIM aplicados en el proyecto según las fases, y la identificación de sus responsables y roles en función del uso.

Mediante estas pautas quedará definido un BEP genérico y flexible que sirva para la redacción específica de distintos proyectos. Entendemos que la actuación en el ámbito académico para conseguir unos resultados correctos, pasa por la cercanía, en fondo y forma, a la experiencia profesional.

El Proyecto de Implantación BIM en las Escuelas debe guardar paralelismos con la forma de entender el proyecto edificatorio mediante el BEP. En las Escuelas de Arquitectura la mayor parte de las áreas de conocimiento tienen una carga lectiva-práctica que puede gestionarse 
en función de las pautas generales citadas anteriormente, pudiendo cada Escuela personalizar su Plan en base a un documento y una filosofía común.

El siguiente esquema muestra la posible relación del BEP con el plan académico:

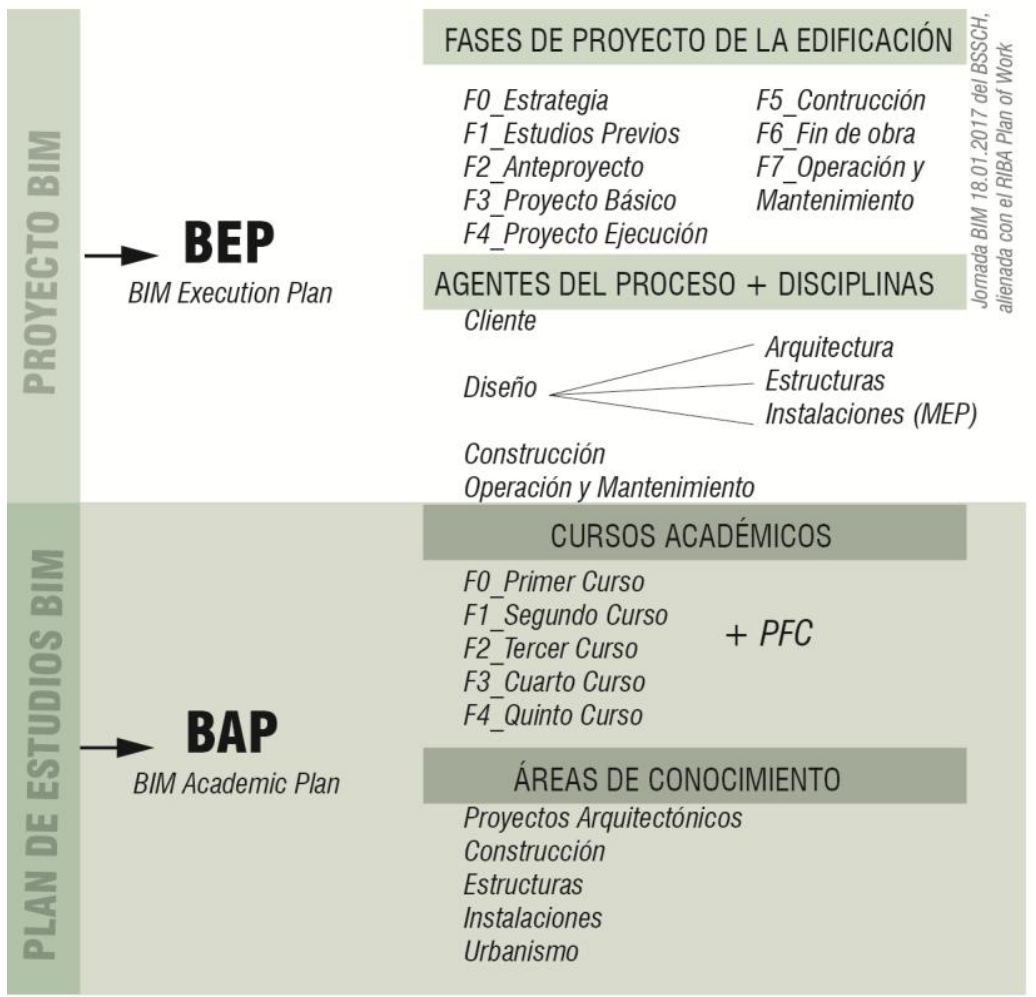

Fig.2. - Relación del Proyecto de edificación BIM con el Proyecto de Implementación del Método BIM en las Escuelas de Arquitectura. Elaboración Propia. 2017

Mediante la re-definición de las Fases del proyecto y sus agentes o disciplinas intervinientes, nace el acrónimo BAP (BIM Academic Plan) como el documento donde regular el Plan de Implantación BIM en las Escuelas. Las fases de un proyecto en concreto, pasan a ser los cursos académicos (fases) de la titulación con su correspondiente estudio de implicación BIM, y los agentes y disciplinas que participan en el proyecto son las distintas áreas de conocimiento con sus respectivos roles dentro de cada una.

Establecidas las relaciones primarias se requiere extender a los distintos campos del BEP la similitud con el BAP. A continuación se desarrollan de forma genérica alguno de los puntos más significativos:

\section{- Niveles de Desarrollo (LOD)}

Evitando futuros malentendidos vamos a entender el LOD como el Nivel de Desarrollo definido en el documento G-202 Building Information Modeling Protocol, del American Institute of Architecs, AIA, 2013 y redefinido en el BIMForum del 2014.

Es decir, el LOD define el nivel de desarrollo de un elemento del modelo, no a la totalidad del proyecto por lo que no tiene lugar vincularlo a las distintas fases del desarrollo. Los niveles son: LOD 100, LOD 200, LOD 300, LOD 350 (más reciente), LOD 400 y LOD 500. 
En la Jornada es.BIM de Enero del 2017, el BSSCH añadió el LOD 000 (001), y el LOD 600. [8]

Debido al carácter del BAP, sólo serán contemplados los niveles de desarrollo del 000 al 350, porque el alcance del Proyecto que se recoge en este documento se entiende que no sobrepasa ese nivel de detalle, aunque la elección de incluir el LOD400 dependerá de cada Escuela. La inclusión del LOD000 permite introducir de forma muy concreta al Área de Conocimiento-Urbanismo dentro del BAP.

\section{- Fases del proyecto / Desarrollo del proyecto}

A la espera de una vinculación directa entre los niveles de Desarrollo de los elementos y las fases del proyecto, se toma como referencia la normativa inglesa PAS 1192-2:2013, donde en el punto 9.9: Levels of model detail and model information, se define de forma escueta la cantidad de información (gráfica y no gráfica) que debe contener cada fase del proyecto. En la Fig.3 se establece la relación que las etapas de la PAS mantiene con el Instituto Real de Arquitectos Británicos ( RIBA), y con las fases del proyecto definidas por el BSSCH en enero de 2017.

En el BAP la última fase considerada de proyecto será - según el BSSCH- la F4P.Ejecución/Constructivo o el "Build and commission",- según la PAS- entendiendo el nivel de Ejecución sin el inicio de obra, sólo como la cantidad de información (gráfica/no gráfica) necesaria para su comienzo.

La fase de desarrollo del proyecto irá relacionada con el Curso Académico y los hitos de entrega. Por ejemplo; en la F1_Segundo Curso sería lógico pedir un Desarrollo de Proyecto F2-Anteproyecto, mientras que en una F4_Quinto Curso, lo normal será pedir un F4P.Ejecución.

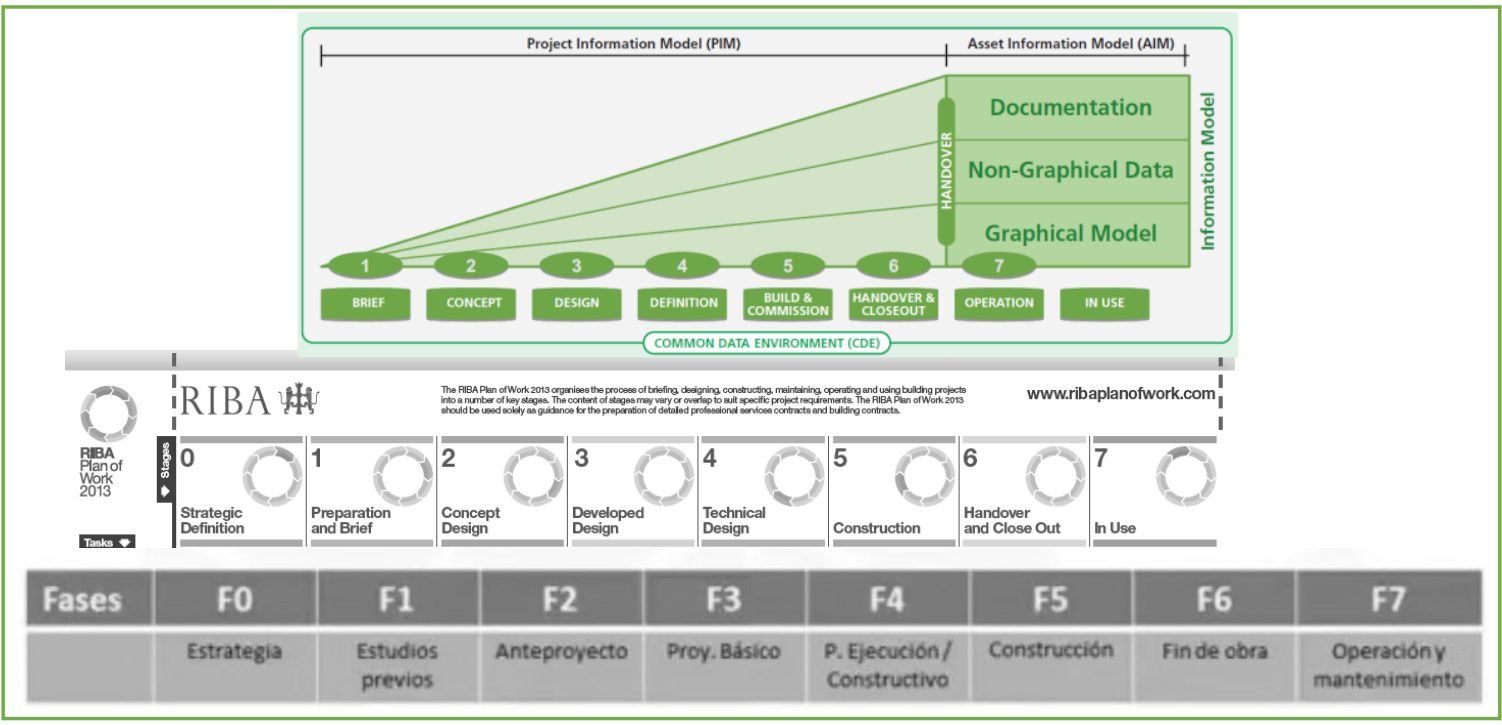

Fig.3.- Relación de fases del proyecto entre (de arriba abajo), la norma PAS 1192-2:2013, el RIBA, y BSSCH. 
Debido a la escala del trabajo se nombran de forma más genérica otros aspectos a estudiar en el BAP, siempre en relación con el BEP:

- Hitos de entrega así como el alcance de cada uno de ellos, mediante los Usos BIM [9] y BIM Goals, de cada Fase ( curso académico), siendo el Objetivo general la Implantación del BIM en la Escuela y teniendo en cuenta que los Usos BIM en el BAP se verán reducidos al ámbito del Diseño.

- La definición de Roles dentro de la propia estructura de la Escuela, en departamentos y dirección, así como dentro del propio alumnado en fases más avanzadas.

- Los protocolos de colaboración en los distintos cursos académicos. Inicialmente la colaboración será mínima, reduciéndose al tipo Alumno-Área de Conocimiento (Cliente), pero a medida que avancen los cursos se establecerán relaciones más complejas. En la Fig.4 se muestra la evolución de los procesos colaborativos según nivel de desarrollo del proyecto.

- La estandarización de la nomenclatura en diferentes aspectos del proyecto. fundamentalmente en: elementos, espacios, vistas y documentación. En la última Jornada es.BIM, en enero de este año (2017), el subgrupo de trabajo 3.3-(Niveles de Detalle), se opta por tomar como referencia el sistema de británico de Clasificación Uniclass, que se ha creado para estructurar la información que usan todos los agentes que intervienen en el proyecto. De este modo, en el BAP tomaremos de referencia el mismo documento, prestando especial atención a las tablas EF (Elements/functions) y SL (Spaces/locations), que se refieren a aspectos con bastante relevancia a la hora de enunciar los objetivos o el alcance de un determinado curso académico ( fase del proyecto). También habrá que establecer criterios para la documentación de la entregas, y sus plantillas de vista

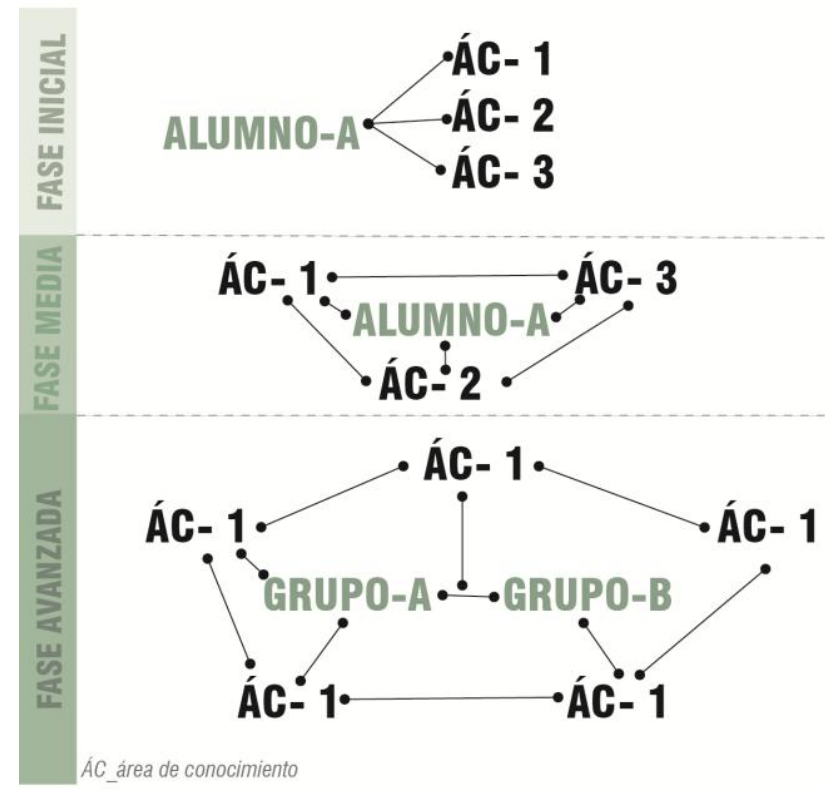

Fig.4.- Definición de los procesos colaborativos en el BAP según la fase de desarrollo del proyecto/curso académico y los agentes del proyecto: alumnos y áreas de conocimiento. Elaboración Propia. 2017. 


\section{Formación}

En el ámbito de la formación el Plan debe tener en cuenta uno de los principios fundamentales de la Filosofía BIM; la interoperabilidad y el trabajo colaborativo. La enseñanza de un único software en las Escuelas, no sólo ayudaría a la monopolización del mercado, sino que iría en contra del trabajo mediante archivos IFC, que aunque en la actualidad este aspecto sea un punto débil en el Método BIM, debemos confiar desde las Escuelas en la mejora del mismo.

\section{AUDITORIA DE MODELOS}

Plantear una estrategia de revisión de "AVISOS SIN RESOLVER"
Plantear un protocolo de higiene de modelos
Desenlazar
Auditar
Compactar
Purgar Patrones de línea
Purgar Materiales
Purgar componentes
Purgar filtros y parámetros de proyecto
Eliminar vistas no necesarias
Controlar el orden en los Worksets
No importar archivos de CAD
Controlar la extensión de los archivos vinculados
Controlar el número de vistas que no están en planos
Ajustar escalas y niveles de detalle
Ajustar visibilidad de links y worksets
Ajustar visibilidad de categorías
Racionalizar la profundidad de vistas especialmente en alzados y secciones
........

Fig.5. - Fragmento de las Buenas prácticas de Modelado de Typsa. Joaquín López.2016

Continuando con el paralelismo con el ámbito laboral, la formación en las empresas/estudios puede darse de forma Externa (mediante consultoras), Interna (incorporación al equipo de nuevos roles), o Mixtas.

En las Escuelas el método de formación será mixto, ofreciendo formación extracurricular de distintos software, para no reducir el contenido de otras asignaturas de la titulación, e internamente en las Escuelas se propone añadir dos nuevas asignaturas en Quinto y Tercer curso respectivamente.

- Gestión de la Información BIM

- Dinámicas de Trabajo:

1. Buenas prácticas de modelado

2. Buenas prácticas de cultura de producción.

Dinámicas de trabajo será una asignatura orientada a la auditoría del modelo independientemente del software que use cada alumno. Se estudiarán medidas como: 
La formación no sólo está orientada a los alumnos, también a profesores y personal de la Escuela directamente relacionado con la implantación del BAP, que deben tener, como mínimo, conocimientos de Gestión de la metodología.

\section{Filosofía BIM}

El tercer y último ámbito está muy relacionado con el nivel de Madurez BIM que se debe alcanzar. Para que la Implantación del BIM en las Escuelas no se quede en soluciones complementarias, es fundamental la implicación y el entusiasmo por parte del equipo Directivo, así como que tengan los conocimientos necesarios para la redacción del BAP. En términos de empresa, el Director de la Escuela tendría su homólogo en un BIM Manager.

Existen muchas actitudes y acciones que pueden generar una atmósfera de cambio favorable al proceso de la Implantación. Algunas de ellas son:

- La adopción temprana de la terminología BIM, en cuanto a roles, protocolos, o formas de trabajo es una buena manera de interiorizar el cambio y familiarizarse con los procesos.

- Plantear las dinámicas de trabajo, de alumnos y profesores, desde el organigrama BIM, basado en la comunicación, frente a la jerarquía rígida de los métodos más tradicionales.

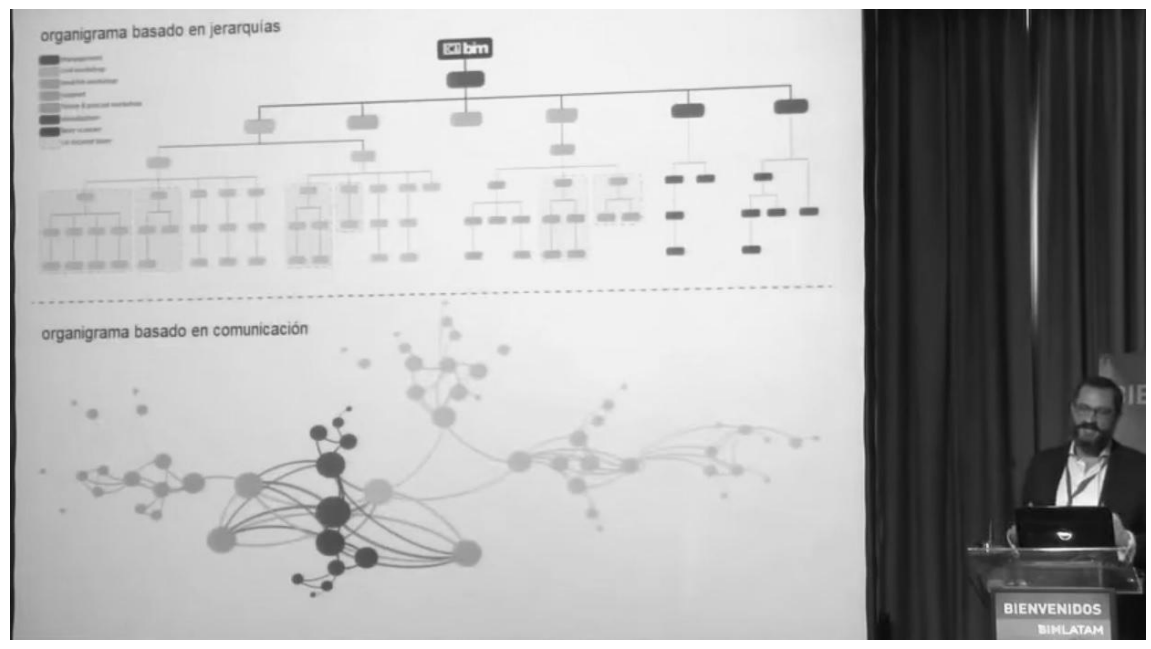

Fig.6.- Comparación del organigrama de jerarquías frente al organigrama de comunicación.1er Congreso Latinoamericano BIMLATAM - Charla de Proyecto BIM en ICA. Marco Vidali.2015

- La utilización de pautas y métodos que permitan la flexibilidad y adaptación del resto de Escuelas españolas, respetando las referencias y normativas que marque el $\mathrm{BSSCH}$, para conseguir una verdadera estandarización en el método a la vez que se deja margen para la personalización.

España se encuentra en el momento adecuado para introducir en sus Escuelas la metodología BIM. Se tiene la oportunidad de avanzar y definir la implantación mediante la 
ayuda mutua del ámbito laboral y el académico. Muchas de las expectativas que se esbozan en el Sector AEC derivadas del nuevo método, pasan antes por una cambio profundo en las Escuelas Técnicas.

El BAP se presenta, no solo como una estrategia de intervención global en las Escuelas, sino como otra herramienta para la reflexión de la vinculación de distintos ámbitos laborales con la formación de las nuevas generaciones.

A corto plazo el BAP pretende eliminar la duplicidad de roles actuales, y definir, de acuerdo a las titulaciones españolas, la correlación con los perfiles/roles británicos, mediante una adecuada formación en la Metodología BIM desde las Escuelas que permita una verdadera especialización después.

A largo plazo pretende ser un documento de referencia para las Escuelas españolas con la intención de estandarizar y establecer unos criterios fijos en la formación de los futuros arquitectos.

\section{REFERENCIAS}

[1] Eastman, Chuck, Liston, Kathleen, Sacks, Rafael y Teicholz, Paul (2008). BIM: Handbook: A guide to Building Information Modeling for Owners, Managers, Designers, Engineers and Contractors.

[2] Gallego Navarro, T y Huedo Dorda, P, Introducción del concepto Building Information Modeling en el Grado en Arquitectura Técnica de la Universidad Jaime I. Congreso Internacional EUBIM 2015.

[3] Cos-Gayon López,Fernando, Experiencia de implantación de metodología BIM en plan de estudios del Máster universitario de Edificación de las Universidad Politécnica de Valencoa, Congreso Internacional EUBIM 2016.

[4] Web: BIM ThinkSpace: BIM Episode 11: The difference between BIM capability and BIM maturity.

[5] Luisa Santamaría, J.H Guadalupe, Salto al BIM: Estrategias BIM de calidad para empresas punteras del sector AEC. 2017

[6] http://bim.psu.edu/

[7] http://www.cpic.org.uk/wp-content/uploads/2013/06/cpix pre-contract bim execution plan bep v2.0.pdf

[8] https://www.youtube.com/watch?v=P-L5j1kOtwk\&t=477s

[9] http://bim.psu.edu/Uses/ 


\title{
MODELADO Y SIMULACIÓN ENERGÉTICA DE EDIFICIOS CON HERRAMIENTAS BIM EN LA DOCENCIA DE GRADO EN INGENIERÍA DE EDIFICACIÓN
}

\author{
Pérez Andreu, Víctor (1). Castilla Pascual, Francisco Javier (2)
}

(1) Universidad de Castilla- La Mancha. victor.perez@uclm.es

(2) Universidad de Castilla- La Mancha. fcojavier.castilla@uclm.es

\section{RESUMEN}

La demanda y el consumo energético de un edificio a lo largo de su vida útil, así como de la energía consumida durante su construcción y las emisiones de $\mathrm{CO} 2$ asociadas a todos estos procesos (como indicador de impacto medioambiental) son cuestiones cada vez más prioritarias y determinantes en la toma de decisiones en un proyecto arquitectónico.

La evaluación de todos estos parámetros en las distintas fases de desarrollo de un proyecto viene siendo un tema recurrente al que distintas plataformas en el entorno Building Information Modelling (BIM) han respondido con sus propios módulos de trabajo. Por otro lado los programas informáticos especializados en simulación energética, así como los requeridos para realizar comprobaciones normativas o certificaciones energéticas no siempre resultan todo lo compatibles que se anuncia con los ficheros de intercambio. La definición de la envolvente de un edifico en el entorno BIM de forma que se pueda interpretar por estos programas es una de las cuestiones claves a resolver.

Con esta ponencia se pretende aportar y discutir la metodología de modelado energético, basada en los resultados obtenidos en prácticas docentes de distinto alcance (trabajos de cursos, trabajos fin de grado, participación en concurso BIM en el grado de ingeniería de edificación, que han permitido establecer unas pautas para la docencia universitaria, donde el flujo trabajo y los resultados sean los adecuados en cada fase, acorde a los objetivos que se persiguen.

Palabras clave: ACV, energía, envolvente, modelado, simulación, docencia

\section{ABSTRACT}

Energy demand and consumption of a building over its whole life, as well as the energy consumed during its construction and the $\mathrm{CO}_{2}$ emissions associated with all these processes (as an indicator of environmental impact) are increasingly determinant and important issues in decision making in an architectural project.

Evaluation of all these parameters in the different phases of development of a project has been a recurrent question to which different BIM platforms have responded with their own working modules. On the other hand, computer programs specialized in energy performance simulation as well as those required to perform regulatory checks or energy certifications are 
not always compatible with the exchange files. The definition of the building envelope in BIM platforms so that it can be interpreted by these programs is one of the key questions to be solved.

This paper intends to contribute and discuss the methodology of modeling, based on the results obtained in teaching practices of different scope (course work, final degree work, participation in BIM competition) in the degree of building engineering, in order to establish guidelines for the working flow and obtain appropriate results in each phase, according to the objectives pursued.

Keywords: LCA, energy, building envelope, modeling, simulation, teaching.

\section{$1 \quad$ INTRODUCCIÓN}

Existen diversas razones que determinan la necesidad de simular el comportamiento energético de un proyecto o de un edificio, así como diversos procedimientos y herramientas que permiten su realización.

Por un lado la reglamentación edificatoria puede determinar la certificación del cumplimiento de unos estándares en esta materia, para los edificios y sus proyectos. Estas certificaciones energéticas oficiales, en el contexto europeo, derivan del cumplimiento de la directiva Energy Performance Building Directive (EPBD) [1] y que se ha aplicado en 29 países en total, enmarcándose en las estrategias políticas y administrativas de lucha contra cambio climático y dependencias energéticas. En 19 de lo estos estados la certificación se exige mediante el uso de un software determinado [2].

Por otro lado existe la necesidad de calcular las demandas energéticas de la forma más automatizada y precisa posible que se ajusten a estos requerimientos y a un nivel de confort determinado. Es habitual realizar el cálculo de cargas de los sistemas de climatización y ventilación, mediante simulación de unas condiciones extremas de denominadas de diseño, establecidas previamente.

También existe la necesidad de realizar simulaciones energéticas del funcionamiento del edificio en el tiempo, normalmente un año tipo, o a lo largo un ciclo de vida estimado, para analizarlo con la pretensión de lograr ciertos retos en materia energética y medioambiental en general, o en las situaciones determinadas por ciertos sistemas de evaluación y de calificación, tales como BREEM, LEED o VERDE, que consideran, cada uno a su manera, además de los parámetros energéticos, muchos otros relacionados con la sostenibilidad, la eficiencia medioambiental y confort de los edificios, establecen un sistema de puntuación que permiten su clasificación, y justificación. Otros sellos, como PASSIVHAUS, LOWENERGY o ZERO CARBON, desarrollan sus propias herramientas de análisis, como es el caso de la aplicación Passive House Planning Package (PHPP).

Finalmente tenemos los Análisis del Ciclo de Vida (ACV) de productos, necesarios para tener un conocimiento completo del alcance del impacto medioambiental de los mismos. 
Estos constituyen una tarea muy compleja, debido a los procedimientos, a la diversidad de agentes y parámetros que son necesarios para su realización, y por lo tanto es necesaria la identificación y gestión de la gran cantidad de información necesaria para llevarse a cabo. En el caso del estudio del ciclo de vida aplicado a los edificios, se multiplica en gran medida la complejidad de su realización si se pretende el análisis pormenorizado para cada uno de los materiales, productos y procesos que interviene. De forma que se recurre a realizar un trabajo por partes, distinguiendo niveles (materiales, componentes y el propio edificio) [3] y fases (extracción de materiales, fabricación de productos, transporte, construcción, uso, mantenimiento, desmontaje, demolición, reutilización, reciclaje y gestión de residuos), utilizando métodos simplificados y definiendo objetivos a alcanzar, que permitan reducir el número de parámetros de estudio de forma directa y determinar la utilización de bases de datos fiables de materiales, procesos, consumos, emisiones, etc. que nacen de estudios específicos ya realizados previamente o basados en datos de declaraciones ambientales de producto.

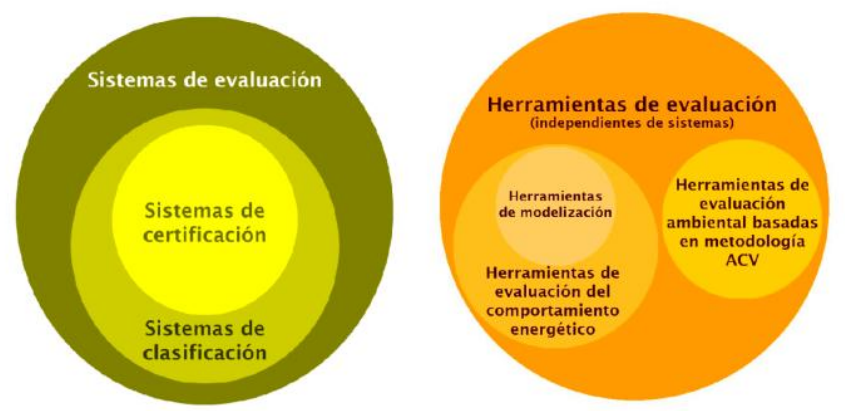

Fig 1. Sistemas y herramientas de evaluación. 2015. IHOBE.

La incorporación de estos procedimientos al ejercicio profesional de una forma normalizada y eficiente, así como a la docencia de las ingenierías y las profesiones relacionadas son absolutamente necesarias para alcanzar los objetivos de las estrategias medioambientales y las políticas humanas para el cambio climático y la reducción de la dependencia energética.

\section{GESTIÓN MEDIOAMBIENTAL DE EDIFICIOS EN ENTORNOS BIM}

El modelado con información para la construcción (BIM, por su siglas en inglés) se presenta como una metodología tecnológica que promueve la productividad y eficiencia en la industria de la construcción que aprovecha la información generada a lo largo de su ciclo de vida mediante la interoperabilidad entre herramientas que comparten bases de datos comunes y dinámicas. El uso del BIM se está extendiendo en el sector de la edificación por una eficacia demostrada, y está en un continuo desarrollo que proporciona el desarrollo tecnológico en general, y el abaratamiento de los medios tecnológicos que lo facilitan, respondiendo a una creciente demanda del sector de la arquitectura, la ingeniería y la construcción ( $A E C$, por sus siglas en inglés).

Desarrollar proyectos considerando los factores energéticos y medioambientales en la toma de decisiones, determina la necesidad de su integración en las fases iniciales, y permitir 
además una conveniente retroalimentación con el resto de disciplinas que condicionan, determinan y conforman finalmente la edificación.

La integración de este tipo de gestión en los proyectos y estudios de edificios en una metodología BIM exige que: la información relacionada con los modelos arquitectónicos, estructurales y los modelos de instalaciones, sea compartida con los modelos energéticos: geometría, materiales constructivos, características de instalaciones, parámetros de acondicionamiento y uso deben ser comunes entre todos los modelos. Por lo tanto, las herramientas de gestión de información energética felizmente integradas en el contexto BIM deben resolver los posibles problemas del tratamiento e intercambio de la información necesaria.

Generalmente, para los análisis del comportamiento térmico de edificios se realizan procesos de simulación del rendimiento energético. Las herramientas que se utilizan basan su funcionamiento en motores de cálculo que permiten la entrada de datos, normalmente alfanuméricos, y salida de los resultados. Habitualmente, en los estudios realizados en un contexto profesional, se utiliza un interfaz gráfico que facilite las entradas de información y las salidas de resultados para la realización de informes de resultados y análisis [4] Sin embargo en los trabajos de investigación que comprenden simulaciones se trabaja con aplicaciones que presentan una mayor versatilidad para un mayor control de los parámetros.

\subsection{Procesos informáticos convencionales para gestión y certificación energética de edificios}

Tratar esta materia precisa particularizar en los diferentes flujos que se producen en el análisis energético y medioambiental de proyectos y edificios. Estos pueden clasificarse de forma general en: certificaciones energéticas, diseño de instalaciones y análisis del comportamiento energético medioambiental de un edificio o de un componente, en el tiempo.

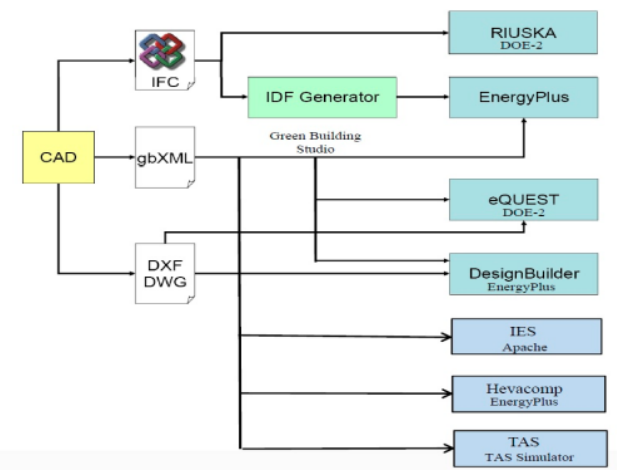

Fig 2. Gráfico actualizado por el autor de diagrama editado por el Center for Integrated Facility

Engineering (CIFE), Stanford University. 2017.

En un contexto general, y en relación a la interoperabilidad entre aplicaciones de simulación energética y medioambiental que se integran en contextos $B I M$, existen dos tipos de flujo de información que se sustentan en los formatos GBXML y el IFCXML respectivamente. Ambos son formatos soportados por diferentes herramientas de simulación energética de edificios, son de código abierto, sirven para la transmisión de los modelos energéticos, y se disponen 
de una gran comunidad apoyando su uso y desarrollo de forma activa. Puede decirse que GBXML es un lenguaje específico para la codificación y transferencia de información relativa a los modelos de análisis energéticos de los edificios, mientras que IFC es primordialmente un formato de archivo en un lenguaje especifico que pretende el intercambio de todos los datos de los modelos BIM.

En cualquier caso, estas exportaciones resultan imperfectas con frecuencia, y a diferencia de lo que cabría esperar, los resultados de exportación siguen siendo de poca calidad y en consecuencia no utilizables directamente, sin revisiones. Esta cuestión, tal y como se expone más adelante, viene siendo de considerable interés durante los últimos años, y se manifiestan en diferentes estudios análisis de investigación sobre exportación de estos dos tipos de archivo, utilizando diferentes plataformas.

\subsection{Procedimientos para la justificación de cumplimiento del marco normativo}

De forma más particular, para el caso de los procedimientos de certificaciones de cumplimiento de la normativa energética relacionada, se deben realizar simulaciones energéticas con una serie de herramientas oficiales que sean compatibles con las diversas situaciones. Aunque existen diversos procedimientos en el contexto del Estado español, aquí se trata únicamente el procedimiento general de análisis y certificación energética mediante la utilización de las herramientas HULC y CALENER GT, por ser las que abordan mayor casuística y las que a priori proporcionan resultados más aproximados, en materia de certificación energética.

CALENER GT utiliza como motor de cálculo el programa DOE.2.2 y como modelador gráfico la aplicación HULC [8]. Esta última utiliza el programa S3PAS. Los procesos de transferencia automática de datos a estas herramientas en un entorno BIM se reducen, a la transferencia de la geometría del edificio mediante la importación de la huella 2D del modelo del edificio en formato DXF para posteriormente implementar el modelo con las herramientas del programa, o bien, en el mejor de los casos, transferir la geometría 3D, incluso con propiedades materiales de los elementos, mediante la utilización de plug-in que convierten datos del programa de origen al formato CTEHEXML propio de la aplicación HULC. En cualquiera de estos casos el modelo geométrico origen debe ser definido o convertido a los requerimientos del programa, por lo que en la práctica este modelo acaba siendo específico y unidireccional. Los sistemas de climatización no se exportan normalmente y se implementan de forma manual dentro del programa, con alguna excepción en las que existe una transformación al tipo de como sistemas ideales de climatización de rendimiento constante.

Realizadas las simulaciones y alcanzado el grado de cumplimiento deseado, la información se dispone en formato CTEHEXML, verificable por oficialidad, y solo reutilizable de forma manual. Los resultados proporcionan información relacionada con la demanda energética, consumos previstos e impacto en emisiones de $\mathrm{CO}_{2}$ necesarios para la justificación de la normativa, y la clasificación reglamentaria por comparación, permitiendo comprender el comportamiento medioambiental del edificio en esa escala. Sin embargo solo son válidos a efectos de justificación de reglamento, y no son suficientemente precisos para un cálculo de 
las demandas del edificio necesarias a nivel del diseño de instalaciones, y por lo tanto, insuficientes como modelización para una auditoría o un proyecto. De tal forma que, los resultados alcanzados, tras las sucesivas fases de ensayo y error que normalmente son necesarias en el programa para alcanzar los estándares normativos, y que determinan y justifican el cumplimiento de los mínimos de exigencia térmicas en la envolvente y de las características de los sistemas, se trasladan posteriormente, de forma manual, al modelo arquitectónico y constructivo que habría que desarrollar de forma detallada como proyecto.

\subsection{Rendimiento operacional de flujos de gestión medioambiental}

Analizando los diferentes flujos y procedimientos se comprueba que la realización de los modelos de simulación energética requiere un significativo esfuerzo en tiempo y costes. A pesar de que los modelos simulación energética precisan de la información existente en los modelos arquitectónicos BIM y que estos contienen aproximadamente el $70 \%$ de la información necesaria para su realización [5], continúan siendo finalmente una laboriosa tarea en la que es fácil acometer errores, convirtiéndose en toda una carrera de obstáculos en la que, con cierta frecuencia, los procesos de intercambio de archivos los resultados obtenidos denotan imperfecciones que incompatibilizan el modelo sin una revisión manual, a la vista de una insuficiente identificación de objetos y de materiales, y baja fiabilidad de resultados [6].

Esto se debe a que las diferencias que existen entre el modelo arquitectónico y el modelo necesario para la simulación no han sido suficientemente resueltas mediante procesos automáticos. La automatización de las conversiones geométricas falla especialmente cuando se originan desde modelos detallados. Las características de los modelos geométricos y de información necesarios para los procedimientos de simulación energética digital no corresponden conceptualmente ni en grado de simplificación a los desarrollados con finalidad del diseño y documentación de las materias arquitectónicas y constructivas.

Así, una imperfecta interoperabilidad entre aplicaciones provoca que en muchos casos la realización de estas tareas siga siendo manual o semiautomática en el mejor de los casos, y que requieran de especialistas de mucha experiencia para su operación, en la revisión, cumplimentación y verificación de los modelos, datos de entrada y salida, que realizan constantes revisiones y actualizaciones manuales de datos [7]. Es evidente que estas situaciones provocan la dilación en el tiempo de los proyectos, la comisión de errores, y pérdidas de calidad de los resultados y aumento de costes.

Por lo tanto en la realidad del contexto profesional sigue siendo complejo integrar de forma conveniente en el flujo BIM la gestión medioambiental de los proyectos, en muchos casos económicamente inviable y en última instancia, más lejana la necesaria adecuación medioambiental del parque edificatorio. A pesar de los enormes avances realizados en esta materia durante los últimos años, todavía es necesario mejorar la automatización y la interoperabilidad de la información relacionada con las simulaciones energéticas en un entorno BIM. 


\subsection{Exposición de metodologías y herramientas docentes utilizadas en la docencia de la gestión medioambiental de edificios en entornos BIM}

El objeto de este apartado es mostrar la implementación de esta materia en el Grado de Ingeniería de Edificación de la Universidad de Castilla La Mancha, reduciendo la cuestión al ámbito profesional y académico que contextualiza esta actividad docente y que ha determinado los objetivos, contenidos científicos técnicos, herramientas y flujos de trabajo y que a través de ella se vienen desarrollando. A continuación se presenta una descripción de estos conceptos para concretar en las interacciones entre aplicaciones y la obtención de resultados que se ha venido obteniendo.

Cuando las simulaciones se realizan para el diseño de instalaciones o el análisis del comportamiento energético de un edificio o proyecto, viene siendo habitual, en nuestro ámbito académico, la utilización de herramientas tales como Revit, Archicad, Green Building Studio también de Autodesk, Cype o DesignBuilder. Este último sustituye en a EnergyPlus en docencia, por tener un interfaz más amigable. Aunque existen otras, no se incluyen en nuestro caso, por la única razón de no formar parte de nuestro catálogo de herramientas disponibles y validadas por nosostrotros, para la docencia y práctica dirigida a nuestros estudiantes, y por tanto están fuera de las experiencias docentes que aquí se exponen.

El catálogo de herramientas incluye también las aplicaciones Arquímedes y TCQ2000, junto a las bases de datos del Generador de Precios y BEDEC, de Cype y el ITeC respectivamente, por facilitar, de forma paralela a la justificación económica de la construcción, la contabilización de parámetros de impacto medioambiental, en forma de emisiones de $\mathrm{CO}_{2}$, como instrumento para un análisis simplificado $A C V$ de edificios (Tab.1).

En el proceso de integración de las metodologías BIM en la docencia del grado de Ingeniería de Edificación de la UCLM, se considera fundamental la colaboración entre las diferentes materias que intervienen para llevar a cabo un aprendizaje eficaz, no repetitivo, en el que las herramientas y el software se integren de una manera natural, sin necesidad de asignaturas específicas para su aprendizaje.

Los métodos de trabajo que se exponen a continuación, han sido experimentados previamente a su empleo en la formación académica, se desarrollan de forma colaborativa entre materias, y tienen que ver con el aprendizaje de utilización de estrategias pasivas para la disminución de demanda energética del edifico y la mejora del diseño de las instalaciones, mediante la práctica de herramientas BIM.

En el diseño de estas actividades, se ha podido comprobar que es con frecuencia es necesario revisar los modelos de intercambio e incluso que en ciertas ocasiones hay desestimarlos totalmente, por ser muy compleja o laboriosa su adecuación mediante revisiones, modificaciones y nuevas entradas de datos. Esto podría deberse a errores de operación, pero tal y como se ha explicado en el apartado anterior con frecuencia se debe a la incompatibilidad entre formatos de datos y sistemas de transferencia.

Más concretamente, se ha experimentado que uno de los principales inconvenientes para la realización de análisis energéticos en el entorno BIM es la dificultad de compatibilizar los 
modelos arquitectónicos definidos por elementos con los modelos basados en espacios y zonas térmicas. También que este inconveniente puede ser resuelto mediante la utilización de modelos geométricos conceptuales iniciales como base de los modelos energéticos para gestión ambiental, aprovechando que los requeridos por los simuladores deben ser geométricamente simplificados y la necesidad de obtener de forma temprana resultados de simulaciones comparadas para desarrollar las soluciones constructivas y de instalación para desarrollar el estudio o proyecto arquitectónico. De esta forma se ha comprobado de manera práctica que simular en las fases iniciales del proyecto arquitectónico, a partir de un modelo conceptual que atienda a las cuestiones energéticas y medioambientales, armonizado con las bases funcionales y de diseño del edificio, no solo es una exigencia del proceso de análisis arquitectónico, sino que determina una mejor interoperabilidad entre herramientas de modelado arquitectónico y energético, permitiendo el desarrollo del proyecto de una forma más eficaz.

Desde esta experiencia, se ha establecido una colaboración progresiva entre diferentes materias que se inicia desde la de Expresión Gráfica del primer curso. Partiendo del conocimiento y manejo básico de las herramientas de modelado de formas geométricas, se formaliza un modelo de masas para configurar un modelo arquitectónico conceptual, con el que se realizan simulaciones básicas de los modelos energéticos correspondientes, para optimizar forma y compacidad del edificio objeto de los ejercicios a partir de resultados obtenidos (Fig. 3).

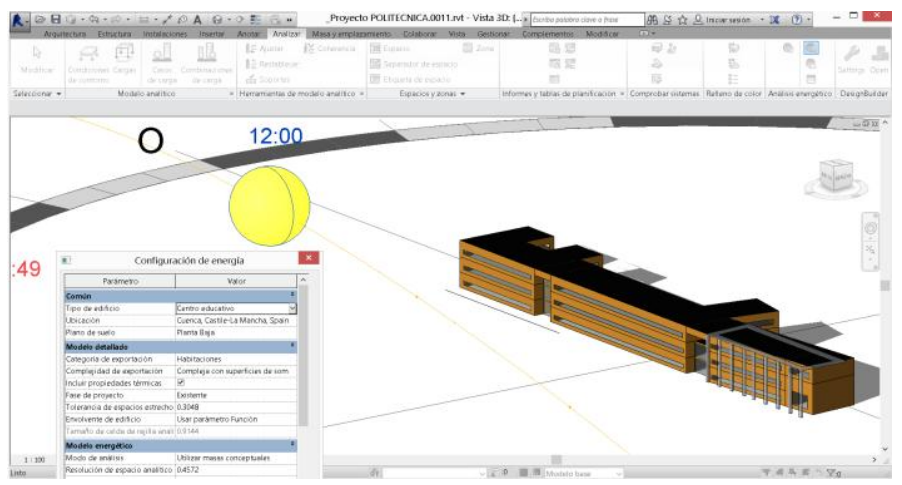

Fig 3. Modelo energético conceptual Revit de la E. Politécnica de Cuenca. Fuente propia. 2015.

Posteriormente se convierte el modelo conceptual optimizado y ensayado en un modelo más detallado convirtiendo sus superficies en sistemas constructivos, mediante las opciones semiautomáticas del programa. Estos elementos constructivos básicos que conforman la envolvente, se caracterizan consecuentemente, detallando sus materiales desde la materia de Construcción correspondiente al mismo curso, y de forma coordinada entre estas dos materias. Esto inicia y facilita al estudiante, ya en sus fases formativas iniciales, la compresión y el manejo de herramientas de gestión, del impacto medioambiental de los edificios, y como este se determina, de forma pasiva, desde la forma geométrica del diseño arquitectónico y su materialización constructiva. 


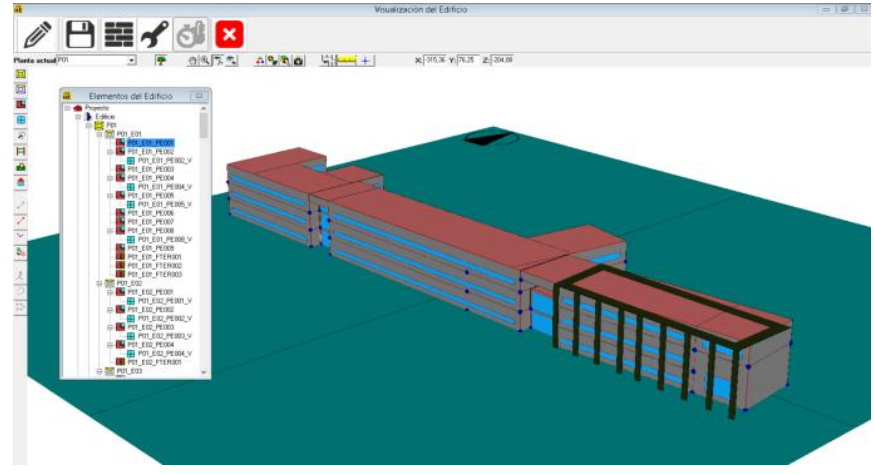

Fig 4. Modelo energético CTEHEXML de la E. Politécnica de Cuenca obtenido por conversión de formato GBXML. Fuente propia. 2015.

En cursos sucesivos el grueso de las materias evoluciona hacia un mayor conocimiento de la ingeniería de la edificación, mediante el estudio fundamental de los elementos y sistemas constructivos, estructurales y de instalaciones, y su gestión documental. Para evitar presentar estas materias de forma fragmentada por la exclusiva perspectiva de cada una de las asignaturas, se considera la oportunidad que proporciona la metodología BIM para la integración práctica de diferentes disciplinas, y se han diseñado actividades que se desarrollan como prácticas coordinadas entre materias. Entre ellas las que abordan cuestiones energéticas y medioambientales, se incluye la modelización del cumplimiento de exigencias normativas (Fig. 4), el cálculo las demandas del edificio para el de los sistemas de instalaciones (Fig. 5), y el desarrollo detallado de modelos completos de edificación que partiendo de estas consideraciones permiten, en algunos casos, practicar la interoperabilidad entre distintas herramientas.

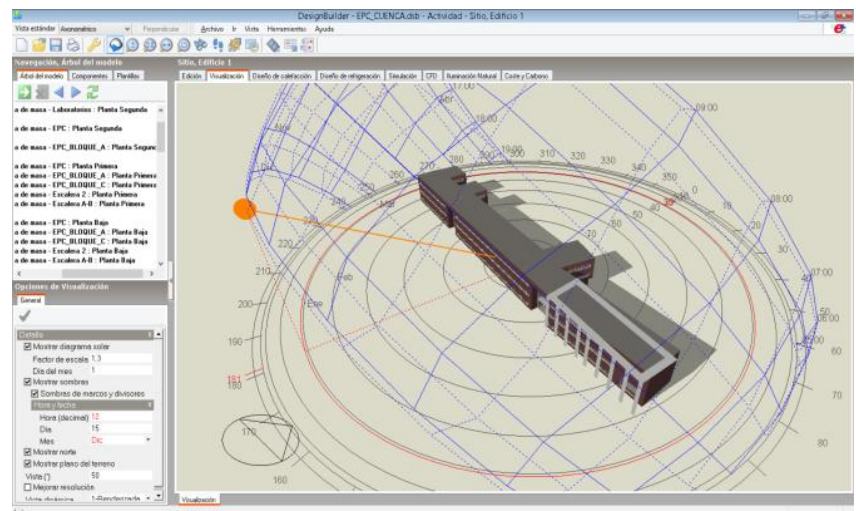

Fig 5. Modelo energético GBXML de la E. Politécnica de Cuenca, en DesignBuilder. Fuente propia. 2015.

En el último curso y en el Proyecto Final de Grado (PFG), de forma optativa por parte del estudiante, se trabaja con la sostenibilidad medioambiental y energética de los edificios de una forma más específica. Se realizan trabajos en los que se configuran modelos de simulación para el análisis completo de comportamientos térmicos, energéticos y medioambientales, que validen las estrategias de determinadas en las fases de diseño conceptual de edificios, y experimentando las transferencias de información entre diversas herramientas BIM que son necesarias. 
Otra de las cuestiones clave a resolver es el trabajo colaborativo. Si la estrategia expuesta nos permite implementar los conocimientos necesarios a nivel individual, es necesario incorporar otras que permitan llevar a la práctica la verdadera esencia del $B I M$, y que implica la coordinación entre especialistas de distintas áreas a través de los modelos de trabajo. En nuestro caso hemos encontrado, en los espacios de participación de concursos o competiciones académicas, una vía eficaz que permite desarrollar estas competencias más específicas para la formación de los ingenieros de edificación, donde existe una motivación adicional para los estudiantes, al tiempo que se experimenta en un mejor conocimiento del alcance y las limitaciones de las diferentes herramientas que intervienen y las posibilidades de transferencia de información entre los distintos software que son habituales para desarrollar un proyecto completo.

En relación a la enseñanza y el aprendizaje de la modelización energética de edificios, en nuestro entorno académico, se presentan ciertos problemas que se van solventando conforme se adquiere experiencia en la docencia de estas materias y en el constante desarrollo tecnológico de las herramientas relacionadas. Por un lado, el estudio del impacto energético de los edificios es una parte muy reducida de los contenidos académicos previstos en el plan de estudios vigente que lo sitúa fundamentalmente en las materias optativas de último curso. Fuera de este marco, la enseñanza de la materia se realiza desde la libertad de cátedra del profesorado. De la misma forma se presenta la incorporación del aprendizaje de las metodologías y las herramientas tecnológicas relacionadas con el BIM.

Así, es necesario encontrar un espacio temporal para armonizar los nuevos aprendizajes sin sacrificar contenidos fundamentales ya previstos en el plan de estudios, y en este contexto solo es posible conseguir todos estos objetivos mediante una metodología que aumente el rendimiento de la docencia. Por último, todo ha de llevarse a cabo con cierta prudencia pues para redefinir el catálogo de metodologías y herramientas académicas se considera, a veces con demasiada normalidad, tecnología que pertenece a diferentes plataformas desarrolladoras de software y que ofrecen herramientas y las compatibilidades bajo sus intereses comerciales.

Teniendo en cuenta estas consideraciones, se establecen y se producen actividades académicas desde las diferentes posibilidades que proporcionan las herramientas dispuestas, los diferentes grados de satisfacción obtenidos por los resultados que proporcionan y su interoperabilidad. En nuestro caso, la confrontación entre los diversos procedimientos desarrollados en los concursos y competiciones, ha permitido determinar la validez académica de las herramientas (Tabla 1) y algunos de los procesos de trabajo, comprobando la facilidad y fiabilidad de la información, y de su reutilización.

Recientemente nuestros estudiantes participantes en los concursos de los congresos BIMTECNIA (BIMValladolid 2017) [9] y del 2017Building Simulation Conference Student Competition [10], pudieron comprobar la validez de los flujos de trabajo desde el aprendizaje académico de un flujo BIM de análisis energético en las primeras fases del diseño del proyecto, además de poder experimentar otras opciones. En estos casos se trabajó con Archicad o Revit para el desarrollo de un modelo arquitectónico conceptual, una vez 
obtenido una primera propuesta la que se incluía la configuración inicial de todos los espacios del programa funcional del edificio, y que conformaba el modelo GBXML, a partir del cual se analizaron parámetros de compacidad como la distribución de huecos y distancias idóneas de voladizos como elementos de protección solar para minimizar la demanda, mediante la exportación a Green Building Studio, para mejorar optimizar la forma y compacidad del edificio y ensayar básicamente diferentes sistemas de instalación. La exportación del GBXML resultante a DesignBuilder permitió la optimización del conjunto, arquitectónico, constructivo y de instalación.

Tabla 1. Herramientas de prácticas de gestión medioambiental de edificios. Fuente propia. 2016.

\begin{tabular}{|c|c|c|c|c|}
\hline $\begin{array}{l}\text { MODELO } \\
\text { GEOMÉTRICO } \\
\text { CONCEPTUAL }\end{array}$ & $\begin{array}{l}\text { ANÁLISIS ENERGÉTICOS } \\
\text { CONCEPTUALES }\end{array}$ & $\begin{array}{l}\text { ENSAYOSY } \\
\text { VERIFICACIÓNES } \\
\text { DEL CTE }\end{array}$ & $\begin{array}{l}\text { SIMULACIÓNES } \\
\text { ENERGÉTICAS } \\
\text { GLOBALES }\end{array}$ & $\begin{array}{l}\text { ESTUDIOS DE COSTES } \\
\text { ECONÓMICOSY } \\
\text { MEDIOAMBIENTALES }\end{array}$ \\
\hline $\begin{array}{l}\text { R } \\
\text { Archingesk } \\
\text { Architecture }\end{array}$ & 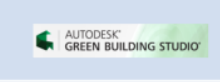 & 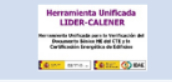 & DesignBuilder & 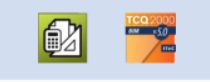 \\
\hline - Revit & $\begin{array}{l}\text { - Green Building } \\
\text { Estudio }\end{array}$ & - HULC & - DESIGNBUILDER & $\begin{array}{l}\text { - Arquímedes } \\
\text { - TCQ2000 }\end{array}$ \\
\hline 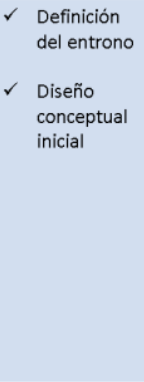 & $\begin{array}{l}\checkmark \text { Ensayos de } \\
\text { compacidades } \\
\text { Ensayos de } \\
\text { transmitancia } \\
\checkmark \quad \text { Ensayos de } \\
\text { esquemas básicos } \\
\text { de instalación }\end{array}$ & $\begin{array}{ll}\checkmark & \text { HEO } \\
\checkmark & \text { HEI } \\
\checkmark & \text { CALIFICACIÓN } \\
\checkmark & \text { CERTIFICACIÓN }\end{array}$ & 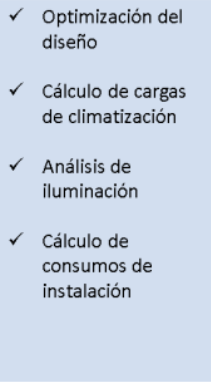 & $\begin{array}{l}\checkmark \text { Análisis y cálculos } \\
\text { económicos } \\
\text { Estimación de } \\
\text { costes } \\
\text { medioambientales } \\
\text { de fases de ciclo } \\
\text { de vida de edificios }\end{array}$ \\
\hline
\end{tabular}

En el primer caso, no fue posible trasladar los resultados más óptimos de los diferentes ensayos y análisis, con tiempo suficiente, a un modelo arquitectónico detallado, pues la tarea de vuelta de resultados al modelo detallado, sigue siendo fundamentalmente manual y demasiado escasa la duración de los tiempos de competición del concurso. Normalmente obtenemos modelos CTEHEXML desde DesignBuilder mediante la herramienta de exportación LIDER, una vez optimizado el modelo, para su comprobación reglamentaria. En esta ocasión, definido el modelo arquitectónico completo se realizó una exportación a HULC, esta vez mediante el plug-in de Aplicad CTE HULC, para la justificación normativa de la propuesta. Para conseguir una correcta transferencia fue necesaria la realización de importantes tareas manuales desde el modelador de Revit para simplificar la geometría a la forma que determina el programa y desde el plug-in para la reasignación de los materiales admitidos por la herramienta oficial.

\section{CONCLUSIONES}

La gestión de la información relacionada con el comportamiento medioambiental de los edificios a lo largo de sus ciclos de vida exige el proceso de grandes cantidades de datos y por ello es imprescindible la utilización de diferentes herramientas informáticas. Para una gestión eficiente de tiempos y costes de los procesos de estudio y gestión de la eficiencia medioambiental de los edificios, es necesario establecer y conocer los niveles y objetivos a 
alcanzar, así como las metodologías y herramientas a emplear, en las fases previas de sus proyectos, con la finalidad de reducir la probabilidad de revisiones y actualizaciones de la información y la documentación ya elaborada.

Se comprueba que la efectividad de transferencia de datos entre las aplicaciones genéricas de diseño arquitectónico BIM, que teóricamente permiten trasladar información a los programas de simulación, está muy relacionada con la forma en la que los modelos sean realizados, ya en origen, con las especificaciones de estos programas, y por tanto, sean realizados con este exclusivo propósito, invalidando en cierta medida la premisa BIM de utilización modelos informativos únicos que eviten información contradictoria y errores. En concreto, la realización de modelos arquitectónicos conceptuales que definan el programa funcional del edificio de forma armonizada con las simplificaciones y al rigor geométrico que necesitan los modelos energéticos, facilita la transferencia de datos entre los programas genéricos de modelado y las diferentes herramientas de simulación energética, generándose procedimientos semiautomáticos que reducen en gran medida los tiempos convencionales de modelización energética. No obstante, existen investigaciones para la mejora de esta automatización un constante desarrollo tecnológico que avanza en esta dirección, esperando abaratar y facilitar estos procesos.

Desde un punto de vista académico, existen ciertas dificultades para incorporar de forma reglada, la enseñanza y el aprendizaje del comportamiento medioambiental de los edificios mediante herramientas de simulación integradas en entornos BIM. Sin embargo se ha comprobado que es posible realizar ese aprendizaje iniciándolo en primer curso, mediante el desarrollo de modelos de edificios comunes a la práctica entre diferentes materias, y la incorporación de estos conceptos, desde modelos y estudios conceptuales a los más detallados, de forma progresiva, a través de las asignaturas troncales y obligatorias de los diferentes cursos del grado. Para completar el mapa de competencias formativas necesarias en estas materias, se puede potenciar la realización de estudios específicos y la utilización de tecnología reciente, de forma más experimental, en las asignaturas optativas y en el proyecto o trabajo final de grado, y especialmente en la participación en competiciones interuniversitarias relacionadas con la simulación energética.

\section{$4 \quad$ REFERENCIAS}

[1] Directive 2010/31/EU of the European Parliament and of the Council of 19 May 2010 on the energy performance of buildings.

[2] Gavilán, A. (2015) Análisis comparativo de la eficiencia energética en edificios existentes en con diferentes herramientas de simulación energética. Tésis Doctoral. Departamento de Energía y Fluidomecánica. Universidad de Valladolid.

[3] INHOBE (2010) Sociedad Pública de Gestión Ambiental del Gobierno Vasco. Green Building Rating Systems: ¿Cómo evaluar la sostenibilidad en la edificación?. Publicación Pag. 54 
[4] Mait, T. Fisher, M. y Baznaj, V. (2007) Building Energy Performance Simulation Tools a Life Cycle and Interoprable Perspective. CIFE, Center for Integrated Facility engineering. Stanford University.

[5] Kim, Y. (2009) Energy Saving and Building Energy Analysis Program for Green Building Design Journal of the KARSE 26 (9) 65-86.

[6] Choi, J. Shin, J. Kim, M. Kim, I. (2016) Development of openBIM-based energy analysis software to improve the interoperability of energy performance assessment. Automation in Construction. 72 52-54

[7] Giannakis,, G.I. Lills, G.N. García, M.A. Kontes, G.D. Valmaseda, C. Rovas, D.V. (2015) A methodology to automatically generate geometry inputs for energy performance simulation from IFC BIM models. 14th Conference of International building Performance simulation Association procedings, India.

[8] IDEA (2009) CALENER-GT: Grandes Edificios Terciarios. Manual Técnico. 19

[9] BIMVa 2017. http://www.bimvalladolid.com/ Consulta: 20/03/2017

[10] Buildina Simulation 2017. http://www.buildingsimulation2017.org/ Consulta: 18/03/2017 


\title{
PRESENTE Y FUTURO DE LA IMPLANTACIÓN DE LA METODOLOGÍA BIM EN LA ESCUELA TÉCNICA SUPERIOR DE ARQUITECTURA Y EDIFICACIÓN UPCT
}

\author{
Pérez Navarro, Julián. Pérez Egea, Adolfo. Vázquez Arenas, Gemma (1)
}

(1) Departamento de Arquitectura y Tecnología de la Edificación. Escuela Técnica Superior de Arquitectura y Edificación. Universidad Politécnica de Cartagena (UPCT).

\section{RESUMEN}

Esta comunicación forma parte del proyecto de innovación docente que está llevando a cabo la Universidad Politécnica de Cartagena (UPCT), con el fin de adaptar la enseñanza de los Grados y Masters a la demanda actual BIM. Para trazar la estrategia a seguir, se parte de los resultados de una encuesta sobre el estado del conocimiento en la materia del Personal Docente e Investigador, así como asignaturas o materias relacionadas, impartidas en las distintas titulaciones de grado y masters de la UPCT.

En un siguiente estadio, se realiza una encuesta a los alumnos de la Escuela Técnica Superior de Arquitectura y Edificación (ETSAE), sobre las expectativas que tienen sobre esta metodología, tratando de obtener conclusiones acerca de los roles y oportunidades profesionales que se brindan con esta tecnología en el futuro inmediato. Finalmente, en esta comunicación se detallan las conclusiones de la propuesta de implantación en el Grado de Ingeniería de Edificación, abarcando el Plan de Estudios actual y con aportaciones concretas a las distintas Guías Docentes de las asignaturas del Grado.

Palabras clave: BIM, grados, ingeniería edificación, metodología, plan de estudios.

\section{ABSTRACT}

The present communication refers to the Teaching Innovation Project, taken by our University. It aims to adapt the impartation of Degrees and Masters, to the demand of BIM. In order to obtain a methodology, we have taken the results of a summary taken by an Investigatory and Teaching Work force, continued with the teaching of the different subjects of the Degrees and Masters given in the UPCT.

In a subsequent study, another survey taken from the students of "Escuela Técnica Superior de Arquitectura y Edificación", will concern the expectations, vis a vis, this system, aiming to obtain conclusions concerning the range of professional opportunities that could emerge with such technology in the immediate future. Finally, this communication will outline the conclusions emerging from the new proposals, its implementation, concerning Building Engineering. It will include the specific guidelines concerning all subjects.

Keywords: BIM, degrees, building engineering, methodology, curriculum. 
INTRODUCCIÓN

La coyuntura socio económica que atravesamos ha supuesto una alteración absoluta de la supuesta "normalidad" del sector de la edificación. Es en estas circunstancias cuando fuera de la zona de confort, se arriesga, se innova y se reinventa. El sector de la edificación se encuentra ante un cambio de paradigma similar al que supuso la aparición del CAD, pero de más hondo calado, pues ahora no se trata de modificar la forma en que se "dibujan" los planos de un proyecto, como ocurrió a mediados de los años 80 , sino en una revolución integral del proceso de gestión del ciclo de vida de la edificación, desde el proceso proyectual y constructivo hasta la completa demolición del mismo. [1]

El actual nivel de desarrollo de la tecnología relacionada con BIM y de las metodologías necesarias para su puesta en práctica está suponiendo un cambio de paradigma laboral que precisa atención para, desde el ámbito Universitario, dotar de las competencias y destrezas necesarias a los nuevos profesionales.

La Directiva 2014/24/UE sobre Contratación Pública de la Unión Europea (EUPD, European Public Procurement Directive) recomienda a los estados miembros el uso de la metodología BIM en los proyectos financiados con fondos públicos a partir de abril de 2016. [2]

El Gobierno Español por su parte el año 2015 constituyó la Comisión para la implantación de la metodología BIM en España con un horizonte de 2018, comisión liderada por el Ministerio de Fomento. [3]

La transformación que esto supone para el sector de la construcción tiene importantes implicaciones para los responsables de la educación superior de los grados en Ingeniería y Arquitectura: deben garantizar la salida de egresados con las competencias BIM que, a causa de la Directiva, van a ser requeridas a los futuros profesionales del sector.

Durante la Conferencia de Directores de Escuelas de Arquitectura Técnica e Ingeniería de la Edificación celebrada en Granada en Abril de 2016 se realizó una llamada a los responsables de la educación superior para garantizar la salida de egresados con competencias BIM adquiridas, ya que, a causa de la Directiva 2014/24/UE1 sobre Contratación Pública de la Unión Europea, van a ser requeridas a los futuros profesionales del sector. Este programa consta de 2 ejes de desarrollo: [4]

1. Modificación de la Orden ECI 3855/2007.

2. Modificación de los Planes de Estudio para adaptarlos a la nueva Orden ECI.

Será en el apartado de modificación de los Planes de Estudio donde nosotros vamos a centrar nuestra investigación.

El cambio de paradigma que representa BIM en el proceso edificatorio, atendiendo a las ya múltiples instancias que abocan a ello, implica la necesidad de dominar tanto metodología como herramientas $\mathrm{y}$, en consecuencia, un reto en lo profesional que debe trasladarse ineludiblemente a los ámbitos docentes. 
Estamos pues ante una oportunidad única para reflexionar no tanto el QUÉ enseñamos en el Grado de Ingeniería de Edificación, sino el CÓMO lo hacemos, [5] ya que el empleo de herramientas y metodología BIM puede vertebrar transversalmente el Plan de Estudios y condicionar las estrategias y metodologías docentes utilizadas.

\subsection{Análisis situación de partida en la ETSAE}

En la coyuntura actual se aprecian esfuerzos unilaterales, por parte de algunos profesores, para la introducción de las nuevas tecnologías BIM en sus asignaturas. Podemos poner como ejemplo experiencias como "InsTaller. Taller de Instalaciones" en las asignaturas de Instalaciones III de los grados de Arquitectura y Edificación [6], que ha sido extrapolada al Master de ciencia y tecnología de la edificación (CYTEA), o los cursos de verano "Entornos BIM en Arquitectura e Ingeniería" [7]. Ambas han contribuido a divulgar y difundir entre los alumnos de los últimos cursos de los estudios de la ETSAE y la UPCT respectivamente la inquietud por esta nueva forma de ejercer la profesión.

Sobre el resto de asignaturas se ha efectuado una lectura transversal de los temarios docentes, recogidos en las guías docentes disponibles de las asignaturas del grado de Ingeniería de Edificación de la ETSAE. El estudio se ha centrado en los contenidos prácticos, evaluando la posibilidad de introducir el empleo de tecnología BIM para la realización de algunos de los contenidos.

Ya desde primer curso del Grado de Ingeniería de Edificación, 2 asignaturas (una anual, Geometría Gráfica, y otra cuatrimestral, Fundamentos de construcción, las cuales suman 15 ECTS) son susceptibles de incorporar entre sus contenidos prácticos tecnología BIM, mientras que en segundo curso son 10 asignaturas cuatrimestrales (48 ECTS) las que resultan susceptibles de incorporar tecnología BIM. En tercer curso serían 11 las asignaturas (57 ECTS) y en cuarto curso 9 asignaturas cuatrimestrales (39 ECTS). Fig 1.

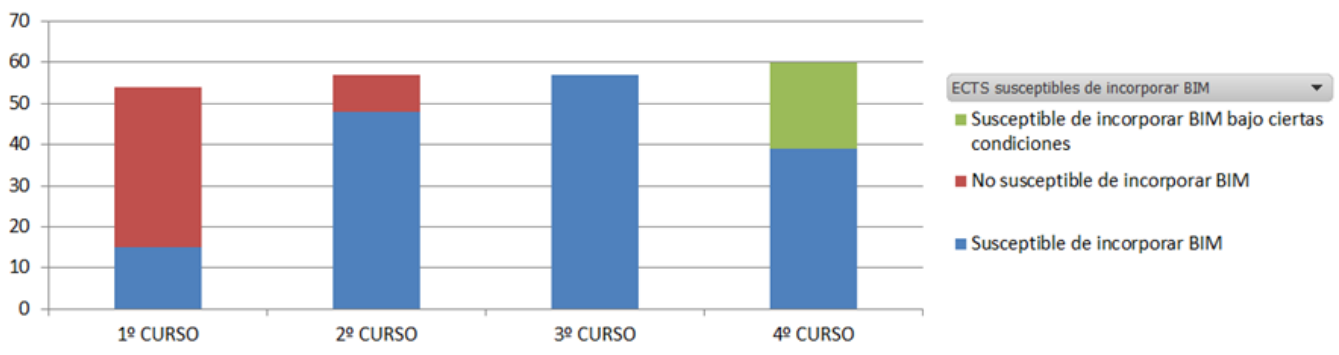

Fig 1. ECTS susceptibles de incorporar BIM en el actual Plan de Estudios.

La implementación en cada una de esas asignaturas sería, por supuesto, de naturaleza diferente. Por ejemplo, en la asignatura de segundo curso Materiales de construcción, actualmente los alumnos realizan dentro de las prácticas de la asignatura una maqueta física de un edificio con expresión de sus materiales. Dicha maqueta puede ser realizada en un entorno virtual con tecnología BIM. No solo se pueden incorporar estas tecnologías en los contenidos prácticos. Sino que también los podemos incorporar en los teóricos. Por ejemplo en la asignatura de tercer curso Gestión Profesional, entre su temario teórico 
incluye temas como "Panorama actual de la profesión de Arquitecto Técnico / Ingeniero de Edificación en España", "Oportunidades a nivel internacional para el Ingeniero de Edificación", "Agentes de la edificación", "Control de recepción en obra de los productos, equipos y sistemas que se suministren a las obras", "Control de ejecución de la obra", "Control de la obra terminada", "Planificación del control de ejecución", "Ministerio de Fomento", "Procedimientos y tramitaciones administrativas en la edificación". Todos estos temas pueden desarrollar contenidos relacionándolos con BIM.

Otro ejemplo singular de los distintos niveles en los que se puede introducir las enseñanzas del BIM lo constituye la asignatura del cuarto curso Idioma. Esta asignatura debería incluir entre el temario impartido una introducción a la terminología usual en entornos BIM, y expresiones usuales en redes colaborativas internacionales.

Es en ese entorno donde se detecta que los alumnos de último curso presentan grandes inquietudes en cuanto al empleo de las nuevas tecnologías y reclaman la implementación de acciones que completen su formación a las demandas actuales del mercado de trabajo.

Pero antes de desarrollar las acciones requeridas para la implementación de metodología BIM en el grado de Ingeniería de Edificación, se analizará la situación de partida en base a los datos recopilados mediante encuestas discrecionales donde los docentes y/o alumnos son interpelados con preguntas concretas sobre temas como identificación poblacional, la actitud ante la incorporación de nuevas tecnologías en, capacidad de adaptación a las nuevas tecnologías, necesidades formativas. Una vez analizados los datos obtenidos serán definidos los objetivos del Proyecto de Innovación Docente [8]. En un principio de la manera más pragmática posible pero sin renunciar a planteamientos más arriesgados en función de la implicación del profesorado y/o alumnado.

\section{$2 \quad$ ANÁLISIS DE LA ENCUESTA}

En la elaboración de la encuesta se han planteado para su estudio los siguientes bloques: Identificación poblacional, Actitud ante la incorporación de nuevas tecnologías, Adaptación a las nuevas tecnologías, Formación e Impacto de las nuevas tecnologías en los procesos.

Siendo estos aspectos primordiales para poder realizar un estudio sobre la posibilidad de la implantación de la metodología BIM dentro de los estudios de educación superior.

\subsection{Identificación poblacional}

La encuesta se ha dirigido a la totalidad de la población de estudiantes y profesores que conforma la Escuela Técnica Superior de Arquitectura y Edificación de la Universidad Politécnica de Cartagena, en la que se cuenta con los Grados de Ingeniería de Edificación y Fundamentos en Arquitectura y los Masters en Patrimonio Arquitectónico y Ciencia y Tecnología de Edificación en Arquitectura. Esta encuesta se ha distribuido mediante circulares enviadas a través del aula virtual de las asignaturas de los grados y másteres, 
además de a través de la Delegación de Alumnos de la Escuela Técnica Superior de Arquitectura y Edificación.

Una vez finalizado el periodo de encuesta, se obtuvo como resultado un número de 135 participantes, de las cuales el 96,30\% eran estudiantes. Analizado (Fig. 2) a que Grado o Master pertenecen estos alumnos, destaca el interés de los alumnos de los Grados $58,46 \%$ y $33,85 \%$, que si se ponderan estos resultados en función del número de alumnos matriculados en cada una de estas titulaciones, resultaría un porcentaje similar.

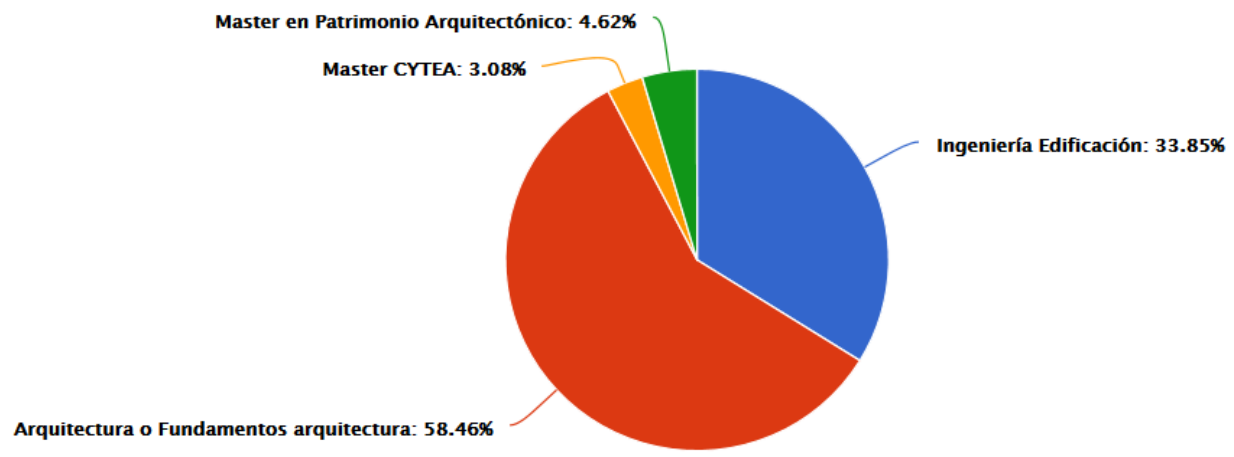

Fig 2. Estudios que están cursando los alumnos en la ETSAE

También se ha preguntado por el curso que están realizando, obteniendo como era de esperar que el resultando de la mayoría de los interesados están en los últimos cursos (más del $60 \%$ ) aunque llama la atención el interés positivo de alumnos de primer curso $(15,62 \%)$.

\subsection{Actitud ante la incorporación de nuevas tecnologías}

La primera pregunta pretendía despertar el interés de la población sobre el estado de implantación de la metodología BIM en la ETSAE, con respecto al entorno exterior. Así se pretendía realizar una reflexión de futuro, sobre si la implantación de Sistemas BIM en la Arquitectura y Edificación, en los que se están formando en estos momentos los agentes del sector, puede suponer una nueva oportunidad para la mejora de las relaciones entre los intervinientes y un valor añadido en el mercado profesional.

Como podemos ver en la Fig 3.1, el 70,37\% de los encuestados tienen esperanzas en que esta metodología mejorará el sector y facilitará su incorporación al mercado de trabajo. Llama la atención que una cuarta parte de los encuestados $(26,67 \%)$ no lo tienen claro, y que solamente un $2,96 \%$ asegura que BIM no supondrá una mejora.

Pasamos a preguntar aspectos sobre los entornos BIM. En la siguiente pregunta nos interesa el punto de vista sobre la oportunidad o amenaza que supone la implantación de los sistemas BIM. Una amplia mayoría $72,95 \%$ opina que se trata de una oportunidad y un $13,11 \%$ lo considera simultáneamente una amenaza. (Fig. 3.2) 
También hemos preguntado sobre la actitud que perciben los alumnos en los compañeros de su entorno respecto a los sistemas BIM (Fig. 3.3). Destaca con más de un $60 \%$, el desconocimiento o desinterés al respecto, frente al $31,97 \%$ que quieren aplicarlo.

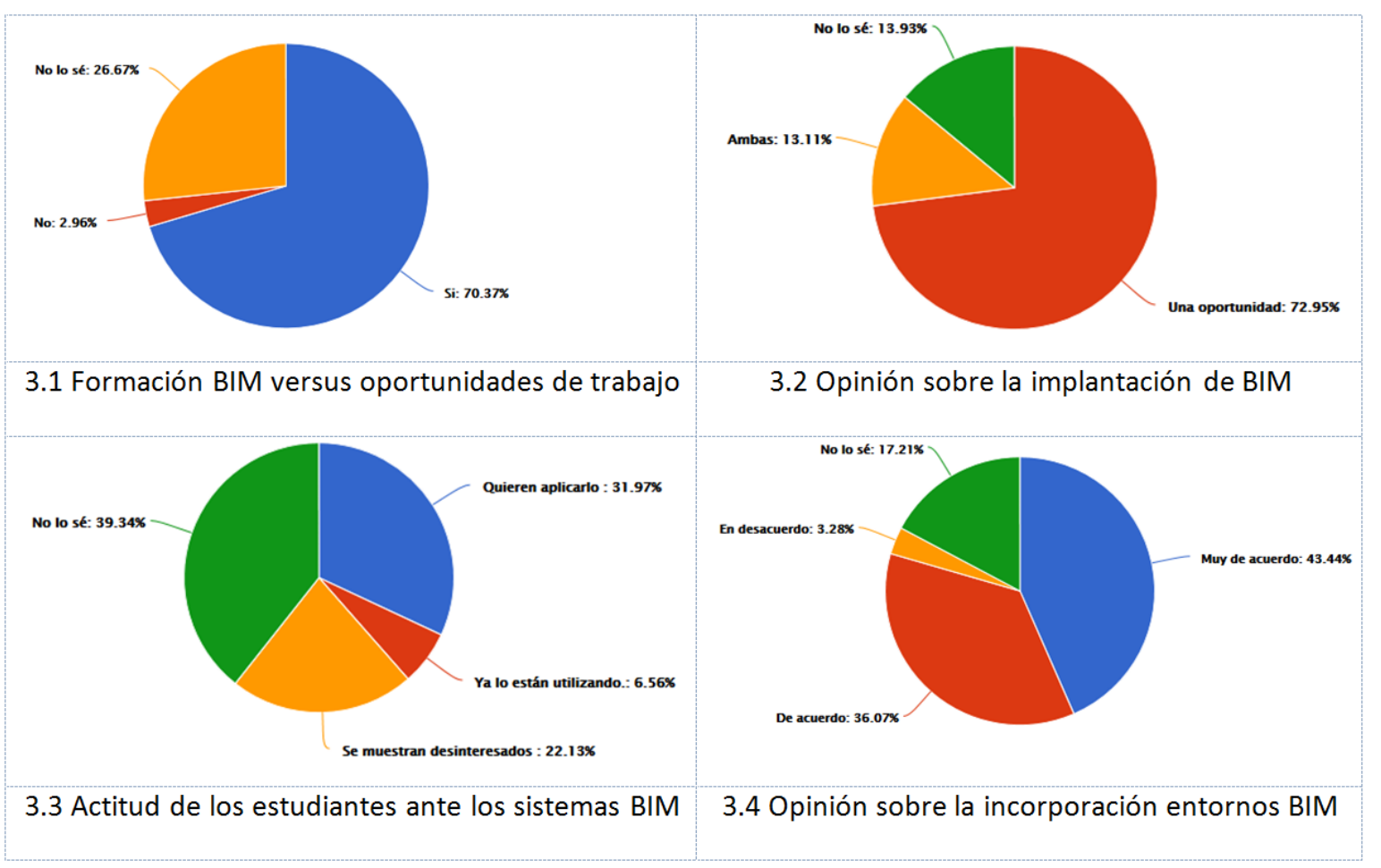

Fig 3. Actitud ante la incorporación de nuevas tecnologías

En contraposición a la actitud de los alumnos, destaca la siguiente pregunta, donde el $79,51 \%$ indica que están muy de acuerdo o de acuerdo en que las asignaturas incorporen el uso de metodología y tecnología BIM (Fig. 3.4). También encontramos un pequeño porcentaje $(17,21 \%)$ de alumnos que no tienen claro este aspecto, posiblemente asociado también al desconocimiento de las oportunidades.

\subsection{Adaptación a las Nuevas Tecnologías}

Se aborda a partir de este momento los aspectos de adaptación a las nuevas tecnologías. En la primera pregunta se pretende conocer si los alumnos tienen conocimientos sobre algún software BIM, donde el $88 \%$ de los encuestados indica que conoce algo, poco o nada, en contraposición con el $12 \%$ que indican disponer bastante o mucho conocimiento. Por tanto, queda clara la carencia de los alumnos respecto a los sistemas BIM.

También nos interesaba conocer si utilizan o piensan utilizar en breve algún software BIM de arquitectura y edificación. De todas las respuestas (Fig. 4), extraemos como destacados Revit $(48,28 \%)$ como software de modelado frente a otras opciones como ArchiCAD o Allplan. En lo que respecta a estructuras, instalaciones y presupuestos, el software de Cype con el 59,48\% también es una alternativa destacada. Finalmente, en cuanto a software de gestión de modelos como Navisworks apenas muestran interés los alumnos, quizá por desconocimiento. 


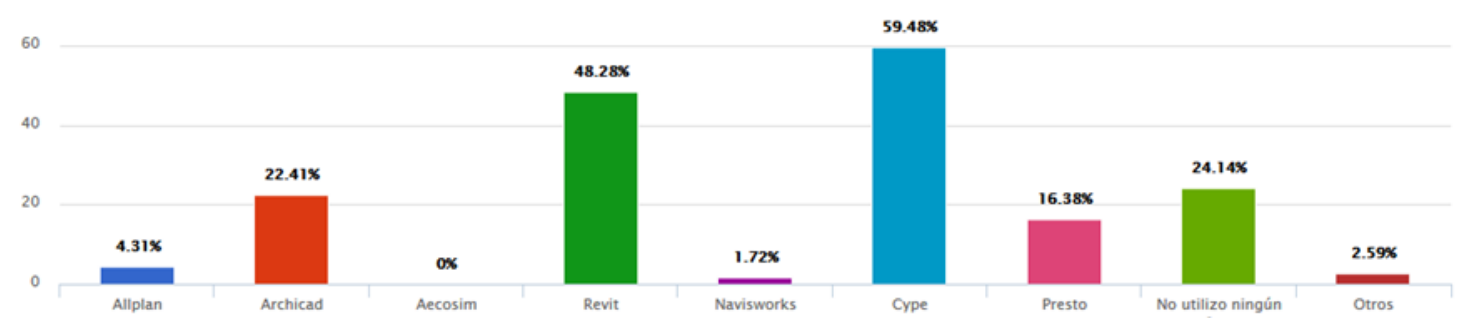

Fig 4. Utilización a corto plazo de software BIM

También llama la atención, que una cuarta parte de los encuestados no utiliza, ni tiene previsto a corto plazo utilizar ningún software BIM. Este resultado se puede asociar a la cantidad de alumnos de la población encuestada que se encuentran en los primeros cursos de los grados, y o lo desconocen o lo ven como algo muy lejano.

En la siguiente pregunta se intenta conocer las causas que pueden ayudar más a que las universidades adopten la tecnología BIM. EI 50,43\% de los encuestados están convencidos de que la adaptación de las soluciones tecnológicas a las necesidades del sector es la razón principal para impulsar el conocimiento e implantación BIM en las universidades. Desde nuestro punto de vista, llama la atención que solamente el $23,93 \%$ de los encuestados opinen que la implicación de la Administración Central y Regional puede impulsar la adopción de la tecnología BIM, cuando los profesores con más experiencia compartimos que el compromiso y liderazgo de la Administración facilita la implantación dentro y fuera de las universidades. Así pues, contrasta la opinión de los alumnos que confían en que este proceso en las universidades, vendrá por el convencimiento de adoptar las nuevas soluciones y necesidades del sector.

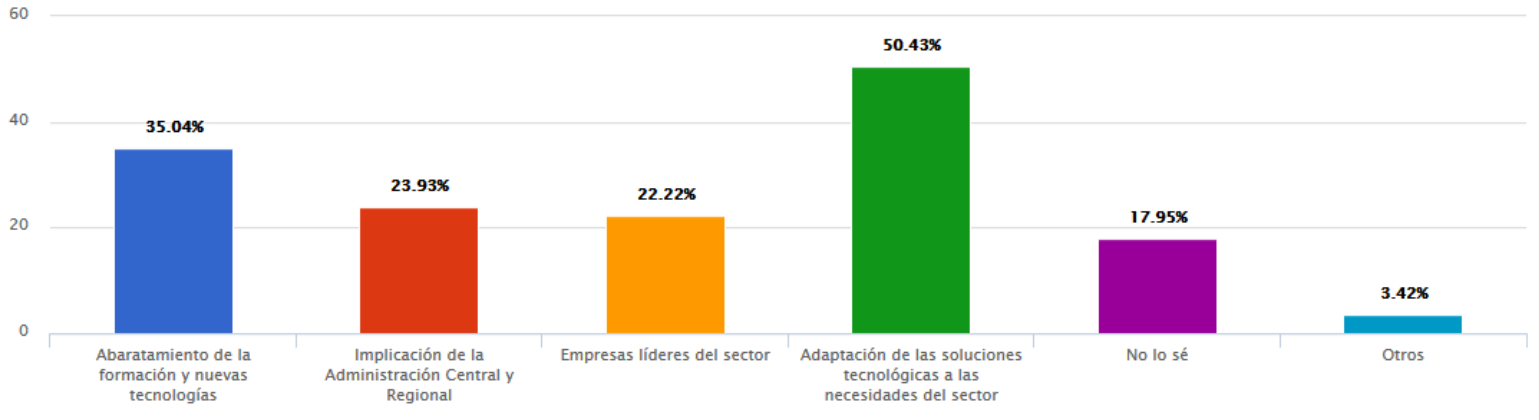

Fig 5. Razones para impulso en las Universidades de sistemas BIM

\section{$2.4 \quad$ Formación}

El siguiente apartado o bloque de la encuesta aborda la formación en metodología BIM. La primera cuestión plantea la procedencia de la formación adquirida por los alumnos. Destacan las opiniones $(65,85 \%)$ en las que los alumnos confirman que los conocimientos los han alcanzado de forma autodidacta o a través de internet, en contraposición con los que los han adquirido a través de alguna asignatura (19,51\%). También se pregunta su opinión sobre si existe suficiente oferta de formación BIM. El 68,75\% confirma que no, opinando que sí el 8,04\%. Otro aspecto planteado es si les gustaría recibir formación BIM en los próximos 
meses. En este punto el $62,28 \%$ indican que si durante este curso o en los próximos meses, mientras que a medio plazo solamente lo señalan el $25,44 \%$

Centrándonos en cuestiones que interesan a la ETSAE, nos interesaba conocer si los alumnos están interesados en recibir formación BIM integrada en el Plan de Estudios que están cursando. Un 92,98\% de respuestas afirmativas no deja dudas sobre la opinión de los alumnos.

Igualmente planteábamos la posibilidad de que la ETSAE ofrezca alguna asignatura optativa sobre BIM y queríamos saber si los alumnos se matricularían. El 92,98\% de los alumnos indican que sí, quedando también muy claro este aspecto.

Para tratar de acotar el interés sobre esta disciplina, en la siguiente pregunta les pedíamos pronunciamiento sobre algunas herramientas y software BIM. Queda claro y en primer lugar, como se ve en la Fig. 6 que la mayoría ha indicado su interés por un curso de iniciación al BIM con Revit. También aparecen en posición destacada cursos avanzados de arquitectura con Revit, Revit Structure, Revit MEP, Técnicas de trabajo colaborativo con Revit y Cype. En contraposición no tiene apenas interés la herramienta de gestión de modelos BIM como es Navisworks. También parece claro que los alumnos se interesan por las herramientas de Autodesk y en menor medida por otras como ArchiCAD o Allplan.

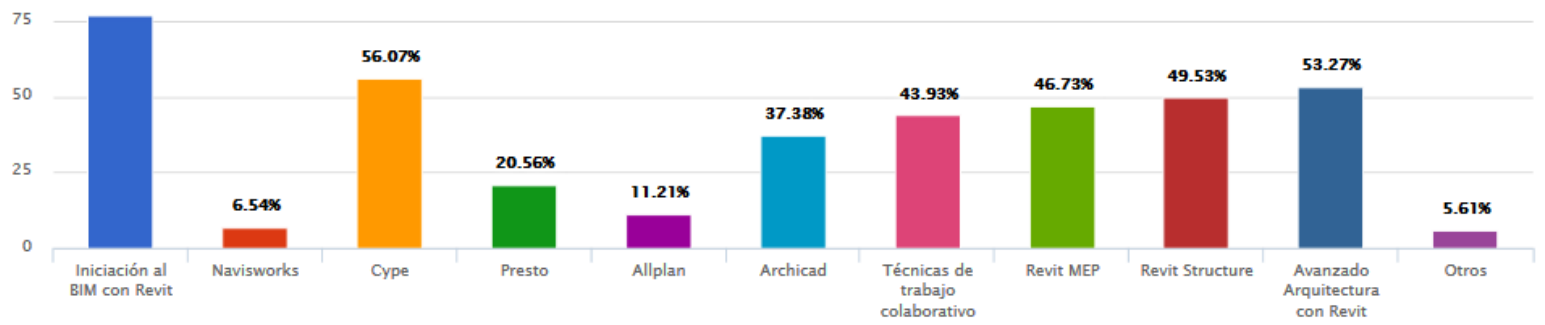

Fig 6. Preferencia de formación de los alumnos en herramientas BIM

Por último se preguntó por el interés en los exámenes de certificación internacional Autodesk, por el interés que pueda tener este reconocimiento en el mercado profesional. El resultado ha sido que el $69,03 \%$ indica que si, el $26,55 \%$ que no lo tiene claro y $4,42 \%$ que no. Por tanto este aspecto interesa pero un alto porcentaje no tienen criterio al respecto.

\subsection{Impacto de las nuevas tecnologías en los procesos}

En el último apartado o bloque de la encuesta, se ha pretendido abordar el impacto que conlleva la implantación de estas herramientas y metodología en los procesos del edificio.

Así la primera cuestión plantea a los alumnos qué fase o fases consideran prioritaria para la implantación de la metodología BIM. Como se desprende del gráfico de la Fig. 7, la mayoría $(57,14 \%)$ consideran que su implantación debe ser global al proyecto y seguimiento de obra. Respecto a las opiniones parciales del proceso, se podría decir que casi de manera aproximada se encuentran el análisis de estructuras e instalaciones, así como redacción planos proyecto, análisis detalles constructivos y redacción mediciones y presupuestos (alrededor 40\%). Los encuestados opinan que es poco importante (alrededor 28\%) la 
aplicación de metodología BIM solamente para el modelado arquitectónico y ejecución y seguimiento de obra.
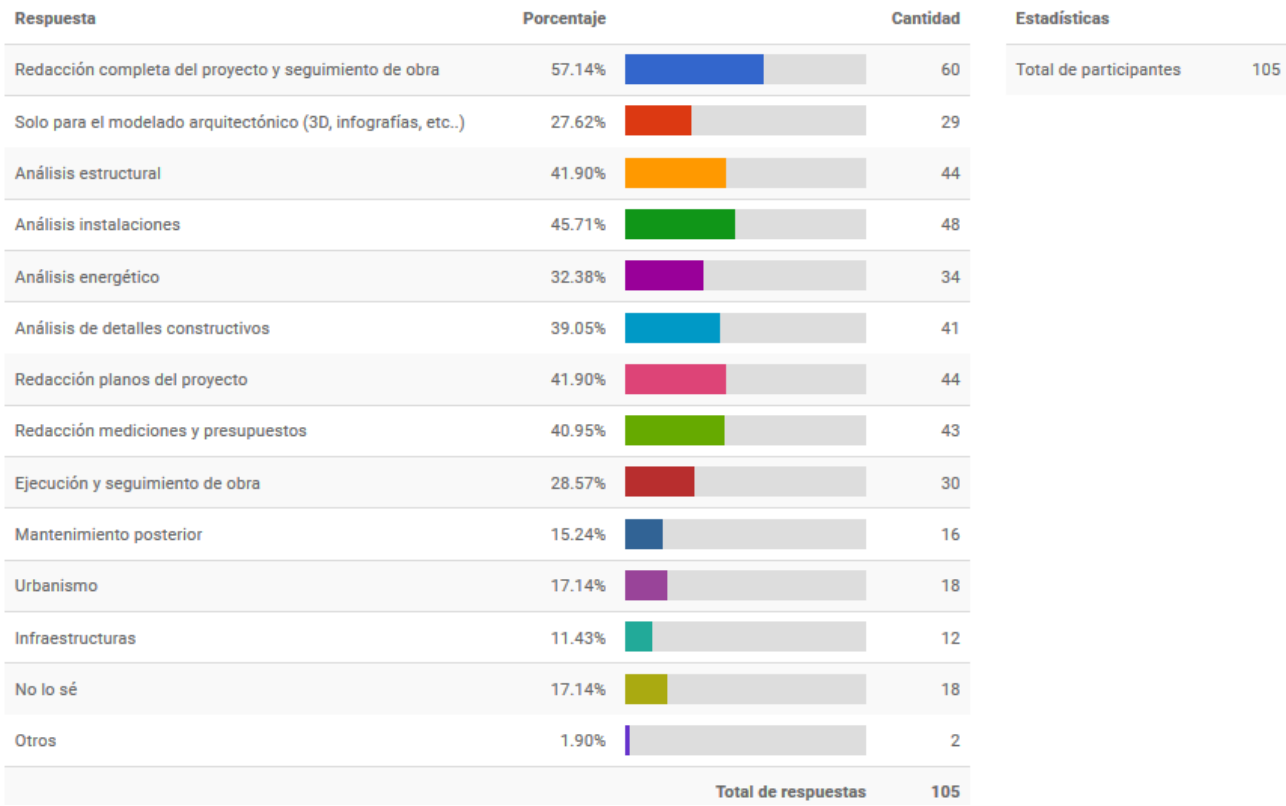

Fig 7. Fases en las que se considera prioritaria la implantación BIM

Respecto a las tecnologías o soluciones tecnológicas que han tenido un mayor impacto en el sector en los últimos años, el 59,8\% de los encuestados opina que ha sido el modelado 3D del proyecto, quedando por debajo del $30 \%$ los Sistemas integrados para el Control de Costes, Sistemas de Información Geográfica SIG, y mapeado digital mediante escáneres 3D y nubes de puntos. Fig 8.
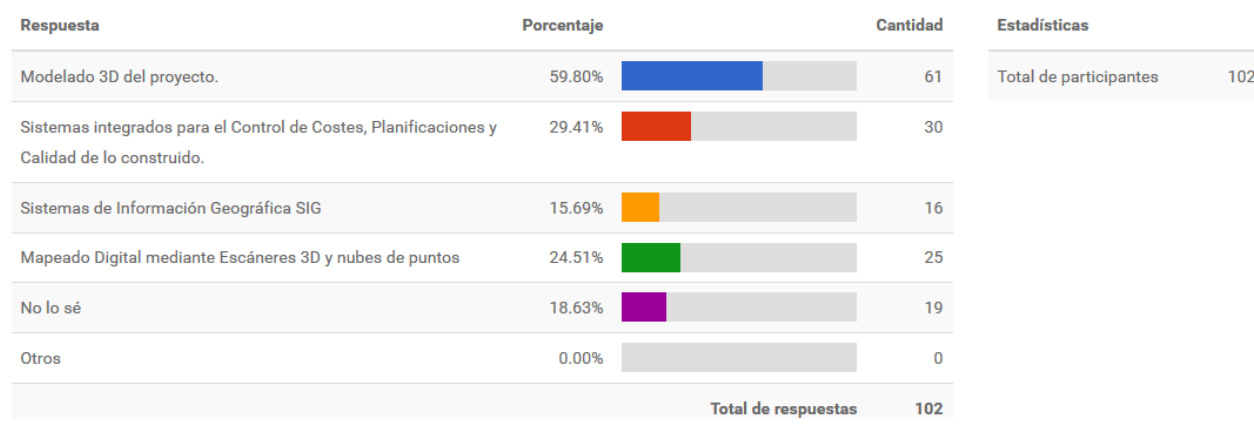

Fig 8. Soluciones tecnológicas con mayor impacto en los últimos años

Por último nos interesaba saber la opinión sobre el uso de algunas de las herramientas BIM. En los resultados de la encuesta destacan tres apartados muy igualados, como son reducción de errores en proyecto, reducción del tiempo de desarrollo del proyecto y el trabajo colaborativo entre especialistas con alrededor del $50 \%$ de las opiniones. Por debajo con un $40 \%$ de opiniones aparece la reducción de conflictos en la construcción. Quedan para los últimos puestos y en menor medida la reducción del tiempo de construcción y la reducción de los costes de construcción. Fig 9. 


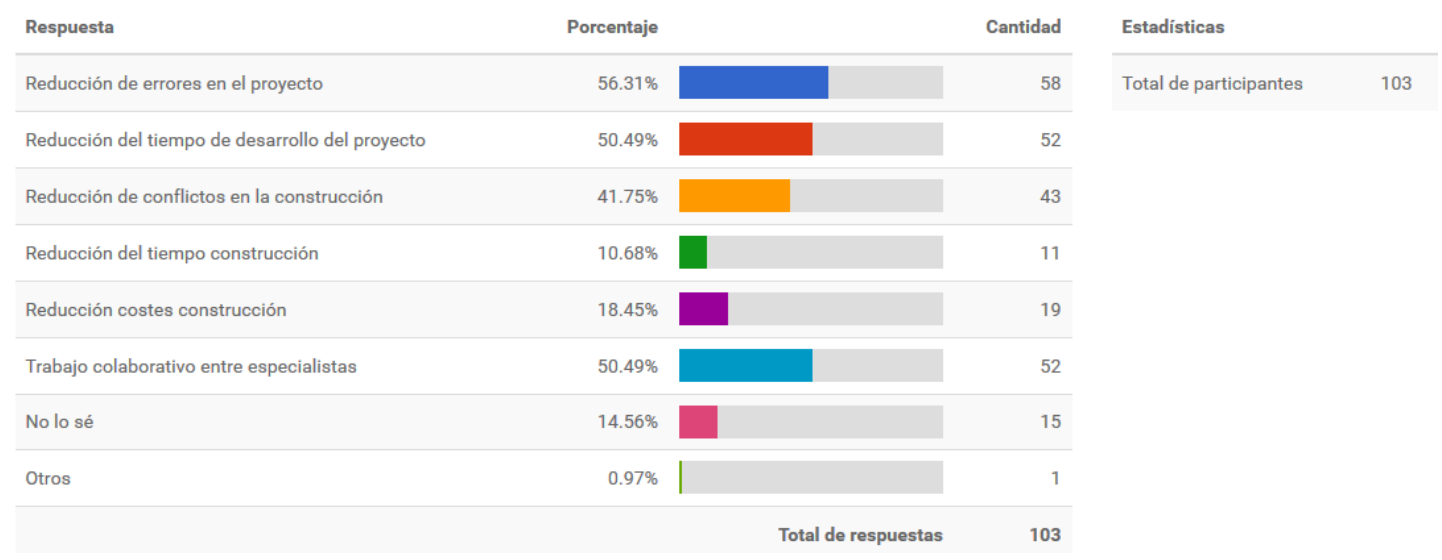

Fig 9. Beneficios del uso de algún software BIM

\section{CONCLUSIONES}

Respecto a los contenidos de las asignaturas impartidas y la modificación del Plan de Estudios del Grado de Ingeniería de Edificación y de la Orden ECI 3855/2007, destaca que:

- De la lectura de las guías docentes, se infiere que la mayoría de las asignaturas estudiadas en el Plan de Estudios son susceptibles de poder incluir entre sus contenidos actuales, prácticas relacionadas con la tecnología BIM. Incluso algunas disponen de contenidos teóricos susceptibles de desarrollar contenidos específicos de BIM. Por lo que en teoría, la implementación en las enseñanzas de la tecnología BIM no debería esperar a modificar los Planes de Estudios ni la Orden ECl, pero es necesario implicar a los profesores responsables de la docencia en estas asignaturas, motivándoles con la formación necesaria y dotándoles de los recursos requeribles.

Con respecto a los datos obtenidos de la encuesta sobre la implantación de la metodología BIM, cabe destacar como conclusiones:

- El interés entre los alumnos de los Grados de Ingeniería de Edificación y Fundamentos en Arquitectura está prácticamente igualado. Si bien el principal interés se centra en los estudiantes de los últimos cursos.

- Los estudiantes están muy de acuerdo o de acuerdo en que las asignaturas incorporen el uso de metodología y tecnología BIM. Los alumnos manifiestan de forma clara la carencia de formación respecto de los sistemas BIM.

- La adaptación de las soluciones tecnológicas a las necesidades del sector es la razón principal para impulsar el conocimiento e implantación BIM en las universidades.

- En relación a la formación adquirida, los alumnos afirman que los conocimientos en BIM los han alcanzado de forma autodidacta o a través de internet. Opinan también que no existe suficiente oferta de formación BIM e indican que tienen interés en formarse durante este curso o en los próximos meses. Casi la totalidad de los 
estudiantes indican que están interesados en recibir formación BIM integrada en el Plan de Estudios que están cursando. $Y$ confirman que se matricularía también en una asignatura optativa.

Todo ello implica que los docentes de los grados de Ingeniería de Edificación y Arquitectura nos encontremos inmersos en una estrategia de largo recorrido, que debe llevar a que nuestros egresados consigan alcanzar las competencias propuestas en el Plan de Estudios y demandadas por el mercado, pero aplicando la última tecnología y herramientas a nuestro alcance, que permitan su integración profesional de forma fluida. Simplemente ofrecer nuestra colaboración y participación al resto de universidades que están en el camino o ya lo han conseguido.

\section{REFERENCIAS}

[1] Cos-Gayon López, Fernando. Experiencia de implantación de metodología BIM en Plan de Estudios del Máster Universitario de Edificación de la Universidad Politécnica de Valencia. EUBIM 2016.

[2] European Union (2014) Directive 2014/24/EU of the European Parliament and of the Council of 26 February 2014 on public procurement and repealing Directive 2004/18/EC

[3] Comisión es.BIM Implantación de BIM en España. Página web: http://www.esbim.es/ (Consultado el 23/03/2017)

[4] Oliver Faubel, I. (2016). Integración de la metodología BIM en la programación curricular de los estudios de Grado en Arquitectura Técnica/Ingeniería de Edificación. Diseño de una propuesta [Tesis doctoral]. Universitat Politècnica de València.

[5] Valverde Cantero, David; Cañizares Montón, Jose Manuel; et All. Implementación BIM en la Escuela Politécnica de Cuenca, experiencia piloto en Proyectos Técnicos 15-16. EUBIM 2016

[6] Pérez Egea, Adolfo; Martínez Conesa, Eusebio J; Guillén Martínez, José A. INS_TALLER. Experiencia integradora BIM en las enseñanzas de Grado y Postgrado de la Universidad Politécnica de Cartagena. EUBIM 2015.

[7] Pérez Navarro, Julián; Pérez Egea, Adolfo; Entornos Bim en Arquitectura e Ingeniería. https://vimeopro.com/user34869842/entornosbim (Consultado el 23/03/2017)

[8] Pérez Navarro, Julián; Pérez Egea, Adolfo; et All. (2017). Proyecto de Innovación Docente Implantación BIM en el Grado de Ingeniería de Edificación de la Universidad Politécnica de Cartagena. 


\title{
EMPLEO DE METODOLOGÍAS BIM EN ASIGNATURAS DE CONSTRUCCIÓN DEL GRADO EN ARQUITECTURA TÉCNICA
}

\author{
Piedecausa-García, B. (1), Pérez-Sánchez, V.R. (2), Mora-García, R.T. (3), \\ Pérez-Sánchez, J.C. (4)
}

(1) Profesora Asociada. Departamento de Edificación y Urbanismo. Universidad de Alicante, piedecausa@ua.es

(2) Profesor Titular de Universidad. Departamento de Edificación y Urbanismo. Universidad de Alicante, raul.perez@ua.es

(3) Profesor Ayudante Doctor. Departamento de Edificación y Urbanismo. Universidad de Alicante, rtmg@ua.es

(4) Profesor Titular de Escuela Universitaria. Departamento de Edificación y Urbanismo. Universidad de Alicante, jc.perez@ua.es

\section{RESUMEN}

El sector de la edificación en España ha sufrido una profunda crisis durante los últimos años que ha implicado una adaptación continua en busca de nuevas oportunidades laborales. Paralelamente, se ha producido una revolución en la forma de diseñar, proyectar y construir a través de entornos BIM, mediante la creación y gestión de información constructiva en un modelo informático tridimensional al que se incorporan datos a lo largo de todo su ciclo de vida. Estas nuevas realidades profesionales hacen necesaria la incorporación de conocimientos BIM en la formación para Graduados del sector de la edificación, garantizando sus futuras salidas profesionales.

El Grado en Arquitectura Técnica de la Escuela Politécnica Superior de la Universidad de Alicante, durante el curso actual 2016-17, ha empezado a incluir contenidos BIM en algunas asignaturas. Prueba de ello es la realización de prácticas en las asignaturas de Construcción de segundo y tercer curso, desarrollando un modelo tridimensional de un edificio que incluye datos de estructura y acabados. Consideramos que una mayor aplicación práctica de contenidos teóricos con herramientas BIM es necesaria en las asignaturas de grados técnicos, y será más eficiente si se desarrollan productos conjuntos entre materias con contenidos relacionados como las de esta propuesta.

Palabras clave: BIM, formación, objetos paramétricos, Revit, universidad.

\section{ABSTRACT}

During the last years, the construction sector in Spain has experienced a deep crisis that has implied a continuous adaptation in searching new job opportunities. At the same time, there has been a revolution in the way of designing and constructing through BIM environments, by the creation and management of constructive information in a three-dimensional computer model to which data are incorporated throughout its life cycle. These new professional realities make it necessary to incorporate BIM knowledge into the training for Graduates of the building sector, guaranteeing their future professional career. 
During the academic year 2016-17, the Degree in Building Engineering of the Polytechnic School (University of Alicante) has begun to include BIM contents in some subjects. This is evidenced by the realization of practices in the subjects of Construction (second and third year), developing a three-dimensional model of a building that includes data of structure and finishes. We consider that a greater practical application of theoretical contents with BIM tools is necessary for the subjects of technical degrees, and it will be more efficient by developing joint programs or initiatives between subjects with related contents, like those pursued in this proposal.

Keywords: BIM, university, parametric objects, training, Revit.

\section{INTRODUCCIÓN}

Durante los últimos años, el sector de la edificación en España ha sufrido una crisis profunda; por ello, los técnicos intervinientes en el proceso arquitectónico y constructivo han tenido que adaptarse a esta situación cambiante, en busca de nuevas oportunidades de trabajo. Paralelamente a este hecho, se ha ido produciendo una revolución que está trasformando la forma de diseñar, proyectar y construir a través de entornos BIM (Building Information Modelling), mediante la creación y gestión de la información en los productos de construcción mediante un modelo informático tridimensional al que se incorporan datos a lo largo de todo su ciclo de vida.

Estas nuevas realidades profesionales hacen necesaria la incorporación de conocimientos de herramientas BIM en la formación de Graduados en Arquitectura Técnica [1], lo que contribuirá al desarrollo de su profesión. Es por ello, que las titulaciones relacionadas con el sector de la edificación deben incluir contenidos BIM para complementar la docencia técnica de las asignaturas, garantizando una formación de calidad para sus futuras salidas profesionales [2,3].

En los últimos años, el Grado en Arquitectura Técnica de la Escuela Politécnica Superior de la Universidad de Alicante ha ido incorporando nuevas tecnologías en el ámbito de distintas materias constructivas $[4,5,6]$; además, tras distintas experiencias previas de los autores del presente trabajo [7], durante el curso actual 2016-17, se han empezado a incluir contenidos BIM en algunas asignaturas del área de Construcciones Arquitectónicas. Prueba de ello es la propuesta de realización de prácticas BIM en las asignaturas de temática constructiva en segundo, tercer y cuarto curso pertenecientes al Departamento de Edificación y Urbanismo, desarrollando un modelo tridimensional de un edificio que incluye datos de estructura y acabados. A continuación, se indican los aspectos fundamentales desarrollados en las asignaturas específicas que conforman el taller:

- CONSTRUCCIÓN DE ESTRUCTURAS I y II (CE1 y CE2) (2 curso, primer y segundo cuatrimestre). En la asignatura se estudian las estructuras de hormigón armado (primer cuatrimestre) así como estructuras metálicas y de madera (segundo cuatrimestre) utilizadas en los edificios desde el punto de vista de la construcción: estudio de los diferentes elementos estructurales, los procesos de ejecución de obra, su forma de 
trabajo, puesta en obra de armaduras y hormigón, sus principios fundamentales y la normativa de aplicación.

- CONSTRUCCIÓN DE ELEMENTOS NO ESTRUCTURALES I (CENE1 y CENE 2) (3 $3^{\text {er }}$ curso, primer y segundo cuatrimestre). El proceso de edificación se divide en diferentes fases u oficios: demoliciones, movimientos de tierra, cimentaciones, estructura, cerramientos, cubiertas, particiones, etc. Esta asignatura engloba todas aquellas construcciones que se realizan una vez se han ejecutado los elementos resistentes (cimentaciones y estructura), para desarrollar particiones interiores, revestimiento de paramentos, solados, falsos techos y encuentros con el terreno (primer cuatrimestre) así como la envolvente de la edificación, fachadas y cubiertas (segundo cuatrimestre). Con ello se abarcarán elementos claves a la hora de trabajar en el ámbito profesional, sea cual sea la dedicación futura del estudiante (jefe de obra, dirección facultativa, técnico en prevención, comercial, investigador, laborante, etc.), así como la ética profesional.

- PROYECTOS TÉCNICOS (PT) (4ํㅡㄴ curso, primer cuatrimestre). El estudiante que la cursa adquiere una visión global de los proyectos técnicos que un profesional de la Arquitectura Técnica puede desarrollar utilizando de manera global los conocimientos previos adquiridos en otras disciplinas técnicas de la titulación, como son las instalaciones, la seguridad, la construcción, etc. Esta visión técnica de los proyectos, no solamente se analiza de forma aislada, sino que se contextualiza con la normativa y legislación aplicable en cada caso concreto.

En todas las asignaturas participantes se desarrollan trabajos prácticos (Fig. 1) complementados con el desarrollo de maquetas virtuales 3D para la visualización de detalles estructurales y constructivos aplicando distintas tecnologías (habitualmente Autocad o Sketchup).
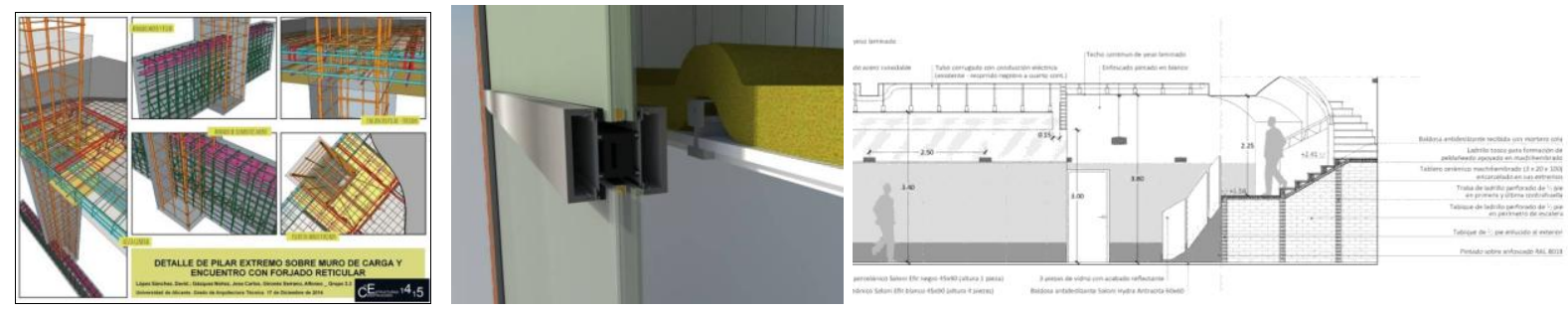

Fig. 1. Izquierda. CE 1. Trabajo de los estudiantes D. López, J. Gázquez y A. Gironés. (2016). Centro: CENE 2. Trabajo de los estudiantes M. Pertusa y C. M. Muñoz. (2016). Derecha: Proyectos Técnicos. Trabajo del estudiante A. Parodi. (2016). Fuente: elaboración propia.

\section{OBJETIVOS}

Con el objetivo principal de introducir contenidos BIM de manera progresiva en las asignaturas del Grado en Arquitectura Técnica (GAT) de la Universidad de Alicante, durante el mes de marzo de 2017 se ha desarrollado un taller transversal gratuito dedicado al aprendizaje de metodologías BIM para los estudiantes del citado grado, que ha sido 
impartido durante 4 sesiones presenciales (5h cada una de ellas) y $10 \mathrm{~h}$ no presenciales de trabajo personal en casa de cada estudiante para el desarrollo de la actividad de evaluación.

El Taller Transversal GAT-REVIT marzo 2017 pretende iniciar a los estudiantes en la formación BIM en el ámbito constructivo mediante la utilización del programa informático REVIT (versión 2017); esta actividad ha sido promovida por el profesorado que imparte las asignaturas de Construcción de Estructuras, Construcción de Elementos No Estructurales y Proyectos Técnicos $\left(2^{\circ}, 3^{\circ}\right.$ y $4^{\circ}$ curso del GAT) como parte de la investigación desarrollada dentro de la Red 3680 COORDINACIÓN VERTICAL EN LAS ASIGNATURAS DEL ÁREA DE CONSTRUCCIÓN EN EL GRADO EN ARQUITECTURA TÉCNICA: APLICACIÓN DE NUEVAS TECNOLOGÍAS incluida en el programa Redes-I3CE (Programa Institucional Innovación, Investigación, Internacionalización y Colaboración en Educación (ICE) 20162020) del Instituto de Ciencias de la Educación de la Universidad de Alicante. Dicha red, incluida en la Modalidad 1 para redes referidas a titulaciones, se enmarca en una temática de aplicación de nuevas tecnologías y coordinación vertical de las asignaturas del área de Construcción del GAT, con el objetivo de incluir herramientas tecnológicas relacionadas con el sector de la edificación y relacionar su aplicación entre las asignaturas anteriormente mencionadas.

De este modo, se propone que el alumnado aprenda el proceso de trabajo constructivo mediante metodologías BIM de una manera coordinada entre asignaturas de cursos sucesivos y adquiera competencias para desarrollar y modelar un prototipo de vivienda 3D, así como extraer información mediante mediciones y planos.

\section{METODOLOGÍA}

Aunque el taller es gratuito, fue necesario realizar una preinscripción para seleccionar los estudiantes finalmente admitidos, teniendo preferencia aquellos que cursan las asignaturas indicadas en el presente cuatrimestre.
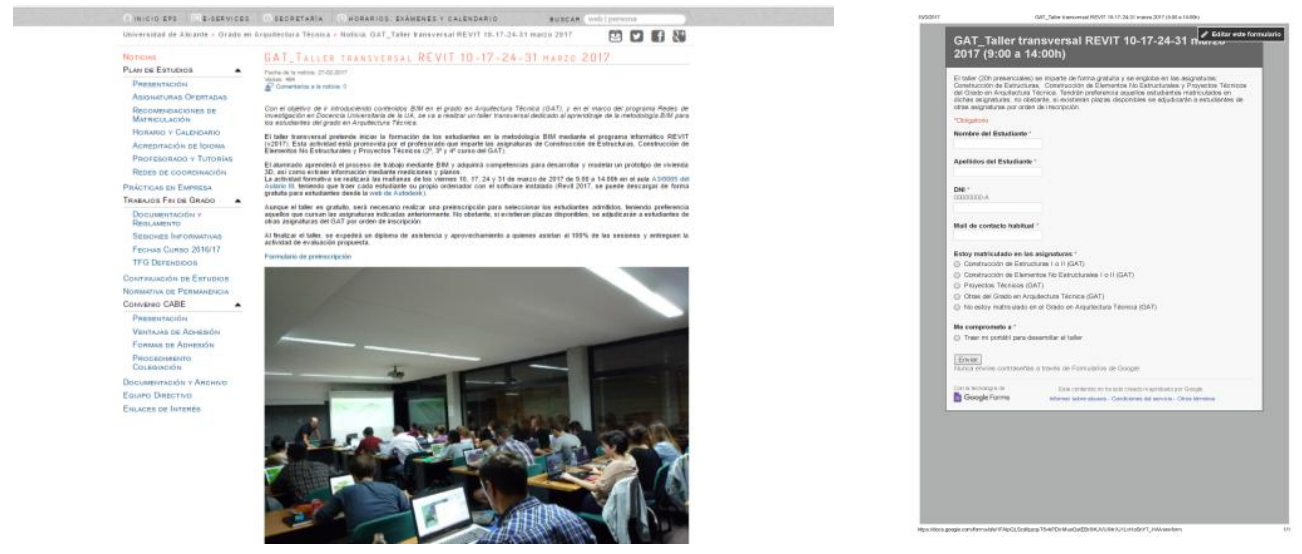

Fig 2. Izquierda: Publicidad del Taller GAT-REVIT en la web de la Escuela Politécnica Superior UA. 2017. Fuente: elaboración propia. Derecha: Formulario de inscripción al Taller Transversal GAT-

REVIT. 2017. Fuente: elaboración propia. 
Con el fin de seleccionar a los asistentes al curso, se publicó un anuncio en la web de la titulación (https://eps.ua.es/es/arquitectura-tecnica) en el que se incluía una descripción de los objetivos a alcanzar, las fechas de desarrollo y los condicionantes de elección de los participantes; también se adjuntaba un link a un formulario a rellenar por los interesados en inscribirse a este taller gratuito (Fig. 2).

Inicialmente, se decidió ofertar un número máximo de 40 plazas en el taller propuesto; sin embargo, tras la publicidad realizada se recibieron más del doble de solicitudes que plazas disponibles (93 estudiantes inscritos) (Fig. 3), de los que el 36,3\% indican que están matriculados en las asignaturas de CENE 1 o 2, el 50,5\% en CE 1 o 2, el 6,6 \% en PT y el restante $6,6 \%$ de otras asignaturas del grado. Por todo ello, finalmente se decidió ampliar a 60 el número de plazas asignadas, tomando como criterio el orden de inscripción y la preferencia de estudiantes matriculados en las asignaturas que organizan el taller. Todos los solicitantes fueron informados de su situación (admitidos o en lista de espera), instando a que confirmasen su participación para, en caso contrario, poder avisar a otros compañeros.

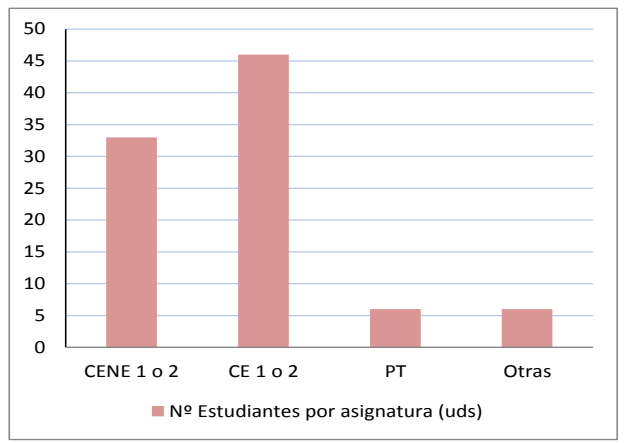

Fig 3. Número de estudiantes inscritos por asignatura. 2017. Fuente: elaboración propia.
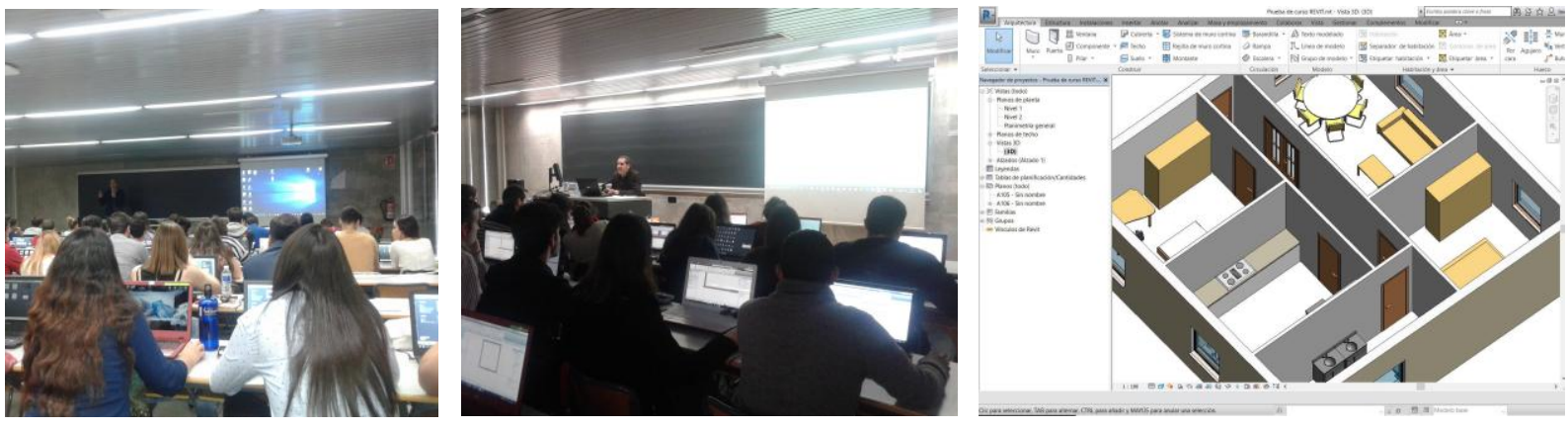

Fig 4. Izquierda y centro: Fotografías del aula durante las distintas sesiones del taller realizado. 2017. Derecha: Captura pantalla del ejercicio de curso realizado. 2017. Fuente: elaboración propia.

La actividad se ha realizado durante cuatro mañanas en horario de 9.00 a $14.00 \mathrm{~h}$, teniendo que traer cada estudiante su propio ordenador con el software Revit 2017 (instalado de forma gratuita desde la web de Autodesk en su versión estudiante). El programa de las distintas sesiones ha englobado una referencia al concepto del Building Information Modelling (2D-3D-4D-5D), introducción general al programa REVIT (tipos de ficheros, menús principales y resultados a obtener), diferencias entre categoría/familia/tipo/ejemplar, 
importación y vínculos, así como manejo de todas las herramientas necesarias para la elaboración de un proyecto básico, aplicado a una vivienda unifamiliar.

Cabe destacar que, con el fin de identificar aspectos previos al inicio del taller, al comienzo de la primera sesión se realizó una encuesta a los asistentes (Fig. 5). Las principales preguntas de dicha encuesta se relacionaban con tres grandes bloques:

\section{a. DATOS DE MATRICULACIÓN:}

- En qué asignaturas de las 45 existentes en el GAT se encuentra matriculado en el curso 16.17 y si la asignatura está aprobada o no.

\section{b. EXPERIENCIA EN PROGRAMAS INFORMÁTICOS RELACIONADOS CON EDIFICACIÓN:}

- Aspectos sobre su formación específica previa en el manejo de los programas Autocad, Revit y Sketchup.

- Años de experiencia en la utilización de dichos programas.

\section{c. ASIGNATURAS DEL GRADO EN ARQUITECTURA TÉCNICA - UA}

- Periodicidad del uso de los programas Autocad, Revit y Sketchup en las asignaturas del GAT que ya han cursado.

- Necesidad de implantación de metodologías BIM para cada una de las asignaturas existentes en GAT.
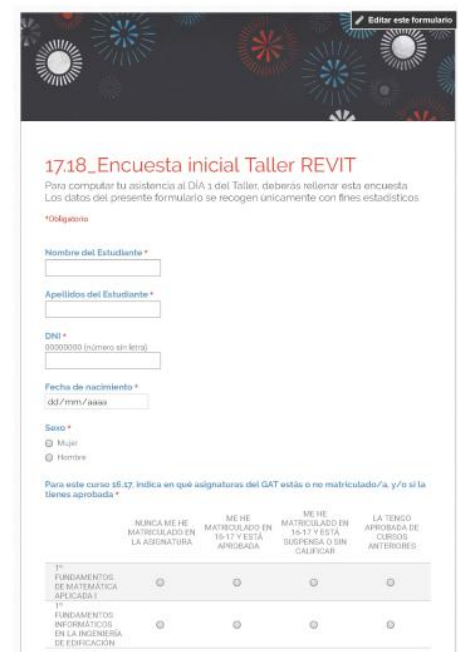

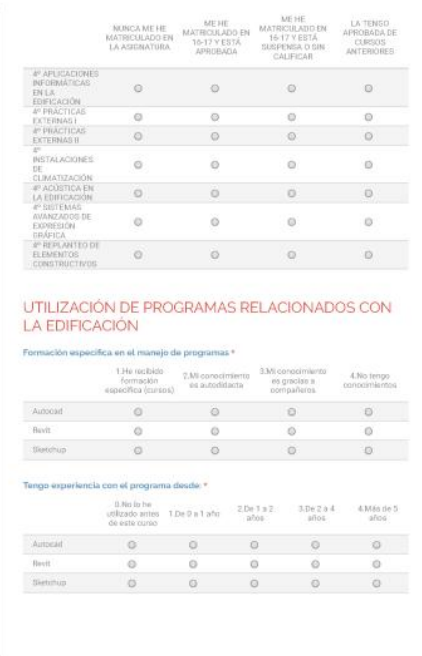

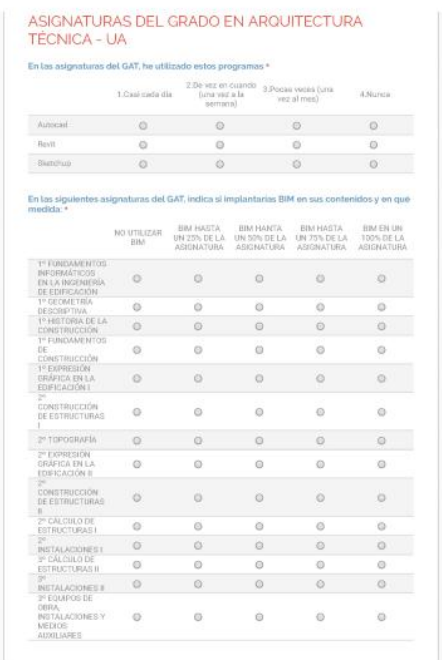

Fig 5. Distintas páginas del formulario online completado por los asistentes en la sesión 1 del taller. 2017. Fuente: elaboración propia.

\section{RESULTADOS}

\subsection{Descripción de la muestra}

La muestra objeto del estudio está formada por 60 estudiantes que se distribuyen de manera equitativa entre hombres y mujeres. En relación a las edades de los participantes, en el 
$70,2 \%$ de los casos están comprendidas entre los 20 y 25 años, mientras que en el 29,8 \% restante las edades se sitúan por encima de los 25 años.

En la Fig. 6 se representa la distribución del alumnado en función de los créditos que tiene superados por curso. La muestra está formada principalmente por estudiantes de segundo y tercer curso, con muy poca presencia de estudiantes que tengan superadas asignaturas de cuarto. Se puede observar que la gran mayoría de los encuestados tiene superados casi completamente los créditos de primer curso, habiendo aprobado más de la mitad de los créditos de la titulación, el 56,7\% de los participantes.

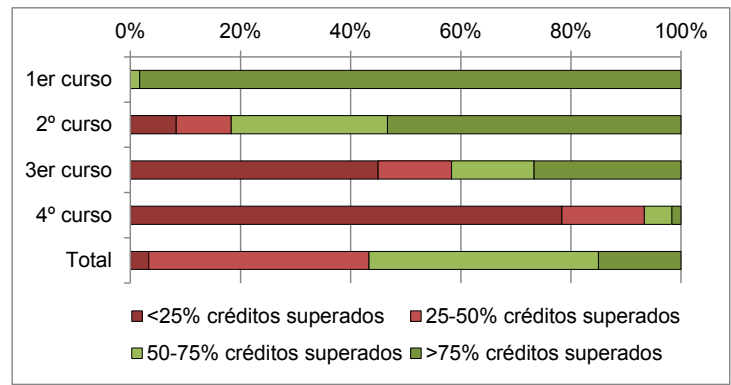

Fig 6. Distribución del alumnado en función de los créditos superados por curso. 2017. Fuente: elaboración propia.

Es importante destacar que en esta investigación se han utilizado los resultados académicos de estudiantes del primer semestre del curso 2016-2017, quedando pendiente por observar la evolución de los registros después de la finalización del segundo semestre y las convocatorias extraordinarias de Julio, lo que sin duda hará que los porcentajes mostrados en la Fig. 6 varíen.

Por otra parte, se ha desarrollado una comparación entre la formación previa de los estudiantes en tres aplicaciones informáticas diferentes: Autocad, Revit y Sketchup (Fig. 7). Como se puede observar, la distribución de la formación recibida en Autocad y en Revit es opuesta, siendo más autodidacta y existiendo un mayor número de estudiantes en los rangos de los distintos cursos en Autocad que en Revit. Por el contrario, en formación Revit, destaca la alta frecuencia que se ha alcanzado para los estudiantes sin conocimientos. En referencia a la formación en Sketchup, el gráfico muestra una mayor variabilidad, no existiendo una diferencia tan marcada entre ninguno de los rangos analizados.

Con respecto a los valores obtenidos, la formación recibida por los estudiantes en Autocad proveniente de cursos alcanza el $51,7 \%$ y mediante aprendizaje autodidacta llega al $43,3 \%$. Estos resultados indican que prácticamente el $95 \%$ de los estudiantes tiene conocimientos en la utilización de esta aplicación informática, frente al $5 \%$ que contesta haber obtenido formación a partir de la interacción con otros estudiantes o no tener ningún conocimiento en su utilización. En referencia a la formación recibida en Revit, los datos indican que el $70 \%$ de los participantes no tienen conocimientos y solamente el $30 \%$ afirma haber recibido algún tipo de formación. En último lugar, y en referencia a la formación en Sketchup, los datos revelan que el $40 \%$ de los encuestados ha aprendido de forma autodidacta o con la 
interacción con otros estudiantes, un $20 \%$ mediante la realización de cursos y el 26,7\% restante no tienen conocimientos de la aplicación.

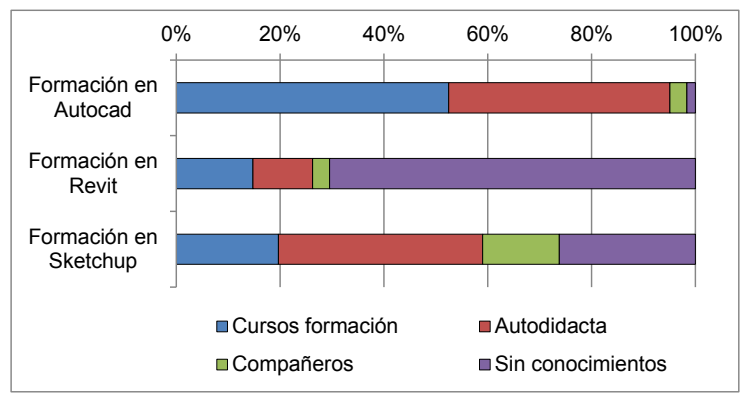

Fig 7. Distribución de la formación previa por los estudiantes. 2017. Fuente: elaboración propia.

En cuanto a la experiencia previa en la utilización de estas tres aplicaciones informáticas, y a la vista de los resultados que se muestran en la Fig. 8, se observa una asimetría entre los datos obtenidos para Autocad y Sketchup, de manera que en el primer caso la frecuencia más elevada se ha obtenido para valores de "3 o más años", mientras que en el segundo para valores de "sin experiencia hasta 1 año". El caso de Revit es distinto a los otros dos, apareciendo unos resultados acordes con los alcanzados en el gráfico anterior, que muestra la elevada frecuencia de estudiantes sin conocimientos en la aplicación.

Con respecto a los valores obtenidos, se puede observar que el 66,6\% de los participantes tiene una experiencia mayor de tres años con la utilización de Autocad mientras que, en el lado opuesto, el 78,3 \% no tienen ninguna experiencia en el uso de Revit. En relación a Sketchup, un $25 \%$ de estudiantes indica no tener experiencia con la aplicación, mientras que el $36,7 \%$ lo usa desde hace menos de un año y el resto, un $38,3 \%$, lo utiliza durante más de un año.

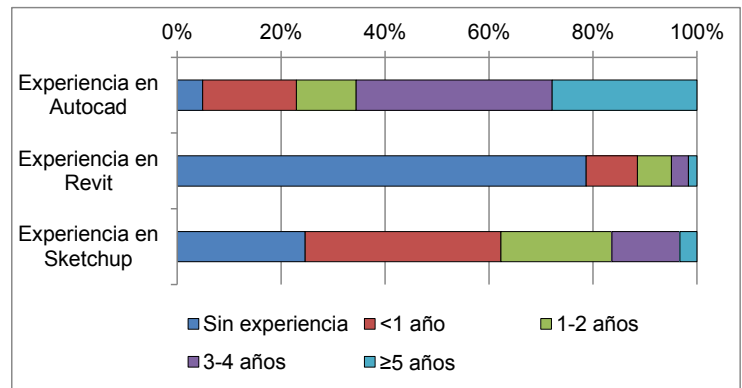

Fig 8. Distribución de experiencia en la utilización de las aplicaciones. 2017. Fuente: elaboración propia.

En cuanto a la frecuencia con la que se utiliza alguno de los tres programas en las asignaturas del GAT, no existe un patrón de utilización que permita una comparación visual entre las tres aplicaciones (Fig. 9).

Los resultados muestran que un $55 \%$ de los participantes utilizan Autocad con una frecuencia semanal y un $28,3 \%$ afirma que lo hace a diario; el resto, el $16,7 \%$, lo utiliza con poca o ninguna frecuencia. En referencia a Revit, solamente un $6,6 \%$ de los participantes afirma que lo usa poco (una vez al mes) mientras que la inmensa mayoría, un 93,4 \%, no lo 
utiliza nunca. En último lugar, la aplicación Sketchup es utilizada semanalmente por un 23,3 $\%$ de los estudiantes, un $48,4 \%$ la usa una vez al mes, y el $28,3 \%$ nunca.

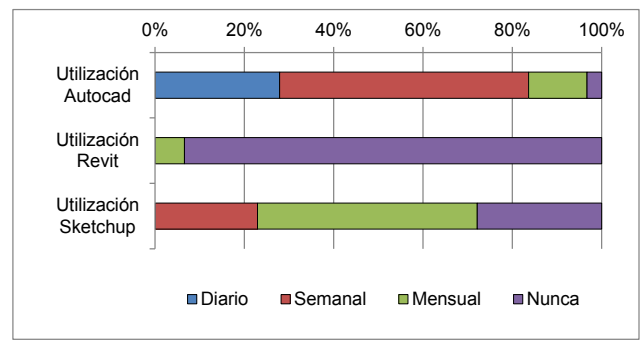

Fig 9. Distribución de la frecuencia de uso de las aplicaciones. 2017. Fuente: elaboración propia.

\subsection{Análisis}

Los estudiantes participantes en la encuesta realizaron una propuesta de implantación de contenidos BIM en determinadas asignaturas del GAT. Para recoger la información se les facilitó un listado de asignaturas en las que tenían que indicar el porcentaje de implantación de contenidos BIM que ellos estimaban como necesario $(0,25,50,75$ o 100\%) para cada una de ellas.

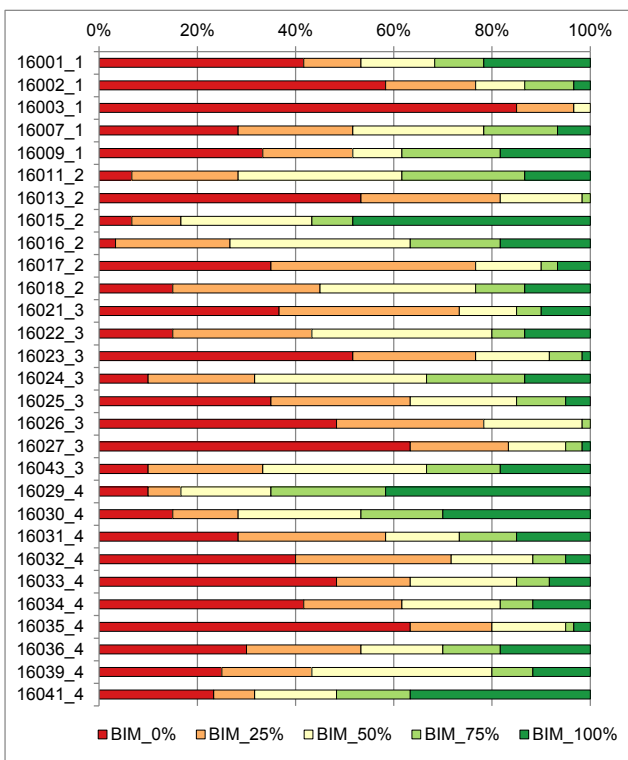

Fig 10. Resultado propuesta implantación BIM. 2017. Fuente: elaboración propia.

Los resultados obtenidos (Fig. 10) muestran que existen cuatro asignaturas en las que los estudiantes han mostrado un mayor interés por implementar contenidos BIM en, al menos, un $75 \%$ de sus contenidos docentes. Por orden de selección, los estudiantes han apuntado que sería necesario su implementación en la asignatura 16029_4 (Proyectos de Edificación), 16015_2 (Expresión Gráfica en la Edificación II), 16041_4 (Sistemas Avanzados de Expresión Gráfica) y 16030_4 (Proyectos Técnicos).

En un nivel inferior, se encuentran las asignaturas 16011_2 y 16016_2 (Construcción de Estructuras I y II), 16024_3 y16043_3 (Construcción de Elementos No Estructurales I y II) y las asignaturas 16018_2, 16022_3 y 16039_4, relacionadas con las Instalaciones. En todos 
estos casos, los estudiantes han indicado que consideran necesario la implantación de BIM en un porcentaje de los contenidos que varía entre el 25 y el $50 \%$.

En el último escalón, respecto a aquellas asignaturas en las que el estudiante no percibe una necesidad de implantar BIM en sus contenidos, se encuentran la 16003_1 (Historia de la Construcción), 16027_3 (Prevención de Riesgos Laborales en Edificación), 16035_4 (Distribución y Organización del Mercado Inmobiliario) y la asignatura 16002_1 (Geometría Descriptiva).

\section{CONCLUSIONES}

Se ha observado la existencia de una baja formación del alumnado en sistemas de trabajo con Revit. Esto puede deberse principalmente a que no se imparten estos contenidos en las asignaturas del grado, a la falta cursos de especialización asequibles, o al coste de oportunidad que el estudiante percibe al tener que adquirir una formación en una herramienta que no aplica directamente en las asignaturas que está estudiando.

Una percepción diferente se ha observado con respecto a las otras dos aplicaciones que forman parte de la encuesta, Autocad y Sketchup. Estos programas son utilizados en asignaturas relacionadas con el dibujo arquitectónico y la construcción, por lo que los resultados muestran un alto interés de los estudiantes en los apartados de formación y utilización de los mismos.

Es destacable también el importante uso de la modalidad de aprendizaje autodidacta que muestran los estudiantes en las aplicaciones de Autocad y Sketchup, que son a la vez las más utilizadas. La importante disponibilidad de recursos en forma de tutoriales o video tutoriales, el coste reducido de su utilización o la posibilidad de adaptar el ritmo de aprendizaje a las necesidades particulares, puede estar detrás de este resultado. Estas aplicaciones muestran curvas de aprendizaje con dos zonas diferenciadas. Una creciente, en la que el estudiante muestra una mayor dificultad en las fases iniciales del aprendizaje, y una segunda en la que la pendiente de la curva se suaviza y muestra que el estudiante avanza con menor dificultad.

En referencia a la aplicación Sketchup, destaca la importancia que adquiere la modalidad de aprendizaje entre compañeros/as. Con este método de aprendizaje cooperativo, se benefician todos los grupos de estudiantes, ya que comparten sus conocimientos y el resultado de transmisión adquiere una dimensión exponencial. Esta estrategia de aprendizaje supone un reto y a la vez una oportunidad que debería ser exportada a la formación de las otras aplicaciones analizadas.

Con respecto a las asignaturas identificadas por los estudiantes como susceptibles de un mayor porcentaje de implantación de contenidos docentes en BIM, principalmente se trata de asignaturas obligatorias de Expresión Gráfica situadas en segundo y cuarto curso de la titulación. Este resultado muestra una visión sesgada de las aplicaciones de la metodología BIM, que el estudiante centra en la parte de diseño gráfico, no siendo conocedores (por falta 
de experiencia con el software) del potencial que esta metodología tiene en otros ámbitos como la gestión. Es posible que un mayor conocimiento del potencial de esta metodología de trabajo hiciera que la importancia sobre la necesidad de aplicación en otras asignaturas se viese afectada.

Por otra parte, existe un segundo nivel de asignaturas, relacionadas con la construcción y las instalaciones que han sido seleccionadas por los estudiantes como susceptibles de implantar BIM en un porcentaje entre el $25-50 \%$. Se trata de asignaturas que tienen una importante interacción y en las que la aplicación de este método de trabajo serviría para avanzar y mejorar en la coordinación de las mismas.

Por último, los resultados muestran que existe un acuerdo amplio sobre un conjunto de asignaturas en las que los estudiantes consideran que no es necesario implementar la metodología BIM. Se trata de asignaturas de primero, tercero y cuarto curso que por sus contenidos no son susceptibles de incorporar BIM y que los estudiantes han detectado con precisión.

\section{REFERENCIAS}

[1] Oliver Faubel, Inmaculada. (2015). Integración de la metodología BIM en la programación curricular de los estudios de Grado en Arquitectura Técnica/Ingeniería de Edificación. Diseño de una propuesta. Valencia: Escuela Técnica Superior de Arquitectura.

[2] Pollock A. (2011). BIM in Academia. Collaborate, adapt, innovate. New York: Skidmore, Owings and Merill LLP.

[3] Barison M.B., Toledo E. (2010). BIM teaching strategies: an overview of the current approaches. Nottingham University Press. Proceedings of the International Conference on Computing in Civil and Building Engineering.

http://www.engineering.nottingham.ac.uk/icccbe/proceedings/pdf/pf289.pdf

[4] Piedecausa-García, B.; Pérez-Sánchez, J.C.; Mateo-Vicente, J.M. (2016). Construcción virtual y realidad aumentada. Aplicación en el Grado de Arquitectura Técnica. Investigación, innovación y enseñanza universitaria: enfoques pluridisciplinares, 263274.

[5] Piedecausa García, B.; Pérez Sánchez, J.C.; Mateo Vicente, J.M. (2014). Modelado y renderizado como complemento docente a los técnicos de la construcción. El reconocimiento docente: innovar e investigar con criterios de calidad, 434-444.

[6] Piedecausa García, B.; Pérez Sánchez, J.C. (2014). 3D teaching: the ideal complement for professionals in design and construction. EDULEARN Proceedings, 4766-4773.

[7] Piedecausa-García, B.; Mateo-Vicente, J.M.; Pérez-Sánchez, J.C. (2015). Enseñanza de sistemas BIM en el ámbito universitario. EUBIM 2015-Encuentro de usuarios BIM, 96103. 


\section{ANÁLISIS, MODELIZACIÓN Y SEGUIMIENTO DE DEFORMACIONES ESTRUCTURALES} MEDIANTE ESCÁNER LÁSER Y SU IMPLEMENTACIÓN BIM

Cos-Gayon López, Fernando(1), Aleixandre Lluesma, Carlos(2), Cordón Llácer, Joan(3), Anquela Julián, Ana Belén (4), Martín Furones, Ángel (5)

(1) Arquitecto Técnico y Arquitecto. Profesor Titular Escuela Técnica Superior de Ingeniería de Edificación. Departamento de Construcciones Arquitectónicas, Universitat Politècnica de València, fcosgay@csa.upv.es

(2) Arquitecto Técnico, carlosaleixandre@hotmail.com

(3) Arquitecto, Máster en Edificación, joacorll@arq.upv.es

(4) Dra. Ingeniera en Geodesia, Cartografía y Sistemas de Información Geográfica. Profesora Titular. Escuela Técnica Superior de Ingeniería Geodésica, Cartográfica y Topográfica, Universitat Politècnica de València, anquela@cgf.upv.es

(5) Dr. Ingeniero en Geodesia, Cartografía y Sistemas de Información Geográfica. Profesora Titular. Escuela Técnica Superior de Ingeniería Geodésica, Cartográfica y Topográfica, Universitat Politècnica de València, aemartin@upvnet.upv.es

\section{RESUMEN}

La utilización de escáner láser para analizar deformaciones estructurales en construcción y su posterior modelización para completar el modelo 3D de la edificación son el objeto de este trabajo. Se analizan las ventajas de una medición con elevada exactitud, no invasiva y cuyos resultados pueden implementarse en BIM, evaluando en tiempo real la deformación de estructuras y pudiendo incorporar la geometría real ejecutada, detectando interferencias con arquitectura o instalaciones con el modelo.

Frente a la complejidad operativa de los ensayos de pruebas de carga en estructuras y su impacto en la organización de las obras, este método no interfiere en los trabajos, se realizan en pocos minutos y puede repetirse en diferentes momentos sin impacto alguno.

Se ha utilizado un escáner láser, con error estimado a la distancia de trabajo menor a 0,20 $\mathrm{mm}$, y una estructura de hormigón armado en construcción; concretamente se estudia la deformación de un voladizo de $3,50 \mathrm{~m}$, escaneando en diferentes momentos de su puesta en carga, midiendo las deformaciones producidas.

Se han comparado y analizado las nubes de puntos con CloudCompare $($, e importado a Revit $₫$ para modelizar la estructura. Se detalla flujo de trabajo y estandarización de procesos para aplicación en caso general.

Palabras clave: escáner láser, deformación, estructural.

\section{ABSTRACT}

The use of laser scanners to analyze structural deformations in construction and their subsequent modeling to complete the 3D building model are the goal of this work. The advantages of a measurement which is high accuracy, non-invasive and whose results can be implemented in BIM are analyzed, evaluating the structures deformation in real time, and 
being able to incorporate the actual geometry executed, clash detection with architecture or facilities with the model.

Faced with the operational complexity of structures tests and their impact in building works management, this method does not interfere with the works, it is done in a few minutes and can be repeated at different times without any impact.

A laser scanner which has less estimated distance error than $0.20 \mathrm{~mm}$, and a reinforced concrete structure under construction have been used; specifically we study the deformation of an overhang greater than $3,50 \mathrm{~m}$, scanning it in different loading up moments, measuring the deformations produced.

The point clouds have been compared with CloudCompare $($, and imported to Revit $\AA$ to model the structure. The workflow and the processes standardization have been detailed to apply them in a real case.

Keywords: lasser scanner, deformation, structural

\section{INTRODUCCIÓN}

La tecnología Escáner Láser 3D permite generar nubes de puntos en tres dimensiones con una altísima precisión milimétrica. La información obtenida tiene infinidad de aplicaciones, siendo las más significativas en la construcción la posibilidad de crear modelos BIM que reflejen el estado real de la obra, con la posibilidad de generar planos, etc...

Pero recientemente, con ocasión de grandes seísmos, se está comenzando a utilizar esta técnica para llevar un seguimiento casi instantáneo de los daños estructurales en las edificaciones, siendo una herramienta vital para garantizar la seguridad de los equipos de rescate. Asimismo, ayuda a tomar decisiones acerca de la viabilidad estructural tras el episodio sísmico.

Con esta investigación se pretende ir algo más allá; utilizar este método de toma de datos para monitorizar el comportamiento de una estructura al ir entrando en carga, y hacerlo en tiempo real. Esto supone un importante avance para los casos de complejidad estructural o constructiva, pudiendo tomar decisiones de manera anticipada.

\section{OBJETIVO}

El objetivo de esta comunicación es exponer la utilización de la toma de datos por escáner láser, su tratamiento en aplicaciones específicas y su integración BIM para realizar un estudio de deformaciones de una estructura y su seguimiento de manera rápida y no invasiva. 
Como ocurre con casi cualquier disciplina integrada en BIM, tan importante como lo que se hace es el cómo se hace; es decir, los procesos y flujos de trabajo necesarios para culminar con éxito el tránsito desde la toma de datos a la toma de decisiones.

\section{METODOLOGÍA DE TRABAJO}

Para la investigación objeto de esta comunicación se ha seleccionado un proyecto en ejecución, con un diseño estructural tal que incorpora vigas de gran canto en voladizos de $3.50 \mathrm{~m}$. Se procederá a realizar un escaneo inicial de estructura y la repetición del proceso implementando carga en el voladizo para comprobar la deformación y, seguidamente, comparar las dos nubes de puntos generadas por el escáner.

El escáner que se ha utilizado para este proyecto es el Faro Focus 3D X130. Obtiene las coordenadas en 3D de cada punto que encuentra a su alcance dentro de un radio de $130 \mathrm{~m}$, pudiendo realizar escaneos en tan solo dos minutos, algo esencial para mostrar la facilidad operativa del procedimiento.

Con la nube de puntos generada por el escáner podemos obtener unas coordenadas en 3D con precisión milimétrica y, posteriormente, generar superficies y modelos 3D para BIM [1] (Arayici, 2007). Con un segundo escaneo al cabo de varios meses se procede a comparar las dos nubes de puntos para obtener las deformaciones de la zona en voladizo.

Para ello combinaremos la tecnología Escáner Láser 3D con software de control de deformaciones. Tomaremos las coordenadas tridimensionales para comparar geométricamente los dos escaneos mediante CloudCompare@), software de análisis de desviaciones.

Finalmente, utilizaremos las nubes de puntos para realizar un modelo BIM mediante el Autodesk@ Revit ${ }^{\mathrm{TM}}$. Además, esta herramienta nos dará la oportunidad de experimentar la tecnología de realidad virtual inmersiva para una visualización del proyecto mediante Smartphone y dispositivo HMD (Head Mounted Display).

\section{$4 \quad$ ESTADO DEL ARTE}

La tecnología de láser escáner tiene infinidad de aplicaciones. En cuanto a la construcción, lo más destacable es que puede utilizarse para hacer seguimientos de obras (pudiendo ofrecer incluso su visualización en realidad virtual inmersiva), localizar las instalaciones, hacer certificaciones de obra, realizar un rápido modelado en BIM, calcular volúmenes, etc... También es extremadamente útil en el campo de la arquitectura y la restauración para la obtención de planos, catalogación del patrimonio, comprobar el estado actual y el control de deformaciones (Fig. 1). 


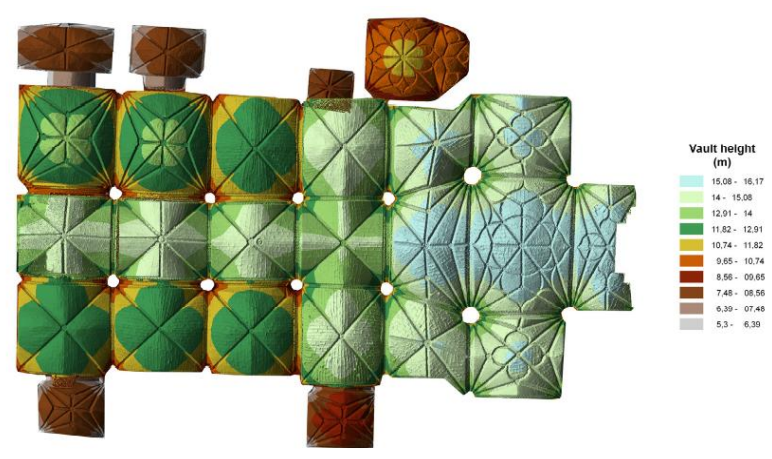

Fig. 1: Control de deformaciones. Faro Spain. (2012).

Otro de los sectores en los que se utiliza mucho esta tecnología es la ingeniería. Desde la construcción de carreteras, puentes y túneles hasta la comprobación de calidad en piezas de todo tipo de industrias e ingeniería inversa.

También se está utilizando en el desarrollo de videojuegos por su capacidad para captar entornos, piezas y personajes. Se utiliza, incluso, en los simuladores de los equipos de competición más prestigiosos del mundo, ya que necesitan que la recreación del circuito sea lo más aproximada posible a la realidad.

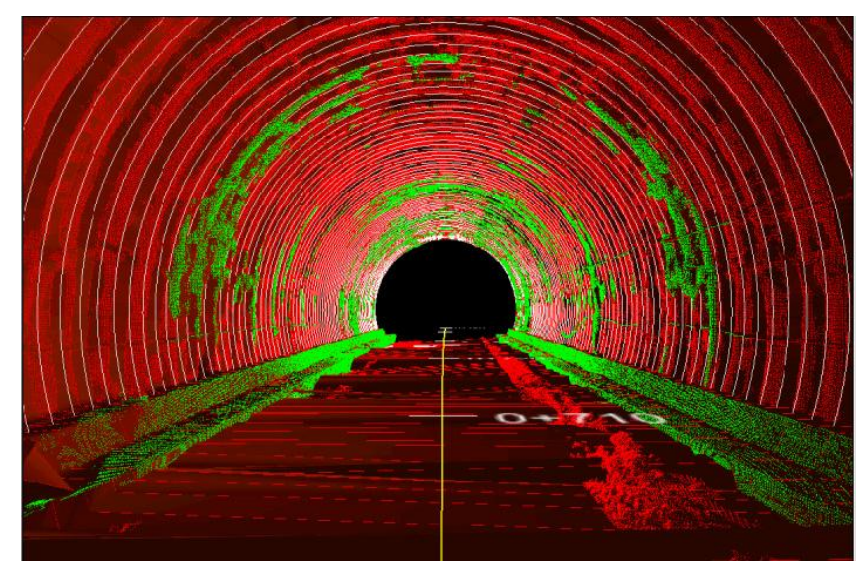

Fig. 2: Construcción de túneles. Faro Spain. (2012).

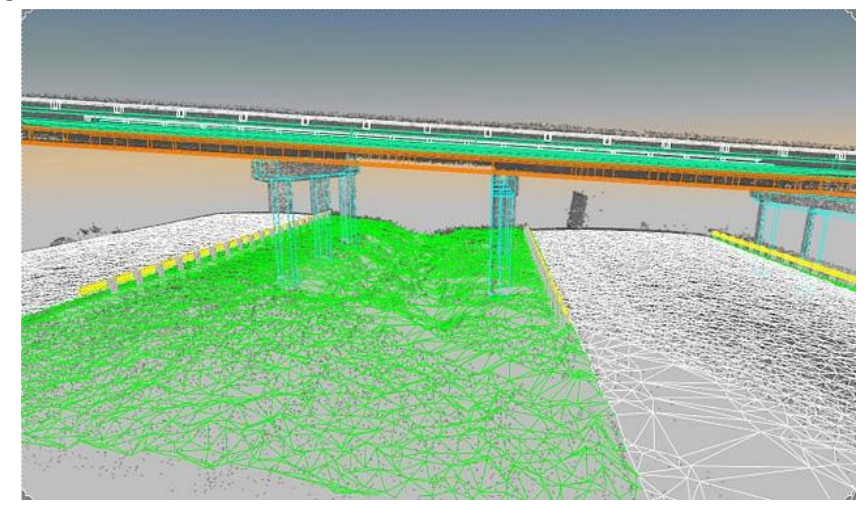

Fig. 3: Construcción de puentes. Faro Spain. (2012). 


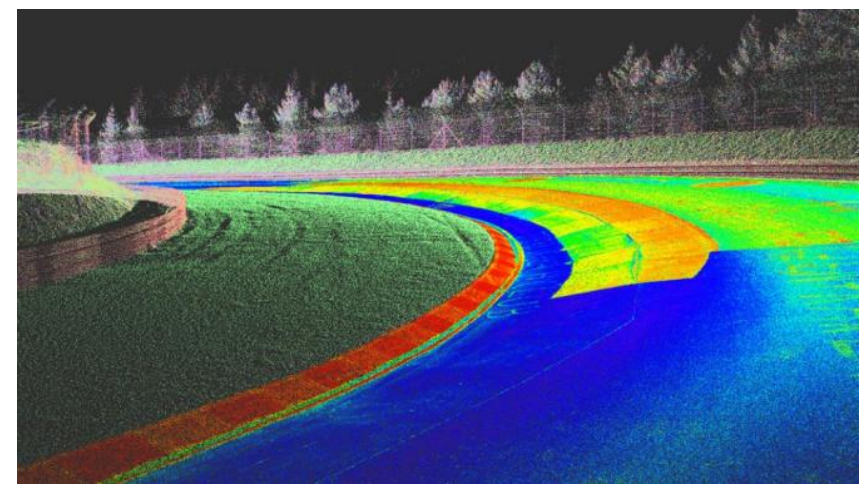

Fig. 4: Escaneado del circuito de Nürburgring. Kunos Simulazioni. (2014).

La tecnología de escaneado láser se ha desarrollado intensamente en los últimos años pues no solo es capaz de obtener geométricamente el estado de una edificación, sino de analizar variaciones en su estado, y esto es un aspecto determinante en esta investigación.

Estas herramientas se han utilizado anteriormente para la monitorización estructural en caso de seísmos, aportando gran cantidad de información, con mucho detalle, por lo que es capaz de obtener las coordenadas en 3D con gran precisión, pudiendo estudiar las fisuras y medir las deformaciones [2] (Bose, 2016).

Asimismo, Olsen describe como se usa el escáner láser para la detección de daños y el análisis de variación de volumen de una estructura [3] (Olsen, 2010).

También puede realizarse un estudio de deformación comparando la nube de puntos generada por un escáner láser con un modelo teórico de elementos finitos (FEM) [4] (Pesci, 2011).

En esta línea, se han combinado diferentes métodos de estudios; como ejemplo, el que combina el escáner láser con la fotogrametría a corta distancia, un georádar y FEM para documentar el estado estructural de puentes [5] (Pesci, 2013).

De cualquier modo, la monitorización estructural se ha llevado a cabo paralelamente mediante otros métodos ajenos a la tecnología escáner láser. Uno de los utilizados ha sido el uso de un sistema de captura de movimiento para la medición de deformaciones de la estructura de un edificio [6] (Park, 2010). Otro de ellos ha sido mediante galgas extensiométricas [7] (Alzate et al., 2007), resultando una tecnología más precisa que la de escáner láser, pero estando limitada en cuanto al tamaño de actuación. El escáner láser tiene mucho más rango y obtiene más información en menor tiempo.

\section{DESARROLLO DEL TRABAJO DE INVESTIGACIÓN}

Para realizar un escaneado 3D completo de una estructura se debe estudiar el recorrido y los enlaces de los diferentes estacionamientos que precisaremos. El escáner capta la información que tiene a la vista por lo que habrá que pensar y organizar bien los 
estacionamientos para que no quede ninguna parte oculta y, además, se realice con mínimo número posible para reducir el tiempo de escaneado y de procesado, facilitando así el manejo de la nube de puntos en el ordenador.

Una de las soluciones para unir escaneos es usar unos objetos esféricos de referencia. Estos objetos actúan como referencias de posición al disponerlos de manera visible en dos escaneos consecutivos.

La Fig. 5 muestra un ejemplo de posicionamiento de dichas esferas. A la izquierda, vemos dos esferas que podrán utilizarse para unir con el escaneo anterior, mientras que a la derecha de la imagen observamos cuatro esferas que van a utilizarse para unir los escaneos siguientes.

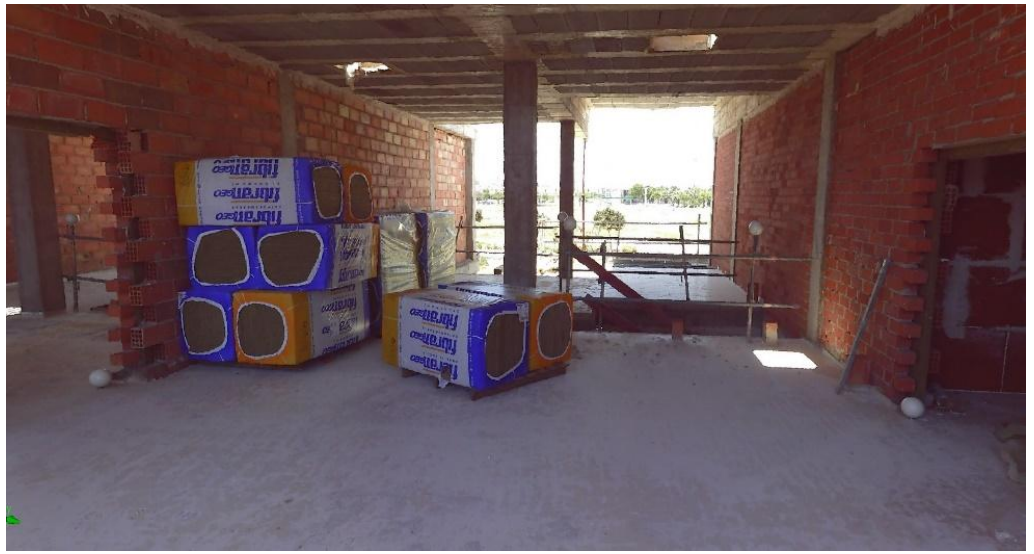

Fig. 5: Posicionamiento de esferas

Un factor a tener en cuenta es el desfase que existe al unir dos escaneos consecutivos. Este desfase es mínimo (décimas de milímetros) pero si vamos a enlazar 31 escaneos, como es el caso, el desfase se multiplica por 30. Por esta razón se ha evitado un enlace consecutivo, creando varios recorridos, minimizando así esos desfases (Fig. 6).

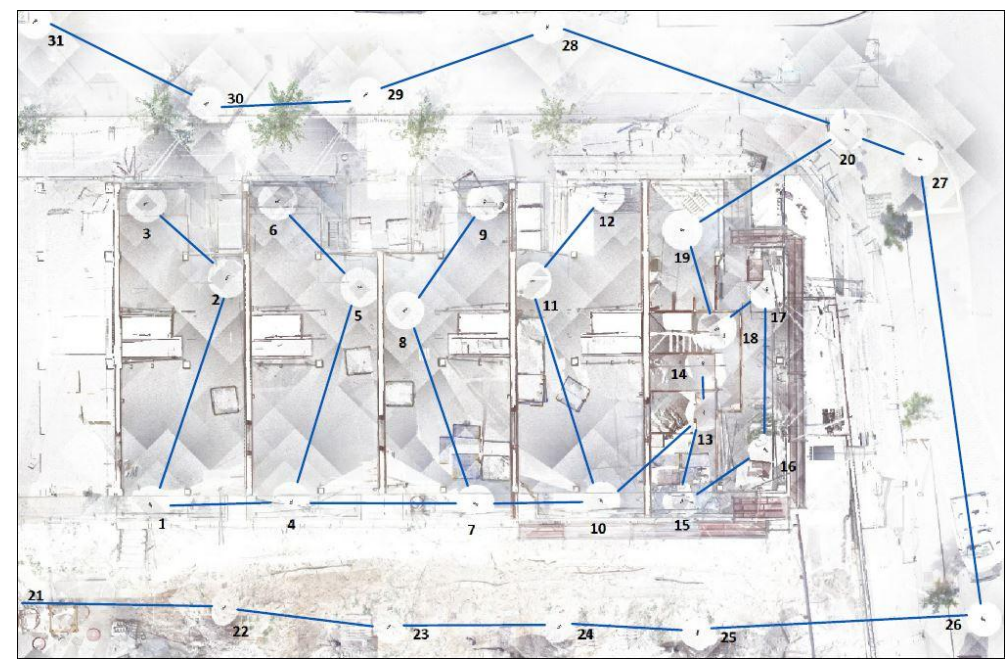

Fig. 6: Posicionamiento de estacionamientos de láser escáner 
Una vez realizado el trabajo de campo se inicia el procesado de los datos. Para ello, hemos utilizamos Scene ${ }^{\mathrm{TM}}$, el software proporcionado por Faro@).

Deberemos cuidar los puntos dispersos (que aparecen porque el punto del láser no es infinitamente fino, sino que tiene un grosor y cuando encuentra un cambio de plano (una esquina, por ejemplo) el punto queda dividido. Se proyecta entonces una línea de puntos de un extremo a otro de la esquina.

También utilizaremos la función del preprocesado para localizar las esferas. Si marcamos la casilla de "Detectar referencias artificiales" nos reconocerá todos los objetos esféricos.

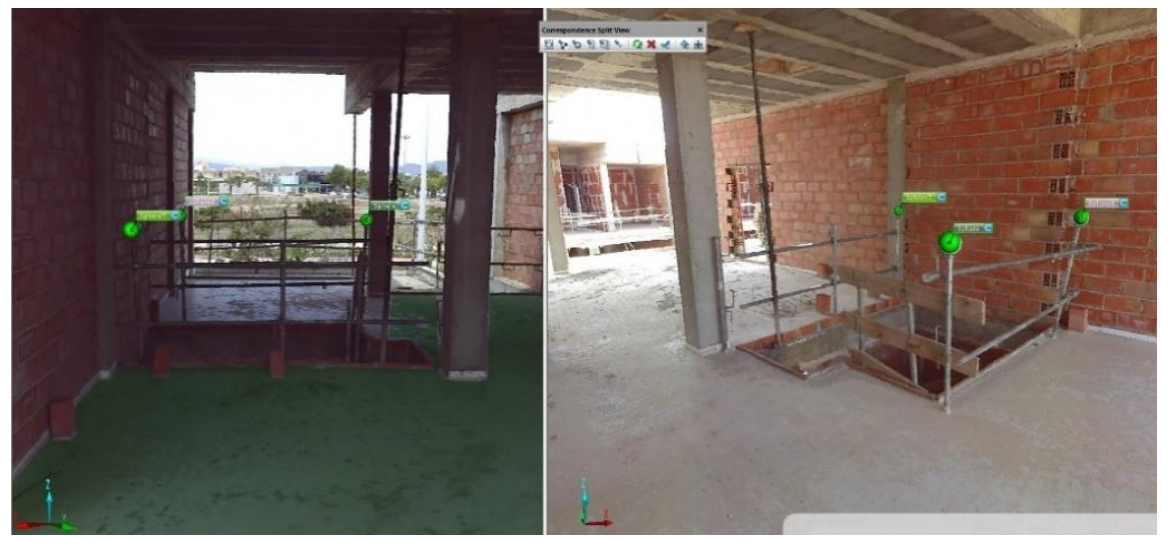

Fig. 7: Relación de estacionamientos

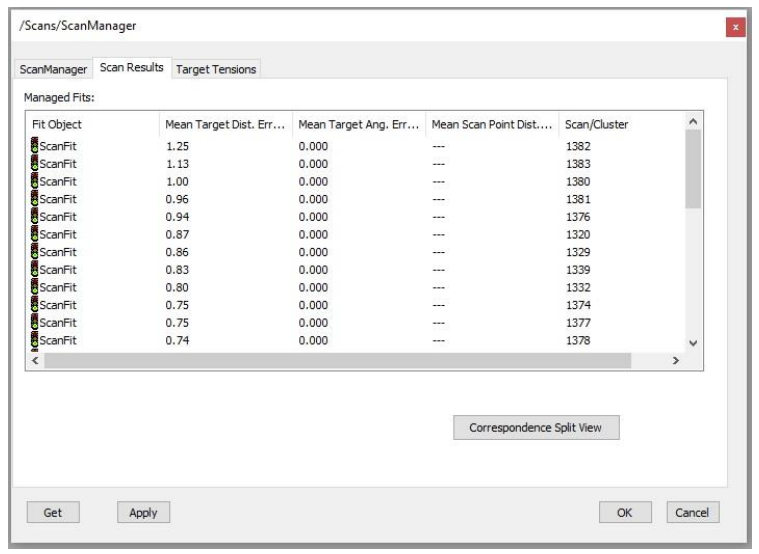

Fig. 8: Resultados

Finalmente, con la nube de puntos creada, podemos realizar secciones con una "clipping box", ortofotos, recorridos virtuales, etc. Para ello, debemos crear una "clipping box" paralela a un plano, que lo definimos por tres puntos. De esta forma, creamos una caja con la que podremos hacer varias cosas: ortofotos, secciones y exportar elementos. 


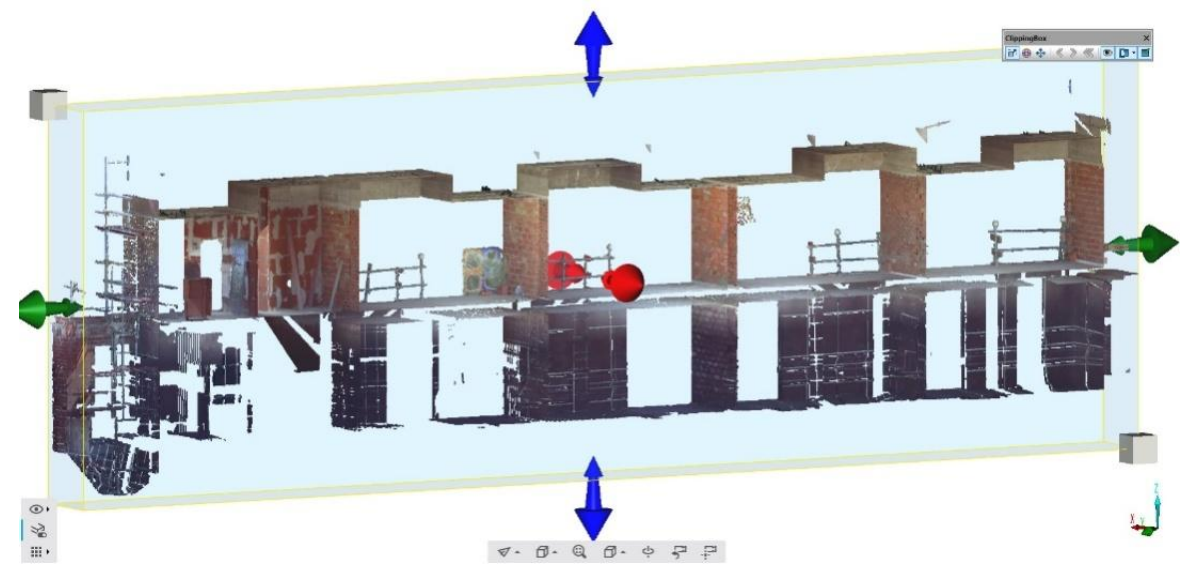

Fig. 9: Clipping box

Para realizar el estudio de deformación se ha decidido escanear una vez la cubierta invertida no transitable de grava cuando ya ha sido ejecutada. Al someter la estructura a una carga pequeña, tenemos que evitar posibles errores. Como el estudio se realiza solamente en el voladizo de la viga, vamos a localizar un escaneo de cada estado. De esta forma evitaremos el pequeño margen de error de solape y solamente nos queda el error del escáner, que es de $2 \mathrm{~mm}$ cada $25 \mathrm{~m}$. Esto significa que si un objeto está a una distancia de $25 \mathrm{~m}$, el margen de error del escáner es de $2 \mathrm{~mm}$. Con este dato podemos establecer que, medida la distancia entre el escáner y el voladizo $(2.22 \mathrm{~m})$, el error máximo será de $0.18 \mathrm{~mm}$ en nuestro estudio de deformación del voladizo.

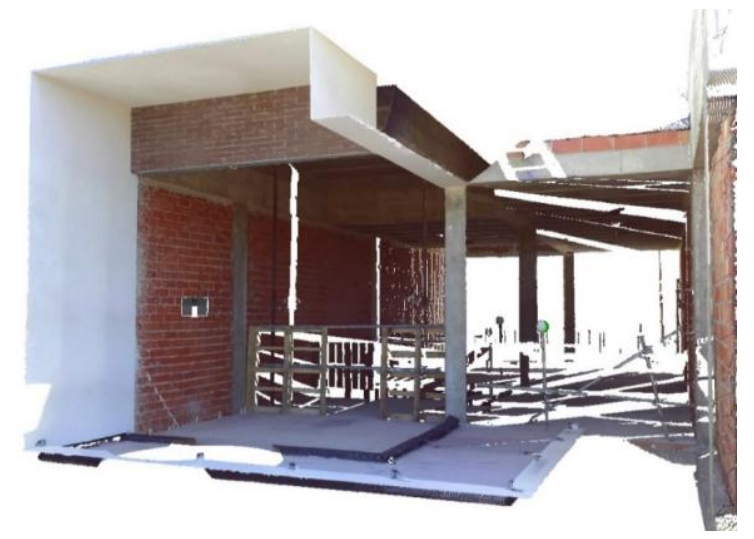

Fig. 10: Estructura en carga

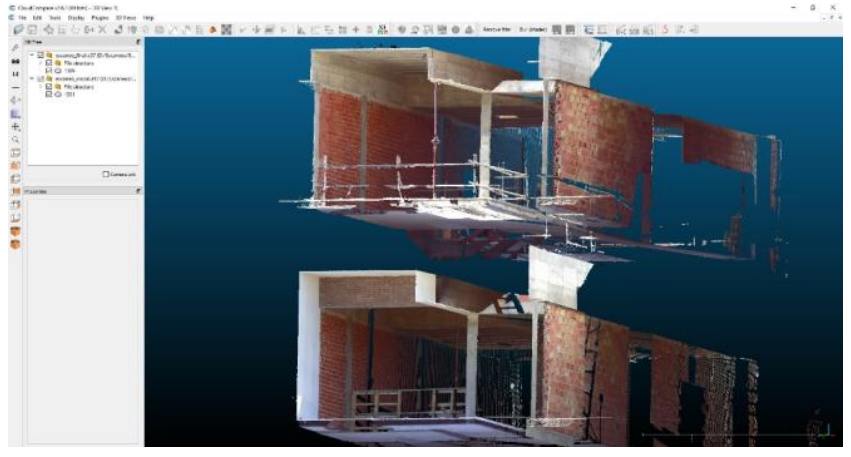

Fig. 11: CloudCompare 
Desde Scene ${ }^{\mathrm{TM}}$ se han exportado los escaneos del voladizo en formato ".e57" y se han importado en CloudCompare $\subset$. Insertamos los dos escaneos y los colocamos de forma que queden aproximadamente en la misma posición. Esto es necesario para facilitar la alineación de las dos nubes. Esta alineación la hacemos con el comando "Registrar nubes previamente alineadas", el icono puede observarse resaltado en la imagen Fig. 12.

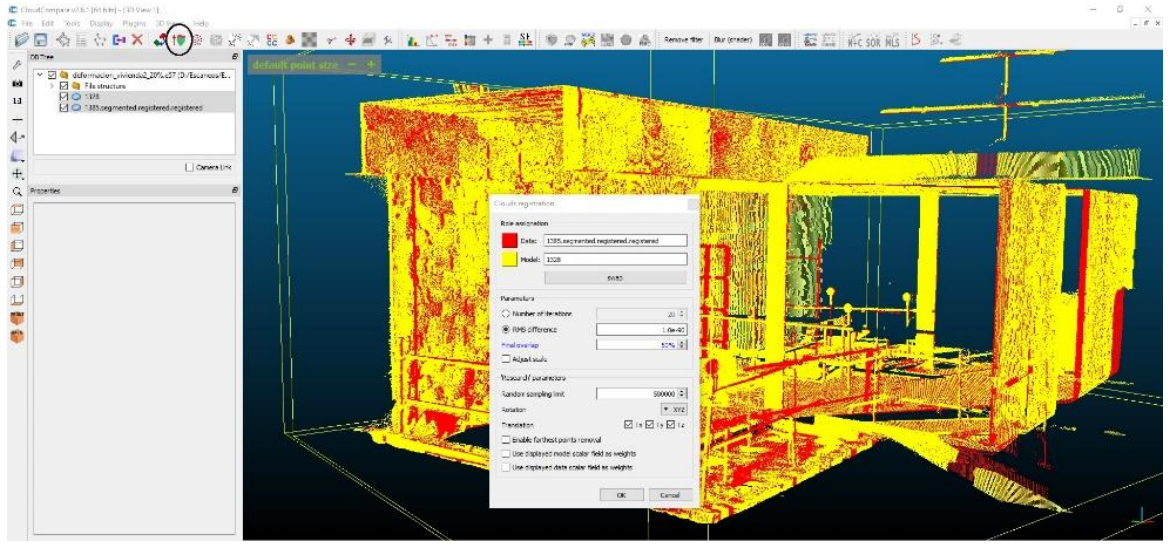

Fig. 12: Alineación de escaneos en CloudCompare@

Utilizamos, como se ha mencionado, el análisis de desviaciones con el programa Cloud Compare $($, software gratuito. Una vez tenemos las dos nubes perfectamente alineadas procedemos a la comparación. Seleccionando el comando "Compute cloud/cloud distance" o "Calcular distancia nube/nube". De nuevo seleccionamos en "Referencia" nuestro escaneo inicial y aceptamos. Elegimos la casilla "Octree level" y lo dejamos en 9, por defecto. Seleccionamos "Compute" y esperamos a que termine el proceso.

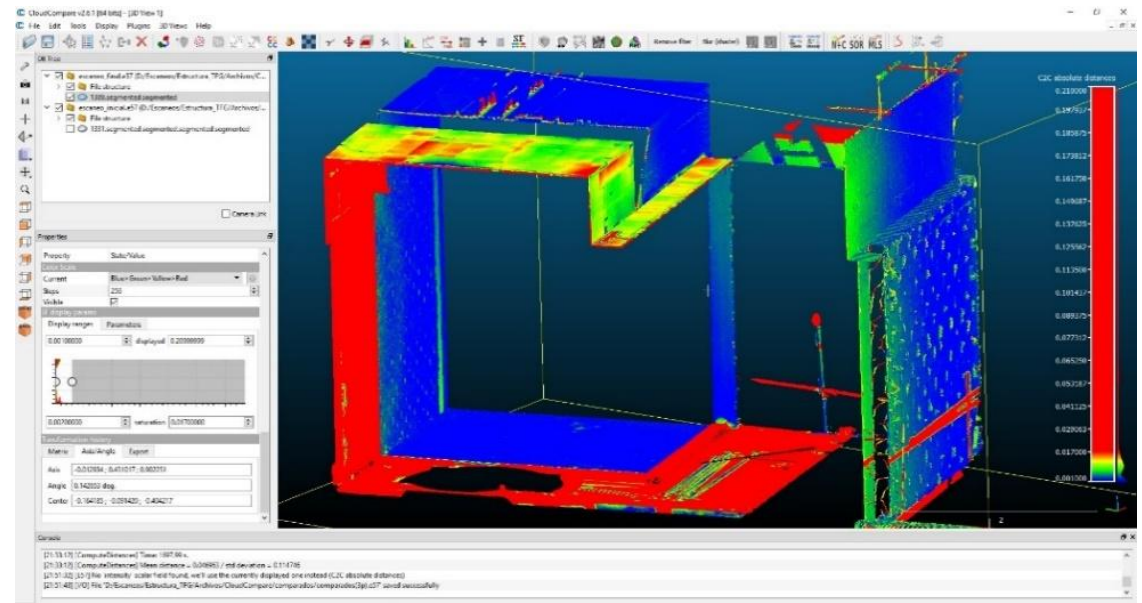

Fig. 13: Análisis de desviaciones

Ya tenemos el análisis de desviaciones realizado. El análisis podemos visualizarlo con una escala de colores que se ha guardado en el escaneo final. Debemos desactivar el escaneo inicial para visualizar solamente el final. Podemos modificar la saturación máxima de modo que muestre en color rojo una cifra inaceptable previamente fijada. Hay grandes zonas en rojo, pues ha habido cambios por el avance de la obra (cerramientos y pendientes de 
terrazas). Dado que el voladizo tiene un recubrimiento de $1 \mathrm{~cm}$ de espesor, se ha modificado la escala de colores para que comience a marcar en rojo a partir de $1^{\prime} 5 \mathrm{~cm}$, lo que supondría un desplazamiento de $5 \mathrm{~mm}$ en la zona del recubrimiento. Se aprecia como en la viga y en la cubierta comienzan a verse zonas intermedias y zonas rojas. Esto puede ser debido a varias razones. La primera es que haya variación en el espesor del enfoscado porque tanto en la zona inicial de ésta como en la final se aprecian zonas rojas y es muy difícil que haya habido deformación tan cerca del pilar. Otra razón sería que la alineación de los dos escaneos no haya sido del todo perfecta. Y la última sería que realmente hubiera una deformación de hasta $5 \mathrm{~mm}$.

Para comprobar si realmente ha habido una deformación vamos a proceder a hacer el mismo proceso pero con dos escaneos diferentes, los de la vivienda colindante.

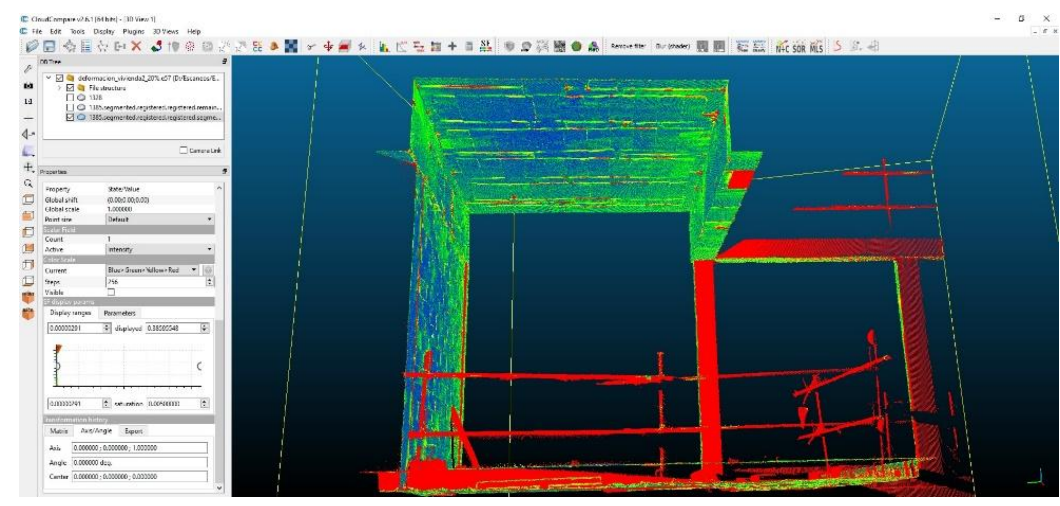

Fig. 14: Resultados segunda vivienda

Los resultados de esta vivienda los podemos ver en la Fig. 14. En esta escala de colores se ha fijado en rojo una distancia de $5 \mathrm{~mm}$ y vemos como no llega a haber zonas que estén tan desviadas. Ajustando este valor podemos observar que empiezan a aparecer zonas rojas con un valor de 1 '5 mm (ver Fig. 15) por lo que podemos decir que la deformación es despreciable.

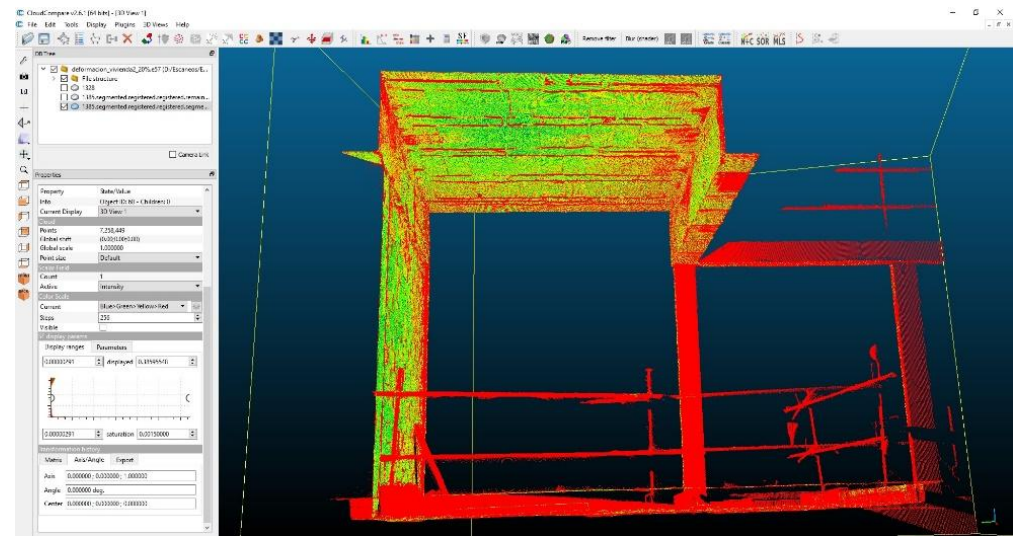

Fig. 15: Resultados a 1'5 mm 
Toda esta información debe ser consolidada para guardar un registro editable y accesible. Para ello, se ha optado por la exportación de las nubes de puntos a Autodesk ${ }^{\odot}$ Revit $^{\mathrm{TM}}$, y la posterior modelización, siguiendo el flujo de trabajo descrito por Cos-Gayón et al. (2016) [8], e incluyendo información con los datos procedentes de los análisis realizados, como se aprecia en las ilustraciones siguientes:

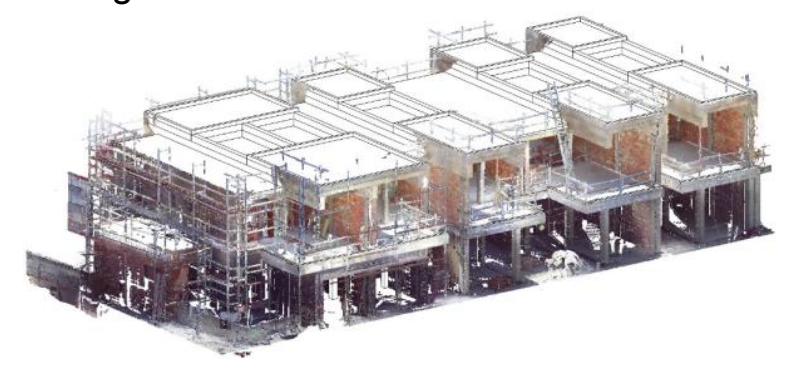

Fig. 16: Vista 3D con nube de puntos activada (Revit)

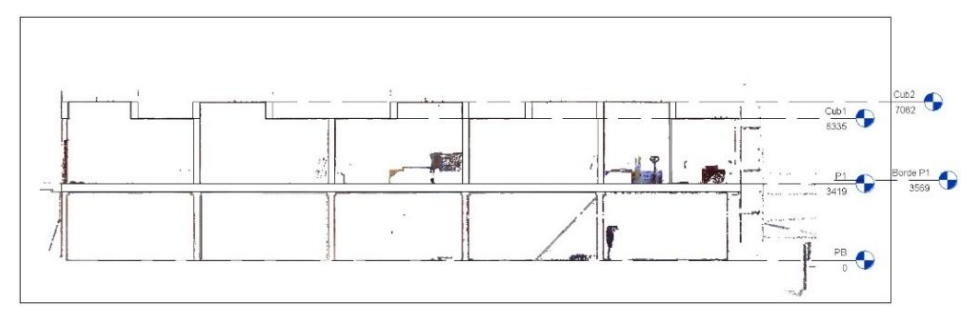

Fig. 17: Niveles (Revit)

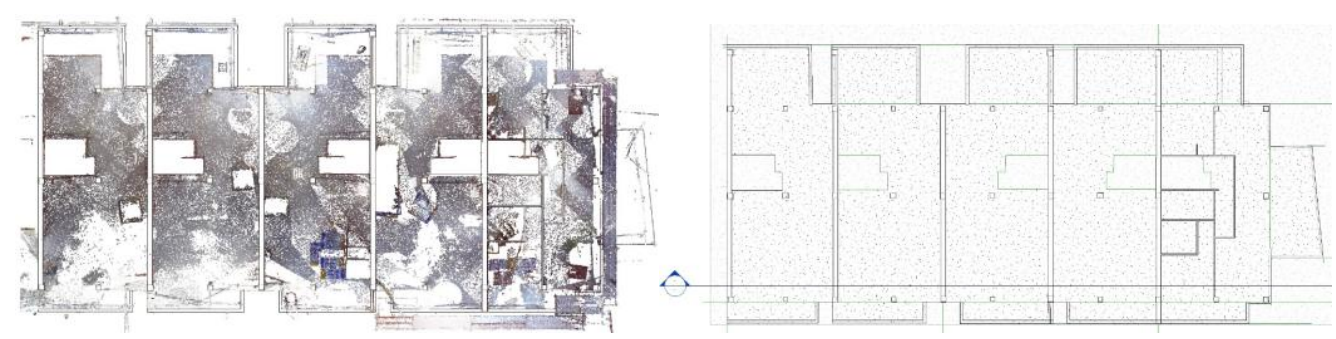

Fig. 18: Primera planta con nube de puntos activada (izq.) y desactivada (dcha.) (Revit)

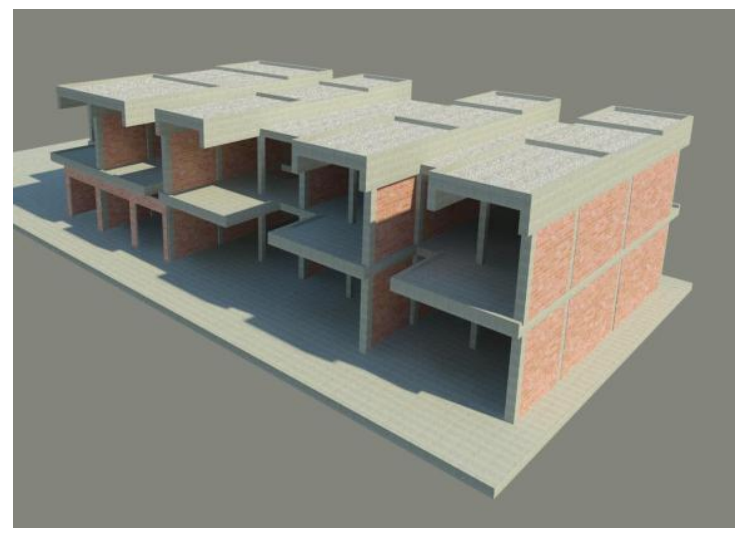

Fig. 19: Renderización (Revit) 


\section{CONCLUSIONES}

En primer lugar, se confirma la hipótesis de partida de esta investigación, es decir, que es posible llevar un seguimiento de la entrada en carga de la estructura de una edificación en tiempo real, con alta precisión, de manera operativa y económica, algo fundamental para que cualquier sistema se pueda implementar en la economía real.

Con relación a su ámbito de aplicación, cabe establecer la limitación que supone la precisión del equipo, en este caso y distancia, de \pm 0 ' $18 \mathrm{~mm}$, por lo que deformaciones inferiores a esta cantidad no serían detectadas.

Por último, toda esa información y análisis se integra en un modelo BIM, lo que permitirá disponer de una valiosa información acerca del comportamiento estructural en edades tempranas, que irá completándose con las intervenciones que pudiera requerir, en su caso, la estructura del edificio.

\section{$7 \quad$ REFERENCIAS}

[1] Arayici, Y. (2007). "An approach for real world data modelling with the 3D terrestrial laser scanner for built environment". Automation in Construction. Vol. 16, Issue 6, September, pp. 816-829.

[2] Bose, S. (2016). "Structural Assessment of a School Building in Sankhu, Nepal Damaged Due to Torsional Response During the 2015 Gorkha Earthquake". Dynamics of Civil Structures, Vol. 2, pp 31-41.

[3] Olsen, M. (2010). "Terrestrial Laser Scanning-Based Structural Damage Assessment". Journal of Computing in Civil Engineering, Vol. 24, Issue 3.

[4] Pesci, A. (2011). "Laser scanning the Garisenda and Asinelli towers in Bologna (Italy): Detailed deformation patterns of two ancient leaning buildings". Journal of Cultural Heritage. Vol. 12, Issue 2, April-June 2011, pp. 117-127.

[5] Pesci, A. (2013). "A laser scanning-based method for fast estimation of seismic-induced building deformations". ISPRS Journal of Photogrammetry and Remote Sensing. Vol. 79, May 2013, pp. 185-198.

[6] Park, H., Lee, H., Adeli, H., Lee, I. (2007). "A New Approach for Health Monitoring of Structures: Terrestrial Laser Scanning". Computer Aided Civil and Infrastructure Engineering. Vol. 22, Issue 1, pp. 19-30.

[7] Alzate, E., Montes, J. W. , Silva, C. A. (2007). "Medidores de deformacion por resistencia: galgas extensiométricas”. Scientia Et Technica, vol. XIII, núm. 34, mayo, 2007, pp. 7-12.

[8] Cos-Gayón, F., Cordón, J., Anquela, A., Bonet, E. (2016). “Aplicaciones de la realidad virtual inmersiva en el Teatro Romano de Sagunto (Valencia, España)". EUBIM 2016 Congreso Internacional BIM / $5^{\circ}$ Encuentro de Usuarios BIM, Ed. UPV. pp. 138-149. 


\section{APLICACIÓN DE LA METODOLOGÍA BIM EN UN PROYECTO FINAL DE CARRERA}

\section{Oya Sala, Tania (1), Torres Marrades, Raquel (2)}

(1) Arquitecta. Máster BIM en IDESIE Business School. oyasala.tania@gmail.com

(2) Arquitecta. Máster BIM en IDESIE Business School. raqueltorresmarrades@gmail.com

\section{RESUMEN}

La aplicación de la metodología BIM en los distintos campos de la arquitectura está cada vez más extendida. El uso de la información que proporciona, permite una clara mejora en estados previos, diseño, ejecución de obra y explotación. Pero, lamentablemente, está poco aplicada en proyectos académicos. ¿Esto quiere decir que no es óptimo, entonces, desarrollar un Proyecto Final de Carrera (PFC) con BIM?

"Recorre Open UPV" es un PFC realizado en la escuela de arquitectura de la Universidad Politécnica de Valencia (UPV) donde se ha trabajado con BIM en cada una de sus fases. Se trata de un complejo de talleres más biblioteca situado en el centro de Valencia, que pretende acercar la cultura a la gente que vive allí. Como en todo PFC se ha exigido un nivel de diseño adecuado en cuanto a arquitectura, instalaciones y estructura. Además de unos detalles constructivos y unas mediciones adecuadas. Todo ello habría sido posible mediante herramientas tradicionales, pero el uso de la metodología BIM ha aportado un plus al conjunto.

En definitiva, se muestran las ventajas e inconvenientes del flujo de trabajo mediante la metodología BIM en un proyecto académico.

Palabras clave: Arquitectura, BIM, Interoperabilidad, Proyecto Final de Carrera.

\section{ABSTRACT}

The application of the BIM methodology in the different fields of architecture is increasingly widespread. The use of the information that it provides, allows a clear improvement in previous phases, design, execution and exploitation. But, unfortunately, it is little applied in academic projects. Does this mean that it is not optimal, then, to develop a Final Degree Project (FDP) with BIM?

"Recorre Open UPV" is a FDP realized in the school of architecture of the Polytechnic University of Valencia (UPV) where it has worked with BIM in each stage. It is a complex of workshops plus library located in the center of Valencia, which aims to bring culture to the people who live there. As in every FDP, an adequate level of design has been demanded in terms of architecture, systems and structure. In addition to constructive details and adequate measurements. All this would have been possible through traditional tools, but the use of the BIM methodology has contributed a plus to the whole. 
In short, the advantages and disadvantages of the workflow through the BIM methodology in an academic project are shown.

Keywords: architecture, BIM, interoperability, Final Degree Project.

\section{INTRODUCCIÓN}

Uno de los principales problemas a los que se enfrentan arquitectos e ingenieros, es la traducción de los datos del proyecto a la obra. Disponer de una herramienta como es la metodología BIM, permite contener tanto información del proyecto, como un modelo de construcción. Es decir, no se trata únicamente de una maqueta en tres dimensiones que aporte información gráfica, sino que está dotado de contenido referente al conjunto o a cada elemento del proyecto. Lo que permite, además, facilitar la labor de mantenimiento en la fase de explotación del edificio.

El BIM da un paso más, y consigue utilizar toda esa información que contiene para relacionarse con distintos programas informáticos necesarios en distintas fases de los proyectos de construcción. No solo consigue homogeneizar y estandarizar los procesos, sino que permite optimizar las labores de los técnicos, obteniendo unos datos lo más exactos posibles.

La aplicación del BIM no es sólo interesante en el mundo laboral, sino que también en el ámbito académico puede tener especial relevancia. Utilizar esta metodología permite al proyectista definir y razonar cada parte del proyecto desde fases iniciales, ayudándole a obtener un resultado de mayor calidad en comparación con las metodologías empleadas hasta el momento.

Un proyecto final de carrera, por norma general, no llega a construirse, pero debe elaborarse como si fuera a llevarse a cabo. Por ello debe incluir las fases necesarias para definirlo y ser capaz de generar información suficiente, adecuada, veraz y atractiva gráficamente.

Por estas razones se decidió llevar a cabo el proyecto 'Recorre open UPV' mediante la metodología BIM, con la finalidad de comprobar por uno mismo cada una de las ventajas y desventajas de la aplicación de dicha metodología en un proyecto académico.

\section{RECORRE OPEN UPV}

Recorre open UPV se ubica en pleno centro histórico de Valencia, más concretamente en Velluters y surge de la necesidad de acercar la universidad a dicha zona. A la hora de abordar el proyecto físico, se pretende mantener el carácter natural de barrio, alterado por el tiempo y la excavadora, pero auténtico. Se busca no imponer un programa, sino que éste surja de las necesidades del barrio, de su historia. Una vez situado Velluters en contexto se 
llega a la conclusión de la importancia de su trama histórica ante las grandes alteraciones, de su carácter artesanal y del respeto hacia todos los colectivos sociales. A pesar de la dificultad de abordar temas tan distintos de manera simultánea, son parámetros que se han tenido en cuenta a la hora de elegir el área de proyecto y se traducen en todo el proceso.

El solar Princesa es un enclave perfecto para el proyecto, debido a su complejidad, su historia, sus accesos, su gran tamaño... De este modo se consigue solucionar los problemas detectados en el barrio, y darle a Velluters lo que tanto tiempo está pidiendo: vida. Además tiene un fuerte carácter histórico, puesto que se ha visto afectado por diversas planificaciones urbanísticas y es parte de una reivindicación vecinal. Se trata de un solar reconocible en el barrio y que necesita de una intervención.

La primera pregunta que se plantea con el proyecto es ¿qué puede aportar la universidad a Velluters? Las respuestas son diversas, incluyendo cultura, ocio, formación, investigación... Pero se establecen dos premisas fundamentales a tener en cuenta a la hora de elegir el programa: crear espacios dedicados a los grupos sociales más vulnerables que se encuentran en el barrio y acercar la universidad a la zona, apostando por la confluencia entre los que vienen y los que están.

Con este punto de partida se van formando una serie de ideas y criterios a seguir, desde los cuales parte el diseño del proyecto: uso de filtros que mejoren la relación pública-privada, rehabilitación de fachadas perimetrales, conexiones visuales y recorrido. Con ello se empieza con el diseño del proyecto, definiendo como programa una biblioteca y unos talleres que puedan tener usos diversos.

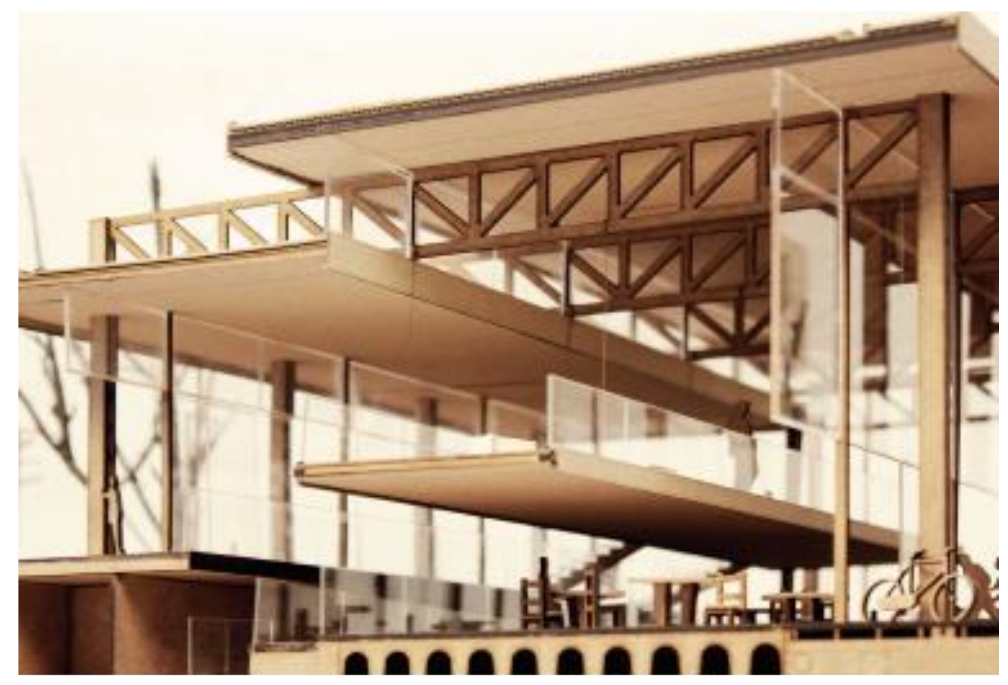

Fig 1. Maqueta constructiva del proyecto. 2016. Fuente: Elaboración propia

\subsection{Planificación}

Se plantea, como se ha nombrado anteriormente, llevar a cabo el proyecto mediante la metodología BIM. En primer lugar, se elabora un mapa de procesos [1] que permita planificar de antemano qué, cuándo y cómo se va a llevar a cabo el proyecto. 
La fecha de inicio del proyecto es septiembre de 2015 y se decide dividirlo en tres fases: anteproyecto, proyecto básico y proyecto de ejecución. A continuación se describe cada una de dichas partes, definidas mediante el mapa de procesos.

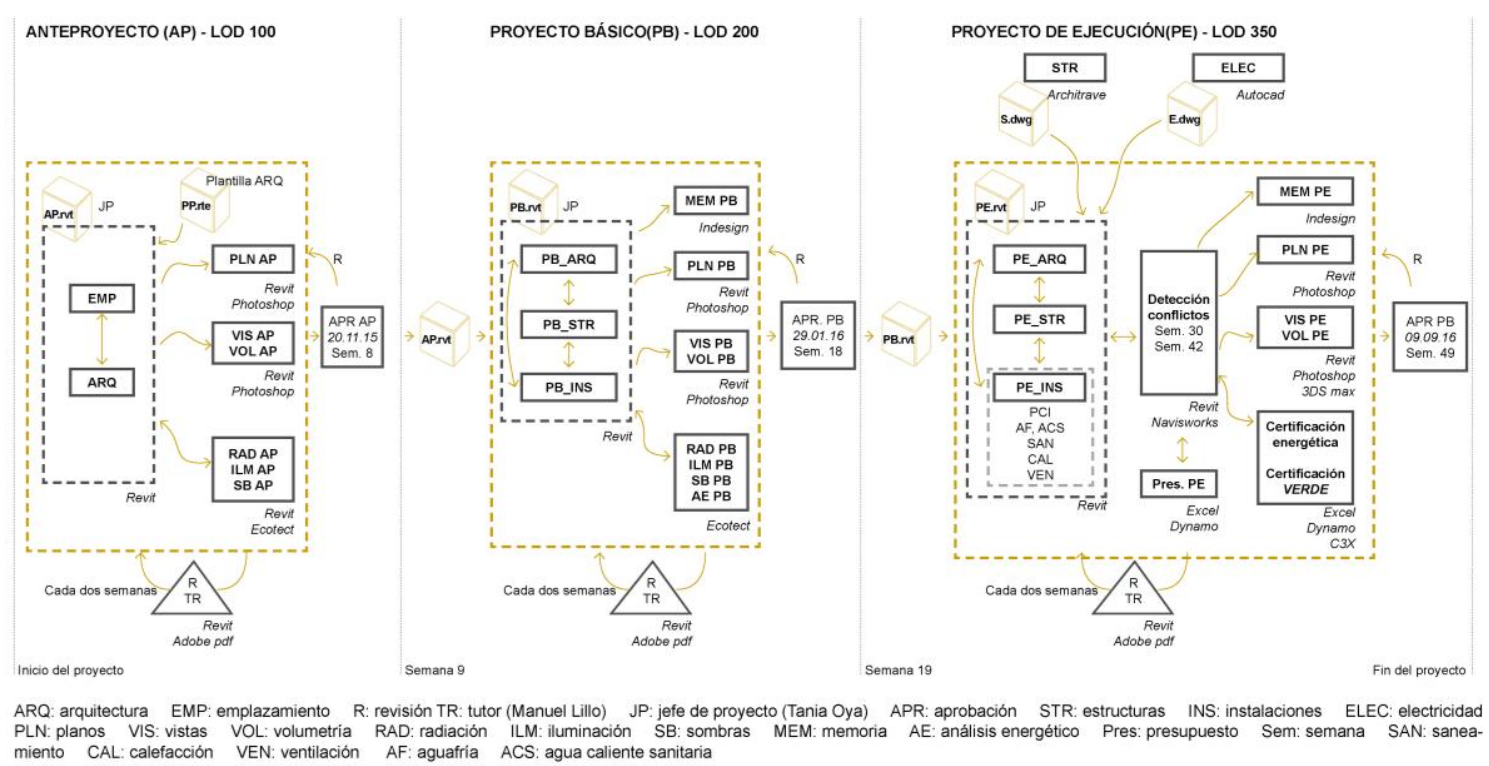

Fig 2. Mapa de procesos. 2016. Fuente: Elaboración propia

\section{$2.2 \quad$ Anteproyecto}

Se decide llevar a cabo un modelo unificado de arquitectura, emplazamiento, estructura e instalaciones. Posteriormente se evalúa si es necesario dividir en distintos archivos y vincular las instalaciones $y / u$ otras disciplinas. Pero se considera innecesario puesto que el tamaño del archivo es inferior a $250 \mathrm{MB}$ y permite un rendimiento adecuado del proyecto. No se considera necesario la creación de un archivo central, puesto que todo el trabajo va a ser realizado por una misma persona.

Se parte de una plantilla de Revit creada anteriormente, para empezar modelando el emplazamiento, teniendo en cuenta los condicionantes urbanísticos, la topografía y las preexistencias. Para ello se utilizan los archivos en cad de Valencia obtenidos de Terrasit, además de la distinta documentación tanto generada como obtenida de distintas plataformas, como la sede electrónica del catastro.

A continuación, partiendo de las necesidades de la UPV, se empieza con el diseño del proyecto, obteniendo su desarrollo volumétrico y utilizando la herramienta de Revit opciones de diseño, para presentar distintas alternativas.

En esta fase se obtienen planos esquemáticos, vistas, volumetrías, alzados y secciones. Todo ello empleando un LOD100. Además se utiliza el modelo para obtener análisis volumétrico en cuanto a sombras, radiación e iluminación mediante la herramienta Ecotect. 
Se realizan revisiones periódicas con el jefe de proyecto (en este caso, Manuel Lillo, tutor del PFC) cada dos semanas hasta la fecha de entrega, fijada el 20 de noviembre. En dicha fecha se pone en común el proyecto con el catedrático y los distintos profesores que forman parte del tribunal, para obtener un feedback de su parte e introducir las mejoras oportunas.

\subsection{Proyecto básico}

Una vez aprobado el anteproyecto, se pasa a la siguiente fase, en la que se llevará a cabo una mayor definición del proyecto, concretamente de un LOD200.

Se sigue con la idea de un único modelo y se dividen las disciplinas en distintos worksets. Se empieza a añadir la estructura, no desde el punto de vista del dimensionado, sino mediante un modelado en Revit aproximado. Se pretende ubicar la estructura para seguir modelando la arquitectura.

Empiezan a añadirse instalaciones en cuanto a equipos de gran tamaño, sin necesidad de incorporar conexiones exactas entre ellos. Se decide aplazar la detección de interferencias para una fase posterior, donde ya esté claro las dimensiones y ubicaciones exactas de todos los elementos.

En esta fase ya se considera de mayor importancia el grafismo en la documentación final. Por ello se decide importar el modelo a 3DStudio Max, para dotarlo de mayor realismo y facilitar la comprensión del mismo.

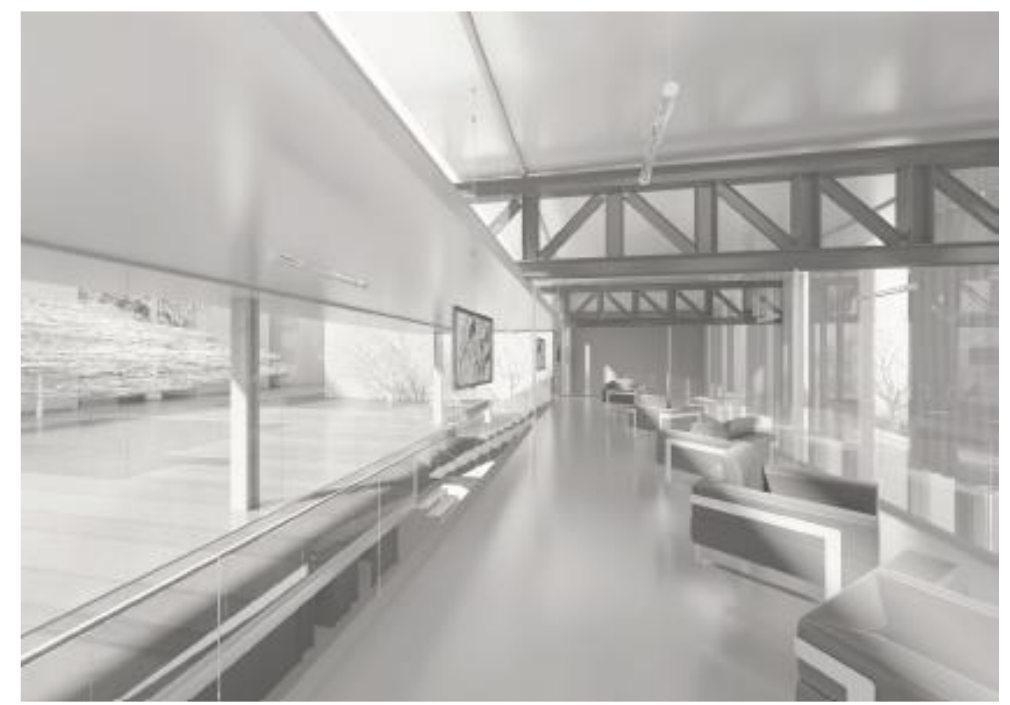

Fig 3. Infografía 3DS Max talleres. 2016. Fuente: Elaboración propia

Además se vuelve a utilizar el Ecotect ya a nivel más concreto. Se calcula para cada fachada la radiación en invierno y verano, se lleva a cabo un análisis de sombras que permita evaluar la influencia del proyecto en el entorno y viceversa y, por último, se analiza la iluminación en los distintos volúmenes a una altura de 1,5 metros en planta. 
La entrega está propuesta para finales de enero de 2016 y se necesita obtener una memoria básica además de una serie de paneles de contenido únicamente gráfico. Para la elaboración de toda esta documentación se recurre a varios programas: Indesign y Photoshop. Indesign se utiliza más para la parte de documentación escrita con algún pequeño apoyo gráfico. Photoshop sirve para modificar mínimamente los planos sacados de Revit, se introducen elementos secundarios como personas o árboles y se realiza alguna pequeña modificación en cuanto al grafismo.

Al igual que en la etapa anterior, se revisa cada dos semanas, aproximadamente, con el tutor del PFC y finalmente se lleva a cabo la puesta en común con el resto del equipo de evaluación.

\subsection{Proyecto de ejecución}

Mediante el modelo de arquitectura se procede a una mayor definición para llegar al LOD350 que puede exigir un proyecto de ejecución. En una primera etapa se llevan a cabo todos los cambios acordados con los profesores. Y posteriormente se pasa a ampliar la definición existente. Llegados a este punto existe un tutor personalizado para cada una de las disciplinas, que es el encargado de revisar el proyecto durante su ejecución.

En cuanto a la estructura, se decide trabajar con el programa Architrave, orientados por el tutor que es su propio desarrollador, aunque, lamentablemente, no tiene conexión directa con ninguna herramienta BIM todavía. Lo que se hace consiste, partiendo de los cálculos definitivos obtenidos, modelarlo con Revit, para posteriormente poder realizar un estudio de interferencias.

Del mismo modo, con el tutor de instalaciones, se llevan a cabo reuniones mensuales donde se desarrollan los distintos esquemas e información necesaria. Se modelan con Revit cada una de las instalaciones en cuanto a los conductos y máquinas necesarias. En el caso de esquemas de funcionamiento, se recurre a Autocad.

En cuanto a la construcción, se llevan a cabo detalles a distintas escalas. Por ello se utilizan distintas herramientas de Revit. Se crea una sección fugada a escala 1/50, con la mayoría de elementos modelados en tres dimensiones, a la que se le añaden algunos elementos de detalle dentro del propio programa. Además se realizan detalles a mayor escala, donde se recurre a la división en piezas de los distintos elementos. 


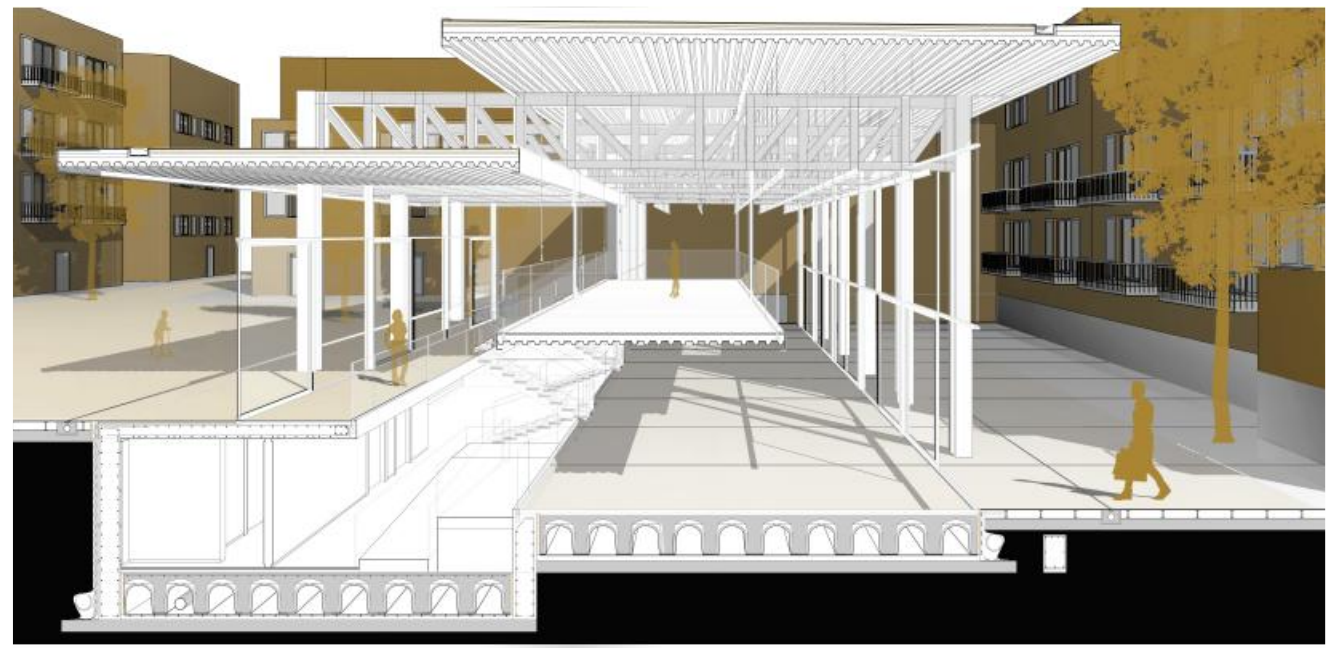

Fig 4. Sección constructiva. 2016. Fuente: Elaboración propia

Se elabora un presupuesto básico mediante Excel. Para ello se emplea una definición de Dynamo que permite la exportación directa de las tablas Revit a Excel, de modo que la información se actualice rápidamente. No se exigen unas mediciones para el proyecto, por lo que se decide sacar unos valores aproximados, apoyándose en estas herramientas y en bases de precios.

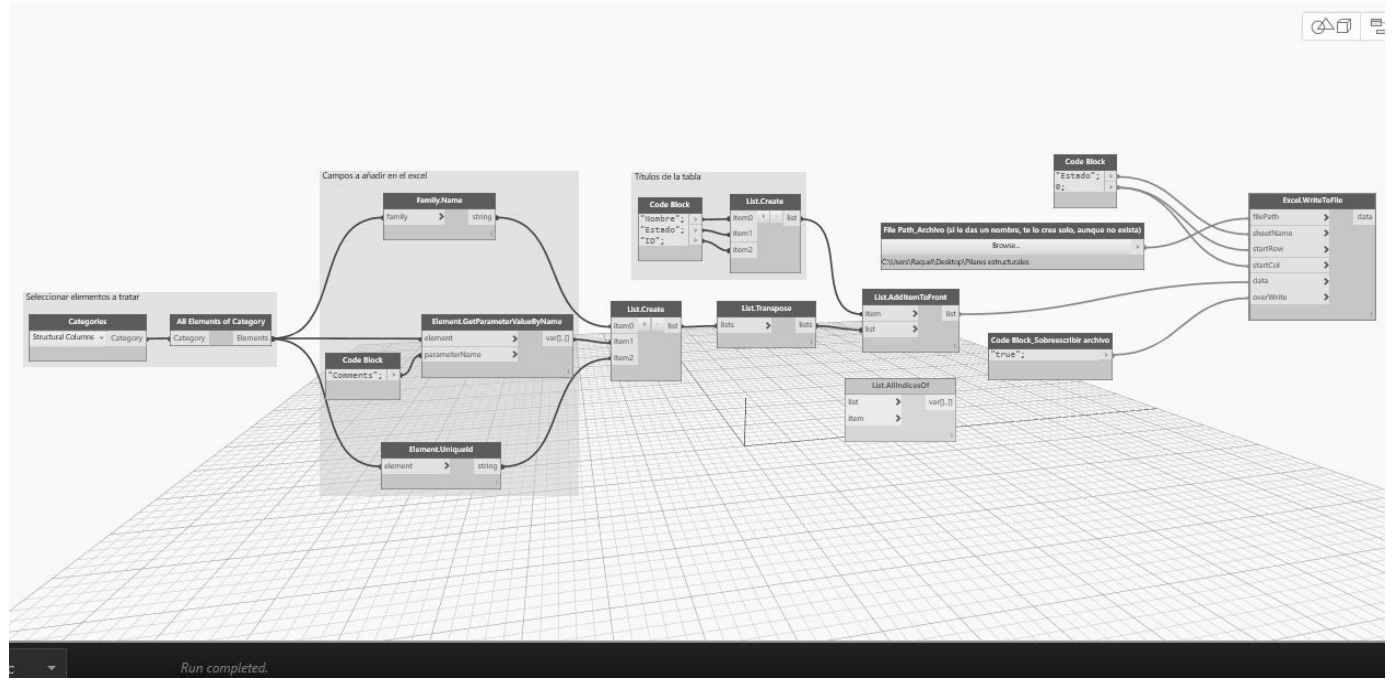

Fig 5. Definición Dynamo para exportar datos a Excel. 2016. Fuente: Elaboración propia

En Navisworks, se detectan las interferencias existentes entre la arquitectura, la estructura y las instalaciones y se actualiza el modelo. De este modo se reducen los problemas que pudieran aparecer en obra y se permite ajustar el coste y el plazo.

También se lleva a cabo un análisis aproximado de la certificación energética del edificio, utilizando herramientas simplificadas. Se introduce el análisis de la certificación VERDE, para valorar el proyecto sosteniblemente, utilizando los datos obtenidos mediante las distintas herramientas indicadas anteriormente. Y por último, se procede a la obtención de las distintas memorias, recurriendo nuevamente a Indesign y Photoshop. 


\section{CONCLUSIONES}

En este apartado se tratan las ventajas e inconvenientes que se han encontrado en cada una de las fases de presentación del proyecto.

\section{VENTAJAS}

\section{Fase de anteproyecto}

Mayor rendimiento y comprensión [2].

Los beneficios observados son en relación al tiempo de dedicación. Se ha conseguido con un menor esfuerzo que con metodologías tradicionales, obtener mayor información y realizar cambios más rápidamente. Facilitando a la vez la comprensión del proyecto por parte de terceros. Para la entrega del anteproyecto se consiguió un alto nivel de detalle en comparación con el resto de proyectos presentados, ejecutados durante el mismo tiempo y con metodologías tradicionales.

\section{Implementar la información}

El hecho de reducir el tiempo de dedicación para el diseño del proyecto, permite dedicarlo a otros aspectos, como es el grafismo o distintos análisis. Como por ejemplo seguir una metodología para la mejora sostenible (clima, situación, sol, temperatura, lluvias, ábacos psicométricos, vientos, cultura, entorno y tipología de edificio) [3].

\section{Mejora de la sostenibilidad}

Se ha podido obtener en una fase muy temprana del proyecto un análisis pasivo del mismo. Añadiéndole calidad al proyecto final, ya que se comprueban que las condiciones de confort de cada zona son las adecuadas. Por ejemplo, se analiza la radiación en el volumen de la biblioteca. Tras el análisis se lleva a cabo una modificación de la geometría de sus voladizos, puesto que tenían una dimensión mayor de la necesaria.

\section{Fase de proyecto básico-ejecución}

\section{Visualización con exactitud de datos}

El modelo se crea directamente en tres dimensiones, en lugar de ser representado por múltiples vistas 2D. Por tanto, en todo momento se puede visualizar el diseño con precisión y seguridad en los datos incorporados.

\section{Correcciones de bajo nivel}

Otra de las ventajas es la ausencia de errores en la geometría y la coordinación espacial. Cualquier modificación se ha podido implementar sin esfuerzos excesivos ni riesgos de introducción de errores. Además, gracias a la detección de problemas, se han podido solucionar a tiempo ciertos puntos incoherentes en el proyecto. En fases iniciales se observó 
que los conductos de ventilación y las bandejas de instalaciones interferían con la cercha en el edificio de talleres, modificándose el recorrido de ventilación debido a la necesidad de adecuación funcional y de diseño.

\section{Generación de documentación exacta y coherente}

Al realizar el diseño en tres dimensiones, se observa que las modificaciones se aplican sobre el modelo, con lo que obtenemos una solución coherente y óptima en toda la documentación que se genera.

\section{Colaboración multidisciplinar}

Mediante la metodología BIM se facilita la colaboración desde momentos muy tempranos con las diferentes disciplinas que intervienen en el proyecto. Se acorta el tiempo necesario para el desarrollo de la definición de la documentación y se reducen las incoherencias y omisiones. En el proyecto se dedicaron escasas horas a la reducción de incoherencias debido a que sólo se detectaron pequeños errores conceptuales en alguna disciplina, todo lo contrario a los proyectos realizados por distintos compañeros de taller que tuvieron que invertir multitud de tiempo en actividades mecánicas de corrección de omisiones e incoherencias.

\section{Fácil evaluación del diseño del proyecto}

La capacidad de medición de la superficie construida o de la cuantificación de materiales, permite controlar en todo momento la edificabilidad y el ajuste del diseño de los planteamientos previstos.

\section{Obtención del presupuesto en fases tempranas}

En cualquier fase de diseño se pueden obtener mediciones y superficies para calcular un presupuesto estimado. En nuestro caso, no ha sido un aspecto muy relevante y por eso se ha sacado en la última fase del proyecto, ya que no se tenían restricciones en cuanto a este aspecto.

\section{Mejora de la sostenibilidad y eficiencia energética}

Se ha podido enlazar el modelo 3D con herramientas de evaluación energética y modificar y ajustar el diseño para un mejor comportamiento. Un ejemplo relevante es que mediante los cálculos energéticos obtenidos se han podido elegir los vidrios solares adecuados para el proyecto. 


\section{INCONVENIENTES}

\section{Fase de proyecto básico-ejecución}

\section{Interoperabilidad}

Aunque existen múltiples programas que permiten relacionarse directamente con Revit, muchos otros no. Este hecho, reduce la veracidad de los datos, aumentando el tiempo de dedicación a los mismos e impidiendo el trabajo uniforme.

En el proyecto Open UPV por ejemplo se ha trasladado esta dificultad en el cálculo de estructuras y a la hora de llevar a cabo la certificación energética.

\section{Restricciones}

Existen ciertas restricciones en Revit a la hora de elaborar geometrías más complejas o gestionar la información de algunos datos. Por esto se ha tenido que llevar a cabo una importante labor de investigación de distintos programas. Uno de los ejemplos más claros es la necesidad de aprendizaje de Dynamo para poder gestionar con mayor agilidad el modelo.

\section{Elaboración de memorias}

Generar las distintas memorias mediante Revit conlleva un trabajo previo que requiere de un tiempo del que no se disponía. Por ello se decidió recurrir a un software más utilizado en este tipo de procedimientos como es Indesign.

\section{Elaboración de maquetas}

Uno de los grandes problemas que se detectaron fue el uso de aproximadamente tres semanas para la generación de documentación en dos dimensiones para cortar las distintas piezas de las maquetas. No se encontró opción de reutilizar el modelo generado en Revit para ello.

\section{REFERENCIAS}

[1] Zaragoza J.M. y Morea J.M. (2015). Guía práctica para la implantación de entornos BIM en despachos de arquitectura e ingeniería.

[2] Fuentes, B. (2014). Impacto de BIM en el proceso constructivo español. Cuadernos EUBIM.

[3] Frygiel E. y Nies B. (2008). Green BIM. Successful sustainable design with Building Information Modeling. 


\section{EXPERIENCIA DOCENTE DE INTEGRACIÓN DE METODOLOGÍA BIM PARA EL CONCURSO BIM VALLADOLID 2016}

\section{Cañizares Montón, Josemanuel (1), Alfaro González, Jesús (2), Valverde Cantero, David (3), Martínez Carpintero, Jesús Ángel (4), Pérez González, Pedro Enrique (5)}

(1) Escuela Politécnica de Cuenca, jose.canizares@uclm.es

(2) Escuela Politécnica de Cuenca, jesus.alfaro@uclm.es

(3) Escuela Politécnica de Cuenca, david.valverde@uclm.es

(4) Ingeniero de edificación y alumno egresado EPCu, jesusangelmartinezcarpintero@gmail.com

(5) Alumno Escuela Politécnica de Cuenca, pedenry@gmail.com

\section{RESUMEN}

La filosofía del concurso BIM Valladolid ha sido clara desde su primera edición: ver hasta dónde puede dar de sí la metodología/herramientas BIM -Building Information Modeling / Modelado de la Información de la Construcción- partiendo de un enunciado común, con un tiempo limitado y desarrollado en equipo.

La posibilidad planteada por la edición 2016 del mismo se entendió como un reto y como una oportunidad única por parte de la Escuela Politécnica de Cuenca. La formación de un equipo multidisciplinar compuesto tanto por profesores como alumnos de las distintas titulaciones de la Universidad de Castilla-La Mancha suponía un valor añadido al ya de por sí atrayente desafío BIM.

La asignación de los distintos perfiles, la elección de aplicaciones, la definición y redefinición de los flujos de trabajo y, sobretodo, la realización de un trabajo "real" en modo colaborativo han supuesto un enorme estímulo para los alumnos que, además, tendrá continuidad con la materialización de varios PFG.

Para el profesorado participar en este desafío ha supuesto la puesta en práctica de una metodología que inexorablemente debe entrar a vertebrar el plan de estudios del GIE y que entronca con la docencia pluridisciplinar defendida por la asignatura de PFG.

Palabras clave: BIM, docencia universitaria, trabajo colaborativo

\section{ABSTRACT}

The philosophy of "BIM Valladolid competition" has been clear since the first edition: check how far BIM methodology/tools can achieve from a common statement, with a limited period of time and developed under a teamwork method.

The possibility planted with the 2016 edition was understood as a challenge and as an exceptional opportunity for the Polytechnic School of Cuenca. Training a multidisciplinary team, composed by both professors and students of different degrees of the University of Castilla-La Mancha, was an added value to the already attractive BIM challenge. 
The assignment of different profiles, the choice of applications, the definition and redefinition of workflows and, especially, the develop of a "real" work in a collaborative way has been an enormous incentive for the students who, in addition, would continue with the realization of several Final Degree Projects.

Participating in this challenge has meant for teachers the implementation of a methodology that inexorably must lead the curriculum of the Degree in Building Engineering and that connects with the multidisciplinary teaching represented by the subject of Final Degree Project.

Keywords: BIM, university teaching, collaborative work

\section{$1 \quad$ INTRODUCCIÓN}

\section{$1.1 \quad$ EI BIM}

BIM [1] es el acrónimo de Building Information Modeling expresión en inglés que se podría traducir como el "modelado de la información de la construcción". BIM no es ningún software; BIM es un entorno de trabajo en donde existe un ecosistema de herramientas aplicaciones informáticas- que permiten, a partir de un modelo tridimensional al que podemos llamar "maqueta virtual" o "modelo de información", extraer dicha información de forma exacta y sobretodo coordinada.

Esta coordinación permitirá que los múltiples agentes que intervienen en la elaboración, ejecución, y futura explotación del edificio lo hagan de la forma más eficaz posible y minimizando al máximo los posibles errores.

Esta metodología de trabajo representa algo más que una evolución en la forma de crear/gestionar el proceso edificatorio, se trata de una verdadera revolución. A nivel gráfico pasamos de trabajar con herramientas CAD que nos ayudan a "delinear" la definición geométrica del edificio a modelarlo volcando en esa maqueta toda la información sobre el mismo.

\subsection{La Escuela Politécnica de Cuenca y la Universidad de Castilla-La Mancha}

La Escuela Politécnica de Cuenca -EPCu- [2] forma parte de la universidad regional de Castilla-La Mancha -UCLM- y desde sus orígenes, hace ya 22 años, ha estado íntimamente ligada a los estudios habilitantes para el desarrollo profesional de la Arquitectura Técnica, estudios actualmente redefinidos como Grado en Ingeniería de Edificación -GIE-.

La coyuntura expuesta en el punto anterior ha sido interpretada en la EPCu como una oportunidad única para repensar no tanto el qué enseñamos sino el cómo lo hacemos, analizando de qué forma la filosofía BIM puede vertebrar el plan de estudios y condicionar las estrategias y metodologías docentes. Fruto de esta reflexión y compromiso colectivo, 
rubricado en la Junta de Centro del ocho de julio de dos mil quince, se puso en marcha la comisión BIM-EPCu para el estudio e implantación de dicha metodología en el plan de estudios de GIE.

\subsection{Implantación BIM en la EPCu}

Los estudios de GIE son los más directamente implicados en la metodología BIM según los resultados de las últimas encuestas dirigidas a determinar el grado de implantación del BIM en los entornos universitarios.

Nuestra iniciativa de implantación BIM de manera transversal en los contenidos de GIE, persigue una actualización completa de la metodología en todo el ciclo de vida de la construcción. La incorporación de nuestro Grupo de Investigación: BIM_UrbEdSo al recientemente inaugurado Instituto de Investigación en Edificación y Telecomunicaciones - IIET- pretende configurarse como el referente BIM en el ámbito académico de la UCLM. La apertura a la colaboración con empresas del sector tras el convenio firmado por parte de la EPCu con FERECO -Federación de Empresarios de la Construcción de Castilla-La Manchapara la incorporación de alumnos con conocimientos BIM a sus cuadros profesionales durante el desarrollo del PFG en modalidad de prácticas de seguimiento de obra, pensamos que puede ser un inmejorable inicio de inserción laboral para el alumno y de conocimiento de la metodología BIM para el sector AECO en la región.

\subsection{El concurso BIM Valladolid 2016}

El enfoque del concurso BIM Valladolid 2016 [3] se engloba dentro del programa del Foro Internacional de la Construcción Inteligente BIMTECNIA desarrollado en Valladolid entre el 13 y 14 de diciembre de 2016 y difiere algo respecto al del año pasado: los equipos debíamos organizarnos para constituir un verdadero equipo BIM asignando los perfiles/permisos necesarios a cada miembro del equipo, eligiendo los programas que utilizarán para realizar, en un breve plazo de tiempo con el objetivo del modelado completo de un edificio no residencial de tamaño medio.

En convocatorias anteriores se desarrollaron modelos muy avanzados partiendo de plantas, alzados y secciones definidas previamente, alcanzando el LOD 300 e incluso 500 . Este año se introdujo la fase de diseño en el enunciado del concurso, lo que suponía una dificultad añadida al integrar la componente "creativa", pero que entendimos iba más allá de la "idea arquitectónica": se nos planteaba tanto el diseño del objeto como el del proceso, la elección de las herramientas y la gestión del equipo -el qué, cómo, cuándo, quiénes y con qué-.

Lo que se buscaba es utilizar BIM precisamente en la fase previa de diseño/concepción del edificio, donde se puede aprovechar para realizar un justificado estudio de viabilidad, análisis energéticos, estudio de alternativas, diseño paramétrico, $y$, en menor medida, el 4D -planificación- y 5D -presupuestos- y especialmente la industrialización del proceso edificatorio... así como cualquier aspecto relacionado con la Construcción 4.0. 
No obstante esa fase previa de diseño/concepción del edificio debía ser también inmediata dadas las características del concurso -su calculada premura-, lo que condicionaría severamente a aquél: el edificio y su ubicación no sólo debían servir para analizar de forma temprana su idoneidad, sino también a casi su inmediata implementación mediante el desarrollo de sus diversos sistemas constructivos. Lo que quisimos resolver mediante una propuesta arquitectónica extremadamente radical y no obstante de personalidad casi poliédrica -todo debía ser posible aun en un marco ciertamente reducido- que, efectivamente, fue al menos capaz de ir adicionando elementos diversos con suficiente sentido. Además entendimos que la puesta a disposición de los concursantes de herramientas de diseño temprano con comprobación de cumplimiento de necesidades funcionales -dRofus- era uno de los ítems a valorar por el jurado. $O$ dicho de otro modo que el uso de la metodología BIM, aplicada a la comprobación funcional y el análisis de sus posibilidades en la fase conceptual, era uno de los retos más sugerente del enunciado.

Sin querer extraer conclusiones al respecto de si ésta es o no una estrategia adecuada para la producción de arquitectura y sin discutir la idoneidad de la metodología BIM como marco de trabajo, sí nos parece conveniente analizar y saber por qué el jurado del concurso no quiso emitir consideraciones arquitectónicas en su fallo y por qué no explicó esa decisión pese a que la calidad arquitectónica era uno de los criterios de valoración fundamentales.

\section{LA EXPERIENCIA}

\section{$2.1 \quad$ El equipo}

El entorno universitario en el que nace el equipo congregó a un grupo amplio de estudiantes, egresados y profesores tanto de la EPCu -Grados de Ingeniería de Edificación y de Tecnologías de Telecomunicación- como de Caminos, Canales y Puertos en Ciudad Real. Inicialmente se desarrolló una fase de captación con distintas conexiones online y que concluyeron en una jornada presencial con la exposición de objetivos realizada en la EPCu por parte de los organizadores del concurso.

Siendo los participantes pertenecientes a centros en diferentes ciudades, y con algunos participantes en diferentes localizaciones, se hizo necesaria el establecimiento de un mecanismo de comunicación online -Teamwork- y de una estructura de almacenamiento y control de archivos -Google Drive-. Asimismo se establecieron unas reuniones online preparatorias del concurso -Skype-. Todo esto ya comenzaba a suponer un nuevo escenario para alumnos y profesores, novedoso y enriquecedor. El grupo de interesados fue creciendo llegando a ser unas 45 personas entre alumnos, exalumnos, profesores y colaboradores. No obstante, no todos se convirtieron finalmente en miembros del equipo final -28 personas-.

\subsection{La organización}

Durante el curso 16-17 se desarrolló un programa de "inmersión formativa BIM" dirigido a profesores mediante la realización del curso BIM A1 de modelado básico en Revit y 
Archicad por un lado; y la organización de un ciclo de conferencias monográfico de BIM abierto a todos por su realización en streaming [4]. Esta experiencia permitió a todos ubicarnos en el amplio mundo de la metodología BIM.

Como parte de la preparación se asistió a un Stress-Test invitados por la Universidad Europea de Madrid y desarrollado en su BIM-Club. Esta primera toma de contacto supuso un acercamiento real tanto a la metodología como al enfoque sobre la gestión -personal/social- de un equipo BIM. Fue muy revelador y estimulante para los asistentes.

Conocida la bondad de la experiencia, decidimos organizar nuestro primer Stress-test en el mes de junio de 2016. La participación fue muy amplia y supuso una puesta en escena del funcionamiento de la interoperatividad entre software, la prioridad de las decisiones a tomar, la actitud personal de cada uno y la relación social entre los miembros de cada área y del grupo en general. La experiencia nos convenció y nos reconocimos como capaces para llevar a cabo el reto propuesto por el concurso. Además se establecieron unas reuniones semanales de coordinación entre áreas para dar continuidad a lo desarrollado en este Stress-test y que sirvieran para acabar de definir procesos concretos.

Paralelamente y, como parte del objetivo académico, se fijaron unas serie de PFGs que se desarrollarían con metodología BIM sobre aspectos concretos del proyecto o de la aplicación de sus enseñanzas sobre otros PFG en curso [5]. También se descubrieron metodologías fácilmente trasladables al desarrollo de prácticas de curso en asignaturas individuales o en grupo.

\subsection{El desarrollo del concurso}

Llegado el momento de la verdad los roles de trabajo se encontraban decididos, aunque no cerrados. El diseño del concurso con la incorporación novedosa de la parte creativa de ideación arquitectónica, implicaba la necesidad de contar con un modelo-boceto inicial en las primeras horas para permitir arrancar al resto de áreas. A pesar de haber varios arquitectos en el equipo, se decidió "nombrar" a uno de ellos para que desarrollara ese papel de forma autónoma, aún sin perjuicio de que sus decisiones fueran consensuadas por el resto de áreas, tras el proceso de análisis particular en una fase de "diseño temprano".

Aunque esta fase generó unas sinergias muy positivas entre áreas (Fig 1) que fortalecieron el diseño inicial obviamente, el desarrollo entre las áreas no fluyó con la continuidad y convergencia deseada:

- la comunicación entre ellas provocó confusiones, retrasos, caminos equivocados,

- la interoperabidad de softwares comenzó a fallar afectando a la fluidez del proceso, o

- los cambios del diseño por requerimientos sobrevenidos provocaban retrasos, molestias y algún enfado. 
En estos momentos el sentimiento de pertenencia al grupo y la gestión del mismo, basado en la "responsabilidad" y el "respeto", resultaron clave para sacar adelante el trabajo. Pues todo constituía aprendizaje. Esta es la "gran verdad" de la aplicación académica del proceso de concurso. Creemos que fue un acierto congregarnos todos en el mismo lugar de trabajo, salvo los miembros que se encontraban en Ciudad Real, Albacete, Madrid, Granada o Varsovia, con los que hacíamos reuniones periódicas por Skype. Esto suponía un contacto personal entre personas -profesores o alumnos, poco importaba- que generó una sinergia social de equipo que fue nuestro gran activo frente a la adversidad.

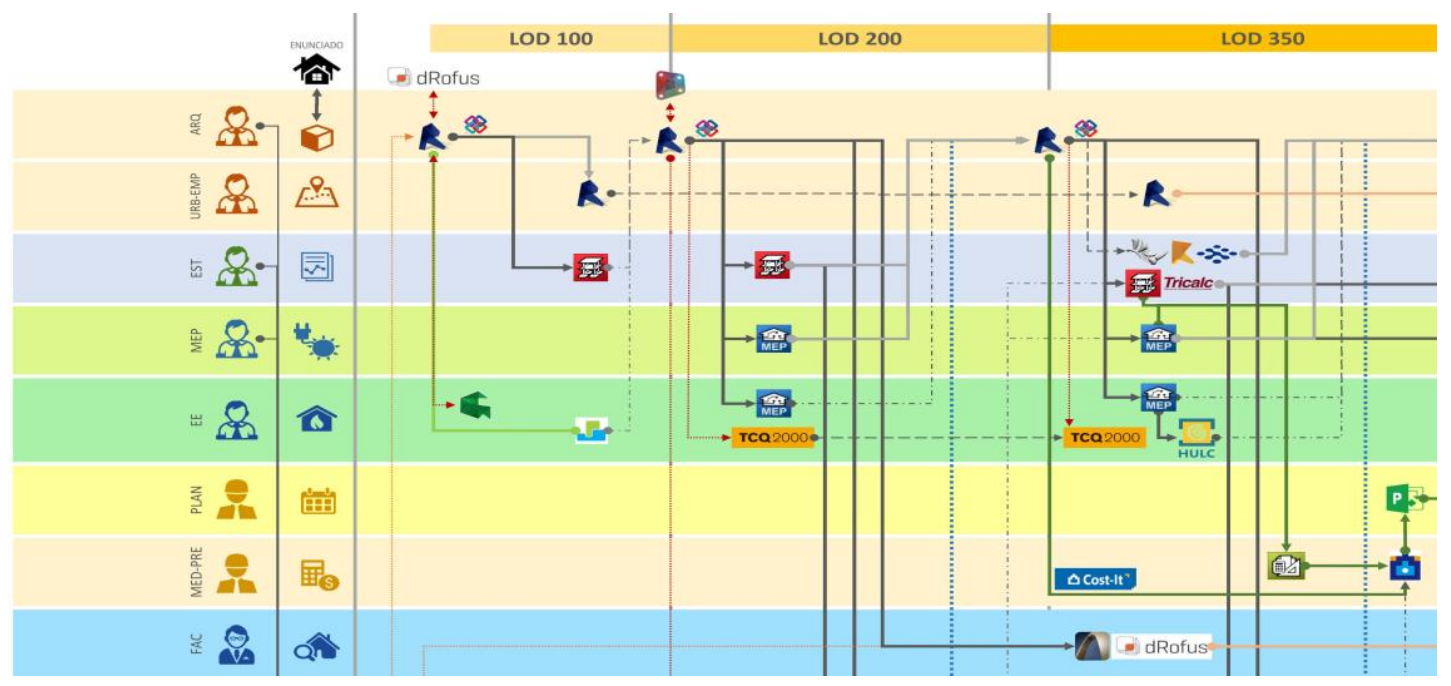

Fig 1. Flujo de trabajo previsto -detalle-. 2016. Elaboración propia.

El momento de la entrega supuso un clímax de stress y nervios que necesitó de una particular dosis de paciencia y entereza para conseguirlo. Todas estas experiencias, más sociales y humanas, que profesionales o académicas, son las que mayor ayuda han dado a la implantación de la metodología BIM en nuestros centros.

\section{RESULTADOS}

\subsection{Propuesta del equipo CuBIM}

Nuestra propuesta (Fig 2) presentaba un edificio estanco y compacto. Su planteamiento responde a los requerimientos del enunciado propuesto obedeciendo a una tensa malla isótropa obtenida por reiteración de elementos modulares -carpinterías, luces estructurales, sistemas constructivos,...- que se adapta, como criterio fundamental, tanto a la solución funcional finalmente elegida como a las distintas situaciones que pudieran plantearse a lo largo de su vida útil.

Nada, ningún recurso de los que quisimos plantear, debía contradecir lo anterior.

A partir de este criterio, la formalización del edificio, su estructura e instalaciones se planteó casi exclusivamente hacia la fachada interior -sureste- de forma que nada, o casi nada, 
exterior a la actividad puede o debe desvirtuar dicha isotropía y mediante un sistema de control del soleamiento -la membrana- se responde a la escena urbana.

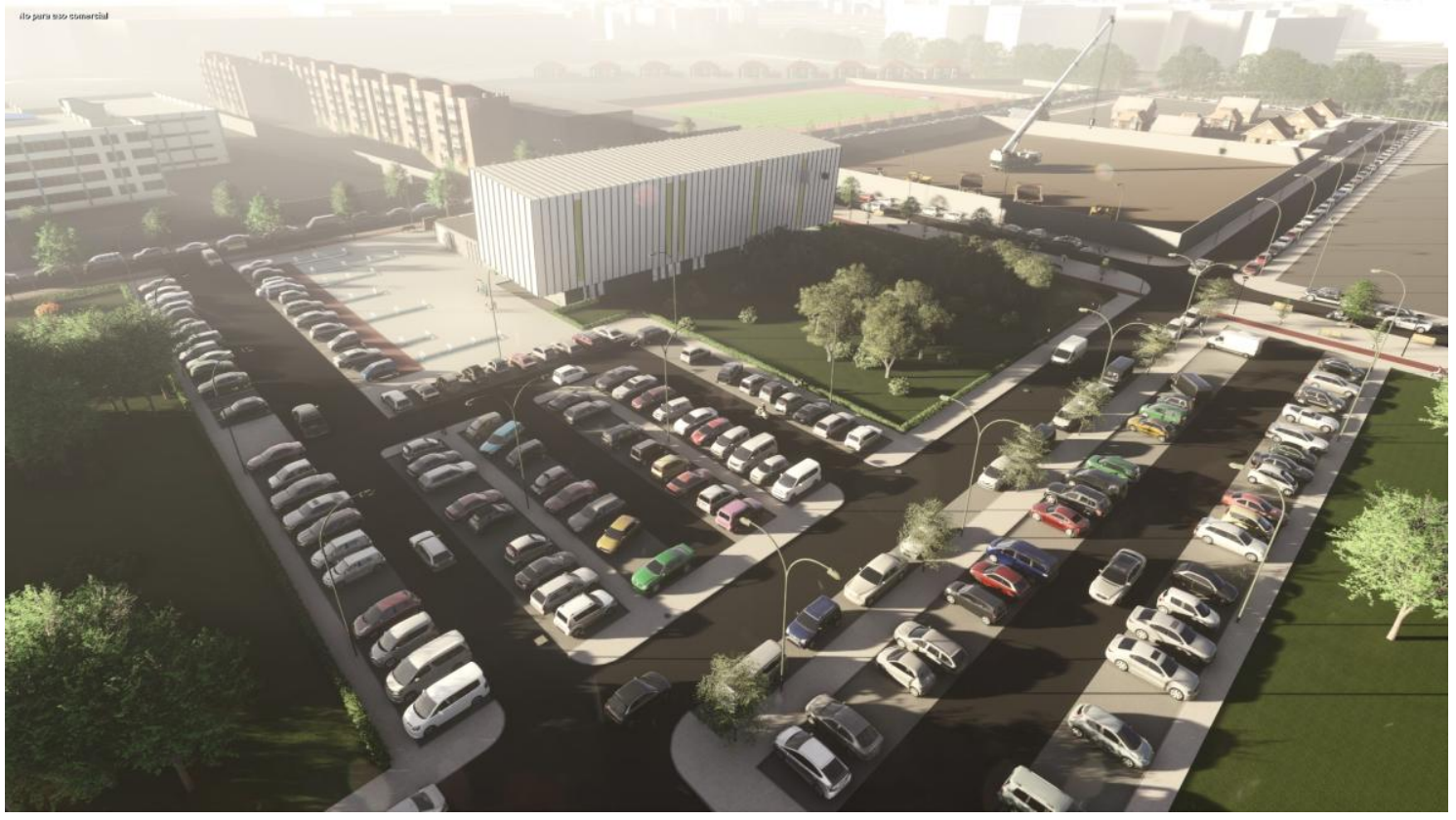

Fig 2. Infografía final exterior del centro de salud. 2016. Elaboración propia.

\subsection{Satisfechos por el trabajo desarrollado}

La satisfacción por el trabajo desarrollado, la cohesión y reconocimiento como grupo CuBIM; la sensación de pertenencia al mismo; la garantía del compañerismo; el "creative common" de una punta a la otra de la mesa de manera directa e inmediata; el respeto y el reconocimiento del compañero, antes desconocido; el descubrimiento de la agradable sensación de enseñar-aprender entre profesores-alumnos sin saber quién hace el papel de qué, en definitiva: la integración social y personal en un equipo de compañeros unidos por un objetivo y una metodología, fue nuestro GRAN PREMIO del concurso [6].

\subsection{Entrega de premios}

La asistencia de una nutrida representación del equipo CuBIM a la entrega de premios, dentro de la jornada de clausura del congreso BIMTECNIA, celebrada en diciembre de 2016 en Valladolid supuso un broche de oro a esta experiencia profesional/académica que, en realidad, no ha hecho más que comenzar.

Del resultado de aunar todas y cada una de las habilidades del equipo, unidas al mismo tiempo a cada una de nuestras debilidades, se configuró un proyecto digno merecedor como mínimo, de gran satisfacción personal. El contexto de competición nos recordaba a cada hora -de las 150 de nuestro countdown- que para potenciar la visibilidad de una propuesta fruto del trabajo de un equipo involucrado y colaborativo, el proyecto debería reflejar, antes que su calidad BIM en sí, la cooperación como equipo y su capacidad de trabajo. Fruto del 
justo balance de ambos ámbitos -calidad y colaboración- fueron los siguientes reconocimientos obtenidos en la competición (Fig 3):

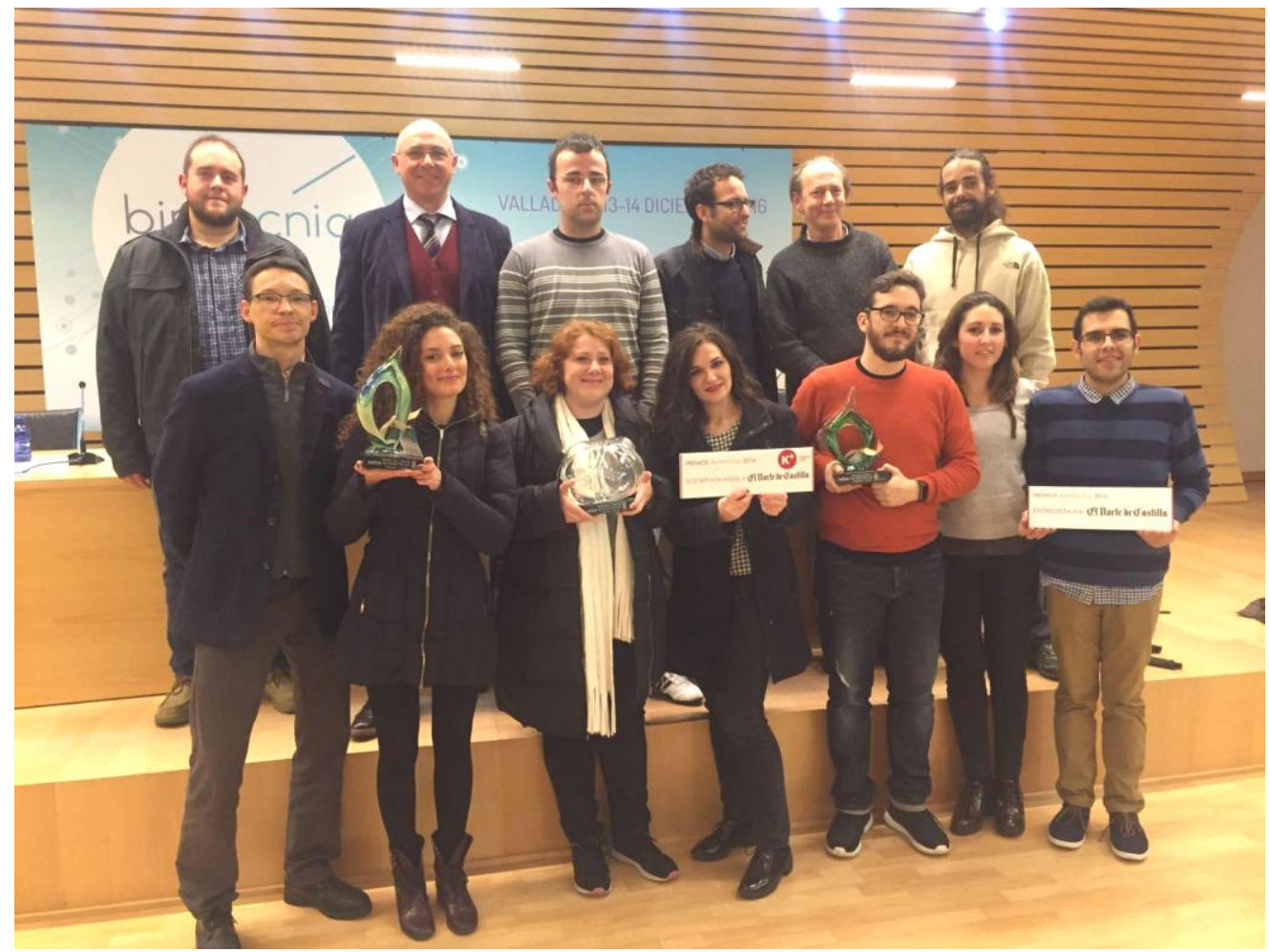

Fig 3. Recogida de premios equipo CuBIM. 2016. Elaboración propia.

- $2^{\circ}$ premio Concurso BIMValladolid 2016,

- premio Diputación de Valladolid. Mención Universidades, y

- premio de votación popular.

\section{$4 \quad$ CONCLUSIONES}

Con ello, los resultados obtenidos no se perciben más que como un impulso para mantener e incrementar si cabe el incentivo para abogar por la metodología BIM, así como la puesta en valor del equipo como entidad única, formada por miembros sin cada uno de los cuales el resultado probablemente no se hubiera podido lograr, y que han afrontado el reto con la misma perspectiva: ilusión y ganas de aprender, todo ello sumado al apoyo que CuBIM ha recibido y recibe por parte de la universidad como institución.

Desde el punto de vista académico la participación en este tipo de iniciativas permite plantear nuevas vías de investigación/formación de alumnos basadas en la resolución de problemas cercanos a su futuro desempeño profesional y que no se "encorsetan" en los rígidos/desfasados planes de estudio vigentes. 


\subsection{Experiencia conjunta profesores-alumnos}

Como primer punto nos gustaría destacar las consecuencias del trabajo colaborativo abordado desde los roles clásicos profesor-alumno:

- colaboración interactiva de igual a igual entre profesores y alumnos,

- aplicación práctica de conocimientos adquiridos durante los estudios previos, y

- establecimiento de protocolos de trabajo/flujo de software.

\subsection{Los próximos pasos}

Fruto de esta primera/intensa experiencia podemos confirmar la continuidad de la propuesta:

- aplicación de la experiencia conseguida en el desarrollo académico del grado y los cursos de especialización,

- participación en proyectos de investigación con aplicación de la metodología BIM,

- oferta de implantación de metodología BIM y LEAN CONSTRUCTION en casos reales a entidades públicas y privadas, y

- experiencia previa para la exportación de conocimiento a la empresa.

Además de servir a la materialización de un incipiente BIM_Lab dentro de la UCLM y con sede en el IIET como:

- plataforma permanente de investigación, desarrollo y aplicabilidad de software en metodología BIM,

- centro de asesoría y consulta para usuarios e investigadores, y

- núcleo de desarrollo de propuestas concursales abiertas susceptibles de aplicación de la metodología BIM.

Y por último, y no por ello, menos importante la contribución a la implantación de la metodología BIM en EPCu-GIE [7]:

- exportación de la experiencia obtenida a las áreas de conocimiento de GIE, con especial incidencia en la creación de flujos de trabajo y las posibilidades de interoperabilidad que, en el plan de estudios, es posible leer como coordinación entre asignaturas y optimización de la carga de trabajo del alumno, y

- núcleo de gestión de contenidos para la implementación del BIM en el grado y en los cursos de especialización y máster. 


\section{REFERENCIAS}

[1] BIM -Building Information Modeling-, como la metodología basada en el modelado de la información del edificio, es decir donde, a partir de la maqueta virtual de un edificio, se puede analizar y gestionar los diferentes elementos y sistemas que lo componen.

[2] Escuela Politécnica de Cuenca https://www.epc.uclm.es [Consulta: 2017.03.28]

[3] Concurso BIM Valladolid 2016 http://www.bimvalladolid.com [Consulta: 2017.03.28]

[4] XXI Ciclo de conferencia de la Escuela Politécnica de Cuenca 2015/2016 https://www.epc.uclm.es/ep/?page id=4808 [Consulta: 2017.03 .28 ]

[5] Valverde Cantero D., Arteaga Martínez J.J. y Alfaro González J. (2012). "Coordinación multidisciplinar de PFG en la titulación de grado en Ingeniería de Edificación". En AA.VV. Actas del XVI Congreso Internacional de Ingeniería de Proyectos AIEPRO, Valencia, 11-13 julio 2012. Valencia: AEIPRO, p. 2.520-2.528. ISBN: 978-84616-0047-2.

[6] Vídeo de presentación del equipo CuBIM para el Concurso BIM Valladolid 2016 https://www.youtube.com/watch?v=BxgYQpzL6xU\&t=63s [Consulta: 2017.03.28]

[7] Oliver Faubel, I. (2015). Tesis. Integración de la metodología BIM en la programación curricular de los estudios de Grado en Arquitectura Técnica/Ingeniería de Edificación. Diseño de una propuesta. Valencia: Universitat Politècnica de València. Disponible en http://hdl.handle.net/10251/61294 


\section{EXPERIENCIA DE IMPLEMENTACIÓN DE LA METODOLOGÍA BIM EN IFRN}

\section{Giesta Pinto, Josyanne (1), Menezes Batista de, Gilda (2)}

(1) Instituto Federal de Educação, Ciência e Tecnologia do Rio Grande do Norte, Diretoria Acadêmica de Construção Civil. josyanne.giesta@ifrn.edu.br.

(2) Instituto Federal de Educação, Ciência e Tecnologia do Rio Grande do Norte, Diretoria Acadêmica de Construção Civil. gilda.menezes@ifrn.edu.br.

\section{RESUMEN}

Las instituciones educativas actúan sobre tres pilares: docencia, investigación y extensión, en este contexto, es necesario que la metodología BIM se implementa en los tres ejes. De esta manera, el Instituto Federal de Educación, Ciencia y Tecnología de Rio Grande do Norte, ha implementado la metodología, como una forma de preparación de los futuros profesionales que actuarán en el área de Arquitectura, Ingeniería y Construcción.

La experiencia de BIM en el IFRN se originó en la creación del centro de investigación, inicialmente a través de proyectos de investigación desarrollados por estudiantes de Edificios, Carreteras y Tecnología de la construcción, que tienen beca y voluntarios, en los estudiantes del proyecto recibieron entrenamiento en software BIM.

En la segunda etapa de la implementación, fue incluido en el plan de estudios una visión más amplia de la metodología, a través de un mini curso de introducción al BIM.

La tercera etapa ha estado trabajando en la difusión de BIM "fuera de los muros de la institución", a través de proyectos de extensión, organización de seminarios y asociaciones con otras instituciones de educación.

Hasta ahora, la aplicación de la metodología BIM en IFRN ha sido muy exitosa, siendo una experiencia interesante para ser difundido.

Palabras clave: BIM, construcción, implementación, institución educativa

\section{ABSTRACT}

Educational institutions act on three pillars: teaching, research and extension, in this context, it's required that the deployment of BIM methodology be acknowledged by these three axes. In this way, the Federal Institute of Education, Science and Technology of Rio Grande do Norte, has sought, in the three segments, the introduction of BIM methodology, as a way of preparation of future professionals who will act in the area of Architecture, Engineering and Construction.

The creation of the Center for Research in BIM originated the BIM experience inside the IFRN, initially through research projects developed by scholars and volunteers of several 
courses: Buildings, Roads and Building Technology, in which the students have received training in BIM software.

In the second stage of the implementation, it was sought to add to the curriculum of the students a broader view of the BIM methodology, being taught a mini course on Introduction to BIM.

The third stage has been working on dissemination of BIM "outside the walls of the institution", through extension projects, organization of seminars and partnerships with other education institutions.

So far, the implementation of the BIM methodology in IFRN has been very successful, representing an interesting practical experience to be disseminated.

KeyWords: BIM, construction, educational institution, implementation

\section{$1 \quad$ INTRODUCCIÓN}

El tema desarrollado en este artículo es parte del enfoque aplicado en el proceso de implantación de Building Information Modeling (BIM) en el Instituto Federal de Educación, Ciencia y Tecnología de Rio Grande do Norte (IFRN), cuyo objetivo es introducir BIM en tres pilares: enseñanza, investigación y extensión, dando a los estudiantes una formación centrada en el uso de software y la enseñanza de la base conceptual.

Saber cómo utilizar BIM en el mercado laboral AEC es esencial, debido a la amplia utilización en el contexto internacional, donde tenemos muchos países con uso obligatorio de BIM en sus proyectos públicos, como Dinamarca, Corea del Sur y Alemania. Este gran interés de los gobiernos a adoptar BIM es debido a la posibilidad de un mayor control sobre los costos de desarrollo, construcción y mantenimiento de edificios.

Sin embargo, la investigación y los estudios han demostrado que el proceso de implementación de BIM en la educación está ocurriendo gradualmente. Fue en 2003 que las universidades comenzaron a enseñar herramientas BIM, sin embargo, la gran mayoría de las universidades este proceso no comenzó hasta 2006 [1]. En Brasil, la discusión de la educación BIM creció en 2010, sobre todo con problemas sobre la mejor manera de integrar los sujetos BIM en el plan de estudios [2]. En este contexto, el trabajo tuvo como objetivo presentar la experiencia de implementación de BIM en IFRN a través de acciones Centro de Investigación en BIM (NP-BIM), e identificar los beneficios y las dificultades actuales en el proceso de implementación.

\section{BUILDING INFORMATION MODELING}

Evolución de los diseños hechos a mano para el diseño asistido por ordenador (CAD) ha traído grandes avances, más eficiencia y la calidad de la representación, sin embargo, la aparición de BIM es una gran revolución tecnológica. Según algunos estudiosos del origen 
de BIM fue cuando la empresa húngara Graphisoft ha creado un programa en 1982 para desarrollar proyectos utilizando dos y tres dimensiones; otros dicen que fue cuando la compañía Autodesk adquirió Revit Technology Corporation en 2002. Pero, de hecho, el primero en difundir este concepto fue el profesor Charles Eastman, pero se popularizó como una representación digital del proceso de construcción por Jerry Laiserin [3].

BIM es un conjunto de políticas, procesos y tecnologías, la creación de una metodología para gestionar el proyecto de construcción y sus datos en un formato digital, a través del ciclo de vida del edificio [4]. Por lo tanto, el conocimiento BIM se vuelve importante para todos los involucrados en el AEC (Arquitectura, Ingeniería y Construcción), tanto en el diseño de proyectos en la planificación del trabajo en la ejecución de la obra, mantenimiento. Este nuevo mercado de trabajo plantea la necesidad de nuevos profesionales.

Después de una revisión de la literatura técnica internacional, los profesionales se han identificado en diferentes contextos de acción [5] (Fig. 1).

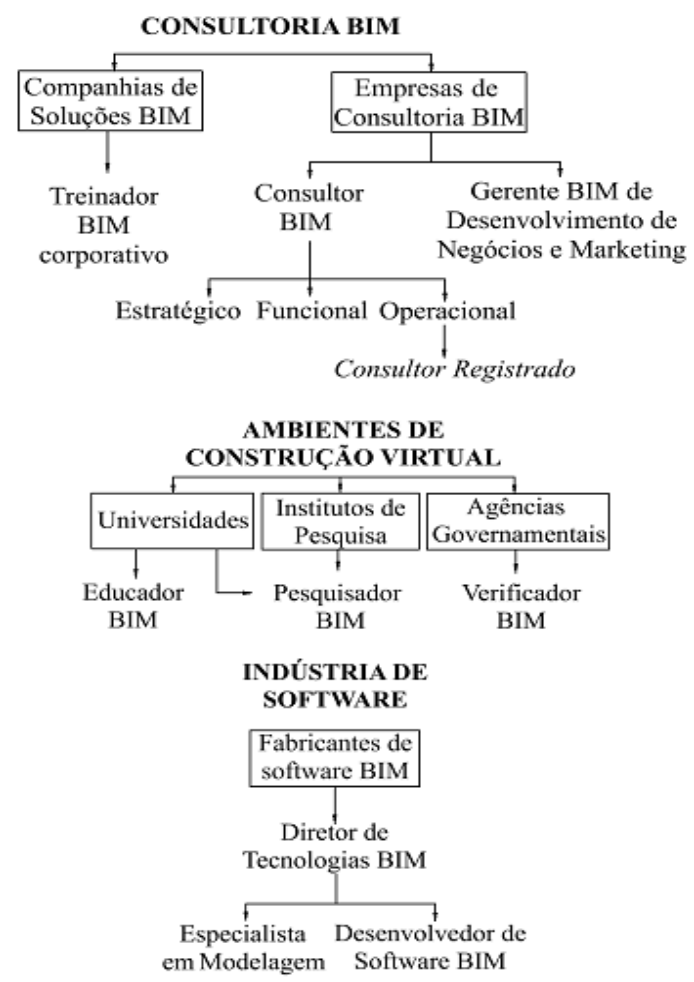

Fig 1. Expertos BIM. 2011. Barison y Santos [6]

BIM expertos que trabajan en estos contextos son: entrenadores, consultores, gestores, educadores, investigadores y otros. Cada uno tiene roles definidos y responsabilidades, que requieren resultados de conocimiento en diferentes niveles de profundidad, tanto en términos de los fundamentos de la BIM y el trabajo práctico con el software.

En el caso de Rio Grande do Norte, la implementación de BIM en estudios de arquitectura y empresas de diseño MEP ha requerido un perfil profesional especializado, que conocen el 
proceso de modelado, debido a la deficiencia que existe en términos de las bibliotecas con los objetos de norma brasileña. Otra necesidad urgente es para profesionales que puedan trabajar como instructores en las empresas de software que ofrecen cursos cortos que enseñan el uso de software BIM, esta necesidad se debe a la falta de instituciones educativas AEC con el plan de estudios ya actualizado con las disciplinas BIM.

EI IFRN ha buscado, a través de la NP-BIM preparar a los estudiantes mediante la enseñanza de BIM con el fin de permitir la integración en el mercado laboral para tomar ventaja de estas oportunidades.

\subsection{Etapas de la adopción de BIM}

La adopción de BIM se produce lentamente y poco a poco, y tratando de satisfacer los deseos específicos de cada posición e institución profesional. Existen varias clasificaciones de niveles de madurez BIM. Una es la IMAC [7], determina cuatro fases BIM ilustración, manipulación, aplicación y colaboración (Fig. 2).

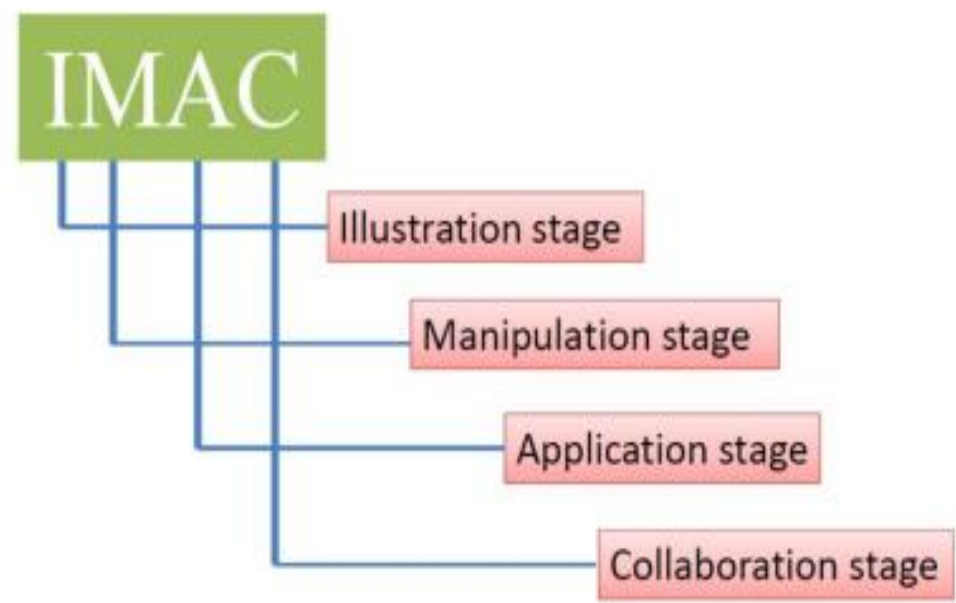

Fig 2. Etapas de adopción BIM - IMAC. 2012. Macdonald [7]

Con base en [7], podemos describir sucintamente, cada una de estas etapas. Ilustración es una etapa introductoria, para conocer y comprender BIM. En el Manipulación los alumnos comienzan a manipular los modelos BIM y se pueden hacer modificaciones sencillas o crear elementos básicos. Para la Aplicación es necesario que los estudiantes ya han adquirido un cierto nivel de conocimientos teóricos de disciplinas específicas, por lo ya puede crear modelos BIM, utilizar herramientas de análisis de modelos BIM y desarrollar 4D planificación. En Colaboración los estudiantes trabajan juntos en proyectos de diferentes disciplinas. En esta etapa es posible aprender por la enseñanza, y hay una gran oportunidad para intercambiar conocimientos.

Análisis de la adopción de BIM en IFRN se produce en cada proyecto de investigación, ya que cada uno requiere que los estudiantes tienen un conocimiento diferenciado en BIM. 


\section{INSTITUTO FEDERAL DE EDUCACIÓN, CIENCIA Y TECNOLOGÍA DE RIO GRANDE DO NORTE}

Campus Natal Central (CNAT) fue inaugurado en 1967, pero la institución tiene más de 100 años, durante este tiempo, los cursos se adaptan a las necesidades del mercado laboral. Diretoria Acadêmica de Construção Civil (DIACON), tiene tres cursos altamente relacionados con segmento AEC: Edificios, Carreteras y Tecnología de la construcción.

El Centro de Investigación en BIM (NP-BIM) vinculada a DIACON tiene un laboratorio, que consta de nueve computadoras con características diseñadas para trabajar con el software BIM, el laboratorio está diseñado para el desarrollo de las clases en BIM y ocupa espacio físico dentro del IFRN-CNAT, en el cuarto piso del edificio NIT.

\subsection{El IFRN experiencia en la enseñanza de BIM}

Los tres pilares de las instituciones educativas son la enseñanza, investigación y extensión, por lo tanto, la implementación de BIM deben tener lugar en estas tres áreas. En este contexto, el IFRN ha tratado de insertar el BIM en la enseñanza, investigación y extensión (Fig. 3).

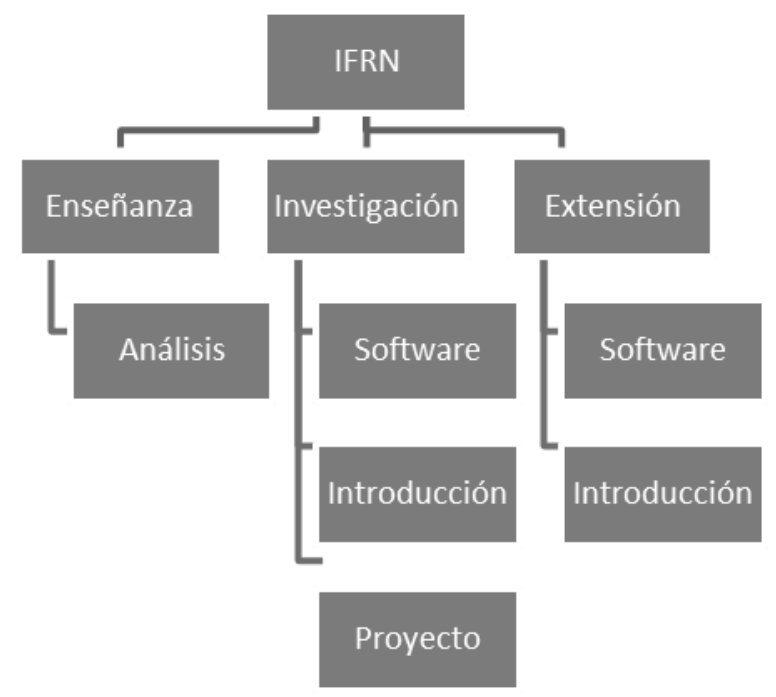

Fig 3. Implementación BIM - IFRN. 2017. Elaboración propia

Con la creación del Centro de Investigación en BIM (NP-BIM) en 2011 IFRN inició el proceso de implementación de la metodología BIM a través de proyectos de investigación con la participación de profesores y estudiantes. Los estudiantes en cuestión son de los cursos de la AEC, a saber: Edificios, Carreteras y Tecnología de la construcción y en la mayoría de los Edificios.

Si BIM no es sólo una nueva herramienta, sino una nueva forma de trabajar, debería demandar con fuerza adecuar nuestras metodologías tanto profesionales como docentes [8]. Así lo teniendo en cuenta que se amplió el proceso de implementación de BIM introduciendo el mini curso de introducción al BIM a los miembros estudiantes de NP-BIM y 
buscó que las acciones superan "las paredes de la institución", hicieron los proyectos de extensión, seminarios sobre el tema y asociaciones con otras instituciones de educación AEC.

La implementación de BIM en la Academia, en la misma forma que en las oficinas de AEC debe ser de manera gradual y evolutiva. BIM no es un paquete de solución, su implementación requiere el aprendizaje en todas las etapas durante su proceso de implementación [9].

En 2017 se inició el proceso informal de analizar el plan de estudios del curso de edificios. Se analizan inicialmente cada uno de los componentes de la matriz y, a continuación se definen las directrices para el proceso de implementación de BIM, con el cambio del Proyecto Político Pedagógico (PPP). Si bien el plan de estudios de los cursos no se modifica, con la introducción de la disciplina BIM, y mucho menos los nuevos contenidos están integrados en las disciplinas existentes, la implementación BIM continúa en IFRN a través de proyectos de investigación y extensión.

La introducción de BIM en el plan de estudios requiere un proceso de motivación de los profesores, no sólo Campus Natal Central (CNAT), sino también otros Campis ofrecer cursos en el área de AEC, y también la posible necesidad de contratar nuevos profesores. Los recursos humanos pueden caracterizarse como una dificultad, lo que requiere la motivación y la implicación [10].

\subsection{Proyectos de investigación y extensión}

Entre 2011 y 2016, NP-BIM ha capacitado a más de ciento diez estudiantes, más de veinte proyectos de investigación han estado o están todavía bajo desarrollo, que requiere entrenamiento en software y también una formación conceptual sobre BIM.

El desarrollo de una sólida base conceptual de BIM y el trabajo práctico con la herramienta de modelado geométrico, posteriormente, proporcionar a los estudiantes el uso de otras herramientas en diferentes disciplinas y la vida profesional con una curva de aprendizaje reducida [11].

Entre los proyectos de investigación incluyen: BIM en el campo de la AEC segmento de la educación en Natal/RN, Diccionario 3D de las palabras usadas en la construcción, BIM Framework académico, Modelado paramétrico de IFC y BIM en la planificación y control de obras.

El proyecto de investigación del BIM en el campo de la AEC segmento de la educación en Natal/RN, presentando inicialmente las distintas modalidades de transferencia de conocimiento de la BIM, a saber: los eventos BIM (seminarios, conferencias, congresos nacionales e internacionales) donde se pueden presentar trabajos técnicos, consulte la investigación que se está desarrollando, así como ampliar su red de profesionales que trabajan en el tema; sitios y blogs sobre el tema BIM (con mini-cursos y capacitación en el software BIM); y la Academia con la producción de trabajos académicos (tesis y 
monografías). Además de la presentación de la realidad BIM en el contexto de la ciudad de Natal, en el campo de la educación de la segmento AEC.

El proyecto de Diccionario 3D de las palabras usadas en la construcción fue una continuación del proyecto de Diccionario 3D a través de software BIM. A través de entrevistas aplicadas a los profesionales del área de AEC, identificamos las palabras que deben incluirse en el diccionario, a continuación, se obtuvieron las dimensiones reales de cada modelo y, finalmente, el diccionario estará disponible en el sitio web de NP-BIM. Ejemplos de modelos son: espaciador, guardia barras de refuerzo y rana.

El BIM Framework académico, es la unión de IFRN con las instituciones educativas (UNI-RN con cursos de Ingeniería Civil y Arquitectura y urbanismo; FACEX el curso de la arquitectura y el urbanismo) y la oficina de arquitectura (Espaço Quatre). Esta unión tiene como objetivo estudiar el proceso de implementación de BIM en cada uno, observando los cambios en el nivel de madurez y flujos de trabajo.

El modelado paramétrico IFC se ha tratado de facilitar la interoperabilidad entre el software BIM de diferentes fabricantes. Este proyecto aborda el desarrollo de un repositorio BIM, cuyos componentes previamente modelados Autodesk Revit, ahora estará libremente disponibles en internet, también en el formato de intercambio IFC, usados para la colaboración entre el software BIM de diferentes fabricantes, Autodesk, Bentley, Tekla, Graphisoft entre otros.

BIM en la planificación y control de obras tiene como objetivo realizar investigaciones sobre los beneficios del software BIM, en especial sus herramientas de análisis incompatibilidades 4D y simulaciones de interferencia entre disciplinas. La metodología es promover el análisis de la utilización de diferentes comandos de software en un proyecto de pre-seleccionada.

Al final de su participación en un proyecto de investigación, el estudiante debe presentar una producción científica, que por lo general se produce mediante la publicación de artículos técnicos que hablan sobre el proyecto. Sólo en el año 2016 había más de diez trabajos científicos presentados.

En cuanto al proyecto de extensión, buscando contribuir al público en general, hemos desarrollado un "entrenamiento BIM para el mercado de trabajo", con la participación de treinta y dos profesionales AEC, que estaban en paro. El proyecto de extensión dirigido a proporcionar una preparación para la nueva realidad del mercado laboral a través de minicurso Introducción a la BIM y la formación en el uso de software BIM.

\subsection{Seminarios y Asociación}

El IFRN se caracteriza por ser un pionero en la aplicación BIM en Rio Grande do Norte, a través de asociaciones con otras instituciones educativas AEC, estudiantes de estas instituciones pueden participar en proyectos de investigación llevados a cabo en NP-BIM. En el año 2016 entre los estudiantes de la institución y los estudiantes de las instituciones asociadas, más de sesenta personas han participado en los proyectos, que actuó como 
investigadores fueron capacitados en el software BIM y tuvo la oportunidad de adquirir bases conceptuales a través de mini curso de introducción a BIM.

Como BIM es un tema nuevo en Rio Grande do Norte, las asociaciones entre las instituciones de educación $\mathrm{AEC}$ ha favorecido el interés y la propagación de BIM, proporcionando oportunidades de difusión, participando como ponente en eventos tales como: II semana de Ingeniería Civil - "Innovar y construir: los retos actuales de la ingeniería civil" (UFRN - 2016) (Fig. 4); Mesa redonda: "lo que el mercado espera que de un ingeniero civil recién formado y como la Universidad se prepara para él" (UFRN - 2016).

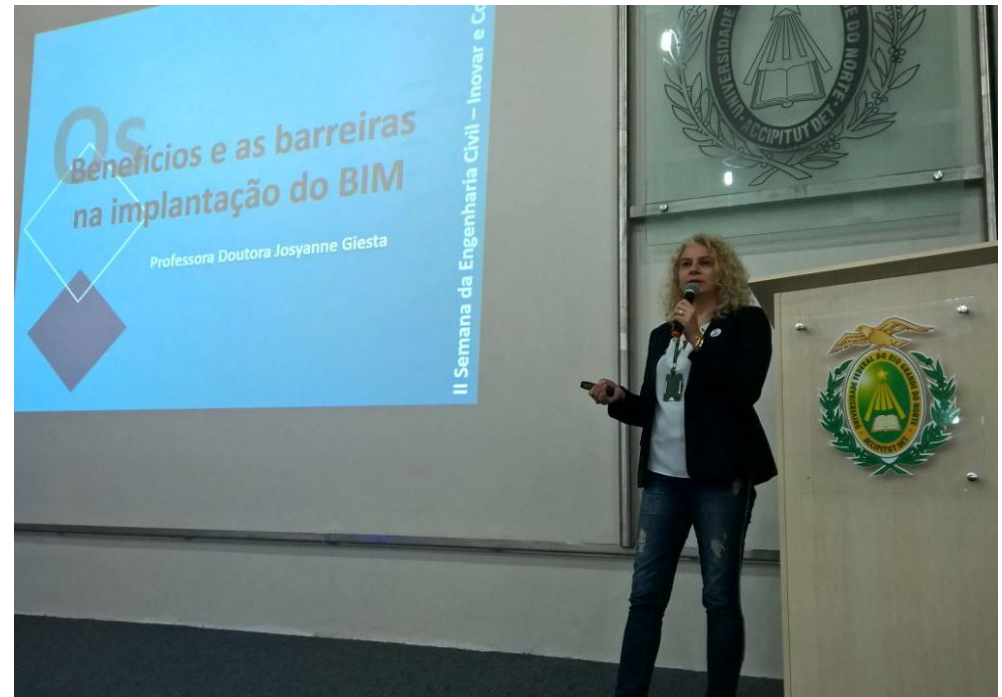

Fig 4. II SEC - UFRN. 2016. Colección propia

Como un mecanismo de difusión y divulgación de la metodología BIM eran promovidos seminarios: I Seminario IFRN de Tecnología BIM, GIS e Plant (2016); I Seminario NP-BIM do IFRN (2017); además de la mediación de $2^{\circ}$ Seminario Regional Sul BIM (2016).

\section{EVALUACIÓN DE LA ETAPA DE ADOPCIÓN DE BIM SEGUNDO IMAC}

Para un análisis de la etapa de adopción de BIM, es necesario tener en cuenta que en cada proyecto de investigación específico, el NP-BIM tiene nuevos estudiantes que inician su proceso de aprendizaje de Building Information Modeling. Por lo tanto, cada proyecto debe ser estudiado por separado.

Con el uso de las medidas propuestas por [7], IMAC, podemos determinar la etapa de cada proyecto, debido a las características específicas de cada uno de ellos (Fig. 5). Al igual que cada ingeniero, o arquitecto, por ejemplo, puede que tenga que desarrollar ciertas habilidades para cumplir sus funciones y para dirigir sus esfuerzos más para el modelado o el análisis de los modelos ya desarrollados.

Como el NP-BIM tiene disciplina teórica de introducción al BIM, capacitación de software BIM, junto con el desarrollo de proyectos específicos de investigación, que estudia BIM. Las 
etapas de llustración y Manipulación siempre se consiguen. La etapa de Aplicación se alcanza en la mayoría de los proyectos, pero con diferente nivel de profundidad y tiene todavía preocupación por la inclusión de los conocimientos específicos de ciertos temas, como temas especiales de las etapas de diseño y ejecución eléctrica e hidro-sanitarias obras civiles. Con respecto a la etapa de Colaboración, el mismo se ha logrado, pero en algunas experiencias en la base de investigación.

\begin{tabular}{|l|c|c|c|c|}
\hline \multirow{2}{*}{ Proyecto de Investigación } & \multicolumn{4}{c|}{ Etapa } \\
\cline { 2 - 5 } & $\mathbf{1}$ & $\mathbf{2}$ & $\mathbf{3}$ & $\mathbf{4}$ \\
\hline BIM en la Educación AEC & & & & \\
\hline Diccionario 3D & & & & \\
\hline BIM Framework Académico & & & & \\
\hline Modelado paramétrico IFC & & & & \\
\hline BIM en la planificación y control de obras & & & & \\
\hline 1- Ilustración; 2- Manipulación; 3- Aplicación y 4- Colaboración \\
\hline
\end{tabular}

Fig 5. Etapa de adopción BIM - NP-BIM. 2017. Elaboración propia

\section{CONCLUSIONES}

El Instituto Federal de Educación, Ciencia y Tecnología de Rio Grande do Norte no tiene en su currículo de cursos AEC, disciplinas y contenido BIM, sin embargo, ha estado cooperando significativamente en el proceso de implementación del Building Information Modeling en noreste de Brasil. Inicialmente a través de la capacitación en el software BIM, proyectos de investigación y más tarde con la inserción del mini curso de introducción al BIM, ampliando así la base conceptual necesaria para la perfecta comprensión del BIM como filosofía de trabajo y no sólo como el uso de software.

EI IFRN la condición de vanguardia en el proceso de implementación BIM ha llevado a la necesidad de transmitir su experiencia a otras instituciones educativas $A E C$, por lo que se crearon asociaciones entre las instituciones. En términos de BIM propagación del conocimiento, hasta ahora restringido a los estudiantes se extendió a través de proyectos de extensión dirigidas a la formación de los profesionales de AEC.

Siendo la filosofía de BIM colaborativa, se requiere la amplitud de su uso. En este sentido, una mayor conciencia de los beneficios de su implementación se logró mediante la organización de seminarios, acciones de participación en conferencias y mesa redonda.

La principal dificultad en el BIM proceso de implementación ha sido la modificación del Proyecto Político Pedagógico (PPP), para la introducción de disciplinas orientadas a la 
educación BIM en el plan de estudios de los cursos AEC IFRN. El proceso de implementación de BIM en IFRN ha ocurrido a través de proyectos de investigación que se caracterizan por una buena elección, mientras que no coloque los cambios necesarios en el plan de estudios. Otra dificultad que se presenta es la renovación constante de los estudiantes en el NP-BIM, ya que los proyectos tienen una duración media de 10 meses, rompiendo continuamente el flujo de desarrollo de la adopción de BIM dentro del núcleo.

A pesar de todas las dificultades mencionadas, el proceso de implementación ha logrado sus objetivos principales, a saber, para preparar a los estudiantes para las nuevas demandas del mercado laboral en términos de BIM, asegurando las posibilidades de inserción, especialmente en las primeras oportunidades, como modeladores y instructores profesionales. Esta experiencia IFRN puede servir como un modelo para las instituciones que también se enfrentan a dificultades y resistencias en el proceso de inserción de BIM en el plan de estudios de los cursos de AEC.

\section{REFERENCIAS}

[1] Barison, M.B. y Santos, E.T. (2011). "Ensino de BIM: Tendências atuais no cenário internacional". Gestão e Tecnologia de Projetos, São Carlos, v.6, n.2, p. 67-80, dez. 2011. ISSN: 19811543.

[2] Ruschel, R.C., Andrade, M.L.V.X de y Morais, M. de. "O ensino de BIM no Brasil: onde estamos?". Ambiente Construído, Porto Alegre, v.13, n.2, p. 151-165, abr./jun. 2013. ISSN 1678-8621.

[3] Curso BIM A0 de ZIGURAT. Disponible en: http://courses.e-zigurat.com [Consulta:04/02/2017]

[4] Succar, B. (2009). "Building information modeling framework: A research and delivery foundation for industry stakeholders". Automation in Construction. v. 18. n.3 p.357-375. 2009. Elsevier B.V.

[5] Barison, M.B. y Santos, E.T. (2010). "An overview of BIM specialists". In: International Conference on computing in civil and building engineering, Nottingham. Disponible en: http://www.researchgate.net/profile/Eduardo_Santos6/publication/289437352_An_overvi ew_of_BIM_specialists/links/56925fb808aec14fa55d6cee.pdf?origin=publication_list. [Consulta:08/02/2017]

[6] Barison, M.B. y Santos, E.T. (2011). "Atual cenário da implementação de BIM no mercado da construção civil da cidade de São Paulo e demanda por especialistas". In: Encontro Brasileiro de Tecnologia de Informação e Comunicação na Construção, 5, Salvador. Disponible en: http://www.uel.br/pessoal/barison/Artigos_Tese/TIC2011a.pdf. [Consulta:08/02/2017] 
[7] Macdonald, J.A. (2012). "A framework for collaborative BIM education across the AEC disciplines". Disponible en: http://codebim.com/wp-content/ uploads/2013/06/2012_Macdonald_AUBEA.pdf. [Consulta:01/03/2017]

[8] Valverde, D.C., Cañizares, J.M., Márquez, D.V., Pérez, P.E.G. y Peso, R.J.P. (2016). "Implementación BIM en la Escuela Politécnica de Cuenca, experiencia piloto en proyectos técnicos 15-16". In: EUBIM 2016. Anais do... Valencia.

[9] Durante, F.K., Mendes Junior, R., Scheer, S. y Garrido, M.C. (2015). "Avaliação de aspectos fundamentais para a gestão integrada do processo de projeto e planejamento com uso do BIM". In: Encontro Brasileiro de Tecnologia de Informação e Comunicação na Construção, 7., 2015, Recife. Anais... Porto Alegre: ANTAC.

[10] Underwood, J., Ayoade, O., Khosrowshahi, F., Grenwood, D., Pittard, S. y Garvey, R. (2015). "Current position and associated challenges of BIM education in UK Higher Education".

[11] Sacks, R. y Barak, R. (2010). "Teaching building information modeling as an integral part of freshman year civil engineering education". Journal of profesional issues in engineering education and practice. ASCE, v.136, n.1, p.30-38, Jan. Disponible en: http://www.ascelibrary.org. [Consulta:10/03/2013] 


\section{IMPLEMENTACIÓN DE LA METODOLOGÍA BIM EN EDUCACION SUPERIOR DE AEC}

\section{García Granja, María Jesús (1)}

(1) Arquitecta. Máster BIM Manager. Profesora de la ETSA de Málaga. Miembro del Grupo de investigación HUM-964 CTA: Comunicación, Tecnología y Arquitectura, de [es]FAB y de GUBIMMLG. mjggranja@uma.es

\section{RESUMEN}

En esta última década se viene observando como el modelo tradicional de diseño, coordinación de ejecución y mantenimiento de edificaciones, utilizado durante los últimos veinte años, está quedando obsoleto frente a las ventajas que ofrece la metodología BIM (Building Information Modelling).

Nos encontramos, pues, en un momento disruptivo dentro del sector AEC (Architecture Engineering and Construction) ya que, al mismo tiempo que se abre un nuevo abanico de oportunidades técnicas, perfiles profesionales y nichos de mercado inexplorados, también se plantean grandes retos en relación a la implementación de dicha metodología en España.

Esta comunicación se centra en concreto en su implementación en el marco de la Educación Superior para formar como profesionales BIM a los alumnos de Enseñanzas Universitarias y de Ciclos Formativos de Grado Superior relacionados con el sector de la Construcción.

Concluyendo con la propuesta de insertar BIM como metodología transversal y vertebradora de las distintas áreas de conocimiento de cada Enseñanza, mediante un método empírico de aprendizaje, en el que diversas asignaturas trabajen en sus prácticas sobre un modelo virtual común y articulando la posibilidad de llegar a adquirir las máximas competencias en materia de coordinación y gestión colaborativa en la nube, mediante Títulos de Másteres Interuniversitarios.

Palabras clave: AEC, BIM, Enseñanza, España, Universidad

\section{ABSTRACT}

In recent times, it has been observed that the traditional design, coordination and execution of buildings, used during the last twenty years, is becoming obsolete in comparison with the advantages of the BIM (Building Information Modelling) methodology.

We are, therefore, in a disruptive moment in the AEC (Architecture Engineering and Construction) Sector, since, at the same time as a new range of technical opportunities, professional profiles and unexplored market niches opens up, there are also great challenges on the implementation of this methodology in Spain. 
These ones are analysed in this communication, focusing specifically on their implementation in the framework of Higher Education to train as BIM professionals the students of University Teachings and Higher Education Training Cycles related to the Construction Sector.

Concluding with the proposal to insert BIM as transversal methodology and supporting of the different areas of knowledge of each Teaching, through an empirical method of learning, in which diverse subjects work in their practices on a common virtual model and articulating the possibility of arriving to acquire the maximum skills in coordination and collaborative management in the cloud, through Interuniversitary Masters Degrees.

Keywords: AEC, BIM, Teaching, Spain, University

\section{$1 \quad$ INTRODUCCIÓN}

Se ha demostrado que los procesos relacionados con la edificación han evolucionado de modo mucho menos efectivo que los relacionados con la producción industrial, cuya progresiva optimización de sus sistemas de fabricación, ha alcanzado cotas mucho más altas desde la Revolución Industrial a nuestros días [1].

Por otro lado, como es sabido, el modelo standard de documentación proyectual, que se ha venido utilizando en edificación durante los últimos veinte años para cualquier Proyecto Básico y de Ejecución, consistía en la representación gráfica en 2D mediante CAD (Computer-Aided Design) de plantas, alzados y secciones, no vinculados automáticamente entre sí -por lo que cualquier cambio era necesario dibujarlo en todas las vistasacompañados, en su caso, de algún modelo en 3D -que facilitase su interpretación visual, pero sin información digital del proyecto- y documentado textual y numéricamente, en lo relativo a mediciones y presupuestos, tablas de planificación, etc. mediante archivos en diferentes formatos, que no ofrecían la posibilidad de rectificación instantánea al modificar el modelo gráfico. Esto obligaba al continuo cotejo de la correcta actualización, ante cualquier cambio en proyecto, de todos los planos, mediciones y presupuestos, modelos y anexos de cálculo de estructura e instalaciones, memoria, pliego de condiciones y demás documentos de proyecto [2].

Sin embargo, hoy día, nos encontramos en un momento clave, en el que los agentes que intervenimos desde los distintos ámbitos en el sector AEC (Architecture Engineering and Construction) tenemos la oportunidad de conseguir mayores cotas de calidad y de ahorro de recursos en la edificación, tanto en las fases de diseño, como de construcción y de mantenimiento de las obras arquitectónicas, gracias a una metodología de trabajo colaborativa para la creación y gestión de proyectos de construcción como es BIM (Building Information Modelling).

Ésta no sólo permite centralizar en un solo modelo digital toda la información de proyecto necesaria para la ejecución en obra de edificios fieles a su diseño, con mediciones y presupuestos reales y vinculados a él, sino que posibilita el ensayo y la detección temprana de interferencias entre arquitectura, instalaciones y estructura, que redunda en un ahorro 
considerable en tiempo y dinero, dada la disminución de errores de proyecto, que no sólo reduce el número de proyectos reformados y de precios contradictorios respecto a los que solían darse durante la ejecución de un edificio diseñado según el modelo tradicional, sino que además, facilita enormemente el mantenimiento del edificio y disminuye su CCV (Coste de Ciclo de Vida), lo que se conoce como $360^{\circ}$ (Figura 1). Dicha centralización de la información es lo que permite la automatización de los cambios, reduciendo al mínimo las discrepancias documentales y el tiempo de dedicación al cotejo de documentos [3].

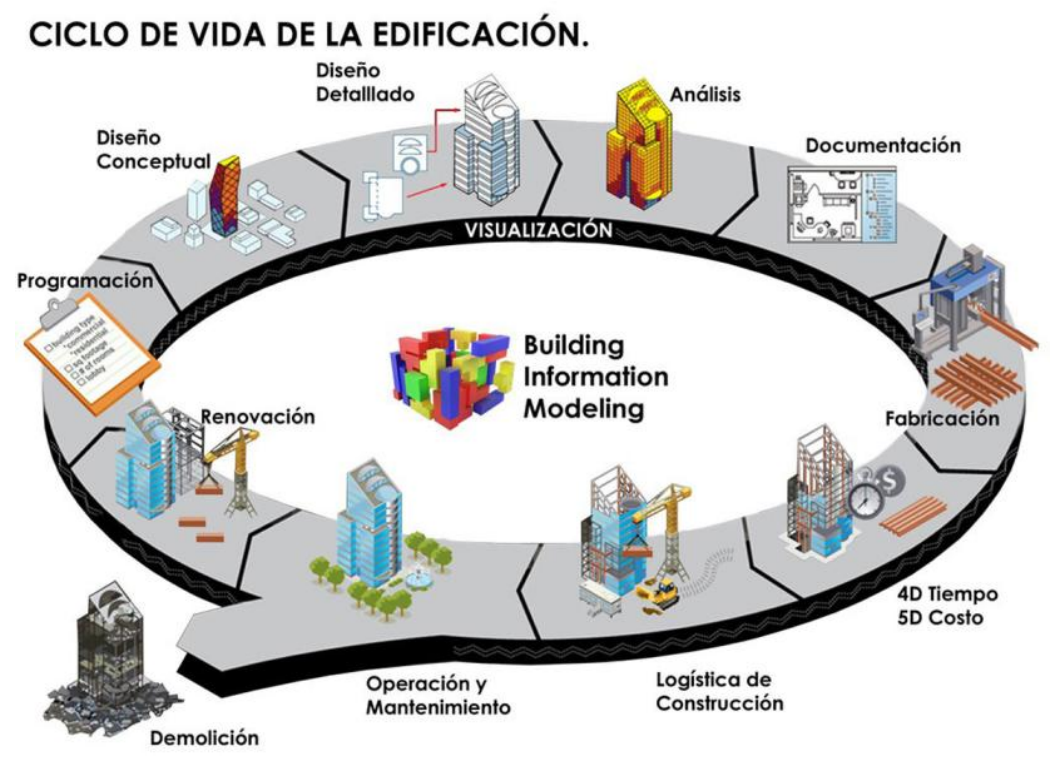

Fig 1. Ciclo de vida BIM de un edificio. 2014. http://mbim.blogs.upv.es/

Por ello, se dice que dicho modelo no sólo incorpora información geométrica 3D, sino que se podría afirmar que esta metodología permite generar un modelo $4 \mathrm{D}$, ya que incluye el factor tiempo, al aportar la posibilidad de incluir fases de proyecto, correspondientes a distintas etapas constructivas, dentro del mismo modelo y permite la planificación temporal de la construcción. Además se convierte en 5D al incluir los costes, en 6D al incorporar la información ambiental y en 7D al introducir los datos necesarios para el mantenimiento. [4]

Las ventajas mencionadas, que reportan esta nueva metodología, son posibles gracias a que BIM permite modelar una realidad virtual dinámica y actualizable automáticamente por los distintos agentes que la crean, los cuales pueden trabajar simultáneamente en ella desde cualquier punto del planeta, realizando una gestión colaborativa en servidor en la nube [5].

Aunque no hay que obviar que este sistema de trabajo requiere la creación y gestión de modelos centrales, modelos vinculados y subproyectos, por parte de profesionales cualificados para ello, así como de la redacción y firma conjunta un BEP (BIM Execution Plan) por parte de todos los agentes implicados en el proceso de edificación, por el cual, cada una de dichas figuras asumirá la carga de trabajo y responsabilidades reflejados en él, aspecto para el cual aún no está adaptado nuestro marco legislativo actual, como es la LOE (Ley de Ordenación de la Edificación). 
Es por todos estos motivos, además de por el hecho de que va más allá de la fase de diseño del proyecto, abarcando también la ejecución y gestión del mantenimiento a lo largo del ciclo de vida del edificio, reduciendo los costes de todas las etapas, lo que ha convertido a BIM en el paradigma de metodología de trabajo en los proyectos de construcción en una gran parte de países, sobre todo en los últimos diez años.

Respecto a cómo se ha operado en cada uno de ellos para lograr la implementación de ésta en sus respectivos sectores AEC, encontramos ejemplos como los de gobiernos de Dinamarca en 2011 o Gran Bretaña en 2016, donde se ha optado por la implantación obligatoria de la metodología BIM a los procesos de diseño, construcción y mantenimiento de edificaciones públicas o superiores a una determinada superficie construida. Aunque existen otros países como Canadá, donde dicha implantación no se ha realizado, de momento, de forma impositiva por sus Administraciones Públicas, sino han optado por incentivarla y no crear normativa oficial sino guías BIM de recomendado cumplimiento en proyectos de edificación, de modo que, de forma progresiva, están consiguiendo que se convierta en una metodología de uso habitual en ellos, como se observa en la Figura 2.

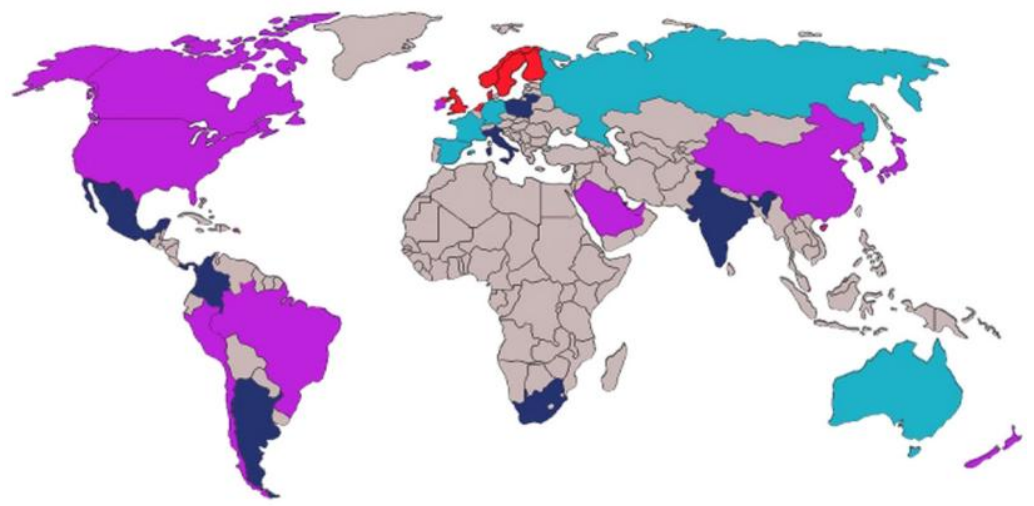

\author{
Uso BIM Obligatorio en Proyectos Públicos \\ Uso Obligatorio previsto en Proyectos Públicos \\ Uso habitual de BIM \\ Uso incipiente de BIM
}

Fig 2. Mapa de implantación BIM. 2016. www.buildingsmart.es/bim/

Pero en cualquiera de las tipologías de implantación analizadas hasta el momento, los resultados en las obras construidas mediante esta metodología están demostrando que es una herramienta muy eficaz para dar paso a una optimización de recursos, que redunde en construcciones de mayor calidad, más eficientes y a menor coste, reduciendo el factor incertidumbre durante el proceso de construcción a las mínimas cotas posibles y asegurando un mantenimiento sostenible en el tiempo de éstas. [6]

No obstante, un cambio de modelo proyectual y constructivo como éste supone, en cualquier caso, una modificación en los modos tradicionales de trabajo en el sector AEC, que conlleva también cambios de rutinas de negocio y de roles profesionales tradicionales, 
tan arraigados en las profesiones A\&E (Architects and Engineers), como puede observarse en la Figura 3.

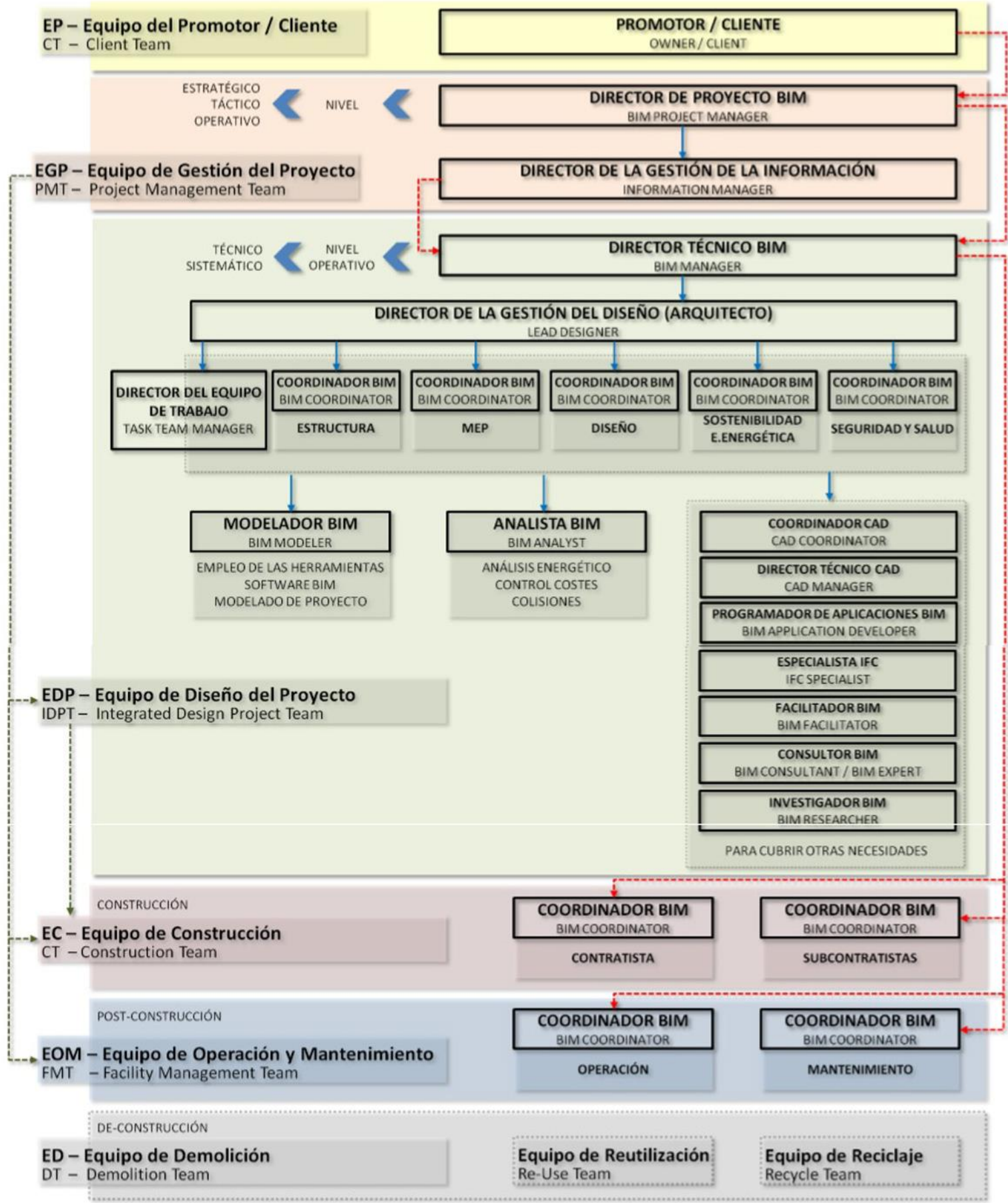

Fig 3. Organigrama de roles BIM. 2016. BIM implantación en España. Comisión BIM. Grupo 2.3

En España, los primeros pasos dados en estos temas comenzaron cuando el Ministerio de Fomento creó en 2015 la Comisión Nacional es.BIM, que hasta hoy sigue analizando cómo implementar BIM en el Sector y cómo introducirlo en las licitaciones públicas. 
Además, en el marco de la Asociación BuildingSMART Spanish Chapter se ha creado, por un lado, el Foro Académico BIM [es]FAB, que es una red española académica BIM, sin ánimo de lucro, cuya misión es la de desarrollar y promover la formación, el aprendizaje y la investigación sobre BIM a través de una estrecha colaboración y cooperación entre sus miembros y otras entidades y organismos, cuya finalidad incluya la mejora del modelo productivo de la construcción y, por otro, está intentando fomentar la estandarización de BIM, mediante el desarrollo de una serie de guías BIM denominadas uBIM, que pretenden facilitar la implantación de la metodología en el Sector de la Construcción español y promover la metodología openBIM, basada en el uso de flujos de trabajos y estándares abiertos, como el IFC (Industry Foundation Classes), que sirve como formato de intercambio de datos entre agentes, procesos y aplicaciones.

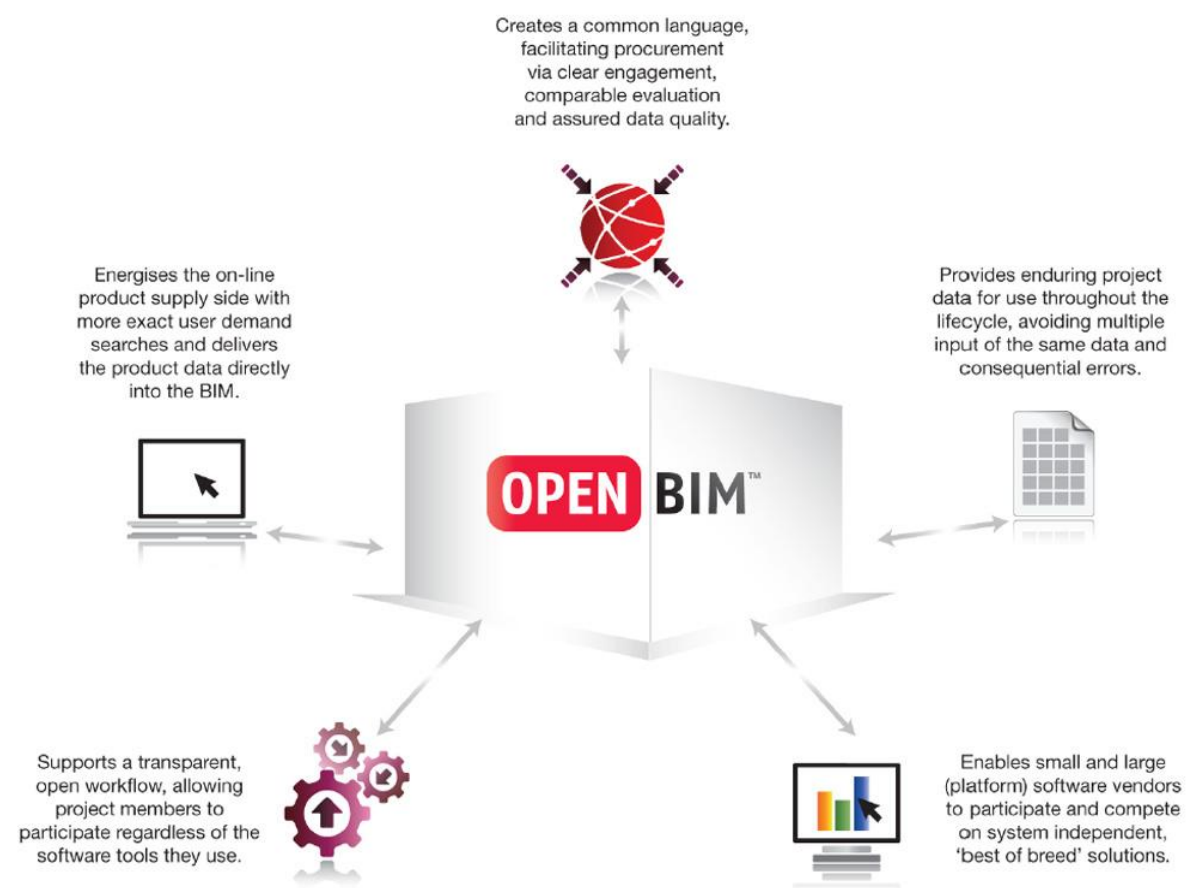

Fig 4. openBIM. 2017. www.applecoredesigns.co.uk

Cierto es que el openBIM es importante porque permite la participación de todos los agentes de un proyecto, independientemente del software que usen -lo cual revierte en beneficio del usuario, por posibilitar la competitividad entre ellos- creando un lenguaje común que genere proyectos transparentes en cuanto a su evaluación comparativa de servicios y con una calidad de datos garantizada, que ofrece datos utilizables durante toda la vida útil del edificio para su mantenimiento e incluso su derribo, como se aprecia en la Figura 4.

Pero no basta con estas medidas, sino que todos los implicados en la Educación Superior, desde Claustros de Gobierno de las Universidades, Gobiernos Autonómicos y Estatal, hasta profesorado y estudiantes, debemos tomar conciencia de las nuevas necesidades formativas que está generando esta situación y realizar un esfuerzo sinérgico para cubrirlas, 
poniendo para ello, cada uno, desde sus distintos ámbitos de actuación, los medios necesarios.

Por todo expuesto hasta ahora cabría preguntarse, en el caso de España, en la que su gobierno ha optado por la inminente implantación por ley de BIM en proyectos de licitaciones públicas de edificación, a partir de 2018 y civiles en 2019 [7], muchas cuestiones como por ejemplo:

- ¿Necesita nuestra legislación sobre de competencias profesionales una revisión para regular las titulaciones y atribuciones de los nuevos perfiles laborales que demanda el uso de esta metodología?

- ¿Los agentes implicados en los procesos edificatorios, están preparados tanto a nivel formativo como para el cambio de mentalidad que supone la puesta en práctica de este marco de trabajo?

- ¿Cómo pretenden articularse las nuevas necesidades docentes que genera a nivel de Educación Superior dicha implantación?

Y es sobre la última de estas preguntas sobre la que versa el contenido de esta comunicación.

\section{CONTENIDO}

Actualmente, en nuestro país, existe gran demanda de formación BIM debido, en gran medida, a la inminente exigencia de aplicación de dicha metodología a las licitaciones públicas, además de por todas las ventajas que reporta en sí misma. Dicha demanda está siendo satisfecha, sobre todo, por centros privados, colectivos profesionales, etc.

Sin embargo, los contenidos y competencias relacionados con la metodología BIM, apenas se encuentran implementados en los Programas de Grado de las Universidades Públicas, aunque, lo que sí empieza a existir, es bastante oferta de Enseñanzas Propias de Posgrado (Másteres Propios Universitarios, Diplomas de Especialización, Experto Universitario, Cursos de Formación Superior). Esta descompensación se debe, en parte, a que un elevado número de profesores de Educación Superior no poseen aún el nivel de formación BIM necesario, como para adaptar su docencia a este nuevo marco, por lo que en aquellas Enseñanzas en las que se intenta implantar, es necesario recurrir a ese tipo de fórmulas, que permiten la impartición de clases por personal externo especializado en la materia.

Son ejemplos de Universidades pioneras en iniciativas BIM, la Universitat Politècnica de Catalunya (UPC), la Universidad Politécnica de Madrid (UPM) [8], la Universitat Politècnica de València (UPV), la Universidade da Coruña (UDC), la Universidad de Alicante (UA), la Universidad Politécnica de Cartagena (UPCT) o la Escuela Politécnica de Cuenca (EPC).

En algunas de ellas, se está tomado como referente Universidades de países como Dinamarca o Reino Unido, que ya contemplan en sus programas la implantación de BIM como metodología docente y en varios de los Grados en Arquitectura de estas 
Universidades españolas, se está trabajando en adecuar las competencias universales tradicionales asociadas con el ejercicio profesional del Libro Blanco de Grado en Arquitectura, a las competencias relacionadas en la Orden ECI/3856/2007, por la que se establecen los requisitos para la verificación de los títulos universitarios oficiales que habiliten para el ejercicio de la profesión de Arquitecto.

Parece evidente que para poder articular, gestionar e implantar nueva metodologías en la estructura docente de Grados, Máster y Ciclos Formativos de Grado Superior, relacionados con titulaciones del Sector AEC es necesario, primero, tener claro qué competencias deben adquirir los estudiantes de cada Enseñanza Superior para que, una vez titulados o egresados, se correspondan con las atribuciones BIM que vayan a poder ejercer en el mercado laboral.

Por lo que, respecto al Grado en Arquitectura, del apartado 3, de la Orden ECl/3856/17, sobre Objetivos-Competencias que los estudiantes de Grado en Arquitectura deben adquirir, resaltaría como especialmente importantes para la implementación de BIM las siguientes:

1. Aptitud para crear proyectos arquitectónicos que satisfagan a su vez las exigencias estéticas y las técnicas.

6. Capacidad de comprender la profesión de arquitecto y su función en la sociedad, en particular elaborando proyectos que tengan en cuenta los factores sociales

7. Conocimiento de los métodos de investigación y preparación de proyectos de construcción.

8. Comprensión de los problemas de la concepción estructural, de construcción y de ingeniería vinculados con los proyectos de edificios.

9. Conocimiento adecuado de los problemas físicos y de las distintas tecnologías, así como de la función de los edificios, de forma que se dote a éstos de condiciones internas de comodidad y de protección de los factores climáticos.

10. Capacidad de concepción para satisfacer los requisitos de los usuarios del edificio respetando los límites impuestos por los factores presupuestarios y la normativa sobre construcción.

11. Conocimiento adecuado de las industrias, organizaciones, normativas y procedimientos para plasmar los proyectos en edificios y para integrar los planos en la planificación. 
Poniendo como ejemplo la aplicación de una metodología docente PBL (Project Based Learning), en el Grado en Arquitectura, los estudiantes de un mismo curso podrían integrar los conocimientos teóricos de todas aquellas materias relacionadas con BIM, aplicando dicha metodología a una práctica común coordinada en la que se fomentaría la adquisición de las competencias fundamentales anteriores.

De este modo y aprovechando la flexibilidad conceptual permitida en los Planes de Estudio en el contexto del EESS (Espacio Europeo de Educación Superior) derivados del Plan Bolonia, se podría incorporar BIM como herramienta docente para lograr los objetivos formativos legalmente establecidos [1].

La idea de aglutinar los conocimientos adquiridos en diversas asignaturas de un mismo curso, dentro en un modelo virtual común a las prácticas de todas ellas, resulta potencialmente enriquecedora, ya que favorece la compresión procedimental de los conceptos teóricos adquiridos, además de posibilitar la adquisición de las competencias necesarias para la futura carrera profesional del alumno.

Más que una transversalidad, BIM puede vertebrar, desde etapas muy tempranas, las diversas disciplinas de estudio. El estudiante creará un modelo tridimensional, que desarrollará y actualizará progresivamente, gestionando de un modo completamente diferente la representación gráfica, ya que proyectará al mismo tiempo en planta, alzado, sección o 3D, según sus necesidades de diseño y extrayendo a posteriori las vistas necesarias para documentar gráficamente el proyecto.

Poniendo como ejemplo un estudiante de Arquitectura, para él dicho modelo crecerá al mismo ritmo que sus conocimientos en las diferentes Áreas, es decir, irá completando su proyecto en 3D, fruto de sus prácticas de Expresión Gráfica y Proyectos, mediante la introducción de información digital relativa a las características gráficas, físicas y económicas de los materiales, así como de los sistemas constructivos, que habrá ido aprendiendo en Construcción Arquitectónica y Fundamentos Físicos, lo que a su vez le ayudará a ir creando unas mediciones y presupuestos acordes al modelo, para así poder llegar a calcular, llegado el momento, los caudales de cálculo de instalaciones, al tener integrados los datos necesarios para ello.

Fundamentos Matemáticos aplicados a la Arquitectura incluirá en su temario aspectos como las fórmulas de programación básicas para la parametrización de familias y tablas de planificación o las coordenadas compartidas para georreferenciar y en la asignatura de Inglés de Oficina se introducirá el vocabulario propio de BIM y los términos correspondientes a acrónimos anglosajones, tan usuales en esta metodología.

En Estructura e Instalaciones se trabajará con modelos vinculados que aprenderá a exportar e importar para su cálculo al software de su elección y pondrá en práctica los aspectos propios de BIM STR (Structures) y BIM MEP (Mechanical, Electrical and Plumbing), a la vez que en los Talleres irá siendo capaz de manejar flujos de trabajo, plugins de utilidad, nubes de revisión, plantillas, libros de estilos, BEP y adquirirá los conocimientos necesarios para 
incorporar las medidas necesarias que garanticen, tanto la eficiencia energética del edificio como la seguridad y salud en obra.

Progresivamente, y ya posiblemente en Postgrado, llegará a gestionar la información colaborativamente con sus compañeros a través de un servidor en la nube compartiendo un modelo central, de forma que los integrantes de un BTG (BIM Task Group) -que podrían pertenecer a distintas universidades o facultades de una misma universidad- llegarían a adquirir las competencias necesarias en materia de coordinación como para poder ejercer en un futuro como BIM Manager o BIM Coordinator de su especialidad. De forma que nuestro estudiante de Postgrado en Arquitectura podría trabajar en equipo con otro de Ingeniería, por ejemplo, para realizar colaborativamente sus TFM (Trabajo Fin de Máster).

Obviamente un esquema de aprendizaje práctico como éste, basado en el diseño integrado y la gestión de la información, debe seguir asentando sus bases en unos conocimientos teóricos sólidos y respetar otras metodologías de desarrollo creativo tradicionalmente efectivas. Además, asignaturas estructurales, de suma importancia para la formación integral del alumno y ajenas al universo BIM, como Historia de la Arquitectura, Urbanismo o Composición Arquitectónica, discurrirán en paralelo a este modelo.

Como ventajas del CODEBIM (Collaborative Desing Edication using BIM) cabe destacar que facilita tanto la comprensión visual de los elementos arquitectónicos y de sus procesos constructivos como del comportamiento estructural, energético y económico, entre otros, del modelo base, lo que redunda en un aprendizaje integral del futuro egresado, cuya empleabilidad estaríamos potenciando al máximo. Pero cabe destacar, como inconvenientes, la gran inversión necesaria en capital humano y tecnológico, así como las como las grandes dosis de esfuerzo intelectual y motivación imprescindibles tanto entre docentes como estudiantes y la dificultad de coordinación entre asignaturas y áreas de conocimiento, en aras de materializar con éxito lo que ahora parece una utopía a la vista de la Figura 6.

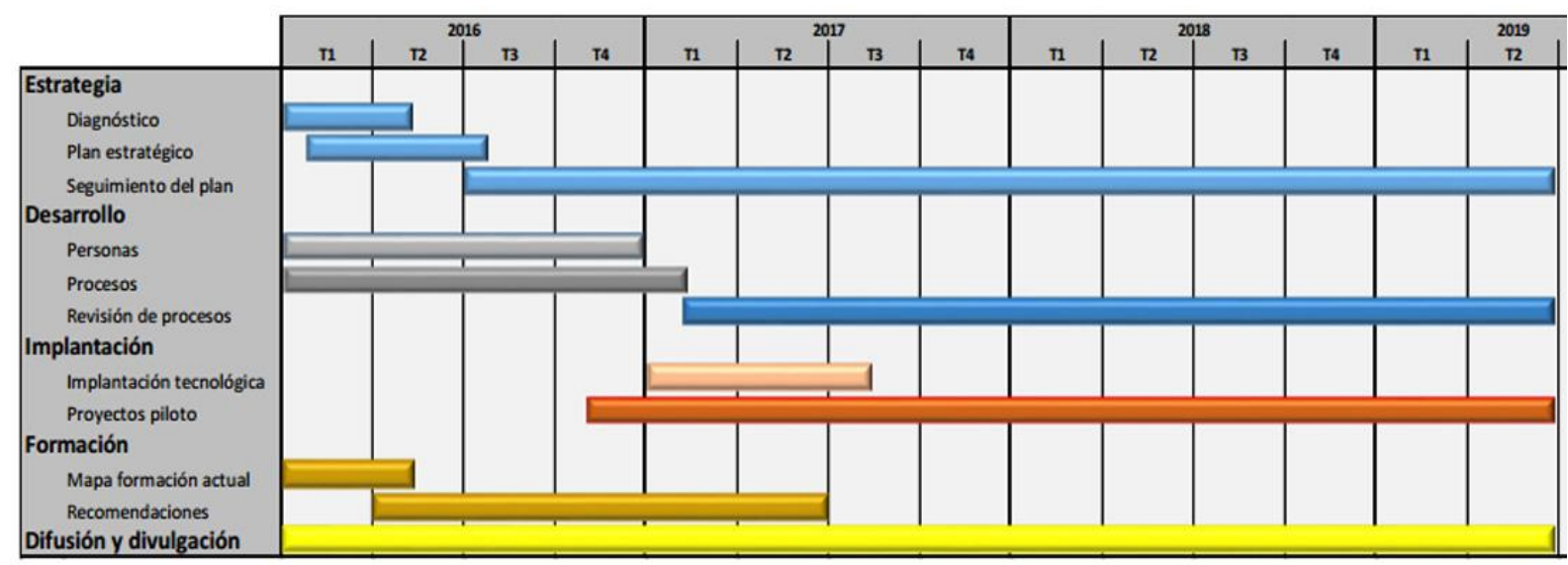

Fig 5. La situación del BIM en España. Presente y futuro de la Arquitectura Edificación y Construcción. 2016. http://aulatematica.com/blog/notes/ 


\section{CONCLUSIONES}

A pesar de mi convicción sobre la posible operatividad de la idea propuesta, no hay que obviar las dificultades que entraña la puesta en práctica de un proyecto piloto como éste.

Por un lado necesita una planificación de conjunto, con un enfoque global, que trasciende a la coordinación dentro de un área de conocimiento e incluso a la transversalidad entre ellas. Y por otro, solo mediante un impulso de todo el colectivo de Educación Superior, unido al compromiso de colaboración de los Gobiernos que la regulan y sostienen, BIM podría ser implementado en las Enseñanzas que lo requieren, para que así puedan consolidarse las necesarias modificaciones de procesos y roles profesionales que conlleva su incorporación al ejercicio profesional de los futuros egresados del Sector AEC.

Ante esta perspectiva, veamos pues, como marcos de oportunidad transitoria de implementación de esta metodología los Másteres, Doctorados y Cursos de Extensión Universitaria BIM, que actualmente pueden ofrecer nuestras Universidades, mediante los cuales, se puede ir paliando temporalmente el retraso en su incorporación integral y efectiva a nuestros Planes de Estudio, al mismo tiempo, que se le da respuesta a la gran demanda de formación reglada existente en esta materia y a la especialización del profesorado.

\section{REFERENCIAS}

[1] Bryde, David et al. (2013). The project benefits of Building Information Modelling (BIM).

[2] Gallardo Salazar, J.M. (2016). Los sistemas de Gestión Documental de Proyectos. Un análisis y optimización aplicada a los Proyectos de Ingeniería en Edificación.

[3] Reijo, Miettinen y Paavola, Sami (2013). Beyond the BIM utopia: Approaches to the development and implementation of building information modelling.

[4] Douglas, M. Brito; 2015; Strategies for representation and analyses of 4D modelling applied to construction project management.

[5] Hernández Silva, N.D. (2011). Procedimiento para la coordinación de especialidades en proyectos con plataforma BIM.

[6] Bergeron, Francois (2008). Project management information systems: An empirical study of their impact on project managers and project success.

[7] Ministerio de Fomento, Gobierno de España (2015). Borrador de Anteproyecto de Ley de Contratos del Sector Público.

[8] Jurado Egea, J. (2016). Aprendizaje integrado en Arquitectura con Modelos Virtuales. Implantación de la metodología BIM en la docencia universitaria. 


\section{ESTUDIO SOBRE EL GRADO DE IMPLANTACIÓN DEL BIM EN LA INGENIERÍA CIVIL EN ESPAÑA}

\section{Lucio Iglesias, Daniel (1), Del Solar Serrano, Patricia (2), Vivas Urías, María Dolores (3), Vilardaga Rodrigo, Iván (4), Liébana Carrasco, Óscar (5)}

(1) Universidad Europea de Madrid, daniel.lucio.iglesias89@gmail.com

(2) Universidad Europea de Madrid, patricia.delsolar@universidadeuropea.es

(3) Universidad Europea de Madrid, mariadolores.vivas@universidadeuropea.es

(4) Universidad Europea de Madrid, ivan.vilardaga@universidadeuropea.es

(5) Universidad Europea de Madrid, oscar.liebana @universidadeuropea.es

\section{RESUMEN}

La aparición de la metodología BIM, que permite una preconstrucción virtual, en diferentes grados de desarrollo, para cualquier tipo de proyecto del sector AECO (Arquitectura, Ingeniería, Construcción y Operaciones), está generando un gran interés internacional en la Ingeniería Civil. Los grandes beneficios técnicos y económicos del estudio de los proyectos en entornos virtuales, están permitiendo su incorporación en las licitaciones de las Administraciones Públicas.

En la comunicación se presentan los resultados de la encuesta realizada en un Trabajo Fin de Grado del Grado de Ingeniería Civil sobre el grado de implantación de esta metodología en España. Estos datos se han comparado con la situación a nivel internacional a partir de los estudios realizados más importantes. Este estudio permite identificar de antemano las barreras y las oportunidades, favoreciendo una implantación más efectiva dentro del sector.

Palabras clave: Ingeniería Civil, implantación, preconstrucción

\section{ABSTRACT}

The emergence of a new working methodology called BIM, which allows the virtual preconstruction of any type of project within the AECO sector, is gaining interest throughout the world. It is remarkable the willingness of multiple goverments to demand this methodology in the bidding of Public Administration's contracts. The fact of being able to develope the project into a virtual environment before its constructed grants great technical and economic benefits that are captivating the AECO sector.

The present document seeks to summarize the Bachelor Degree's Final Work which focus on the implementation's degree of this new methodology in the spanish Civil Engineering as well as the opportunities presented by BIM procedure. For this purpose, a survey was carried out and the results were compared to the international BIM levels which were deduced from 
the most important surveys. This study also aims to clarify what barriers BIM could find in Spain in order to indentify them in advance and present early solutions that could help to improve the implementation of BIM in this country.

Keywords: Civil Engineering, Infrastructure, preconstruction

\section{INTRODUCCIÓN}

\subsection{Situación del BIM en la Ingeniería Civil}

La presente comunicación nace de un trabajo de investigación desarrollado a lo largo del curso 2015-2016 encuadrado en la asignatura de Trabajo de Fin de Grado del Grado de Ingeniería Civil de la Universidad Europea de Madrid, teniendo por objetivo el estudio del grado de implantación del BIM en la Ingeniería Civil española en el año 2016.

El crecimiento del interés que presentan la mayoría de países desarrollados por la metodología de trabajo colaborativo, comúnmente llamada BIM, puede entenderse como fruto de dos importantes situaciones: la crisis económica mundial del 2008 y el desarrollo tecnológico experimentado desde comienzos del siglo XXI [1]. Este cataclismo económico conllevó la adopción definitiva de una visión más austera de la economía, centrada en la optimización de recursos como así se puede comprobar en la obligación de los países miembros de la Unión Europea de mantener el déficit público por debajo del 3\% del PIB [2] obligando a los países miembros a buscar nuevas formas de controlar las riendas de sus respectivas economías, basadas éstas en la contención del gasto público. Por otro lado, se encuentra el Libro Blanco del Transporte (2011) [3], documento guía para los miembros de la UE en lo referente a la planificación del Transporte, y por ende las infraestructuras necesarias deberán responder a las necesidades y alcanzar los objetivos que en él se detallan. En el Anexo I (Anexo I: 36, 37) se exponen los principios para una financiación eficiente de las infraestructuras. Destacando también aspectos como la adopción de Sistemas integrados de gestión del transporte y de información que faciliten servicios inteligentes de movilidad, gestión del tráfico para un mejor uso de la infraestructura (Anexo l: 24), Desarrollo de un plan de inversión para nuevos servicios de navegación, vigilancia del tráfico y servicios de comunicación que permitan la integración de los flujos de información, sistemas de gestión y servicios de movilidad basados en un Plan Europeo de Información y Gestión Multimodal Integrada (Anexo l: 25), Estrategias de contratación pública que garanticen la rápida adopción de nuevas tecnologías (Anexo I: 26), La movilidad urbana integrada en una posible asociación para la innovación "Ciudades Inteligentes" (Anexo I: 31).

Retornando al aspecto económico, caben destacar sendos párrafos de la Directiva 2014/24/UE sobre contratación pública: "el contrato se concede al participante con la oferta más ventajosa económicamente, que se determinará en particular en función de la mejor relación calidad-precio. Este criterio tiene en cuenta factores como la relación coste-eficacia general, la calidad, los aspectos medioambientales y sociales, y las condiciones de comercio 
y de entrega" [4] y "La legislación introduce un nuevo procedimiento para impulsar el desarrollo de productos, servicios o trabajos innovadores. Para facilitar la participación de pequeñas empresas, las nuevas normas recomiendan a las autoridades públicas que dividan los contratos grandes en lotes individuales" [4].

Tras la revisión de los ejemplos anteriores muestran que en Europa se persigue la adopción definitiva de un enfoque eficiente de la Economía y por ende, de todas la ramas que de ella dependen.

El otro aspecto importante que ha favorecido el crecimiento de esta nueva metodología de trabajo ha sido el desarrollo tecnológico experimentado desde comienzos del siglo XXI, destacando el desarrollo de Tecnologías de la Información que pueden ser aplicadas al sector AECO como por ejemplo el Big Data, siendo esto "una nueva generación de tecnologías, arquitecturas y estrategias diseñadas para capturar y analizar grandes volúmenes de datos provenientes de múltiples fuentes heterogéneas a una alta velocidad con el objetivo de extraer valor económico de ellos" [5], la explosión del Internet of things (IoT) que es la generación de cualquier tipo de información por parte de cualquier dispositivo sensorizado, [6] y el crecimiento de la Nube que "es una nueva generación de infraestructuras de computación que proporciona soluciones de cómputo para la gestión, descubrimiento, acceso y procesamiento de los grandes volúmenes de datos para su conversión en conocimiento, y el consiguiente soporte a la toma de decisiones" [5],[7] permiten desarrollar, junto a las continuas mejoras que venimos experimentando en el ámbito de la Informática desde hace unas décadas, nuevos enfoques y aplicaciones de la técnica más potentes y eficientes que permiten, entre otras cosas, el trabajo colaborativo, buscando siempre la optimización del proceso de diseño del objeto de cada proyecto.

Estos condicionantes favorecen la adopción del BIM, ya que se trata de una "Metodología de trabajo colaborativa para la creación y gestión de un edificio o infraestructura a lo largo de todo el ciclo de vida, centralizando toda la información en un modelo digital creado por todos los agentes participantes" [8].

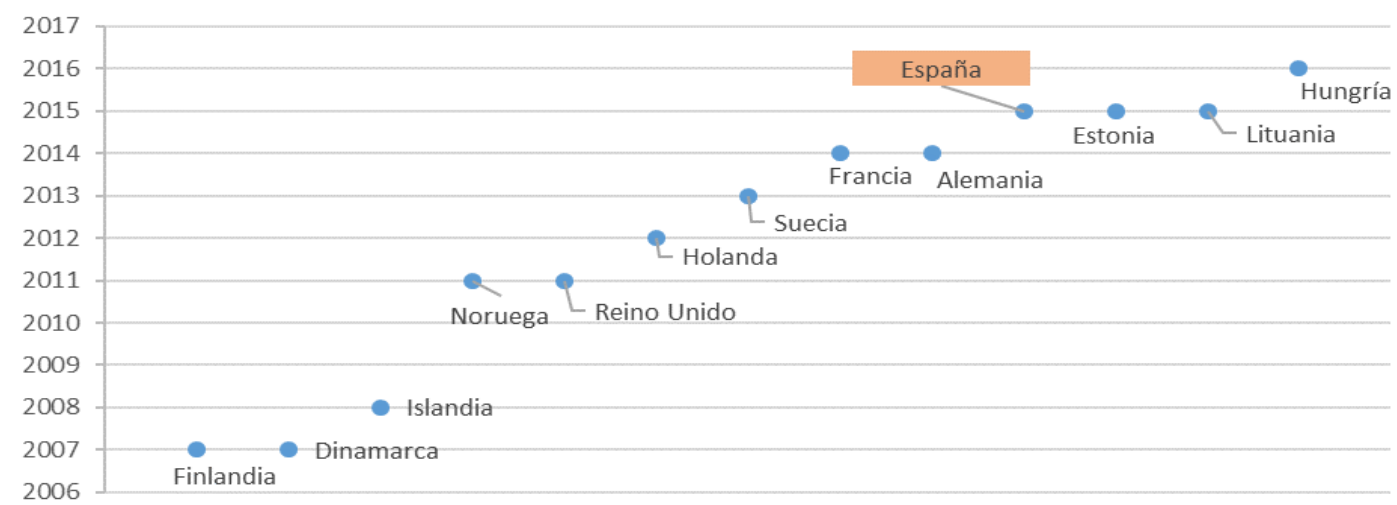

Figura 1: Interés estatal por el BIM en Europa. Elaboración propia según datos presentados por Jesús Silva, European BIM Summit. 2016 [9] 


\subsection{Principales encuestas}

Se expone en un breve análisis la situación del BIM en el mundo con el fin de comprender el grado de implantación de esta metodología. Para discernir la implantación del BIM se pueden presentar tres enfoques suplementarios entre sí, deducidos de la naturaleza de las siguientes encuestas a continuación enumeradas. El primer enfoque es generalista [10]. El segundo se centra en el usuario, en este caso británico, con intención de conocer sus percepciones, sus ideas sobre esta metodología y sobre el uso de los diferentes programas informáticos que emplea [1]. Y el tercero presenta un enfoque directo a la Ingeniería Civil, en este caso dentro de los Estados Unidos [12]. Dichas encuestas son:

- Business Value of BIM in Global Markets 2014 - McGraw Hill. [10]

- National BIM Survey, de Reino Unido, años 2012, 2013, 2014, 2015, 2016. Recopilación y análisis (Incluido dentro del Trabajo de Fin de Grado) [1]

- The Business Value of BIM for Infrastructure - McGraw Hill Construction. 2012 [11]

Partiendo del enfoque más generalista [10], se puede determinar que aquellas regiones que presentan una mayor vinculación con la metodología BIM son Estados Unidos, Reino Unido y Canadá. Según datos extraídos de la propia encuesta, las regiones con una metodología BIM más asentada fueron América del Norte, Japón y Corea del Sur. Es destacable también que el grado de vinculación con el BIM está estrechamente ligado al tamaño de la empresa ya que conforme aumenta el tamaño de ésta, la vinculación también lo replica. Es destacable que ya en 2013, para realizar uniones temporales de empleo, recomendaban que sus potenciales socios presentaran experiencia en BIM, superando el $30 \%$ de las empresas encuestadas. Enfocándose en la Ingeniería Civil, destaca que los países en donde más se empleó BIM para la realización de obras civiles fueron Reino Unido, Canadá, Australia y Nueva Zelanda. En lo referente al tipo de actividad para la cual empleaban BIM en 2013 destacaban la coordinación entre empresas (60\%) y la visualización del modelo (52\%).

Prestando atención a la experiencia del usuario [1], así como el conocimiento que posee como individuo, destacan interesantes aspectos tales como que la estimación del aplazamiento del uso de la metodología BIM se demora en el tiempo 5 años, en todas las encuestas desde su comienzo. Es sentir común de aquellos encuestados que la Industria todavía no está preparada para trabajar bajo los estándares BIM así como la necesidad de catálogos de objetos BIM emitidos por los diferentes fabricantes. Es muy destacable que la mayoría de los encuestados británicos tienen claro que BIM es sinónimo de colaboración y que si el modelo generado no aporta información, no puede ser tratado como modelo BIM. Otro aspecto a remarcar son las diferentes vías de obtención de conocimiento que presentan aquellos usuarios. Desde el comienzo de la NBS hasta el año 2016 la principal fuente de obtención de información son los contactos profesionales y los allegados más directos. 
Centrando la atención sobre la situación del BIM en la Ingeniería Civil en los Estados Unidos [11], es destacable que en 2012 sólo un $32 \%$ de los ingenieros civiles no estructuristas sí empleasen BIM frente a un 48\% que siendo estructuristas, sí lo usaban. En 2012 era relativamente novedoso el empleo de esta nueva metodología de trabajo en proyectos de infraestructuras, encontrándose por debajo de la media del tipo de proyectos de Ingeniería Civil. Diferenciando por ramas la Ingeniería Civil, aquella en la cual más se empleaba en 2012 esta nueva metodología es la rama de la Hidrología (Gestión de recursos hídricos) seguida de la de Transportes (Ferrocarriles, Carreteras, Aeropuertos, Logística y Puentes) y Urbanismo. Según los datos facilitados por esta encuesta, los beneficios aportados por esta metodología en proyectos de infraestructuras son la reducción de conflictos y cambios durante la construcción, mejora de la calidad general del proyecto, mejora en la estimación de beneficios y la mejora en la prefabricación de elementos complejos. Por otro lado, los lastres, en 2012, que afectarían al BIM en la Ingeniería Civil son la falta de eficiencia en proyectos pequeños, los altos costes y la falta de conocimiento y entrenamiento. Este documento también destaca que la demanda de BIM por parte de la Propiedad, el desarrollo de los diferentes programas informáticos específicos, la mejora de la interoperabilidad entre los mismos y una mayor definición del marco legal serían factores que mejorarían, o al menos, ayudarían a desarrollar el uso de esta metodología.

\section{METODOLOGÍA - SPANISH CIVIL ENGINEERING SURVEY 2016 (SCE) [1]}

Habiéndose detectado un interés en la metodología BIM por parte del sector AECO, a nivel general, y de la rama de la Ingeniería Civil, a nivel particular, así como el estudio en profundidad de las principales encuestas, se decidió realizar un estudio estadístico sobre el grado de implantación del BIM en la Ingeniería Civil española mediante la redacción y difusión de una encuesta inspirada en las siguientes: Business Value of BIM in Global Markets 2014 - McGraw Hill y National BIM Survey de Reino Unido, desde los años 2012 al 2016.

Dicha encuesta se ha centrado exclusivamente en los siguientes profesionales españoles: Ingeniero de Caminos, Canales y Puertos; Ingeniero Técnico de Obras Públicas; Graduado en Ingeniería Civil + Máster Habilitante; Graduado en Ingeniería Civil y Estudiantes de Grado en Ingeniería Civil.

Para ello se realizó una campaña de difusión que consistió en la publicación de la encuesta en la red profesional Linkedln. Dicha red social profesional otorga la posibilidad a sus usuarios de suscribirse a grupos de diversa naturaleza técnica y del conocimiento. De esta manera se optó por buscar los grupos que mejor representasen al público objetivo de esta encuesta para proceder a su difusión. También se procedió a su difusión entre los profesores del Departamento de Ingeniería Civil de la Universidad Europea de Madrid. Dichos grupos elegidos fueron los siguientes: 


\begin{tabular}{|c|c|c|}
\hline Origen del grupo & Nombre del grupo & $\begin{array}{c}\text { Integrantes del grupo (a 6 de } \\
\text { julio de 2016) }\end{array}$ \\
\hline $\begin{array}{c}\text { Red profesional de contactos: } \\
\text { Linkedln }\end{array}$ & $\begin{array}{c}\text { Agrupación Española de } \\
\text { Ingeniería Civil }\end{array}$ & 3.457 \\
\hline $\begin{array}{c}\text { Red profesional de contactos: } \\
\text { Linkedln }\end{array}$ & $\begin{array}{c}\text { Grupo de Ingenieros de } \\
\text { Caminos, Canales y Puertos }\end{array}$ & 25 \\
\hline $\begin{array}{c}\text { Universidad Europea de Madrid } \\
\text { Profesorado del Departamento } \\
\text { de Ingeniería Civil }\end{array}$ & Tamaño de población (N) & 9.485 \\
\hline
\end{tabular}

Tabla 1: tamaño de la población. Elaboración propia. 2016

\subsection{Definición de la encuesta}

El principal objetivo de la encuesta es determinar el nivel de implantación de esta nueva metodología de trabajo en España, por lo que se pretende, entre otras cosas, que el usuario ofrezca su punto de vista sobre dicha metodología, por esta razón se decidió incluir preguntas que permitiesen al encuestado ofrecer, de forma libre, su opinión sobre el tema.

En total se realizaron 25 preguntas. Con las preguntas iniciales de la encuesta se pretendió determinar tanto la edad del encuestado como su lugar de trabajo, así como la experiencia que posee en su campo de trabajo. Acto seguido, las siguientes preguntas buscaban encauzar la encuesta y profundizar conforme se desarrolla la misma hacia su tema principal, el uso de BIM en Ingeniería Civil.

En lo referente a los parámetros estadísticos óptimos, error del $5 \%$, confianza del $95 \%$ y desviación estándar del 0.5 , se determinó que el tamaño de la muestra mínima necesaria para alcanzar estos parámetros era de 370 encuestados.

\subsection{Resultados obtenidos}

El alcance de la encuesta fue muy reducido, 27 encuestados válidos (error del 16\%, confianza del $90 \%$ y desviación estándar del 0.5), alcanzando unos valores estadísticos muy por debajo de los óptimos, de modo que la información facilitada por ésta sólo debería ser empleada con carácter orientativo, no obstante, se pueden realizar ciertas conclusiones, aunque muy sesgadas.

El 26\% de los encuestados presentan una experiencia laboral dentro de la Ingeniería Civil menor o igual a 5 años, seguidos por aquellos que presentan una experiencia comprendida entre los 16 a 20 años (22\%). A su vez, cabe destacar que sólo el $30 \%$ de los encuestados declararon que sí usaban BIM y dentro de ese $30 \%$, el $62 \%$ declaró que lo empezaron a usar dentro de un plazo inferior a un año. 


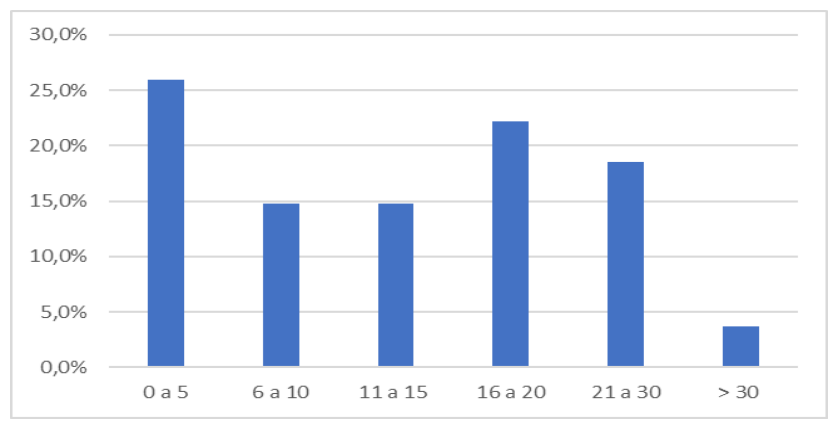

Figura 2: Años de experiencia de los encuestados en la Ingeniería Civil. Elaboración propia.

En lo referente al conocimiento sobre BIM el $45 \%$ de los encuestados declararon tener un ligero conocimiento sobre qué es BIM. Por otro lado, a pesar de que un alto porcentaje de encuestados declararon tener un conocimiento reducido al respecto, las principales ventajas que, según los encuestados, el BIM ofrece es el Control de diseño y dimensionamiento (25\%) y Mejora en el proceso de colaboración entre diferentes disciplinas (25\%). En lo referente a las razones que lastran el uso del BIM en la Ingeniería Civil destacó la falta de experiencia y habilidad (27.5\%) y alto coste de los diferentes programas informáticos (21\%).

Es destacable también que la mayoría de los encuestados (62\%) piensa que BIM se instaurará en 4 años o más. Hay que recordar que estos resultados representan al año 2016, esto quiere decir que esperan usarlo desde el año 2020 en adelante.

En lo referente al tipo de proyectos en los cuales empleaban metodología BIM, destaca que la mayoría no empleaba esta nueva metodología de trabajo colaborativo, no obstante, de la minoría que sí declararon su uso, destacan que lo emplearon en proyectos de Obra Lineal, Estructuras, Ingeniería del Transporte e Ingeniería del Terreno, es decir, lo han empleado, mayoritariamente, en proyectos de Infraestructuras (Carreteras, Ferrocarriles, Puertos y Aeropuertos).

En cuanto al uso de programas de dibujo y modelado, cálculo y planificación temporal de proyectos destacan mayoritariamente AutoCAD, AutoCAD Civil 3D, Excel y MS Project sobre programas que permiten y facilitan la operativa en metodología BIM, como pueden ser Revit para estructuras, ProjectWise para la gestión de la información y de los permisos de cada archivo o bien Navisworks para la supervisión global del proyecto.

\subsection{Comparativa encuesta SCE 2016 con la serie histórica de la encuesta británica NBS}

Como se mostró anteriormente, el análisis temporal de la serie histórica de las encuestas NBS británica respondió a la intención de detectar patrones de comportamiento entre los usuarios británicos extrapolables a los españoles, siempre teniendo presente que la información facilitada por la encuesta SCE 2016 es orientativa. No obstante, se muestran posibles similitudes que futuras encuestas de la SCE podrían llegar a confirmar. 


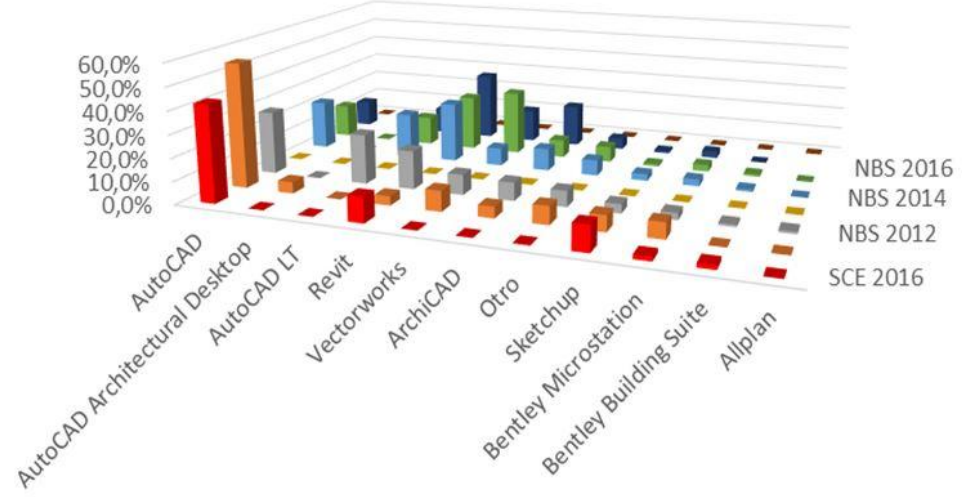

Figura 3. Comparativa software más usados. Elaboración propia. 2016

A pesar de contar con un número reducido de respuestas en la encuesta SCE 2016 comienzan a mostrarse patrones, que deberán ser confirmados por estudios futuros, que indican cierto grado de relación entre los diferentes programas empleados por los usuarios británicos y los españoles. Así pues, destaca el uso en ambos mercados, de programas de la familia Autodesk. En lo referente a los beneficios que presenta esta metodología, sendos grupos de usuarios comparten una misma percepción: BIM mejora la coordinación y aumenta la productividad.

Al comparar las expectativas de uso presentadas en el análisis de la serie histórica de las encuestas británicas de la NBS con la encuesta propia SCE 2016, a pesar de presentar esta última un reducido número de resultados válidos comienza a trazarse cierta tendencia en España similar a la mostrada en Reino Unido, es necesario recordar que dicha tendencia deberá ser sustentada sobre nuevos datos facilitados por estudios futuros.

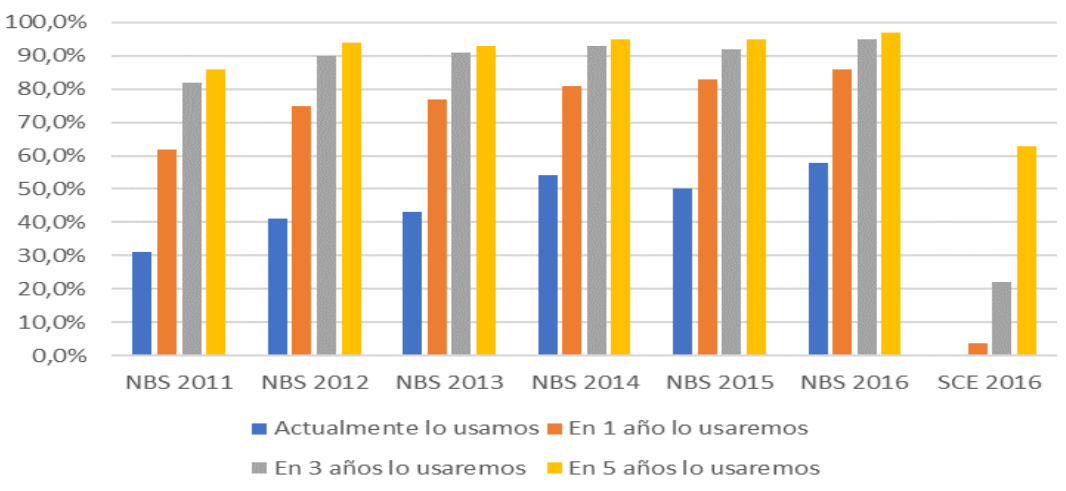

Figura 4. Comparativa expectativas de uso. Elaboración propia. 2016

El hecho de que la opción más popular entre los encuestados por la SCE 2016 ha sido aquella que retrasa su uso hasta dentro de 5 años, permite pensar, que no afirmar, que las expectativas de uso podrían ser similares a las presentadas en Reino Unido. 


\subsection{Comparativa encuesta SCE 2016 con Business Value of BIM for Infrastructure, McGraw Hill}

Recordando las limitaciones a tener en cuenta con la SCE 2016, se comparó el comportamiento en relación al BIM entre usuarios de países semejantes, se procedió a realizar una comparativa más enfocada al sector en estudio, la Ingeniería Civil.

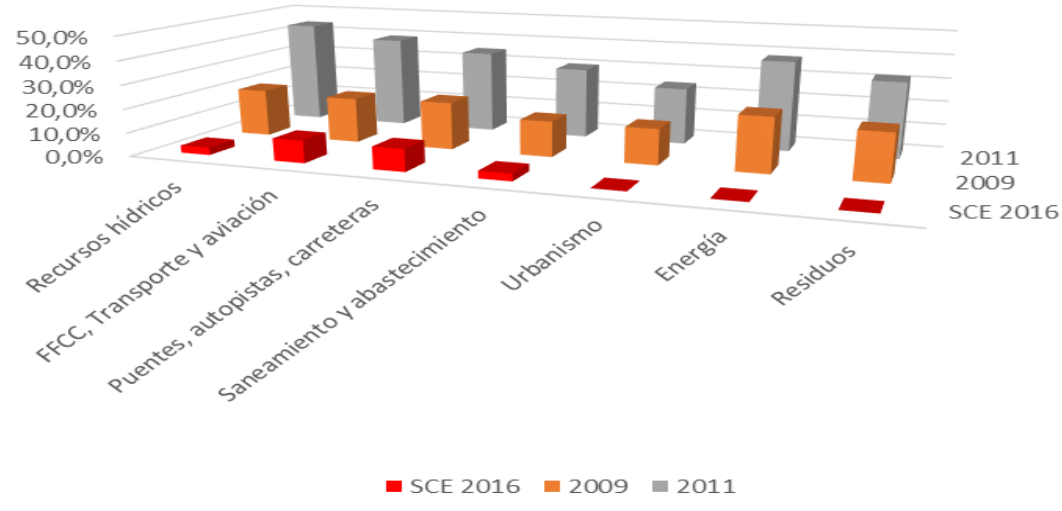

Figura 5. Usos de BIM en diferentes ramas de la profesión. Elaboración propia. 2016

Es destacable el uso por parte de los estadounidenses del BIM para temas energéticos, así como para la gestión de residuos. Por otro lado, no hay que perder de vista que el BIM puede ser empleado también en áreas como el Urbanismo o la gestión de los recursos hídricos de un país, como así lo atestiguan los datos facilitados por las encuestas estadounidenses de los años 2009 y 2011. En lo referente a la comparación entre la percepción de las ventajas e inconvenientes que presentan ambos mercados, cabe mencionar que el mercado americano, debido a que la implantación del BIM está mucho más avanzada que en España, sí identifica ciertas ventajas que actualmente los encuestados en la SCE 2016 no entienden como tal. Estas son el ahorro de tiempo y el ahorro económico. Por otro lado, los encuestados en la SCE 2016 identifican que, de forma similar a los estadounidenses, BIM ofrece ventajas en el control sobre el diseño $y$ dimensionado, así como en la mejora en el proceso de colaboración entre diferentes disciplinas.

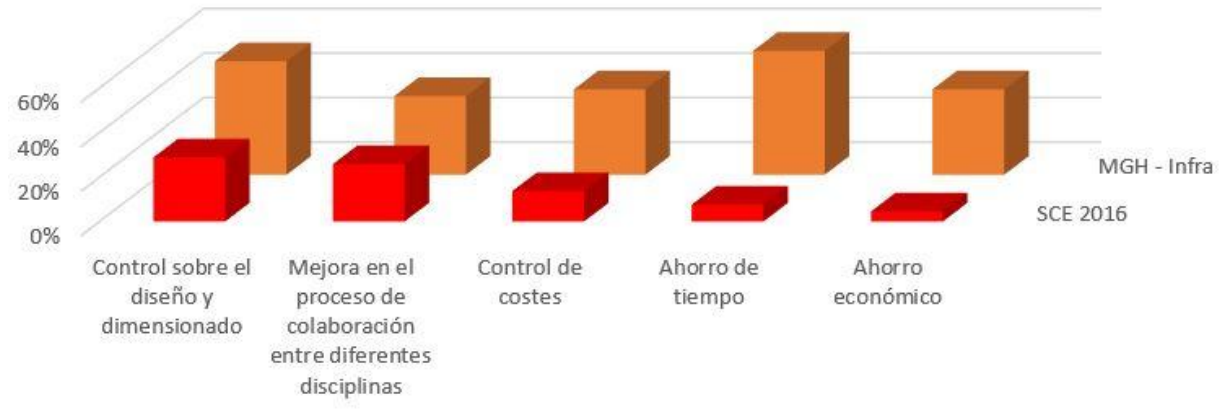

Figura 6. Percepción de ventajas del BIM en la Ingeniería Civil. Elaboración propia. 2016 
En cuanto a los inconvenientes percibidos por los diferentes usuarios analizados por la encuesta de McGraw Hill y la SCE 2016, cabe mencionar que, teniendo presente el condicionante ligado a la SCE 2016, la percepción de los inconvenientes es similar en sendos casos.

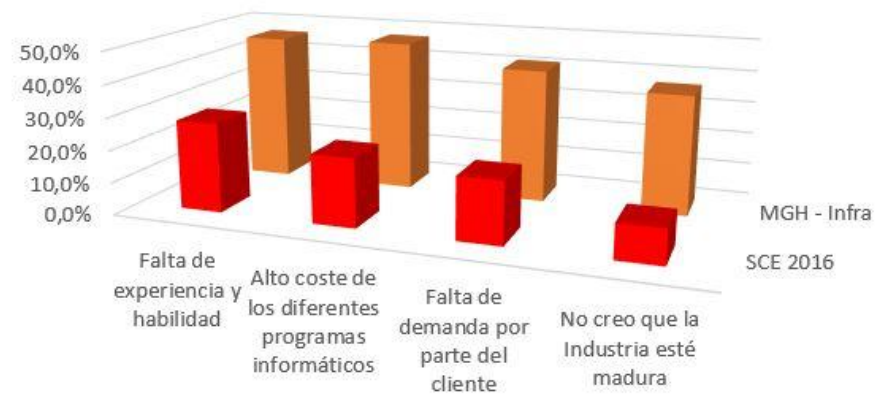

Figura 7. Percepción de los inconvenientes del BIM en la Ingeniería Civil. Elaboración propia. 2016

\section{CONCLUSIONES}

Habiendo analizando los diferentes usos del BIM, así como las principales preferencias y patrones de comportamiento que presentan las principales encuestas [10],[11] así como de la serie histórica de la NBS británica [1] se puede estimar que el Nivel BIM que presenta la Ingeniería Civil española es menor al mostrado por dichas encuestas. De este modo, el nivel mostrado por los encuestados españoles, que no el nivel general de los ingenieros españoles, responde a un NIVEL 1. Esto está estrechamente ligado con el amplio uso de programas CAD (AutoCAD) y un comienzo en la generación de modelos 3D básicos mediante programas Revit y SketchUp.

Se reafirman en la mayoría de las encuestas, tanto en la SCE 2016 como en las internacionales una similitud en la percepción de las fortalezas del BIM: mejora en la coordinación y control de costes. Y en las debilidades que lastran su implantación: falta de abastecimiento de objetos BIM, falta de destreza y conocimientos sobre BIM y alto coste de los programas.

En lo referente a la falta de abastecimiento de objetos BIM por parte de los fabricantes, se puede subsanar mediante la inclusión de las Universidades a este proceso de implementación ya que en ellas se pueden desarrollar proyectos internos con el objetivo principal de generar objetos BIM que abastezcan a la Industria e indirectamente se estaría reduciendo otro lastre del BIM, la falta de destreza, pues los mismos estudiantes que generan dichos objetos, que serán los futuros ingenieros, ya habrán adquirido habilidades BIM.

Este hecho sitúa a la Ingeniería Civil española en el punto de partida para adoptar y desarrollar esta nueva metodología de trabajo colaborativo, por tanto, se puede afirmar que el BIM tiene un largo recorrido dentro de este sector, presentando de esta forma numerosas 
oportunidades de investigación así como de negocio, debido entre otras cosas, a la necesidad de abastecimiento de bibliotecas BIM así como de entrenamiento a los diferentes profesionales del sector.

Por estas razones, al no ser España una nación pionera en BIM le otorga la posibilidad de aprender de los éxitos y errores cometidos por países en los cuales el grado de implantación del BIM se encuentra más desarrollado, con el fin de poder adoptar esta metodología de una forma lo más óptima y eficiente posible.

\section{REFERENCIAS}

[1] Lucio Iglesias D. (2016). Estudio sobre el grado de implantación del BIM en la Obra Civil en España y propuesta de flujo de trabajo para su implementación, Trabajo de Fin de Grado: UEM.

[2] Consejo de la Unión Europea. (2012). Tratado de Estabilidad, Coordinación y Gobernanza en la Unión Económica y Monetaria. Documento legislativo: Unión Europa http://www.consilium.europa.eu/es/home/

[3] Comisión Europea - Dirección General de Movilidad y Transportes (2011). Libro Blanco del Transporte. Hoja de ruta: Unión Europea.

https://www.google.es/url?sa=t\&rct=j\&q=\&esrc=s\&source=web\&cd=1\&cad=rja\&uact=8\&v ed=0ahUKEwiGlaPfh bNAhWG2BoKHUVHCl4QFggcMAA\&url=http\%3A\%2F\%2Fec.eur opa.eu $\% 2$ Ftransport $\% 2$ Fthemes $\% 2 F$ strategies $\% 2 F d o c \% 2 F 2011$ white paper $\% 2 F$ white-

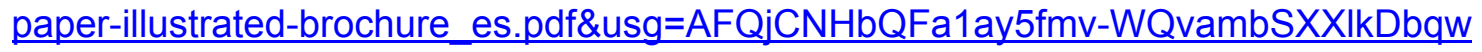

[4] Parlamento Europeo y Consejo Europeo (2014). Directiva 2014/24/UE. Directiva europea: Unión Europea.

http://eur-lex.europa.eu/legal-content/ES/TXT/?uri=celex\%3A32014L0024

[5] Joyanes Aguilar L. (2014). Análisis de grandes volúmenes de datos en organizaciones. vol. 1, no. 1, 3.

[6] Ahston K. (2009). That "Internet of things" Thing. Artículo: RFID Journal. http://www.rfidjournal.com/articles/pdf?4986

[7] Dodson S. (2003). The Internet of things. Artículo: The Guardian. https://www.theguardian.com/technology/2003/oct/09/shopping.newmedia

[8] Muñoz S. Introducción al BIM. BuildingSmart. Conferencia: es-BIM. http://www.esbim.es/wp-content/uploads/2016/06/esBIM-Sergio-Munoz-BuildingSmartIntroduccion-al-BIM.pdf 
[9] Silva J. (2016). La estrategia nacional: es.BIM. Ponencia: BIM European Summit.http://www.apabcn.cat/documentacio/comunicacio/bim/book 2016 1.pdf

[10] McGraw Hill Construction Research \& Analytics/Industry Insights \& Alliances. (2014). The Business Value of BIM for Construction in Major Global Markets: How contractors around the world are driving innovation with Building Information Modeling. SmartMarket Report.

[11] McGraw Hill Construction Research \& Analytics/Industry Insights \& Alliances. (2012). The Business Value of BIM for Infrastructure: Addressing Americas's Infrastructure Challenges with Collaboration and Technology. SmartMarket Report. 



\section{EUBIM 2017}

Congreso Internacional BIM / $6^{\circ}$ Encuentro de Usuarios BIM

BIM International Conference

EUBIM

Escuela Técnica Superior de Ingeniería de Edificación

Universitat Politècnica de València

Valencia, 19 y 20 de mayo 2017

\section{DISEÑO Y CONSTRUCCIÓN CON BIM}





\title{
UTILIZACIÓN DEL ALMACENAMIENTO EXTENSIBLE DE AUTODESK@ REVITTM PARA
} ALMACENAR Y CONSULTAR DOCUMENTACIÓN NO GRÁFICA EN OBJETOS BIM

\author{
Abellán Alemán, José María
}

jm.abellan@BiMMate.com

\section{RESUMEN}

Suele convenirse que la clave del BIM está en la 'l' de información, aunque no suele haber consenso sobre qué información (y en qué momento) debe ser incorporada a los modelos. La tecnología BIM ha abierto un inmenso campo de investigación para la arquitectura y la ingeniería, brindando oportunidades para mejorar los flujos de trabajo existentes desde la concepción y desarrollo de los proyectos AEC hasta su ejecución y gestión a lo largo de su ciclo de vida.

Uno de esos campos de investigación es la información que los modelos deben incorporar. Recientes ponencias de los grupos de trabajo de la comisión es.BIM así lo afirman, siendo loable el esfuerzo realizado para sistematizar el contenido de los modelos (proyectos y objetos o sistemas constructivos). Uno de los puntos débiles de la información es aquella que es útil sólo para el proyectista durante la fase de modelado y prescripción, como por ejemplo la consulta de normativa aplicable, documentos de idoneidad técnica, manuales de usuario o declaraciones ambientales de producto, por ejemplo.

En esta ponencia se desarrollará un método para integrar dicha información no gráfica en el modelo sin aumentar su tamaño o repercutir negativamente en el rendimiento de la aplicación.

Palabras clave: DAP, DIT, información, manual, normativa.

\section{SUMMARY}

It is normally assumed that the key element in BIM is the 'l' of information, though there is normally no agreement about the type of information (and at what point) it should be added to the models. BIM technology has opened up a great field for investigation in architecture and technology, giving thus the opportunity to improve the work flows from the initiation and development of the AEC projects up to its realisation and management all through the life of the project.

The information that models should include is one of this fields of investigation, at least that is what the latest reports from BIM work groups state, in fact, it is praiseworthy the effort they have made to systematize the content of the models (projects and objects or structural systems). One of the weak points of information is the information that it is only useful for the project designer during the modelling and prescription phase, such as the applying 
regulations, the technical suitability documents, user manuals or environmental product declarations.

In this presentation, we will develop a method to incorporate the said non-graphical information together with the model, without broadening its size or reducing its performance.

Keywords: DIT, information, manual, PED, regulation.

\section{$1 \quad$ INTRODUCCIÓN}

BiMMate es una plataforma BIM integrada por arquitectos, aparejadores e ingenieros españoles que supera los 1200 miembros registrados. Entre los asociados de BiMMate se encuentran los COA de Murcia, Aragón, Córdoba, Huelva, Asturias y Castilla y León Este.

BiMMate es un proyecto de investigación que abarca:

- Desarrollo de soluciones constructivas y objetos para integrar en proyectos AEC, adaptados a normativa española.

- $\quad$ Desarrollo de flujos de trabajo alternativos para la optimización de recursos.

- Desarrollo de aplicaciones para automatización de procesos y superación de limitaciones de software en entornos colaborativos.

- Desarrollo de aplicaciones para integrar información no gráfica en modelos BIM (Mediciones automáticas, Pliegos de Condiciones, DITE, Manuales, DAP...)

Desarrollo de aplicaciones para la comunicación del modelo BIM con plataformas y sistemas gubernamentales (Catastro, PNOA, HULC, etc.)

Hemos estado presentes en charlas en los COA de Valencia, Castellón, Murcia, Granada, Córdoba, Aragón, Asturias, Guipúzcoa, Navarra, Segovia, Ávila, Valladolid y Burgos, el COAATIE de Murcia, la ETSIE de la UPV/EHU y la de la UPC. Los desarrolladores de BiMMate somos los formadores BIM de los Colegios de Arquitectos de Valencia, Castellón, Murcia, Granada, Huelva y Guipúzcoa entre otros.

\section{CONTENIDO}

Uno de los principales retos a que nos enfrentamos en BiMMate a la hora de modelar objetos para Autodesk@ Revit ${ }^{\mathrm{TM}}$ que vayan a ser utilizados en entornos BIM profesionales, es la demanda de información de los proyectistas. No se trata de añadir información indiscriminada que no resulta útil en términos de definición constructiva, sino de añadir la exacta información que ayude a determinar las prestaciones de un sistema constructivo y que permita controlar el comportamiento paramétrico de los objetos de la manera más conveniente, y, obviamente, reproduciendo el comportamiento del objeto real. 
Este punto de partida debería ser concurrente en todos los profesionales que nos dedicamos al modelado de objetos y sistemas constructivos, aunque desafortunadamente no suele serlo. Pero, además, los proyectistas necesitamos consultar una gran cantidad de información no gráfica sobre un determinado objeto o sistema en el momento de su prescripción en un proyecto, la cual no suele estar incrustada en el mismo (y tampoco debe estarlo). Nos referimos, por ejemplo, a la documentación técnica del elemento, al documento de idoneidad técnica del sistema, a un manual de usuario sobre la utilización del contenido, a la declaración ambiental de producto o, simplemente, a la normativa que es de aplicación al mismo.

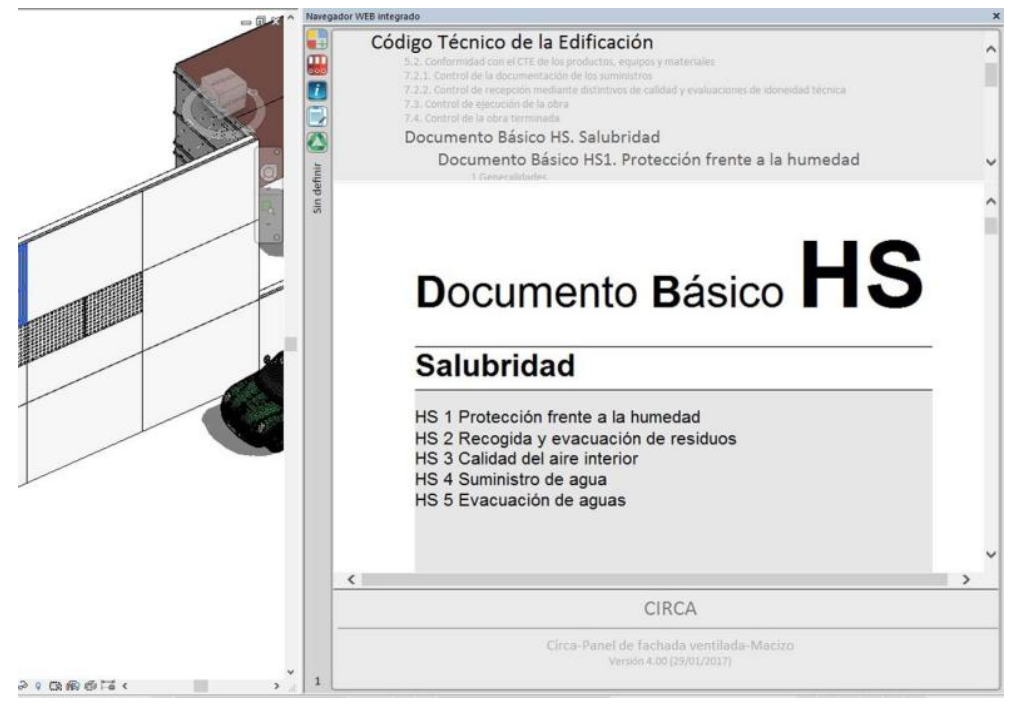

Figura 2. Paleta acoplable del navegador web. Año 2017. Fuente BiMMate

Ese es el punto de partida de la presente comunicación: desarrollar un sistema de integración de datos no gráficos en objetos o sistemas BIM accesibles al proyectista, de manera instantánea, desde el mismo software de modelado (Revit ${ }^{\mathrm{TM}}$ de Autodesk@), pero sin que suponga un incremento del tamaño del modelo o reduzca el rendimiento de la aplicación.

\subsection{Sobre la problemática a resolver}

De manera nativa Revit ${ }^{\mathrm{TM}}$ dispone de parámetros en los elementos en los que puede almacenarse información. Todos los elementos de Revit, sean familias del sistema o componentes, disponen de un parámetro de tipo denominado URL [1] (Uniform Resource Locator) en el que puede colocarse un hipervínculo, de modo que, cuando el usuario accede a estas propiedades, puede, pulsando sobre este campo, abrir una nueva instancia del navegador web por defecto del sistema operativo con la página almacenada en dicho campo. El funcionamiento es simple, aunque no inmediato, por lo que no es operativo a la hora de consultar información de manera instantánea. 
En realidad, son dos los problemas a resolver:

- Cómo almacenar en cada elemento del modelo la información que se debe mostrar.

- Cómo mostrar información no gráfica de los objetos en el mismo entorno de modelado de manera rápida y eficaz.

\subsection{Sobre el almacenamiento de la información}

Se ha comentado que los elementos del modelo en Revit ${ }^{\mathrm{TM}}$ disponen de parámetros [2] para almacenar la información. Los parámetros pueden utilizarse para controlar la representación gráfica del elemento o para almacenar información que luego pueda utilizarse en tablas o etiquetas. Desafortunadamente, no pueden almacenarse en dichos parámetros documentos complejos como PDF o HTML. Tampoco sería apropiado, por otro lado, hacerlo así, pues incrementaría notablemente el tamaño del proyecto. La normativa de aplicación, los documentos de idoneidad técnica (DIT), los manuales de usuario o las declaraciones ambientales de producto, son ejemplos de documentos que es necesario consultar durante las labores de modelado, pero que, por su tamaño y complejidad, no pueden ser almacenados en dichos parámetros.

Y afortunadamente Autodesk@ resolvió el problema añadiendo en la versión 2012 de Revit ${ }^{\mathrm{TM}}$ el almacenamiento extensible [3] (extensible storage). Esencialmente se trata de almacenar datos de casi cualquier tipo [4] en una entidad de datos basada en esquema que se 'cuelga' de algún elemento del modelo, en el caso que nos ocupa, de la propia familia.

En BiMMate hemos decidido, en una primera fase, incorporar a los objetos y sistemas constructivos los siguientes datos/documentos:

- La documentación técnica del objeto o sistema, y, si existe, el Documento de Idoneidad Técnica o su equivalente.

- Un manual de usuario que explique el funcionamiento del objeto en un proyecto BIM.

- La normativa que es de aplicación al objeto o sistema constructivo.

- La Declaración Ambiental de Producto.

En el futuro inmediato añadiremos los conceptos descompuestos o partidas de medición que son de aplicación al elemento, y el pliego de condiciones técnicas particulares asociado al mismo. Decidido el contenido no gráfico que queremos incrustar en los objetos, la siguiente pregunta es cómo:

- Se podría convertir cada documento en una matriz de bytes y almacenarlo en formato binario en un campo de análogo tipo de una entidad de datos. Este camino es sencillo, pero conlleva un alto coste en términos de espacio en disco (algunos documentos PDF pueden alcanzar los $80 \mathrm{Mb}$ ) y de procesamiento (cargar de nuevo en memoria grandes cantidades de datos es una tarea larga). Es preferible utilizar lo que en lenguaje C\# se 
denomina programación asíncrona [5], de modo que el hilo de procesamiento actual no se interrumpa por esta causa.

- Se puede utilizar los hipervínculos para almacenar las URL donde se encuentran dichos documentos. En previsión de ampliar la cantidad de documentos relacionados en el futuro inmediato, $y$, dado que una entidad de datos basada en un esquema no puede coexistir en Revit ${ }^{\mathrm{TM}}$ si existe cargado previamente una versión distinta de dicho esquema, lo mejor es optar por almacenar todas las URL en un único campo codificado en formato XML [6] (eXtensible Markup Language). Este método requiere el despliegue de un servidor DHCP ${ }^{[7]}$ (Dynamic Host Configuration Protocol) donde ir almacenando los documentos.

El siguiente proceso muestra cómo crear una entidad de datos basada en un esquema y asociarla a una familia. El primer paso es crear el esquema de datos, que en C\# podría hacerse con el siguiente método:

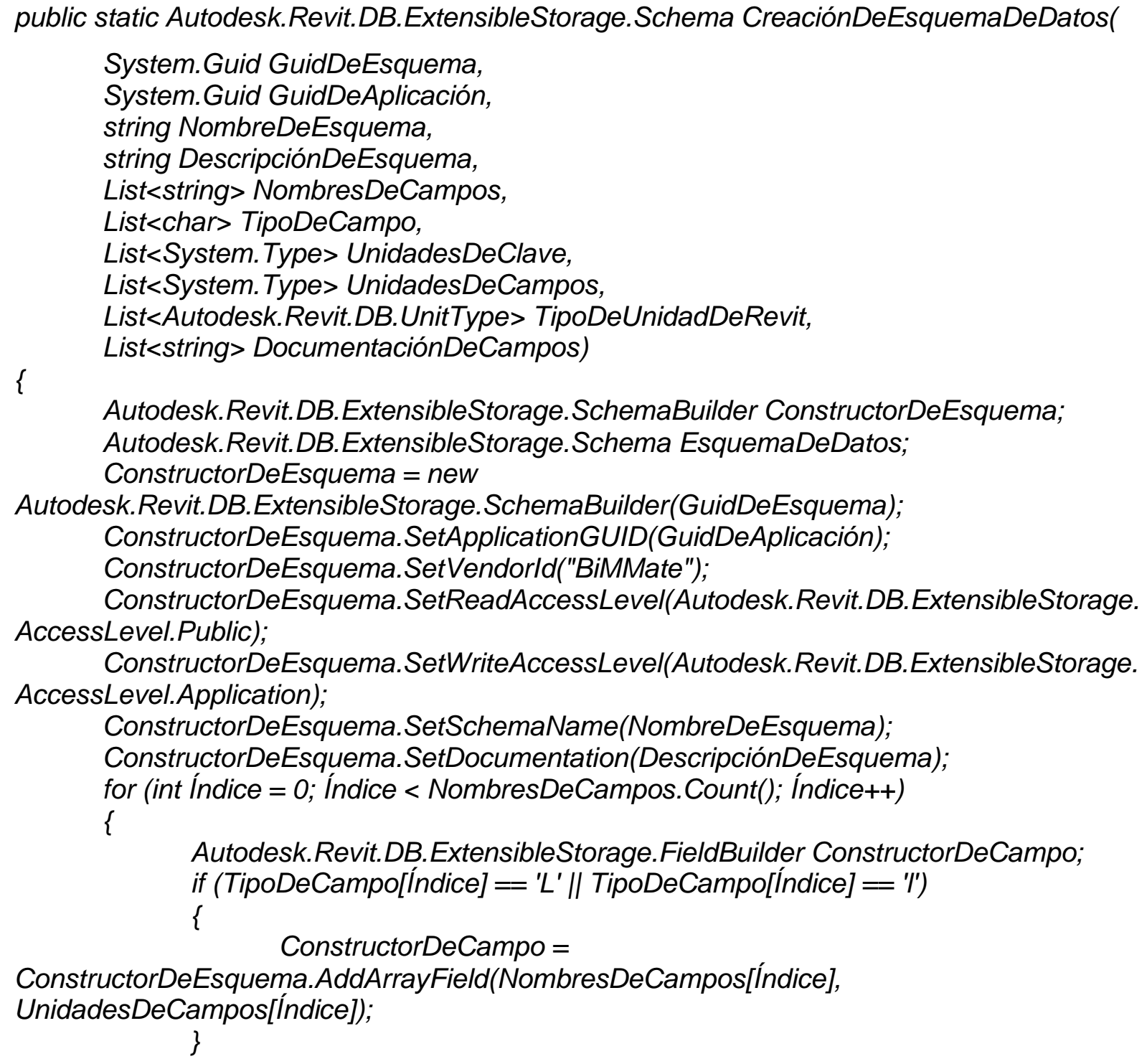

Autodesk.Revit.DB.ExtensibleStorage.SchemaBuilder ConstructorDeEsquema;

Autodesk.Revit.DB.ExtensibleStorage.Schema EsquemaDeDatos;

ConstructorDeEsquema = new

Autodesk.Revit.DB.ExtensibleStorage.SchemaBuilder(GuidDeEsquema);

ConstructorDeEsquema.SetApplicationGUID(GuidDeAplicación);

ConstructorDeEsquema.SetVendorld("BiMMate");

ConstructorDeEsquema.SetReadAccessLevel(Autodesk.Revit.DB.ExtensibleStorage. AccessLevel.Public);

ConstructorDeEsquema.SetWriteAccessLevel(Autodesk.Revit.DB.ExtensibleStorage.

AccessLevel.Application);

ConstructorDeEsquema.SetSchemaName(NombreDeEsquema);

ConstructorDeEsquema.SetDocumentation(DescripciónDeEsquema); for (int Índice = 0; Índice < NombresDeCampos. Count(); Índice++)

\{

Autodesk.Revit.DB.ExtensibleStorage.FieldBuilder ConstructorDeCampo; if (TipoDeCampo[Índice] == 'L' // TipoDeCampo[Índice] == 'I') \{

ConstructorDeCampo =

ConstructorDeEsquema.AddArrayField(NombresDeCampos[Índice],

UnidadesDeCampos[Índice]); 


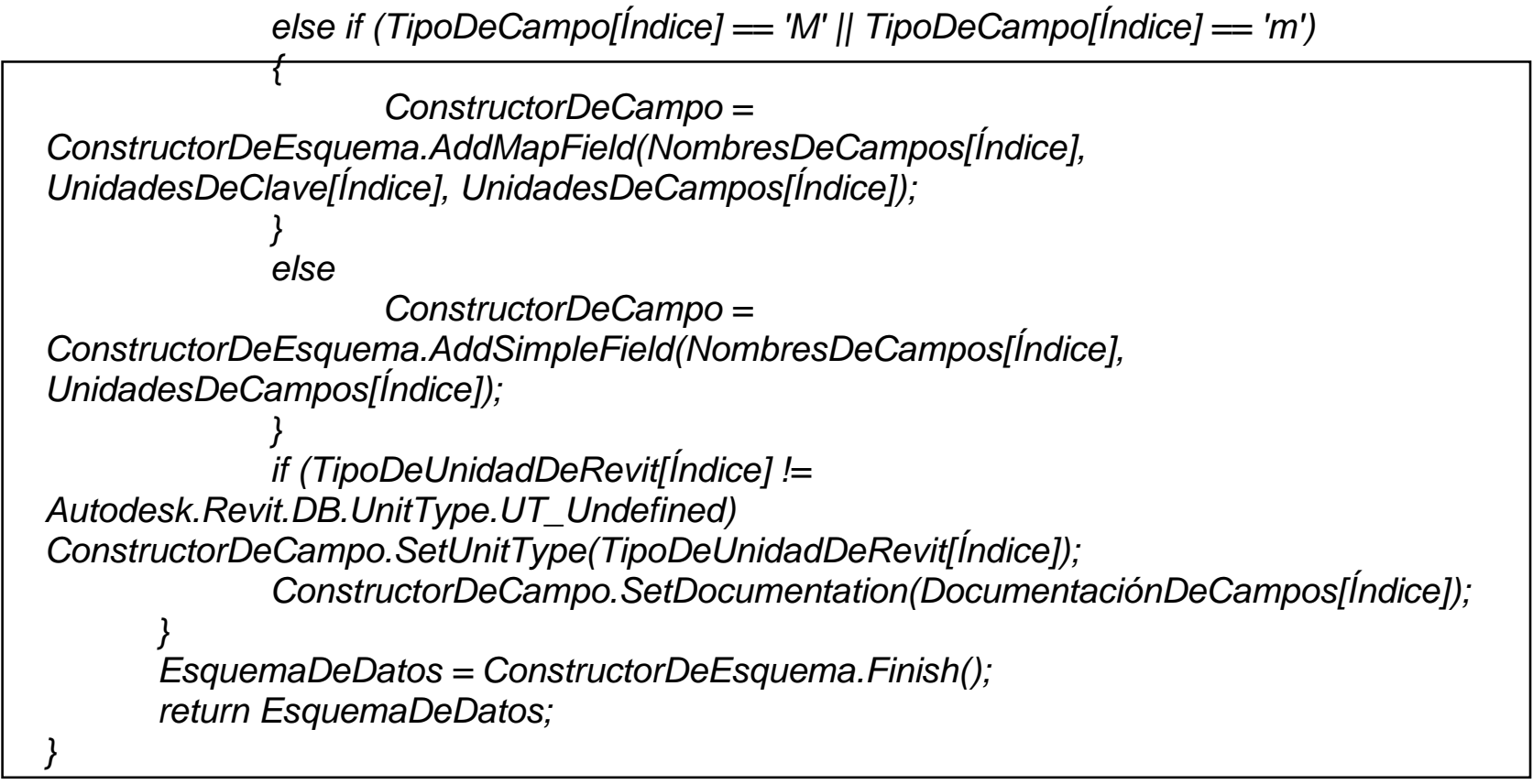

Basta llamar al método anterior para obtener un esquema de datos con los campos suministrados, por ejemplo:

CreaciónDeEsquemaDeDatos(

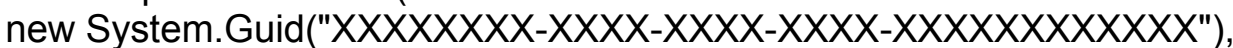

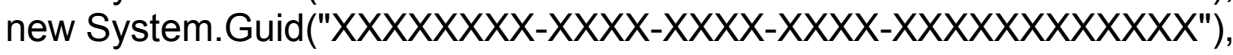

"EsquemaDeDatosDeTiposDeFamilia",

"Datos generales de BiMMate asociados a los tipos de familia", new List<string> $\{$ "CódigosDeConceptosDescompuestos" $\}$,

new List $<$ char $>\{$ 'L'\},

new List $<$ System.Type $>$ \{null $\}$,

new List $<$ System.Type $>\{$ typeof(string)\},

new List<Autodesk. Revit.DB.UnitType> \{

Autodesk.Revit.DB.UnitType.UT_Undefined\},

de familia."\});

new List<string> $>$ "Lista de códigos de conceptos descompuestos asociados al tipo

Ahora que tenemos creado un esquema de datos podemos crear una nueva entidad de datos basada en dicho esquema, siendo 'EsquemaDeDatosDeFamilia' el esquema creado con la llamada al método anterior:

Autodesk.Revit.DB.ExtensibleStorage.Entity EntidadBasadaEnEsquemaDeDatosBiMMate = new Autodesk.Revit.DB.ExtensibleStorage.Entity(EsquemaDeDatosDeFamilia);

Tras el proceso de creación de la nueva entidad de datos se puede proceder a asignarle valores a los campos que se hubieran definido. En nuestro caso tenemos un campo denominado 'URLsParaEINavegadorWEB' que es de tipo 'string' al que asignaremos el valor de las URL:

EntidadBasadaEnEsquemaDeDatosBiMMate.Set<string>("URLsParaEINavegadorWEB", URLsParaEINavegadorWEB); 
En el ejemplo anterior el segundo campo es la variable que contiene la información que queremos incrustar en el campo, de tipo cadena.

Como se ha citado anteriormente, queremos que la solución sea escalable, por lo que no es razonable almacenar cada URL en un campo como inicialmente pudiera parecer lógico. Esto es así porque si se define una entidad de datos basada en un esquema con una serie de campos, $y$, más adelante, se modifica ese esquema para añadir más campos (por ejemplo, el pliego de condiciones técnicas particulares), en un proyecto donde coexistiesen familias con ambas entidades, irremisiblemente una de las entidades se perdería. En BiMMate hemos optado, como ya se citó, por almacenar todas las URL en un único campo, pero serializado en formato XML para que pueda contener cuantas cadenas URL nos hagan falta en el futuro [8].

\subsection{Sobre el acceso a la información}

Ahora que tenemos resuelto el problema de incrustar datos o documentos no gráficos en los elementos del modelo a través de sus URL (los documentos finales en formato PDF residen en un servidor DHCP), el problema es acceder a dicha información y visualizarla rápidamente sin que haya interferencia en el proceso de modelado. Existirían dos soluciones para conseguirlo:

- Crear un nuevo formulario no modal [9] que pueda colocarse flotante en el escritorio o en un segundo monitor.

- Crear una nueva paleta acoplable [10] en Revit ${ }^{\mathrm{TM}}$.

En BiMMate hemos optado por la segunda vía, ya que permite una integración más natural con Revit ${ }^{\mathrm{TM}}$. Los pasos necesarios para dicho procedimiento serían los siguientes:

1. Crear un nuevo formulario del tipo WPF [11] (Windows Presentation Foundation). Los formularios tradicionales no son aptos para esta funcionalidad de Revit ${ }^{\mathrm{TM}}$.

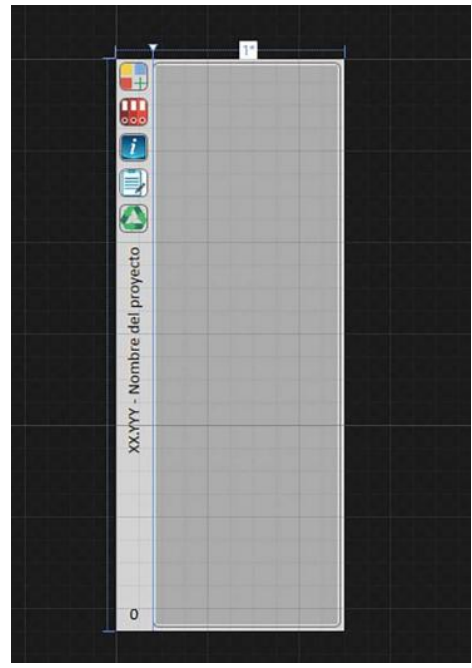

Figura 2. Formulario WPF diseñado en VS2015. Año 2017. Fuente BiMMate 
El formulario debe contener un navegador web para poder mostrar el contenido de las diferentes URL. El siguiente fragmento de código XAML [12] (eXtensible Application Markup Language) lo hace:

<Border Grid.Column="1" BorderThickness="1" CornerRadius="5" Margin="0,3,3,3" orderBrush="\{DynamicResource $\{x:$ Static SystemColors.GrayTextBrushKey\}\}" RenderTransformOrigin="0.5,0.5">

<Grid x:Name="MarcoDeVentanaDelNavegadorWEB" x:FieldModifier="public"> $<$ WebBrowser x:Name="VentanaDelNavegadorWEB" x:FieldModifier="public" ScrollViewer.HorizontalScrollBarVisibility="Auto" ScrollViewer.VerticalScrollBarVisibility="Auto" Margin="2"

$</$ Grid $>$ ScrollViewer.CanContentScroll="True"/>

$</$ Border $>$

2. Registrar la paleta acoplable en la aplicación en modo 'Zero State Document', lo que equivale a ejecutar el siguiente código dentro de una aplicación, no de un comando externo:

_AplicaciónControladaPorLalnterfazDeUsuario.RegisterDockablePane(

IDDeLaPaletaAcoplableDelNavegador,

"Navegador WEB integrado", InstanciaDePaletaAcoplableDelNavegadorWEB as IDockablePaneProvider);

En el ejemplo anterior '_AplicaciónControladaPorLalnterfazDeUsuario' es la copia en caché de la 'UIApp' de Revit ${ }^{\mathrm{TM}}$ e '_InstanciaDePaletaAcoplableDeINavegadorWEB' es una nueva instancia del formulario WPF mencionado.

3. Suscribirse a los eventos ${ }^{[13]}$ de activación de vista y de disponibilidad de la aplicación. El primero es necesario porque con cada activación de vista puede cambiarse de documento (proyecto). El segundo porque hay que detectar cuándo hay una modificación de la selección y la API (Application Programming Interface) de Revit ${ }^{\mathrm{TM}}$ no dispone todavía de un evento específico para tal fin. El siguiente fragmento de código ilustra lo expuesto:

NavegadorWEBIntegrado._AplicaciónControladaPorLaInterfazDeUsuario.Idling $+=$ new System. EventHandler<Autodesk.Revit.UI.Events.IdlingEventArgs>(NavegadorWEBIntegr ado.ActualizaciónDeDatosDeLaPaletaAcoplableDependientesDeLaSelección);

NavegadorWEBIntegrado._AplicaciónControladaPorLalnterfazDeUsuario. ViewActivated $+=$ new

System. EventHandler<Autodesk.Revit.UI.Events. ViewActivatedEventArgs $>$ (NavegadorW EBIntegrado.ActualizaciónDeDatosDeLaPaletaAcoplableDependientesDeLaVista);

Los comandos anteriores los métodos

'ActualizaciónDeDatosDeLaPaletaAcoplableDependientesDeLaSelección' y 'ActualizaciónDeDatosDeLaPaletaAcoplableDependientesDeLaVista' a los eventos correspondientes de la aplicación de la interfaz de usuario.

4. Definir los métodos anteriores. En el caso del método de disponibilidad de la aplicación debe tenerse en cuenta lo siguiente: 
- El evento de 'idling' se ejecuta con mucha frecuencia, por lo que el método que se suscriba a él debe ser lo más rápido posible.

- Para el elemento seleccionado debe obtenerse la entidad de datos basada en el esquema que se creó al principio con:

ElementoAMostrar.GetEntity(EsquemaDeDatosDeVersión).Get<string >("URLsPa raEINavegadorWEB");

Siendo 'ElementoAMostrar' el elemento de la selección actual, 'EsquemaDeDatosDeVersión' el esquema de los datos mencionado y 'URLsParaEINavegadorWEB' el nombre del campo de la entidad de datos donde están almacenadas las URLs.

- Como se procedió a serializar en XML el contenido del campo, debe procederse ahora a deserializar la misma cadena.

System.Xml.Serialization.Xm/Serializer SerializadorXML $=$ new System.XmI.Serialization.Xm/Serializer(typeof(string[]));

System.XmI.XmIReader LectorXML = System.XmI.XmIReader.Create(new StringReader(CadenaXML));(string[])SerializadorXML.Deserialize(LectorXML);

- Deben actualizarse las propiedades estáticas globales que contienen las diferentes URL que muestra la paleta acoplable y llamar al método que navega hasta la URL que corresponda:

if (System.Uri.TryCreate(MatrizDeCadenasConVariasURL[0], UriKind.Absolute, out DirecciónURL))

\{ NavegadorWEBIntegrado._URLDeLaDocumentación = DirecciónURL.ToString();\}

$\cdots$

_InstanciaDePaletaAcoplableDeINavegadorWEB.NavegarADirecciónURL(_URLQ ueCorresponda);

En los ejemplos anteriores 'DirecciónURL' es una URL comprobada que se pasa a la propiedad global estática '._URLDeLaDocumentación' de la paleta acoplable, y '_InstanciaDePaletaAcoplableDeINavegadorWEB' es la instancia de la paleta acoplable del navegador web.

\section{CONCLUSIONES}

Es posible integrar en objetos o sistemas BIM de Revit ${ }^{\mathrm{TM}}$ información no gráfica compleja y/o extensa sin que ello suponga un incremento del tamaño del modelo o una ralentización de la aplicación. La clave está en integrar, en una entidad de datos basada en un esquema, las diferentes URL que apuntan a los documentos que se quieran incrustar. Por motivos de escalabilidad lo mejor es una entidad con un único campo de tipo cadena que contenga, a 
su vez, una serie de cadenas serializadas en formato XML. Deben alojarse los documentos originales en un servidor DHCP.

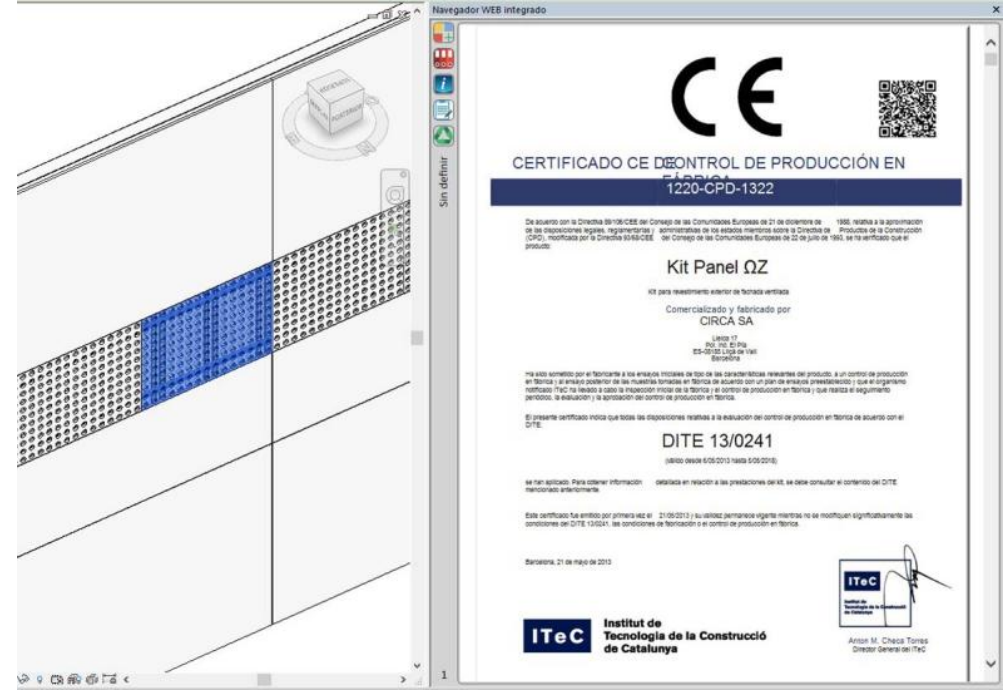

Figura 3. Paleta acoplable (Documento de Idoneidad Técnica). Año 2017. Fuente BiMMate

Debe programarse una nueva paleta acoplable en Revit ${ }^{\mathrm{TM}}$ que se actualice automáticamente con los eventos de activación de vista y de modificación de la selección de usuario (a través de la disponibilidad de la aplicación). Con ello es posible, por ejemplo, desarrollar contenido para Revit ${ }^{\mathrm{TM}}$ que permita consultar en tiempo real la web del fabricante, la documentación técnica del producto, el manual de usuario, incluso con enlaces a vídeos de YouTube, la normativa que le es de aplicación, o la Declaración Ambiental de Producto.

El contenido desarrollado en esta comunicación puede descargarse desde la web de BiMMate, siendo gratuita su utilización cumpliendo los requisitos fijados por la Junta de Gobierno del Colegio Oficial de Arquitectos de Murcia: https://m1.bimmate.com/magento1/downloads/dl/file/id/3081/Navegador\%20WEB\%20integra do.exe.

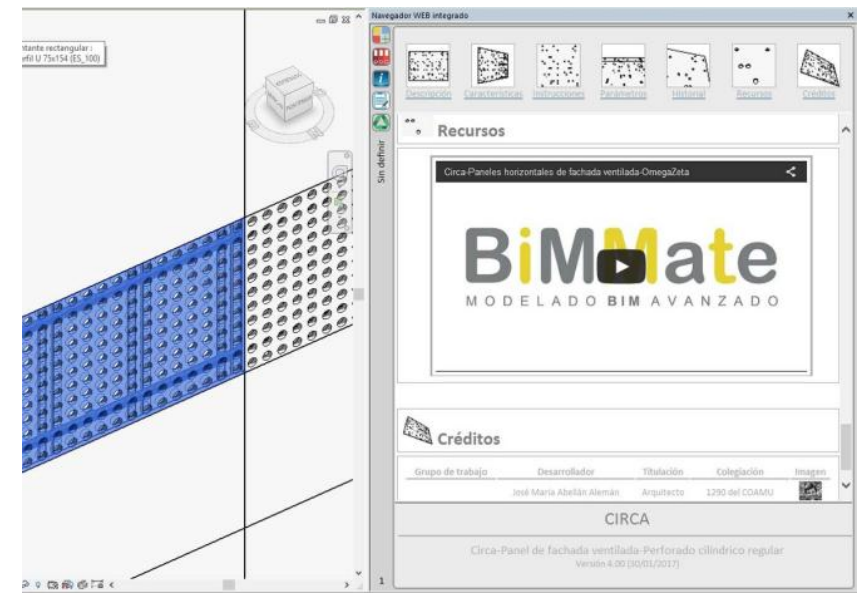

Figura 4. Paleta acoplable (manual de usuario). Año 2017. Fuente BiMMate 


\section{REFERENCIAS}

[1] Puede consultarse la definición de URL en: https://es.wikipedia.org/wiki/Localizador de recursos uniforme.

[2] Puede consultarse la web de Autodesk ${ }^{\odot}$ : https://knowledge.autodesk.com/support/revitproducts/learn-explore/caas/CloudHelp/cloudhelp/2016/ENU/Revit-Model/files/GUIDAEBA08ED-BDF1-4E59-825A-BF9E4A871CF5-htm.html.

[3] La definición del almacenamiento extensible puede encontrarse en: https://knowledge.autodesk.com/searchresult/caas/CloudHelp/cloudhelp/2016/ENU/Revit-API/files/GUID-113B09CA-DBBB41A7-8021-005663B267AE-htm.html.

[4] Los tipos de datos soportados son int, short, double, float, bool, string, GUID, Elementld, UV, XYZ, Array, Map y Entity:

http://thebuildingcoder.typepad.com/blog/2011/04/extensible-storage.html.

[5] Puede consultarse una breve guía de programación asíncrona en C\# en NET Framework 4.5 en: https://msdn.microsoft.com/es-es/communitydocs/net-dev/dev/programacionasincrona-en-net.

[6] Puede consultarse una descripción del lenguaje XML en: https://es.wikipedia.org/wiki/Extensible Markup Language.

[7] Puede consultarse la definición DHCP en: https://es.wikipedia.org/wiki/Dynamic Host Configuration Protocol.

[8] Este proceder es similar al que describió, en febrero de 2012, el blog Revit Addin Wizard: http://spiderinnet.typepad.com/blog/2012/02/revit-api-2012-extensible-storage-a-supereasy-and-cool-revit-data-operator.html.

[9] Puede encontrarse más información sobre formularios modales y no modales en la página web de Microsoft: https://msdn.microsoft.com/eses/library/aa984358(v=vs.71).aspx.

[10] Puede encontrarse más información sobre las paletas acoplables en: https://knowledge.autodesk.com/support/revit-products/learnexplore/caas/CloudHelp/cloudhelp/2014/ENU/Revit/files/GUID-4C190F29-187F-48A39D1E-7081D5F6428C-htm.html.

[11] Puede obtenerse más información sobre formularios WPF en: https://es.wikipedia.org/wiki/Windows Presentation Foundation.

[12] Puede encontrarse una breve descripción del lenguaje XAML en: https://msdn.microsoft.com/es-es/library/cc295302.aspx.

[13] Los eventos habilitan una clase u objeto para notificarlo a otras clases u objetos. La clase que genera el evento recibe el nombre de publicador y las clases que controlan el evento se denominan suscriptores. Puede encontrarse más información en:

https://msdn.microsoft.com/es-es/library/awbftdfh.aspx. 


\title{
GESTIÓN DE AUSCULTACIÓN Y SEGURIDAD DE PRESAS CON BIM
}

\author{
HOPPE, Stefan (1)
}

(1) OFITECO, shoppe@ofiteco.com

\section{RESUMEN}

La gestión de Seguridad de Presas engloba un conjunto de trabajos que incluye el análisis de comportamiento estructural basado en datos de auscultación e inspecciones visuales, así como la realización de diferentes trabajos de mantenimiento correctivo y preventivo.

Para gestionar esta información se ha empleado una solución BIM que incorpora varias herramientas. Se elaboró un modelo en tres dimensiones de una presa de arco-gravedad de $90 \mathrm{~m}$ de altura, incluyéndose los elementos principales de la estructura y todo el sistema de instrumentación. Los datos de auscultación y los formularios para la realización de las tareas de mantenimiento y las inspecciones visuales, incluidas las listas de verificación y la documentación fotográfica, fueron preparados y relacionados con los elementos correspondientes en el modelo.

Se registran y categorizan las anomalías observadas, tal como filtraciones, grietas y deslizamientos de laderas, además de poderse señalar con marcadores en el modelo en 3D. De este modo, el modelo en 3D se convierte en una biblioteca visual que incluye todas las observaciones significativas de la seguridad y la vida útil de la presa. Permite cruzar fácilmente datos de auscultación con las observaciones de inspección visual y labores de mantenimiento.

Palabras clave: auscultación, gestión, inspección, instrumentación, mantenimiento

\section{SUMMARY}

Dam Safety Management consists of a series of tasks that include the analysis of structural behaviour based on monitoring data, visual inspections, and the execution of corrective and preventive maintenance works.

For managing this information, a BIM solution was adopted that incorporates various tools. Therefore, a 3D model of an Arch Gravity Dam with a height of $90 \mathrm{~m}$ was created, including the main structural elements and the entire monitoring system. Monitoring data and forms for carrying out maintenance works and visual inspections, including verification lists and photographical documentation, were prepared and linked to the corresponding elements of the model.

Anomalies and incidents like seepage, cracks and landslides are registered, categorized and assigned to its location in the 3D model. In this way, the 3D model is turned into a virtual library that includes all significant observations regarding dam safety during the life cycle of 
the dam. Monitoring data can easily be compared and correlated to observations from visual inspections and maintenance works.

Keywords: inspection, instrumentation, maintenance, management, monitoring

\section{$1 \quad$ INTRODUCCIÓN}

La supervisión de la seguridad estructural de infraestructuras requiere el análisis continuado de un gran volumen de información. Esto afecta sobre todo a las infraestructuras que presentan un gran riesgo potencial como suelen ser las presas, puentes y túneles, tanto durante la fase de construcción como explotación. Los instrumentos de medición recogen una multitud de datos que tradicionalmente han requerido un proceso muy laborioso para su gestión, supervisión y análisis.

Con el fin de gestionar los registros de medición, control y monitorización, tomados en los sistemas presa-embalse, de manera eficiente, es imprescindible disponer de una potente aplicación informática, que ayude a analizar e interpretar los datos obtenidos y transformarlos en información útil, de forma que se permita al usuario final conocer exhaustivamente el nivel de seguridad, el comportamiento de la presa y el estado del sistema, ayudando en la gestión y evitando posibles desastres.

Por otro lado, hay trabajos periódicos de inspección visual de las presas para comprobar su estado de seguridad en campo y registrar posibles anomalías que no capta el sistema de auscultación. Durante estas inspecciones no solo se registran anomalías relacionadas con la seguridad de la presa, sino también con el funcionamiento adecuado de los diferentes componentes del sistema de auscultación. Además, se realizan trabajos de mantenimiento preventivo y correctivo de la obra civil y diferentes instalaciones hidromécanicos y eléctricos.

Las tecnologías actuales de presas almacenan grandes cantidades de datos de forma inmediata, pero la interpretación y el análisis de esta compleja información técnica a menudo consume mucho tiempo, lo que afecta la eficiencia de trabajo y retrasa decisiones importantes.

En la actualidad existen diferentes aplicaciones para gestionar datos de auscultación. Hay programas generales y soluciones desarrolladas específicamente para el control de presas, obras de túneles o puentes. Sin embargo, no suelen enlazar los datos con una geometría tridimensional o utilizar formatos comunes. Tampoco ofrecen un enlace directo con aplicaciones desarrolladas para la gestión de trabajos de mantenimiento.

Para poder gestionar la información y las labores relacionadas con la seguridad y el mantenimiento de las presas, se ha desarrollado ODIS (online dam information system), una solución basada en tecnología BIM que incorpora varias herramientas. Para ello, se elaboró un modelo en tres dimensiones de una presa de arco-gravedad de $90 \mathrm{~m}$ de altura, incluyéndose los elementos principales de la estructura y todo el sistema de instrumentación. 
ODIS ha sido especialmente desarrollado como un sistema en línea de seguimiento de presas con una interfaz fácil de usar. La gestión de la información basada en el modelo no sólo supone un ahorro de costes sino también considerables ahorros de tiempo en el proyecto.

Los objetivos principales han sido:

- Una compilación comprensiva de datos e información relacionada con las presas

- Datos en tiempo real, evaluación flexible y fácil navegación utilizando un modelo 3D

- Estudio comparativo de los requisitos de seguridad

- Transformación de los datos complejos en información inteligente presentado en informes definidos por el usuario que acelera el proceso de toma de decisiones

- Introducción de datos desde dispositivos móviles en formularios estandarizados, aumentando accesibilidad en campo y oficina.

En el presente artículo se describen las funcionalidades más importantes de la aplicación, así como las lecciones aprendidas.

\section{DESCRIPCIÓN GENERAL DE ODIS}

ODIS es una aplicación web que se ejecuta con un navegador comercial de internet. Con un acceso personal, el usuario obtiene acceso a un portal web que consiste en los siguientes 4 módulos: Adquisición de datos, 3D BIS, DAMDATA y Management View (fig 1).

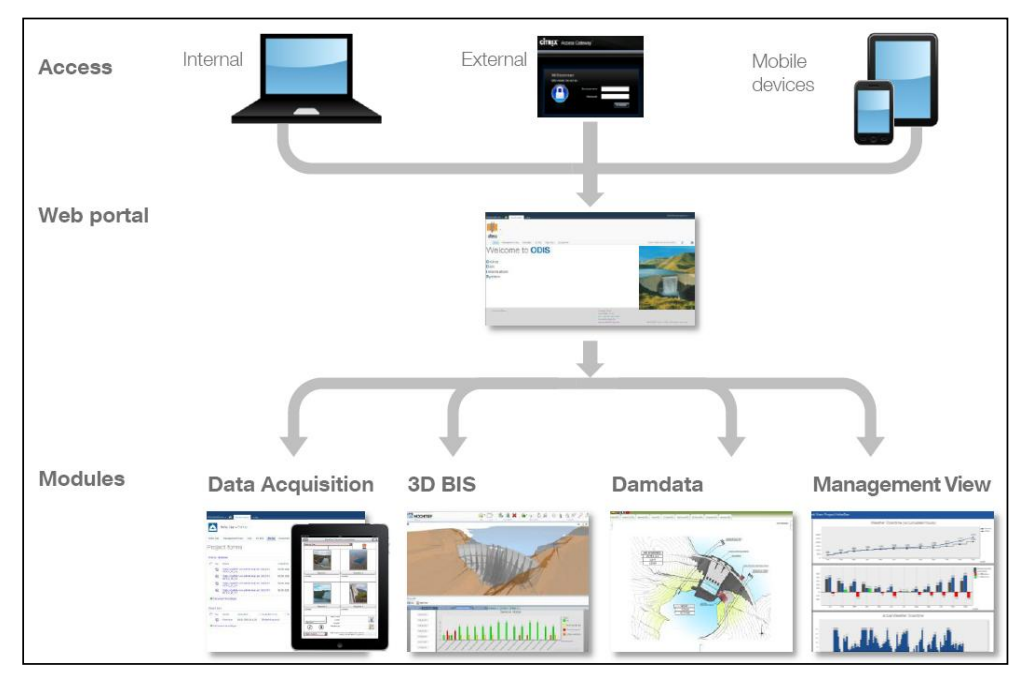

Fig 1. Modular structure of ODIS

Esta configuración modular permite una adaptación individual del ODIS a los requerimientos de cada explotador de presas y también puede ser ampliado con otros programas. 
A continuación se describen las diferentes funcionalidades del programa.

\subsection{Adquisición de datos}

La adquisición de información de los inspectores de campo es un paso vital para mantener la información de la plataforma al día. Los formularios que pueden ser operados en dispositivos portátiles y móviles, proporcionan un método fácil para los inspectores a llevar a cabo la documentación fotográfica, inspecciones visuales, obras de mantenimiento, registro de sensores, revisión de dimensiones y posiciones. Los datos introducidos se envían a la base de datos común conectado con el portal web, que proporciona un acceso a todos los miembros del proyecto.

En la figura 2 se muestra un ejemplo de un formulario de inspección visual, documentación fotográfica, así como el interface del administrador de formularios.
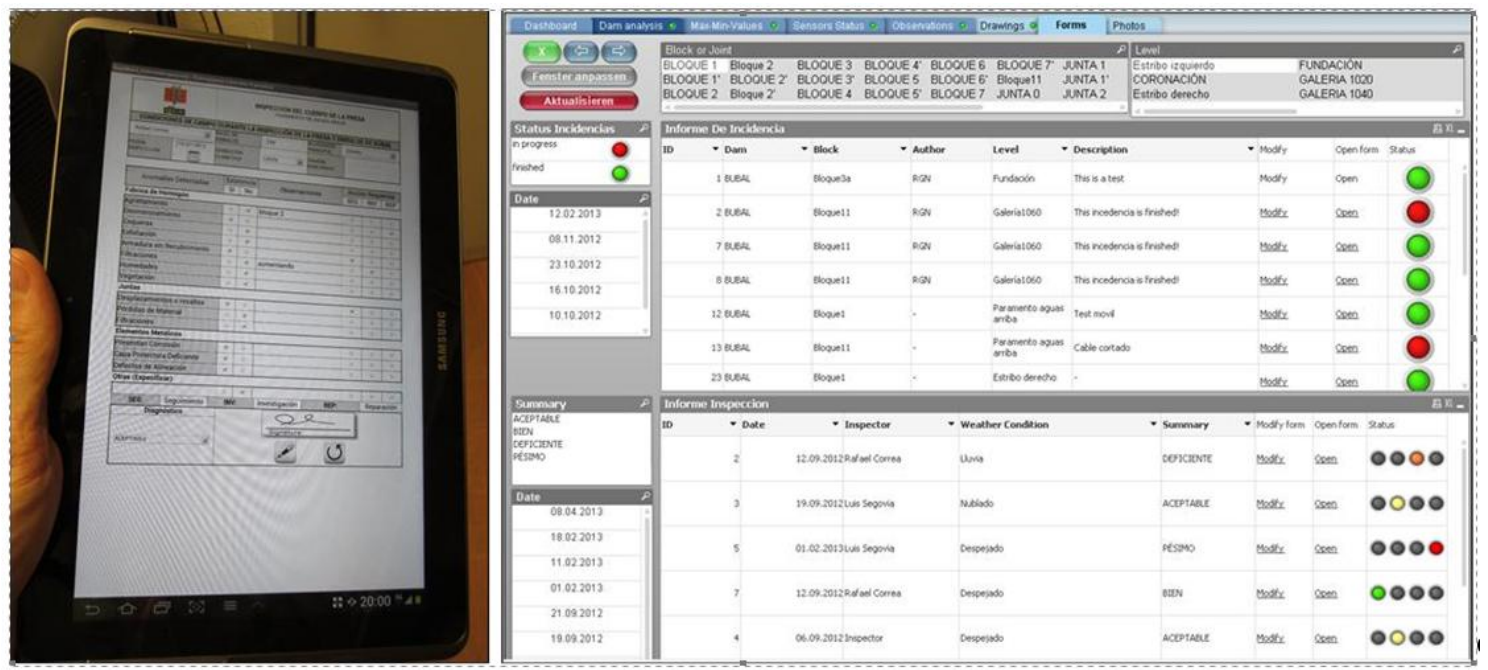

Fig. 2. Ejemplo de formularios y administrador de datos

El administrador de formularios incluye el historial completo de formularios e indica cuales están pendientes y cuáles cerrados. Esto se utiliza sobre todo para el control de incidencias para los trabajos de mantenimiento correctivo.

También permite la adquisición manual de datos de auscultación en campo mediante dispositivos móviles que ayuda a introducir los datos del sensor al portal web de forma inmediata.

\subsection{DAMDATA}

DAMDATA proporciona las herramientas necesarias para gestionar los datos de monitorización en tiempo real y transformarlos en información valiosa. Se incluyen vistas SCADA, adquisición de datos automáticos desde la presa y una herramienta de cálculo flexible y abierta que permite transformar las señales eléctricas de los sensores en valores ingenieriles. Se pueden asignar umbrales y gestionar las alertas. 
La funcionalidad de visualización permite crear y exportar gráficos multivariables en función del tiempo, espacio y otras variables. Estos se utilizan para la generación de informes detallados sobre el estado de seguridad de la estructura. El modelo estadístico permite un análisis más detallado de los datos y la predicción de diferentes escenarios futuros.

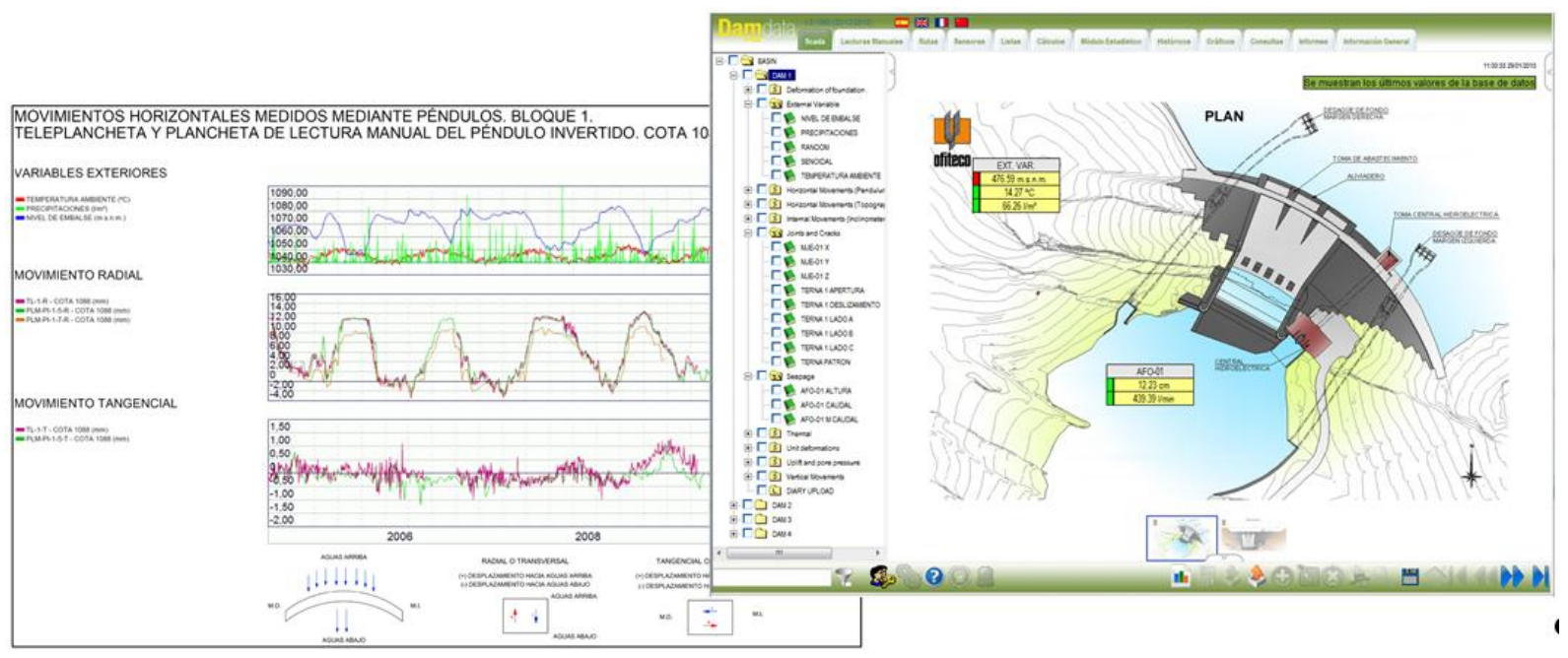

Fig. 3. Ejemplo visualización de datos y SCADA de DAMDATA

DAMDATA procesa datos de auscultación y facilita información de sensores clave a los otros módulos del sistema, especialmente al 3D BIS. De esta forma se combina la herramienta de trabajo especializada en auscultación con otras funcionalidades BIM para obtener un gestor de seguridad de presas.

\subsection{Sistema de información 3D (BIS)}

El Sistema de información 3D (BIS) combina un modelo 3D de la presa con información relacionada con auscultación y seguridad de presas: Trabajos de mantenimiento, inspecciones visuales y datos de auscultación facilitado por el programa DAMDATA.

Para la elaboración del 3D BIS, se generó un modelo tridimensional de una presa de arco gravedad de una altura de $90 \mathrm{~m}$.

Con el fin de enlazar información al modelo, se asignaron propiedades a los elementos principales, tal como bloques, juntas, galerías y cimentación. Además, se incluyeron todos los sensores de auscultación en el modelo, utilizando las identificaciones de sensores de DAMDATA. Se estableció una conexión bidireccional entre del modelo 3D y la información.

El menú de navegación permite mover el modelo en cualquier dirección, dando un mejor entendimiento de la ubicación de cada elemento, así como de la geometría y emplazamiento de la estructura. También es posible "andar" por las galerías y hacer un zoom sobre los diferentes elementos del modelo. Una herramienta permite incorporar notas y croquis que se pueden exportar fácilmente y utilizar para la ilustración de informes y formularios. 


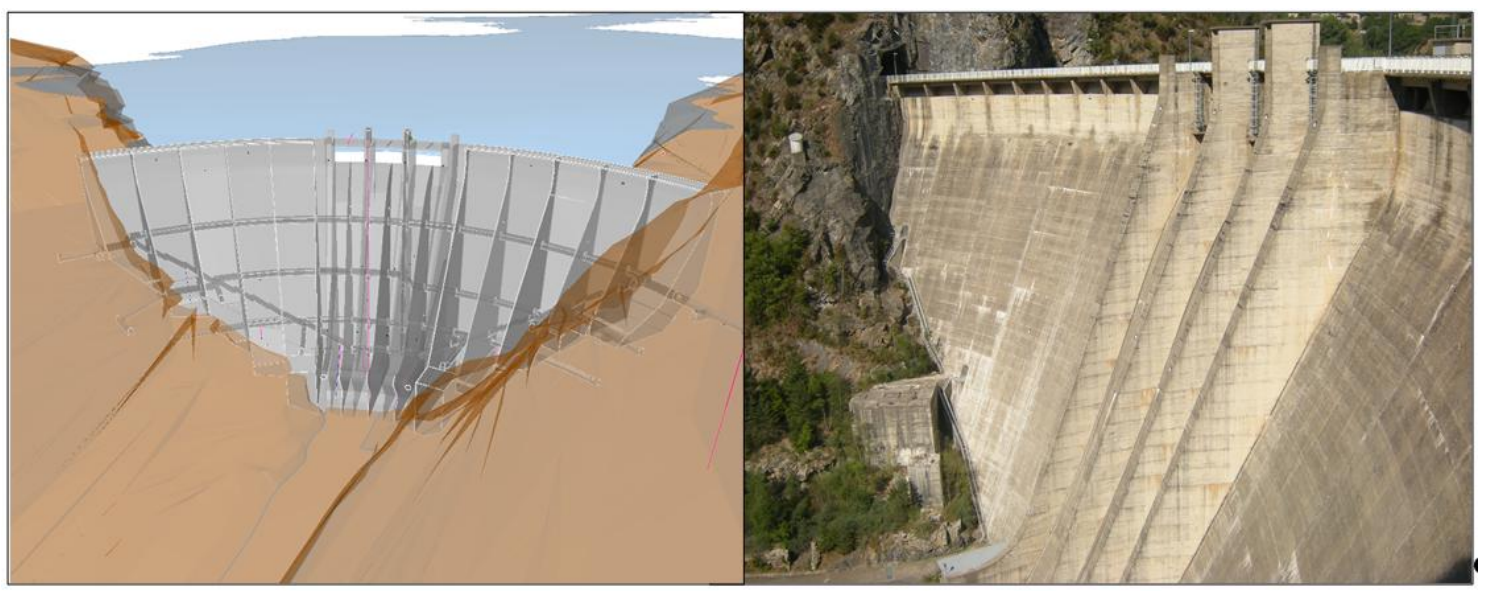

Fig. 4. Modelo y foto de la presa

Cuando la base de datos del proyecto se encuentra conectado con el modelo 3D del proyecto, se crea un sistema todo-en-uno, donde los datos numéricos y geométricos están vinculados entre sí. La conexión bidireccional entre el modelo 3D y diversos datos del proyecto incluyendo los datos de seguimiento, el estado del sensor, observaciones, fotos y documentos permiten a los usuarios encontrar y analizar los datos rápidamente.

Se han incluido las siguientes funcionalidades en el 3D BIS.

Herramienta de análisis de datos: La herramienta de análisis de datos muestra datos selectos facilitados por el módulo de DAMDATA. Hace un resumen de información y la relaciona con el modelo $3 \mathrm{D}$. Por un lado, se pueden elegir datos en la base de datos utilizando los filtros disponibles y mostrar los sensores correspondientes en el modelo 3D. Por otro lado, se pueden seleccionar zonas en el modelo y la base de datos visualiza los datos correspondientes en la base de datos. De esta forma, toda la información relacionada con la cimentación, bloques o juntas pueden visualizarse fácilmente, lo que permite una evaluación clara de los datos.

En la figura 5 se muestra un pantallazo de la herramienta. En la parte superior se muestra el modelo 3D de la presa y en la parte inferior los datos de auscultación de un piezómetro seleccionado. A lado de la vista tabular, se muestran los datos de forma gráfica en relación con los umbrales correspondientes y el nivel de embalse.

Inspecciones visuales: Para la realización de inspecciones visuales, se prepararon formularios personalizados para todos los elementos principales de la presa, incluyéndose un checklist y documentación fotográfica (figura 5).

Además, observaciones de anomalías como filtraciones, grietas y deslizamientos han sido registrados y clasificados y se han han asigando a su ubicación en el modelo 3D. De esta forma, toda la información recogida durante las inspecciones visuales ha sido registrada. Sensores ubicados cerca de anomalías pueden identificarse fácilmente, y se pueden correlacionar los datos de auscultación con las inspecciones. 


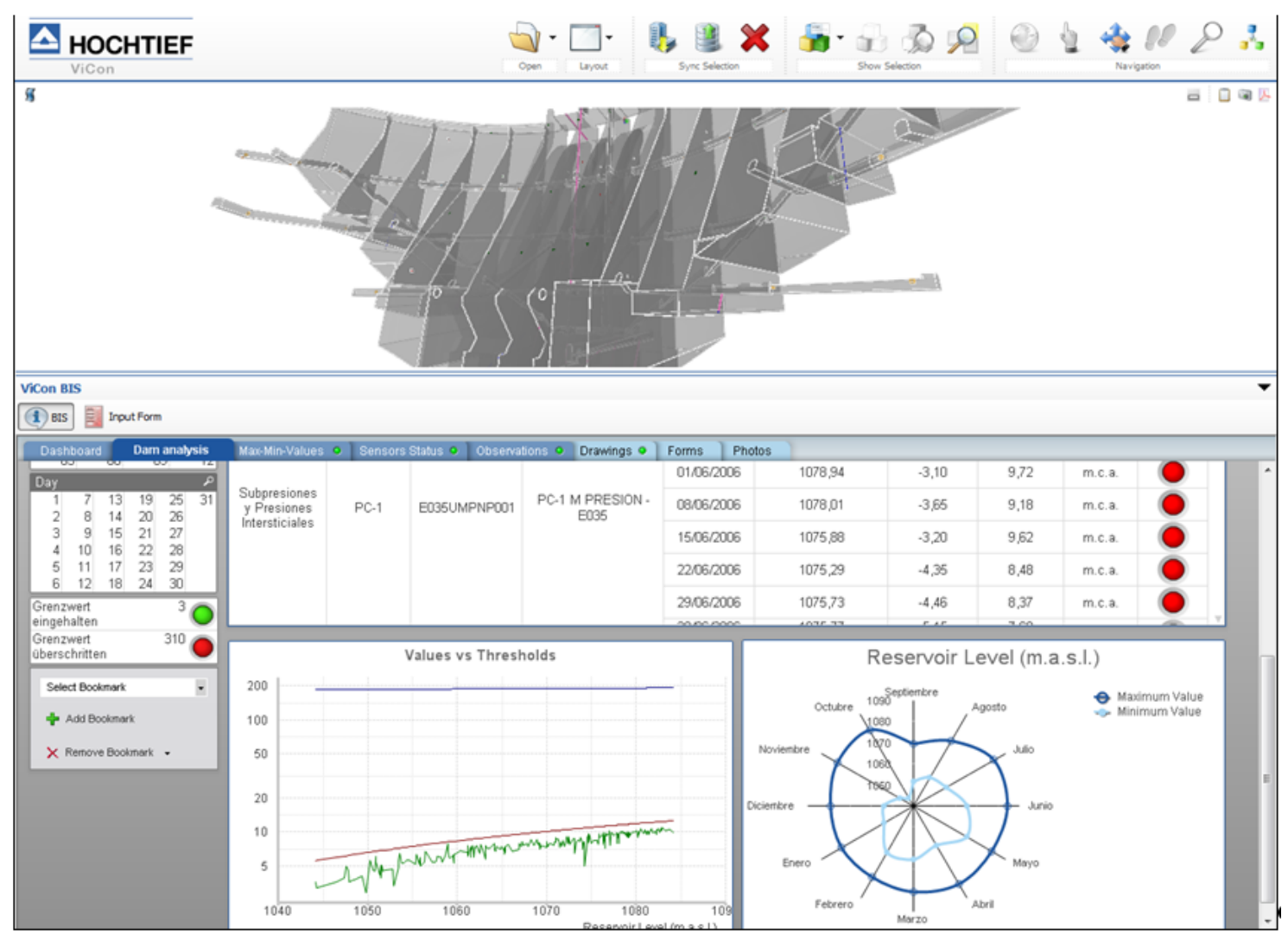

Fig. 5. Ejemplo de análisis de datos con 3D BIS

Estado de sensores: Para la correcta interpretación de datos de auscultación, información relacionada con el estado de funcionamiento de cada sensor es crucial. Esta información fue elaborada por especialistas en instrumentación durante las inspecciones visuales y trabajos de mantenimiento y se documenta con formularios mediante tablets.

Se organiza la información en el 3D BIS, ofreciendo las herramientas necesarias para hacer un informe sobre el estado de funcionamiento de los sensores. Además, se puede mostrar tanto el estado actual, como su historial (figura 6).

Acceso a documentación fotográfica y planos: Durante el ciclo de vida de una presa, se elabora una gran cantidad de documentos y fotos. Con el fin de gestionarlos de forma más eficaz, se han incorporado en el sistema y asignado a su ubicación. La herramienta de navegación tiene filtros flexibles que permiten un acceso fácil a toda la información (figura 6). Por ejemplo, todas las fotos relacionadas con un bloque o gallería pueden mostrarse con un solo clic. 


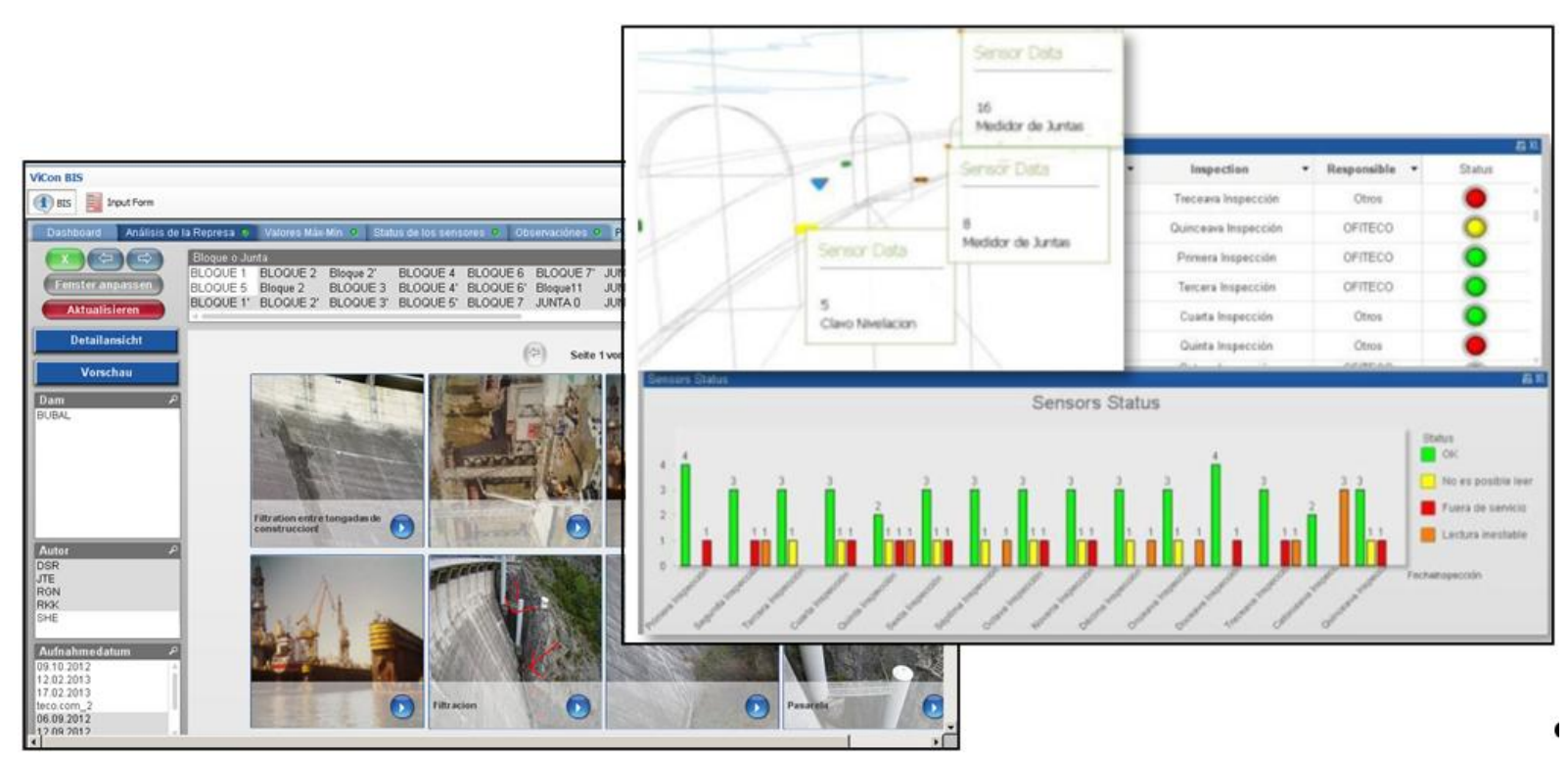

Fig. 6. Ejemplo de estado de sensores y acceso a documentación

\section{$2.4 \quad$ Interfaz de gestor}

El interfaz de gestor presenta todos los datos reunidos en la base de datos desde una perspectiva analítica. Los diagramas presentan los datos filtrados, indican el estado de los procesos en curso y ayudan a tener una rápida visión general de un componente individual de la estructura, de la estructura en su totalidad o de un grupo de ellas con tan solo algunos clics. Incorpora sistemas adicionales como los SIG (Sistemas de Información Geográfica), Google maps, etc. a fin de proporcionar al cliente un resumen de todos los proyectos en curso.

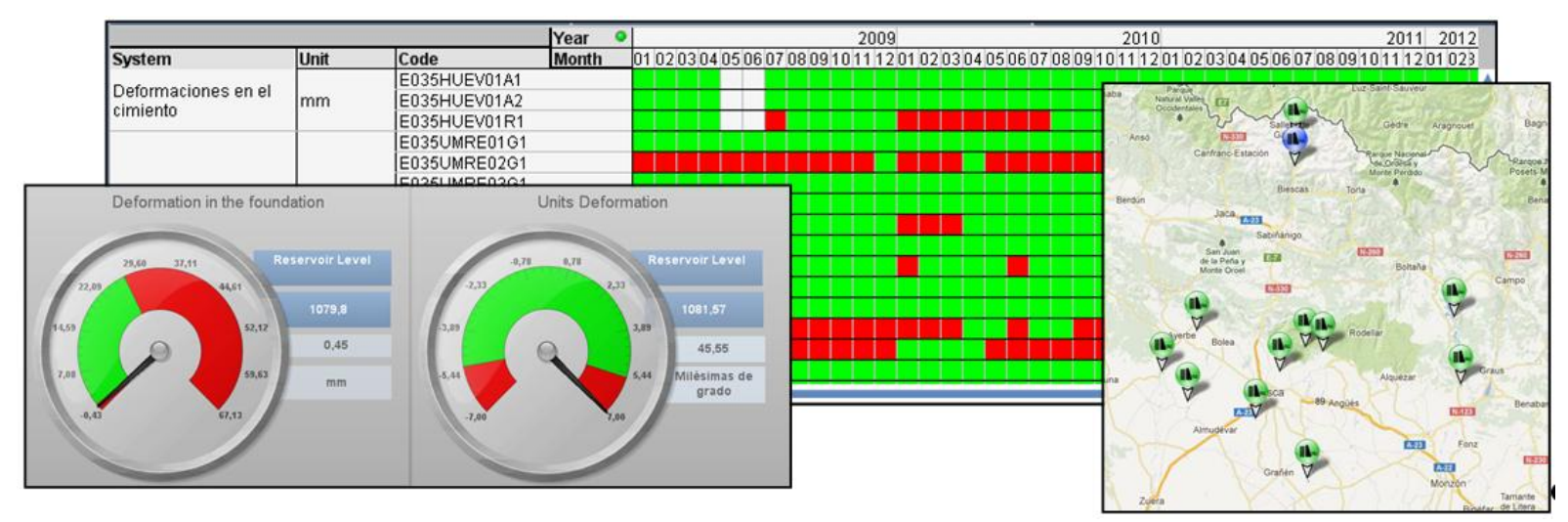

Fig. 7. Interfaz de gestor

\section{CONCLUSIONES}

La metodología BIM puede aplicarse para administrar la información sobre la seguridad de las infraestructuras de un modo innovador y eficiente. La comprensión del nivel de seguridad real de la estructura puede aumentarse mediante las sinergias entre los distintos tipos de 
información proporcionada y permitiendo una interpretación orientada a objetivos. El resultado es la transformación de una elevada cantidad de datos complejos en información útil y fácil de entender.

Se puede acceder fácilmente y en tiempo real a los datos de monitorización, además de las fotos y formularios realizados durante las inspecciones visuales y las tareas de mantenimiento con dispositivos portátiles. De esta manera se acelera el proceso de toma de decisiones, lo cual ayuda a ganar tiempo y reducir costes.

La herramienta permite gestionar los trabajos de diferentes expertos y técnicos de forma coordinada: Técnicos e ingenieros de auscultación, encargados de presas, personal de explotación de presas, jefes de servicio y expertos externos.

A través del enlace con el gestor de auscultación DAMDATA, se ha podido integrar una aplicación web a una solución BIM. Teniendo en cuenta la versatilidad de la aplicación, está previsto aplicarla también para el control de otras estructuras, no solo durante la fase de explotación sino también la construcción. 


\section{ANÁLISIS DEL CICLO DE VIDA IMPLEMENTADO EN PLATAFORMAS BIM. ÚLTIMOS AVANCES}

\section{Ruiz Alfonsea, Marta (1), Gómez de Cózar, Juan Carlos (2), Llatas Oliver, Carmen (3), García Martínez, Antonio (4)}

(1) Universidad de Sevilla, Departamento de Construcciones Arquitectónicas I, marruialf1@alum.us.es

(2) Universidad de Sevilla, Departamento de Construcciones Arquitectónicas I, gcozar@us.es

(3) Universidad de Sevilla, Departamento de Construcciones Arquitectónicas I, cllatas@us.es

(4) Universidad de Sevilla, Departamento de Construcciones Arquitectónicas I, agarcia6@us.es

\section{RESUMEN}

Los problemas ambientales procedentes del sector de la construcción requieren herramientas que ayuden a frenar el consumo de recursos y el impacto ambiental. El análisis del ciclo de vida ( $\mathrm{ACV}$ ) está reconocido como uno de los métodos más válidos para el análisis ambiental, aunque su aplicación es compleja y es necesaria su estandarización para hacerlo operativo. Building Information Modeling (BIM) se define como un modelo 3D que integra información gráfica y datos sobre los materiales y elementos de un modelo. La integración de ACV en plataformas BIM supone una simplificación en el proceso de evaluación del impacto ambiental. Actualmente es escasa la bibliografía y el desarrollo de herramientas de simulación basadas en modelos BIM-ACV.

En esta comunicación se analiza el estado actual de estudios que vinculan modelos BIM con ACV y las metodologías seguidas para realizar la vinculación y la obtención de resultados. Se pondrá de manifiesto la necesidad de estandarizar el ACV implementado en plataformas BIM para simplificar el proceso y obtener resultados de impacto ambiental en tiempo real desde la fase de diseño. Se mostrarán varios casos de estudio realizados en el Máster Universitario en Innovación en Arquitectura: Tecnología y Diseño de la Universidad de Sevilla.

Palabras clave: Análisis del ciclo de vida (ACV), arquitectura, Building Information Modeling (BIM), impacto ambiental, sostenibilidad.

\section{ABSTRACT}

Current environmental problems arising from the building sector require tools to evaluate new designs to reduce the environmental impact. Life Cycle Assessment (LCA) is recognised as one of the most complete tool to quantify the environmental impacts of the building sector, although there is a need to standardise the method application to optimise its use, including the design stage. Building Information Modeling (BIM) is defined as a virtual 3D model that integrates graphical information and a database of model elements. The integration LCA and BIM could simplify the evaluation process of environmental impact. Currently, there is a lack of literature about this subject and the development of simulation tools based on BIM-LCA models are limited. 
In this paper, it is analysed the current state of matter related with the integration of BIM-LCA and the methods used to integrate these tools and obtain results of environmental impact. In this way, it is highlighted the need to standardise LCA integrated into BIM with the aim of simplifying the process and obtaining results of environmental impacts automatically, including the design stage. Several case studies developed in Official Master's Degree in Innovation in Architecture: Technology and Design at University of Seville will be shown.

Keywords: Life cycle assessment (LCA), architecture, Building Information Modeling (BIM), environmental impact, sustainability.

\section{$1 \quad$ INTRODUCCIÓN}

El incremento de la población y el agotamiento de los recursos naturales son una prioridad en la actualidad [1, 2, 3]. En la Unión Europea, el sector de la construcción es el responsable más del $40 \%$ del consumo de energía y del impacto ambiental total [4]. Además, este sector consume el $44 \%$ de las materias primas y genera el $33 \%$ de las emisiones de $\mathrm{CO}_{2}$ [5]. Por otro lado, el sector de la construcción tiene un gran potencial de intervención para reducir el consumo de recursos y el impacto ambiental que produce [6]. Por este motivo, la demanda de edificios que produzcan un mínimo impacto ambiental está creciendo notablemente y la industria de la construcción necesita adoptar técnicas para reducir el impacto ambiental que produce [7] La sostenibilidad y su desarrollo es, en la actualidad, una de las estrategias más importantes para reducir en impacto ambiental y el consumo de energía producido por el sector de la edificación [8-10].

Hay múltiples herramientas de análisis y evaluación para implementar el desarrollo de la sostenibilidad en los edificios [11, 12]. El análisis del ciclo de vida (ACV) está considerada como una de las herramientas científicas más apropiadas y completas para cuantificar los impactos ambientales asociados a un determinado proceso o material [13-16]. No obstante, existen múltiples estudios que señalan la necesidad de estandarizar la metodología del ACV aplicada a la edificación [12, 17].

Las herramientas Building Information Modeling (BIM) están basadas en modelos inteligentes $3 \mathrm{D}$ que contienen tanto la información gráfica como las propiedades de los materiales y elementos que componen una determinada edificación [18]. Es una herramienta de gran utilidad ya que mediante su uso se reduce el tiempo y el esfuerzo empleados al gestionar gráficos y datos [19]. Desde el punto de vista de la sostenibilidad, las plataformas BIM cuentan con un gran potencial para incluir datos e información que permitan realizar el diseño de un edificio sostenible [20].

El desarrollo de herramientas que vinculen BIM y ACV está creciendo. Aunque aún la bibliografía es escasa, cada vez hay más estudios que subrayan el potencial de la integración BIM-ACV $[21,17,18]$ y que desarrollan metodologías de vinculación [14, 15, 22]. La fase de diseño es la que tiene más influencia en el resultado final de un edificio debido a que es la fase en la que se pueden realizar más cambios. La vinculación BIM-ACV debería ser aplicada en esta fase ya que a menudo el ACV se usa como herramienta de análisis 
cuando un edificio está terminado y no como una herramienta de diseño que ayude en la toma de decisiones [21].

La comunicación que se presenta queda enmarcada en una línea de investigación que busca establecer una relación entre arquitectura-materialidad-contexto [23] con el objetivo de reducir el impacto ambiental que produce una determinada construcción no sólo durante su vida útil, sino durante todo su ciclo de vida.

\section{ANÁLISIS DEL CICLO DE VIDA Y SU VINCULACIÓN CON BIM}

Para el desarrollo del presente trabajo se ha realizado una búsqueda basada en publicaciones y estudios recientes que integren ACV y BIM. La selección de artículos y publicaciones que se han consultado para la presente comunicación se ha obtenido de las siguientes fuentes: Web of Science, Science Direct, Mendely, Scopus, Taylor and Francis and Springer Link.

\subsection{Análisis del Ciclo de Vida}

Como se ha explicado anteriormente, el ACV constituye una herramienta con un gran potencial que permite la cuantificación de los principales impactos que produce un edificio durante todo su ciclo de vida [24] y que permite determinar cuáles son los sistemas constructivos que producen un menor impacto ambiental, con el objetivo de buscar aquellas soluciones constructivas que minimicen el impacto ambiental generado.

De acuerdo con la Norma ISO 14050 [25], el ciclo de vida son etapas consecutivas asociadas a un determinado producto, considerando desde que se extrae las materias primas que lo conforman hasta su disposición final. La Norma ISO 14040 [26] define el término de ACV como la recopilación y evaluación de las entradas y salidas y los impactos ambientales que tiene un determinado producto a lo largo de su vida útil. Además, establece las etapas interrelacionadas a considerar en la realización de un ACV: objetivos y alcance, inventario del ciclo de vida, evaluación del impacto y resultados [26]. La Norma EN 15804 [27] establece una clasificación para las etapas a considerar en el ciclo de vida: A1-3 fase de producción, A4-5 fase de construcción, B1-7 fase de uso, C1-4 fase de de-producción.

Existen numerosas publicaciones que realizan ACV aplicado a la arquitectura y a la construcción. Es frecuente encontrar estudios que se centran en el análisis de un material o elemento constructivo concreto, sin tener en cuenta su integración dentro del edificio. Liu et al. [28] realizan un ACV aplicado a un sistema de techo refrigerante. Pons et al. [29] centran su estudio en el ACV de una cubierta. Fraile García et al. [30] realizan un ACV centrándose en estructuras de hormigón armado. Fernández García et al. [31] realizan un estudio basado en ACV aplicado a diferentes tipos de particiones interiores. Iribarren et al. [32] se centran en la comparación de cerramientos compuestos por diferentes materiales mediante ACV. EI estudio de Sierra Pérez et al. [33] consiste en la realización del ACV a diferentes tipos de 
aislante térmico en cerramientos. Además, también existen diversos estudios y publicaciones que realizan ACV a edificios completos [34-38].

Son numerosos los autores que coinciden en la complejidad que conlleva la aplicación del ACV [17]. Esta complejidad se debe a la falta de estandarización en la metodología de aplicación. Es por este motivo que la mayoría de los estudios se centran en un elemento o material completo. Son pocos los estudios que analizan todas las fases del ciclo de vida según la clasificación de la Norma EN 15804 [27] y que estudian todas las categorías de impacto ambiental.

\subsection{Vinculación BIM-ACV}

Aunque la mayoría de la bibliografía pone de manifiesto el potencial que tendría la vinculación BIM-ACV [38] son escasos los estudios que realizan y aplican esa vinculación a casos prácticos.

En la mayoría de los casos de estudio el modelado BIM se realiza únicamente con el objetivo de obtener la cuantificación de materiales y elementos que componen un determinado edificio [36] debido a la complejidad de vinculación de los datos incluidos en el modelo BIM y las bases de datos de ACV. Además, de acuerdo con el estudio de Soust et al. [16], en el que se realiza un análisis pormenorizado de diferentes estudios de casos prácticos en los que se vincula BIM y ACV, la extracción y el intercambio de datos en la mayoría de los estudios que se realiza mediante tablas de cálculo, lo que supone una falta de automatización en el proceso.

\subsection{Herramientas de vinculación BIM-ACV}

En la actualidad se están desarrollando software para realizar ACV directamente desde modelos BIM de forma automática. Un ejemplo de estas herramientas es Tally [39], un plugin para Autodesk Revit que cuantifica el impacto ambiental que producen los materiales y elementos que componen un edificio basado en la metodología de ACV para diferentes categorías de impacto ambiental. Además, permite realizar un análisis comparativo, siguiendo esta metodología, entre varias opciones de diseño [39]. Actualmente, la aplicación está geográficamente adaptada para Estados Unidos [39]. Además de la herramienta Tally, el software Cocon-BIM [40] está dedicado al estudio de la calidad ambiental de los materiales, de los edificios y del ACV a través de los modelos BIM. El programa está adaptado a diferentes normativas europeas y se nutre de bases de datos provenientes de diversas fuentes de Francia, Alemania y Suiza [40].

Aunque existen estas herramientas no se ha encontrado en las bases de datos consultadas, ningún estudio de casos prácticos en los que se realice ACV a partir de modelos BIM empleando alguna de estas aplicaciones. 


\subsection{Aplicación BIM-ACV. Casos prácticos}

En los últimos años, dentro de la línea de investigación en la que se enmarca esta comunicación, centrada en la búsqueda de modelos que minimicen el impacto ambiental, y dentro del Máster Universitario en Innovación en Arquitectura: Tecnología y Diseño (MIATD), se han desarrollado diferentes estudios y Trabajos Fin de Máster (TFM) en los que se realizan ACV partiendo de modelos BIM. A partir de estos trabajos se ha podido constatar la escasez de herramientas de vinculación BIM-ACV.

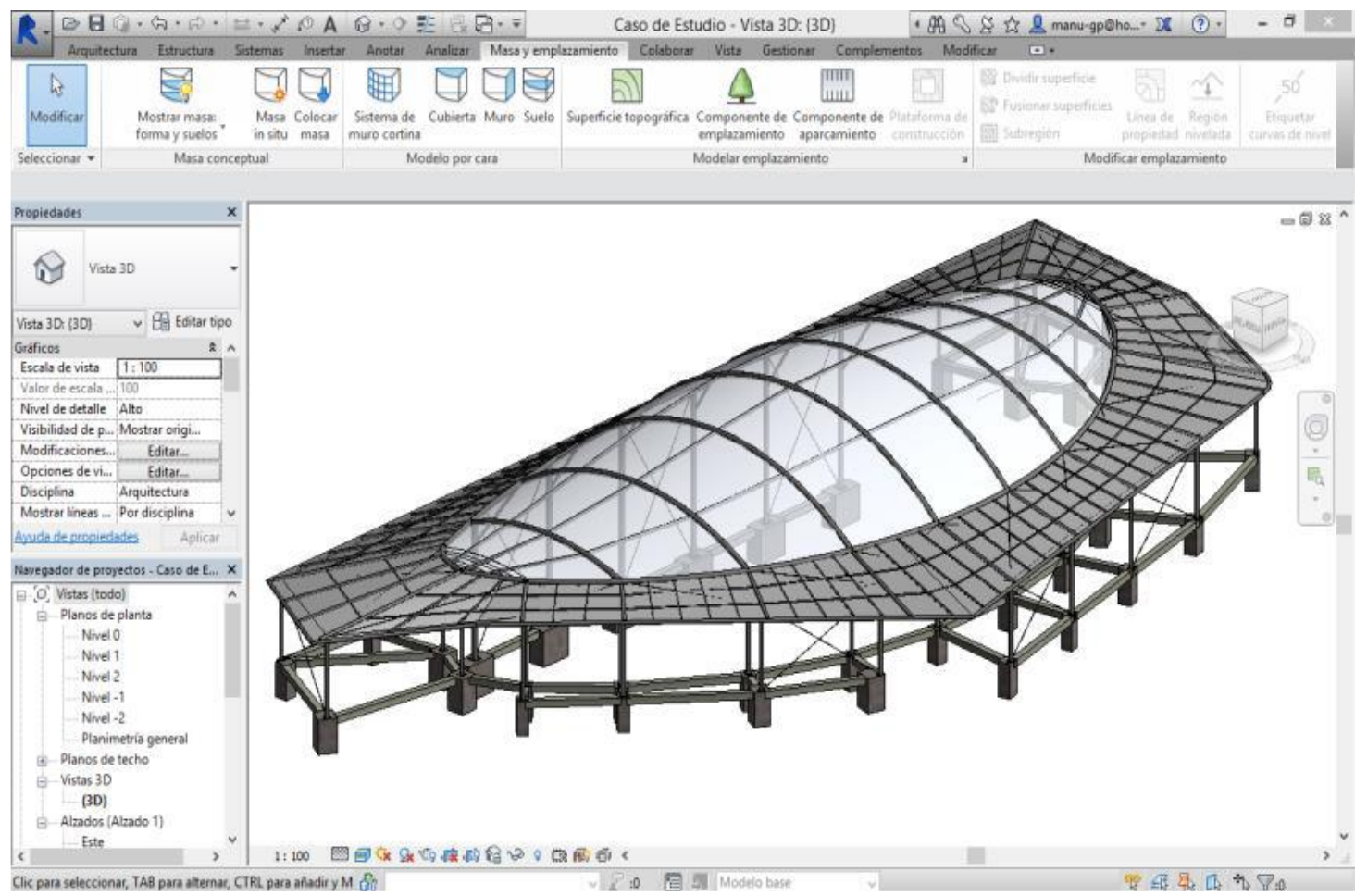

Fig. 1. Caso de estudio en BIM. 2014. TFM Manuel Gómez Pérez [42]

Mesa González en su TFM [41] pretende sentar las bases de la relación entre ligereza e impacto ambiental aplicando el análisis a un sistema ligero y de rápido montaje. Para el ACV parte de un modelo realizado en un programa de diseño paramétrico y diseña una herramienta de ecodiseño para evaluar los impactos ambientales producidos por sistemas ligeros y de rápido montaje. A partir de este primer trabajo desarrollado, y siguiendo esta línea de investigación, se han realizado diversos TFM [42-47] todos enfocados a la aplicación de ACV, siempre desarrollado a partir de modelos BIM de diferentes casos de estudio. El objetivo común de todos los trabajos consistió en averiguar cuál de los casos de estudio y sistemas constructivos analizados y comparados produce el menor impacto ambiental. Además, la finalidad de la realización de todos los trabajos anteriormente mencionados dentro de la línea de investigación y del MIATD es la creación de una base de datos de los impactos ambientales que producen diferentes modelos y sistemas constructivos, poniendo de manifiesto cuáles son aquellos casos de estudio que producen el menor impacto ambiental durante todo su ciclo de vida. 
Escuela Técnica Superior de Ingeniería de Edificación Universitat Politècnica de València

Valencia, 19 y 20 de mayo 2017

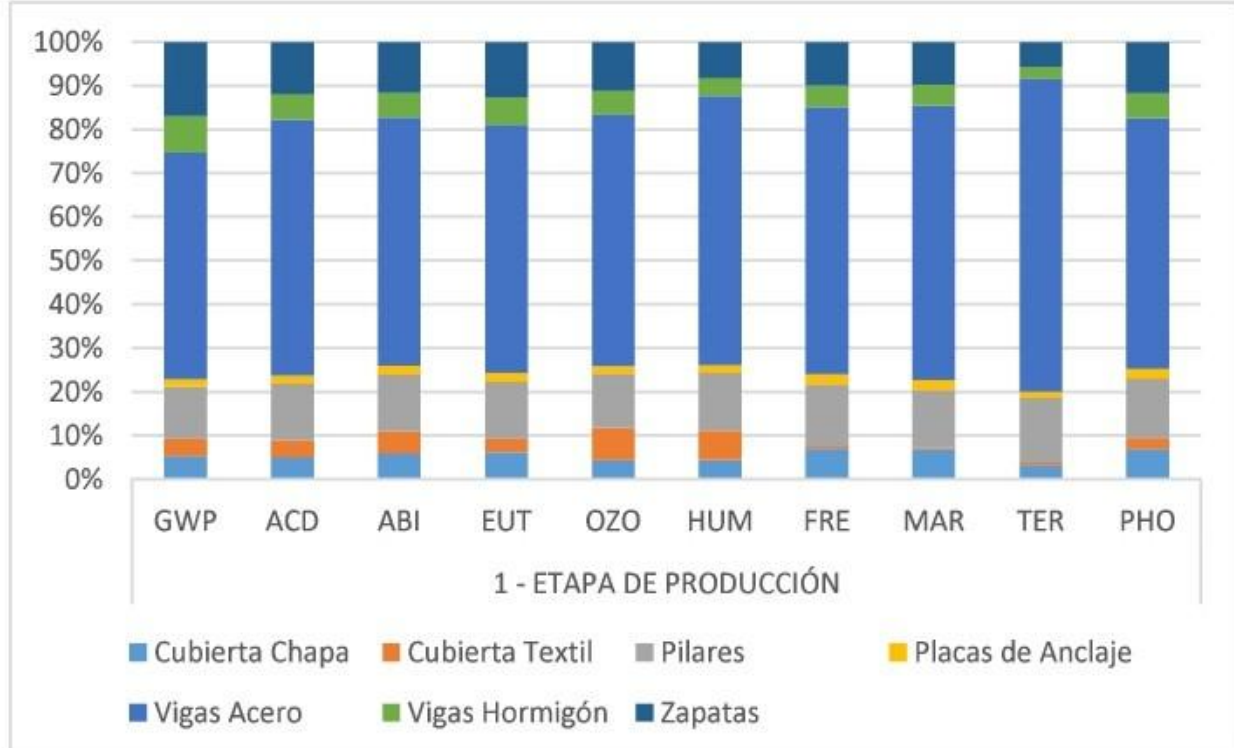

Fig. 2. Porcentaje valores ACV. 2014. TFM Gómez Pérez, Manuel [42].

Categorías de Impacto analizadas: Calentamiento Global Potencial (GWP), Acidificación Potencial (ACD), Agotamiento Abiótico (ABI), Eutrofización Potencial (EUT), Agotamiento de la capa de ozono (OZO), Toxicidad humana (HUM), Ecotoxicidad de agua dulce (FRE), Ecotoxicidad agua marina (MAR), Ecotoxicidad terrestre (TER) y Oxidación fotoquímica (PHO).
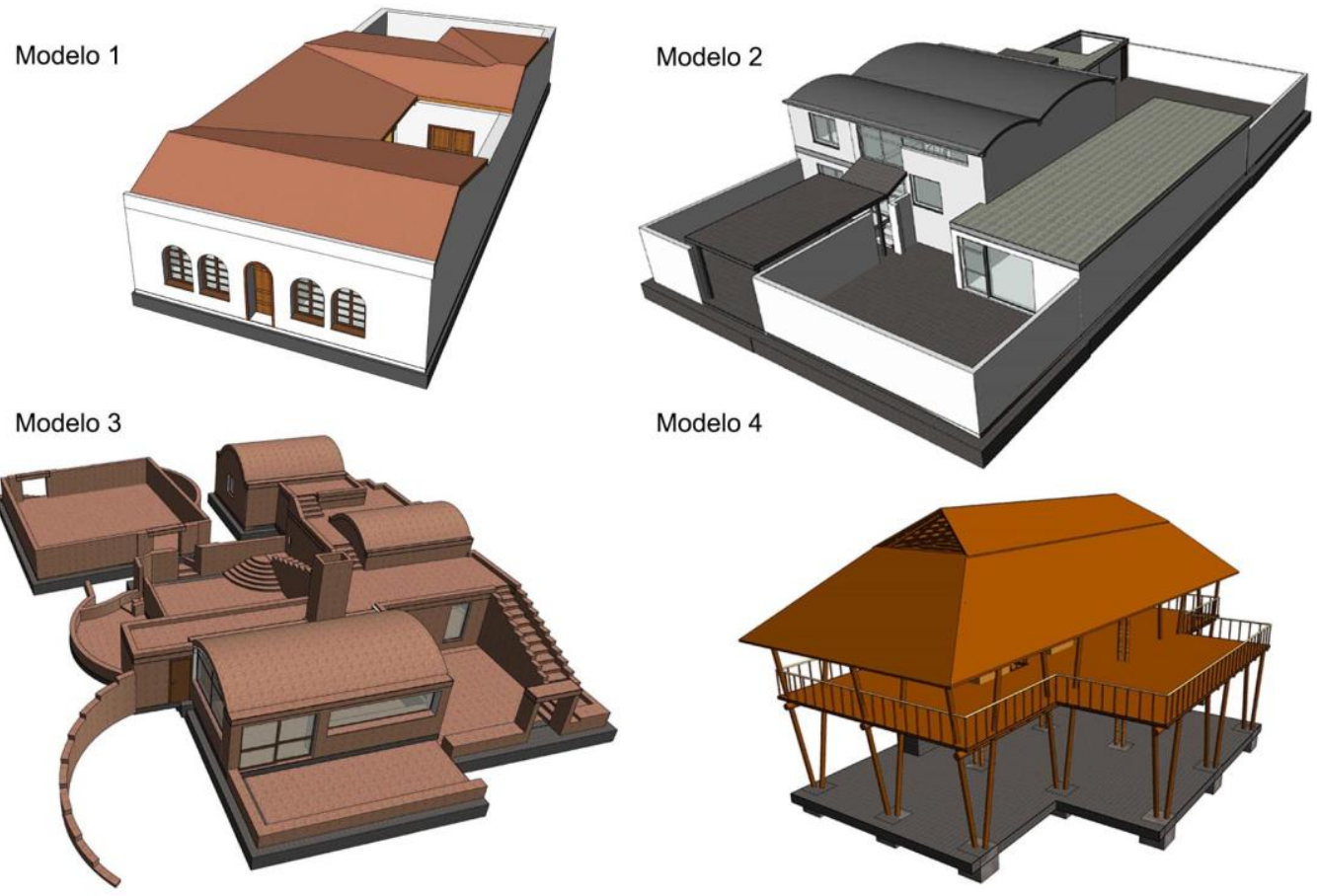

Fig. 3. Casos de estudio en BIM. 2015. TFM Ruiz Alfonsea, Marta [46] 


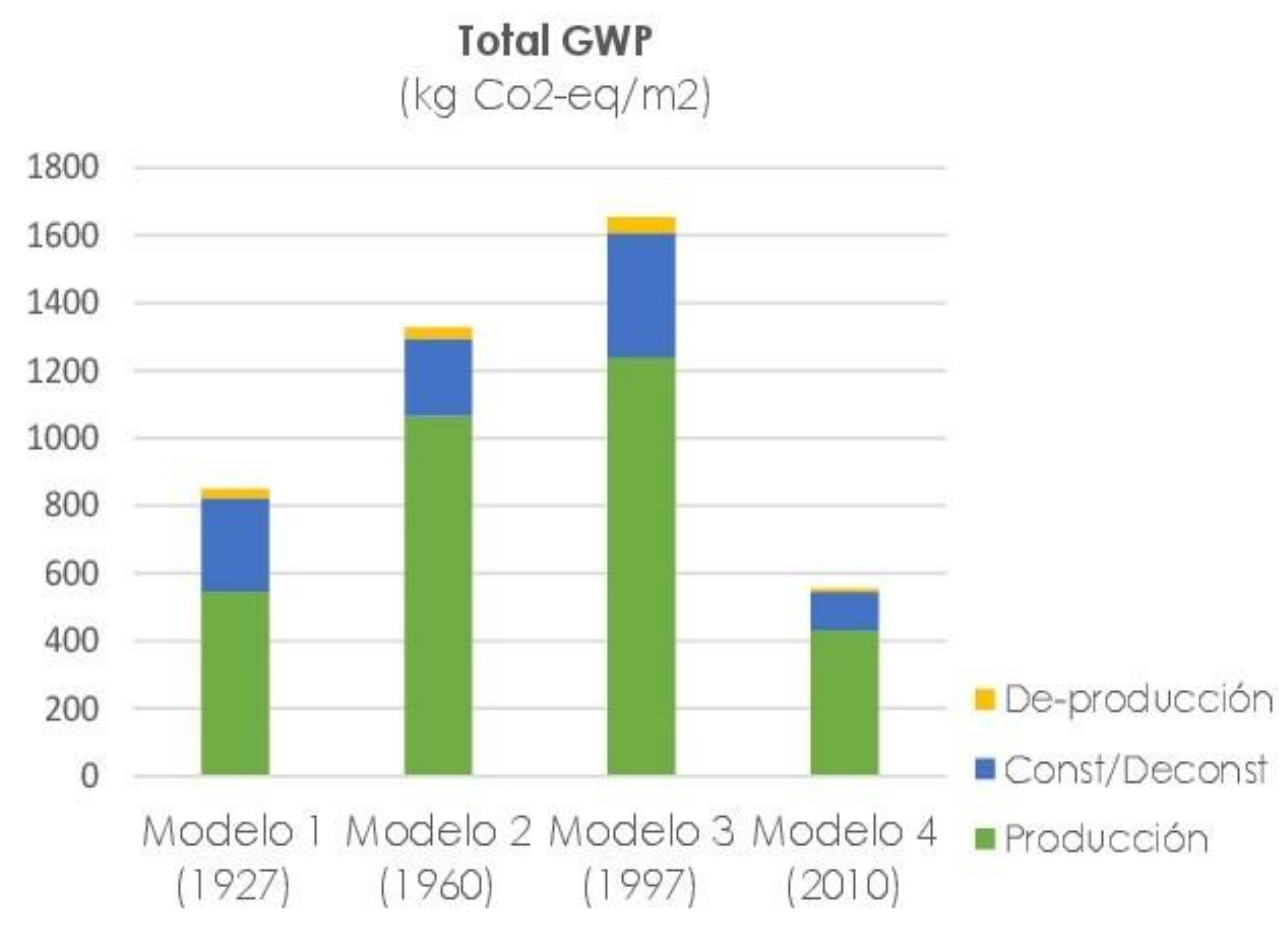

Fig. 4. Resultados ACV categoría de Impacto GWP. 2015. TFM Ruiz Alfonsea, Marta [46]

\section{CONCLUSIONES}

Para que se puedan obtener herramientas versátiles y eficaces para el uso diario es necesario estandarizar, en primer lugar, la metodología de desarrollo del ACV para edificios (que según las normativas que lo regulan, sigue siendo un proceso suficientemente abierto) para, posteriormente, estandarizar la vinculación con sistemas BIM.

La bibliografía que aborda la vinculación BIM-ACV en arquitectura, tal como se ha puesto de manifiesto en las referencias presentadas en esta comunicación, para análisis de edificios, es escasa. En todo caso la que se ha encontrado pone de manifiesto la necesidad, interés y beneficio de vincular estos dos conceptos.

Las herramientas existentes, que actualmente vinculan ACV-BIM, tienen poco alcance y no terminan de abordar por completo la problemática real que implica el análisis de un edificio y la toma de decisiones en fase de diseño. Tal como se ha puesto de manifiesto en los ejemplos analizados, son herramientas de evaluación que necesitan un elemento totalmente definido para poder obtener conclusiones, situación que se aleja de las exigencias del proceso de diseño arquitectónico. Así pues, queda patente que es necesario el desarrollo de una herramienta simplificada que permita obtener resultados de impacto ambiental desde las fases de diseño en tiempo real.

El trabajo realizado por los autores de esta comunicación en el entorno del Máster Universitario en Innovación en Arquitectura: Tecnología y Diseño, pone de manifiesto el 
potencial real de la vinculación ACV-BIM y sus implicaciones en fase de diseño mediante el empleo de software de diseño paramétrico.

En la actualidad se está trabajando en el desarrollo de una herramienta específica ACV-BIM.

\section{REFERENCIAS}

[1] Yeheyis, M., Hewage, K., Alam, M.S., Eskicioglu, C., Sadiq, R. (2012). An overview of construction and demolition waste management in Canada: a lifecycle analysis approach to sustainability. Clean Technologies Environmental. Policy, vol 15, no. 1, 81-91.

[2] Wackernagel, M., Rees, W. (2014) Ecological Footprints for Beginners, The Ecological Design And Planning Reader. Island Press/Center for Resource Economics 501-505.

[3] Karami, P., Al-Ayish, N., Gudmundsson, K. (2015). A comparative study of the environmental impact of Swedish residential buildings with vacuum insulation panels. Energy and Building, vol. 109 183-194.

[4] European Comission, (2010). Energy Performance of Buildings. Directive 2010/31/EU (EPBD), Brusels.

[5] Gundes, S. (2016). The Use of Life Cycle Techniques in the Assessment of Sustainability. Procedia - Social and Behavioral Sciences vol. 216, 916-922.

[6] Sierra-Pérez, J., Boschmonart-Rives, J., Gabarrell, X. (2015). Environmental assessment of façade-building systems and thermal insulation materials for different climatic conditions. Journal of Cleaner Production, vol. 113, 102-113.

[7] Eadie, R., Browne, M., Odeyinka, H., Mckeown, C., Mcniff, S. (2013). BIM implementation throughout the UK construction project lifecycle: An analysis. Automation in Construction, vol. 36, 145-151.

[8] EN 15978, BS EN 15978:2011 (2011). Sustainability of construction works - assessment of environmental performance of buildings - calculation method, Int. Stand.

[9] EN 15643-1, EN 15643-1:2010 (2010). Sustainability of construction works sustainability assessment of buildings - part 1: general framework, Int. Stand. 1-25.

[10] EN 15643-3, EN 15643-3:2012 (2012) Sustainability of construction works - assessment of buildings - part 3: framework for the assessment of social performance, Int. Stand. (2012) 1-36.

[11] Kang H.J. (2015). Development of a systematic model for an assessment tool for sustainable buildings based on a structural framework, Energy and Buildings, vol. 104, 287-301. 
[12] Alwan, Z., Jones, P. Holgate, P. (2016). Strategic sustainable development in the UK construction industry, through the framework for strategic sustainable development, using Building Information Modelling. Journal of Cleaner Production, vol. 140, no. 1, 349-358.

[13] Proietti, S., Sdringola, P., Desideri, U., Zepparelli, F., Masciarelli, F., Castellani, F. (2013). Life Cycle Assessment of a passive house in a seismic temperate zone. Energy and Buildings, vol. 64, 463-472.

[14] Shadram, F., Johansson, T.D., Lu, W., Schade, J., Olofsson, T. (2016). An integrated $B I M$-based framework for minimizing embodied energy during building design. Energy and Buildings, vol. 128, 592-604.

[15] Eleftheriadis, S., Mumovic, D., Greening, P. (2017). Life cycle energy efficiency in building structures: A review of current developments and future outlooks based on BIM capabilities. Renewable and Sustainable Energy Reviews, vol. 67, 811-825.

[16] Soust-Verdaguer, B., Llatas, C., García-Martínez, A. (2017). Critical review of bim-based LCA method to buildings. Energy and Buildings, vol. 136, 110-120.

[17] Soust-Verdaguer, B., Llatas, C., García-Martínez, A. (2016). Simplification in life cycle assessment of single-family houses: $A$ review of recent developments. Building and Environment, vol. 103, 215-227.

[18] Kota, S., Haberl J.S., Clayton, M.J., Yan W. (2014). Building information modelling (BIM)-based daylighting simulation and analysis. Energy and Buildings, vol. 81, 391-403.

[19] Bryde D., Broquetas, M., Volm, J.M. (2013). The project benefits of building information modelling (BIM). International Journal of Project Management, vol. 31, 971-980.

[20] Jalaei, F., Jrade, A. (2015). Integrating building information Modelling (BIM) and LEED system at the conceptual design stage of sustainable buildings. Sustainable Cities and Society, vol. 18, 95-107.

[21] Antón, L., Álvarez Díaz, J., (2014). Integration of life cycle assessment in a BIM environment. Procedia Engineering, vol. 85, 26-32.

[22] Kreiner, H., Passer, A., Wallbaum H. (2015). A new systemic approach to improve the sustainability performance of office buildings in the early design stage. Energy and Buildings, vol. 109, 385-396.

[23] Gómez de Cózar, J.C., García Martínez, A., Ariza López, I., Ruiz Alfonsea, M. (2017). Lightweight and quickly assembled: the most eco-efficient model for architecture. Journal of Computational Methods and Experimental Measurements, vol. 5, no. 4, 539-550.

[24] Pombo, O., Rivela, B., Neila, J. (2015). The challenge of sustainable building renovation: assessment of current criteria and future outlook. Journal of Cleaner Production vol. 123, no. 1, 1-13. 
[25] UNE-EN ISO 14050:2010. (2010). Gestión ambiental. Vocabulario. (UNE-ISO 14050:2009). AENOR, Ed. España.

[26] UNE-EN ISO 14040:2006. (2006). Gestión ambiental. Análisis del ciclo de vida. Principios y marco de referencia. AENOR, Ed. España.

[27] UNE-EN 15804:2012. (2012). Sostenibilidad en la construcción. Declaraciones ambientales de producto. AENOR, Ed. España.

[28] Liu, S., Schulz, U. W., Sapar, M. J., Qian, S. (2016). Evaluation of the environmental performance of the chilled ceiling system using life cycle assessment (LCA): A case study in Singapore. Building and Environment, vol. 102, 207-216.

[29] Pons, O., Nadal, A., Sanyé-Mengual, E., Llorach-Massana, P., Cuerva, E., SanjuanDelmàs, D., Muñoz, P., Oliver-Solà, J., Planas, C., Rovira, M. R. (2015). Roofs of the Future: Rooftop Greenhouses to Improve Buildings Metabolism. Procedia Engineering, vol. 123, 441-448.

[30] Fraile-Garcia, E., Ferreiro-Cabello, J., Martinez-Camara, E., Jimenez-Macias, E. (2017) Repercussion the use phase in the life cycle assessment of structures in residential buildings using one-way slabs. Journal of Cleaner Production, vol. 143, 191-199.

[31] Fernández García, Ferrández-García, A., Ibáñez-Forés, V., Bovea, M. D. (2015). Ecoefficiency analysis of the life cycle of interior partition walls: a comparison of alternative solutions. Journal of Cleaner Production, vol. 112, 649-665.

[32] Iribarren, D., Marvuglia, A., Hild, P., Guiton, M., Popovici, E., Benetto, E. Life cycle assessment and data envelopment analysis approach for the selection of building components according to their environmental impact efficiency: A case study for external walls. Journal of Cleaner Production, vol. 87, no. 1, 707-716.

[33] Sierra-Pérez, J., Boschmonart-Rives, J., Gabarrell, X. (2015). Environmental assessment of façade-building systems and thermal insulation materials for different climatic conditions. Journal of Cleaner Production, vol. 113, 102-113.

[34] Desideri, U., Arcioni, L., Leonardi, D., Cesaretti, L., Perugini, P., Agabitini, E., Evangelisti, N. (2014). Design of a multipurpose "zero energy consumption" building according to European Directive 2010/31/EU: Life cycle assessment. Energy and Buildings, vol. 80, 585-597.

[35] Gervasio, H., Santos, P., Martins, R., Simoes da Silva, L. (2014). A macro-component approach for the assessment of building sustainability in early stages of design, Building Environment, vol. 73, 256-270.

[36] Houlihan Wiberg, A., Georges, L., Dokka, T. H., Haase, M., Time, B., Lien, A. G., Mellegard, S., Maltha, M. (2014). A net zero emission concept analysis of a single-family house, Energy and Buildings, vol. 74, 101-110. 
[37] Iddon, C. R., Firth, S. K. (2013) Embodied and operational energy for new-build housing: A case study of construction methods in the UK. Energy and Buildings, vol. 67, 479-488.

[38] Wong, J.K.W., Zhou, J. (2015). Enhancing environmental sustainability over building life cycles through green BIM: A review. Automation in Construction, vol. 57, 156-165.

[39] KT Innovations, Autodesk. (2016). Tally-Autodesk. http://choosetally.com/

[40] Eosphère SARL. (2016). Cocon-BIM. http://www.cocon-bim.fr/

[41] Mesa González, A. (2013). Análisis de Ciclo de Vida de soluciones arquitectónicas ligeras y de rápido montaje: el Sistema Florín. MIATD, Universidad de Sevilla.

[42] Gómez Pérez, M. (2014). Análisis medioambiental de sistemas constructivos y edificatorios. Desarrollo instrumental a partir de herramientas tipo BIM. MIATD, Universidad de Sevilla.

[43] Navarro Osto, A. (2014). Arquitectura ligera y de rápido montaje: búsqueda de modelos. El Análisis de Ciclo de Vida como herramienta de evaluación y corrección de los diseños. MIATD, Universidad de Sevilla.

[44] Fernández Lobato, L. (2015) Análisis del Ciclo de Vida de los tres modelos ganadores de Solar Decathlon 2014. Obtención de parámetros para el diseño. MIATD, Universidad de Sevilla.

[45] Martín Miranda, M. D. (2015). Análisis del Ciclo de Vida de Construcciones ligeras y de rápido montaje. La obra de Shigeru Ban. MIATD, Universidad de Sevilla.

[46] Ruiz Alfonsea, M. (2015). Análisis del Ciclo de Vida de modelos habitacionales construidos en entorno de clima tropical (Colombia, s. XX-XXI). MIATD, Universidad de Sevilla.

[47] Molinero Morente, M. (2016). Análisis del Ciclo de Vida de modelos constructivos tradicionales en entornos de clima tropical (Colombia, s. XVI-XIX). MIATD, Universidad de Sevilla. 


\section{PROPUESTA METODOLÓGICA PARA LA IMPLEMENTACIÓN DE LA INFORMACIÓN GEOTÉCNICA EN MODELOS BIM}

\section{Martínez-lbáñez, Víctor (1), Pellicer, Eugenio (2)}

(1) Escuela Técnica Superior de Ingenieros de Caminos, Canales y Puertos, Departamento de Ingeniería del Terreno, vicmarib@trr.upv.es

(2) Escuela Técnica Superior de Ingenieros de Caminos, Canales y Puertos, Departamento de Ingeniería de la Construcción, pellicer@upv.es

\section{RESUMEN}

La identificación de imprevistos en fases tempranas del proyecto es uno de las principales ventajas del uso de la metodología BIM; de este modo, los cambios y modificaciones son menos costosos que en las fases de construcción y mantenimiento. La reducción de incertidumbres en las condiciones del terreno debería ser un aspecto principal a tener en cuenta, dado que una gran parte de los problemas en el ciclo de vida de las infraestructuras están relacionados con cuestiones geotécnicas. Para lograr la transmisión efectiva de la información, juega un importante papel la existencia de formatos de transferencia de información digital geotécnica, implantada desde hace años en Reino Unido a partir de archivos AGS, y de la accesibilidad de la información geotécnica histórica en bases de datos como la HAGDMS de la Highways Agency. Teniendo en cuenta este contexto, el artículo presenta una propuesta metodológica para determinar la percepción que tienen los agentes intervinientes en relación con la utilidad de compartir la información geotécnica en base a modelos BIM. Por último, el artículo discute los retos tecnológicos y estructurales que, a juicio de los autores, deberían abordarse para lograr la adaptación de la información geotécnica en la metodología BIM.

Palabras clave: BIM, Building Information Modeling, civil engineering, geotechnical, metodology

\section{ABSTRACT}

Identifying unforeseen problems in the early stages of the project is one of the main advantages of using the BIM methodology; thus, changes and modifications are less expensive than in the construction and maintenance phases. Reducing uncertainties in ground conditions should be a major consideration, given that a large part of the problems in the life cycle of the infrastructure are related to geotechnical issues. In order to achieve the effective transmission of information, have an important role the existence of geotechnical digital information transfer formats, which have been implemented for years in the United Kingdom using AGS files, and the accessibility of historical geotechnical information in databases as the HAGDMS of the Highways Agency. Taking into account this context, the article presents a methodological proposal to determine the perception that the intervening agents have in relation to the utility of sharing geotechnical information based on BIM models. Finally, the article discusses the technological and structural challenges that, 
according to the authors, should be addressed in order to achieve the adaptation of the geotechnical information in the BIM methodology.

Keywords: BIM, Building Information Modeling, civil engineering, geotechnical, metodology

\section{$1 \quad$ INTRODUCCIÓN}

Según la comisión es.BIM [1], la industria de la construcción cuenta con índices de competitividad y productividad más bajos que el resto de sectores industriales. La metodología tradicional de desarrollo y gestión del proceso constructivo no facilita la incorporación de los avances tecnológicos, de innovación y gestión, que facilitarían mejorar los objetivos de plazo, coste y calidad.

Con el objeto de aportar un mayor grado de fiabilidad y precisión al proceso constructivo, la industria se encuentra en pleno proceso de aplicación de la metodología BIM. Según es.BIM [2], "BIM (Building Information Modeling) es una metodología de trabajo colaborativa para la gestión de proyectos de edificación u obra civil a través de una maqueta digital. Esta maqueta digital conforma una gran base de datos que permite gestionar los elementos que forman parte de la infraestructura durante todo el ciclo de vida de la misma".

Así pues, se trata de una pre-construcción digital en la que intervienen de forma colaborativa los diferentes agentes implicados en todo el ciclo de vida de la obra. Esto facilita una concepción de la construcción con gran precisión y bajo grado de incertidumbre, y supone un repositorio único con información ordenada, coordinada, coherente y compartida, con trazabilidad, y que se actualiza en tiempo real durante las fases de la obra: proyecto, construcción, y explotación.

El modelo puede contener toda la información de la construcción, ya sea mediante metadatos o enlaces a documentos externos, y puede cubrir diferentes aspectos, desde la geometría del objeto hasta sus datos físicos, características de ecoeficiencia, coste, tiempo de ejecución, procedimientos de mantenimiento, factura de compra, resumen de los trabajos de mantenimiento o reparación, y también datos relativos a la geotecnia.

A nivel europeo, la Directiva 2014/24/UE sobre contratación pública establece la necesidad de emplear sistemas electrónicos (medios de comunicación y herramientas para modelar los datos del edificio) en procesos de contratación de obras, servicios y suministros a partir de septiembre de 2018.

En España, donde se vienen empleando desde hace tiempo la metodología BIM, principalmente en el ámbito de la edificación, el establecimiento de la hoja de ruta y el calendario de implantación recae en es.BIM, comisión abierta promovida por el Ministerio de Fomento para la implantación de BIM. En su 4a reunión de 22 de julio de 2016 [3], la comisión fijó el objetivo de exigir el empleo de la metodología BIM como requisito para la contratación en licitaciones de edificación en diciembre de 2018, y en licitaciones de infraestructuras en julio de 2019. 
Dada la inminencia en la exigencia del uso de la metodología BIM, deberá estudiarse la oportunidad y viabilidad de incorporar en la metodología BIM la información relativa a la ingeniería del terreno, como parte fundamental en el proyecto, construcción y mantenimiento de cualquier infraestructura. Para ello, deberá revisarse el grado de conocimiento sobre la metodología BIM entre los profesionales del mundo de la geotecnia, la percepción de los mismos sobre las posibles mejoras que puede aportar, determinar qué información es relevante en cada una de las fases del ciclo de vida de la obra, y qué formatos serán necesarios para el intercambio de información geotécnica desde y hacia el modelo.

\section{POR QUÉ INCORPORAR INFORMACIÓN GEOTÉCNICA EN BIM}

La curva de McLeamy [4] refleja cómo influye el esfuerzo de diseño a lo largo del ciclo de vida de la obra. La idea básica es que una obra es mucho más difícil y costosa de cambiar cuanto más desarrollada se encuentra. La metodología BIM concentra el esfuerzo de diseño en fases tempranas, donde puede analizarse más fácilmente diferentes alternativas, y es económico realizar cambios. Además, las decisiones que se tomen en esta fase son las que más impacto tendrán en los costes del ciclo de vida.

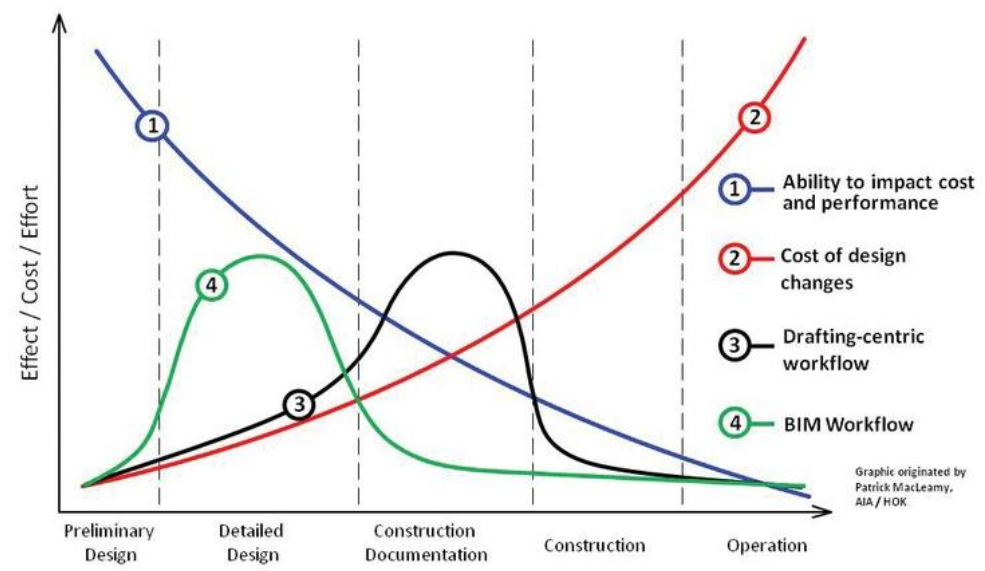

Fig 1. Curva de esfuerzo de MacLeamy. 2010. P. McLeamy (HOK) [4].

La investigación geotécnica es coherente con el esquema anterior. La mayor parte del esfuerzo se centra en las fases preliminares, lo que es esencial para acotar la aparición de imprevistos durante las obras, y de patologías en la etapa de mantenimiento de la infraestructura. Trabajar con la información geotécnica en base al modelo digital colaborativo puede permitir una mejor comprensión e interacción entre los diferentes agentes geotécnicos, logrando una mayor coherencia, facilitando un mejor análisis de alternativas, y contribuyendo a la detección de problemas en fases tempranas.

La investigación realizada por Morin, Hassar y Chandler [5] en Reino Unido, trató de determinar los beneficios reales de la implementación de la información geotécnica en BIM, apoyándose en casos reales, en colaboración con la empresa Mott McDonald, centrándose en las fases preliminares, que corresponden al diseño de la infraestructura. En la fase de planificación de la campaña, disponer de una visualización en 3D de los datos puede 
permitir localizar más cómodamente los puntos donde realizar la campaña de campo, y anticiparse a los potenciales problemas que pueden presentarse in situ. Incluir la campaña de campo en el modelo puede permitir extraer directamente la valoración económica de la misma, compartir datos con la empresa que ejecutará la campaña, y generar documentación 2D de forma más ágil. En esta fase preliminar el modelo se genera a partir de datos cartográficos y bases de datos procedentes de fuentes públicas accesibles, y de los primeros tanteos del equipo de diseño de la infraestructura.

La siguiente fase es la ejecución de la campaña de investigación. El modo de trabajo habitual consiste en que la empresa consultora encarga a la empresa especialista en geotecnia la ejecución de una campaña de campo. Este trabajo dura semanas, tiempo en el que pueden haber cambiado las bases de partida, como puede ser la aparición de terrenos inadecuados, o el planteamiento de nuevas alternativas, y que obligan a cambios en la ubicación de elementos constructivos. Debido a las exigencias de costes y de plazos, por lo general se trata de no alterar ni ampliar la campaña, por lo que se pierde la oportunidad de refinar los resultados de la campaña y que se ajusten mejor a la obra a desarrollar. Las experiencias realizadas en Reino Unido utilizando "software" y archivos de intercambio de datos adecuados, relatan el registro casi inmediato de los resultados de la campaña de campo y de laboratorio, su envío a la empresa consultora, y la visualización en el modelo, facilitando una reacción más rápida frente a imprevistos.

Por último, en la fase de diseño geotécnico el uso de BIM permitiría la comunicación del modelo con el "software" de análisis, tomando información de partida directamente del modelo, y le devolvería información elaborada. Esto supondrá visualizar en el modelo los resultados analíticos cuando se altere, por ejemplo, las dimensiones o la posición de una cimentación, o esta se apoye en terrenos diferentes. Esta fase no está todavía resuelta en gran parte debido a la falta de estándares en los archivos de información geotécnica, por lo que se presenta como un interesante campo de desarrollo.

El estudio de Morin, Hassar y Chandler [5] no llega al estudio en fases de construcción y explotación, pero resulta intuitivo proponer algunas ventajas. En la fase de construcción, disponer de toda la información geotécnica relevante en el modelo permitiría el planteamiento y valoración de nuevas alternativas constructivas, así como reaccionar más rápidamente frente a modificaciones de la obra en curso. En fase de explotación, el modelo puede comunicarse con bases de datos de mantenimiento, lo que le permite servir de repositorio en el que mantener actualizados los datos, aportando una visión histórica.

\section{FORMATOS DE INTERCAMBIO DE INFORMACIÓN}

Es posible vincular información externa con entidades BIM, y de él se puede extraer cualquier documentación de construcción que se desee en función de la información con la que se haya enriquecido el modelo. Para ello, es esencial la existencia de fuentes de información geotécnica accesibles digitalizadas, y el uso de formatos de intercambio de información geotécnica entre los diferentes agentes geotécnicos. 
Morin, Hassar y Chandler señalan la importancia de lo anterior, para poder aplicar BIM a la información geotécnica. En su estudio citan los recursos disponibles en Reino Unido, como es el caso del formato de transferencia de información geotécnica AGS Data, y la base de datos de información geotécnica digitalizada y accesible de la Highways Agency Geotechnical Data Management System (HAGDMS). El formato de intercambio de información geotécnica AGS Data comenzó a desarrollarse en 1989 por la Association of Geotechnical and GeoEnvironmental Specialists (AGS), y actualmente es ampliamente utilizado en la industria de la geotecnia del Reino Unido para intercambiar información geotécnica entre agentes. Además, un gran número de aplicaciones informáticas utilizan este formato. Lo anterior es coherente con la filosofía del BIM, que está pensado para que la información pueda ser gestionada por diferentes herramientas informáticas, extrayendo la información de partida del modelo, gestionándola, para ser devuelta posteriormente al mismo. Los formatos de intercambio de información geotécnica y el "software" específico deben ser coherentes con lo anterior.

El otro pilar fundamental para poder trabajar con un modelo geotécnico es poder enriquecerlo a partir de una base de datos de información geotécnica digitalizada, y de libre acceso. En el caso de Reino Unido, la Highways Agency Geotechnical Data Management System (HAGDMS) responde a esta filosofía. Se trata de una base de datos que recoge información geotécnica de la red principal de carreteras de Reino Unido. La base de datos ofrece información georreferenciada sobre sondeos e informes geotécnicos escaneados, y es accesible por cualquier usuario que se registre. Es ampliamente utilizada y hoy por hoy supone una herramienta fundamental para los profesionales que intervienen en aspectos geotécnicos en todo el ciclo de vida de la obra.

El homólogo al HAGDMS en España es el Catálogo de Información Geocientífica del IGME. El portal web del IGME dispone de información temática amplia, fidedigna, georreferenciada y de acceso rápido, relacionada con una amplia temática dentro de las ciencias de la Tierra. Dentro de su litoteca de sondeos existen datos relativos a las columnas de sondeos y cortes estratigráficos realizados en sus trabajos por el IGME [6]. Los datos se refieren a situación, uso, edad de los terrenos cortados, materiales, ensayos realizados, etc. Sin embargo, para poder acceder a los datos es necesario rellenar un formulario de solicitud de servicio, del que se obtiene un número de registro, y que no da acceso inmediato a la información. Esta forma de obtención de los datos no es ágil, y no facilita la incorporación de la información a la metodología BIM.

El Sistema de Información Geográfica de Urbanismo del Ayuntamiento de Madrid [7] sí permite la consulta, a través de un visor, de los diferentes sondeos realizados en el municipio. La documentación que se ofrece es fácilmente legible y se acompaña de documentación complementaria en PDF. Esta accesibilidad rápida a los datos es muy conveniente, pero el portal no facilita el intercambio de esta documentación en formatos importables por "software" geotécnico. 


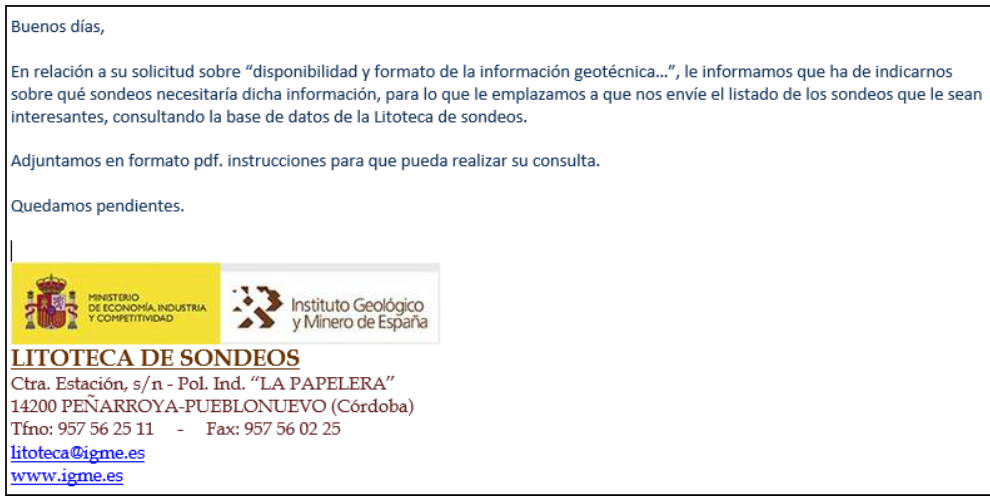

Fig 2. Respuesta de IGME a la solicitud online de datos de sondeos. 2017. Elaboración propia

En general no resulta sencillo encontrar bases de datos con información geotécnica en España, y más difícil que esta se encuentre accesible y georreferenciada. Además, la información no está disponible en formatos que permitan incorporarla a las herramientas de diseño geotécnico, ni al modelo BIM. El uso en España de formatos de intercambio de información geotécnica está todavía por generalizarse. La elección de estándares deberá basarse en el análisis de la idoneidad de los diferentes formatos disponibles, campo que ha sido objeto de diferentes estudios como el de Mokarram [8]. Deberá tenerse en cuenta que, en su esfuerzo por adaptarse a la metodología BIM, la industria geotécnica debería decantarse por estándares abiertos y universales, interoperables entre sí para garantizar el libre acceso a la tecnología, y para ser coherentes con la tendencia en el uso del Open BIM marcada por la comisión es.BIM.

\section{GRADO DE IMPLANTACIÓN DE LA METODOLGÍA BIM EN LA INDUSTRIA GEOTÉCNICA}

Se parte del estudio de Tawelian y Mickovski [9] realizado en Escocia en 2016, que se resume en el análisis DAFO expuesto en la Figura 2. En su caso, combinaron la realización de encuestas a un total de 28 miembros del Scottish Geotechnical Group, con el análisis de un caso real: la estabilización de un terraplén perteneciente a una carretera estatal en Reino Unido.

Es destacable que un $80 \%$ de los profesionales de la geotecnia entrevistados expresa un uso habitual de la metodología BIM. Esta circunstancia es coherente con el grado de maduración presente en Reino Unido. En este sentido, el estudio realizado se refiere un alto grado de acuerdo en que la incorporación de la geotecnia en los modelos BIM mejorará las etapas del ciclo de vida, en términos de coste y tiempo.

Es esperable que lo anterior contraste con la realidad española, en la que el conocimiento y uso de la metodología es mucho menor, especialemente en el mundo de las infraestructuras. También se parte de una situación en la que existe un formato de intercambio de datos establecido desde hace años y comunmente utilizado (AGS), aunque se reconoce que debe ser completado y adaptado para garantizar la interoperabilidad. El 
uso de este tipo de formatos es más limitado en España, por lo que no puede considerarse una fortaleza.

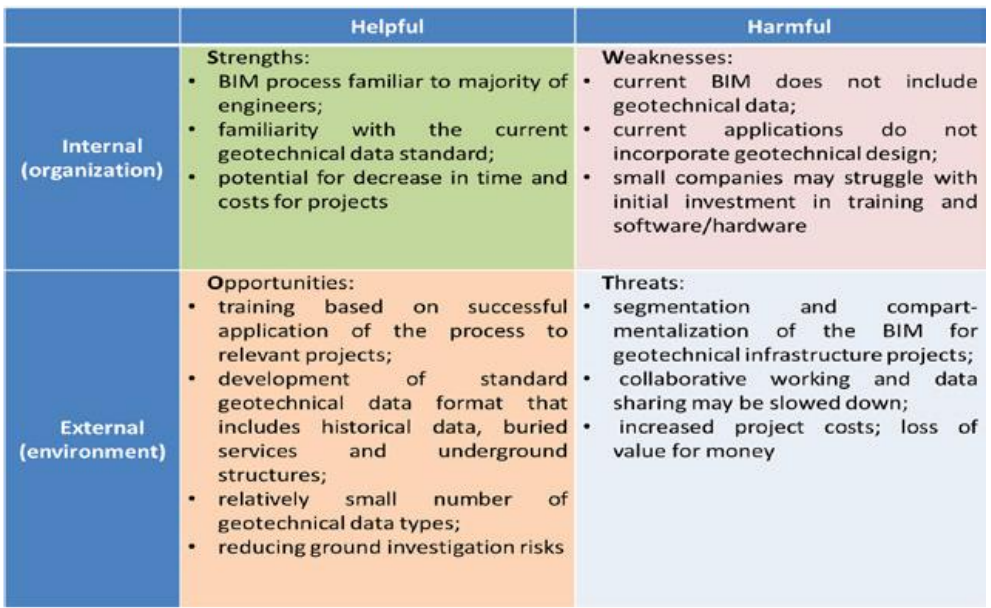

Fig 3. Análisis DAFO. 2016. Tawelian L., Mickovski S [9].

Ambas realidades, española y escocesa, comparten algunos de los retos a afrontar. En el caso de empresas medianas y pequeñas, la inversión en formación e implantación de la metodología BIM puede suponer al inicio unos costes altos en relación a la contratación. La promoción pública y privada debería tener en cuenta este sobreesfuerzo a la hora de planificar la contratación. Al reto anterior deberá sumarse la consolidación de una cultura colaborativa entre los agentes geotécnicos, facilitada mediante el uso de plataformas y formatos adaptados a tal uso.

\section{PROPUESTAS PARA LA IMPLEMENTACIÓN DE LA INFORMACIÓN GEOTÉCNICA EN MODELOS BIM}

La forma en que se incorpore la información geotécnica deberá lograr un amplio consenso en la comunidad geotécnica, y estar coordinada con la implantación general de la metodología BIM en España. Por ello, se propone fomentar la participación de profesionales del mundo de la geotecnia en los diferentes grupos de trabajo que componen la comisión es.BIM.

La información geotécnica que deberá incorporar el modelo tendrá diferentes grados de intensidad en función de la fase de estudio, y deberá permitir el análisis geotécnico, de riesgos geológicos y medioambiental en función del propósito del modelo, del tipo de construcción a abordar, y del tipo de análisis que se desee realizar.

En una primera fase, la de planificación, es necesario disponer de cartografía geológica pública a una escala adecuada, descargable de los repositorios nacionales y autonómicos, y accesible para su incorporación al modelo a partir de formatos GIS. En este sentido, existe una gran diversidad entre Comunidades Autónomas. Por ejemplo, el Insitut Cartogràfic i Geològic de Catalunya pone a disposición del usuario cartografías a escala 1;25.00, así como cartografías de zonas urbanas y de especial interés a escala 1:5000. En el extremo 
opuesto encontramos territorios que no han apostado por desarrollar cartografías adecuadas, y para los que únicamente están disponibles las correspondientes al IGME, po lo general a escala 1:50.000.

De la misma forma, deberá fomentarse la existencia de un registro público de sondeos y calicatas, en el que se pueda acceder a los informes geotécnicos completos, incluyendo también la información geofísica, tomando como punto de partida los avances que se han llevado a cabo en el Ayuntamiento de Madrid. En relación a la disponibilidad de esta información, cabe en este punto diferenciar los estudios geotécnicos realizados para proyectos de infraestructuras, de titularidad pública, y la mayor parte de los estudios para edificación, de titularidad privada. Los primeros son más fácilmente accesibles para formar una base de datos pública, mientras que son necesarios ciertos cambios legislativos para la obtención de los segundos, por lo cual se propone condicionar la obtención de licencias a la entrega de los estudios geotécnicos realizados en un formato adecuado para su incorporación a la base de datos pública.

Para lograr un mayor avance en el desarrollo de cartografías y bases de datos será necesaria inversión pública. Se sugiere la creación dentro de es.BIM de un grupo de trabajo específico, que coordine a colegios y asociaciones profesionales, con el objetivo de transmitir a los gestores públicos la necesidad de invertir en estos desarrollos para lograr infraestructuras más económicas, de calidad y sostenibles.

Deberá también hacerse avanzar el "software" disponible para visualizar e incorporar al modelo la información geotécnica. Recientemente se incorporó a Autocad Civil 3D el denominado Geotechnical Module, que permite visualizar y manipular información geotécnica básica, a partir de archivos de intercambio AGS y CVS. Este "software", que está en constante evolución, no permite todavía la incorporación de datos imprescindibles para el análisis geomecánico como resultados de ensayo o posición del nivel freático.

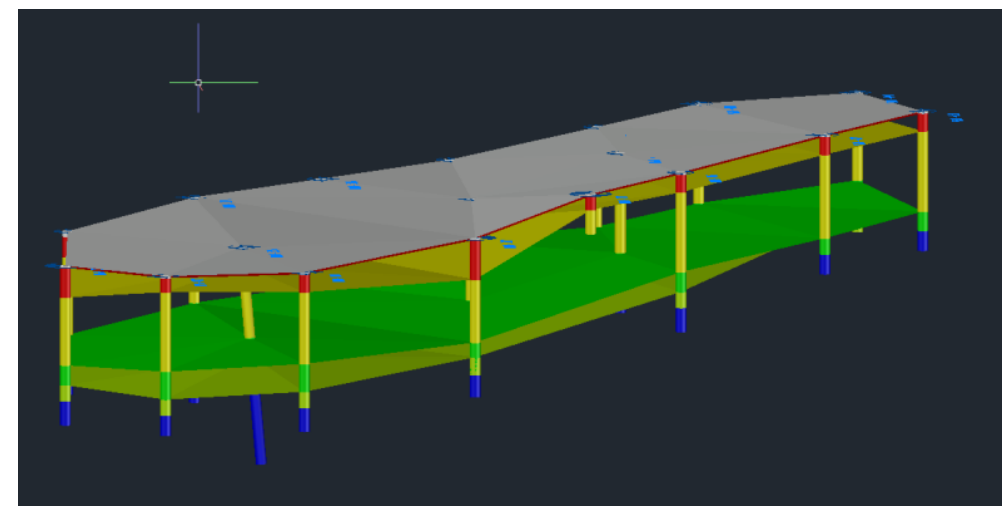

Fig 4. Representación de estratos a partir de datos de sondeos en Geotechnical Module. 2016. Gary Morin, Curso "An Introduction to the Geotechnical Module", Autodesk University.

El mercado del "software" asignará más recursos a estos desarrollos cuando los técnicos demanden este tipo de soluciones. Dado que la comunidad de especialistas en geotecnia en España presenta todavía un bajo grado de conocimento de la metodología BIM, para lograr un avance más rápido se propone el establecimiento de foros, la celebración de cursos y 
congresos donde se de especial relevancia a los modelos geotécnicos. Se considera que una mayor demanda por parte de los técnicos, también hará avanzar el desarrollo de los formatos de intercambio de información geotécnica, y la interoperabilidad entre plataformas de modelado y de análisis geotécnico.

Un reto a afrontar es determinar el tipo de información geotécnica que se debe incorporar al terreno, que diferenciaremos entre objetiva e interpretada. La información objetiva es la procedente principalmente de ensayos de campo y laboratorio, así como de cartografía y bibliografía ampliamente contrastada. La información interpretada es aquella que se elabora para el análisis de un problema específico, y parte de la información objetiva. Es el caso de los parámetros geotécnicos de cálculo que, a partir de unos resultados de ensayo, el profesional de la geotecnia deduce a partir de correlaciones con fórmulas empíricas o modelos de uso común. No es habitual disponer de todos y cada uno de los valores, por ejemplo, de ángulos de rozamiento y cohesión a corto y largo plazo de todos y cada uno de los estratos presentes, sino que el técnico ofrece los más probables según la zona de terreno que se va a ver afectada por las obras, y según el tipo de construcción que se va a realizar (bien sea una cimentación superficial, profunda, o la comprobación de un talud, por ejemplo). Evidentemente en fases posteriores del ciclo de vida de la obra, las zonas de terreno afectadas o el tipo de construcción a acometer pueden variar, siendo necesario disponer de parámetros geomecánicos adicionales a los inicialmente disponibles.

Por todo ello, se sugiere la incorporación de todos todos los datos disponibles al modelo, es decir, la información objetiva y la interpretada. De esta forma, el "software" de análisis podrá acceder a los parámetros geotécnicos disponibles del modelo directamente, pero también podrá ofrecer parámetros geotécnicos adicionales a partir de la información objetiva.

Con el objetivo de lograr el mayor consenso posible entre la comunidad geotécnica, se propone la realización de una encuesta de situación actual, sobre una muestra representativa de profesionales del mundo de la geotecnia. Las preguntas versarán sobre diferentes cuestiones, y que incluirán cuál es el grado de conocimiento sobre el BIM, qué ventajas supondría a criterio del entrevistado la adopción de la metodología, o qué datos serían más relevantes para integrar en el modelo en diferentes supuestos.

Una vez analizados los resultados de la encuesta, se sugiere la puesta en marcha de proyectos piloto donde se pueda extraer conclusiones de la práctica real de la incorporación de la información geotécnica al modelo, observando no solamente las limitaciones técnicas del "software" y sus archivos de intercambio, sino también los roles entre los diferentes agentes geotécnicos que intervienen en la vida útil de la infraestructura, así como las prescripciones a incorporar a los BEP.

Por último, se considera conveniente el establecimiento de un periodo de seguimiento de uso, en el que nuevamente se consultará mediante encuestas a la industria de la geotecnia para determinar cuestiones como el grado de aceptación de la metodología, su influencia en la productividad, o las limitaciones técnicas y operativas detectadas. 


\section{CONCLUSIONES}

El empleo de la metodología BIM será una exigencia en los pliegos de contratación de las futuras obras de edificación y obra civil. BIM es ya una realidad consolidada en el mundo de la arquitectura en España, y se están realizando ya las primeras pruebas piloto en obras de infraestructuras.

Las experiencias e investigaciones acerca de la incorporación de la información geotécnica en la metodología BIM son por ahora escasas. Las realizadas en Reino Unido, donde existe una mayor experiencia en el uso de la metodología, apuntan a la conveniencia de introducir la información geotécnica en los modelos, vislumbran las ventajas económicas, en plazo y calidad que pueden aportar a las obras. También evidencian los retos tecnológicos y estructurales a afrontar, relacionados principalmente con la interoperabilidad entre el modelo y el "software" de análisis, y el desarrollo de los estándares de intercambio de información.

La industria de la geotecnia en España debe tomar conciencia de la circunstancia anterior. Le corresponde valorar la conveniencia de la incorporación de la información geotécnica en la metodología, y estudiar qué datos son los más adecuados en cada fase. Además, deberá afrontar retos adicionales. El conocimiento y uso de la metodología BIM en España es mucho menor, lo que dificultará a los profesionales vislumbrar sus ventajas.

Se propone en el artículo medidas concretas que, a juicio de los autores, pueden contribuir a mejorar la disponibilidad de información de partida, el desarrollo de software y formatos de intercambio de archivos, y la información que deberá incorporarse al modelo.

Para lograr un gran consenso y acelerar el desarrollo en este campo, se considera necesaria la elaboración de una encuesta para tener un conocimiento representativo del estado actual de la implantación de BIM en el mundo de la geotecnia. También acelerará la implantación del BIM en geotecnia la formación de grupos de trabajo específicos dentro de es.BIM, y la posterior puesta en marcha de experiencias piloto, que permitan avanzar en el desarrollo del "software" y formatos de intercambio de archivos, en las relaciones entre los agentes, y en la incorporación de prescripciones específicas en los BEP.

\section{REFERENCIAS}

[1] es.BIM (2016). BIM en 8 puntos. http://www.esbim.es/wpcontent/uploads/2017/01/Documento_difusion_BIM.pdf

[2] es.BIM (2016). Sobre BIM. http://www.esbim.es/

[3] es.BIM (2016). $4^{\text {a }}$ reunión de la Comisión BIM. http://www.esbim.es/wpcontent/uploads/2016/08/esBIM-Cuarta-reunion.pdf

[4] P. McLeamy (2010). Effort Curve. HOK, http://www.hok.com 
[5] Morin, Hassar, Chandler (2014). Case study - The real-life benefits of Geotechnical Building Information Modelling. Information Technology in Geo-Engineering. D.G. Toll et al.

[6] IGME (2017). Litoteca de sondeos. http://info.igme.es/litoteca/

[7] Ayuntamiento de Madrid (2017). Portal del Sistema de Información Geográfica. http://www-2.munimadrid.es/urbanismo_inter/visualizador/index_inter.jsp

[8] Mokarram N. (2010). Data Exchange in geotechnical engineering. A Dissertation Presented to the faculty of the USC graduate school university of Southern California.

[9] Tawelian L., Mickovski S. (2016). The Implementation of Geotechnical Data into the BIM Process. Advances in Transportation Geotechnics 3. The 3rd International Conference on Transportation Geotechnics (ICTG 2016). 


\section{AEROFOTOGRAMETRÍA ESTEREOSCÓPICA: ESTUDIOS TRIDIMENSIONALES Y BUILDING INFORMATION MODELING}

\section{Carrato Gómez, Alfredo (1); Carmona Ayuela, Covadonga (2)}

(1) Arquitecto y BIM Manager, AGi architects, acarrato@agi-architects.com

(2) Arquitecto y especialista BIM, ARGESPLAN 2000, ccarmona@finarsa.es

\section{RESUMEN}

Los avances tecnológicos facilitan el desarrollo creciente de técnicas de extracción masiva y procesamiento de datos, aplicables al sector de la construcción. Como agente productor de big data, la fotogrametría aérea agiliza notablemente la labor de recopilación de información contextual a arquitectos e ingenieros, permitiéndoles abordar proyectos con mayores garantías desde la perspectiva del levantamiento fiable de elementos naturales y/o construidos dentro de su ámbito de estudio.

Las posibilidades derivadas del uso de estas herramientas incluyen (entre otras) el examen minucioso de entornos tridimensionales, el análisis de edificaciones preexistentes, la evaluación del impacto sobre el lugar por parte de las intervenciones propuestas o el planteamiento de opciones de diseño a partir de la información procesada.

La presente comunicación pretende ahondar en el flujo de trabajo de la fabricación de modelos tridimensionales a partir de la aerofotogrametría estereoscópica, y en su conexión posterior con bases de datos y sistemas de modelado de información. Mediante la captura de material gráfico con drones ligeros y su posterior tratamiento con software específico, resulta posible trazar el proceso de transformación de metadatos aparentemente independientes a información cohesionada, todo ello realizado con el fin de aportar conocimiento y valor añadido al producto (modelo) final.

Palabras clave: aerofotogrametría, big data, dron, triangulación, malla.

\section{ABSTRACT}

Technological advances enable the growing development of mass data extraction and management techniques, applicable (among others) to the building sector. As a big data generator, aerial photogrammetry significantly facilitates the process of gathering contextual information to architects and engineers, allowing them to approach projects with greater security from the perspective of reliable survey of natural and/or constructed elements in site analyses.

The possibilities derived from the use of the aforementioned tool include - but are not limited to - detailed exploration of three-dimensional environments, examination of preexisting buildings, impact evaluation of intervention/s on site or design study options that take into consideration the processed information. 
The present paper intends to delve into the workflow of three-dimensional modeling from stereoscopic aerophotogrammetry, plus its subsequent connection with databases and information modeling systems. Through the capture of graphic material with lightweight drones and its successive treatment with specific software, it becomes possible to trace the transformation of apparently unrelated metadata to cohesive information, all carried out in order to provide knowledge and added value to the final product (model).

Keywords: aerophotogrammetry, big data, drone, triangulation, mesh.

\section{$1 \quad$ INTRODUCCIÓN}

El desarrollo reciente de la tecnología ha puesto a disposición del mercado nuevos elementos de captura, extracción y tratamiento de datos que multiplican la capacidad para abordar trabajos relacionados con la construcción de manera más efectiva y eficiente. Uno de los avances más destacados de los últimos años ha sido la fotogrametría aérea [1], que agiliza el levantamiento de modelos tridimensionales a partir de la triangulación de fotografías tomadas previamente desde el aire. Comparada con métodos tradicionales de reconstrucción, la aerofotogrametría [2] permite aumentar el alcance de los trabajos y comprimir los tiempos de ejecución, reduciendo asimismo los costes del proceso y facilitando la interoperabilidad de los modelos generados con otras herramientas de modelado y visualización de información.

Dentro de dichas herramientas pueden incluirse programas de Building Information Modeling, que a partir del modelo tridimensional son capaces de enriquecerlo y/o complementar su información para incorporarlo posteriormente a nuevos modelos de información. Su salida como elemento de realidad virtual o aumentada también resulta posible gracias al rigor geométrico y la texturización fidedigna que realizan los softwares de conversión, así como la utilización del modelo triangulado para elaborar impresiones 3D o infografías con la ayuda de utilidades específicas.

\section{OBJETIVOS}

El objetivo principal de esta investigación es demostrar la capacidad de producir un modelo tridimensional a partir del tratamiento de doscientas cincuenta fotografías, tomadas desde la cámara no profesional de un dron ligero. Se pretende también comprobar la fiabilidad del proceso, la precisión del modelo generado, la capacidad de exportación del mismo a otros softwares y la comparación del método empleado con los procedimientos tradicionales. 


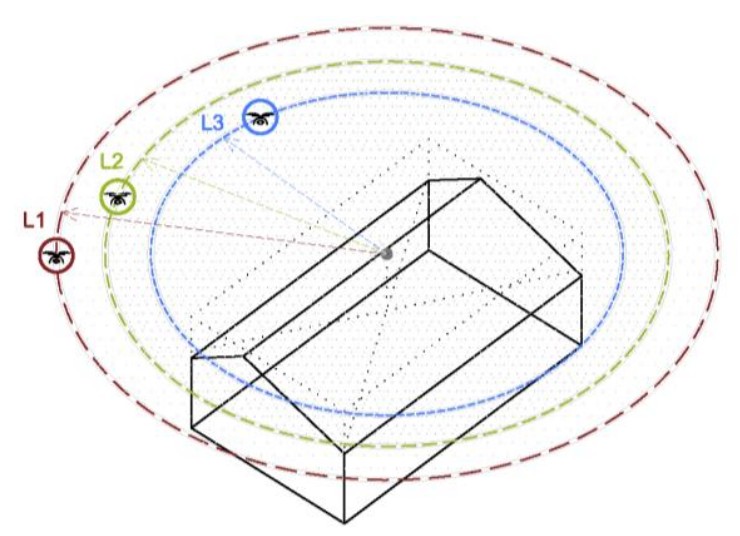

\begin{tabular}{|c|c|c|c|c|c|c|}
\hline & $\begin{array}{c}\text { Radio } \\
{[\mathbf{m}]}\end{array}$ & $\begin{array}{c}\text { Altura dron } \\
{[\mathbf{m}]}\end{array}$ & $\begin{array}{c}\text { Altura objetivo } \\
{[\mathbf{m}]}\end{array}$ & $\begin{array}{c}\text { Ángulo } \\
{[\mathbf{0}]}\end{array}$ & $\begin{array}{c}\text { No de fotos } \\
{[\mathbf{n} \text {; ; o/foto] }}\end{array}$ & $\begin{array}{c}\text { Velocidad dron } \\
{[\mathbf{k m} / \mathbf{h} ; \mathbf{s} / \mathbf{r e v}]}\end{array}$ \\
\hline Nivel 1 [ L1 ] & 48 & 28 & 7 & 27 & $80 ; 4,5$ & 4,$5 ; 240$ \\
\hline Nivel 2 [ L2 ] & 39 & 24 & 3 & 28 & $80 ; 4,5$ & 3,$7 ; 240$ \\
\hline Nivel 3 [ L3 ] & 33 & 20 & 0 & 31 & $90 ; 4$ & 3,$1 ; 240$ \\
\hline
\end{tabular}

Fig. 1. Características y condiciones del análisis. 2017. Elaboración propia.

\subsection{Puntos de partida}

Con el fin de acotar el alcance de la investigación, antes del comienzo de la misma se definen los datos de partida, las condiciones y las premisas a tener en cuenta para los procesos de extracción y tratamiento de los datos:

- El material para la toma de datos (dron ligero, cámara de fotos y aplicación para smartphone) será de uso no profesional, con el fin de demostrar la accesibilidad universal a la tecnología aplicada.

- Entre los propósitos del estudio se incluye la obtención de los mejores resultados con el presupuesto más contenido que sea posible. Se consideran por lo tanto soluciones gratuitas en la elección de softwares y aplicaciones, así como el uso de estándares y formatos abiertos en el proceso investigador.

- El edificio sometido a estudio debiera tener unas dimensiones apropiadas para la inspección, teniendo en cuenta el material empleado y el tiempo requerido. Es por ello que se escoge una construcción cuya superficie en planta no excede los $2000 \mathrm{~m}^{2}$ y su altura los $15-20 \mathrm{~m}$. Cuenta con una accesibilidad magnífica y carece de construcciones adyacentes que pudieran obstaculizar las tareas de levantamiento, con la consiguiente agilización del trabajo de campo.

El experimento que sigue tuvo lugar en el mes de enero del año 2017, en un municipio costero de la provincia de Alicante. Tuvo una duración total de ocho horas de trabajo, repartidas en dos días consecutivos. 
Para llevar a cabo la prueba se definieron tres etapas bien diferenciadas, que necesariamente debían sucederse de manera consecutiva con relaciones fin a inicio. Cada una de ellas se desarrolló posteriormente en un lugar diferente, con unas condiciones y unos condicionantes distintos, que se detallan a continuación.

\subsection{Planificación, provisión de material y programación del trabajo de campo}

En primer lugar se definió el alcance del proyecto y se estimaron su duración y su coste. También se buscó un edificio adecuado para efectuar la investigación, que permitiera extraer la mayor cantidad de información y el mayor número de conclusiones. A partir de dichas premisas se seleccionaron las herramientas adecuadas para acometer el trabajo necesario, que incluyeron un dron ligero con cámara, un smartphone (o tablet) con aplicación específica de programación y un ordenador con software de elaboración de modelos a partir de fotografías.

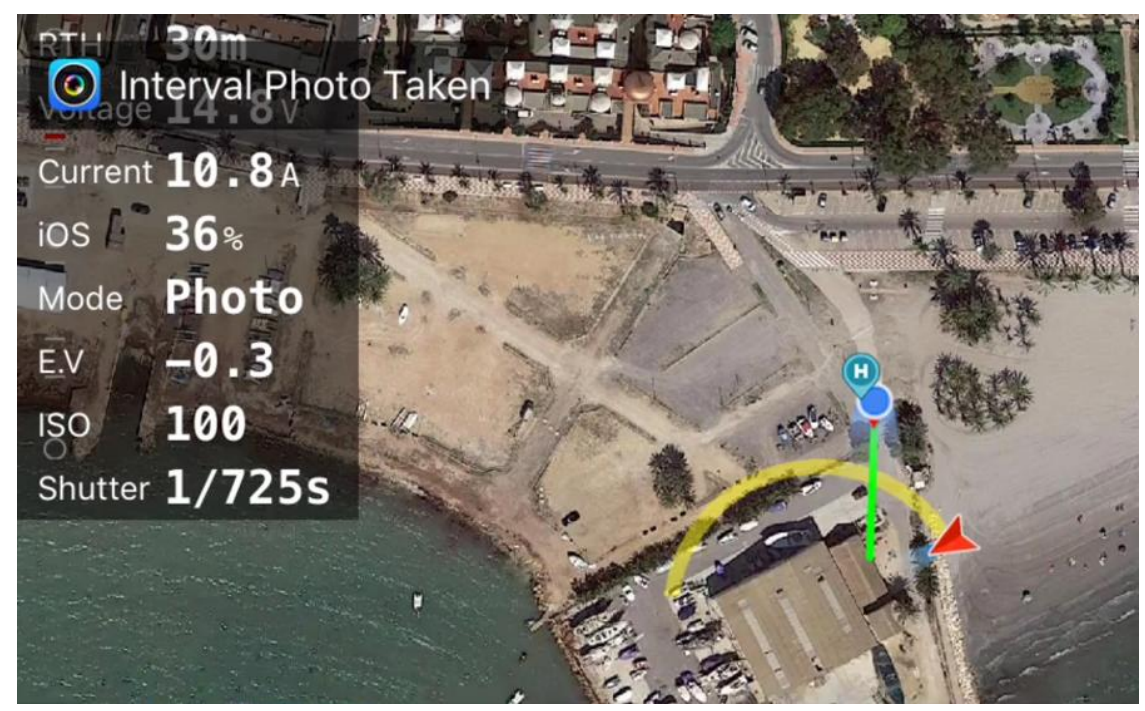

Fig. 2. Toma de fotografías y seguimiento de dron. 2017. FPV Camera for DJI.

Para la toma de las fotografías se escogió un DJl Phantom 3, que en su versión Standard cuenta con una cámara de $12 \mathrm{MP}$ y un objetivo equivalente de $20 \mathrm{~mm}$. En cuanto a la planificación del vuelo, se realizaron previamente unos tanteos con el fin de determinar el número de revoluciones (niveles) necesarias para levantar el modelo completo. También se definieron la distancia entre la construcción y el dron, el ángulo que forman entre ellos y la velocidad del dron para cada una de las vueltas. Una vez fijados todos los parámetros, se introdujeron en la aplicación para móvil FPV Camera for DJl, que es una solución no oficial pero que sin embargo ofrece excelentes resultados en la transferencia de programaciones de vuelos - entre otros tweaks - a cualquier aeronave de la marca china. Tenidas en consideración todas las advertencias y recomendaciones, se procedió a transferir dicha programación al dron ligero. 


\subsection{Trabajo de campo: toma de fotografías y análisis del edificio}

Después de haber programado el vuelo, éste se formalizó en el lugar designado. Se comprobaron previamente las conexiones de la aplicación con el dron, se ajustó la posición definitiva de inicio/final para el vuelo y se aseguró que el recorrido establecido para los tres niveles carecía de obstáculos que impidieran el correcto desarrollo de la prueba. Al final de la jornada de trabajo se obtuvieron un total de doscientas cincuenta fotografías de $12 \mathrm{MP}$, en un tiempo estimado de cincuenta minutos.
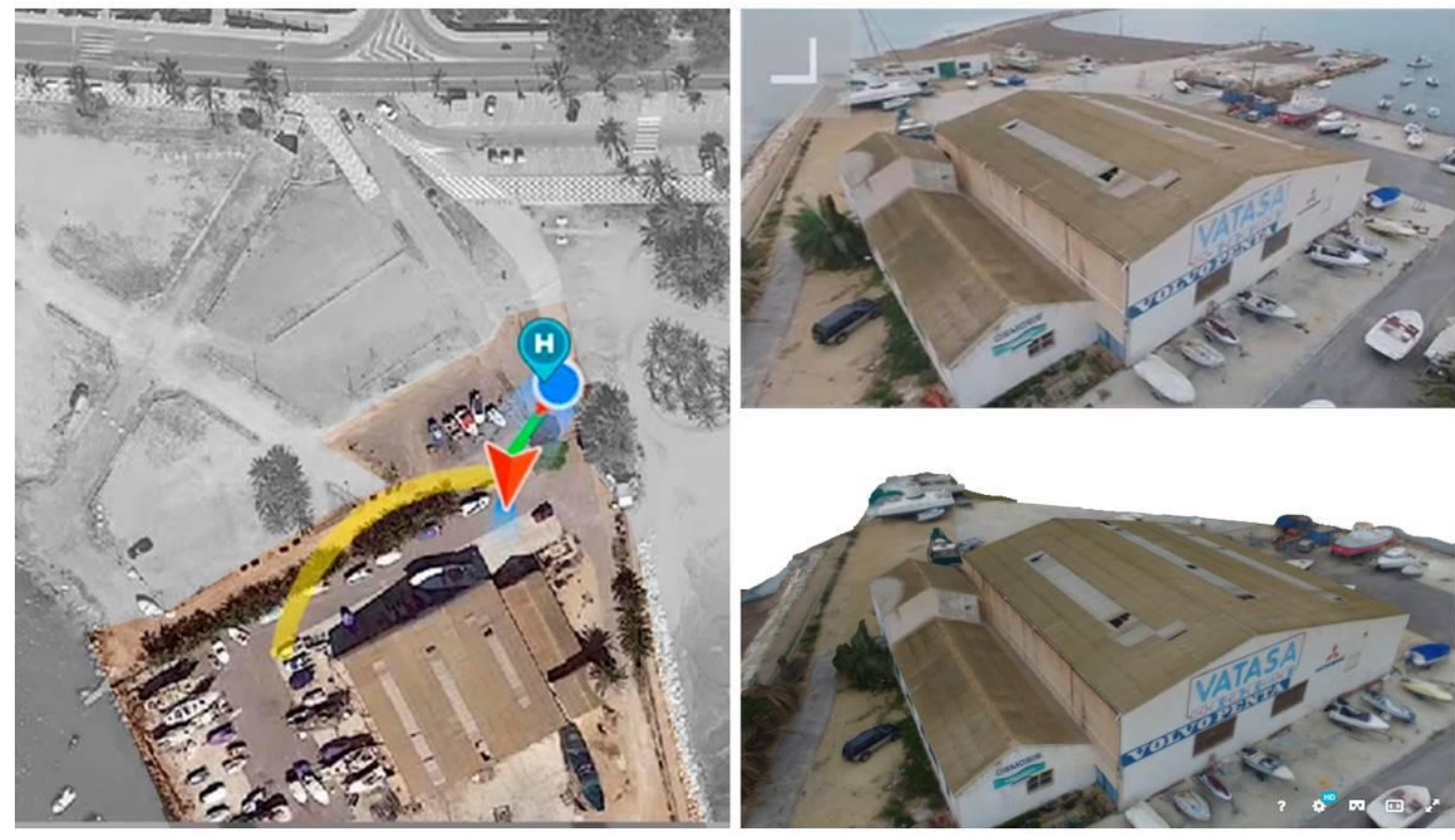

Fig. 3. Recorrido de dron, fotograma de cámara y modelo tridimensional. 2017. Elaboración propia.

\subsection{Tratamiento de material gráfico y levantamiento de modelo tridimensional}

Una vez completado el trabajo de campo, la post-producción de las fotografías se llevó a cabo utilizando software específico para la conversión de la realidad capturada a una malla tridimensional de alta definición. Para ello se escogió la solución Autodesk ReMake, en su versión gratuita para fines no comerciales. Una vez procesados los datos de entrada, el modelo tridimensional resultante quedaba preparado para su tratamiento posterior y exportación a nuevas herramientas, que permitieran un enriquecimiento del mismo y su aportación - útil y valiosa - a futuros modelos de información.

\section{4}

\section{RESULTADOS}

La malla generada en Autodesk ReMake, a partir de las doscientas cincuenta fotografías de $4000 \times 3000$ px procesadas en la nube, contó con 337639 vértices y 587512 polígonos. La precisión del modelo fue centimétrica, y la texturización del mismo sorprendentemente realista. Para documentar el proceso investigador y la solución alcanzada, se llevó a cabo en paralelo la elaboración de un vídeo-resumen que recoge tanto el trabajo de campo realizado como la malla resultante [3]. 
Adicionalmente al levantamiento del modelo, desde la interfaz del programa se permitía la exportación a otros formatos - tales como OBJ, FBX y XYZ - que permiten su importación posterior en distintas plataformas BIM. Asimismo, Autodesk ofrece en su herramienta ReCap 360 soluciones adicionales que profundizan en la reparación, limpieza y edición de las mallas para su uso externo.

\section{DISCUSIÓN}

La fabricación de un modelo completo, digital y tridimensional, a partir de la triangulación de doscientas cincuenta fotografías tomadas desde el aire por un dron ligero, arroja en su mayoría resultados solventes y algunas reflexiones a tener en consideración. El proceso investigador cubre de manera sobrada los objetivos iniciales, y las estadísticas manifiestan una optimización en el alcance, los tiempos, el coste y la calidad del producto final con respecto a los métodos tradicionales. En comparación con el levantamiento de modelos a partir de escaneos tridimensionales, la aerofotogrametría proporciona un mayor alcance a menor precio y en un tiempo más reducido, en detrimento seguramente de la precisión absoluta del modelo generado.

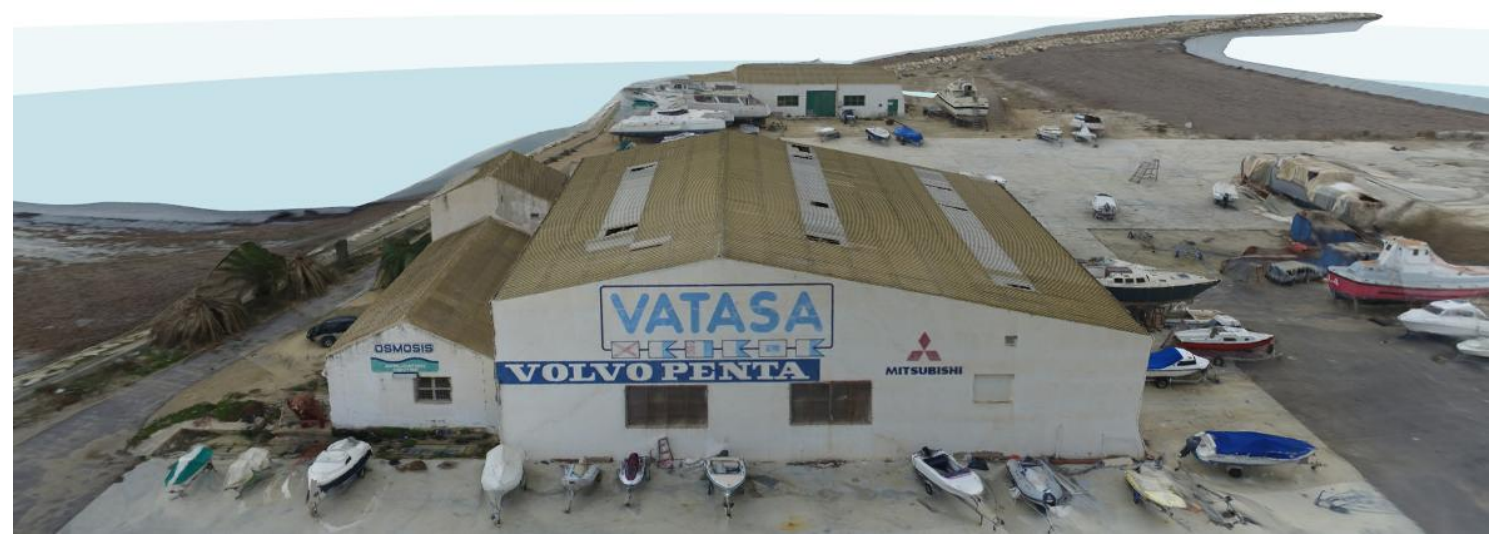

Fig. 4. Fotograma de modelo tridimensional. 2017. Autodesk ReMake.

En cuanto a posibles limitaciones detectadas en el transcurso del experimento, destacan sobre las demás aquéllas relacionadas con las propiedades de la perspectiva aérea [4]. La posición del dron durante el análisis puede causar que ciertos elementos resulten inaccesibles a su cono capaz de visión, ya sea por encontrarse bajo voladizos, cubiertas u otros cuerpos de considerable dimensión. La solución reside en afinar la programación del vuelo, aproximando el dron por debajo de dichos elementos a fin de que el ángulo que forma la cámara con la construcción permita capturar el máximo número de volúmenes desde el mayor número de puntos de vista. También se ha detectado que la resolución de las fotografías, el nivel de superposición de las mismas o el rendimiento del material de levantamiento son susceptibles de influir en el resultado final. Otras limitaciones incluyen la duración de las baterías del dron (alrededor de veinticinco minutos cada una), lo cual para un experimento de estas características resultó significativamente restrictivo. 


\section{CONCLUSIONES}

El método practicado confirma la solvencia del levantamiento de modelos tridimensionales triangulados a través de la aerofotogrametría. A su vez, las impresiones extraídas de la presente investigación invitan a determinar que, una vez obtenidos, el abanico de posibilidades y aplicaciones derivadas de dichos modelos permiten su contribución y beneficio en un elevado número de situaciones o supuestos:

- El análisis riguroso de entornos tridimensionales, dentro del cual se incluyen la reconstrucción volumétrica de parcelas y superficies destinadas al diseño y construcción de infraestructuras y/u otros proyectos urbanísticos, edificatorios o de índole dotacional.

- La inspección de edificaciones y construcciones existentes [5], consiguiendo mayor precisión en la determinación de los estados de los mismos. Asimismo, dicho proceso facilita también la reducción en los tiempos de ejecución de los trabajos de campo, así como la posibilidad de gestionar un mayor volumen de información de manera remota.

- La evaluación del impacto sobre el lugar por parte de la/s intervenciones propuestas, que mejora el resultado y el alcance de métodos tradicionales gracias a la viabilidad de realizar simulaciones virtuales $u$ otras pruebas específicas.

- El planteamiento de opciones de diseño a partir de la información procesada, permitiendo la consideración de implicaciones que de otra manera no habrían sido tenidas en cuenta y obteniendo una óptima respuesta al mayor número de variables como sea posible.

- El levantamiento de modelos tridimensionales durante el seguimiento de las obras, que facilita la mejora - en términos cualitativos - de la ejecución material de las mismas. De igual manera resulta posible abordar la optimización en la utilización de recursos, con un mayor y mejor control gracias a la creación de modelos periódicos en tiempo (casi) real.

- La impresión 3D y los modelos de realidad virtual/aumentada, cuya creación refuerza la comprensión de espacios y relaciones a clientes y otros interesados en los proyectos de construcción. Las mallas generadas a partir de la fotogrametría son compatibles con la tecnología necesaria para elaborar dichos productos, siendo susceptibles de incorporar la información necesaria para aportar mayor realismo a las soluciones adoptadas.

- La creación de un registro de modelos tridimensionales, que puede utilizarse por parte de entidades (públicas y/o privadas) para su clasificación, análisis, tratamiento e incorporación a portafolios de proyectos.

- El levantamiento (a mayor escala) de modelos urbanos a partir de información georreferenciada - GIS - que puedan ser utilizados posteriormente para enriquecer mapas, planos $u$ otros sistemas dependientes en tiempo real [6]. 


\section{REFERENCIAS}

[1] Mikhail, E.M; Bethel, J.S; McGlone, J.C. (2001). Introduction to Modern Photogrammetry. New York: John Wiley \& Sons, Inc.

[2] Wolf, P; Dewitt, B; Wilkinson, B. (2014). Elements of Photogrammetry with Applications in GIS, Fourth Edition. New York: McGraw-Hill Education.

[3] Carrato, A. (2017). VATASA - stereoscopic aerophotogrammetry [archivo de vídeo]. Disponible en: https://vimeo.com/203819104 [último acceso: 26 de abril de 2017].

[4] Scapozza, C; Schenker, F.L; Castelletti, C; Bozzini, C; Ambrosi, C. (2016). Digital monoand $3 \mathrm{D}$ stereo-photogrammetry for geological and geomorphological mapping. EGU General Assembly Conference Abstracts, vol. 18, 4787.

[5] Tuttas, S; Braun, A; Borrmann, A; Stilla, U. (2015). Validation of BIM Components by Photogrammetric Point Clouds for Construction Site Monitoring. ISPRS Annals of the Photogrammetry, Remote Sensing and Spatial Information Sciences, vol. II-3, 231-237.

[6] Ahmadi, F.F; Ebadi, H. (2009). An Integrated Photogrammetric and Spatial Database Management System for Producing Fully Structured Data Using Aerial and Remote Sensing Images. Sensors (Basel), vol. 9(4), 2320-2333. 


\title{
USO DE BIM EN LA FASE PRELIMINAR DEL DISEÑO ARQUITECTONICO. ESTADO DEL ARTE
}

\author{
Folgar Erades, Alejandro (1), Vazquez Vicente, Enrique (2), Sánchez Sánchez, José (3)
}

Arquitecto, Doctorando en la Universidad de Sevilla, alefolera@alum.us.es

Arquitecto, Profesor Asociado en Dto. Estructuras de Edificación e Ingeniería del Terreno, ev@us.es

Arquitecto, Catedrático en Dto. Estructuras de Edificación e Ingeniería del Terreno, josess@us.es

\section{RESUMEN}

En la actualidad, la concepción y diseño del proyecto arquitectónico en sus fases preliminares no se está beneficiando de todo el potencial que ofrecen las tecnologías en general, y en concreto, las metodologías BIM. Es por ello que uno de los principales objetivos de este estudio, sea identificar las ventajas y posibles carencias del uso de este tipo de software en esta fase temprana, pero a la vez determinante, del proyecto arquitectónico; y por otro lado, concretar la forma en que pueden colaborar los distintos agentes que en él intervienen.

Aunque el uso de BIM está considerablemente extendido, su empleo se limita en general, al desarrollo técnico del proyecto y la gestión y/o control de la obra. Es decir, empleamos la tecnología BIM para calcular, justificar, documentar, coordinar, hacer simulaciones y muchas otras tareas; pero en cambio, la concepción del diseño arquitectónico suele partir en la mayoría de los casos, de la experiencia de lo ya construido (se hace así desde la edad media) o de una idea base preconcebida, la llamada idea de proyecto, que se chequea y adapta después para cumplir con los requerimientos urbanísticos y la normativa técnica.

Existe, por tanto, un enorme potencial aún por explorar, en cuanto a la concepción arquitectónica y el apoyo del software a estas tareas. Sin entrar en los aspectos más artísticos, personales o abstractos, el domino de la técnica y de las herramientas que ésta pone actualmente a nuestro alcance, es también fundamental para que el producto arquitectónico final sea la mejor versión de sí mismo.

Palabras clave: BIM, diseño arquitectónico, diseño conceptual, preliminar.

\section{ABSTRACT}

Nowadays, concept design in architectural process on early stages, is not taking the fully potential of, broadly speaking, technology and specially BIM processes. At that point, the aim of this paper is point at advantages and shortcomings, os using this kind of software on early conception of the building framework; and on the other hand, specify the way that can collaborate the different stakeholder whom are involved.

Although the use of BIM is considerably extended, use is generally limited to the technical development of the project, and the management and/or control of the work. I.e., we use the Bim technology to calculate, justify, document, coordinates, do simulations and many other tasks; but instead, the conception of the design architectural usually splitting in it most of them cases, of the experience of it already built (is makes so from the middle ages) or of an 
idea base preconceived, it called idea of project, that is checks and adapts then for meet with them requirements urban and it normative technical.

There is therefore a huge potential yet to explore, in terms of the architectural design and software support for these tasks. Without going into the aspects more artistic, personal, or abstract, on the other hand aspects inherent to this phase; the domino of the technique and tools it currently puts at our disposal, it is also essential to make the final architectural product the best version of itself.

Keywords: BIM, architectural design, conceptual, preliminary design.

\section{INTRODUCCIÓN}

La mayoría de los esfuerzos, implantaciones, desarrollos e investigaciones acerca de BIM que se están desarrollando en el sector AECO (Architecture, Engineering, Construction and Operation), se enmarcan en las fases de producción, construcción y mantenimiento. Es importante, antes de nada, recalcar que el encuadre disciplinar de este documento es el diseño arquitectónico, por tanto, se centra en una parte muy pequeña del proyecto en el sentido amplio del término, que comprendería desde su concepción a la explotación.

El objeto de esta comunicación es profundizar en el uso de BIM y analizar su idoneidad para las fases previas del proyecto, el diseño preliminar o conceptual, el anteproyecto o ciertos aspectos del proyecto básico. También se pretende analizar el estado de la cuestión y buscar nichos de oportunidad o temas en los que profundizar en estudios más específicos.

Las fases preliminares del proyecto, tanto si hablamos de BIM como herramienta o como metodología, no están actualmente suficientemente exploradas. La mayoría de los artículos y publicaciones científicas se centran en otros aspectos de la edificación y construcción, obviando estas primeras fases del diseño arquitectónico.

Generalmente, cuando se piensa en fases previas en relación con el BIM, solo se tiene en cuenta la geometría al considerar que BIM aporta 3D, y que en las siguientes fases iremos añadiendo 4D, 5D, etc. [1]

Los temas más recurrentes, cuando hablamos de BIM en fases tempranas, son principalmente dos: las geometrías complejas, incluyendo la llamada arquitectura paramétrica o driven-design; y los análisis previos de sostenibilidad y comportamiento energético.

Esta concepción de BIM, desaprovecha un gran potencial y podríamos estar gestionando un modelo preliminar, con una gran cantidad de información útil en esta fase y que vaya evolucionando, completándose y definiéndose en las siguientes fases

Pensamos que la metodología y las herramientas BIM tienen algo más que aportar a estas fases del proyecto, y es posible utilizar de una forma más productiva y útil el modelado de información desde la concepción de la idea arquitectónica. 


\section{ESTADO DEL ARTE}

El mundo BIM está más enfocado actualmente a la producción que al diseño. En España especialmente, pero incluso en países con una madurez BIM importante como Estados Unidos, autores como Briscoe [2] reflejan esta realidad. Aunque es cierto que ciertas oficinas y empresas de arquitectura tienen completamente integrado e interiorizado la metodología y las herramientas BIM como partes fundamentales de sus diseños desde el momento inicial; generalmente, estos estudios son también los que se decantan por optar por una arquitectura paramétrica o generativa. [3], [4].

\subsection{Investigaciones y artículos sobre BIM}

Como primera aproximación, se ha realizado en una de las bases de datos de mayor influencia científica como es "Web of Science" de Thomson Reuters (en adelante WoS), una búsqueda sobre "BIM", limitándola a los campos de arquitectura, construcción e ingeniería. De los resultados obtenidos, y que se muestran en la figura 1, se desprende que los artículos que incluyen "BIM" como palabra clave se concentran en los años 2010 a la actualidad, lo que podemos considerar incluso lógico. Además, el número de estos artículos crece de forma exponencial en estos años, y lo mismo ocurre con las citas o referencias. No obstante, cabe destacar que desde el 1998 ya se recogen en la WoS artículos con este acrónimo.

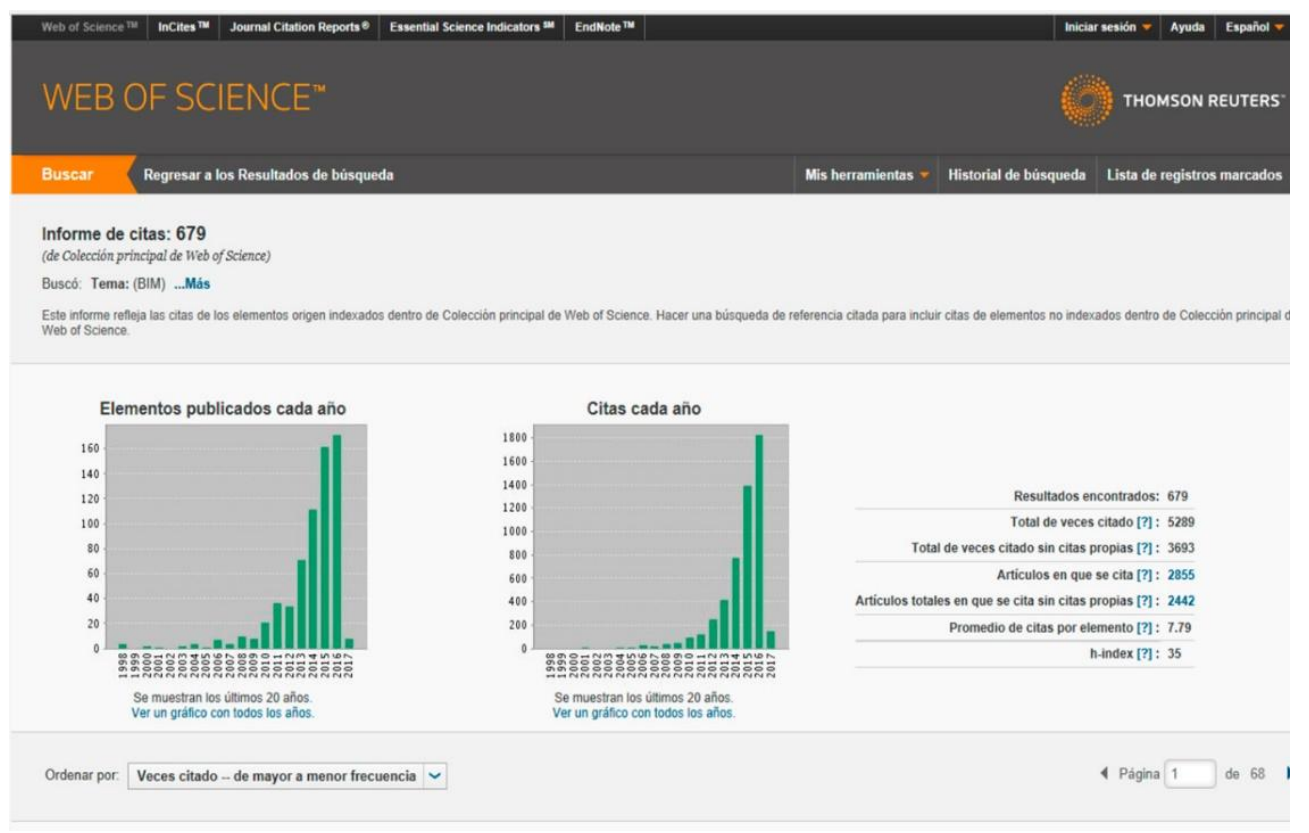

Fig 1. Búsqueda del término "BIM". Febrero 2017. webofknowledge.com

Después de realizar estas búsquedas, se ha realizado una selección con los 100 artículos más citados en la colección principal de WoS. Estos artículos los hemos agrupado en función de la temática general que abordan, y que se recogen en la figura 2, quedando patente la escasez de artículos que abordan puramente temas de diseño arquitectónico. En publicaciones dedicadas al análisis de las investigaciones en temática BIM, como el profundo análisis semántico para detectar temas principales y tendencias en las 
publicaciones sobre esta materia realizado por Yalcinkaya y Singh, Aalto University [5] y otros estudios de la literatura existente [6] o [7]; observamos que las temáticas siguen el mismo patrón, y el diseño arquitectónico está poco presente en las publicaciones sobre BIM.

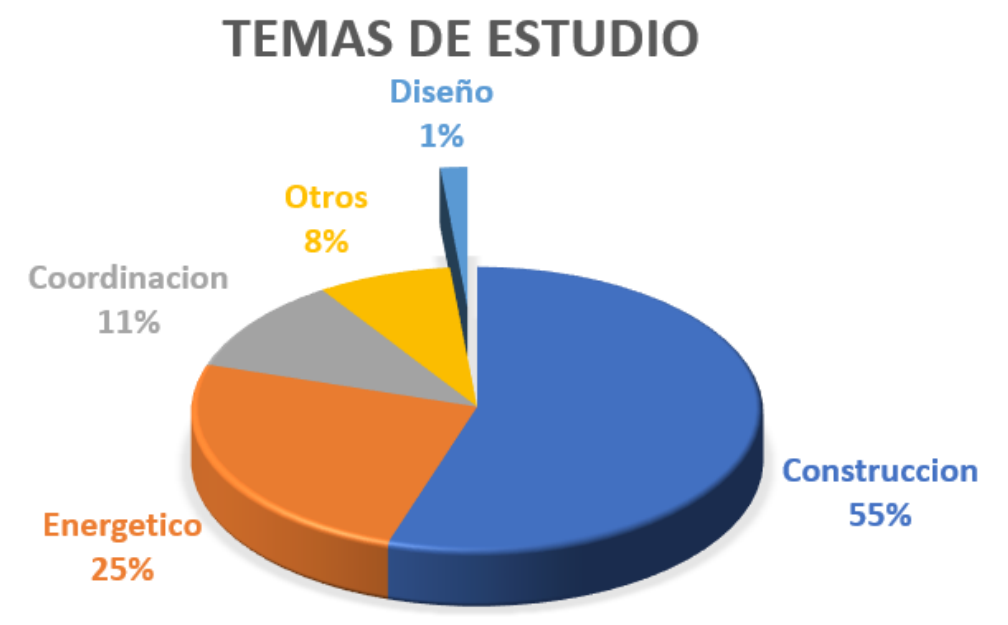

Fig 2. Clasificación de los principales estudios sobre BIM. Febrero 2017. Elaboración propia

\subsection{Adopción de BIM en fases preliminares por los arquitectos}

En relación con la adopción por parte de los arquitectos de la metodología BIM [8], encontramos estudios recientes que determinan que la mayoría de los arquitectos la perciben como una tecnología útil, pero solo en ciertos ámbitos; y la consideran muchas veces poco dinámica para las fases previas de proyecto (anteproyecto o incluso proyecto básico) [9]. Algunos estudios, como muestra el gráfico de la figura 3, reflejan que los arquitectos en general, confían más en BIM cómo método para simplificar las tareas repetitivas y la documentación del proyecto, o controlar los costes de la obra, que como herramienta para el desarrollo del proyecto en fases tempranas [10] [11].

Existe también una tendencia a pensar que los métodos tradicionales de dibujo son más adecuados para estas fases, y hay cierto estigma en general al dibujo generado por ordenador, por considerarlo no tan expresivo o creativo [12]. No obstante, es cierto que la percepción de los arquitectos por el dibujo asistido está evolucionando $\mathrm{y}$, aunque consideramos que siempre será necesario el dibujo hecho a mano [13], cada vez es más aceptado y valorado el dibujo producido por medios digitales. Algunos arquitectos que utilizan BIM en sus procesos de trabajo siguen considerando, como recoge la entrevista a Elena Manferdini [2], que es muy útil para colaborar con otros agentes o definir ciertos aspectos del proyecto, pero "en nuestro flujo de trabajo, uno de los momentos más interesantes es cuando convertimos nuestros modelos tridimensionales en bidimensionales... cuando los volúmenes se vuelven planos, algo interesante tiene lugar... 
la horizontalidad es donde las artes plásticas, diseño gráfico, arquitectura o pintura pueden coexistir en un plano abstracto".

Respecto a las herramientas específicas existentes en el mercado para diseño preliminar, existen algunas como Formit o Dynamo [14] que podemos englobar dentro de la metodología BIM. El uso de estas herramientas se puede integrar dentro del proceso de diseño y luego ir avanzando por las diferentes fases, aunque no es menos cierto que estas herramientas solo cubren aspectos muy concretos de las fases previas, como pueden ser modelado de masas o diseño paramétrico a través de programación visual. También existen herramientas de chequeo automático de modelos y comprobación de ciertas normativas; como Sheperd, que define como verificación automática de diseños en BIM [15]. Otra herramienta de este tipo es Solibri Model Checker, pero tiene la particularidad de no estar integrada en los programas de diseño y estar pensada más como control externo que como ayuda para el desarrollo del mismo.

Thinking about the projects you were involved in last year, did you...

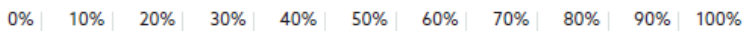

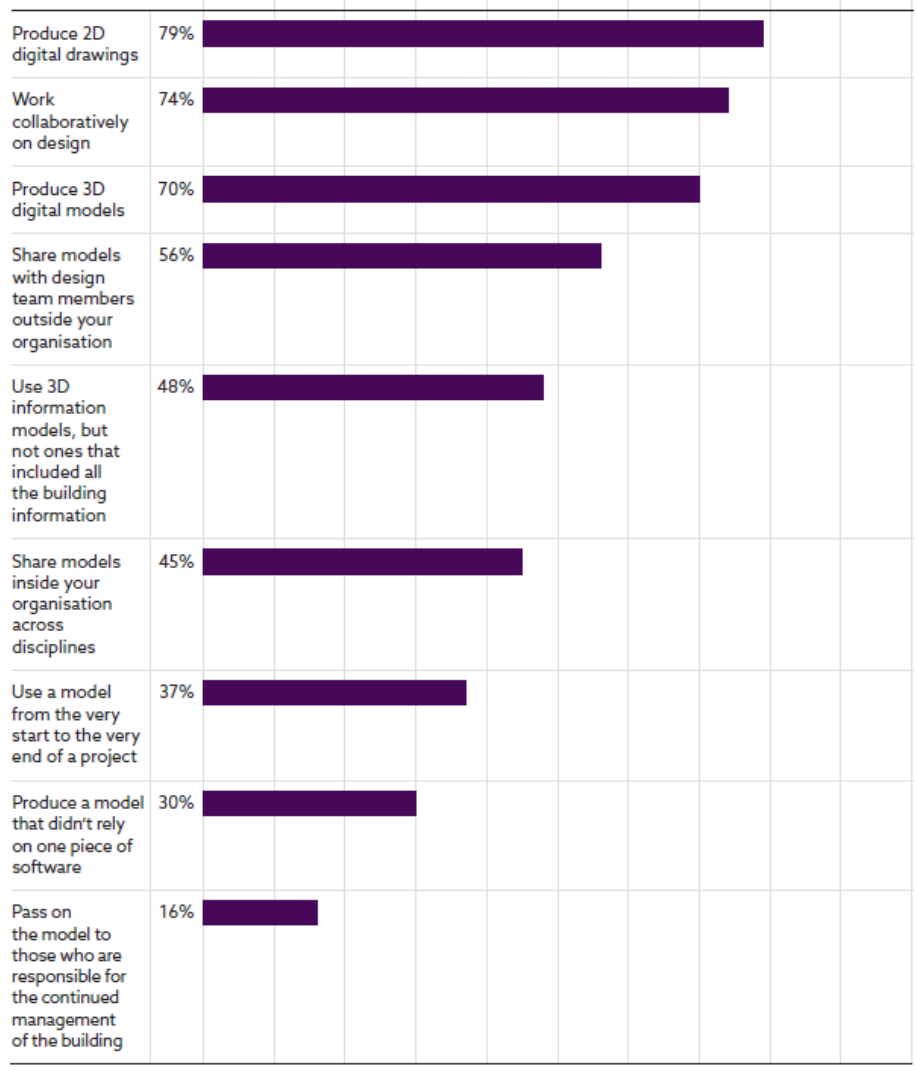

Fig 3. Tareas realizadas con BIM. 2016. National BIM Report [11]

\subsection{Diseño paramétrico}

El diseño paramétrico es, actualmente, un recurso habitual en la fase conceptual del diseño arquitectónico. Algunas veces utilizado solo para configurar formalmente el edificio, pero cada vez más como forma de incorporar datos, de diversas fuentes y de muy distinto 
contenido. En este sentido, nos parece especialmente interesante disponer de datos que, directa o indirectamente, pueden conformar y/o armar el proceso de diseño arquitectónico.

Algunos autores hablan de "un nuevo estructuralismo" [16], y ciertamente parece adecuado pensar que este tipo de arquitectura está muy relacionada con el diseño estructural y muchas veces la propia definición del edificio y la sustentación vienen definidas por un proceso reiterativo de afinado tanto de la forma como de la materialidad. Algunos ejemplos muy significativos de este tipo de arquitectura se muestran en la figura $n^{\circ} 4$. Son algunas de las obras estructurales de Sasaki [17], [18], donde la forma, la estructura o el material están presentes desde el principio de la concepción del edificio y el diseño se va afinando y concretando respondiendo a los tres factores, tal como se recoge en Oxman: "StructureFirst; Material-First, Form-First" [19].

También podemos englobar dentro de este gran grupo las corrientes de arquitectura digital, de las que Lynn [20] es un referente. En cualquier caso, parece inevitable que la arquitectura se adapte a los tiempos actuales en los que vivimos y en los que "el papel de la tecnología o la era de la información" [21] no puede pasar desapercibido.

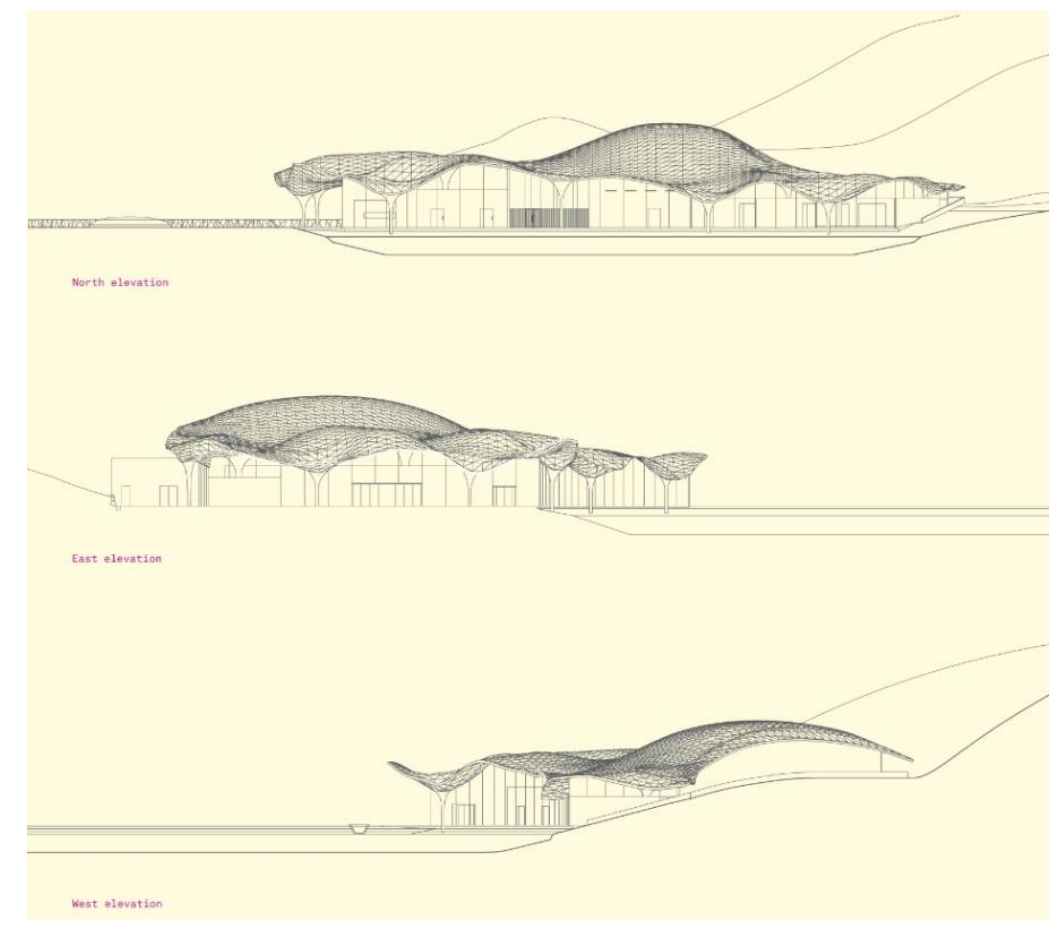

Fig 4. Alzados Crematorium in Kakamigahara. 2008. Ito, toyo.

\section{CONCLUSIONES}

Existen algunas empresas y arquitectos que tienen completamente implantado en todas las fases del proyecto arquitectónico la metodología BIM; pero otras, la mayoría, sólo utilizan está metodología para las fases de ejecución y control de obra, y no en las fases previas de proyecto. Si hablamos de las fases iniciales del proyecto, parece que hay cierta relación en el tipo de arquitectura que se realiza en la empresa y la adopción temprana de herramientas BIM. 
Los procesos de diseño arquitectónico, a pesar de haber sido estudiados, son desconocidos incluso por los propios arquitectos; y no ocurre en este campo lo mismo que en la industria, donde en general todos los procesos están optimizados y asumidos por la mayoría de los actores.

Por último, el campo de la enseñanza de arquitectura puede verse gratamente recompensado por un uso y mejora de las herramientas BIM en las fases previas. En especial a los estudiantes jóvenes, les puede resultar muy útil y didáctico empezar a pensar y diseñar con estas herramientas, incluso llegando a la gamificación para, por un lado, asimilar conceptos complejos de forma sencilla; y por otro, interiorizar metodologías y procesos que serán habituales en su futura labor profesional.

En resumen, existe cierta desconfianza general en relación al software, las herramientas, y la metodología BIM, y en su empleo para el desarrollo de proyectos en fase temprana. Por varios motivos, entre los que se encuentran los comentados en este artículo, la colaboración se ve a veces como una nueva traba al proceso creativo y las herramientas digitales, son vistas por algunos arquitectos como una merma de su creatividad. No obstante, dado lo inexorable de la incorporación de la metodología y herramientas BIM al proceso de creación arquitectónica, consideramos fundamental realizar una profunda reflexión en este campo, que nos ayude a resolver los conflictos que puedan surgir y nos oriente sobre cómo encauzar su potencial en el desarrollo de los proyectos. Al mismo tiempo que no oriente sobre cómo afrontar el nuevo reto que supone la incorporación de la descomunal cantidad de información que tenemos a nuestro alcance para abastecer nuestras decisiones de proyecto.

\section{REFERENCIAS}

[1] Ding, Lieyun, Zhou, Ying y Akinci, Burcu (2014) Building Information Modeling (BIM) application framework: The process of expanding from 3D to computable $\mathrm{nD}$. Automation in Construction, 46, pp. 82-93.

[2] Briscoe, Danelle (2015) Beyond BIM: architecture information modeling, New York, Routledge.

[3] Schnabel, Marc Aurel (2007) Parametric Designing in Architecture, en Computer-Aided Architectural Design Futures (CAADFutures) 2007, Dordrecht, Springer Netherlands, pp. 237-250.

[4] Coloma Picó, Eloi y Mesa Gisbert, Andrés de (2012) The teaching of parametric representation: parametric representation and nonlinear processes. EGA: revista de expresión gráfica arquitectónica, (19), pp. 200-211. Disponible en: <https://dialnet.unirioja.es/servlet/articulo?codigo=3962575> [Fecha de consulta: 12 febrero 2016]

[5] Yalcinkaya, Mehmet y Singh, Vishal (2015) Patterns and trends in Building Information Modeling (BIM) research: A Latent Semantic Analysis. Automation in Construction, 59, pp. $68-80$. 
[6] Ghaffarianhoseini, Ali, Tookey, John, Ghaffarianhoseini, Amirhosein, Naismith, Nicola, et al. (2016) Building Information Modelling (BIM) uptake: Clear benefits, understanding its implementation, risks and challenges. Renewable and Sustainable Energy Reviews.

[7] Volk, Rebekka, Stengel, Julian y Schultmann, Frank (2014) Building Information Modeling (BIM) for existing buildings - Literature review and future needs. Automation in Construction, 38, pp. 109-127.

[8] Son, Hyojoo, Lee, Sungwook y Kim, Changwan (2015) What drives the adoption of building information modeling in design organizations? An empirical investigation of the antecedents affecting architects' behavioral intentions. Automation in Construction, 49, pp. 92-99.

[9] Fernández Usón, Tono (2013) BIM IS NOT ENOUGHT - Entornos Convergentes. 1er Congreso Nacional BIM y Encuentro de Usuarios, Universidad Politécnica de Valencia.

[10] Dodge Data \& Analytics (2015) SmartMarket Brief: BIM Advancements n.1.

[11] Waterhouse, Richard y Philp, David (2016) National BIM Report. National BIM Library, pp. 1-28.

[12] Barbarash, David (2016) Representation stigma: Perceptions of tools and processes for design graphics. Frontiers of Architectural Research, 5(4), pp. 477-488.

[13] Coloma Picó, Eloi; y Regot Marimón, Joaquín M. (2010) Tecnologia BIM per al disseny arquitectònic. Tesis Doctoral. Barcelona:Universitat Politècnica de Catalunya. Departament d'Expressió Gràfica Arquitectònica I. Disponible en: <http://tdx.cat/handle/10803/318369> [Fecha de consulta: 16 diciembre 2015]

[14] Beaman, Michael Leighton (2013) Scripting for the Masses? Architectural Record, 201(8), p. 1.

[15] Shepherd, David (2015) The BIM management handbook NBS, R. (ed.).

[16] Oxman, Rivka y Oxman, Robert (2010) New Structuralism: Design, Engineering and Architectural Technologies. Architectural Design, 80(4), pp. 14-23.

[17] Sasaki, Mutsuro, Pugnale, Alberto y Sassone, Mario (2007) Algoritmi di progetto. II giornale dell architectura, (January 2015), p. 57.

[18] Sasaki, Mutsuro, Ito, Toyoo y Isozaki, Arata (2007) Morphogenesis of flux structure, Aa Publications.

[19] Oxman, Rivka (2010) MORPHOGENESIS IN THE THEORY AND METHODOLOGY OF DIGITAL TECTONICS. Journal of the International Association For Shell And Spatial Structures, 51, p. 195. 
[20] Lynn, Greg. y Gage, Mark. (2010) Composites, surfaces, and software: high performance architecture, Yale School of Architecture.

[21] Fernández Álvarez, Ángel José (2015) La arquitectura como interfaz: el paradigma informacional en la nueva arquitectura. Tesis Dcotoral. A Coruña: Universidad de A Coruña. Departamento de Representacion y Teoría Arquitectónica Disponible en: <http://ruc.udc.es/dspace/handle/2183/15878> [Fecha de consulta: 12 febrero 2016] 


\section{REALIDAD VIRTUAL COMO HERRAMIENTA PARA EXPERIENCIAS INMERSIVAS APLICADAS A UNA PLANTA INDUSTRIAL}

\section{Santamarta Martínez, Jaime (1), Panadero Jiménez, Álvaro (2)}

(1) Head of BIM, Acciona Ingeniería, jaime.santamarta.martinez@acciona.com

(2) BIM Modeller, Acciona Ingeniería, alvaro.panadero.jimenez@acciona.com

\section{RESUMEN}

La realidad virtual es una tecnología que aporta valor a los proyectos. Ésta, permite que a través de la navegación virtual inmersiva dentro del modelo, se pueda reproducir en detalle cualquier proceso constructivo de una manera rápida, sencilla y sin errores ni interferencias en la obtención de información del modelo. En definitiva, su puesta en escena permite mejorar la calidad del trabajo reduciendo notablemente los plazos y costes de proyecto.

En Acciona Ingeniería, se apuesta por este tipo de tecnología para llevar a cabo procesos tanto comerciales como de coordinación y seguimiento de los proyectos. Apoyados en el desarrollo para dispositivos HMD (Head Mounted Display) se ha facilitado al cliente la comprensión de diseños a veces complejos de visualizar empleando técnicas tradicionales 2D. Tal es el caso de su aplicación para experiencias inmersivas en proyectos de plantas industriales, donde el entendimiento del proceso industrial resulta complejo.

En este sentido se hace uso del software de realidad virtual Autodesk Live, que es interoperable a través de un plugin con Revit, para posteriormente postprocesar el modelo en el software Stingray y dotar así las escenas de hiperrealismo e interactividad. Finalmente, el modelo se integra en los dispositivos HTC Vive.

Palabras clave: HMD, industrial, inmersiva, realidad, virtual

\section{ABSTRACT}

Virtual reality is a technology that brings value to projects. This allows, through immersive virtual navigation within the model, to reproduce in detail any construction process in a fast and simple way without errors or interferences when obtaining model information. Therefore, it improves the quality of work by significantly reducing project deadlines and costs.

At Acciona Ingeniería, there is a commitment to use this type of technology both in commercial processes and coordination and monitoring of projects. Supported by the development of HMD (Head Mounted Display) devices, customers have the possibility of understanding complex designs instead of using traditional 2D techniques. Such is the case of its application for immersive experiences in industrial plant projects, where the understanding of the industrial process is complex. 
In this sense, Autodesk Live virtual reality software is used, which is interoperable through a plugin with Revit. The VR model created with Live is later postprocessed with Stingray software to endow the scenes with hyperrealism and interactivity. Finally, the model is integrated into HTC Vive devices.

Keywords: HMD, industrial, immersive, reality, virtual

\section{INTRODUCCIÓN}

La metodología BIM, supone una transformación en la manera de desarrollar tanto los proyectos como las obras de construcción. Si bien la esencia de esta metodología se basa en la generación de un modelo tridimensional, la visualización de éste a través de dispositivos bidimensionales hace que la experiencia e interacción con el modelo no sea plena.

Es por ello que la aparición en el mercado de nuevas tecnologías como la realidad virtual [1] y la realidad aumentada, abren un amplio abanico de posibilidades ligadas al sector. Mientras que la realidad virtual consiste en la inmersión en un entorno de modelo plenamente digital, la realidad aumentada reproduce elementos digitales aislados, sobre el entorno físico real (Fig. 1).

La inmersividad consiste en poder visualizar en un entorno simulado escenas gráficas generadas por ordenador donde el usuario es el centro de las mismas. En ellas éste puede navegar e interactuar en tiempo real pudiéndose mover por el modelo diseñado en una panorámica de $360^{\circ}$. Para ello, se hace uso de dispositivos tipo HMD (Head Mounted Display) que posibiliten capturar la voluntad del usuario y le conduzcan a una inmersión sensorial plena [2].

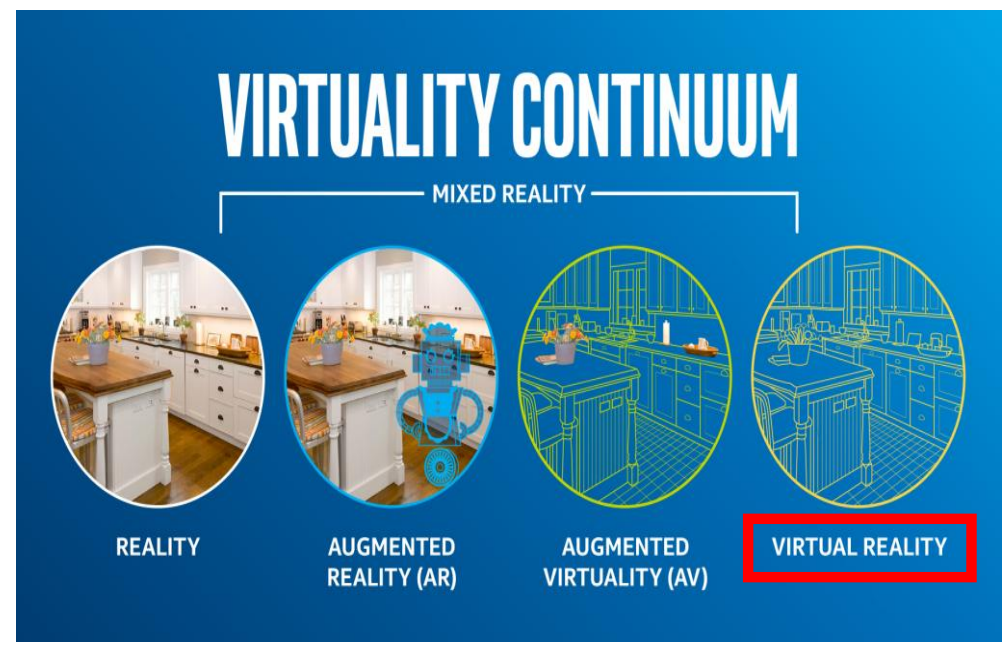

Fig 1. Secuencia de la realidad física a la realidad virtual. 2016. Intel

De este modo, el salto del papel a la pantalla del ordenador, o lo que es mejor, a un entorno inmersivo, abre un amplio abanico de posibilidades. Importantes empresas multinacionales, 
entre las que se encuentra Acciona Ingeniería, han empezado ya a apostar por este tipo de tecnología para llevar a cabo procesos tanto comerciales, como técnicos en labores de coordinación y seguimiento de los proyectos.

Haciendo uso de los principios fundamentales del BIM: trabajo multidisciplinar y colaborativo, interoperabilidad, planificación, orden y coordinación, en Acciona Ingeniería se ha procedimentado una metodología de diseño específica (Fig. 2) conjugando éstos sobre un motor de videojuegos de manera innovadora. Así, por ejemplo, también se podrán abordar aspectos como la prevención en el diseño a través de simulaciones de seguridad y evacuación, o verificaciones de los procedimientos constructivos mediante animaciones virtuales, [3].

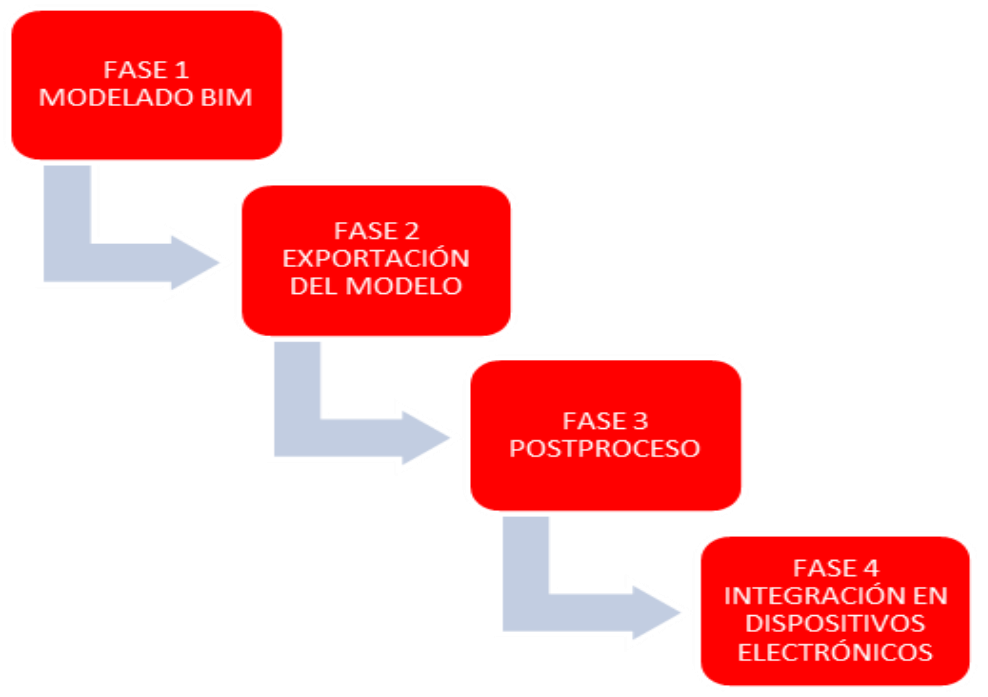

Fig 2. Flujograma de fases. 2016. Acciona Ingeniería

Para testar la utilidad y validez de dicho procedimiento, éste se ha aplicado de manera práctica a diversos proyectos, entre los que se pueden destacar el diseño de un viaducto atirantado, la rehabilitación arquitectónica de los interiores de una estación de metro o el proyecto de una planta industrial de biomasa. En todos ellos, la generación de una realidad virtual ha supuesto sin duda alguna un salto cualitativo en el desarrollo del proyecto. Sin embargo, es en el caso de la infraestructura industrial donde cobra especial valor, ya que la simulación de los procesos industriales son siempre complejos de entender en un entorno bidimensional o incluso tridimensional, cuando éste no posee funcionalidades inmersivas.

\section{OBJETIVOS}

La realidad virtual es una tecnología que aporta valor a los proyectos. Trabajar en un entorno tridimensional virtual ayuda a tener una mejor percepción de lo que se diseña y construye. Por lo tanto, esto nos lleva a establecer como objetivos, entre otros, la detección de posibles errores de manera anticipada, lo cual a la postre ahorrará costes en términos económicos, y minimizará riesgos y accidentes en términos de seguridad. Es decir, ayudará 
a tomar decisiones tempranas libres de interpretaciones, aumentando las capacidades del coordinador del proyecto, [4].

Esta tecnología, permite además que a través de la navegación virtual inmersiva dentro del modelo, se pueda reproducir en detalle cualquier proceso constructivo de una manera rápida, sencilla y sin errores ni interferencias en la obtención de información del modelo.

Apoyados por tanto en el desarrollo para dispositivos HMD (Head Mounted Display), el objetivo principal es facilitar al cliente, y en general a los técnicos de toda la cadena de producción, la comprensión de diseños a veces complejos de visualizar empleando técnicas tradicionales. Tal es el caso ya mencionado de su aplicación para experiencias inmersivas en proyectos de plantas industriales, donde el entendimiento del proceso industrial resulta complejo.

\section{METODOLOGÍA}

\subsection{Modelado BIM}

Previo a la generación de la realidad virtual inmersiva, se parte de la creación de un modelo digital BIM del proyecto, para lo que se requiere de softwares específicos de modelado. Son muchos los desarrolladores informáticos que actualmente ofrecen este tipo de soluciones en el mercado. En el caso que nos ocupa, se empleará el programa Revit de Autodesk para el desarrollo del proyecto de la planta industrial de biomasa (Fig. 3).

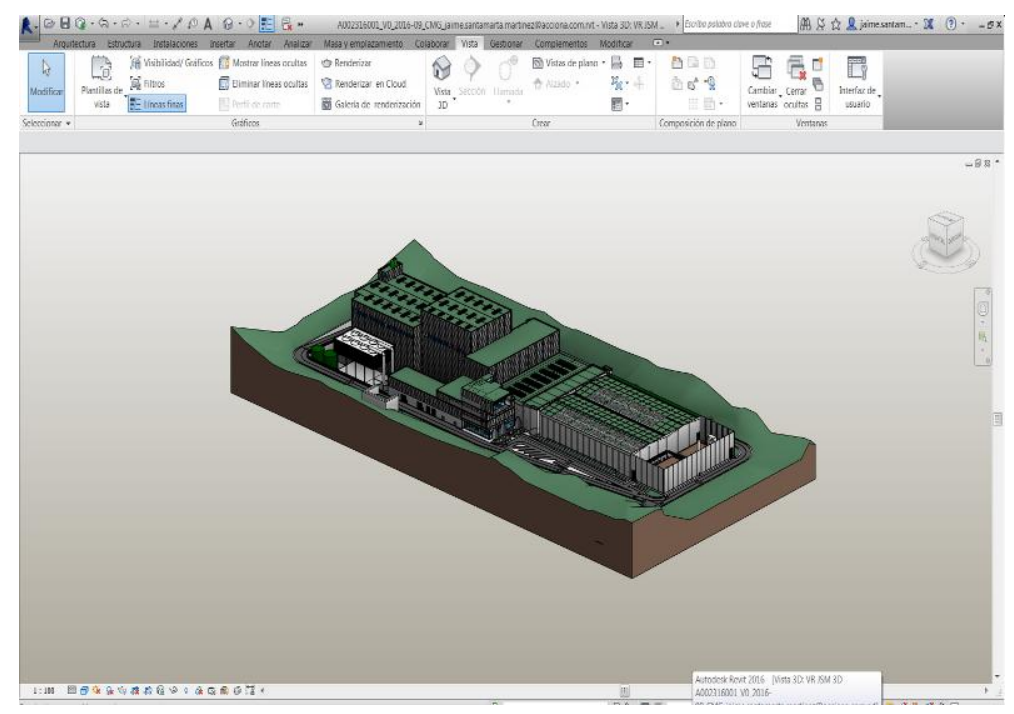

Fig 3. Modelo Revit de la planta industrial. 2016. Acciona Ingeniería

En este escenario, resulta preciso acotar mediante diversas reglas cómo debe realizarse el modelo de Revit, de modo que a la postre sea operativo en la integración con el motor de videojuegos. 
Por consiguiente, la primera fase consistirá en la generación de un modelo compatible. Un modelo que siga las siguientes pautas o reglas de buena práctica [5]:

1. El modelo debe tener un tamaño cuya dimensión sea moderada en bytes, tomando como regla de buena práctica no superar los 100-300 megabytes. Para ello, no se debe dotar de una parametrización e información sobreabundante a los elementos y familias, cuando éstas resulten innecesarias. Del mismo modo, se ha de minimizar el número de polígonos simplificando las geometrías, pero manteniendo su semejanza con la realidad en la mayor medida posible.

2. Hay que facilitar que los movimientos que se puedan hacer al recorrer el modelo en la realidad virtual, permitan un paseo cómodo, fluido y natural. Hay que anticiparse a la voluntad del "jugador" indicándole encubiertamente el camino. Para ello se recomienda dejar pasos abiertos en aquellas zonas o espacios en los que se requiera llevar a cabo por ejemplo, un seguimiento o un control de interferencias. En el lado opuesto, se bloquearán o cerrarán puertas en aquellas otras áreas que no se desee que sean visitadas. En el marco de una acción comercial, estos principios pueden aplicarse como una estrategia para mostrar y potenciar los espacios que resulten atractivos.

3. Se ha de evitar incorporar al modelo elementos o familias que sobrecarguen el modelo si éstos no van a aportar mayor realismo a las escenas. En esta línea, se evitará modelar aquello que no vaya a visualizarse en la experiencia inmersiva.

4. Hay que tener en cuenta que las texturas de Revit, generalmente no son compatibles con los motores de videojuegos, por lo que no merece la pena dotar al modelo BIM de hiperrealismo. Esto será algo que se incorpore en una fase posterior en el propio motor de videojuegos.

\subsection{Exportación del modelo}

Actualmente existen diversos programas para generar entornos de realidad virtual a partir de modelos BIM, como son Unity o Unreal que funcionan bajo una interoperabilidad con Revit. Éstos están fundamentalmente concebidos para crear contenidos de juego en lugar de visualización de diseños. Es por ello que requieren del empleo de una cantidad excesiva de tiempo para hacer que el contenido funcione en aplicaciones de ingeniería de edificación, industrial o civil [6].

Sin embargo, las funcionalidades que aporta la nueva plataforma Autodesk Live [7] permiten crear rápidamente una interactividad donde el usuario (cliente, técnico, coordinador de proyecto, etc.) podrá navegar de manera inmersiva y dinámica.

Para ello, Autodesk Live dispone de un plugin de interoperabilidad con Revit que opera bajo conexión con A360 en la nube. Al ejecutar el plugin, se requiere por ende el registro de usuario, tras lo cual, el modelo de Revit se sube automáticamente a la nube de Autodesk, 
donde mediante el motor de videojuegos Stingray, se renderiza el modelo y se generan las escenas de navegación (Fig. 4).

El modelo de realidad virtual creado con extensión .Ivmd se descarga automáticamente de la nube de Autodesk, bien para llevar a cabo directamente la navegación en soporte pc, móvil o Tablet, bien para llevar a cabo un postproceso de mejora gráfica o de implementación de funcionalidades dinámicas orientadas al uso de HMD (Head Mounted Display).

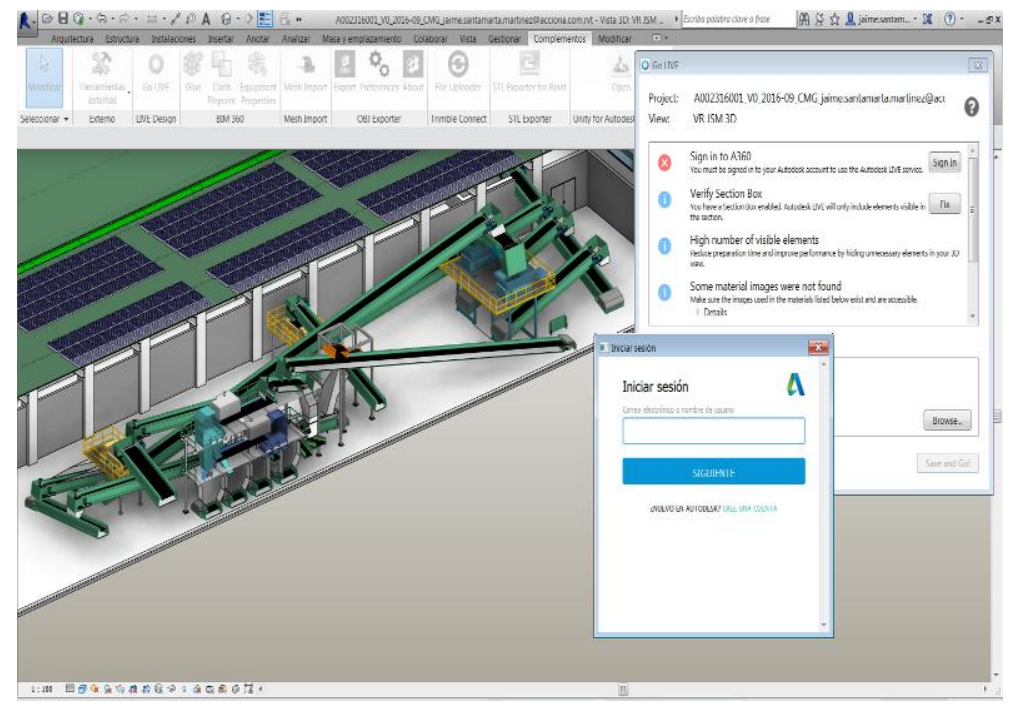

Fig 4. Plugin Autodesk Live para Revit. 2016. Acciona Ingeniería

\subsection{Postproceso}

En los casos en los que no se precise una integración HMD, Autodesk Live posee un visor gratuito a través del cual puede llevarse a cabo la experiencia de realidad virtual. En este sentido, dado que el producto final es un fichero entregable al cliente, la extensión .Ivmd (fichero Stingray comprimido para uso en el editor de Autodesk Live) se convierte a live para así bloquear las funciones de edición del modelo de realidad virtual.

Por otra parte, cuando se desee mejorar las escenas de Autodesk Live, tal como se ha mencionado anteriormente, se empleará el software de Autodesk Stingray. Con él, se podrán implementar animaciones, agregar, borrar o modificar cámaras, crear o editar materiales y texturas, o importar nuevos elementos.

En todo caso, para garantizar la interoperabilidad entre Live y Stingray, se deberá utilizar la misma versión de lanzamiento; 1.6 por ejemplo para ambos casos. Asimismo, se deberán tener en consideración ciertas restricciones que aplican en el flujo de proceso cuando se vaya a tratar una escena de Live en Stingray: 
1. Los cambios realizados en Live Editor no aparecen en Stingray.

2. Live utiliza su propio skydome y configuración de luz directa/sol. Así pues, los cambios realizados en Stingray en el skydome, en la luz ambiental, en la intensidad del sol y el color, no son soportados por Live.

3. Las entradas de teclado no se pueden utilizar para activar un evento en el flujo de nivel. Sólo el nodo de nivel cargado se puede utilizar para activar nodos.

4. Los controladores de caracteres no activarán los disparadores de volumen.

5. La modificación de la configuración de una habitación y la adición o modificación de assets en el proyecto, a menudo causan colisiones incorrectas con el controlador de caracteres. Para solucionar este problema, se deberá utilizar la ventana de navegación para regenerar el Navmesh de la escena.

6. La edición de un archivo .fbx en 3ds Max puede hacer que se pierda toda la información BIM.

\subsection{Integración en dispositivos electrónicos}

En cuanto a la integración en dispositivos electrónicos, hay que diferenciar entre los soportes bidimensionales (consola, Tablet o PC) y aquellos que generan una experiencia inmersiva, los sistemas HMD (Head Mounted Display). Con ambos tipos puede llevarse a cabo una navegación virtual interactiva, pero sin embargo, es con los últimos, con los que se alcanza la verdadera sensación de penetrar en el modelo, [8].

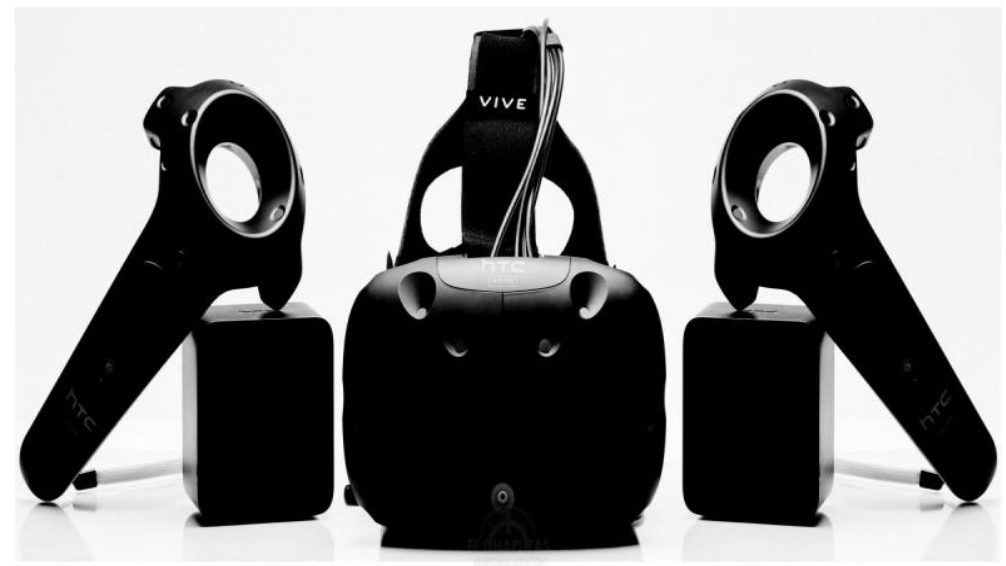

Fig 5. Dispositivos HMD HTC Vive. 2016. HTC

Autodesk Live ofrece una fácil integración de los modelos en dispositivos móviles con sistemas operativos Android o iOS, así como en dispositivos HMD (Head Mounted Display) de grandes distribuidoras, como las Oculus Rift o las HTC Vive. Una vez llevado el modelo a 
uno de estos sistemas a través del comando VR de Live, se puede entonces navegar de manera inmersiva pudiéndose además hacer uso de los controladores específicos del dispositivo y así aportar más interactividad para el usuario (rotación de vistas, escalado, rotación y desplazamiento del minimap, teletransporte).

\section{RESULTADOS}

La aplicación de la metodología antes descrita, en el diseño de la planta incineradora de biomasa, ha permitido durante el proceso de desarrollo del proyecto crear experiencias inmersivas de cara a la revisión de los procesos industriales de la propia planta. Más allá de esto, ha posibilitado controlar las posibles interferencias entre el diseño estructural y arquitectónico del edificio, con el equipamiento industrial incorporado al modelo (tolvas, cintas transportadoras, caldera, filtros, turbina o escape de humos).

Entre los resultados más destacables, se encuentra la transferencia de información del modelo BIM con el modelo de realidad virtual. Es decir, una vez creada la experiencia inmersiva, los elementos del modelo conservan la información paramétrica introducida en el modelo de Revit (Fig. 6). A través del menú de navegación de vistas de Live, se puede acceder directamente a las zonas en las que se desea consultar los datos de un equipo o elemento concreto.

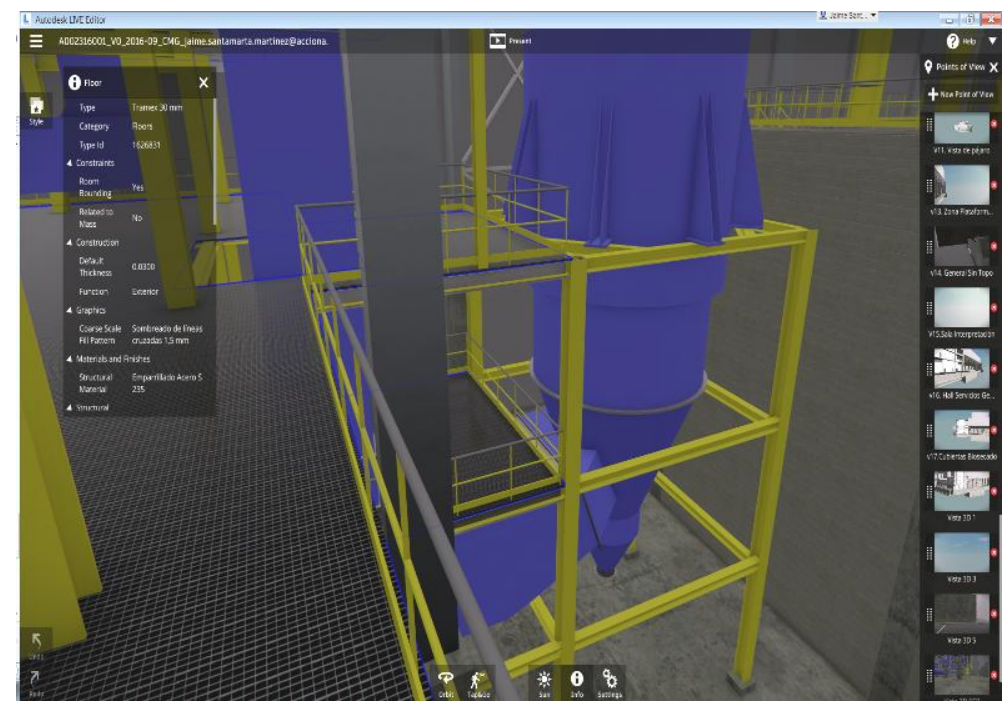

Fig 6. Árbol de vistas e información BIM. 2016. Acciona Ingeniería

Otra funcionalidad con resultados positivos, ha consistido en el control de la iluminación, tanto solar como artificial (Fig. 7 y 8). Para poder regular ésta última, las luminarias del modelo de Revit se tuvieron que introducir como elementos mep para que los parámetros de iluminación (intensidad, luminiscencia, etc.) pudieran ser importados por el programa Live. 


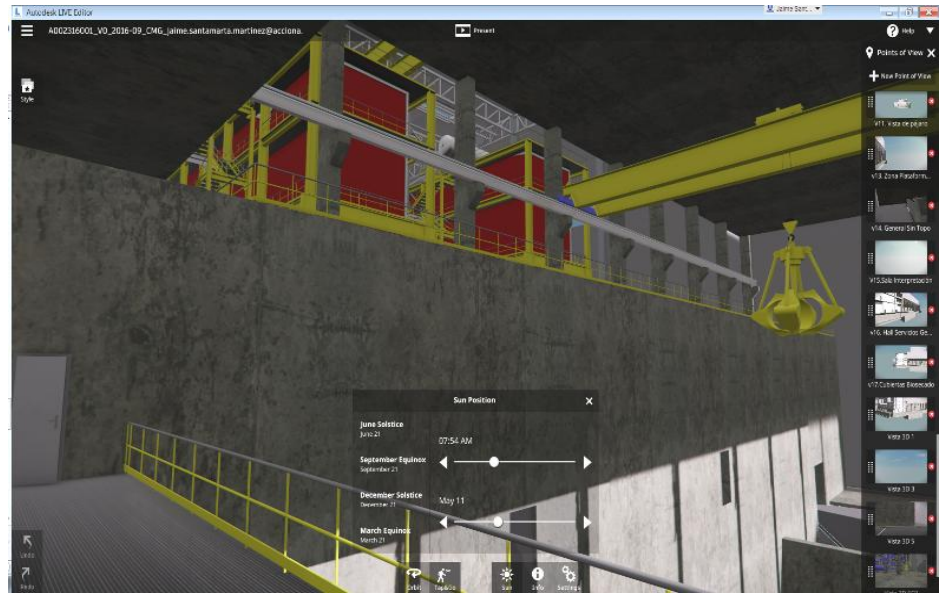

Fig 7. Control solar. 2016. Acciona Ingeniería

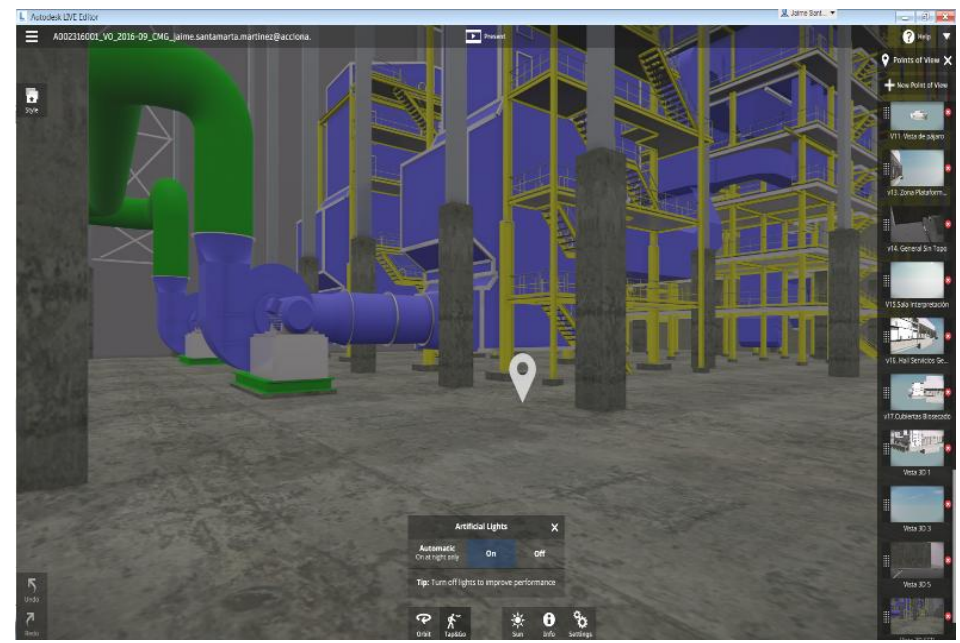

Fig 8. Control de iluminación artificial. 2016. Acciona Ingeniería

\section{CONCLUSIONES}

Desde un punto de vista comercial, la resolución gráfica, la interactividad con el modelo y en definitiva, su acercamiento a la realidad, conlleva a un objetivo básico del BIM. Se trata de la creación de un entorno verdaderamente colaborativo, ya que agentes no especializados en las fases de diseño, podrán interactuar aportando valor al proyecto sin que ello implique tener grandes conocimientos de las herramientas informáticas de modelado y cálculo.

Para materializar todos estos objetivos, resulta esencial protocolizar un flujo de trabajo estableciendo una metodología clara y unívoca que quede recogida en un procedimiento técnico. En este procedimiento se han de establecer los criterios a tener en cuenta en el modelado dentro del entorno BIM, así como el motor de videojuegos a emplear y su interoperabilidad de cara a una experiencia inmersiva. 
En el caso que nos ocupa, el empleo de Autodesk Live en plantas industriales, permite mejorar la calidad del trabajo reduciendo notablemente los plazos y costes de proyecto, y también facilita el entendimiento del proceso industrial cuando éste resulta complejo.

La unión del entorno de trabajo BIM (Building Information Modelling) y el del VR (Virtual Reality) sin duda mejoran el producto final de un proyecto de construcción, dotándolo de mayor valor respecto de los métodos tradicionales llevados a cabo hasta el presente.

\section{AGRADECIMIENTOS}

Agradecimientos al equipo de la Dirección de Innovación de Acciona S.A.

\section{REFERENCIAS}

[1] Rawn, Evam (2015). Unreal visualizations: 3 pros and 3 cons of rendering with a video game engine. Plataforma de Arquitectura. Recuperado de www.plataformaarquitectura.cl [Consulta: 9 Diciembre 2016].

[2] James Melzer (2014) Digital Avionics Handbook. CRC Press, third edition, pp. 257-280. Print ISBN: 978-1-4398-6861-4, eBook ISBN: 978-1-4398-6898-0.

[3] Van Hampton, Tudor; Rubenstone, Jeff; Sawyer, Tom (2016). How video games became design and construction tools. ENR Engineering News Record. Recuperado de www.enr.com [Consulta: 12 Diciembre 2016].

[4] Otero, Antonio; Flores, Julián (2011). Realidad virtual. Un medio de comunicación de contenidos. Icono14, año 9 Vol. 2, pp. 185-211.

[5] Santamarta Martínez, Jaime; Gallo Salazar, Paula; Raya Castro, Luis. (2016). Realidad virtual inmersiva a partir de un modelo BIM. Dibujar, construir, sonar. Investigaciones en torno a la expresión gráfica aplicada a la edificación. Tirant lo Blanch.

[6] Kean Walmsley (2016). Reducing the pain of VR content generation: Autodesk LIVE Through the interface. Recuperado de www.through-the-interface.typepad.com [Consulta: 01 Mayo 2017].

[7] Autodesk Software. www.autodesk.com/products/revit-live/overview. [Consulta: 20 Noviembre 2016].

[8] Serrano, Berenice; Botella, Cristina; Baños, Rosa María (2012). Realidad virtual y virtualidad aumentada. Usos y aplicaciones para incluir emociones. Editorial Académica Española. 


\section{GESTIÓN DE LA INFORMACIÓN A TRAVÉS DE DATOS ENLAZADOS PARA EL REDISEÑO DE UNA ESTACIÓN DE BOMBEO EN HOLANDA}

\section{Malvar Gómez, Víctor (1) Moreno Barbero, Patricia (2) Kuppens, Johan (3)}

(1) Neanex BVBA. victor.malvar@neanex.com

(2) Infranea BVBA. patricia.moreno@infranea.eu

(3) Neanex BVBA. johan.kuppens@neanex.com

\section{RESUMEN}

Se analizará el proyecto llevado a cabo por nuestras empresas tras el encargo de "Waternet" (compañía responsable del suministro de agua potable para la ciudad de Ámsterdam y su área metropolitana), que tenía como fin la consecución de dos objetivos distintos y a la vez interrelacionados:

1. Obtención del modelo BIM de la estación de bombeo LDN2 (arquitectura, estructura e instalaciones) a partir del escaneado 3D (nube de puntos) de la misma.

2. Integración de las diversas plataformas de software y simulación utilizadas en el proyecto a través de datos enlazados.

Durante la comunicación se expondrá la sistemática seguida para la consecución de ambos objetivos describiendo flujos de trabajo, flujos de información, dificultades encontradas, utilidad potencial de esta sistemática y resultado final de este proyecto piloto.

Palabras clave: Datos enlazados, RDF, BIM, Coordinación, Gestión de la Información.

\section{ABSTRACT}

Information management trough linked data for the redesign of a pump station in the Netherlands.

We will analyse the pilot project that has been performed by our companies after the assignment made by "Waternet" (company responsible for the Amsterdam and its metropolitan area potable water supply), that had as goal the achievement of two different but inter-related objectives:

1. Creation of the LDN2 pump station BIM model (including architecture, structure and installations) having as starting point the 3D scan - point cloud data.

2. Integration of all software applications and simulation tools used in the project trough linked data. 
During the communication we will analyse the system procedure that has been followed to achieve both objectives describing workflows, information flows, difficulties we have found, potential use of this systematic and the final result of this pilot project.

Keywords: Linked data, RDF, BIM, coordination, information management.

\section{INTRODUCCIÓN}

El ministerio de obras públicas holandés, "Rijswaterstaat" (responsable de la dirección de todas las obras públicas realizadas en el país además de la gestión del tráfico rodado, las vías agropecuarias, los sistemas de distribución y saneamiento de aguas y de la prevención de inundaciones), impulsó a partir del año 2012 un programa estratégico de gestión integrada de la información generada en la industria de la construcción ("Building Information Management") que incluía la implantación de las siguientes metodologías en todos los proyectos de los cuales el ministerio fuera titular:

- "Building Information Modelling": Modelado tridimensional del proyecto asociado a bases de datos conteniendo información geométrica y no geométrica del mismo.

- "Asset Information Management": entendida como la gestión de la información sobre activos cuya titularidad es el propio ministerio y que debe ser actualizada, fidedigna y correcta para el adecuado mantenimiento de esos activos.

- "Information Flow Control": entendido como la obtención de la información correcta, en el formato correcto y en el momento adecuado durante cualquiera de las fases del proceso definición del proyecto-diseño-construcción-mantenimiento.

Este programa viene dado por la nueva estrategia adoptada por los diferentes gobiernos holandeses por la cual el ministerio de obras públicas ya no está directamente envuelto en el diseño o construcción de los grandes proyectos de infraestructuras, los cuales han pasado a ser DBFM (Design, Build \& Maintenance), y tan solo se va a ocupar de la dirección (y por supuesto titularidad) de los mismos.
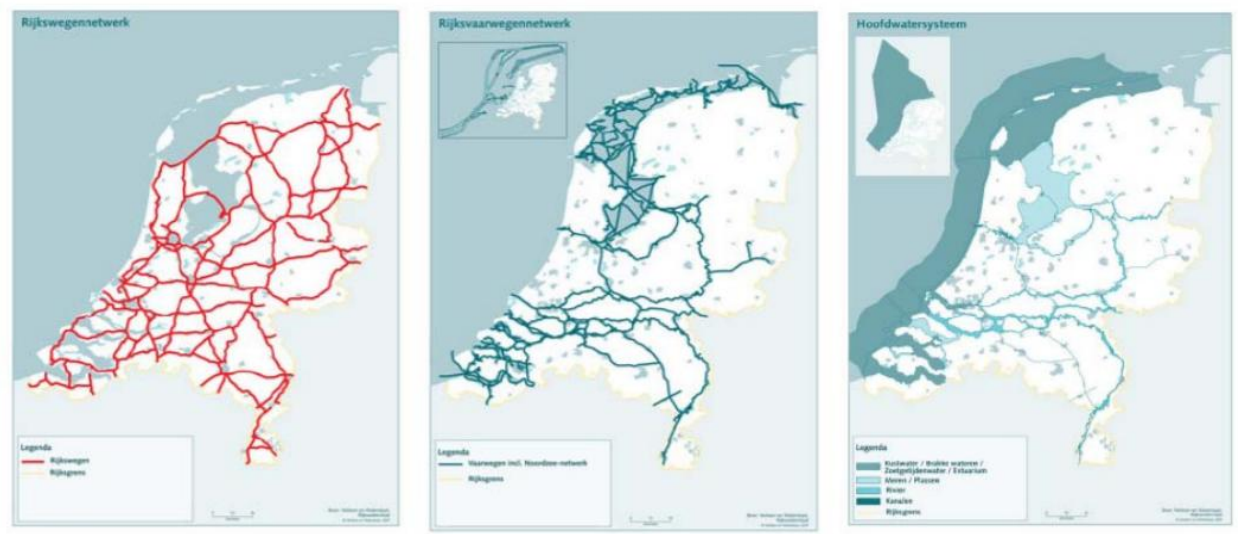

Fig 1. Principales redes de infraestructuras de las que es titular el ministerio de OOPP Holandés: Carreteras, canalizaciones y conducciones fluviales. 2016. Rijkswaterstaat. 
La premisa de Rijswaterstaat es que la dirección de esos proyectos estará basada en la correcta gestión de la información que se genere en los mismos y los objetivos del ministerio holandés eran los siguientes:

- Mayor cooperación dentro de todos los agentes envueltos en el proceso.

- Menores gastos en las transacciones de información.

- Menores fallos en las transacciones de información.

- Acelerar el proceso proyecto construcción (desde su definición hasta su entrega y mantenimiento).

Para ello se decidió que el intercambio de información estaría basado en estándares abiertos y se crearían librerías de objetos tipo (Object type libraries - OTL) definidas por la propia administración completamente abiertas y a disposición de todos los agentes implicados en el proceso.

Todo esto teniendo en cuenta que desde el año 2009 el mismo ministerio ya adoptó de facto la aplicación de la ingeniería de sistemas como metodología obligatoria para los proyectos de construcción.

En este contexto se enmarca el proyecto piloto llevado a cabo por diferentes empresas (entre ellas las nuestra) y promovido por "Waternet" (empresa pública de gestión de aguas en Holanda) para la adecuación de sus metodologías de trabajo a la nueva sistemática definida por el ministerio.

\section{CONTENIDO}

El proyecto piloto consistió en el rediseño de la estación de bombeo LDN2 que abastece el área metropolitana de Amsterdam y adoptó la nueva metodología de gestión integrada de la información en proyectos dentro del sector de la arquitectura, ingeniería, construcción y mantenimiento impulsada por el ministerio de obras públicas holandés [1].

Los objetivos principales del proyecto fueron, por tanto, demostrar los beneficios del uso de datos enlazados para la gestión de la información durante el proyecto:

- Reducir los tiempos de comunicación entre todos los agentes implicados en el proyecto frente a un proceso tradicional (plataforma común de trabajo).

- Promover la interacción y colaboración entre todos los agentes implicados (cero email).

- Reducir costes de material (cero papel).

- Realizar una entrega digital completa del proyecto a la finalización del mismo.

Para la consecución de estos objetivos seguimos dos fases diferenciadas dentro del proyecto piloto, la primera para definir los métodos, procesos y herramientas que usaríamos durante el piloto, y la segunda en el que los diferentes agentes implicados harían uso de la 
plataforma tecnológica definida integrado los diseños y simulaciones a lo largo del tiempo definido por el cliente.

\subsection{Métodos, procesos y herramientas}

Atendiendo a las necesidades definidas por el cliente en cuanto a ser lo más fidedigno posible a las directrices designadas por el ministerio de OOPP holandés, desde el principio sabíamos que deberíamos soportar los procesos de ingeniería que nos llevarían a la consecución del proyecto bajo las metodologías de la ingeniería de sistemas y BIM (entendida esta última como la introducida al principio de esta comunicación).
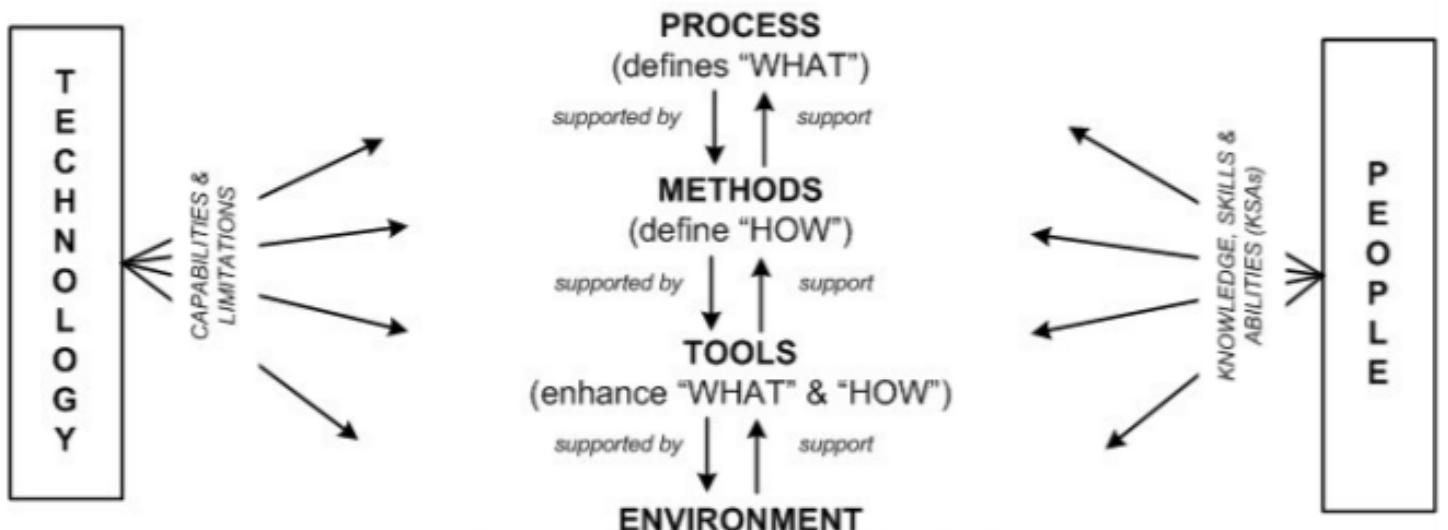

(enables/disables "WHAT \& "HOW")

Fig 2. Survey of Model-Based Systems Engineering (MBSE) Methodologies. Jeff A. Estefan. 2007

Era por tanto nuestra misión en esta fase definir esa plataforma, ese entorno, que, con la tecnología disponible, nos permitiese soportar los objetivos del proyecto [2] [3].

Nos decantamos desde el principio por una plataforma de integración de la información híbrida [3], esto es, aquella en la que se mezclan integraciones mediante estándares abiertos y aquellas en las que tenemos que realizar integraciones "ad hoc".

El objetivo final era que toda la información transferida en el proyecto se realizase de forma que la plataforma tecnológica implementada supiera interpretar el tipo y contenido de información que se estaba intercambiando. 


\section{hybrid integration}

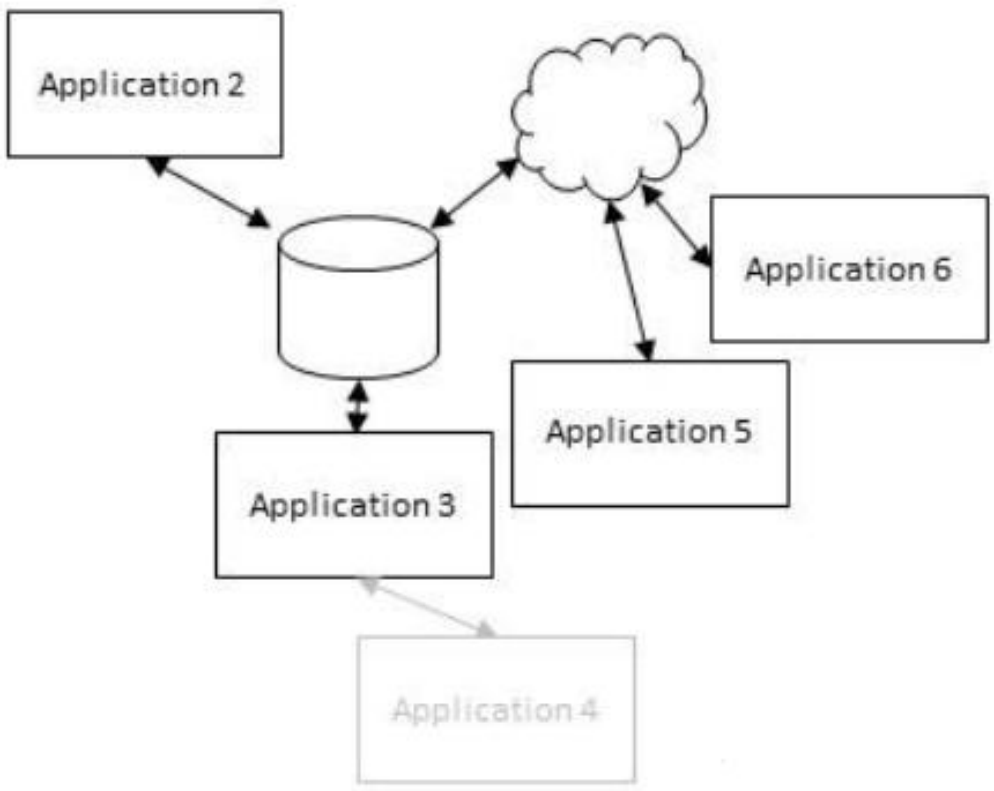

Fig 3. Integración Híbrida. Semmtech bv. 2016

La plataforma podría almacenar, recibir y transmitir datos enlazados en formato de triples (RDF) y estaría basada en formatos web estándar [4]. Así, y según la definición creada por Tim Berners-Lee en [5], utilizaríamos URIs para identificar los recursos publicados en la Web y Waternet podría decidir que recursos serían públicos de tal forma que podría:

- Aprovechar el HTTP de la URI para que la gente pueda localizar y consultar (es decir, desreferenciar) estos recursos.

- Proporcionar información útil acerca del recurso cuando la URI haya sido desreferenciada.

- Incluir enlaces a otras URI relacionadas con los datos contenidos en el recurso, de forma que se potencie el descubrimiento de información en la Web

Para integrar todas las aplicaciones que se utilizarían durante el proceso de diseño, Neanex crearía software específico que integraría esas aplicaciones a la citada plataforma de datos enlazados permitiendo incluso comunicación entre los distintos usuarios de las diferentes aplicaciones mediante la misma plataforma utilizando tecnología ya desarrollada y usada en otros proyectos [6].

Además, Waternet podría interactuar con el resto de integrantes del proceso directamente a través de una interfaz que da acceso directo a la plataforma de datos enlazados y que permitiría la completa interacción de todos los integrantes del proyecto piloto en un entorno completamente colaborativo y basado en modelos de información.

Por tanto, y de forma resumida los procesos y herramientas que estarán integradas en la plataforma tecnológica descrita anteriormente serán: 


\begin{tabular}{|c|c|c|}
\hline Proceso(s) & Herramienta(s) & Agente(s) \\
\hline $\begin{array}{l}\text { Definición de metas, } \\
\text { funciones y } \\
\text { requerimientos }\end{array}$ & Relatics & Waternet \\
\hline $\begin{array}{c}\text { PFD (Process flow } \\
\text { diagram) }\end{array}$ & AutoCAD & Sweco \\
\hline $\begin{array}{l}\text { P\&ID (Process and } \\
\text { Instrumentation } \\
\text { Diagrams) }\end{array}$ & AutoCAD & Sweco \\
\hline $\begin{array}{c}\text { Arquitectura y } \\
\text { estructura }\end{array}$ & Revit & iNFRANEA \\
\hline Modelado bombas 3D & AutoCAD Plant 3D & Sweco \\
\hline $\begin{array}{c}\text { Intercambio información } \\
\text { mediante software ad- } \\
\text { hoc }\end{array}$ & $\begin{array}{l}\text { Neanex iBIM } \\
\text { connectors }\end{array}$ & $\begin{array}{c}\text { Sweco \& } \\
\text { iNFRANEA }\end{array}$ \\
\hline Coordinación geometría & Navisworks & Infranea \\
\hline $\begin{array}{l}\text { Coordinación } \\
\text { información }\end{array}$ & $\begin{array}{l}\text { Linked Data } \\
\text { Platform }\end{array}$ & $\begin{array}{l}\text { Neanex \& } \\
\text { Semmtech }\end{array}$ \\
\hline $\begin{array}{l}\text { Verificación de los datos } \\
\text { de proyecto contra los } \\
\text { requerimientos del } \\
\text { cliente }\end{array}$ & $\begin{array}{l}\text { Linked Data } \\
\text { Platform }\end{array}$ & $\begin{array}{c}\text { Sweco \& } \\
\text { iNFRANEA }\end{array}$ \\
\hline Validación del proyecto & $\begin{array}{l}\text { Linked Data } \\
\text { Platform }\end{array}$ & Waternet \\
\hline
\end{tabular}

Tabla 1. Procesos y herramientas integradas en la plataforma tecnológica diseñada para el proyecto

\subsection{Plataforma tecnológica y flujo de datos}

En la figura 3 de la presente comunicación hemos esquematizado a grandes rasgos la arquitectura de la plataforma tecnológica diseñada para soportar todos los procesos que tienen lugar en el proyecto, vamos a especificar y describir en detalle todos esos componentes.

Plataforma de datos enlazados: acorde a lo definido por W3C [7] y que contiene la descomposición de objetos realizada por los líderes de proyecto y basadas en la clasificación de objetos que utiliza el ministerio de obras públicas holandés. Esos objetos son introducidos a la plataforma tecnológica usando la herramienta para gestión de proyectos.

Neanex iBIM connectors: Plug-ins instalables para todas y cada una de las herramientas de modelado CAD/BIM utilizadas en el proyecto (Revit, Navisworks, AutoCAD, Plant3D, etc.) y que permiten la extracción de datos de dichas aplicaciones para ser enviadas como datos enlazados a la web y adjuntadas a los objetos que corresponda.

Herramientas de modelado CAD/BIM: Las utilizadas para modelar los objetos anteriormente citados. Tener en cuenta que un mismo objeto puede tener distintas representaciones gráficas en diferentes aplicaciones CAD/BIM. Por ejemplo una bomba de la estación de 
bombeo puede estar representada en el diagrama de flujo (2D), pero también tendrá una representación gráfica en el modelado 3D de las bombas.

Simulación y dimensionamiento: Software utilizado para la simulación de los flujos de agua en toda la instalación y que transmite la información a través de archivos CSV. Esa información se adjunta (también) a todos los objetos que forman parte de la estación y que han sido definidos por los líderes de proyecto.

De forma esquemática:

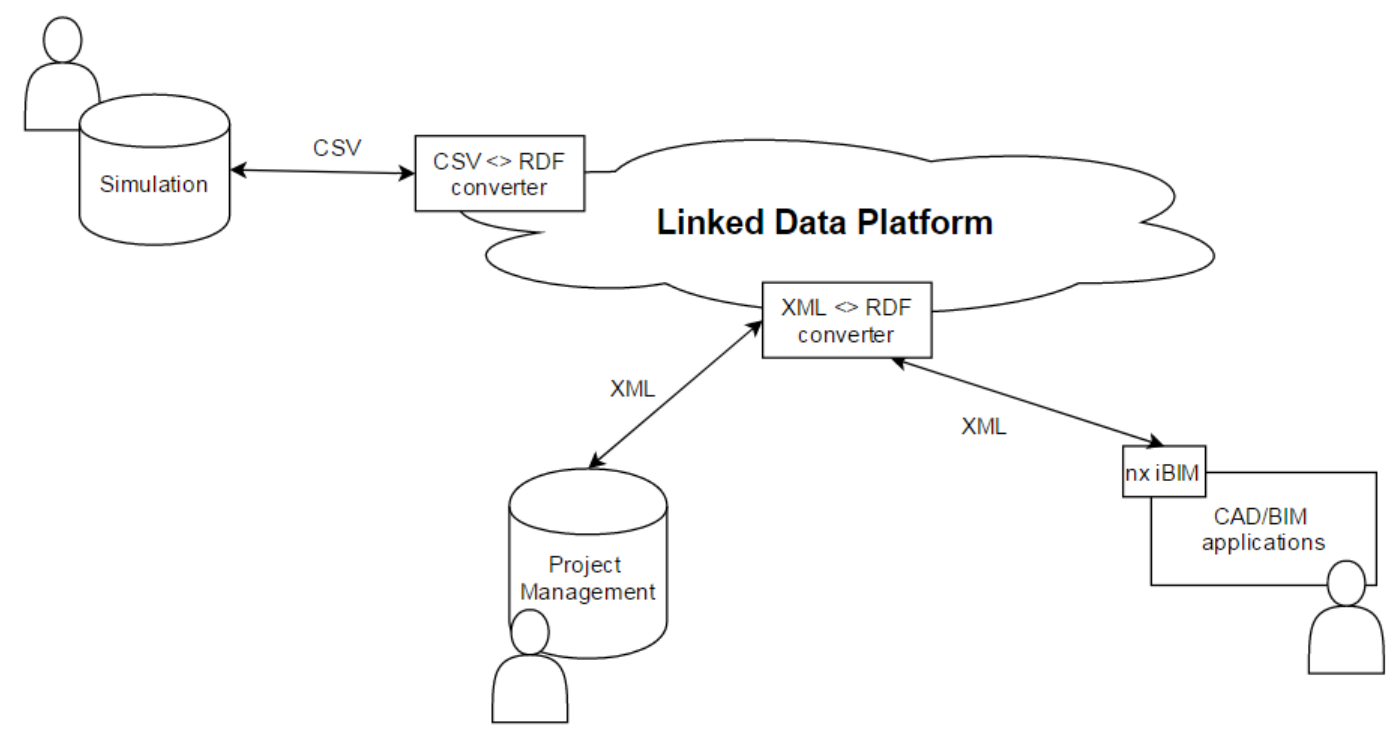

Fig 5. Esquema de flujo de datos. Neanex bvba. 2017

\subsection{Ingeniería, modelado y coordinación BIM}

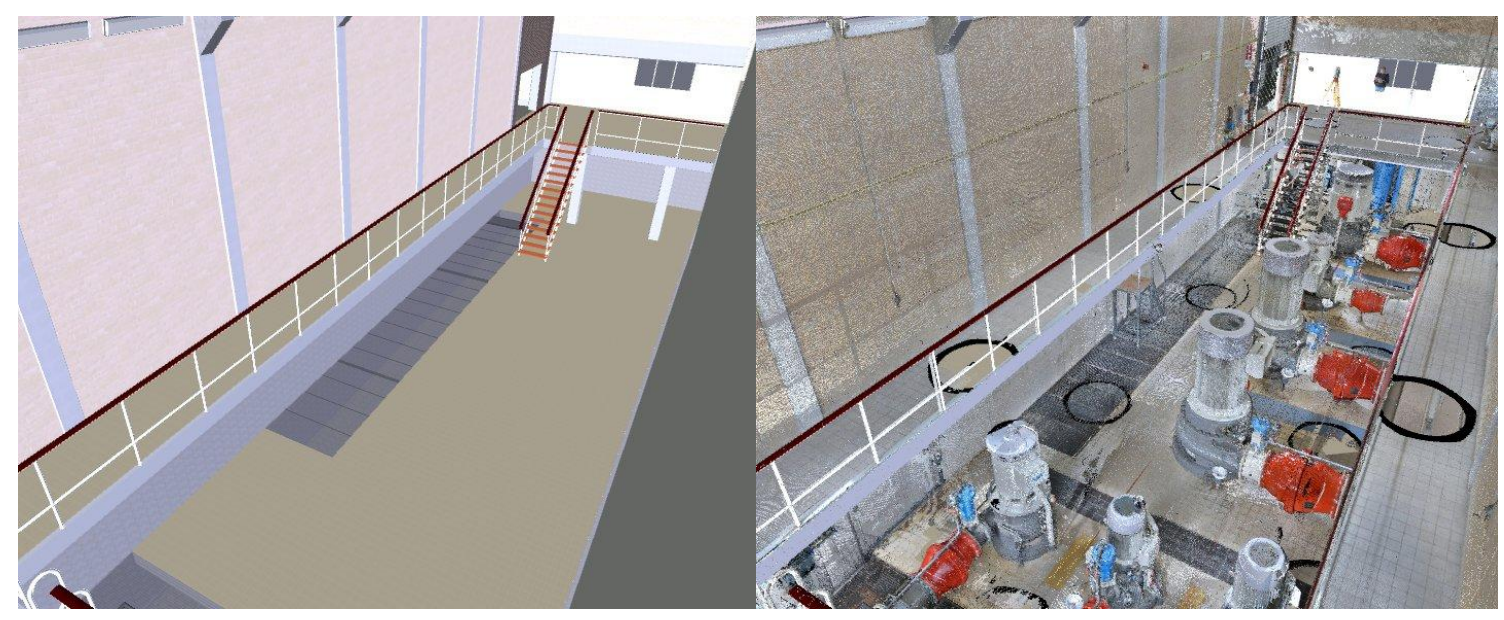

Fig 5. Superposición entre el modelo Revit y el escáner 3D. Infranea bvba. 2016

Resaltar que no se realizó ningún tipo de cálculo estructural a nivel arquitectónico del edificio. El objetivo de Waternet era poder contar con el modelo tridimensional del edificio y redimensionar, eso sí, la capacidad de la estación para suplir de agua potable a la zona de Amsterdam. 
La ingeniería Sweco se hizo cargo por tanto de todos los cálculos en cuanto a las nuevas instalaciones mientras que el rol de iNFRANEA fue modelar la arquitectura existente y coordinar el modelo BIM con el objetivo de que en una eventual construcción del mismo no hubiera interferencias de carácter geométrico.

El modelo tridimensional de la estación de bombeo, necesario para la óptima gestión de la información, se realizó en base a los documentos 2D proporcionados por Rijswaterstaat y los datos obtenidos de un escáner 3D del que se obtuvo una nube de puntos.

Esta información se insertó en Revit y se utilizó para el modelado pormenorizado del edificio.

Para configurar el modelo integral, el software elegido fue Navisworks. La nube de puntos, la geometría modelada en Revit y los elementos modelados y proporcionados por Sweco mediante Autocad Plant 3D conforman el modelo integral.

En lo referente a equipamientos, se modelaron e insertaron dos situaciones distintas: la situación actual y los nuevos equipos que se instalaran en el futuro, con el objetivo último de prever ambos escenarios de trabajo y posibles interacciones geométricas y espaciales.

\section{CONCLUSIONES}

El Proyecto se llevó a cabo de acuerdo a los tiempos estimados siendo el tiempo total de 6 meses, durante los cuales los 3 primeros se utilizaron fundamentalmente para diseño de flujos de trabajo, desarrollo de software específico para el proyecto y toma de datos.

Así, se consiguieron los objetivos iniciales:

- Creación de una plataforma donde toda la información (explícita) quedó almacenada en forma de datos.

- Todo el proyecto se desarrolló bajo un entorno de completa colaboración sobre la misma plataforma.

- El correo electrónico no era admitido como modo de transferencia de datos mediante los agentes implicados.

- Se realizó una entrega digital del proyecto.

Pero también encontramos problemáticas para la consecución del mismo:

- Desarrollo de software específico capaz de traducir información a estándares abiertos (RDF) a la plataforma de datos enlazados.

- Rendimiento (lentitud) de la plataforma de datos enlazados a la hora de reaccionar ante la llegada de nuevos datos.

- Reticencias por parte de la ingeniería a colaborar de forma completamente abierta con el cliente en la misma plataforma. 
Es por ello que creemos que el proyecto fue un éxito pero las metodologías implementadas tienen mucho margen de mejora sobre todo en el lado tecnológico lo que hará que todos los agentes implicados muestren menos reticencias a la hora de usarlas.

\section{REFERENCIAS}

[1] Winkels, Herman. (2014). BIM at Rijkswaterstaat Infrastructure user requirements, business strategy and open standards.

[2] Jeff A. Estefan (2007). Survey of Model-Based Systems Engineering (MBSE).

[3] Charalambous, G. (2013). Collaborative BIM in the cloud and the communication tools to support it.

[4] Wikipedia. (2017)Datos enlazados De: https://es.wikipedia.org/wiki/Datos enlazados.html

[5] Berners-Lee,Tim. (2006). Linked Data. De:

https://www.w3.org/Designlssues/LinkedData.html

[6] Malvar Gómez, Victor. Moreno Barbero, Patricia. (2016). Seguimiento de incidentes con metodología BIM. Una revisión a los flujos de trabajo actuales y una mirada al futuro. EUBIM 2016.

[7] W3C. (2015) Linked Data Platform 1.0 De:

https://es.wikipedia.org/wiki/Datos enlazados.html 


\title{
PLANIFICACIÓN BIM 4D EN LA REHABILITACIÓN DEL SALÓN DE REINOS
}

\author{
Muñoz Pardo, Efraín (1), Guadalupe García, Rafael (2), G. Valderrama, Fernando (3)
}

(1) Universidad Politécnica de Madrid, efrain.munoz.pardo@alumnos.upm.es

(2) Universidad Politécnica de Madrid, rafael.guadalupe@upm.es

(3) RIB SPAIN SA, fernando.valderrama@rib-software.es

\section{RESUMEN}

Se trata de una simulación de la rehabilitación del deteriorado Salón de Reinos, el edificio que se convertirá en la ampliación del Museo del Prado, y que próximamente llevarán a cabo Norman Foster y Carlos Rubio con su proyecto.

Se acometió una planificación 4D a partir de un modelo arquitectónico 3D enlazándolo con una planificación clásica para obtener un BIM 4D.

Debido a la envergadura del edificio se dividió en dos zonas Norte-Oeste (con andamios en el patio) y Sur-Este (con andamio móvil por la acera). Con el vídeo realizado se ve el progreso y necesidades de una forma visualmente muy sencilla.

Palabras clave: modelos, planificación, simulación 4D, VDC

\section{ABSTRACT}

This is a simulation of the rehabilitation of the deteriorated Salón de Reinos, the building that will become the extension of the Prado Museum, and soon to be carried out by Norman Foster and Carlos Rubio with his project.

A 4D planning was undertaken from a 3D architectural model linking it with a classic planning to obtain a 4D BIM.

Due to the size of the building, it was divided into two North-West zones (with scaffolding in the courtyard) and South-East (with mobile scaffolding on the sidewalk). With the video, the progress and the needs are checked in a visually very simple way.

Keywords: Models, 4D Simulation, Scheduling, VDC

INTRODUCCIÓN

El Salón de Reinos es un ala del antiguo Palacio del Buen Retiro, una de las pocas partes no destruidas del mismo durante la Guerra de la Independencia. Fue durante mucho tiempo Museo del Ejército, luego pasó a formar parte de la ampliación del Museo del Prado (2007), pero no se acometió su rehabilitación, hasta ahora que si va a ser realizado. Se acomete 
una planificación BIM 4D para la rehabilitación del Salón de Reinos a partir de un PFC (Proyecto Fin de Carrera) [1].

Se utilizó el programa Synchro Pro, herramienta de planificación 4D mediante el VDC (Virtual Design Construction), una construcción mediante un diseño virtual del modelo, utilizando la sincronización para intercambio de datos importando el modelo $3 \mathrm{D}$ del programa de modelado 3D AutoCAD y la planificación CPM (Critical Path Method en sus siglas en inglés, Método del Camino Crítico) de la rehabilitación realizada con el Primavera P 6.8.

Los trabajos en rehabilitación BIM 4D aún no están muy extendidos en España, actualmente se están realizando trabajos de reconstrucción virtual de los yacimientos arqueológicos MLEIHA 5,6,7,8 EAU (Emiratos Árabes Unidos) por un equipo de profesores y alumnos de la UPM dirigidos por la profesora Mercedes Farjas Abadía.

\section{CONTENIDO}

Partiendo de un modelo 3D se trata de obtener una planificación BIM 4D mediante el uso del VDC [2] para programar el proyecto de rehabilitación del Salón de Reinos. De esta forma tendremos una manera virtual de gestionar el proyecto y actuar en consecuencia, según se detecten conflictos o incoherencias.

\subsection{Modelo 3D}

El modelo 3D se realizó hace 20 años para un PFC en la titulación de Infografía para la Arquitectura [3] sobre la primera ampliación del Museo del Prado. En este modelo en tres dimensiones generado con AutoCAD tuvo que volverse a redistribuir todas las capas realizadas anteriormente pensando en que ahora iba a servir para la construcción (o rehabilitación) del edificio para poder utilizarlo en la planificación 4D. Incluso creando algunas nuevas y modificando capas de bloques (como pueden ser las ventanas). Las capas se podrían haber multiplicado, más atendiendo a la zonificación del edificio (Norte, Oeste, Sur, Este) para su correcta planificación, pero las capas creadas en AutoCAD no distinguían estas zonas del edificio. Esto se decidió hacer en el Synchro debido a que es más fácil, rápida e intuitiva la selección de objetos 3D.

\subsection{Planificación 4D}

La planificación 4D es igual a 3D más planificación. La generación de videos [4] [5] permite ver la evolución de la obra y determinar las zonas de acopios y las interferencias con el medio.

La metodología de planificación que se ha seguido en Primavera ha sido la siguiente:

1. Objetivos del proyecto. 
2. Fecha de inicio.

3. Estructura de segregación del trabajo (Work Breakdown Structure, WBS).

4. Estimación de la duración de las actividades.

5. Relaciones entre las actividades.

6. Establecer una base de datos de recursos.

7. Asignar recursos a las actividades.

8. Determinar camino crítico y la holgura libre total [6] [7] así como la sobreasignación de recursos.

Aplicación en el caso que nos ocupa según la siguiente planificación:

- Después de la firma del contrato (hito de comienzo de obra) procedemos al análisis de la rehabilitación.

- A las peticiones y estudio de ofertas, para luego negociar y adjudicar las escogidas.

- Mientras se hacen las contrataciones para la implantación en obra.

- En obra ya se realiza el vallado perimetral y se instalan casetas, baños, acometidas, etc.

- Comenzamos la ejecución de la obra con la tira de cuerdas.

Procedemos ahora de la siguiente manera.

- Las tareas se dividen en cuatro zonas correspondiendo con las fachadas del edificio orientadas a los puntos cardinales, debido a la gran dimensión del edificio. En la fachada Norte-Oeste se colocan andamios continuos que realiza un equipo, y otro en la fachada Sur-Este mediante un andamio móvil.

- Primero se quitan ventanas y se tapan los huecos.

- Segundo se hacen los saneamientos de piedra natural, limpieza de ladrillo y los elementos ornamentales.

- Las tareas se ejecutan de arriba hacia abajo, debido a que los residuos de quitar las ventanas o limpieza de zonas caen hacia abajo.

- $\quad$ Tercero se ponen las ventanas, también de arriba hacia abajo.

- El aislamiento de pizarra se hace primero en las cubiertas seguido de los paramentos verticales. 
- El aislamiento, impermeabilización y solado de terrazas (tercera planta, zona sur) se realiza al retirar los andamios.; en la primera (en el patio de entrada, zona norte) al retirar también las casetas, baños y material sobrante.

- Se termina reparando escaleras y pintando el muro perimetral para hacer después la limpieza de obra.

- Se acaba todo con el hito de final de obra.

Esta sería una metodología clásica de planificación, y teniendo el modelo 3D sólo quedaría asignar los objetos del modelo a las actividades de la planificación. Con lo cual tenemos todas las ventajas de una planificación 4D las cuales veremos en el apartado de conclusiones.

Con la planificación 4D se genera colaboración trabajando con los datos integrados en el edificio virtual, con una simulación en seguridad, generando informes compartidos y comparativos. Los objetivos son reducir costes, plazo de ejecución, ordenar personas, procesos y herramientas. La simulación de la construcción permite resolver conflictos, dar soporte a la obra y mejorar la planificación de la obra al detectar conflictos espaciotemporales (como muestran las Fig. 1 y 2 ).

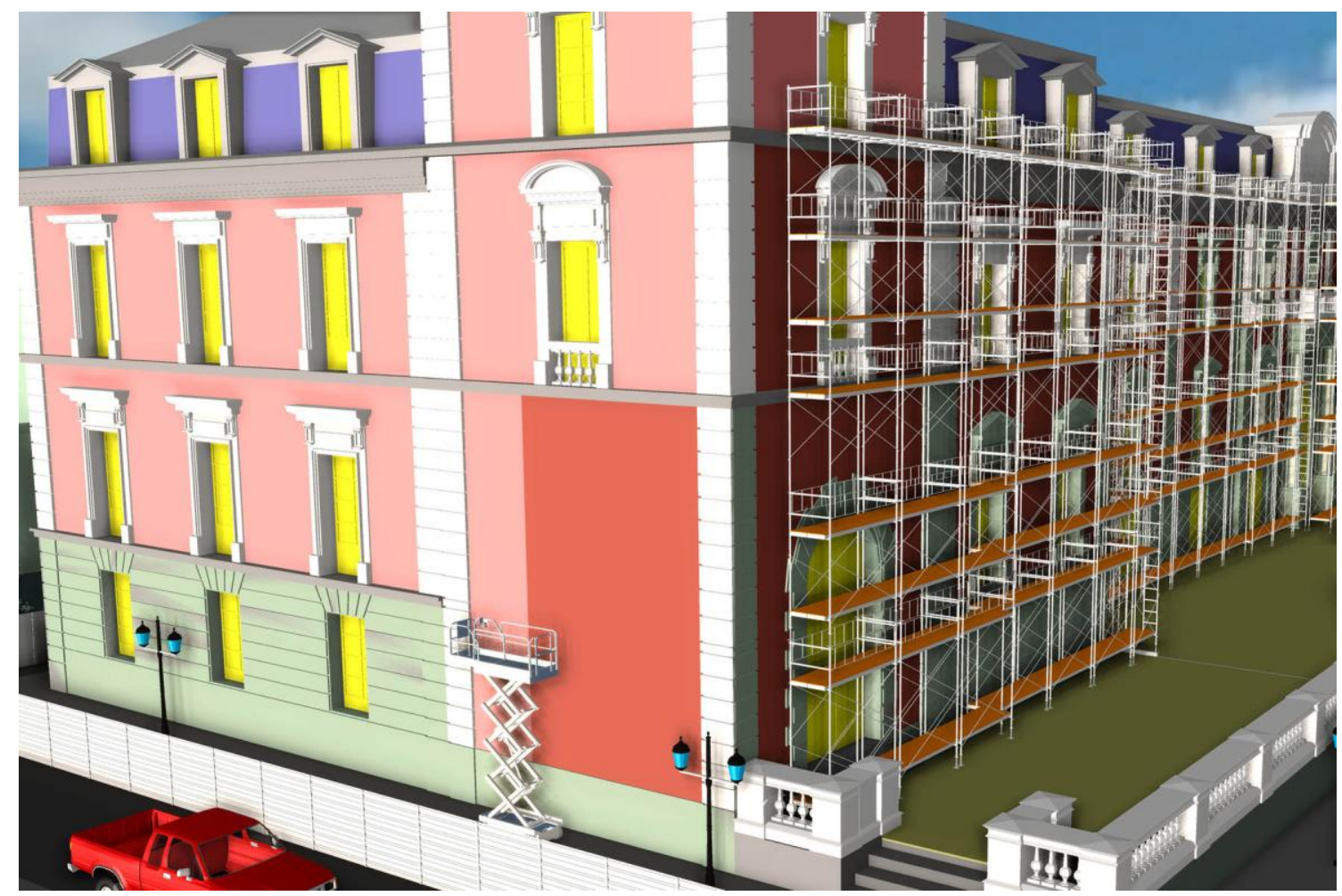

Fig. 1. Vista Noreste del modelo 3D del Salón de Reinos limpiándose el ladrillo (durante la rehabilitación). 2016. Fuente propia. 


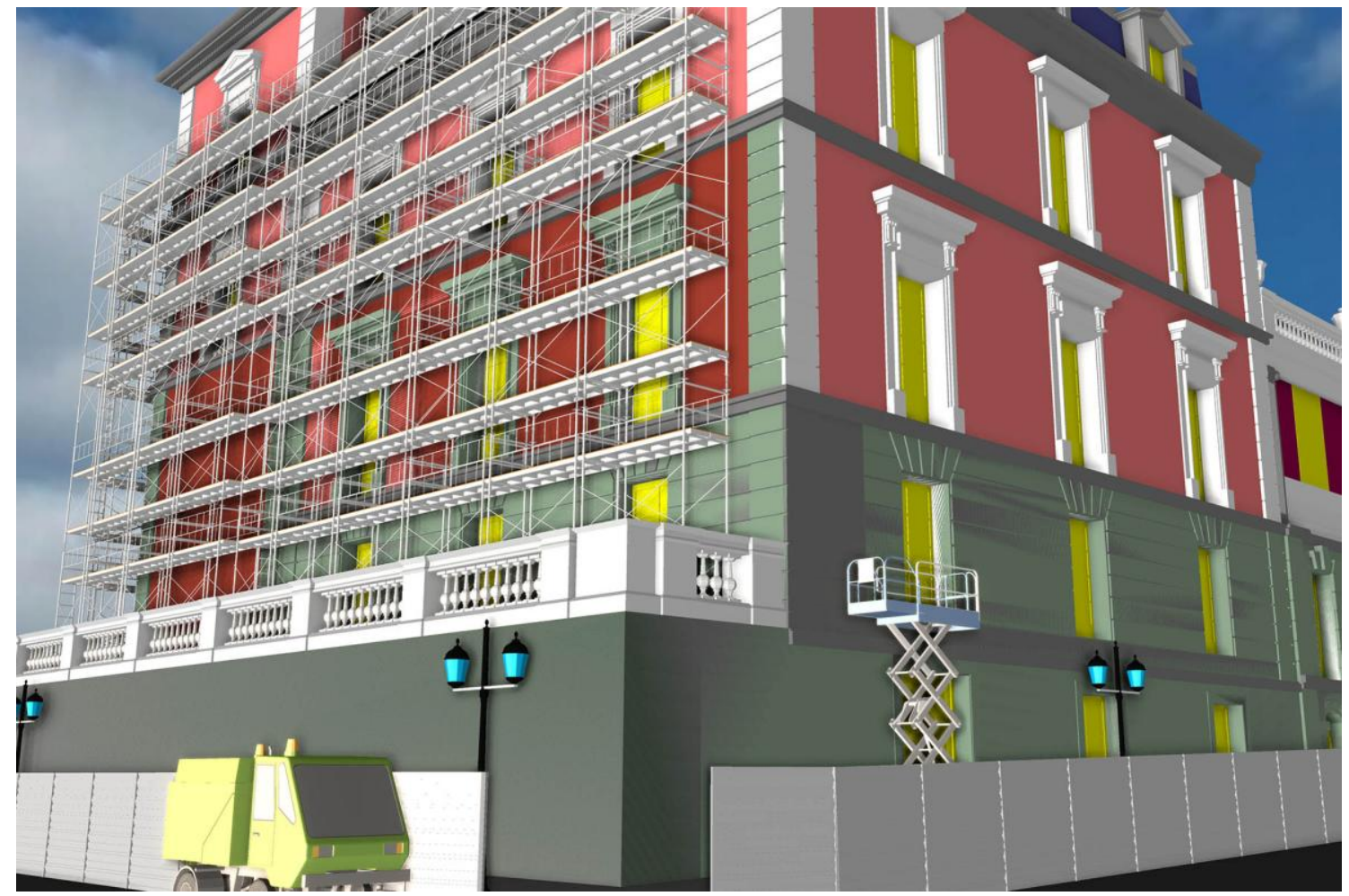

Fig. 2. Vista Suroeste del modelo 3D del Salón de Reinos limpiándose la piedra (durante la rehabilitación). 2016. Fuente propia.

\subsection{Tiempo atribuido a las tareas}

Consultando con profesionales de la carpintería de madera antigua [8] se supone un tiempo de retirada de cada ventana de 2 horas y de puesta de 4, por un equipo de 2 personas, un oficial y un peón. Lo que supone al día hacer un total de 4 ventanas (según la localización sería como se muestra en la Fig. 3 y aplicándolo a la planificación quedaría como se ve en la Fig. 4) y 2 ventanas respectivamente. Estos tiempos son debidos al tipo de ventana antiguo y sus grandes dimensiones. La protección de huecos de cada ventana sería $1 / 2$ hora y con un retardo de $4 \mathrm{~h}$ con respecto a la retirada.

La limpieza de paramentos verticales (chapar, reparar piedra y ladrillo) con maquinaria a presión así como la pintura (con rodillo) de muros de contención del edificio se calcula en 8 $\mathrm{m}^{2}$ de superficie de producción por hora de trabajo. Haciendo $64 \mathrm{~m}^{2}$ al día. Siempre que sean zonas fácilmente accesibles, a medida que se trabaja a más altura (menos accesible) para la persona el rendimiento es menor. 
Escuela Técnica Superior de Ingeniería de Edificación Universitat Politècnica de València

Valencia, 19 y 20 de mayo 2017

$\begin{array}{cll}\text { Retirada de carpinterías de fachadas } \\ \text { Planta } & \text { Zona } & \text { Ubicación } \\ \text { Baja Fachada } & \text { Sur } \\ 1 \text { Fachada } & \text { Norte } \\ 1 \text { Fachada } & \text { Oeste } \\ 1 \text { Fachada } & \text { Sur } \\ 1 \text { Fachada } & \text { Este } \\ 2 \text { Fachada } & \text { Norte } \\ 2 \text { Fachada } & \text { Oeste } \\ 2 \text { Fachada } & \text { Sur } \\ 2 \text { Fachada } & \text { Este } \\ 3 \text { Fachada } & \text { Norte } \\ 3 \text { Fachada } & \text { Oeste } \\ 3 \text { Fachada } & \text { Sur } \\ 3 \text { Fachada } & \text { Este } \\ 4 \text { Fachada } & \text { Norte } \\ 4 \text { Fachada } & \text { Oeste } \\ 4 \text { Fachada } & \text { Sur } \\ 4 \text { Fachada } & \text { Este } \\ 5 \text { Torre } & \text { Oeste } \\ 5 \text { Torre } & \text { Este }\end{array}$

\begin{tabular}{rrr}
\multicolumn{3}{c}{2 cada día (8h) } \\
N Ventanas Horas & Días aplicabl $\epsilon$ \\
25 & 50 & 6 \\
13 & 26 & 4 \\
3 & 6 & 1 \\
24 & 48 & 6 \\
3 & 6 & 1 \\
12 & 24 & 3 \\
3 & 6 & 1 \\
17 & 34 & 4 \\
3 & 6 & 1 \\
15 & 30 & 4 \\
4 & 8 & 1 \\
17 & 34 & 4 \\
4 & 8 & 1 \\
14 & 28 & 4 \\
4 & 8 & 1 \\
17 & 34 & 4 \\
4 & 8 & 1 \\
8 (pequeñas & 4 & 1 \\
8 (pequeñas & 4 & 1
\end{tabular}

Fig. 3. Tabla de días aplicables a la tarea de "Retirada de carpinterías de fachadas" según planta y zona. 2016. Fuente propia.

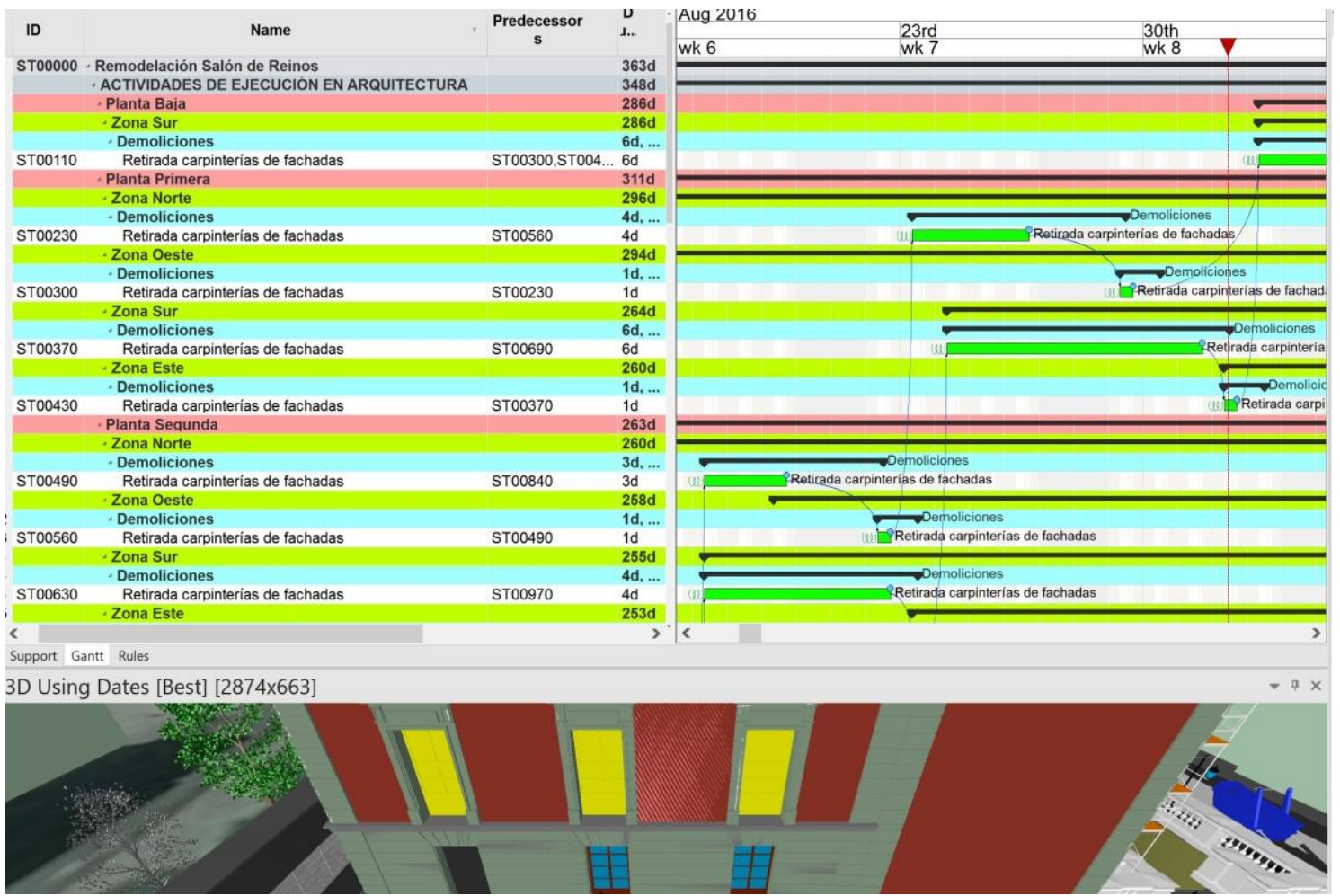

Fig. 4. Diagrama de Gantt con tareas de "Retirada de carpinterías de fachadas". 2016. Fuente propia.

\section{CONCLUSIONES}

A lo largo de todo este proceso, se aprecia que no es lo mismo un modelo 3D para infografía, análisis o como en este caso para su planificación y su construcción, de ahí los diferentes grados de detalle y desarrollo (LOD). Para una infografía el modelo 3D puede ser 
una piel, puesto que sólo se requiere una imagen exterior del mismo. Para planificar una construcción se requieren los objetos $3 \mathrm{D}$ con todas sus parámetros; tales como volumen, material, forma, tal y como será esa pieza en la realidad, etc.

La planificación en BIM 4D trata de unir una planificación tradicional con el modelo tridimensional (3D), con lo cual se puede realizar una visualización temporal de cómo va variando el $3 \mathrm{D}$ a lo largo del tiempo según se ejecuta la obra. Es decir se realiza una construcción virtual antes de la ejecución real de la obra. Las ventajas de utilizar el modelo BIM 4D serían las comentadas a continuación. Así en un edificio por ejemplo se muestra el proceso de construcción del mismo en el tiempo, es decir realizamos una construcción virtual antes de proceder a la construcción real. De esta forma se pueden detectar las posibles colisiones (clash detection) tanto estáticas (entre elementos 3D) como dinámicas (entre el 3D y elementos móviles del entorno, como puede ser un andamio móvil en relación a su entorno de trabajo). Se observó, gracias al 3D y su evolución en el tiempo (4D), la mejor zona de posicionamiento de maquinaría y útiles de la construcción (andamios fijos y móviles). Se crearon caminos 3D para simular el paso de peatones o vehículos en obra, movimiento de andamios eléctricos o grúas, los cuales no se pueden generar en una planificación clásica como es lógico. Se generaron videos desde perspectivas generales a detalles para detectar errores, colisiones, incompatibilidades (como que no esté el andamio si todavía no ha terminado la tarea de limpieza del ladrillo). Además de controlar el camino crítico, las necesidades de materiales, recursos.

La utilización del BIM 4D repercute en una mejoría del tiempo en el proceso constructivo rehabilitador, con el consiguiente ahorro monetario. Comenzada la ejecución de la obra y habiéndose establecido la línea base correspondiente, se podrá observar en dos ventanas diferentes el desfase entre la construcción virtual y la real en el tiempo.

\section{REFERENCIAS}

[1] Muñoz, Efraín. 2016. PFC Proyectos de Construcción 4D. Publicaciones de la UPM.

[2] Khan, Ricardo. (Publicado el 18 jun. 2015 a las 1:12:08 P.M.). BIM and VDC defined, The Mortenson perspective. http://blog.synchroltd.com/bim-and-vdc-defined-themortenson-perspective [Fecha de acceso 27/04/2017]

[3] Muñoz, Efraín. 1998. PFC Ampliación del Museo del Prado. Publicaciones de la UPM.

[4] Muñoz Pardo, Efraín [UPM](Publicado el 27 jul. 2016). Proyectos de Construcción 4D Rehabilitación del Salón de Reinos (1/2). Vídeos del proyecto fin de carrera del alumno Efraín Muñoz Pardo [Archivo de vídeo]. Recuperado de https://www.youtube.com/watch?v=5bxkgcVoz3k [Fecha de acceso 27/04/2017]

[5] Muñoz Pardo, Efraín [UPM](Publicado el 27 jul. 2016). Proyectos de Construcción 4D Diagrama de Gantt - Rehabilitación del Salón de Reinos (2/2). Vídeos del proyecto fin de 
carrera del alumno Efraín Muñoz Pardo [Archivo de vídeo]. Recuperado de https://www.youtube.com/watch?v=Ze6DvKQPXns [Fecha de acceso 27/04/2017]

[6] Mattos, Aldo D. Valderrama, Fernando. 2014. Métodos de Planificación y Control de Obras. Del Diagrama de Barras al BIM. Ed. Reverté., Barcelona.

[7] Rafael Guadalupe García, María Castro Malpica y Roberto Rodríguez-Solano Suárez. 2006. Guía para la elaboración y gestión de proyectos. Publicado por la Escuela Técnica Superior de Ingenieros en Topografía, Geodesia y Cartografía. ISBN: 978-84-96244-90-0

[8] Ortiz Gutiérrez, Jaime. 1993. Elementos de edificación. Carpintería de madera. Cap.4 U.D.2 Publicado por la Escuela Nacional de Educación a Distancia. Fundación Escuela de la Edificación. ISBN: 84-86957-50-8 


\title{
EMPLEO DE LA METODOLOGÍA BIM EN PROCESOS DE INVENTARIO FÍSICO DE CENTRALES NUCLEARES - EMPLOYMENT OF THE BIM METHODOLOGY FOR PHYSICAL INVENTORY PROCESSES IN NUCLEAR POWER PLANTS
}

\author{
de Paz Sierra, Jesús; Ballester Muñoz, Francisco; Rico Arenal, Jokin
}

(1) Universidad de Cantabria jesus.depaz@unican.es.

(2) Universidad de Cantabria francisco.ballester@unican.es

(3) Universidad de Cantabria Jokin.rico@unican.es

\section{RESUMEN}

La implantación de la metodología BIM está aumentando exponencialmente en proyectos de nueva construcción. Sin embargo, existen algunos sectores como el nuclear, donde no se emplea debido a la antigüedad de su diseño.

Las centrales nucleares generan un elevado nivel de información. Esta información está asociada al gran número de componentes, instalaciones y elementos físicos. Además, hay que sumar una información muy importante, la información radiológica, que pertenece a cada uno de los elementos situados en la central.

Para mejorar el proceso de inventario físico y procesos asociados a este, se está desarrollando un modelo 3D parametrizado BIM que ha comenzado con el edificio del reactor.

Se deberá modelar los edificios dividiendo cada planta en zonas que presentan diferentes características radiológicas. Del mismo modo se deberán modelar todos los elementos pertenecientes a una zona incluyendo toda la información requerida para poder realizar de forma eficiente el inventario físico.

El estudio muestra una clara mejora de la eficiencia dado que con un modelo BIM es posible realizar una búsqueda de cada uno de los elementos incluidos en una zona, facilitando significativamente el inventario físico, procesos de planificación de toma de muestras, control de dosificación, planificación de actividades, entre otras actividades.

Palabras clave: BIM, Inventario, Nuclear, Paramétrico, Planificación 


\section{ABSTRACT}

The implementation of the BIM methodology is increasing exponentially in new construction projects. However, there are some sectors such as nuclear, where it is not used due to the high age of the plants.

Nuclear power plants (NPP) generate a high level of information. This information is associated with the large number of components, installations and physical elements. Furthermore, a very relevant information, the radiological information, must be added. This information is different for each element located in the NPP.

To improve the physical inventory process and associated processes, a BIM parameterized 3D model is being developed. It has started with the reactor building.

Its structure has been modelled and each plant has been divided into zones with different radiological characteristics. In addition, all the elements belonging to a zone have been modelled and all the information required has been included in order to develop a physical inventory productively.

The results show a clear improvement in efficiency since using this model it is possible to perform a search of all the elements included in a specific zone. This significantly facilitate the physical inventory, sampling planning processes, dosing control, planning of activities, among other activities.

Keywords: BIM, Inventory, Nuclear, Parametric, Planning 


\section{$1 \quad$ INTRODUCCIÓN}

El sector energético presenta una gran importancia en la actualidad fundamentalmente debido a la gran demanda de electricidad que requiere realizar cualquier tipo de actividad.

Dentro del sector energético se encuentra el sector nuclear que por ahora genera energía mediante un proceso de fisión nuclear y genera alrededor de un $11,5 \%$ de la electricidad mundial. [1]

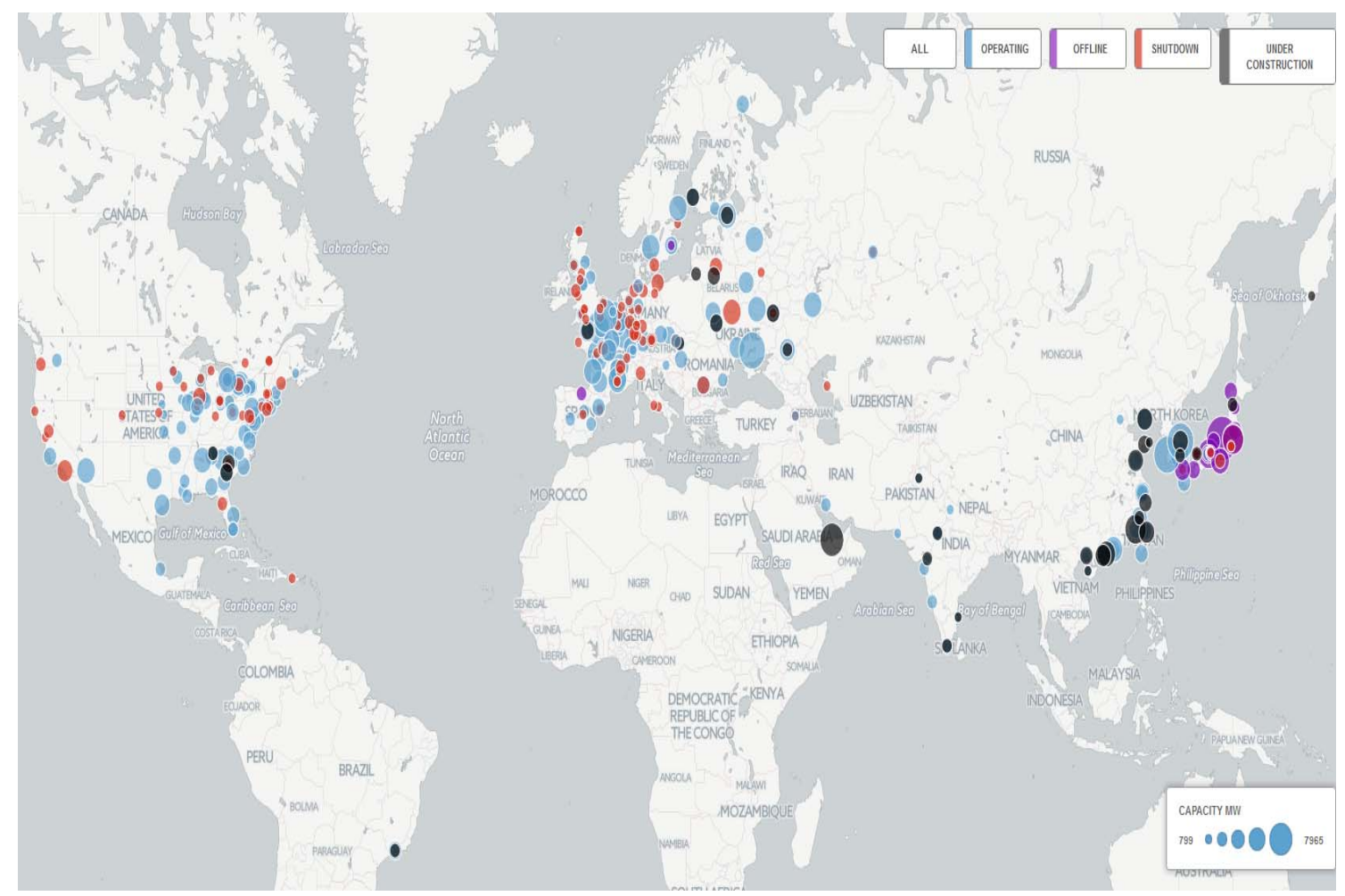

Fig 1. Reactores nucleares en el mundo, CarbonBrief, 2016 [2]

Cada país presenta diferentes políticas de futuro en relación a esta fuente de energía. Algunos como China, India, Rusia, Corea del Sur, Finlandia o Francia han apostado por su expansión diseñando un total de 61 centrales que se encuentran en construcción. [3]

Por otro lado, existe una evolución tecnológica y computacional la cual en el sector energético nuclear se ha venido implementando de forma paulatina y gracias a la cual se ha podido apreciar una mejoría y una facilitación en los diferentes procesos a llevar a cabo. En el caso de la central de José Cabrera, se han llegado a desarrollar modelados 3D de forma que se pudiesen realizar planificaciones, visualización, control y seguimiento de actividades, detectando interferencias entre elementos en fases de desmantelamiento [4] 


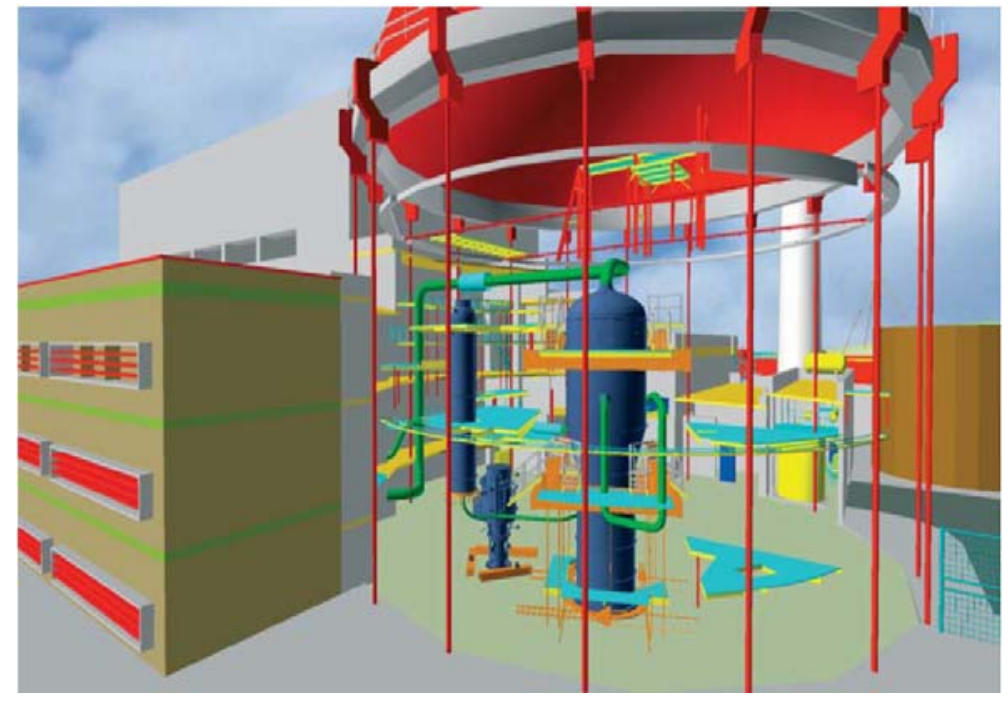

Fig 2. Maqueta virtual 3D de la central José Cabrera, revista Estratos, 2011 [4]

Sin embargo, aunque la metodología BIM se encuentra en auge, y se han realizado pequeños estudios concretos dentro de una zona acotada de una central nuclear [5][6][7], no existe ningún proyecto completo hasta el momento, guiado por esta metodología, para una central nuclear en operación.

El objeto del presente artículo es estudiar los procesos a seguir para desarrollar un modelo 3D BIM completo en unas instalaciones de este tipo de forma que se podrían reducir los plazos y costes asociados al realizar actividades de forma más eficiente en fases de operación, mantenimiento y desmantelamiento.

La aplicación de este estudio puede verse reflejada en la central nuclear de José Cabrera, donde si el tiempo invertido en el desarrollo de los modelos 3D se hubieran destinado a la generación de modelos BIM, estos podrían haber sido útiles para muchos más procesos tareas y actividades en la fase de desmantelamiento.

El estudio realizado contempla los procesos que se deben seguir para la elaboración de un modelo BIM de una central nuclear construida, que contenga toda la información necesaria para facilitar y hacer más eficientes los diferentes procesos requeridos a lo largo de su ciclo de vida, desde la operación y mantenimiento hasta el desmantelamiento.

El desarrollo de este estudio generará una nueva ventana de negocio dado que el know-how adquirido podrá facilitar el desarrollo de nuevos proyectos dentro de este sector que hasta ahora permanecía ajeno a esta metodología. 


\section{CONTENIDO}

Durante el proceso de desmantelamiento de la central nuclear de José Cabrera (2003-2019), primer desmantelamiento completo de una central nuclear en España [8], se realizaron una serie de actividades, las cuales, disponiendo de un modelo BIM se podrían haber realizado en un menor tiempo y por lo tanto habrían supuesto una reducción de costes.

Aunque en este caso en concreto, la central se encuentra en una fase de desmantelamiento, en cualquier otra fase sería necesaria la realización de un proceso conocido como la caracterización radiológica [9] que consiste en realizar una serie de toma de muestras, mediciones y ensayos, que permitan fijar un estado radiológico real de cómo se encuentra la central y cada uno de los elementos que contiene.

La caracterización radiológica se realiza en varias ocasiones durante todo el ciclo de vida de una central nuclear, presentando en la fase de desmantelamiento un carácter obligatorio para poder conseguir la autorización de desmantelamiento necesaria para comenzar los trabajos.

Es por esto que el enfoque principal de este estudio se ha centrado en la mejora de los procesos para realizar la caracterización radiológica de forma que la solicitud de autorización de desmantelamiento pueda enviarse lo antes posible gracias a una reducción de tiempos motivada por el modelo 3D BIM.

\subsection{Caracterización Radiológica}

La realización de una caracterización radiológica requiere de la preparación de un plan de toma de muestras donde se debe decidir el número de muestras a realizar y los puntos y lugares donde se deben tomar. Para ello se deben tener en cuenta todos los datos de cada uno de los elementos que se encuentran ubicados dentro de la central nuclear.

Por lo tanto, es necesario realizar un proceso conocido como inventario físico que consta de una identificación de todos los elementos con sus medidas, pesos, materiales y demás características.

Este proceso, sin la utilización de un modelo BIM, requiere de un análisis manual dentro de las bases de datos, de planos, documentos, características técnicas de cada elemento, etc. así como una serie de trabajos de campo para la identificación de muros, tanques, válvulas, motores, tuberías, de las cuales no se disponga de la suficiente información en las bases de datos. Además, en algunos casos donde los valores sean de difícil obtención se realizan estimaciones de pesos, volúmenes y otras características.

La disposición de un modelo BIM de la central nuclear facilitaría el proceso de realización de un inventario físico dado que tanto la información como el cálculo de determinadas características se obtendrían de forma más cómoda. Pudiendo reducir los plazos y el personal destinado a estas actividades. 
Posteriormente a la realización del inventario físico, la información pasa por un software que, mediante una serie de cálculos, proporciona los puntos donde se deben hacer las muestras y ensayos. El modelo BIM también puede ayudar en este proceso ya que se puede planificar de forma más exacta el tiempo de exposición de los operarios durante la toma de muestras además de permitir a los mismos visualizar los puntos donde se debe tomar las muestras antes de situarse en el interior del emplazamiento.

Finalmente, ese mismo software junto con los valores radiológicos obtenidos de las muestras analizadas, proporciona una clasificación radiológica para cada elemento de la central. Este valor retornará al modelo BIM de forma que el modelo siempre se encuentre actualizado y se pueda hacer una trazabilidad del estado radiológico de la central.

El estudio realizado ha estimado una serie de condiciones de contorno para la elaboración del modelo BIM en base a la calidad de la información de la que se puede disponer dentro de una instalación de este tipo que presenta cierta antigüedad.

\subsection{Planificación de los trabajos}

El primer paso que se debe realizar es definir correctamente el alcance de los trabajos y la planificación de los mismos.

El alcance se debe definir en base a la calidad de la información y por ello es necesario realizar un BEP (BIM EXECUTION PLAN) en el que queden recogidas las bases del trabajo identificando de forma exhaustiva lo que se va a modelar y con qué nivel de desarrollo, y lo que no se va a modelar.

Para poder llevar a cabo un inventario físico de forma eficiente es necesario disponer del modelo de los edificios, del modelo de las instalaciones y equipos de las mismas y de modelos de elementos de gran tamaño como escaleras, tramex, etc. con un nivel tanto gráfico como de información (LOD) alto. Sin embargo, para el resto de elementos como soportes, luminarias, etc. se pueden agrupar y organizar en paquetes por zona e incluir modelos genéricos que contengan un nivel de información elevado. De esta forma el modelo BIM podrá servir por un lado para gestionar toda la información necesaria y por otro lado para planificar los trabajos a realizar gracias a la visualización gráfica de la mayoría de los elementos importantes.

Dentro del BEP también deberán quedar reflejados los parámetros necesarios que permitan una buena gestión de los activos y ayuden a la realización de actividades, no solo en el desmantelamiento sino también en fases de operación y mantenimiento.

A continuación, se proponen una serie de parámetros, para cada una de las especialidades. Teniendo en cuenta que en los edificios además de las propiedades de los elementos que lo componen (paramentos, suelos y techos), se debe prestar especial atención a facilitar posteriormente, la búsqueda por zona de los distintos equipos e instalaciones. 


\begin{tabular}{|l|l|l|l|}
\hline \multicolumn{1}{|c|}{ EDIFICIOS } & ELEMENTOS DEGRAN TAMANO & \multicolumn{1}{c|}{ INSTALACIONES } & \multicolumn{1}{|c|}{ RESTO DE ELEMENTOS } \\
\hline Cota de ubicación & Cota de ubicación & Cota de ubicación & Cota de ubicación \\
\hline Código de la zona & Código de la zona & Código de la zona & Código de la zona \\
\hline Código de paramento & Código del elemento & Código del elemento & Código del elemento \\
\hline Tipo de paramento & Tipo de elemento & Tipo de elemento & Tipo de elemento \\
\hline Material de paramento & Material & Material & Material \\
\hline Espesor total & Superficie & Densidad material & Superficie \\
\hline Espesor Impactado o contaminado & Volumen & Diámetro exterior & Volumen \\
\hline Superficie & Densidad material & Espesor & Peso \\
\hline Volumen & Peso & Espesor de recubrimiento & Caracterización radiológica \\
\hline Densidad material & Caracterización radiológica & Material de recubrimiento & \\
\hline Peso & & Densidad material de recubrimiento & \\
\hline Caracterización radiológica & & Tipo de fluido que transporta o contiene & \\
\hline & & Superficie & \\
\hline & Volumen & \\
\hline & Peso & \\
\hline & Caracterización radiológica & \\
\hline
\end{tabular}

Fig 3. Parámetros propuestos para cada especialidad, Propia, 2017

Otro punto importante a definir antes de comenzar los trabajos es la planificación y el equipo de trabajo adecuado para desarrollar los trabajos de forma eficiente. Un número muy elevado de personas dentro del equipo puede resultar contraproducente a la hora de trabajar en un entorno colaborativo.

El equipo propuesto será de 12 personas que deberán dividirse en cada una de las disciplinas.

Para el desarrollo de los edificios se ha considerado la posibilidad de destinar $1 / 4$ del equipo siguiendo un criterio de modelado de los edificios diseñado en función de la importancia del edificio y al del número de instalaciones que contiene en su interior.

Para las instalaciones se ha considerado destinar $3 / 4$ del equipo. Las instalaciones presentan distintos tipos de sistemas por lo que, para no interferir en los trabajos se deberán repartir las tareas a desarrollar por sistema. A continuación, se muestra una planificación estimada para poder llevar a cabo los trabajos con el equipo descrito en aproximadamente 6 meses. 


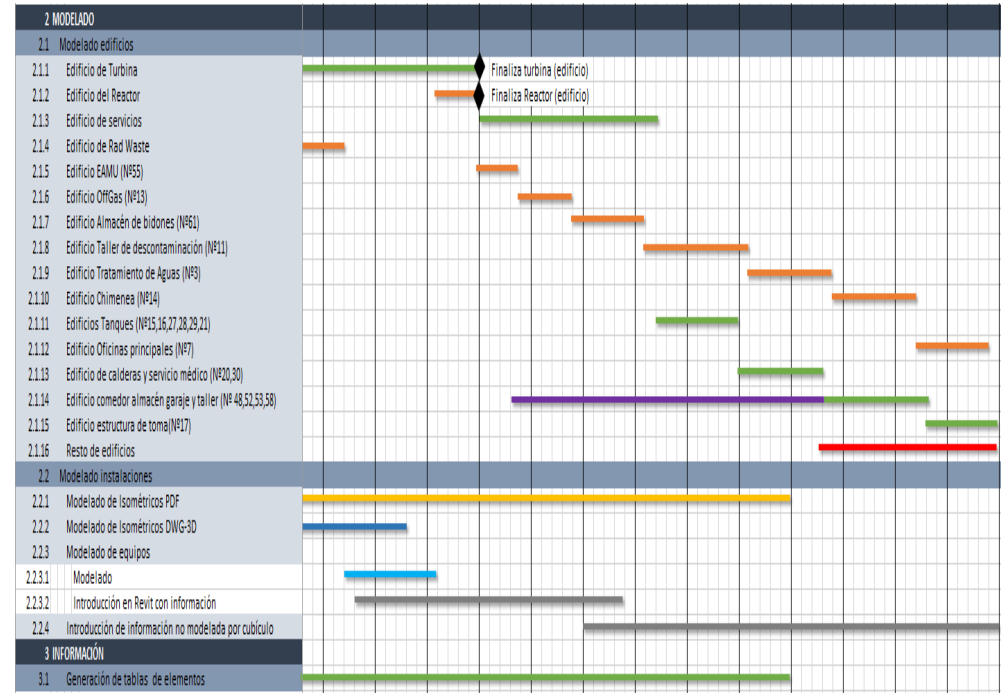

Fig 4. Diagrama Gantt de la planificación propuesta para realizar los trabajos, Propia, 2017

\subsection{Modelado de los edificios}

La primera fase de modelado recae en los edificios, necesarios para poder introducir de forma coherente las instalaciones.

Se ha priorizando en la planificación en la elaboración de los edificios del reactor y de turbina, fundamentalmente debido a que albergan la mayor parte de las instalaciones. De esta forma a medida que se avanza en el modelado de edificios se pueden realizar las fases previas del modelado de instalaciones sin generar retrasos en ninguna de las actividades.

Para la fase de modelado se han valorado las distintas opciones disponibles entre las que destacan sistemas de escaneo 3D y modelado 3D con fotogrametría. Sin embargo, dada la gran cantidad de instalaciones que se pueden encontrar en el interior de los edificios existen numerosos puntos ciegos y habitaciones que hacen que el coste del escaneo, dada la magnitud de cada uno de los edificios, sea demasiado elevado. Adicionalmente esto se requiere de un post-procesado de las nubes de puntos generadas para definir el modelo BIM. Lo mismo sucede con la fotogrametría. Si bien, se pueden utilizar estos sistemas en casos concretos donde se requiera un mayor detalle de los elementos estructurales.

El estudio determinó, que era más viable la realización de un modelado partiendo de los planos de construcción fundamentalmente debido a que La ventaja de este tipo de instalaciones es que los edificios presentan pocas modificaciones de diseño con respecto a los planos constructivos. Además, en caso de realización de alguna modificación esta se añade a los planos pertinentes por lo que se puede modelar en base a planos actualizados. Adicionalmente el estudio recomienda la realización de una serie de visitas a la central de forma que el equipo de trabajo se familiarice con el entorno. 
Durante el proceso de modelado, uno de los requisitos necesarios para realizar de forma correcta la caracterización radiológica es que cada edificio debe estar subdividido en plantas y cada planta en zonas. Cada una de las zonas va a presentar unas características radiológicas diferentes por lo que deben quedar completamente diferenciadas mediante una codificación única. Por otro lado, dentro de una zona, es importante hacer una distinción de cada uno de los paramentos los cuales deben adquirir también un código único que permita identificar en qué zona se encuentra y cuál es el paramento.

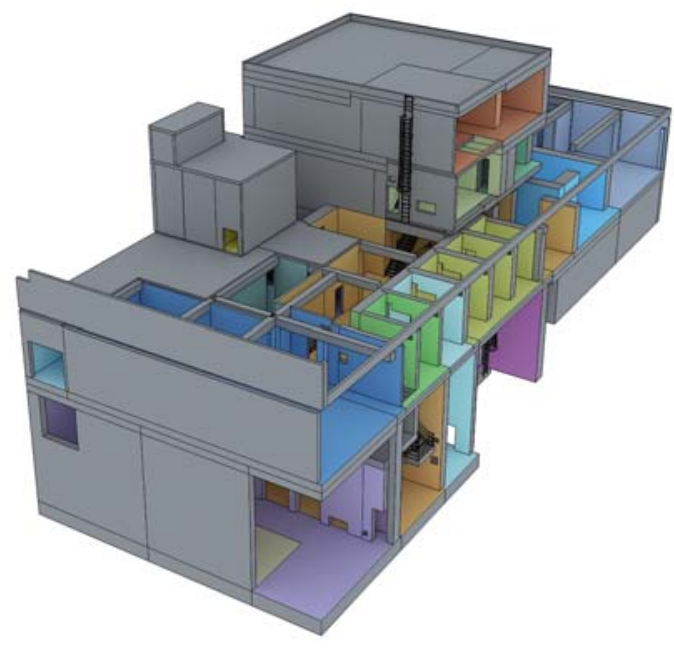

Fig 5. Modelo 3D BIM de un edificio de una central nuclear con sus zonas, Propia, 2017.

La ventaja de disponer el modelo 3D BIM es que una vez codificados los paramentos, los distintos valores necesarios como el área, el espesor, la zona donde se encuentran, el código del paramento, la longitud, el material, la densidad, la masa, etc. se obtienen de forma directa o mediante cálculos sencillos.

Este proceso llevado a cabo sin el modelo 3D requeriría de un análisis de los planos, cálculos de distancias, áreas, volúmenes, pesos y todo esto sumado a un trabajo de campo que implicaría un mayor tiempo y por lo tanto un mayor coste. Además, el modelo 3D no solo ayuda en este proceso de obtención de valores, sino que proporciona resultados más exactos de las distintas mediciones.

\subsection{Modelado de las instalaciones}

El desarrollo de las instalaciones se debe ir realizando en paralelo al modelado de los edificios tal y como está representado en la planificación. Este proceso presenta una serie de fases previas debidas a la calidad de la información de la que se parte, que permite el avance de los edificios de forma que para cuando se van modelando las instalaciones se dispone del edificio y sus zonas para facilitar que cada uno de los elementos de las instalaciones tenga asignado además de su código de componente un código que indique la zona en la que se encuentra. 
Al igual que para los edificios se valoraron las opciones de escáneres 3D y fotogrametría, detectando prácticamente las mismas problemáticas de zonas oscuras y posterior tratado de datos. Por lo tanto, en este caso la información de partida puede proceder de varias fuentes distintas.

La primera fuente de información, y la más común debido a la antigüedad de las instalaciones suele estar presente en planos isométricos de las instalaciones. Estos planos pueden estar realizados a mano o bien digitalmente si se han realizado modificaciones y se han actualizado. Los planos isométricos presentan toda la información necesaria para realizar el modelo ya que contienen además de las distintas cotas y distancias, los materiales, pesos, diámetros, espesores y características de cada uno de los elementos que aparecen como válvulas, motores, tanques, tuberías, codos, reductores, etc.

Otra fuente de información puede proceder de modelos 3D realizados de algún sistema que se ha modificado recientemente. En este caso, dependiendo del software de modelado es posible realizar o no una exportación mediante el formato IFC del modelo 3D a un software BIM. Adicionalmente se deberá realizar una revisión de la información que se proporciona en estos modelos dado que se podría requerir ser completada con información adicional.

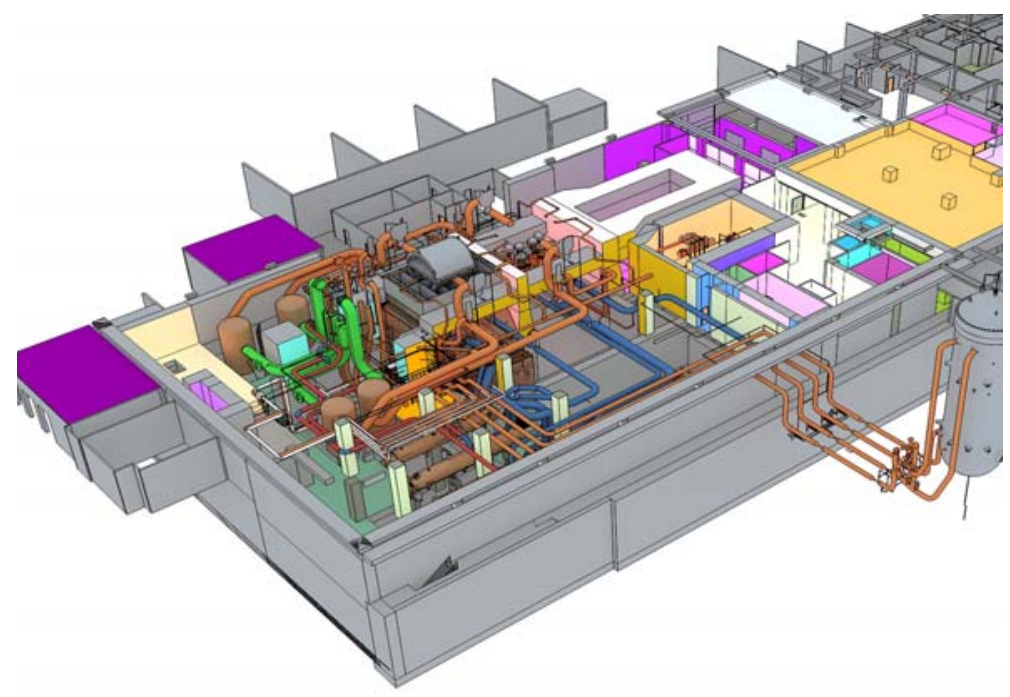

Fig 6. Modelo 3D BIM de instalaciones y equipos dentro de un edificio de una central nuclear, Propia, 2017.

Este proceso llevado a cabo sin el modelo 3D requeriría de un análisis de los isométricos o de los modelos 3D además de todos los planos de planta de los edificios para conseguir ubicar los isométricos en las zonas correspondientes, proceso que en el modelo 3D es prácticamente automático. Además, el modelo 3D, al integrar el modelo del edificio con el de las tuberías, permite revisar que los isométricos son correctos detectando posibles longitudes erróneas que generen interferencias. En caso de no disponer el modelo BIM, esta revisión requeriría de un gran tiempo para su realización. 


\subsection{Modelado de equipos de las instalaciones}

Otra parte importante se refiere a los distintos equipos de las instalaciones. En función de su tamaño presentan mayor importancia y presentan mayor información por lo que en el BEP se debe definir correctamente el nivel de detalle y de desarrollo (LOD) de cada uno de los elementos a modelar y cómo se realizará ese modelado.

Algunos podrán ser modelados de forma genérica como las bombas y motores, a los cuales se les asociará la información encontrada en sus fichas técnicas. Sin embargo, existirán otro tipo de elementos como los tanques los cuales podrán ser modelados de forma exacta a los reales obteniendo desde el modelo información adicional como la superficie exterior que normalmente no se encuentra definida dentro de sus fichas técnicas.

Estos equipos se pueden modelar o bien partiendo de los planos de las especificaciones técnicas del elemento o bien, en caso de ser necesario se pueden implementar procesos de fotogrametría o escaneo 3D.

A medida que se van modelando los equipos se deben ir introduciendo en el modelo dado que servirán de referencia para poder comprobar que los sistemas están correctamente modelados y posicionados.

La ventaja fundamental del modelo BIM es este caso es que además de proporcionar una gran cantidad de información de cada elemento, al contener la información de la zona en la que se encuentra, es posible hacer búsquedas de los equipos situados en cada una de las zonas o buscar un equipo por su código y poder conocer la zona en la que se encuentra y visualizarla.

\subsection{Resto de elementos}

Finalmente, existe otra parte de elementos que no serán modelados y cuya información se irá incluyendo dentro del modelo como elementos genéricos que contengan información de forma que se puedan situar en la zona donde se encuentran y de esta forma se facilite el proceso de inventario físico y caracterización radiológica.

\section{CONCLUSIONES}

La industria nuclear se ha encontrado hasta la actualidad detrás de la curva de la evolución de las tecnologías digitales. Con los avances actuales, es el momento de adoptar estas nuevas tecnologías y metodologías de trabajo para comprobar lo que realmente puede lograrse.

Tal y como se viene observando en los últimos años los distintos gobiernos están apostando por la metodología BIM dado que es vital para cualquier proceso de construcción. proporcionando resultados de mayor precisión, fomentando un trabajo colaborativo y, lo que 
es más importante, generando un gasto mucho menor al reducir los desperdicios durante la fase de construcción.

Las instalaciones nucleares son unos activos a largo plazo y el mantenimiento eficaz es fundamental para asegurar que se mantengan seguras, eficientes y accesibles a lo largo de su ciclo de vida.

Por lo tanto, el BIM aplicado al proceso de construcción es solo el principio. Cuando el modelo BIM se interconecta con la gestión del ciclo de vida del producto, proporciona una solución digital completa que soporta todas las fases, ayudando a la planificación de tareas y actividades y reduciendo costes y tiempo en su desarrollo. Esto se ha demostrado con el estudio para la actividad de caracterización radiológica.

Sin embargo, este modelo debe realizarse conforme a una buena planificación de los trabajos a realizar y a un BEP que defina correctamente el alcance del proyecto.

Por otro lado, el desmantelamiento es otro proceso de gran importancia que puede ser llevado a cabo mediante la metodología BIM. Las actuales instalaciones nucleares españolas presentan una antigüedad que obligará en un futuro a ser desmanteladas. En el caso de disponer de modelos BIM el estudio indica que es posible planificar el desmantelamiento y desarrollar de forma eficiente una gestión de los residuos que se generan al poder identificar el grado de contaminación de cada elemento a desmantelar y sus dimensiones, materiales, volumen y peso. Las oportunidades para ahorrar costos y aumentar la seguridad son enormes tal y como se ha demostrado en la central de José Cabrera donde con un simple modelo 3D no BIM han ayudado al desarrollo de determinados procesos.

Finalmente, y no menos importante, el modelo 3D puede ser empleado para infinidad de soluciones, entre ellas, se pueden desarrollar programas de formación de operarios que realicen las actividades en un entorno de realidad virtual. De esta forma se reducirá el riesgo de exposición de cada operario al reducir el tiempo de trabajo en zonas controladas.

\section{REFERENCIAS}

[1] Foro nuclear http://www.foronuclear.org/es/energia-nuclear/energia-nuclear-en-el-mundo

[2] http://www.carbonbrief.org/mapped-the-worlds-nuclear-power-plants]

[3] http://www.world-nuclear.org/nuclear-basics/global-number-of-nuclear-reactors.aspx

[4] Revista estratos, empresa nacional de residuos radiactivos No99 verano 2011

[5] In-Su Jung, Woo-Jung Kim. Direction for the Estimation of Required Resources for Nuclear Power Plant Decommissioning based on BIM via Case Study. Transactions of the Korean Nuclear Society Spring Meeting Jeju, Korea, May 29-30, 2014

[6] Jason Boyle, John Robison. BIM approach to a nuclear project: Seafield Maintenance Facility. TheStructuralEngineer November 2013

[7] Nuclear España No358 Enero 2015

[8] Web Enresa, desmantelamiento de la cn José Cabrera

[9] Web Reunionanualsne, 40 Reunión de la SNE, monograficas 


\section{EUBIM 2017}

Congreso Internacional BIM / $6^{\circ}$ Encuentro de Usuarios BIM

BIM International Conference

EUBIM

Escuela Técnica Superior de Ingeniería de Edificación

Universitat Politècnica de València

Valencia, 19 y 20 de mayo 2017 



\section{GUÍAS PROPIAS DE BIM PARA LA GESTIÓN DE PORTFOLIO}

Di Giuda, Giuseppe Martino (1); Re Cecconi, Fulvio (2); Dejaco, Mario Claudio (3);

\section{Villa Valentina (4) Maltese, Sebastiano (5)}

(1) Politecnico di Milano, Department of Architecture, Built Environment and Construction Engineering, giuseppe.digiuda@polimi.it

(2) fulvio.rececconi@polimi.it

(3) mario.dejaco@polimi.it

(2) Politecnico di Torino, Department of Structural, Geotechnical and Building Engineering, valentina.villa@polito.it

(5) sebastiano.maltese@polimi.it

\section{RESUMEN}

BIM se está desarrollando en muchos países, pero en su mayoría no es claro cómo y quién debería gestionar su adaptación. El mercado de BIM crece cada día, con un número significativo de cursos de formación y software disponibles, pero aún hace falta definir directrices y procedimientos que permitan orientar a clientes (propietarios e usuarios) a través del complejo proceso de adopción de BIM. Este trabajo pretende mostrar los principales resultados de una investigación realizada por los autores en un caso de estudio para un cliente público italiano que comprende: elaboración de guías, procedimientos, objetos BIM y plantillas para la gestión de una cartera de activos. Las directrices desarrolladas están destinadas a resolver problemas como, por ejemplo, datos faltantes o desactualizados, pérdida de control por parte de los subcontratistas y calculo inexacto de cantidades. Partiendo de una clara definición de los roles y las actividades a realizar, la investigación se concentró en los pasos a seguir para redactar directrices comprensibles dedicadas a construcciones nuevas, edificaciones existentes y al mantenimiento de las mismas. Los resultados de la investigación guiarán al cliente público en su transición desde procedimientos tradicionales a procedimientos basados en BIM. En este documento, se proveen ejemplos con la intención de ejemplificar el uso de directrices específicas, el caso de estudio presentado en este artículo es el asentamiento de la RAl (Emisora pública italiana) en Bologna (Italia), compuesto por el conjunto de cuatro edificaciones utilizados para diferentes propósitos.

Palabras clave: AIM, gestión de activos, BIM, CDE, directrices.

\section{ABSTRACT}

BIM is blooming in many Countries but in most of them it is unclear how its adoption can be governed and by whom. The BIM-market is increasing every day, with plenty of training courses and software, but there still is a great lack of guidelines and procedures to take clients (owners and users) through the risky path of BIM adoption. This paper aims to show main results of a case study research carried out by the authors for a public Italian client: development of guidelines, procedures, BIM objects and templates to be used for managing an asset portfolio. The proprietary guidelines developed are meant to solve problems related 
to e.g. missing and not updated data, loss of subcontractors' control and inaccurate quantity take-offs. Starting from a clear definition of roles and activities to be done, the research focused on the steps to be taken to write some comprehensive guidelines that deal with new construction, existing buildings and maintenance. The results of the research will guide the public client in his transition from traditional to BIM-based procedures. Examples are provided in this paper aim at exemplifying the use of the proprietary guidelines; the case study presented in this paper is the RAI (Italian public broadcaster) settlement of Bologna, composed by a set of four buildings used for several activities.

Keywords: AIM, asset management, BIM, CDE, guideline.

\section{$1 \quad$ INTRODUCTION}

Building Information Modelling (BIM) can be considered one of the major and innovative evolutions of processes and instruments in the AEC sector (Architecture, Engineering, Construction); despite the fact that the BIM potential is clear and software are every year more capable, the client has frequently a role very similar to the traditional one, while a step forward is needed to efficiently work with BIM. There are many excellent examples of BIM guidelines to be used by both clients and contractors all over the world (NY and NJ Port Authority [1], PennState University [2], NBIMS [3], etc.), but Italian commissioning bodies, especially public but also private, need to define their own requirements according to the PAS 1192-3:2013 [4]. This activity could take longer than the definition of the bid documents themselves, as it implies the detailed definition of client's needs, to be translated, thanks to the PLQs (Plain Language Questions) into the EIRs (Employer's Information Requirements), to be inserted in the BEP (BIM Execution Plan). Traditionally Italian private clients followed the path made by public commissioning bodies (e.g. for the design and tendering process); so the adoption of a strong BIM strategy from the government would result in the adoption in the private sector. The importance of having a guideline to follow during both daily activities (e.g. space layout changes, components replacement, etc.) and tendering (e.g. construction of a new building) is crucial to be able to set the requirements and then to control the material submitted by contractors (designers, construction companies, FM providers, etc.). Moreover, proprietary guidelines are fundamental for an efficient top down approach of the BIM strategy in an institution: the management is demanded to set the objectives in a plain and comprehensible language, to be translated into BIM-technical instructions by BIM managers and technicians. The relationships among actors and the activities are hence described in the guideline, allowing a robust organisational structural, necessary in BIMoriented processes.

\section{STATE OF THE ART}

In this paragraph the latest and guidelines are reported aiming at clarifying the context and the purpose of the research. In Fig 1 some interesting approaches to BIM processes are reported, divided by the main countries all over the world. The references are intended as 
examples, as many other interesting documents, both from public and private organisations, can be retrieved. Fig 1 provides a clear view of the BIM adoption panorama. The trend is clearly set and all the major governments are adopting it for their public projects; the same is for relevant private projects, while a great effort should be paid to implement BIM processes at a smaller scale.

At European level, a particular attention is provided by the European directive 23, 24 and 25/2014. They have the aim to increase freedom in the choice of the authorities (i.e. MEAT) [13], but in the meanwhile they are asking more skills empowering them. The European directive 24/2014 aims at: (i) procedural simplification; (ii) reducing fragmentation of the contracting authority; and (iii) estimation of the ratio of qualitative to price. Some of all these future measures will concern BIM, which has been introduced in Italy in the art. 23 c. 13 of D.Lgs. 50/2016 [14]. It has been translated by the Italian legislator with the expression "methods and electronic instrument, through open format, not proprietary"; this definition is close to the original one, contained in the Dir. 2014/24/UE, art. 22 c.4. The process is characterised by a strong partnership among the employer and all the suppliers and bidders. In the Italian law (D.Lgs. 50/2016 art. 23 c. 13) BIM is set as a possibility and not as a commitment, based on the fact that Italy do not have an actual law (as the UNI 11337 [18]) and because there are only few people which are trained in this field, even if the situation is changing rapidly.

\begin{tabular}{|c|c|}
\hline Country & Description \\
\hline $\begin{array}{l}\text { Singapore } \\
{[5]}\end{array}$ & $\begin{array}{l}\text { The East, as the USA, are characterised by high prefabrication, construction } \\
\text { technologies abundantly using steel, tower buildings and construction sites } \\
\text { with presence of many more workers than European standards. This adoption } \\
\text { of BIM has been also pushed by the need of having higher performance tools } \\
\text { to enable building design that until a few years ago would not have been } \\
\text { possible. }\end{array}$ \\
\hline Finland [6] & $\begin{array}{l}\text { As well as Norway and Sweden, it is one of the most advanced European } \\
\text { countries in the use of BIM. Here the push to use BIM did not arrive from the } \\
\text { government, but from below: companies and designers have wisely adopted } \\
\text { this new form of design and management, seeing in it a way to reduce the } \\
\text { time, cost and to guarantee a better outcome. }\end{array}$ \\
\hline $\begin{array}{l}\text { France [7] } \\
\text { and } \\
\text { Germany } \\
{[8]}\end{array}$ & $\begin{array}{l}\text { Both governments have invested heavily in } 2014 \text { and in } 2015 \text { to digitize the } \\
\text { building process both for buildings and for infrastructure. }\end{array}$ \\
\hline Italy [9] & $\begin{array}{l}\text { Maybe Italy started a bit after other European Countries, but it is gaining } \\
\text { ground on BIM field; in fact, some public tenders that require BIM design and } \\
\text { model set up for operation and management are currently ongoing. Many } \\
\text { businesses and engineering companies are upgrading to BIM and also the } \\
\text { BIM design became part of the new procurement code. }\end{array}$ \\
\hline $\begin{array}{l}\text { Spain }[10] \\
{[11]}\end{array}$ & $\begin{array}{l}\text { The BuildingSMART Spanish chapter made a very broad work, analysing the } \\
\text { use of BIM in all the building lifecycle stages; this work is based on the } \\
\text { Common BIM requirements } 2012 \text { [6]. In addition to this, the es.BIM initiative } \\
\text { is actively working for exploiting BIM in the country. }\end{array}$ \\
\hline United & Very devoted to the use of BIM, in public, private and infrastructure sectors. \\
\hline
\end{tabular}




\begin{tabular}{|l|l|}
\hline $\begin{array}{l}\text { Kingdom } \\
\text { [12] }\end{array}$ & $\begin{array}{l}\text { Various ministries (e.g. the Ministry of Justice) have created their own } \\
\text { guidelines for use of BIM and the government has decided that from 2016 } \\
\text { new public projects are managed in BIM. BIM is very developed in central } \\
\text { administrations and national projects, but it still needs to be exploited in local } \\
\text { governments, such as rural municipalities. }\end{array}$ \\
\hline USA [1] & $\begin{array}{l}\text { USA could be considered the inventors of the BIM process, which fits well } \\
\text { with prefabricated construction technologies and system engineering, which } \\
\text { are the critical aspects of their buildings. They are among the largest creators } \\
\text { of guidelines for BIM; among them, it is useful to mention the one of the Port } \\
\text { Authority of the states of New York and New Jersey, very detailed and lean. }\end{array}$ \\
\hline
\end{tabular}

Fig 1. BIM adoption in major Countries. 2017. Made by the authors.

\section{RESEARCH METHODOLOGY}

This research lasted almost two years, including literature review and development of procedures, instruments, tools and application to a real case study. The final objective was to create a BIM guideline to be used to manage an existing asset portfolio; together with the guideline, BIM models templates and BIM objects have been produced according to the requirements, with specific sets of attributes and functions to be carried out with linked models (i.e. structural, architectural and MEP). These models have been connected to external databases to better manage historical data about buildings and their components (e.g. documents and maintenance operations). This paper is focused on the contents and application of the guidelines, aiming at describing the principles with which has been developed and the actions that can be governed with it. The development of the guideline can be divided into the following steps: (1) analysis of the requirements of the client; (2) analysis of procedures and workflows currently adopted by the client; (3) analysis of issues and potential of the current strategy; (4) definition of a BIM strategy and new roles; (5) definition of main contents of the guideline; (6) definition of informative and graphical content of objects and model to meet client's objectives; (7) writing of the core parts of the guideline; (8) modelling of objects, models, database creation and testing; (9) writing of the final guideline and annexes documents (EIR, BEP, objects attributes, etc.); and (10) final testing to fine tune procedures and templates. The testing of the guidelines and connected documents has been performed on the RAl settlement of Bologna. This testing has been firstly made by modelling the buildings and inserting the data (documents, pictures, attachments related to the current situation) according to the guidelines and then trying to use the new system and procedures to manage daily asset management activities. The tests have been performed by both high-level managers and facility managers of the settlement. The guideline has been written starting by major existing guidelines all over the world and following the ISO 12911:2012 [15], so to have a guideline tailored to client's needs but also valid at the international level. The next paragraphs contains a detailed description of the guideline, how to use it in recurring asset management activities and some applications to the case study, with the aim of clarifying potential and field of application of the guideline. 


\section{THE PROPRIETARY BIM GUIDELINE}

In this paragraph main contents and features of the guidelines are described, paying also attention to their practical and direct application into asset management activities. The development of a precise and detailed guideline is mandatory for a profitable application of BIM procedures in a company, no matter if private or public, because it sets both the objectives and the ways to achieve them, allowing both bidders to make their work and the company to control their results, achieving the objectives respecting both time and money constraints. In the next paragraphs connections with current standards and best practices, main contents of the guideline and its application to practical workflows is presented, with the aim of explaining how BIM can be fruitfully introduced in a company management process.

\subsection{Connections with current standards}

The ISO/TS 12911:2012 [15] has been one of the most important references in the development of the guideline, as it specifies how to make a proper BIM commissioning; relevant topics are implementation of repeatable processes, guidance testing and completeness of guidance documents. What comes out from the analysis of the standard is that the more the process is guided and properly explained, the more the output can be controlled; a detailed guideline is mandatory for the BIM implementation into a company. The guideline developed is in between the company and the software related use (Fig 2): it sets macro and sub-objectives, process and sub-processes to achieve them, but also main steps to be carried out in the various software involved in the processes. The document is not a software guidance, but some steps to be followed are critical for the organization and effectiveness of the output and of the process, especially in a complex and large company like RAl (e.g. setting output, even complex, may be not enough for achieving company's objectives). Attributes of the objects and, more in general, data required by the company (in terms of information flows and exchanges) have been organised according to the guidance provided by the ISO 29481-1:2010 [16]. Company's requirements have been divided by stage (e.g. design, construction, operation and maintenance) and the turned into technical specifications to be fulfilled in the Asset Information Model (AIM). The PAS 1192-2 [17], focused on the information delivery, LOD and LOI definition has been a valuable guidance during the definition of the workflows and of the attributes of the BIM objects and models. The PAS 1192-3 [4] helped in the transposition of the asset management processes from plain language to technical requirements; moreover, it had a fundamental role during the definition of the structure of the guideline and of the macro-processes. With these premises, the proprietary BIM guideline developed can be considered compliant with the current international framework; moreover, part of this work has been inserted in the UNI 11337:2017 [18], becoming part of the current national framework. 


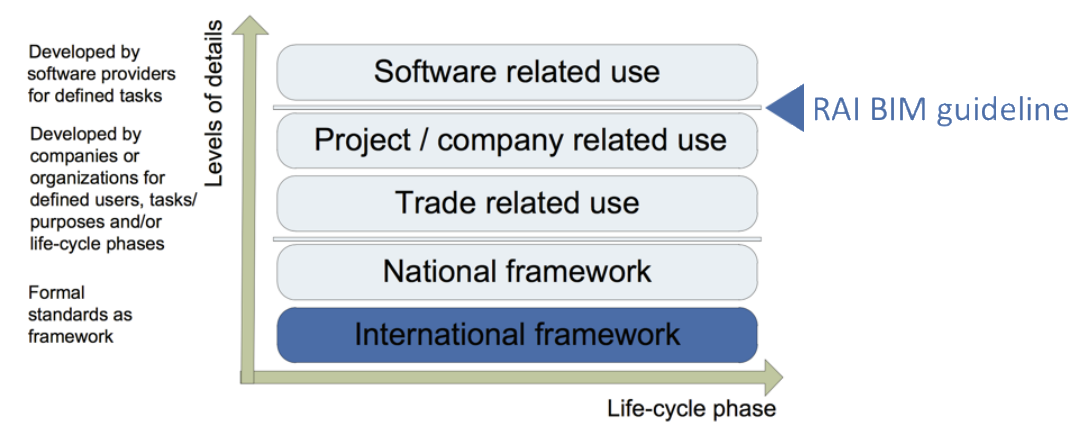

Fig 2. Detail of the guideline developed. 2017. Scheme from ISO/TS 12911:2012 elaborated by authors.

\subsection{Contents}

The contents structure has been defined according to the best examples and the standards cited above. Here main contents of the guideline are described.

Introduction: this is not only a simple foreword of the guideline, but an important section of the document, in which actors and their workflows are described. The introduction sets the boundaries of the use of the guidelines, together with application purposes and objectives. It describes the path to be followed, using predefined documents and tools.

Denomination: this guideline is demanded to set up and control complex procedures, with consequences on the whole process. The guideline defines a robust process and precise nomenclatures, to be used in the management of documents and in objects/buildings modelling. This chapter includes the denomination of models, documents, disciplines, families, materials, etc. according to the RAI standard: (1) settlement code; (2) building code; (3) storey code; (4) room code; and (5) object code. In this chapter the directory, with its main folders, is defined: 2D drawings, database, families, models and pdf is described. All views, phases, browsers, plans and connected files are defined in terms of nomenclature and relationships among them.

BIM Template: this chapter defines all the key characteristics and features of the BIM templates, divided in architectural (including fire system), structural, mechanical, electrical and master; the last is a coordination template collecting all the other models, linked according to the rules contained in this chapter. Rules about these topic are written: project browser, title block (used to track relevant changes in the model), organisation of levels, grid, views, schedules, rooms, areas and output. This chapter is both a description of the templates but also a guide to produces new ones, compliant with the rules.

BIM library: this chapter contains information about how BIM objects families have been modelled and have to be modelled, in case new objects or types are required. For this first version of the guideline, 197 families have been created; to them, all the families built in the template have to be added (e.g. slabs, walls, roofs). All the objects modelled have been described in specific datasheets that contain all the shared parameters associated to them (name, type/instance, group, unit of measure). Autodesk Revit 2016 has been used in this 
process, so the objects may suffer constraints/characteristics due to the BIM authoring software used. This chapter contains the rules to be used in the management of the BIM library. Materials colours have been defined, so to make objects immediately recognisable in the various model views.

Use of the BIM templates: this chapter describes with plenty of details the procedures to use the various templates, modelling buildings and creating digital assets, containing all the data necessary for the management. This chapter contains precise procedures to link the models (e.g. architectural and structural, mechanical and architectural). This chapter is slightly different from current guidelines, as it sets with an high level of detail not only the objectives to be achieved, but also the correct procedures to reach them; this requires a robust definition of both objectives and activities to be carried out by the actors, but it allows the company to control subcontractors, designers and services providers. Then this guideline is forcing people to follow fixed procedures; this has been a matter of great discussion, research and experiments, but it eventually allowed to exploit BIM into RAI current asset management strategy. Setting only the objectives, as can be seen in the case study section, would not allow for a precise control of models and processes, especially during this transition to BIM.

Template DB (database): the databases are associated to the BIM templates and allow to perform activities different but complementary to the ones carried out with the models. Moreover, databases can be fruitfully used by managers, who have great experience and who are demanded to make decisions, but that are not skilled in the use of BIM authoring tools. This chapter contains all the key characteristics and features of the DB templates, divided in architectural (including fire system), mechanical, electrical and master; all the database, except from the master, are linked to the related BIM models. The DB master is linked with all the other databases, but with no BIM model (to avoid duplicated data). This chapter contains also indication about information that has been collected from RAI documents (e.g. maintenance datasheets, contracts, etc.) and then opportunely organised. This chapter describes also the relationships of the databases (relational, made with Microsoft Access), main tables, queries, macros and buttons to automate activities.

Use of the DB templates: this chapter, similarly to the fifth, explains procedures and tools to be used, when and by whom, to use the databases and to manage the data contained in them. The main activities for which they are used are related to the management of: maintenance (input of data about maintenance operations performed associated to objects), documents and spaces. All the procedures described are guided and strongly connected to the objects in the BIM models.

The guideline has been created together with a set of annexes, necessary for its correct use, as well as model and database templates.

LOD and LOI definition. This annex is fundamental for the proper implementation of the BIM strategy in the company and for the correct use of BIM templates and of the guideline in general. This annex defines the Level of Detail (LOD) and the Level of Information (LOI) of all the objects modelled in the BIM library or to be modelled by future designers. This document 
allows for controlling the BIM objects, checking the presence of the parameters for the correct implementation of the guideline. Moreover, the annex defines when these data must be filled according to the Italian law [14] and by whom.

EIR (Employer's Information Requirements). The objective of this document is to define the specific objective of the company according to the new BIM processes adopted in the guideline. This template, to be used in case of tendering, contains these chapters: objectives, laws references, procedures, IT characteristics, project characteristics, time and costs validation rules and process management rules. This template has to be filled by the company in case of development of new projects to be assigned to external contractors.

BEP (BIM Execution Plan) template. This document defines the boundaries in which the various actors of the BIM process must operate, share information and deliver the project as requested by the client. The BEP must be submitted by the contractor after the award of the tender and updated during the whole process. This document and the previous one have been fitted to the RAI needs in terms of BIM adoption strategy.

\subsection{Operational workflows}

The guideline pays great attention to the workflows to be followed by the various actors to make their duties. These workflows have been borrowed from the current practice of the company and then adapted to meet the new BIM-compliant procedures. Moreover, they comply with main standards related to portfolio, asset and facility management [19] [20] [21].The result is a set of defined roles and workflows to be adopted during the operational phase by current managers; the goal in this part was to develop procedures BIM-compliant but also ready to be used by the stakeholders. Creating workflows robust but also comprehensible and readily applicable, with the necessary training, has been one of the leading criteria in the development of this research. In this paragraph some of the workflows defined are briefly presented, also in combination with relevant BIM models and databases involved in the management process.

New construction: objective of this workflow is to guide the creation (design, construction, operation) of a new settlement or of a new building in an existing settlement. This workflow starts with the necessity expressed in plain language by the portfolio manager, transferred into the EIR by the BIM manager; of course this necessity must be approved by the management according to the company's strategy. Designers can then participate to the tender with a pre-contract BEP and then, after the award, they can submit the post-contract BEP and produce the necessary documents and models in accordance with the RAI proprietary guideline and its annexes. So the BIM manager validate the models and the documents submitted and, if no changes are required, deliver the Asset Information Model to the BIM coordinator of the settlement, which is eventually demanded to update the databases connected with the BIM models.

System replacement: objective of this workflow is to guide the replacement of a system (or a relevant part of it) into an existing settlement. The director of the settlement, in accordance with the facility manager, ask for the approval the portfolio manager, which should be 
informed in case of important expenses and modifications. Then the workflow is similar to the previous, except for the fact that the BIM model is delivered by the BIM manager to the designers, which have the duty to update the BIM models according to the guidelines. Once the project is ended and validated by the BIM coordinator, the facility manager can update data in the database and provide information and benchmarks to the director of the settlement. Eventually the ordinary maintenance can be carried out, as explained in the next workflow.

Routine maintenance: objective of this workflow is to guide the archiving process of data related to the maintenance operations performed on the buildings and their parts. The maintenance operation is approved or requested by the facility manager, which refers to one or more maintenance operators that are connected to the company (with a global service or other types of contract). The operator performs the maintenance as requested and fills a report. The facility manager validate the documents submitted and updates the database with the information provided. The BIM coordinator exports the data from the databases to the BIM models (with a guided procedure described in the guideline), so to update them.

The central idea behind these workflows is to have always a robust validation of the information and of the models provided by actors external to the company. The second idea is to have a robust hierarchy that links the BIM manager, at portfolio level, and the BIM coordinators at the settlements level, so to have always updated, reliable and univocal data. These workflows have been tested and validated by the company; some examples are provided in the next chapter.

\section{CASE STUDY}

The BIM guideline has been applied to the settlement of Bologna, made of four buildings with different function, for a total of $15^{\prime} 000 \mathrm{~m}^{2}$ of gross floor area. This settlement is representative of the RAI Italian portfolio, so it has been considered a suitable case study for the validation of the guideline. In the next paragraphs two examples of application are presented, with the aim of showing the guideline and its main features.

\subsection{Settlement description}

The settlement consists of four existing buildings (Fig 3): the main one contains mainly offices, direction and production rooms (TV and radio studios, offices, canteen, underground parking, etc.), while the others contain respectively the entrance (which is regulated for security issues), services rooms, mechanic's workshop and garage. The masterplan has been made linking together all the models, divided by discipline (architecture, structure, systems) and by building; the main purpose of this model is coordination and visualisation, while management (e.g. maintenance operations data storage, documents management, space management, etc.) is carried out in the single BIM models and databases. While the three ancillary buildings are quite simple in terms of shapes and technologies, the main building has five storeys and a complex infill, with a mixture of different technologies and finishing, mainly due to the modifications occurred over the years. This complexity, initially 
perceived as an obstacle in the modelling phase, helped for the creation of a robust coding system able to define spaces and technologies, being eventually able to manage all the finishing in connection to spaces and zones of the building.

The building has been surveyed to update and correct the as-built and design drawings provided by the client; only minor changes to the model (respect to the drawings provided) have been performed as all the main components where in the correct position. On the opposite, a detailed survey has been performed to gather all the different finishing of each space (floors, walls, ceiling), with more than one hundred of types. Great attention has been paid to structures, which have been modelled as a stand-alone BIM model, linked to the architectural one; structural drawings where up-to-date and no modification has been necessary. Regarding the systems, as-built drawings and layouts have been used to locate and model main components (e.g. heat generators, fan coils, plugs, air terminals, etc.); a detailed survey has been performed to validate number and type of light bulbs. The models contain totally more than $33^{\prime} 000$ objects over the settlement. For this first case study, ducts, piping and circuits have not been modelled, as not surveyed. The survey has been conducted with the rules written in the guideline, which have been also updated with feedbacks from both RAl asset management team and the professionals demanded to create the BIM models. The models have been eventually set up with all the attributes described in the guideline and in the attached document related to LOD and LOI definition.

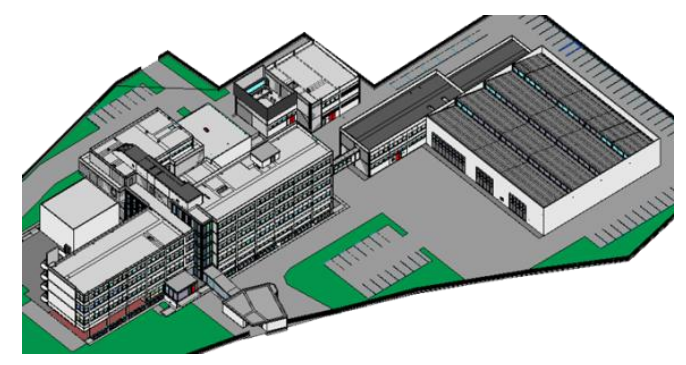

Fig 3. BIM masterplan of the settlement. 2017. Made by the authors.

\section{$5.2 \quad$ Existing buildings}

Existing buildings, especially offices, frequently need to be modified, to meet higher standards or client's requirements. The guideline has been set up to regulate the information exchange, as instance, in case of internal layout modification.

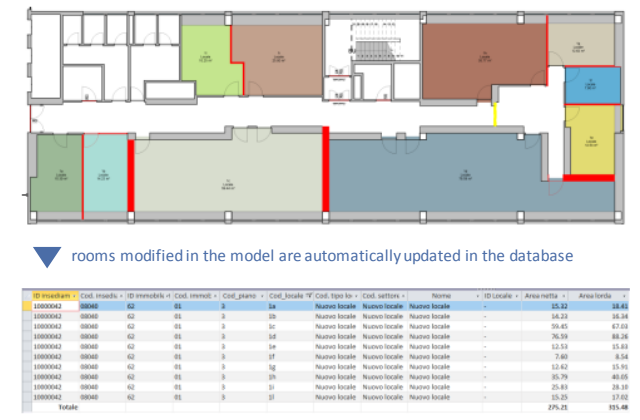

Fig 4. Comparison plan in case of layout modification. 2017. Made by the authors. 
In this brief example, main steps of the process are reported, aiming at showing potentials and criticalities of the guideline. A change in the offices layout (internal walls, systems and rooms surface) has been simulated to test procedures, workflows and instruments developed. Here an extract of the comparison plan (demolition and new construction) is presented (Fig 4). The workflow allowed the client to express his need, the designer to modify the model (adding a new phase) and eventually the facility manager to update data about systems and surfaces. At the portfolio level, spaces naming, areas and functions have been updated. All the data were consistent and updated in all the phases.

\subsection{Ordinary maintenance}

In this example some maintenance operations are performed on one of the two heat generators. Thanks to the instruments developed, the maintenance operator, after the operation, has been able to enter the summary data and to associate them to the object in the mechanical BIM model. The attribute "last maintenance performed" on the heat generator has been also automatically updated. In the Fig 5 an extract of the maintenance sheet (left) and the updated BIM object (right) is presented.

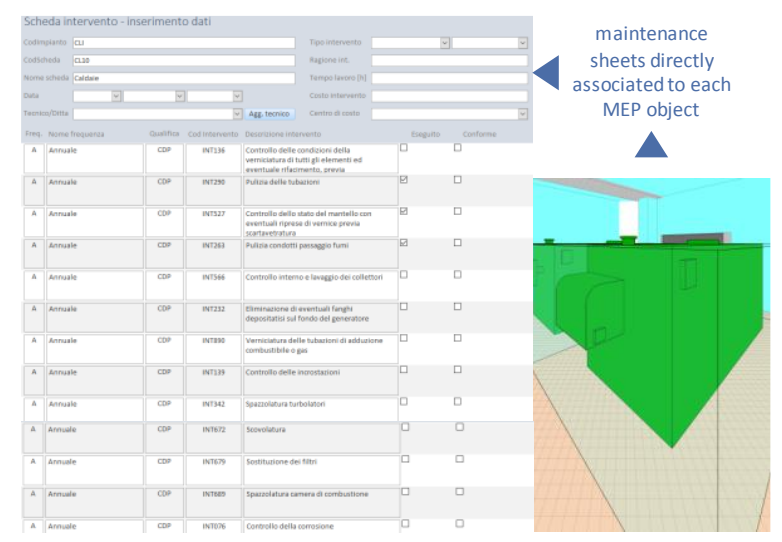

Fig 5. Maintenance operations data entry. 2017. Made by the authors.

This procedure, fully described in the guideline, helps in dealing with information during the settlement management. The data can be further elaborated to benchmark the behaviour of services providers and components failure rates, so to improve the settlement operation and cut operational costs.

\section{DISCUSSION AND CONCLUSIONS}

BIM processes are a mandatory step for the development of the AEC sector; nevertheless, more than software, BIM-oriented strategies are needed. This guideline aims at filling the gap between operators and managers, allowing the latter for a better asset and portfolio management strategy. The guideline developed can be considered an innovation of the current state of the art as it states not only input and output (e.g. plans, bill of quantities), but also defines precise actors and workflows to be followed, allowing the client to control operators' work. This is relevant in the current panorama, characterised by a great 
uncertainty of the roles and of the procedures to be adopted. This guideline clarifies both strategy, at high level, and objectives, at middle and low levels, supporting activities and interactions among actors. Authors planned to revise and improve the guideline with feedbacks coming from the client, which is currently using it; moreover, additional procedures, related to the management of construction sites (to deliver as-built BIM models) are currently in the development phase. The Italian government, once set is strategy on digitisation of the construction process according to D.Lgs. 50/2016 art. 23 c. 13 [14] (currently is just an indication), will be probably asking for interoperable formats to make the process more standardised; this guideline could be then adapted to these requirements, including as instance the use of IFC models to store and exchange data (allowing different BIM authoring software) but for now, the goal was delivering a set of procedures and tools ready to be implemented in the current asset management process of the company. Moreover, processes, workflows and data described in the guideline can fit into an interoperable process, as it will be requested by the government, as they are not connected to a specific tool.

\section{AKNOWLEDGEMENTS}

This research work was funded by RAI - radio Televisione Italiana. Authors greatly acknowledge Francesco Paleari, Marco Schievano and Paolo Ettore Giana for their fundamental work in the research team.

\section{REFERENCES}

[1] The port authority of New York and New Jersey (2016). E/A design division BIM standard manual, last updated October 2016.

[2] PennState University (2013). BIM planning guide for facility owners, Version 2.0.

[3] National BIM Standard - NBIMS (2017). National BIM Guide for Owners.

[4] British Standards Institution (2014). PAS 1192-3, Specification for information management for the operational phase of assets using building information modelling.

[5] COnstruction and Real Estate NETwork - CORENET (2013). Singapore BIM guide 2.0, last updated August 2015.

[6] COBIM (2012). Common BIM Requirements 2012, Version 1.0.

[7] MediaConstruct (2015), Guide méthodologique pour des conventions de projets en BIM.

[8] ZukunftBAU (2013). BIM-Guide for Germany. 
[9] Di Giuda, G. M., Re Cecconi, F., Dejaco, M. C., Maltese, S., Villa, V. and Schievano, M., Information management guideline for asset operational phase, proceeding of the ISTeA conference - Back to 4.0: rethinking the digital construction industry, Napoli (I), pp. 3949.

[10] BuildingSMART Spanish Chapter (2014). Guì uBIM - Documentos D1-D13.

[11] es.BIM (2017). es.BIM - Implantación del BIM en España. Accessible at: www.esbim.es [Visited: 26/04/2017].

[12] AEC (UK) Initiative (2015). AEC (UK) BIM Protocol, Version 2.1.

[13] Di Giuda, G., Villa, V. and Loreti, L. (2015). BIM to manage public procurement with award criterion Most Economically Advantageous Tender, proceeding of the ISTeA conference, Milano.

[14] Repubblica Italiana (2016). D.Lgs. 50/2016, Attuazione delle direttive 2014/23/UE, 2014/24/UE e 2014/25/UE sull'aggiudicazione dei contratti di concessione, sugli appalti pubblici e sulle procedure d'appalto degli enti erogatori nei settori dell'acqua, dell'energia, dei trasporti e dei servizi postali, nonche' per il riordino della disciplina vigente in materia di contratti pubblici relativi a lavori, servizi e forniture.

[15] International Organisation for Standardisation (2012). ISO ISO/TS 12911:2012, Framework for building information modelling (BIM) guidance.

[16] International Organisation for Standardisation (2010). ISO 29481-1:2010, Building information modelling - Information delivery manual, Part 1: Methodology and format.

[17] British Standards Institution (2013). PAS1192-2, Specification for information management for the capital/delivery phase of construction projects using building information modelling.

[18] Ente Italiano di Unificazione (2017). UNI 11337, Gestione digitale dei processi informativi delle costruzioni.

[19] International Organisation for Standardisation (2014). ISO 55000, Asset management - Overview, principles and terminology.

[20] International Organisation for Standardisation (2008). ISO 15221-1, Facility Management, Part 1: Terms and Definitions.

[21] International Organisation for Standardisation (2014). ISO 21504, Programme and portfolio management. 


\section{FOMENTO ESTRATÉGICO DE CITOPIC A LA METODOLOGÍA BIM}

\section{Perea Mínguez, Rafael (1); Dueñas Abellán, Carlos (2); Bielsa Artero, Alicia María (3)}

(1) Colegio de Ingenieros Técnicos de Obras Públicas e Ingenieros Civiles: bim@citop.es

(2) Colegio de Ingenieros Técnicos de Obras Públicas e Ingenieros Civiles: presidente@citop.es

(3) Colegio de Ingenieros Técnicos de Obras Públicas e Ingenieros Civiles: secretariotecnicocv@citop.es

\section{RESUMEN}

Los colegios profesionales como corporaciones de derecho público y nexo entre el entorno universitario y el mundo profesional, deben estar en la vanguardia tecnológica. Se transmiten las estrategias del Colegio de Ingenieros Técnicos de Obras Públicas e Ingenieros Civiles (CITOPIC) en el ámbito BIM y su implementación en la zona de Valencia y Castellón. No es certero reducir la concepción del BIM a un software incluso resulta negligente ignorar su potencial como metodología de trabajo integradora basada en la participación colaborativa.

Desde la relevancia del BIM en la actualidad profesional y la necesidad de fomento de su uso por el valor añadido para profesionales y a la sociedad en general, el primer objetivo estratégico del CITOPIC es la planificación y el liderazgo. Tras la creación de la Comisión BIM responsable de diagnosticar la situación de partida, se planifica un panel de objetivos clave y decisiones estratégicas del entorno BIM en concordancia con los de la institución. Establecidas estas bases, se define el plan y hoja de implementación (BIP). A medio plazo, se establece como iniciativa emblemática la procedimentación de normas BIM que sirvan al colectivo CITOPIC de referencia para acometer su uso, así como indicadores para medir los resultados alcanzados.

Palabras clave: plan estratégico BIM, ingeniero civil, BIP, colegio profesional

\section{ABSTRACT}

Professional Institutions are public corporations acting as nexus between the university and the professional world. Due to this later characteristic, these Institutions must be at the forefront of technology. This idea has led the Colegio de Ingenieros Técnicos de Obras Públicas e Ingenieros Civiles (CITOPIC) to establish a BIM framework which has been implemented in Valencia and Castellón. BIM should not be considered just as a mere software and it would be a dereliction to ignore its potential as a work methodology based on collaborative participation.

BIM has clear relevance to today's professionals. This fact, together with the need to promote its use in order to add value to professionals and to society in general, established the key objectives for CITOPIC: planning and leadership. Following the creation of the BIM Commission, responsible for diagnosing the 'baseline scenario' a panel of key objectives and strategic decisions for the BIM framework was planned in accordance with those of the Institution. Once established these bases, the BIM Implementation Plan (BIP) is defined. In the medium term two different activities are considered as flagship: the development of BIM 
standard procedures which help CITOPIC to undertake future works and the development of indicators to measure the results achieved.

Keywords: BIM strategic plan, civil engineering, professional institutions

\section{INTRODUCCIÓN}

La construcción ha sido a lo largo de la historia símbolo de progreso e innovación. La primera revolución en términos de diseño asistido por ordenador permitió generar planos independientes y manejar la información de forma lógica asociando propiedades a las entidades geométricas. Las herramientas computer-aided design han supuesto un gran impacto en la productividad al reducir notablemente el tiempo invertido en la elaboración de proyectos de construcción. Aunque estas tecnologías han ganado en estabilidad, velocidad y prestaciones desde su aparición en el mercado, la complejidad de los proyectos, la optimización del diseño antes de acometer la construcción y la alerta temprana en caso de discrepancias [1] requieren un cambio de paradigma. Estas diferencias pueden deberse a interferencias derivadas de la deficiente integración entre las diferentes etapas o a las incompatibilidades como resultado de la falta de relación entre los diferentes planos del proyecto [2]. Irrumpen así diferentes herramientas que permitan la colaboración entre los diferentes agentes, mejoren el diseño abordando la información contenida en el proyecto e integren el ciclo de vida de la construcción para llevar a cabo un mantenimiento sostenible. Metodologías como Project y Construction Management, Lean Construction Integrated, Project Delivery y Building Lifecycle Management se orientan hacia estos objetivos [3]. Sin embargo, cada una de ellas aborda la problemática de forma aislada, y no es hasta la aparición de Building Information Modelling, donde todas ellas se combinan en una metodología colaborativa, integradora y sistémica capaz de abordar las interferencias e incompatibilidades que las tecnologías tradicionales no son capaces de resolver en dos dimensiones.

La Unión Europea es consciente de la necesidad de construir de forma digital antes de construir la realidad. En este sentido, aboga por un cambio en la contratación pública que desempeña un papel clave en la estrategia de un país para su crecimiento inteligente, sostenible e integrador, garantizando al mismo tiempo un uso más eficiente de los fondos públicos. Por ende, la directiva europea 2014/24/UE sobre contratación pública [4], reconoce la conveniencia de prever contratos públicos de obras adjudicados por separado como la adjudicación conjunta de los contratos para el proyecto y la ejecución de las obras. En ambos casos, la participación colaborativa de todos los agentes implicados y la interoperabilidad cobran especial relevancia. De la directiva cabe destacar la referencia en el artículo 22 a las herramientas de modelado electrónico y de información de las construcciones (building information electronic modelling tools). De esta forma se abre la posibilidad a que los Estados miembros de la UE exijan el uso de herramientas específicas para el modelado electrónico de datos de las construcciones en sus procesos de contratación. Y conscientes de su importancia, la UE insta a los países miembros para que aborden la modernización de las normativas de contratación fomentando el uso de BIM en proyectos de construcción. Hasta el siglo XX la industria de la construcción ha servido como elemento de medición del grado de desarrollo de la sociedad y era el motor que motivaba la fabricación de productos relacionados [5]. La digitalización de la construcción ha dejado de ser un elemento innovador para convertirse en una necesidad. La industria de la 
construcción se basa en proyectos y anclarse en tecnologías tradicionales resulta ineficaz para garantizar una evolución estratégica en términos de plazo, coste y calidad.

El incremento de la implementación de BIM en la industria de la construcción es una realidad en algunos países [6] y es un claro ejemplo de su auge y constante crecimiento. Reino Unido, Estados Unidos y norte de Europa han publicado sus estándares y guías de implantación. El sector de la construcción, aunque resentido por la crisis sigue manteniendo una influencia que representa actualmente el 9\% del PIB mundial con elevados efectos de empuje y arrastre sobre el total de la economía. A pesar de la importancia económica y social que la construcción tiene, sigue siendo la industria con menores índices de competitividad y productividad. En España los indicadores de actividad y empleo [7] informan en este sentido de niveles muy bajos que alertan de la necesidad de cambio.

La realidad es que el entorno BIM en nuestro país se limita a la etapa de diseño en edificios residenciales y los profesionales opinan que al menos necesitan 4 años para completar la integración en los proyectos [8]. Sin embargo, la Administración Pública ha comenzado la andadura y desde la Subsecretaria de Fomento se establece como objetivo que las infraestructuras públicas de presupuesto superior a dos millones de euros se modelen en BIM en sus fases de diseño y construcción estableciendo el 2018 como año horizonte. No será hasta 2020 cuando todas las infraestructuras públicas independientemente de su presupuesto e incluyendo la fase de mantenimiento verán la luz en BIM. No parece una apuesta inmediata, pero la realidad es que esta segunda revolución orientada hacia la digitalización de la construcción demanda profesionales con las competencias requeridas para responder a las nuevas exigencias del mercado y en la actualidad no estamos preparados para acometerlo. Según un informe norteamericano la cifra porcentual de arquitectos que recurrían al uso de BIM en sus proyectos en 2012 era del 60\%, mientras que los ingenieros civiles [9] eran algo menos de la mitad. En España el nivel de uso de la metodología BIM por los ingenieros civiles es incluso inferior y únicamente representa el $7,4 \%$ [8]. Es un vacío profesional de ingenieros civiles que ofrece interesantes perspectivas laborales tanto a profesionales con experiencia que quieran ampliar sus conocimientos en procesos BIM como a los recién titulados. La falta de personal con habilidades en BIM es una limitación importante en el uso de esta tecnología en la ingeniería y la industria de la construcción. Conscientes de esta necesidad, las instituciones universitarias han iniciado su andadura identificando la necesidad de preparar a los futuros profesionales [10] y adaptando de sus planes de estudio. El nivel de implementación en planes de estudios de Ingeniería Civil es liviano [11] pero comienza a potenciarse más allá de los proyectos de edificación.

Los colegios profesionales como corporaciones de derecho público y nexo entre el entorno universitario y el mundo profesional, deben estar en la vanguardia tecnológica y por tanto deben ser un referente en la implantación de BIM, liderando y fomentando el cambio de metodología entre sus colegiados. El Colegio de Ingenieros Técnicos de Obras Públicas e Ingenieros Civiles (CITOPIC) consciente de la necesidad de un salto cualitativo incluye entre sus líneas estratégicas el fomento del uso de la metodología BIM entre sus colegiados. Se requiere una apuesta clara al demandar la industria de la construcción técnicos especialistas BIM. La metodología BIM supone el sustrato donde la digitalización de la industria de la construcción fija sus raíces para ofrecer nuevas experiencias profesionales a los ingenieros asociados al sector de la construcción. Cualquier estrategia que pretenda ser efectiva 
precisa como pilares básicos la diagnosis, la planificación de procesos y una hoja de ruta liderada convenientemente.

Desde la relevancia del BIM en la actualidad profesional y la necesidad de fomento de su uso por el valor añadido para profesionales y a la sociedad en general, se establece como objetivo del presente artículo dar a conocer la hoja de ruta estratégica del CITOPIC desde la visión de la situación actual del BIM y su grado de implementación en la Ingeniería Civil. Una estrategia basada en personas, tecnologías y procesos, que requiere para ser eficaz una planificación y liderazgo en el panel de objetivos clave del entorno BIM en concordancia con los de la institución y la definición del BIM Implementation Plan (BIP).

\section{CONTENIDO}

Para cumplir los objetivos de la directiva 2014/24/UE [4] el Ministerio de Fomento crea la Comisión esBIM como grupo de trabajo público-privado para abordar las medidas de implantación de la metodología y la transposición de la directiva en España como país miembro de la UE. La Comisión esBIM se divide en cinco grupos de trabajo discretizados en diferentes subgrupos donde CITOPIC tiene presencia activa en los grupos de Tecnología y Personas con la participación de un colegiado en cada uno de ellos.

Tras la creación de la Comisión BIM se establece como necesaria la involucración activa del CITOPIC en el cambio de paradigma que precisa el sector y liderar el cambio entre sus colegiados. Decidida la apuesta estratégica del CITOPIC por el BIM se perfila de forma estructurada el itinerario progresivo de adaptación ante el posible impacto tanto en las actividades colegiales como en el futuro a corto plazo de los colegiados.

Se acomete por ello la planificación del panel de objetivos clave y decisiones para poder afrontar y gestionar el cambio. Establecidas estas bases, se define un plan de implantación BIM con la elección de líderes y basado en la formación y difusión. Como proceso de mejora continua incluye el análisis de los resultados de la implantación, y tras la adopción de medidas correctivas, se acomete la planificación del siguiente ciclo.

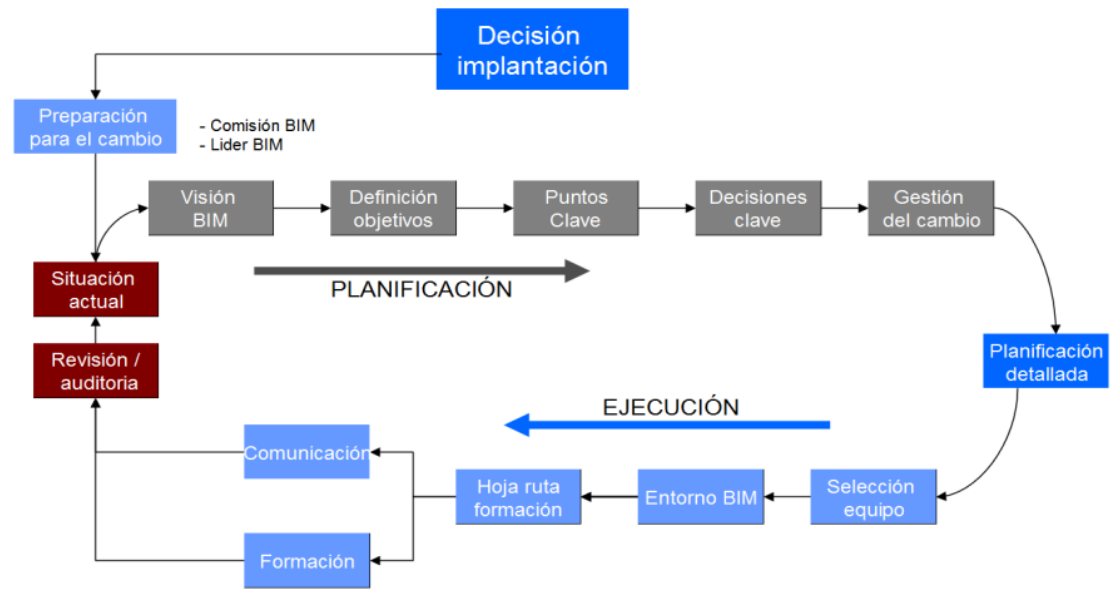

Fig 1. Esquema Planificación estratégica BIMcitopCV. Fuente: Elaboración Propia 


\section{Liderazgo}

Los factores de éxito en proyectos de cambio tecnológico relacionados con el individuo y los grupos involucrados, deben abarcar más allá de factores de administración de proyectos, delegación de tareas o distribución de la información. Su consecución con éxito en tiempo y acorde a la satisfacción esperada requiere que la dirección esté capacitada para su enfoque por resultados, administrar el cambio, liderar el equipo de trabajo y una actitud proactiva para emprender una dinámica compatible con la organización [12]. Por ende y como factor clave de la implementación, es necesario definir una comisión BIMcitopCV integrada por el Decano y especialistas en BIM, así como nombrar a los líderes BIM que proporcionen el soporte requerido por este cambio de paradigma.

Sin obviar un análisis de impacto desde el punto de vista técnico y financiero, una de las piezas clave de los cambios tecnológicos es el factor humano como generador de procesos. Por ello los miembros de la comisión BIMcitopCV deben poseer el conocimiento, el CITOPIC responsabilizarse de la integración y el equipo de liderazgo ser el motor de difusión y puesta en funcionamiento.

Peter Drucker, en su artículo "The Discipline of Innovación" se refiere al líder como la función que define recursos a partir de incongruencias, necesidades de los procesos y cambios tras ocurrencias inesperadas. Para ser generador de cambios el líder debe desarrollar la capacidad creativa propia y de su equipo [13]. La comisión BIMcitopCV asume este liderazgo en virtud del cual desarrolla la visión BIM, comunica y refuerza los objetivos a las partes interesadas (colegiados, colaboradores, administraciones públicas) y supervisa el progreso de la implantación proporcionando los recursos necesarios cuando sea necesario.

\section{Situación Actual}

El primer paso que debe acometerse es el diagnóstico de la situación presente de la institución. La cuantificación y cualificación de personas, tecnología y procesos internos sirvió de base en CITOPIC para elaborar la Estrategia de Implantación BIM (BIP). Con apoyo en las diferentes bases de gestión del CITOPIC se evalúa la estructura orgánica y funcional de la institución y se accede a datos que determinan el marco de actuación como el número de colegiados, su situación laboral, sector de especialización, nivel de formación, tipología de trabajos visados o la ratio de interesados en nuevas tecnologías.

Tras un pretest orientado a un grupo seleccionado para validar la metodología, se lleva a cabo la recogida de información a través de encuestas al colectivo. Tras el análisis de los datos se traduce en información fiable que reporta la opinión del colegiado en referencia a los beneficios futuribles tras la implantación BIM, los principales flujos de trabajo para elaborar un proyecto, los canales habituales de entrada de información o la sistemática de colaboración con otros agentes implicados en el proyecto. De forma específica en atención a BIM la encuesta potencia recabar aspectos como las principales dificultades con el flujo actual de trabajo CAD, las preocupaciones en la implantación del BIM, las expectativas en esta metodología de trabajo y la ratio de profesionales con formación en este ámbito.

\section{Planificación}

Analizada la situación actual del CITOPIC, se requiere definir la visión estratégica para la implantación en el colectivo, establecer los objetivos BIM y adoptar la matriz de decisiones 
claves que servirán de base para crear el BIM Implementation Plan (BIP) como guía para integrar la metodología en el mapa de procesos corporativos. Un factor esencial para la correcta implementación de BIM es la adopción de una visión concisa y articulada por parte de los líderes ejecutivos. En el caso del CITOPIC, se analizan los beneficios que aporta al colectivo, los elementos de la transformación y la apariencia evolutiva que tendrá en sus diferentes etapas. Se requiere un enfoque meticuloso para no reducir la concepción del BIM al uso de un software e ignorar su potencial como metodología integradora y de participación colaborativa.

El despliegue de objetivos es liderado por el Decano territorial a partir de las metas estratégicas de CITOPIC como ser referente en Ingeniería Civil, la retroalimentación de los resultados de implantación en las restantes zonas colegiales, la comunicación de los avances y la generación de oportunidades de empleo a los colegiados.

Establecida la visión, misión y valores BIM se establece el Esquema de Temas Importantes como siguiente etapa en la implantación, crucial para el diseño del Plan de implantación de BIMcitopCV y entre los que cabe destacar:

Formación: Una inversión necesaria y dirigida en tres trayectorias diferenciadas, nuevos flujos de trabajo, herramientas y personas. Una apuesta por la evolución madurativa tanto en herramientas como en estándares, como el promovido desde BuildingSmart OpenInfra IFC para el intercambio de información.

Difusión: Como medio de cristalización entre la institución y los colegiados haciendo partícipe a los usuarios de los procedimientos, los instrumentos, los resultados y como vía de involucración en el proceso a las partes interesadas.

Innovación: Bajo la creación de grupos de trabajo colaborativos como BIMcitopIC, talleres interdisciplinares o concursos de ideas se refuerza la interacción entre los procesos de innovación tecnológica que surgen de la digitalización de la construcción y la innovación social que potencia la productividad y la competitividad del sector.

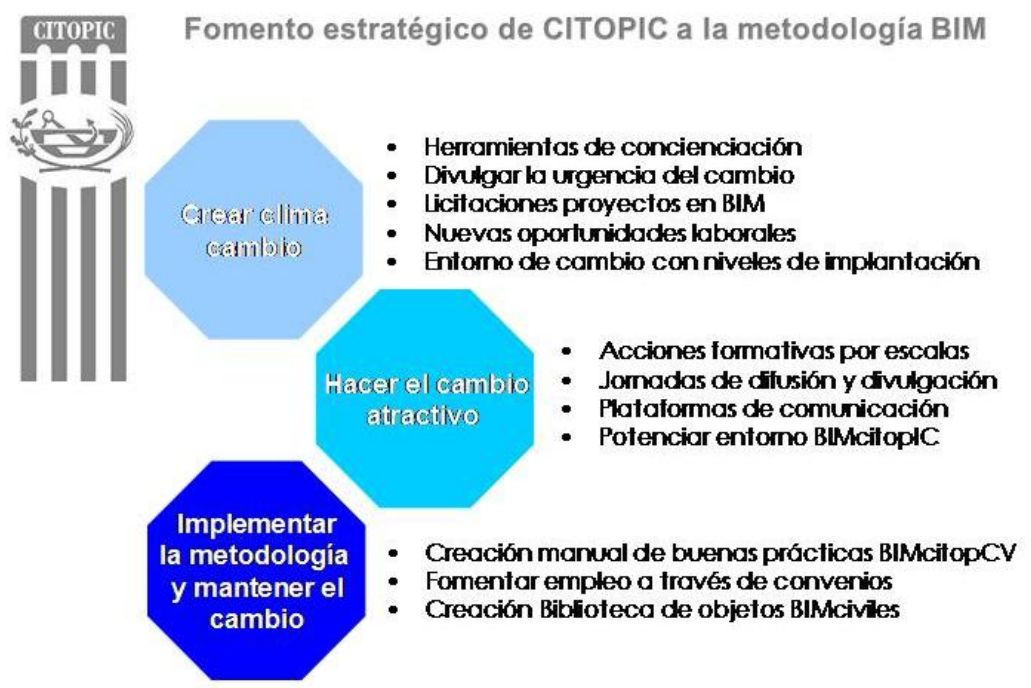

Fig 2. Esquema Temas Importantes en Plan BIMcitopCV 2016-2018. Fuente: Elaboración Propia 
Una de medidas aplicadas para aumentar la efectividad de la implantación consiste en secuenciar temporalmente la adaptación al cambio. Los ciclos de implantación se acometen en tres etapas, integración, gerencia estratégica y respuesta tras la medición del desempeño para garantizar una gestión del cambio flexible, eficaz y perdurable.

\section{Implementación}

Decidida la planificación del cambio se aborda la materialización de las medidas como proceso continuo de despertar organizacional que afianza en CITOPIC como entidad pública y entre sus colegiados un sentido estratégico compartido como única posibilidad de éxito.

La selección del equipo BIMcitopCV es factor clave como función responsable del desarrollo del plan de implantación BIM. Es un órgano colegiado que debe contar con representación equilibrada de todas las partes y ámbitos, contando sus participantes con una mentalidad abierta al cambio, entusiasta y dispuesta a invertir esfuerzo de forma proactiva.

\section{Formación:}

La formación focalizada en proyectos piloto en el ámbito de la ingeniería civil se diseña cubriendo las herramientas de trabajo, las metodologías y los procesos operativos en tres niveles discretizados por el nivel de complejidad.

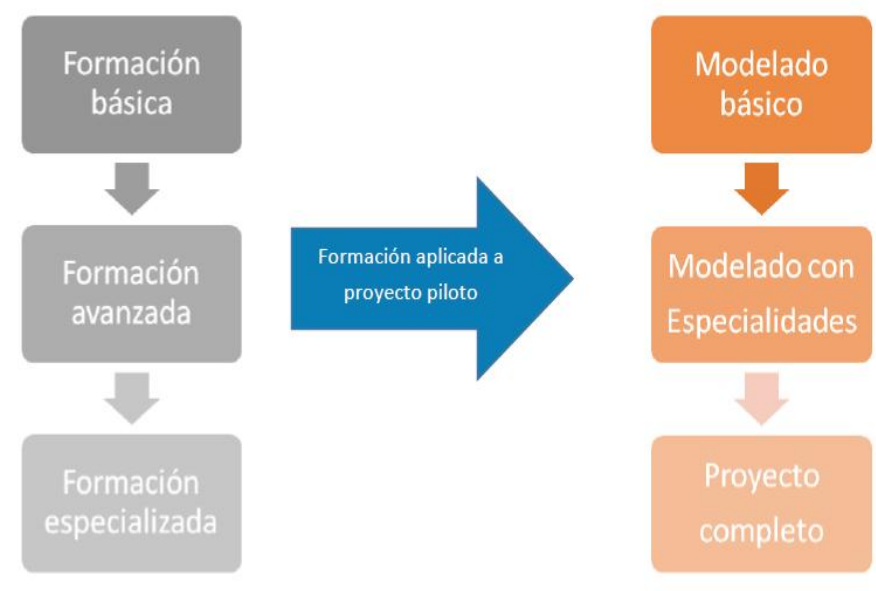

Fig 3. Estructura Formación BIM. 2017. Fuente: BIMfor

Debe incluir cursos personalizados que respondan a las necesidades formativas, cursos a corto plazo en herramientas y metodología así como divulgación de tutoriales y manuales de para cubrir aspectos como la preparación de una licitación BIM o la creación de un BEP.

\section{Comunicación 360:}

Para alcanzar altas cuotas de potencialidad de la comunicación como herramienta en procesos de cambio debe instaurarse como un estado de diálogo constante [14] donde convive la metodología que evalúa en detalle a sus públicos y los medios que la instituyan como altamente predictiva, multimodal e integradora. La comunicación interna debe ser un elemento transversal a todos los procesos capaz de gestionar escenarios futuros y convertirlos en nuevos motores de cambio.

El desafío último de la comunicación $360^{\circ}$ integrada en la Planificación estratégica BIMcitopCV es la permeabilidad y la flexibilidad para optimizar el diálogo y la participación 
activa de las partes interesadas al tiempo que mejora el modelo de intervención con herramientas accesibles que vehiculizan el BIM en todas las direcciones.

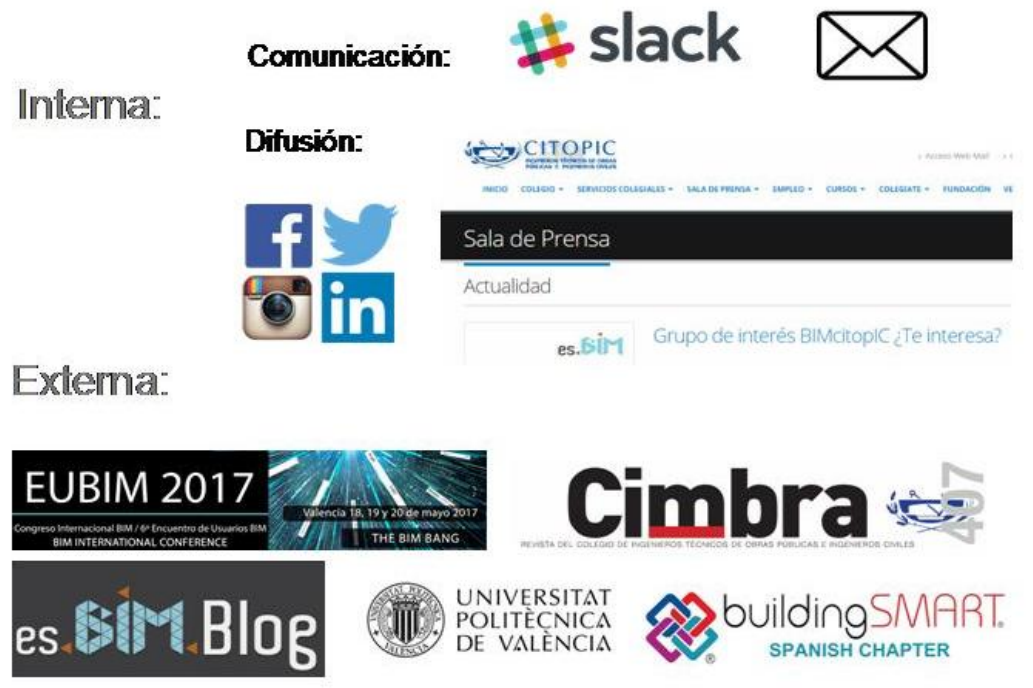

Fig 4. Elementos de Comunicación $360^{\circ}$ en Plan BIMcitopCV 2016-2018. Fuente: Elaboración Propia

\section{Medición del desempeño}

Como última etapa del proceso de implantación del BIM y con el objetivo de evaluar la calidad de las medidas, se acomete la medición del desempeño a través de indicadores. Debe incluir los resultados de los procesos operacionales y la capacidad resiliente del sistema implementado. Se analiza la eficacia operativa, la adecuación a cambios, la permeabilidad en los ámbitos de actuación y la sensibilización de los perfiles vulnerables.

En el ámbito objetivo se diferencian los proyectos de ingeniería civil discretizados por administraciones públicas, alcance de las actividades constructivas, fases de implantación de BIM requeridas en licitación o ratio de visados colegiales. Respecto al ámbito subjetivo cabe diferenciar entre los colegiados con formación específica en BIM, el nivel de competencias adquiridas o la capacidad de atracción en público con falta de interés.

\section{CONCLUSIONES}

Actualmente el proceso de cambio hacia la metodología BIM es lento, tal como ocurrió en la adaptación de las técnicas manuales al uso de la metodología CAD, pero la necesidad de adaptación y la competitividad en el mercado, aboca a ello y requiere en un futuro cercano profesionales preparados para ello. La formación de los profesionales de la construcción que debe ir de la mano con las nuevas tecnologías presentes en el mercado. La realidad virtual y la metodología BIM son parte de esta innovación tecnológica que se vienen implementando en la industria y en la formación de actores en el sector de la construcción.

Pese a ser el sector de la construcción uno de los principales motores reconocidos de crecimiento, competitividad e innovación de un país, la digitalización de su industria a través de un entorno BIM muestra escasos ejemplos en el campo de la ingeniería civil. De la misma forma que BIM es una metodología de trabajo colaborativa, los Colegios Profesionales deben asumir cierto grado de responsabilidad ética con la sociedad y 
colaborar con la administración en este cambio de paradigma. La dirección estratégica de su colectivo, la concienciación de la necesidad de cambio y la formación específica son actuaciones que deben liderar los Colegios profesionales por el valor añadido para sus asociados y a la sociedad en general.

La planificación estratégica, la dirección, el liderazgo, la medición del desempeño, la concienciación, la motivación y la formación son aspectos clave en cualquier proceso de implantación. La situación de partida requiere de una diagnosis de los recursos. Los Colegios profesionales cuentan con su colectivo como recurso más valioso, y como nexo entre el mundo universitario y el profesional, deben ser el soporte que necesita la digitalización de la industria de la construcción más allá de las expectativas de la sociedad.

El Colegio de Ingenieros Técnicos de Obras Públicas e Ingenieros Civiles ha tomado conciencia de la revolución que supone la metodología BIM para construir de forma digital antes de construir la realidad. La industria de la construcción actual demanda profesionales con las competencias requeridas para responder a las nuevas exigencias del mercado y los Colegios Profesionales tienen las herramientas y los recursos para convertirlo en viable.

\section{REFERENCIAS}

[1] Taboada García, J., Alcántara Rojas, V., Lovera, D., Santos, R., Diego, J., y Alcántara, H. (2011). Detección de interferencias e incompatibilidades en el diseño de proyectos de edificaciones usando tecnologías BIM. Revista del Instituto de Investigación de la Facultad de Ingeniería Geológica, Minera, Metalúrgica y Geográfica, vol. 14, no. 28.

Disponible en: $\underline{\text { http://revistasinvestigacion.unmsm.edu.pe/index.php/iigeo/article/view/672 }}$

[2] D' Paola Puche, E. (2014). Nuevas tecnologías en la enseñanza de la ingeniería civil: BIM y realidad virtual (Maestría en Ingeniería, Tesis, Universidad EAFIT).

Disponible en: $\underline{\text { http://hdl.handle.net/10784/2855 }}$

[3] Oya Sala, T. (2015). Impacto del BIM en la gestión del proyecto y la obra de arquitectura: Un proyecto con REVIT (Grado en Fundamentos de la Arquitectura, Trabajo fin de grado, Universitat Politècnica de València)

Disponible: $\underline{\text { http://hdl.handle.net/10251/55227 }}$

[4] Unión Europea (2014). Directiva 2014/24/UE del Parlamento Europeo y del Consejo, de 26 de febrero de 2014, sobre contratación pública y por la que se deroga la Directiva 2004/18/CE.

Disponible en: https://www.boe.es/diario boe/txt.php?id=DOUE-L-2014-80598

[5] Fuentes Giner, B. (2014). Impacto de BIM en el proceso constructivo español. Editorial Servicios y Comunicación IGV S.L., 248 páginas.

[6] Rodríguez-Castells, R.L., Martín-Dorta, N. y González de Chaves Assef, P. (2016). OpenBIM en infraestructuras as built: La gestión de activos con software open source a partir del modelo IGC. Congreso Internacional EUBIM 2016. Editorial Universitat Politècnica de València, 150-159. 
Disponible en: $\underline{h t t p: / / h d l . h a n d l e . n e t / 10251 / 64633 ~}$

[7] Consejo Económico y Social (2016). El papel del sector de la construcción en el crecimiento económico: competitividad, cohesión y calidad de vida.

Disponible: $h$ ttp://www.ces.es/documents/10180/3557409/Inf0216.pdf

[8] Del Solar Serrano, P., Andrés Ortega, S., Vivas Urías, M. D., de la Peña González, A., y Liébana Carrasco, O. (2016). Uso de BIM en proyectos de construcción en España. Spanish Journal of Building Information Modeling, núm 16(1), 4-12.

Disponible: $\underline{\text { http://hdl.handle.net/11268/5890 }}$

[9] Liébana Carrasco, O. y Gómez Navarro, M. (20). S-BIM in the structural building education. Innovación Educativa, 1-11.

Disponible:

http://www.academia.edu/download/31887206/oliebana mgomez SBIM ACHE Jn13.pdf

[10] Sánchez Botero, T., D' Paola Puche, E. y Botero Botero, L.F. (2015). Building Information Modeling como nueva tecnología en la enseñanza de la ingeniería civil, la arquitectura y la construcción. Arquetipo, vol. 10, enero-junio 2015. 87-110.

Disponible en: https://dialnet.unirioja.es/servlet/articulo?codigo=5653986

[11] Viladarga Rodrigo, I., López-Terradas Aparicio, B., Fernández Sánchez, G. y Liébana Carrasco, O. (2016). Congreso Internacional EUBIM 2016. Editorial Universitat Politècnica de València, 102-111.

Disponible en: $\underline{\text { http://hdl.handle.net/10251/64633 }}$

[12] Leyva, C. A. (1998). El impacto del liderazgo en la implementación del cambio tecnológico (Tesis doctoral, Instituto Tecnológico y de Estudios Superiores de Monterrey, Universidad Virtual).

Disponible en: https://repositorio.itesm.mx/ortec/handle/11285/569441

[13] Drucker, P. F. (1985). The discipline of innovation. Harvard business review. Disponible en: http://i2ge.com/wp-content/uploads/2012/01/Drucker-Discipline-ofInnovation1.pdf

[14] Véliz Montero, F. (2006). Cambio de Mirada en las organizaciones: Comunicación en 360 grados. Revista Latinoamericana de Comunicación Chasqui.

Disponible en: http://www.redalyc.org/pdf/160/16009311.pdf 


\title{
RETOS EN LA IMPLANTACIÓN DE BIM EN LA INGENIERÍA CIVIL Y PROPUESTAS PARA ACELERAR SU APLICACIÓN
}

\author{
Martínez-lbáñez, Víctor (1), Pellicer, Eugenio (2), Alcobendas, Julio (3), \\ Casado, Sergio (4)
}

(1) Escuela Técnica Superior de Ingenieros de Caminos, Canales y Puertos, Departamento de Ingeniería del Terreno; KREUM.S.A, Área de ingeniería, vicmarib@trr.upv.es

(2) Escuela Técnica Superior de Ingenieros de Caminos, Canales y Puertos, Departamento de Ingeniería de la Construcción, pellicer@upv.es

(3) AYESA, Área de Ingeniería Civil y Arquitectura, jalcobendas@ayesa.com

(4) AYESA, Área de Ingeniería Civil y Arquitectura, scasado@ayesa.com

\section{RESUMEN}

Desde finales de 2016, la administración autonómica catalana está desarrollando las primeras pruebas piloto para la implantación de BIM en la ingeniería civil. Estas experiencias, pioneras en España, se apoyan de forma natural en "software" y protocolos de trabajo propios de la edificación, donde la experiencia en BIM es más dilatada. Sin embargo, las formas de contratación y el tipo de relación entre los agentes intervinientes son muy diferentes, y las soluciones de "software" de arquitectura no están pensadas para el desarrollo de obras lineales. Además, los formatos IFC todavía no han sido desarrollados para infraestructura civil, y no permiten un intercambio de información de forma completa y ágil. En cualquier caso, la puesta en marcha de los primeros desarrollos BIM en infraestructuras están permitiendo a los agentes implicados acumular una valiosa experiencia, y evidenciar los retos a afrontar en el futuro. Entre estos retos urge la necesidad de desarrollar los formatos de comunicación IFC y BCF. El presente artículo recoge la visión de los profesionales de la ingeniería que están contribuyendo de primera mano en la aplicación innovadora del BIM a las infraestructuras lineales en España; incluye propuestas para acelerar la aplicación del BIM a la ingeniería civil.

Palabras clave: BIM, Building Information Modeling, Civil Engineering, Infrastructure, Roads

\section{ABSTRACT}

Since the end of 2016, the catalonian regional administration is developing the first pilot tests for the implementation of BIM in civil engineering. These experiences, pioneers in Spain, rely naturally on "software" and work protocols of the architectural building, where the experience in BIM is more extensive. However, the forms of contracting and the type of relationship between the agents involved are very different, and architectural software solutions are not intended for the development of linear infrastructure. In addition, IFC formats have not yet been developed for civil infrastructure, and do not allow full and agile information exchange. In any case, the implementation of the first BIM developments in infrastructures is allowing the agents involved to accumulate valuable experience and to highlight the challenges to be faced in the future. Among these challenges is the need to develop IFC and BCF communication formats. The present article gathers the vision of the engineering 
professionals who are contributing firsthand in the innovative application of the BIM to the linear infrastructures in Spain; Includes proposals to accelerate the application of BIM to civil engineering.

Keywords: BIM, Building Information Modeling, Civil Engineering, Infrastructure, Roads

\section{$1 \quad$ INTRODUCCIÓN}

Según la comisión es.BIM [1], la industria de la construcción cuenta con índices de competitividad y productividad más bajos que el resto de sectores industriales. La metodología tradicional de desarrollo y gestión del proceso constructivo no facilita la incorporación de los avances tecnológicos, de innovación y gestión, que facilitarían mejorar los objetivos de plazo, coste y calidad. Con el objeto de aportar un mayor grado de fiabilidad y precisión al proceso constructivo, la industria se encuentra en pleno proceso de implantación de la metodología BIM.

En España, donde se vienen empleando desde hace tiempo la metodología BIM, principalmente en el ámbito de la edificación, el establecimiento de la hoja de ruta y el calendario de implantación recae en es.BIM, comisión abierta promovida por el Ministerio de Fomento para la implantación de BIM. En su 4ª reunión de 22 de Julio de 2016 [3], la comisión fijó el objetivo de exigir el empleo de la metodología BIM como requisito para la contratación en licitaciones de edificación en diciembre de 2018, y en licitaciones de infraestructuras en julio de 2019.

El presente artículo recoge la visión de los profesionales de la ingeniería que están contribuyendo de primera mano en la aplicación innovadora del BIM a las infraestructuras lineales en España.

\section{IMPLANTACIÓN DE BIM EN INFRAESTRUCTURAS EN ESPAÑA}

La comisión es.BIM realizó entre septiembre de 2016 y enero de 2017 en torno a 2000 encuestas con el fin de obtener datos sobre el nivel de conocimiento e implantación del BIM en España. Los resultados de estas encuestas, que no han sido publicados a fecha de presentación del presente artículo, arrojarán objetividad sobre una realidad que, a criterio de los autores, presenta un panorama de desconocimiento generalizado del sector de las infraestructuras en relación a la metodología BIM, donde raramente se percibe su implantación como una oportunidad. 

1567 RESPUESTAS

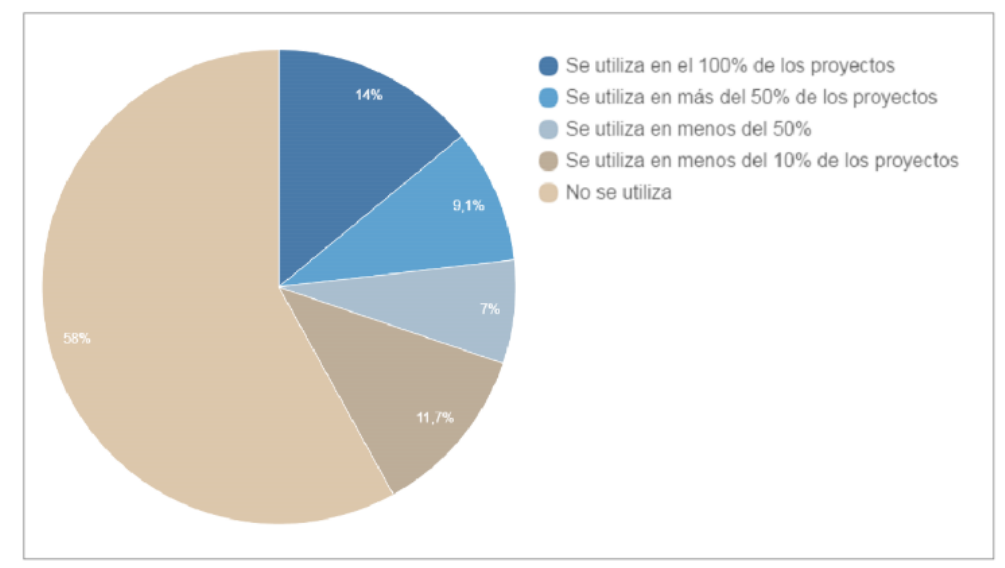

Fig 1. Implantación BIM en estudios de arquitectura. 2016. Consejo superior de Colegios de Arquitectos de España [2].

La referencia más utilizada hasta el momento son los resultados, publicados en mayo de 2016, de la encuesta de Consejo Superior de los Colegios de Arquitectos de España [2]. En base a ella, la comisión es.BIM presenta un contexto español marcado por el escaso conocimiento y uso de la metodología, con una incorporación lenta, donde se desarrollan iniciativas dispersas y poco coordinadas, que no cuentan con estándares, guías o recomendaciones estatales. La encuesta anterior no sondea el campo de la ingeniería civil, cuyo contacto con la metodología BIM en España es muy reciente.

El Grupo Procesos GT3 de es.BIM expresó en 2016 [3] las dificultades en el uso de BIM en infraestructuras. Para las empresas de ingeniería la adopción de BIM en sus procesos supone una inversión inicial importante, en comparación con los importes contratados para la redacción de proyectos. A esta inversión, le acompaña una fase inicial de menor productividad hasta llegar a un determinado nivel de maduración.

Los procedimientos de contratación todavía no tienen en cuenta que los proyectos desarrollados en BIM deberán tener un mayor peso económico en el total de la obra. Todo ello lleva a una inercia al cambio por parte del sector, que ralentiza la implantación de la metodología. Por otra parte, el "software" no está suficientemente evolucionado, todavía no existen estándares ni guías, y falta por establecer la forma de garantizar la propiedad de la información y el establecimiento de responsabilidades dentro del modelo.

Las experiencias reales documentadas de aplicación del uso de BIM en infraestructuras son escasas. Las referencias encontradas pertenecen a empresas españolas y han sido desarrolladas en ámbito internacional.

Desde finales de 2016, la administración autonómica catalana está desarrollando sus primeras pruebas piloto para la implantación de BIM en las infraestructuras, lo que contribuirá a la penetración de la metodología en el sector, y a afrontar los diferentes retos técnicos, operativos y de gestión que lleva aparejados. 
Las pruebas mencionadas se llevan a cabo con el apoyo de las ingenierías adjudicatarias de proyectos de carreteras. Así, en determinados proyectos de carreteras que se encuentran en fase de redacción, la administración catalana y la ingeniería acuerdan desarrollar parte del proyecto siguiendo la metodología BIM.

A modo de ejemplo, en el caso del "Projecte constructiu de millora general. Varíant de Tornabous i la Fuliola. Carretera C-53 del PK 119+750 al 128+000. Tram: Tornabous - La Fuliola. Clau: VL-04002", adjudicado a la unión temporal de empresas AYESA, y KREUM,S.A, se explora, entre otros desarrollos, las posibilidades de generación de un modelo BIM de la propia infraestructura lineal, su exportabilidad a los formatos de intercambio disponibles en la actualidad, y la información que este modelo puede llevar asociada.

\section{ESTRATEGIA DE IMPLANTACIÓN BIM EN PROYECTOS DE LA ADMINISTRACIÓN PÚBLICA. EL CASO DE LA GENERALITAT DE CATALUÑA}

En mayo de 2016 el Departamento de Territorio y Sostenibilidad de la Generalitat de Cataluña hace pública una nota de prensa [4] en la que visibiliza el impulso que esta administración está dando a la metodología BIM. Las primeras pruebas piloto sobre proyectos y obras de edificación iniciaron el año anterior. A raíz de estas experiencias, en la actualidad dicha administración está valorando la incorporación obligatoria de esta metodología en los futuros pliegos de sus concursos públicos. Las experiencias BIM de esta administración se están llevando casi exclusivamente en el campo de la edificación de forma satisfactoria, gracias a la experiencia existente en otros países y a la existencia de un "software" BIM en continua evolución.

La Generalitat es consciente que la implantación de la metodología BIM debe ser progresiva, ya que representa un modelo de transformación integral del sistema de trabajo actual para todos los actores que participan en las obras públicas. Para conducir esta transformación, la Generalitat creó una comisión interdepartamental, con el objeto de poner en marcha pruebas piloto sobre determinados proyectos de obra pública previamente seleccionados. Las acciones mencionadas están encaminadas a cumplir con los objetivos recogidos en el "Manifiesto BIMCat" [5], compromiso adquirido por la Generalitat de Catalunya y el Ayuntamiento de Barcelona en febrero de 2015, y en el que se estipula el siguiente calendario de trabajo e hitos a conseguir:

- Objetivo 2015-2016: Consensuar un mandato BIM en Cataluña.

- Objetivo 2017: Adopción de unos estándares, guías, clasificaciones y procesos de entrega del modelo digital pensando en cada fase del proyecto constructivo, de su ejecución, del posterior mantenimiento y de su integración en la ciudad. Implica la definición de unos protocolos comunes en la creación y definición de la información compartida entre los agentes orientados a la plena interoperabilidad entre las partes. 
- Objetivo 2018: Los equipamientos y las Infraestructuras públicas de presupuesto superior a $2 \mathrm{M} €$ deberán producirse en BIM en las fases de Diseño a Construcción. Se circunscribe este objetivo a los proyectos de obra nueva.

- Objetivo 2020: Todos los equipamientos y las Infraestructuras públicas deberán producirse en BIM en todas las fases, Diseño - Construcción - Explotación (Mantenimiento y "Facility Management"). Se ciñe este objetivo a todos los proyectos de obra nueva y rehabilitación.

La administración catalana considera que, con la adopción de este calendario, se da el tiempo suficiente y necesario, tanto a la industria como a los diferentes agentes que intervienen en el ciclo de la construcción y la edificación, para la adopción paulatina de la metodología BIM.

\section{EXPERIENCIAS REALES DE IMPLANTACIÓN DEL BIM EN INFRAESTRUCTURAS}

\subsection{Relación entre las partes y forma de contratación}

La curva de McLeamy [6] refleja cómo influye el esfuerzo de diseño a lo largo del ciclo de vida de la obra. La idea básica es que una obra es mucho más difícil y costosa de cambiar cuanto más desarrollada se encuentra. La metodología BIM concentra el esfuerzo de diseño en fases tempranas, donde puede analizarse más fácilmente diferentes alternativas, y es económico realizar cambios. Además, las decisiones que se tomen en esta fase son las que más impacto tendrán en los costes del ciclo de vida.

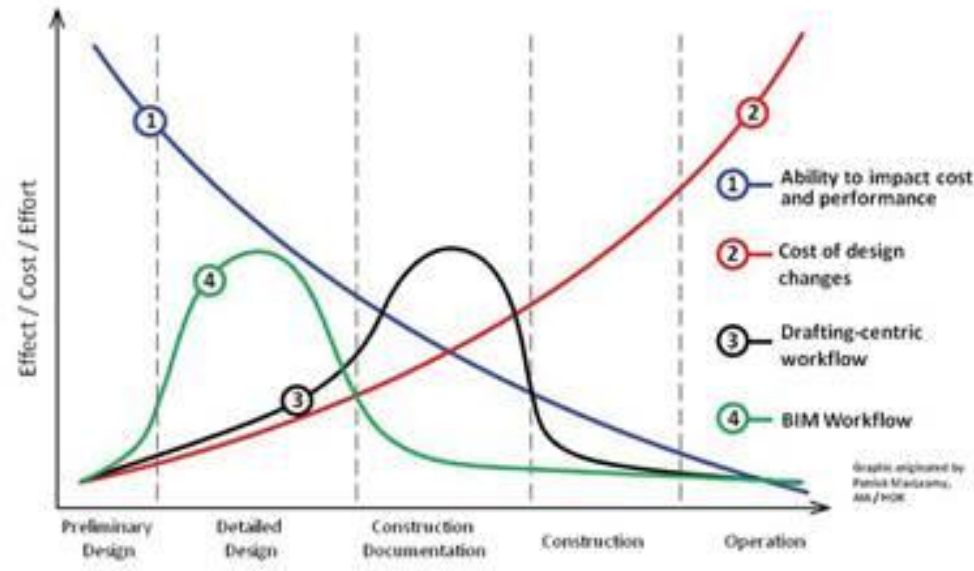

Fig 2. Curva de esfuerzo de MacLeamy. 2010. P. McLeamy (HOK) [6].

Los modos de contratación actuales en el mundo de las infraestructuras presentan el proyecto, construcción y mantenimiento como establecimientos estancos. Los procesos de contratación de cada una de estas partes están desplazados en el tiempo; hasta que no finaliza la fase de proyecto y se dota de partida presupuestaria por parte de la 
Administración, no arranca la fase constructiva. Finalmente, la conservación de la infraestructura no se contrata hasta que la infraestructura se pone en servicio.

La anterior circunstancia lleva aparejada que los diferentes agentes que intervendrán en el ciclo de vida de la obra no están determinados desde las fases previas, y por lo tanto no puede existir una dinámica de colaboración entre ellas, que enriquezca y refine el modelo BIM desde el inicio. Esta situación lleva a la aparición de indefiniciones, incoherencias y soluciones constructivas o de mantenimiento no óptimas y que llevan a cambios y modificaciones en las etapas de construcción y mantenimiento, donde los plazos son estrictos, y las modificaciones difíciles de abordar por resultar más caras. Caminar hacia un modelo que permita un alto grado de definición del modelo en fases tempranas, y que contemple cada una de las fases del ciclo de vida, requerirá un cambio en la forma de plantear las licitaciones de obra pública, con las modificaciones legales que ello conlleva.

En relación a las exigencias y expectativas, en esta parte es fundamental el escaso grado de conocimiento de la metodología BIM en la industria de las infraestructuras. Las referencias más visibles provienen del mundo de la arquitectura, lo que lleva a la idea inicial y errónea de que los proyectos de infraestructuras pueden desarrollarse en BIM con el mismo grado de desarrollo que aquellos. La realidad es que las herramientas informáticas no están igualmente preparadas, el sector todavía no tiene formación ni experiencia, y la mencionada forma de contratación condiciona plenamente la relación entre los agentes a lo largo del ciclo de vida de la infraestructura.

Las primeras experiencias que se están desarrollando en Cataluña están tratando de determinar la aplicabilidad del BIM a infraestructuras, qué es razonable y técnicamente viable incluir en los modelos, y qué información puede resultar útil en cada fase del ciclo de vida. Para ello, se establece un diálogo público-privado a partir de pruebas piloto, de las cuales emanarán las exigencias BIM a incluir en los futuros pliegos de contratación de infraestructuras.

\subsection{Software e intercambio de información y plataformas de trabajo colaborativo}

Es importante diferenciar dos grandes tipologías de infraestructuras: por un lado, la edificación (y las estructuras), y por otro lado, la obra lineal. Ambos se diferencian por tener un desarrollo vertical en un ámbito territorial localizado, en el caso de las primeras, y un desarrollo horizontal en un ámbito territorial extenso en el caso de las segundas. Las soluciones de "software" BIM en edificación y estructuras están en continua evolución, mientras que en las obras lineales es donde más problemática se está encontrando, por el menor grado de adaptación a la metodología BIM del "software" específico.

La amplia aplicación de la metodología BIM a la arquitectura lleva a intentar aprovechar para las obras lineales las soluciones "software" desarrolladas para edificación. Estas soluciones "software" no están pensadas para obras con un desarrollo horizontal, y no tiene sentido insistir en utilizarlas por el mero hecho de que son capaces de reconocer los ficheros de intercambio de modelos. No puede admitirse la afirmación de que se está aplicando BIM por 
el hecho de trabajar con herramientas preparadas para el trabajo sobre modelos. BIM es una metodología, y el "software" es la herramienta, y no al revés.

Cabe destacar los esfuerzos de determinadas plataformas por integrar la metodología BIM en sus flujos de trabajo, como el caso de Autodesk, que desarrollan las soluciones para obras lineales Infraworks y Civil3D. Sin embargo, las altas exigencias de la industria llevan a los usuarios al uso de programas con un alto nivel de especificidad para el diseño de obras lineales, principalmente Istram/Ispol de Buhodra Ingeniería en el mercado español y latinoamericano, o Bentley InRoads en el mercado anglosajón. Los flujos de trabajo dependerán plenamente de las posibilidades de exportación de los modelos a partir de los programas más ampliamente utilizados, aspecto que se encuentra en fase de desarrollo.

En un entorno de trabajo BIM las plataformas de los diferentes "softwares" se comunican a través del formato IFC. Se trata de un estándar que en edificación tiene un muy buen progreso, pero que en obra civil a día de hoy no es una solución válida si entendemos BIM como una metodología de trabajo integral, y no sólo como el uso de determinado software.

No obstante, desde la base de conocimiento BSI (buildingSMART) se está desarrollando una mejora en el formato de trabajo IFC4 actual, se trata del IFC4X1 que incorpora en fase de desarrollo el IFC Aligment (versión 1.0.1). Este formato (IFC Alignment) para infraestructuras fue liberado en julio de 2015 por buildingSMART [7]. En este formato IFC se puede comunicar, además de los volúmenes geométricos, información de las alineaciones en planta y en alzado, y hacer un primer análisis de la coordinación.

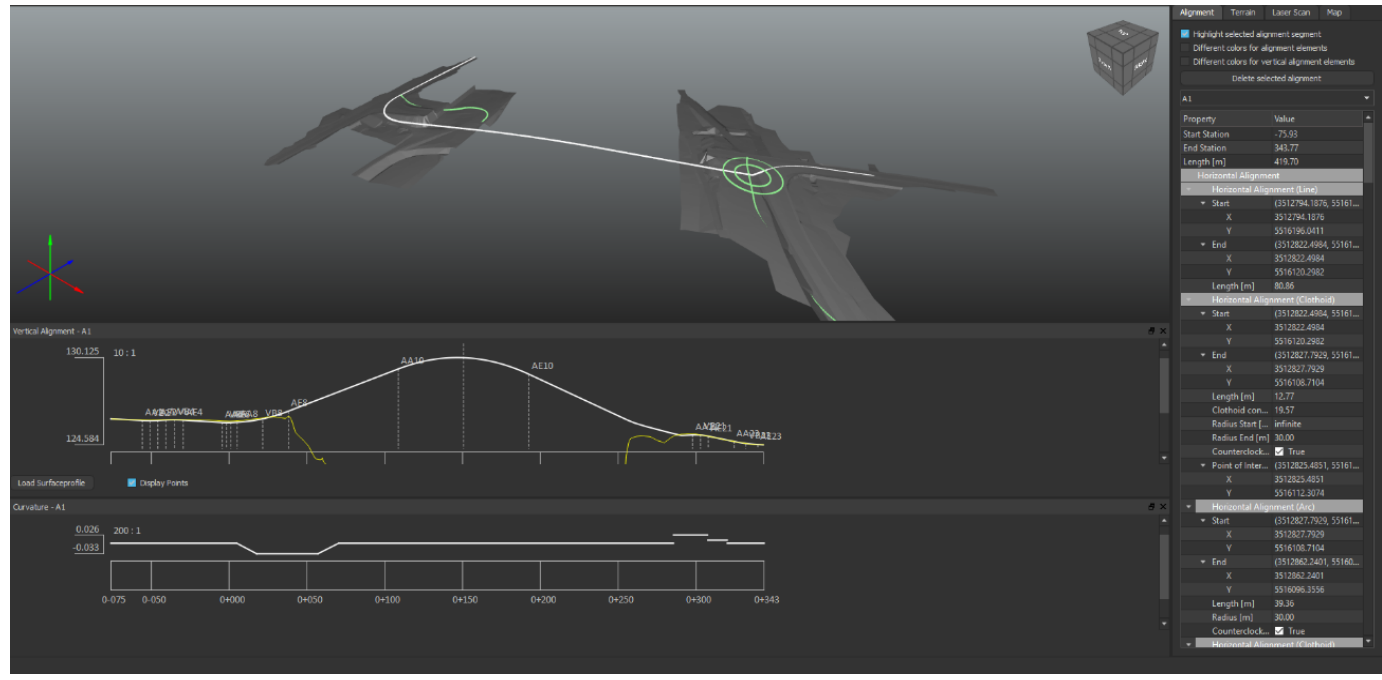

Fig 3. Imagen: Ejemplo de lectura de fichero IFC Aligment en el programa TUM - Open Infra Platform. 2017. Elaboración propia.

El "software" de control que asuma la comunicación entre las diferentes plataformas BIM que participen en un proyecto de infraestructuras tiene que poder reconocer el futuro formato IFC4x1 para trabajar con la información de las alineaciones de los ejes de un proyecto de obra lineal. Según las pruebas realizadas por los autores del artículo, actualmente uno de los "softwares" que exporta el formato IFC Alignment es Istram/Ispol, que previamente a la 
exportación del fichero muestra a través de un motor openGL la visualización de la información en formato 3D e información de las alineaciones de cada eje.

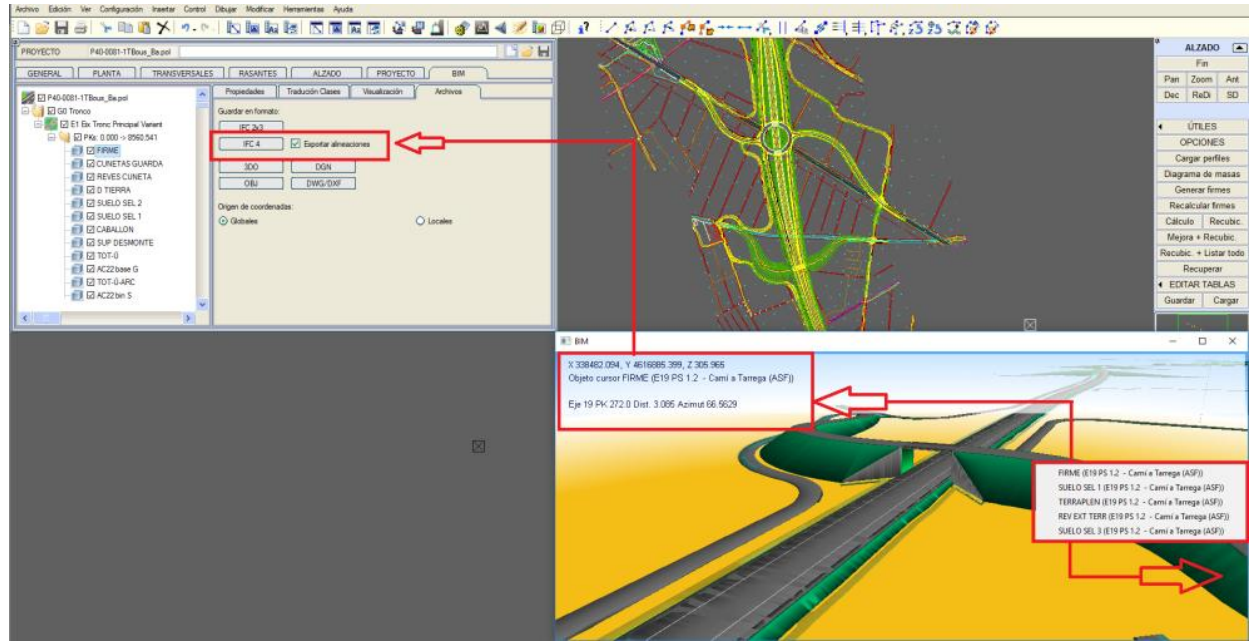

Fig. 4. Imagen Programa Istram/Ispol: Ejemplo de exportación IFC4 e IFC-Aligment 1.0. 2017. Elaboración propia.

El "software" TUM - Open Infra Platform 2017 (en fase de desarrollo por la Universidad Técnica de Múnich), sí reconoce los ficheros del programa Istram/Ispol con alineaciones. Por el contrario, las pruebas realizadas con otros programas de diseño BIM como Navisworks, Solibri, IFCviewer y Bimvisión, no han podido comunicar con este formato (IFC Alignment).

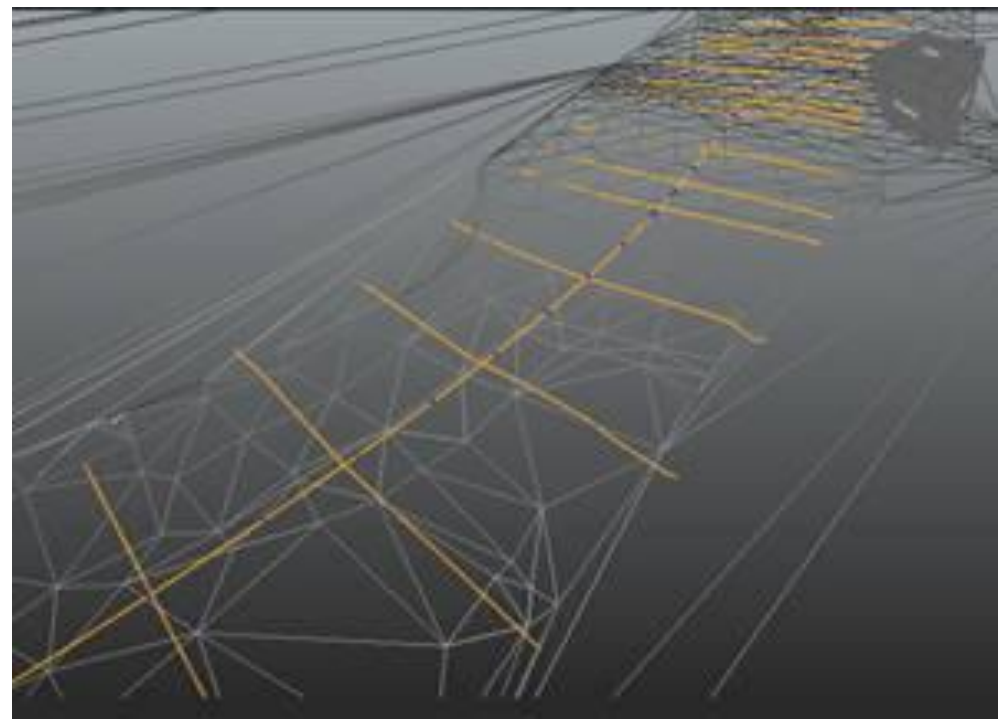

Fig. 5. Imagen programa TUM - Open Infra Platform 2017: Ejemplo de importación de IFC-Aligment. 2017. Elaboración propia.

Esto nos hace ver que en algo tan necesario como conocer la información de las alineaciones del mecanizado de un eje no se pueden controlar desde la mayoría de las plataformas preparadas para la coordinación de los proyectos actualmente. Es de esperar que un futuro cercano el desarrollo del formato IFC4x1 y los "softwares" irán implementando estas mejoras muy necesarias para una buena gestión, a los que se sumarán más adelante 
los siguientes formatos en desarrollo para BIM infraestructruras: IFC-Roads e IFC-Bridge, de los que el IFC Alignment es un primer desarrollo de ellos [8].

Es importante hablar del formato para la colaboración BCF (BIM Colaboration Format). Sus orígenes parten de Solibri y Tekla, en el año 2010, y se trata de un formato adoptado como estándar por BuildingSMART. En su versión actual bcfXML V2.1, este formato completa la información de modelado del IFC, con datos para comunicar incidencias o revisiones. En obra lineal las incidencias más comunes son las de duplicado de mediciones por intersección entre taludes, o sobredimensionamiento de firmes por omisión de líneas frontera que delimitan cada vial. Con este formato de comunicación puede enviarse estas detecciones de errores en las revisiones del modelado. Además, y siempre a la espera de que se alcance un mayor desarrollo en los formatos IFC $4 \times 1$, también podría comprobarse incumplimientos en definiciones de eje en planta, alzado, o coordinación entre ambos, y completar un historial de diagnóstico analítico del trazado.

\subsection{Desarrollo de BEPs para infraestructuras}

La metodología BIM es un sistema de trabajo que involucra a todos los actores en el ciclo de vida de la infraestructura de forma directa. Esto exige adoptar nuevos protocolos de comunicación, cooperación y estandarización para que el flujo de información sea ágil, coherente y trazable. Para tal fin, en el inicio de cualquier proyecto a desarrollar siguiendo esta metodología, es preceptiva la realización de un BIM Execution Plan (BEP). Se trata de un documento (o conjunto de documentos) donde quedará definida la estrategia para el desarrollo y control de la información/documentación que se irá desarrollando a lo largo de la vida de un proyecto, y donde quedará establecido claramente no sólo la información básica del proyecto, la relación entre los participantes y los hitos temporales, sino también la definición de los modelos que se generarán para ese proyecto, el nivel de detalle de los mismos y los protocolos de comunicación de esos modelos entre distintas plataformas de software. Es en esto en donde estriba la principal diferencia entre un BEP y un sistema de planificación de proyectos "estándar" (que en la práctica se reducía a un organigrama de los actores y un cronograma con los hitos del proyecto).

La necesidad de establecer un BEP para un proyecto ejecutado con metodología BIM se percibió como necesaria desde los primeros estadios de esta tecnología. La primera referencia académica para establecer y dar carácter normativo al BEP queda recogida en la investigación de Saluja [9]. Desde entonces la experiencia acumulada, fundamentalmente en el campo de la edificación, ha ido perfeccionando y dando contenido a estos BEP a medida que las posibilidades de "software" iban en aumento, para poder generar modelos más completos y complejos, que podían albergar información ya no sólo dimensional (modelo 3D), sino también de planificación temporal (modelo 4D), presupuestaria (modelo 5D), de sostenibilidad (6D) y de operatividad (7D).

De la misma forma que ha sucedido con el software, en el campo del BIM aplicado a las infraestructuras lineales se ha tratado de aprovechar la dilatada experiencia del BIM en edificación para establecer BEPs partiendo de esa base, pero ni el nivel de desarrollo del "software" actual permite la exacta transmisión de la información que requiere una obra 
lineal (como se ha visto en el apartado anterior) ni el nivel de detalle de los modelos o la clasificación de los objetos (taxonomía) que componen un proyecto tipo de obra lineal ha sido estandarizada.

\section{$5 \quad$ RETOS Y PROPUESTAS}

Entre los retos a los que debe enfrentarse la implantación de BIM en el mundo de la obra civil, se encuentra la necesidad de lograr un alto grado de definición del modelo en fases tempranas. Para ello es necesario que los diferentes agentes, que deben colaborar y enriquecer el modelo desde del inicio, queden establecidos en la fase de concepción de la infraestructura. Será necesario introducir cambios en la forma de plantear las licitaciones de obra pública, con las modificaciones legales que ello conlleva. Se propone explorar otros modelos de contratación más colaborativos [10], tales como el proyecto-obra ("designbuild"), la dirección integrada de proyectos ("construction management at risk") y los proyectos integrados ("integrated project delivery"); la utilización del libro abierto ("open book") o el precio máximo garantizado ("guaranteed máximum price") son estrategias que también pueden ayudar mucho en este sentido.

Un reto adicional es el de diferenciar la forma de afrontar la elaboración de dos tipos de modelos claramente diferenciados: los de edificación o asimilables a edificación, y los de obra lineal. Actualmente se dan casos de modelos de obra civil desarrollados a partir de herramientas BIM pensadas para la edificación, lo que obliga a los usuarios a realizar un gran esfuerzo para obtener modelos poco precisos. Se considera muy importante dar a conocer a los profesionales implicados los límites de los programas de edificación para el desarrollo de obras lineales, y las posibilidades actuales para la generación de modelos de obras lineales utilizando el software específico, así como la exportabilidad de los mismos. Se propone el establecimiento de foros, y la celebración de cursos y congresos donde se de especial relevancia a la generación de modelos de obra lineal.

Otro de los desafíos importantes está relacionado con la disponibilidad de archivos de intercambio, que deberán ser capaces de comunicar toda la información relevante del modelo de obra lineal, de forma equivalente a los modelos de edificación: geometrías, materiales y volúmenes. Para avanzar en este campo, se propone la formación de grupos de trabajo integrados por un amplio número de profesionales del sector, donde se decida la información que debe ser capaz de transmitir el formato. También se sugiere debería difundir y hacer fácilmente accesibles las versiones intermedias de los nuevos formatos, para realizar testeos masivos de los mismos, agilizando así la puesta en funcionamiento de IFC-Roads y IFC-Bridge.

Otro de los retos que hay que superar está relacionado con el "software" integrador de los modelos. Actualmente el "software" más común no es capaz de interpretar adecuadamente el formato de intercambio, y no permite conservar y mostrar la información relevante del modelo de obra lineal. Sin duda el mercado del "software" asignará más recursos al desarrollo de sus productos cuando los técnicos demanden este tipo de soluciones. Para 
ello, se vuelve a hacer mención de la importancia de dar a conocer a los profesionales del desarrollo de proyectos de obras lineales el "software" específico para la generación de modelos de obra lineal y sus limitaciones actuales.

Por último, el desarrollo de BEP's específicos para proyectos de obras lineales debe diferenciados de los de edificación, definiendo específicamente la información que debe contener el modelo, el nivel de detalle, y la clasificación de los objetos. De forma paralela al desarrollo de los archivos de intercambio y del "software" asociado, la elaboración de proyectos piloto se está demostrando como una forma adecuada de estandarizar y marcar las exigencias de los modelos de obra lineal, por lo que se propone emprender un mayor número de pruebas pilotos, y fomentar el intercambio de experiencias y resultados obtenidos. Para ello, se vuelve a insistir en la conveniencia del establecimiento de foros y congresos específicos.

\section{REFERENCIAS}

[1] es.BIM (2016). BIM en 8 puntos. http://www.esbim.es/wpcontent/uploads/2017/01/Documento_difusion_BIM.pdf

[2] CSCAE (2016). Resultados de la Encuesta CSCAE sobre implantación de sistemas BIM. http://www.anfapa.com/downloads/55_resultados-encuesta-bim-.pdf

[3] Es.BIM (2016). BIM en infraestructuras lineales. http://www.esbim.es/wpcontent/uploads/2016/06/esBIM-Elena-Puente-Ineco-BIM-en-infraestructuras-lineales.pdf

[4] Departamento de Territorio y Sostenibilidad de la Generalitat de Cataluña (2016). Catalunya impulsa la metodologia de treball virtual en 3D a l'obra pública. Oficina de Comunicació i Premsa Departament de Territori i Sostenibilitat.

[5] Manifiesto BIMCat (2015). https://www.buildingsmart.es/2015/02/19/manifiesto-bim-cat/

[6] P. McLeamy (2010). Effort Curve. HOK, http://www.hok.com

[7] BuildingSMART - P6 Project Team (Project Lead Thomas Liebich tl@aec3.de) (2015). IFC Alignment Project, Conceptual Model (informative). http://www.buildingsmarttech.org/downloads/ifc/ifc5-extension-projects/ifc-alignment/ifcalignmentconceptualmodel-fs 
[8] Amann J, Borrmann A (2015). Creating a 3D-BIM-compliant road design based on IFC alignment originatinfrom an OKSTRA-accordant $2 \mathrm{D}$ road design using the TUM Open Infra Platformand the OKSTRA class library. Technische Universität München.

[9] Saluja, Chitwan (2009). A Process Mapping Procedure for Planning Building Information Modeling (BIM) Execution on a Building Construction Project. Architectural Engineering Master Thesis. Universidad Estatal de Pensilvania.

[10] Pellicer E., Benlloch, A., Esmaeili, B., Molenaar, K.R. (2014). Collaborative Behavior In The Spanish Building Industry: a Preliminary Analysis Of The Dataset. 18th International Congress on Project Management and Engineering, 789-798. 


\section{IMPLEMENTACIÓN DE GESTIÓN DE PEQUEÑOS PROYECTOS DE REFORMA MEDIANTE LA METODOLOGÍA BIM}

\section{De Frutos Ramírez, Adolfo (1) Liébana Carrasco, Oscar (2) Cabrero Seral, Juan Carlos (3)}

(1) Escuela Arquitectura, Ingeniería y Diseño Universidad Europea de Madrid. adolfo.defrutos@universidadeuropea.es

(2) Escuela Arquitectura, Ingeniería y Diseño Universidad Europea de Madrid. oscar.liebana@universidadeuropea.es

(3).Estudio Juan Carlos Cabrero, jccabrero@prefabricar.org

\section{RESUMEN}

En estos momentos existe una gran duda entre las pequeñas empresas sobre la metodología BIM y sus beneficios en la pequeña escala del interiorismo, de las reformas de viviendas o de locales singulares. En este caso de estudio, una pequeña empresa que pretende ser referencia de innovación en su ramo y ofrecer la excelencia en la gestión de los proyectos a sus clientes, ha realizado un estudio comparativo entre este nuevo proceso de diseño y el tradicional que utiliza actualmente en 2D, evaluando principalmente si existen diferencias que hagan mejorar o no la satisfacción del cliente y de los diferentes agentes del proceso.

El presente trabajo muestra la parte inicial del estudio, donde se compara el proceso de desarrollo de los proyectos con ambas metodologías, generando un proceso eficiente en el desarrollo de los modelos BIM con la información estricta que permita su ejecución. Este trabajo inicial concluye con la necesidad de crear proyectos BIM, menos interpretativos que los actuales, que permitan extraer la información de manera correcta tanto en el proceso de venta como de gestión, permitiendo una gran reducción de incertidumbre en la ejecución, pero con la importancia de no complejizar ni saturar de información un modelo inútilmente.

Palabras clave: comparativa, interiorismo, reformas

\section{ABSTRACT}

Nowadays small companies are hesitating about BIM methodology and its benefits on the small scale of interior design, home refurbishing, or commercial spaces. In this study, a small company try to be a reference of innovation and offer excellence in the project management to its clients, has made a comparative study between this new design process and the traditional one that it currently uses in $2 \mathrm{D}$, evaluating mainly if there are differences that improve or not, the satisfaction of the client and the different agents of the process.

The present work provides the initial part of the study, comparing the process of Project development with both methodologies, generating an efficient process in the development of BIM models with the strict information that allows its execution. This initial work concludes with the need to create BIM projects, which are less interpretive than the current one, that allow the information to be extracted correctly in the sales and management processes, 
allowing a great reduction of uncertainty in execution, but with the importance of not complicating or saturating.

Keywords: comparative, interior design, reforms

\section{$1 \quad$ INTRODUCCIÓN}

Dentro de la rama del sector dedicada a las reformas y acondicionamiento de pequeños proyectos cobra especial importancia el tiempo en el que se desarrollan los proyectos. La empresa dentro de la que se realiza el estudio dedica aproximadamente 4-5 meses desde la captación inicial hasta la entrega definitiva de la vivienda o local reformado

En este tiempo, es la propia empresa la que gestiona el proyecto desde el inicio hasta el final por lo que una correcta coordinación entre los diferentes intervinientes parece, más que necesaria, exigible. Proyectista, contrata, dirección facultativa quedan integrados dentro de la misma empresa con un interés común, lo que obliga a un trabajo totalmente colaborativo y de equipo

Los clientes promotores persiguen con la contratación de una empresa de gestión integral de la reforma o al acondicionamiento un servicio que les permita la tranquilidad de no sufrir sobresaltos durante los trabajos confiando plenamente desde la primera persona que acude a realizar la visita de toma de datos a todos los demás que intervienen en el proceso.

La indefinición, las incidencias o los errores que se cometen en el proceso son elementos que en el sector donde nos movemos pueden suponer la pérdida de clientes o retroceso en el avance empresarial.

Según Brad Hardin y Dave McCool "Los clientes inteligentes, frustrados con los resultados de los métodos de adjudicación de contratos anteriores, han encontrado nuevas formas de seleccionar un constructor. Estos clientes son muy conscientes de las complejidades del proyecto y están buscando empresas que utilicen la tecnología para superar estos desafíos". [1]. Entendiendo que los clientes generalmente están mucho más capacitados y poseen mucha más información para afrontar los proyectos

Igual que el cliente es importante, también lo es la empresa contratada para la ejecución de los trabajos. Se debe contar con contratas que estén alineadas con las exigencias de la empresa en cuanto a la satisfacción del cliente [2]. Para ello, la empresa principal debe trabajar con herramientas que ofrezcan la información de manera clara y ágil que permita a las contratas poder mejorar sus rendimientos y productividad

Observando el proceso llevado a cabo mediante la metodología 2D, se detectan incidencias que se repiten de manera general a lo largo de las diferentes obras, en mayor o menor medida. Si bien, el cambio de mentalidad en el propio proceso o la propuesta de algunos elementos podría subsanar los errores o incidencias y mejorar el rendimiento de producción siendo más eficientes y eficaces, se debe aprovechar la tendencia contrastada por 
diferentes estudios que nos indica las bondades de la metodología BIM, para pretender su implementación y comparar los resultados dentro de la propia empresa. [3][4][5]

Se pretende con esta comunicación; siendo la primera parte del estudio completo sobre la implementación de la metodología BIM en una empresa de reformas; abordar el proceso de creación del modelo y la información que facilite, debiendo ser fácilmente manejable para las exigencias reales de los propios proyectos y la estructura de la empresa en estudio

\section{OBJETIVO PRINCIPAL}

El objetivo principal de la comunicación persigue el desarrollo de un proyecto específico de reforma que ofrezca la mayor eficiencia posible, traducida en tiempos de creación del proyecto menores o iguales al empleado en la confección del proyecto en $2 \mathrm{D}$, pero que mejoren en la claridad y representación frente a los clientes aportando valor de un modelo $3 \mathrm{D}$ frente al modelo $2 \mathrm{D}$ y mejorando en la resolución de incidencias en la fase de obra y en la posterior fase de mantenimiento o post-venta, consiguiendo como dice Phil Berstein dentro del artículo de Gideon Fink Saphiro "si no tienes que preocuparte por donde discurre un conducto, puedes usar tu cerebro para mejorar el edificio". [6].

\section{PROCESO DE TRABAJO 2D}

Para poder determinar las necesidades de la empresa y poder actuar en la implementación de la metodología BIM se hace necesario reconocer el proceso de trabajo actual mediante proyectos $2 \mathrm{D}$..

Existe una primera fase realizada por el equipo de captación que se encarga de asimilar las necesidades del cliente escuchando sus propuestas, y tras conocer sus circunstancias proponer opciones adicionales o alternativas, considerando especialmente factores como la eficiencia energética y la accesibilidad arquitectónica. Este equipo es el encargado de realizar las mediciones de las viviendas a reformar con tomas de datos singulares de la misma.

La siguiente fase llevada a cabo por el equipo de proyectos consiste en el proceso de desarrollo en 2D del proyecto en sí, confeccionando la documentación del estado actual, para seguidamente realizar el estudio de posibilidades y bocetos de trabajo del estado reformado a presentar al cliente, acompañado las propuestas de un presupuesto elaborado en Presto. Se inicia a partir de este momento un trabajo de definición y negociación, siempre dentro del entorno $2 \mathrm{D}$ y con el propio cliente para determinar la distribución final, las instalaciones y los acabados definitivos; hasta cerrar la fase con la firma del contrato de ejecución

A partir de la firma de contrato con la información desarrollada anteriormente se inicia la fase de ejecución donde el equipo de obra debe gestionar la contratación y control de los trabajos hasta la entrega definitiva. 
Como garantía de compromiso y seguimiento de posibles incidencias posteriores se dispone de un equipo de post-venta y mantenimiento durante un año para la resolución de las mismas, dentro de la última fase del proceso.

\section{$4 \quad$ INCIDENCIAS DETECTADAS}

Dentro del proceso de captación y proyectos se detectan de manera general incidencias tales como.

- Falta de definición de algunos acabados o falta de localización correcta de los mismos

- Falta de solución clara de las instalaciones, habitualmente centrado en los equipos de AA y las instalaciones de saneamiento, que por sus dimensiones y condiciones de trabajo vinculan en gran medida las posibilidades de distribución

- Diseños incompletos de equipamientos, tales como cocinas, armarios, carpinterías

- Error en el replanteo de ciertos muros al no contar con los espesores reales y la localización correcta de las estructuras lo que supone modificaciones de los planos finales

- Falta de información rápida entre empresa y contratas lo que supone desmontajes y reposiciones de unidades de obra

- Incorrecta gestión de las incidencias de postventa por falta de actualización de los planos, sobre todo los correspondientes a las instalaciones o por falta de información sobre los acabados y equipamientos instalados para reposición por rotura o avería.

\section{JUSTIFICACIÓN DE LA METODOLOGIA BIM}

Considerando el proceso de trabajo en 2D correcto en las diferentes fases por equipos, la implantación no debe modificar de manera total el mismo, sino permitir una mayor coordinación de los equipos eliminando las incidencias detectadas o aun existiendo algunas como consecuencia de la tipología de la obra, contar con una herramienta que permita su rápida respuesta.

No debe quedarse el nuevo proceso en una mera representación gráfica obtenida mediante la herramienta de diseño seleccionada, en este caso Revit 2015, o un renderizado del modelo con la multitud de herramientas disponibles en el mercado, sino que está, a través de la metodología BIM, debe permitir una mayor participación de todos los equipos de trabajo en el proceso de diseño, pasando de ser elementos estancos a un verdadero proceso participativo y un contenedor de información que conecte las diferentes necesidades. La metodología debe ser motivo de mejora en los procesos ya existentes y que funcionan y un animador de nuevos elementos que mejoren la eficiencia del producto final. Si BIM es un 90 por ciento de sociología y sólo un 10 por ciento de tecnología, entonces la cultura de la empresa tiene que ser tenida en cuenta como un factor importante en la colaboración, tanto alentadora como desalentadora [7]

El planteamiento para el desarrollo de los proyectos 3D no difiere del anteriormente indicado para la metodología 2D, pero sí se alteran algunas responsabilidades. Dentro del entorno BIM es ahora el equipo de captación el que desarrolla el estado actual. A partir de la 
medición toma de datos y las anotaciones realizadas se entiende que es dicho equipo el que podrá desarrollar el modelo de manera objetiva sin lugar a que terceras personas pudieran hacer una interpretación errónea de los datos disponibles

Recibido el modelo 3D del estado actual con la información acorde a la directrices establecidas es el turno del equipo de proyectos, el cual desarrolla las mismas tareas que las encomendadas anteriormente hasta la firma del contrato, pero dentro de un entorno BIM

Tanto el equipo de obra, como el equipo de post-venta para este estudio mantienen las atribuciones contempladas en la metodología 2D, si bien será necesario desarrollar nuevas competencias para adaptarse a la nueva metodología de trabajo

\section{PUESTA EN MARCHA DEL PROCESO BIM}

\subsection{BIM Manual}

Antes de desarrollar el modelo con la herramienta elegida; se deben dar las pautas necesarias de para que se quiere el modelo, y como se debe gestionar. Esto deberá realizarse a través de un BIM Manual [8] creado por la empresa que de indicaciones concretas del objeto y alcance de la metodología. No se pretende la modificación de los equipos de trabajo sino su adaptación a la metodología planteada.

Como objetivo de la comunicación se persigue que el modelo obtenido de la aplicación del BIM Manual corresponda con la necesidad de no ser complejo ni excesivo en la información que se trabaje en el mismo. Después de la observación del proceso de gestión de proyectos actual se decide una primera implementación basada en Revit-arquitectura, sin que se entienda necesaria la intervención de otras herramientas

Dentro del BIM Manual quedan recogidos fundamentalmente los siguientes condicionantes.

- LOD de Trabajo. Se persigue un modelo dirigido más a la gestión del proceso global que a la representación gráfica, pero que permita una correcta gestión de la información para su puesta en obra y mantenimiento posterior, por lo que es necesario el modelado en términos generales a un nivel 300-400 [9] según las especificaciones de AIA ( The American Institute of Architecture )

- Nota clave. Todas las familias generadas por parte de la empresa deberán quedar codificadas de acuerdo a las categorías acordadas. Esta nota clave será importante de cara a la gestión de las tablas informativas.

- Creación de familias. Todas las familias vendrán denominadas de manera clara anteponiendo siempre el código xxx

- Parámetros de trabajo. De cara a la gestión de la información obtenida del modelo pero con la premisa de no sobrecargar el mismo se consideran como imprescindibles los parámetros de Familia, Tipo y nota clave, la descripción, los materiales, la unidad de medida para coste, tiempo, superficies, etc...y la URL que nos redirija a la ficha técnica correspondiente. 


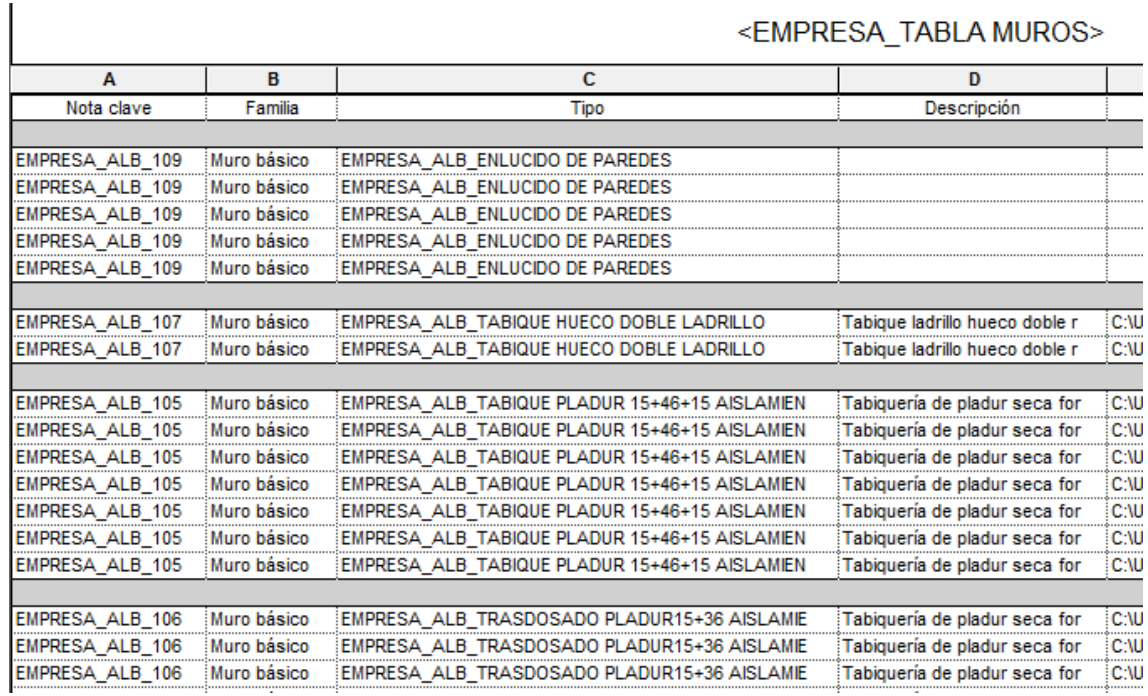

Fig 1. Tabla de Muros y Parámetros de Proyecto. 2016. Fuente propia

- Organización del navegador. En este punto se deberá definir las vistas necesarias para cada proyecto, siendo por lo general una vista del estado actual, una vista del estado reformado y vistas para las diferentes instalaciones. Igualmente se platean vistas en 3D para cada una de las anteriores.

- Criterios de modelado Quedan marcados dentro del BIM Manual cuáles serán los criterios de modelado. En este aspecto se realiza un estudio de los presupuestos realizados por la empresa para determinar el tipo de unidades con las que se trabaja con el fin de adaptar la metodología BIM a las directrices de los presupuestos, o bien estudiar el adaptar los presupuestos a las posibilidades de la herramienta de modelado. En esta primera fase de implementación se atiende a la primera opción al observar que las unidades de trabajo no suponen especial complicación para su desarrollo con Revit 2015 [10]

\subsection{Catálogo de familias}

En el trabajo con el software de modelado trabajaremos con familias, que quedan definidas como todos aquellos objetos que encontraremos en el modelo y que comparten una serie de propiedades, comparten representación gráfica y el mismo uso dentro del modelo. [11].

Como ejemplo, una puerta, un muro o un aparato sanitario constituyen familias diferentes. Dentro de cada uno de ellas podremos definir subgrupos o categorías atendiendo a propiedades diferentes. En el caso de las puertas podemos generar puerta de una hoja, de dos hojas, acristaladas, etc. Dentro de una propiedad común como puede ser puerta de una hoja podemos distinguir puertas de 62,5 cts. de hoja, 72,5 cts. de hoja, creando dentro de una misma familia diferentes tipos. Cada objeto del modelo 3D posee propiedades que comparte con otros objetos que le hacen formar parte de un tipo y en un rango superior de una familia, como los citados anteriormente, pero también posee datos que le hacen único, como por ejemplo su ubicación. 
La eficacia de la metodología, que permita una mayor agilidad en el proceso creativo y de gestión, debe venir precedida de un trabajo previo de creación de familias de todo tipo en las cuales queden recogidos todos los parámetros de acuerdo a lo que marca el BIM Manual desarrollado

\section{$7 \quad$ MODELO DE PROYECTO}

Contando hasta este punto con las bases para la creación del modelo de trabajo se inicia el proceso con la confección del proyecto [12] del estado actual, incluyendo la información obtenida en la toma de datos. Tipología de tabiquería, localización del saneamiento, salidas de humos, shunts de ventilación, posición de máquinas de Aire Acondicionado, localización de huecos de fachada y tipología de forjados, son según las observaciones realizadas en el proceso los puntos singulares para la toma de decisiones.

A partir del modelo actual se genera la vista de demoliciones empleando un parámetro concreto denominado "demoliciones" de tipo si/no de manera que mediante el empleo de filtros de vista se realiza la selección de los elementos que quedan definidos en la vista creada para este fin, tal y como muestra la imagen se ve la tabla con las mediciones correspondientes a los muros demolidos y su posición en el plano. Igualmente se puede realizar anotaciones indicativas para mejor comprensión

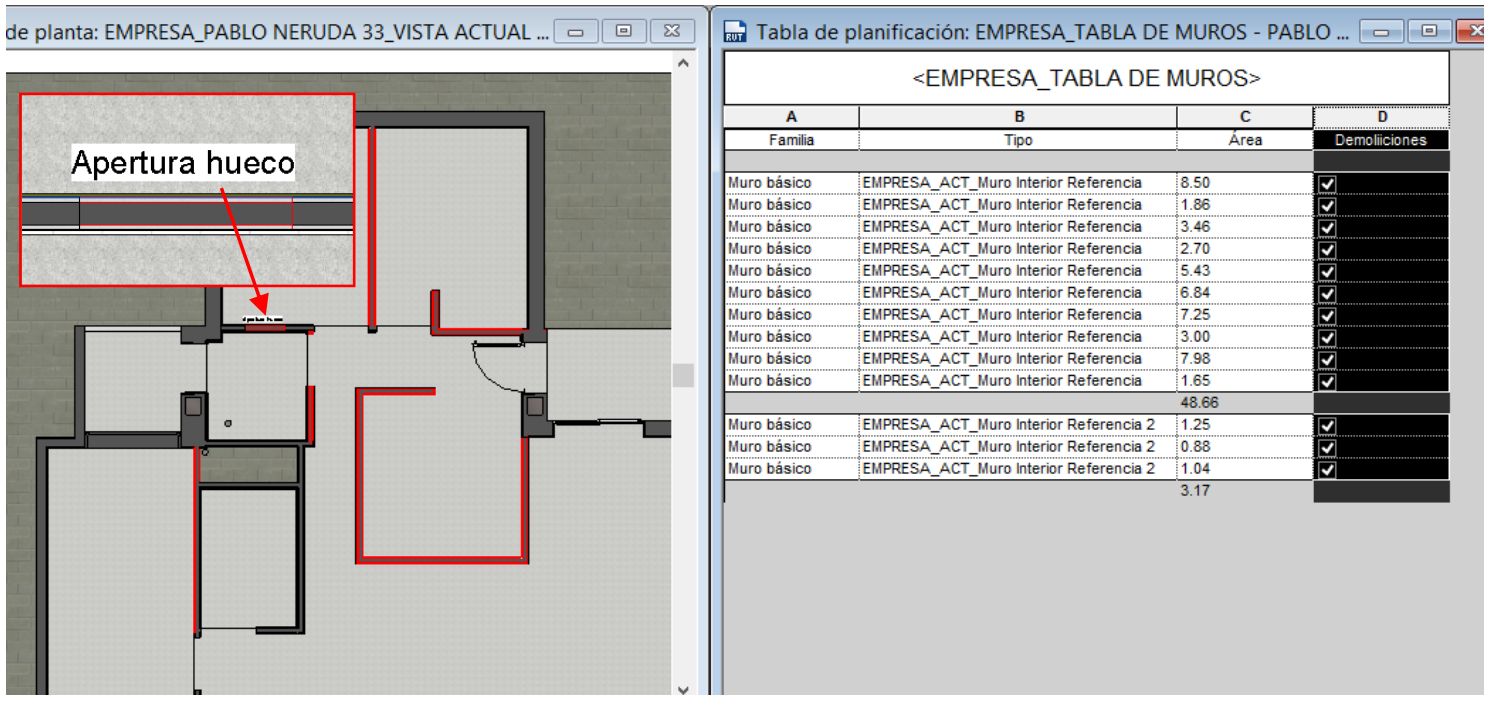

Fig 2. Vista de Demoliciones. 2016. Fuente propia

Finalmente se entra en el diseño de la distribución que se le presentará al cliente para su aprobación y posterior puesta en marcha, fase en la que deberán quedar definidos los elementos que comunmente provocan las incidencias posteriores.

Para esta fase se han empleado las familias tipo que previamente se han desarrollado en la fase de implementación debiendo generar aquellos elementos singulares que pueda necesitar el propio proyecto. 
El desarrollo del proyecto del estado reformado se hacer a partir de la vista del estado actual y demoliciones mediante el control de filtros creados anteriormente. Si en la fase anterior se perseguía poder ver con claridad los elementos demolidos en esta fase, mediante la anulación del mismo se puede ver el estado de la obra una vez realizadas las demoliciones.

La fase correspondiente a la creación del proyecto es una fase donde se debe aunar el proceso de venta con el posterior proceso de gestión de la obra. Esto obliga dentro del compromiso de la implementación generar modelos que satisfaga a unos como a otros. Que sea lo suficientemente claro para que un cliente entienda y vea las posibilidades de las obras de reforma o acondicionamiento a realizar en su local o vivienda, pero que sea igualmente claro y con la información rigurosa y ordenada para la correcta gestión de la obra.
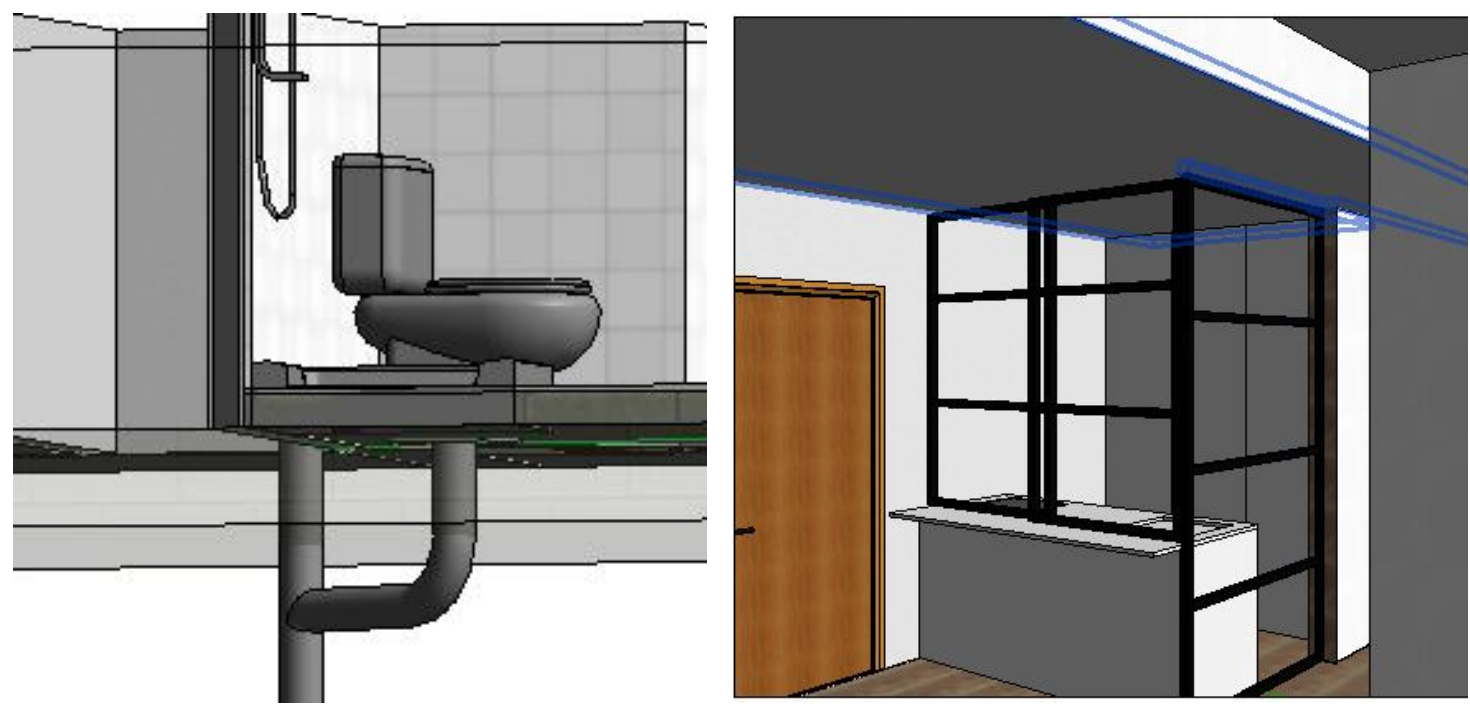

Fig 3. Detalles Modelo 3D. 2016. Fuente propia

Realizado el modelo la extracción de las mediciones se hace a paritr de las tablas de planificación. El modelo de implantación requiere un sistema sencillo por lo que el número de tablas no debe ser excesivo para una gestión de las mismas de manera agil. Se busca una sintonía entre las necesidades de la estructura de la empresa atendiiendo al volumen de cada uno de los proyectos y las virtudes y limitaciones de la herramienta seleccionada. La categorización de las famlilas empleadas por Revit 2015 y cierta dificultad en la obtención completa de la información debe gestionarse para que se realice de manera sencilla.

Es una pretensión de la implementación que quedará recogida en el BIM Manual la necesidad de reducir el número de tablas de planificación para una gestión más eficiente. Actualmente el paso de las mediciones al presupuesto de Presto, como herramienta de generación de presupuestos y mediciones, se realiza de manera manual, es decir; si el suso de ningún software de conexión entre Autocad y Presto. Una vez implantada la fase de diseño se podrá pasar a la fase de gestión integral a partir de herramientas como Cost-it de Presto, si bién se esta trabajando en el uso de herramientas como Bim-One o Dynamo para 
exportar/importar la información a través de Excel lo que permitiría poder emplear dicha información en otros cometidos.

Finalmente el proyecto permitirá la posterior gestión de la post-venta y entrega de documentación al cliente habiendo realizado las modificaciones que por cualquier motivo se hayan originado en el proyecto inicial. Es intersante acompañar el modelo con imágenes obtenidas durante la obra para conocer la realidad de las instalaciones.

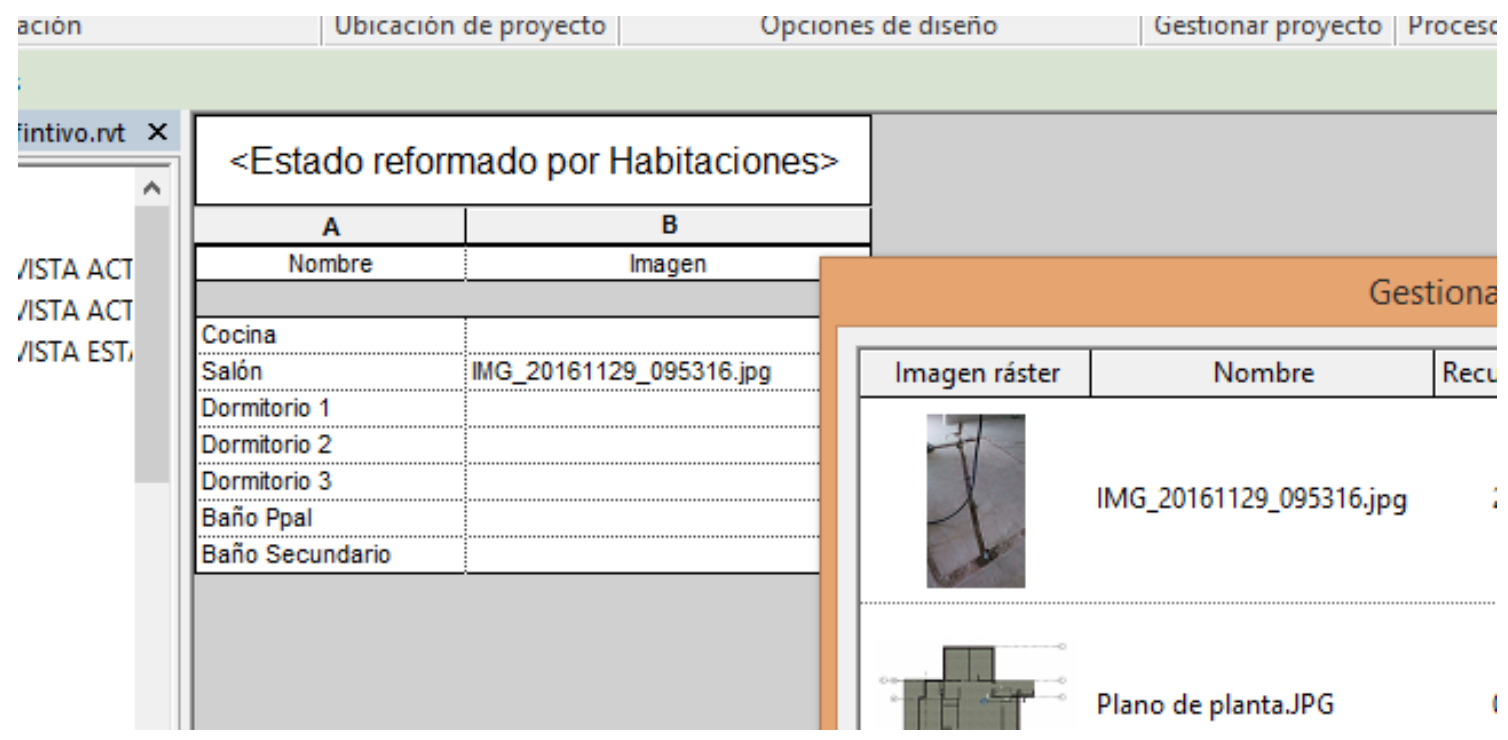

Fig 4. Imagen de Rozas de Instalaciones. 2016. Fuente Propia

\section{COMPARATIVA 2D Y BIM}

La comparativa entre el método trabajo 2D y la metodología BIM que se pretende implementar se basa en las opiniones reflejadas por el equipo de captación y el equipo de proyecto a falta de la resolución en la gestión de las obras. Se establece un tiempo de familiarización con la herramienta que supone un incremento de los tiempos frente al uso de la metodología 2D empleada hasta el momento. Siendo así se determina tras la observación realizada.

El tiempo dedicado al desarrollo del estado actual en cada uno de los proyectos no se reduce considerablemente debido a la necesidad de mayor definición y a la necesidad de crear un buen número de familias diferentes atendiendo a la gran variedad de elementos que se pueden encontrar en las viviendas y que no coinciden con las familias del catálogo. Se deberá generar un catálogo de familias estándar que agilice este proceso

El tiempo de desarrollo de los bocetos para presentación a los clientes se ha reducido dada la agilidad y facilidad en el proceso creativo a partir del modelo del estado actual. Se trabaja con filtros que permiten identificar de manera sencilla las diferentes fases y se obtiene las mediciones de manera automática. Esto provoca un tiempo menor en la generación de los presupuestos, aunque todavía se realizan de manera ajena a la herramienta de modelado debiendo incluir manualmente las mediciones. 
El desarrollo de familias nuevas no catalogadas lleva mayor tiempo con la metodología a implementar que con la metodología 2D. Esto supone un elemento discordante respecto al resto del proceso valorado positivamente por los equipos

El proceso de desarrollo del modelo valido para construcción y aprobado por el cliente se resuelve de manera rápida a partir de los modelos presentados. Los planos de instalaciones son los que ocupan mayor tiempo al tener que considerar elementos que anteriormente no se reflejaban en la documentación 2D.

La percepción del equipo de obra respecto a la metodología es positiva atendiendo a una mayor claridad de los trabajos habiendo participado previamente en su desarrollo, debido al condicionante de coordinación exigido en todo el proceso, una información más clara y ordenada y una mejor propuesta para resolución de dudas en la puesta en obra al disponer de secciones e imágenes 3D gráficamente más intuitivas.

\section{CONCLUSIONES}

El proyecto generado mediante la metodología BIM es una muestra de la realidad constructiva posterior que permite subsanar incidencias comunes en el proceso con herramientas 2D, ofreciendo una representación gráfica válida para todos los intervinientes que formas parte de la empresa y que aporta una información sencilla y fácilmente consultable y manejable para su gestión

La metodología BIM se enmarca dentro de los procesos de calidad y mejora continua de la organización donde se pretende implementar en busca de la excelencia en los procesos, considerándose por tanto como una apuesta para adoptar herramientas más actuales en línea con las demandas del sector que favorecen el desempeño de los intervinientes y que tiene el propósito de los procesos actuales convirtiéndolos en más cooperativos desde el primer instante.

La implementación se está llevando a cabo desde el punto de partida de no alterar la configuración de equipos, ni modificar las atribuciones en gran medida, manteniendo los roles y perfiles actuales, que bajo la dirección de un BIM Manager sean capaces de adoptar las nuevas competencias que la metodología exige. Esto está permitiendo que el proceso se realice como una adaptación y no como un cambio, lo que lo hace más natural y sencillo.

El empleo de la metodología, será beneficiosa para los procesos internos si con ello se obtiene como así parece una mayor satisfacción del cliente, que ve una apuesta por la modernización del sector y principalmente porque se elimina la inquietud por el resultado final al reducir los riesgos de error

Con el uso de la metodología permitirá un mayor control de la obra y una mejor coordinación con las empresas que ejecutarán los trabajos al disponer de la información de manera más ágil reduciendo el tiempo de visitas y desplazamientos, lo que permitirá una mayor producción. 
[1] Hardin Brad, McCool Dave, (2015), BIM and Construction Management Proven Tools, Methods, and Workflows, John Wiley \& Sons, Inc., Hoboken, New Jersey.

[2] AENOR (2008) Certificación de sistemas de gestión de la calidad UNE-EN-ISO 90012008

[3] Loyola, M. (2016) Encuesta Nacional BIM 2016: Informe de Resultados, Departamento de Arquitectura. Universidad de Chile.

[4] Del Solar; Patricia; Andrés, Silvia; De la Peña Aranzazu (2016) Estudio del estado actual del conocimiento y uso de las herramientas BIM en España

[5] RIBA Enterprise Ltd. ( 2016 ) NBS National BIM Report visto el 10 de febrero de 2017 en https://www.thenbs.com/knowledge/national-bim-report-2016

[6] Gideon Fink Saphiro (2014) Setting a Standard in Building Information Modeling visto el 10 de enero de 2017 en http://www.architectmagazine.com/technology/setting-astandard-in-building-information-modeling_o

[7] Deutsch Randy, (2011) BIM and Integrated Design, Strategies for Architectural Practice, John Wiley \& Sons, Inc., Hoboken, New Jersey

[8] AEC (UK) (2012) BIM Protocol. Implementing UK BIM Standards for the Architectural, Engineering and Construction Industry visto en 2016 en https://aecuk.files.wordpress.com/2012/09/aecukbimprotocol-v2-0.pdf

[9] BimForum (2016) Level Of Development Specification visto el 10 de diciembre de 2016 en http://bimforum.org/lod/

[10] Revit (ver2015) (Software) 2014 Autodesk, Inc

[11] Autodesk Revit Help (2016) Understanding Revit Terms visto el 12 de febrero de 2017 en http://help.autodesk.com/view/RVT/2016

[12] Arrieta, Emilio (2016) Manual Avanzado Autodesk Revit $®$ Arquitecture. Visto el 15 de enero de 2017 en www.espaciobim.com/recursos 


\section{CÓMO ESTABLECER UNA ESTRATEGIA VENCEDORA EN UN PROCESO BIM}

\section{Reina Rojas, Andrea (1), Sarrocco, Matteo (2)}

(1) Parallel Digital, andrea.reinarojas@parallel.digital

(2) Parallel Digital, matteo.sarrocco@parallel.digital

\section{RESUMEN}

Coordinación BIM de Doha Major Stations a cargo de One Works (Milán, Doha) como proyectista. Empresas que participan en el proceso son Parallel Digital (Roma) para gestión BIM, HSS (Chennai) como modelador, Inhabit Group (Hong Kong) como estudio luminotécnico.

Apoyándose en experiencias anteriores Parallel Digital realiza una estrategia, un BIM Implementation Plan. Objetivo, establecer la estrategia BIM, auditar el trabajo y procedimientos del equipo modelador y garantizar el workflow entre Chennai, Hong Kong, Doha, Milán y Roma.

Una primera fase consiste en convertir el material de la empresa anterior al formato RVT en un plazo de 2 meses, estableciéndose una estrategia de modelado básica basándose en nuestros modelos de otras estaciones de metro, siguiendo un avanzado sistema de auditoría para proporcionar al cliente la calidad exigida.

La segunda fase conste en la extracción de información de los modelos, así como la interoperabilidad entre las diferentes disciplinas en un plazo de 3 meses, con lo cual se tiene que reestructurar la estrategia de manera que el equipo receptor de la información pueda proporcionar en dicho tiempo el material necesario para la ejecución del proyecto.

Resultado obtenido en 5 meses, obtención de BoQs, Clash detection y planimetría con LOD 300.

Palabras clave: Auditoría, Dynamo, Interoperabilidad, Revit, Workflow

\section{ABSTRACT}

BIM coordination of Doha Major Stations in charge of One Works (Milan, Doha) as project leader. The companies inside of the process are Parallel Digital (Roma) for BIM management, HSS (Chennai) as modeller, Inhabit Group (Hong Kong) as lighting design.

With the support of previous experiences Parallel Digital designs a strategy, a BIM Implementation Plan. The objective, to develop a BIM strategy, audit the procedures of the modeller team and ensure the workflow between Chennai, Hong Kong, Doha, Milan and Rome.

The first phase was represent the work of the previous company in RVT format in 2 months. It was established a basic model strategy based on our models about metro stations, following an advanced model checker system to provide the client the requested quality. 
The second phase was the data extraction of the models, and also the interoperability between the different disciplines in 3 months, in order to obtain from the different teams the necessary material to execute the project it was necessary to upgrade the strategy.

The result was to obtain in 5 months the BOQs, Clash detection and drawing productions in a LOD 300.

Keywords: Model checking, Dynamo, Interoperability, Revit, Workflow

\section{INTRODUCCIÓN}

El Metro de Doha es uno de los proyectos más importantes de Oriente Medio en los últimos años, atrayendo a la mayor parte de las constructoras y estudios de arquitectura e ingeniería de todo el mundo [1]. El proyecto consiste en la construcción de tres líneas de metro (roja, verde y oro) con un total de 37 estaciones abarcando hasta $37 \mathrm{~km}$ de longitud.

En la primera fase de desarrollo, el proyecto fue asignado a UNStudio quien redacta un "Architectural branding manual" consistente en un documento con una serie de reglas tipológicas del diseño, y la elección de los materiales para asegurar la calidad del proyecto.

El proyecto ejecutivo se concede a diferentes UTEs (Unión Temporal de Empresas) para cada línea de metro, las cuales se ocupan de los detalles, la coordinación de los proyectos y de la ejecución de las obras. [2]

En este caso se analizan las dos estaciones más importantes de toda la red de metro, las Major Station, Musheireb (Red, Gold y Green Line) y Educational City (Green Line). Nuestro trabajo se trata de la coordinación BIM en la fase M3 (Milestone M3, es una fase que presta especial atención al proyecto de interiores y de rivestimientos) de la disciplina arquitectónica, de un complejo equipo de trabajo localizado en diferentes ciudades del mundo.

Los objetivos impuestos son facilitar la gestión del flujo de trabajo, la producción de los modelos con LOD 300, la planimetría y las mediciones extraídas directamente de los modelos.

Además de seguir el ya citado Architectural Branding Manual se tienen que seguir las Qatar Rail Bim Guidelines (QRBG).

Las QRBG son las especificaciones técnicas del proceso BIM que aseguran la calidad de las entregas y del proyecto. Dentro de las QRBG se incluyen las directivas sobre el Clash Detection, LOD de referencia, Quality check y secuencia 4D.

Como en todos los procesos BIM, inicialmente se definen los objetivos y plazos que se deben respetar, y como consecuencia se crean los equipos de trabajo.

La actividad se divide en dos fases principales:

\section{Fase 1 (dos meses):}

- Modelo de Revit del proyecto definitivo (Front of House, Shelters, Landscape)

- BoQs (Mediciones)

- Realización de documentos gráficos

- Modelado de geometrías complejas realizadas con Dynamo 
- Auditoría de los modelos

\section{Fase 2 (3 meses):}

- Modelo Revit del proyecto ejecutivo (Front of House, Shelters, Landscape)

- BoQs

- Interoperabilidad entre las diferentes disciplinas (IFC str-mep / lighting designer)

- Ralización de documentos gráficos

- Auditoría de los modelos

Equipo de trabajo:

1 Bim Manager, 1 Bim Coordinator, 1 Project Manager, 25 modeladores Bim, 3 computational designers, 5 proyectistas.

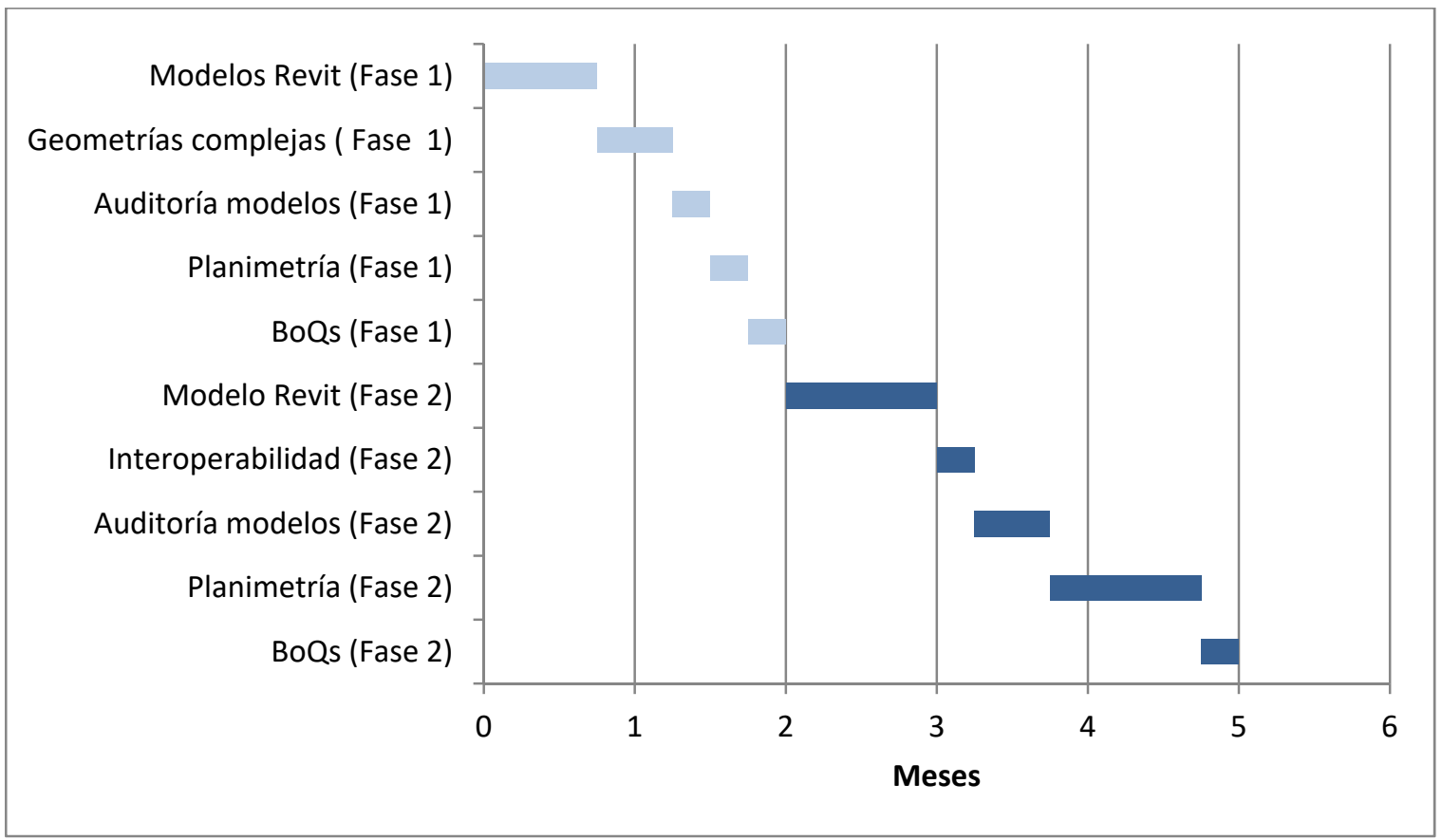

Fig 1. Diagrama de planificación. 2016. Parallel Digital

\section{CONTENIDO}

Se realiza un Bim Implementation Plan (actualizado durante todo el proceso) que ayude a los agentes intervinientes en el proceso a comprender mejor cuales son los Usos Bim, y principalmente, el procedimiento y los instrumentos a utilizar para alcanzar los mencionados Usos Bim.

El ya nombrado BIM Implementation Plan está compuesto por dos documentos, el Model development ad BoQs procedure y una Checklist:

- Model development ad BoQs procedure: Es un documento de Google (Google Doc), en el cual se encuentran enumerados los grupos de elementos que se tienen que introducir en el modelo, divididos por los capítulos de las mediciones, los parámetros que se debían usar y como compilarlos. Este documento establece a qué nivel de 
detalle se tiene que llegar, pero sobre todo muestra cuál es la manera de extraer cantidades para las mediciones de los elementos que han sido modelados.

Este documento se redacta como complemento al BEP, Bim Execution Plan, documento que contiene las instrucciones para la ejecución BIM y se basa en los requisitos del cliente. Define la comunición entre programas y equipo, cuales son los objetivos del mismo y cómo se organiza la información. [3]

\section{USOS BIM}

\begin{tabular}{|c|c|}
\hline DATOS & $\begin{array}{c}\text { Input } \\
\text { Output }\end{array}$ \\
\hline PROCESOS & Flujo de trabajo \\
\hline SISTEMAS & \\
\hline TECNOLOGICOS & Programas \\
\hline
\end{tabular}

Fig 2. Usos BIM. 2016. Parallel Digital

\begin{tabular}{|l|c|c|c|}
\hline \multicolumn{1}{|c|}{ CHAPTER } & REV. N & REVISION DATE & LAST MODIFICATIONS \\
\hline FLOOR & 5 & $03 / 10 / 2016$ & Main floor \\
\hline FLOOR STRIPS & 2 & $06 / 10 / 2016$ & \begin{tabular}{c} 
Postion- \\
\hline SPECIAL EQUIPMENT
\end{tabular} \\
\hline CEILINGS & 4 & $25 / 09 / 2016$ & $\begin{array}{c}\text { Escalators bogs } \\
\text { parameters and poles }\end{array}$ \\
\hline COMPLEXGEOMETRIES & 3 & $25 / 09 / 2016$ & $\begin{array}{c}\text { Reference DWG. } \\
\text { names. }\end{array}$ \\
\hline CEILINGS & 1 & $21 / 09 / 2016$ & - \\
\hline STAIRS & 1 & $21 / 09 / 2016$ & - \\
\hline AIR SYSTEM & 1 & $25 / 09 / 2016$ & - \\
\hline WALLS & 1 & $29 / 09 / 2016$ & - \\
\hline PLATFORM END WALL & 1 & $29 / 09 / 2016$ & - \\
\hline PSD DOORS & 1 & $29 / 09 / 2016$ & - \\
\hline DOORS & 1 & $06 / 10 / 2016$ & - \\
\hline STRUCTURALFRAMING & 1 & $04 / 10 / 2016$ & \\
\hline SKIRTING & 1 & $06 / 10 / 2016$ & \\
\hline
\end{tabular}

Fig 3. BIM Implementation Plan. 2016. Parallel Digital 


\section{NAME OF THE FAMILIES}

\begin{tabular}{|l|l|}
\hline DWG Layer & RVT FLOOR family type \\
\hline A_S07 Dark & G331-Floorint-20-Terrazzo, dark colour \#3-S07 \\
\hline A_S06 Medium & G331-Floorint-20-Terrazzo, medium colour \#2-S06 \\
\hline A S05 Light & G331-Floorint-20-Terrazzo, light colour \#1-S05 \\
\hline Follow the external boundary of dwg & G331-Floorint-130-Screed-S23 \\
\hline
\end{tabular}

FAMILY MATERIALS

\begin{tabular}{|l|l|l|l|l|}
\hline FLOOR types & Material & RGB EDU & RGB MUS & Keynote \\
\hline $\begin{array}{l}\text { G331-Floorint-20-Te } \\
\text { rrazzo, dark colour } \\
\# 3 \text {-S07 }\end{array}$ & $\begin{array}{l}\text { ONW-Terrazzo Floor, cement } \\
\text { based Tiles Dark Colour \#3 }\end{array}$ & 197.203 .200 & 202.200 .167 & S07 \\
\hline $\begin{array}{l}\text { G331-Floorint-20-Te } \\
\text { rrazzo, medium } \\
\text { colour } \# 2 \text {-S06 }\end{array}$ & $\begin{array}{l}\text { ONW-Terrazzo Floor, cement } \\
\text { based Tles Medium Colour } \# 2\end{array}$ & 212.215 .212 & 217.214 .195 & S06 \\
\hline
\end{tabular}

Fig 4. BIM Implementation Plan. 2016. Parallel Digital

- Checklist: es una tabla excel de Google (Google Sheet), en el cual se monitoriza a tiempo real y accesible desde cualquier aparato informático el estado del modelo. Este documento de excel se complementa con un modelo "work-in-progress" usado con el único objetivo de corrección y coordinación siguiendo los criterios del Architectural Branding Manual, las QRBG y los estándares internacionales tipo BS11925 respecto a los nombres de los archivos, sus versiones y ubicación en carpetas de trabajo. [4]

\subsection{Planificación del trabajo}

Se establece la estructura del trabajo en una modalidad de multi-modelo, conforme a los estándares internacionales, prestando especial atención en no sobrepasar el tamaño máximo de los modelos y estructurando una jerarquia de la información con el fin de garantizar en cada fase de trabajo rapidez y eficacia. La producción de la planimetría y documentos gráficos se ha establecido en modelos externos, en los cuales se han enlazado todos los modelos 3D, de esta manera se permite realizar contemporaneamente la actividad de modelado $3 \mathrm{D}$ y el trabajo gráfico $2 \mathrm{D}$.

La complejidad del trabajo debido a los plazos tan ajustados, a la cantidad de modelos y documentos gráficos y a las grandes diferencias geográficas de todos los agentes intervinientes en el proceso, llevan a la necesidad de utilizar un método que permita optimizar los trabajos reduciendo los tiempos de gestión. El método elegido es el "Kanban". Teniendo la necesidad de trabajar en la nube, se decide usar la aplicación online Kanbanchi, donde se convierten las actividades de trabajo en "cards" asignadas a los profesionales responsables. Este método permite tener simultaneamente bajo control las exigencias del cliente, de los proyectistas y el estado de los trabajos respetando los plazos de entrega establecidos.

El espacio de trabajo de Kabanchi se divide en tres columnas principales: To Do (Actividad por realizar), Doing (Actividad iniciada), Done (Actividad finalizada). Cada vez que se finaliza una actividad, se tiene que actualizar la correspondiente card y actualizarla con respecto al 
calendario, de esta manera se tienen controlados a tiempo real la situación del trabajo, los recursos humanos activos y las actividades prioritarias.

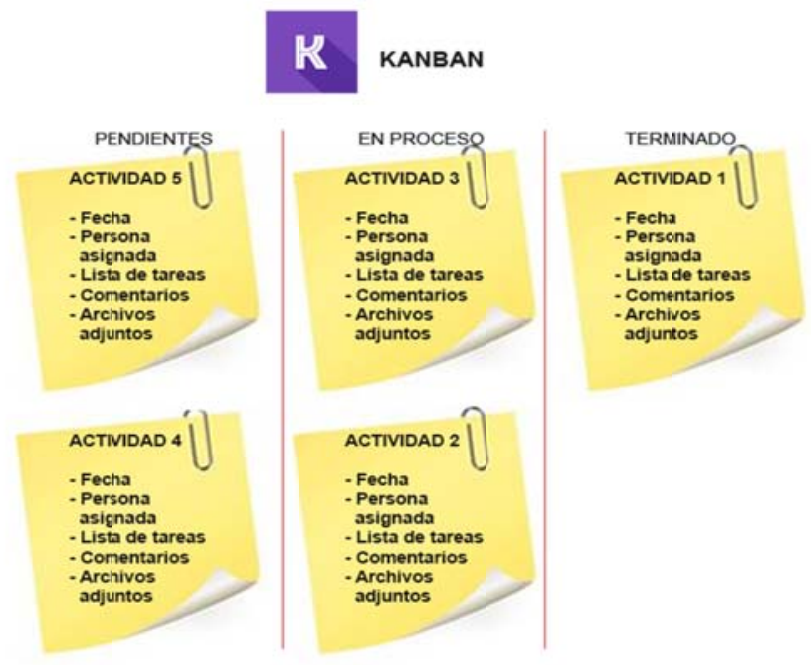

Fig 5. Dashboard Kanbanchi para la coordinación de equipos. 2016. Parallel Digital

Los programas utilizados en el proceso son:

- Autodesk Revit: modelado de las estaciones, empaginado e impresión

- Autodesk Dynamo: Addin de Revit que se utiliza para la construcición de geometrías complejas de las estaciones y para automatizar algunos procesos de las mediciones, control del modelo y optimización y purgado de los modelos.

- Autodesk model review: Addin de Revit, programado especificamente para el control automático de los modelos y de la información contenida.

- Autodesk Autocad: Proyectación de los detalles y estudio del diseño básico.

- Navisworks manage: Clash detection, "clash" es el nombre que Navisworks usa para identificar una interferencia física en el modelo (cuando dos objetos ocupan la misma posición). [5]

- Dialux: Analisis luminotécnico

- 3D Studio Max: exportación de 3Ds para la interoperabilidad con Dialux

- Tekla Bimsight: Visualizador de IFC

\subsection{Flujo de trabajo del modelado}

El modelado empieza con la base de un modelo llamado URS (Unique Reference System), se trata de un modelo perfectamente georreferenciado que contiene los ejes estructurales partiendo de la base de un archivo CAD aportado por Qatar Rail. El modelado de la parte arquitectónica se ha desarrollado a partir de un modelo en formato IFC creado por la sociedad proyectista anterior.

Con el objetivo de garantizar la coordinación entre los modelos de las diferentes disciplinas (instalaciones y estructurales) ejecutadas por otras sociedades y softwares diferentes, se decide utilizar el formato IFC para la interoperabilidad e intercambio entre los agentes. 
El formato IFC es considerado el formato internacional de intercambio e interoperabilidad en entre los considerados software BIM, pero aún hoy en día existe una gran dificultad para conseguir un buen funcionamento, principalmente entre modelos provenientes de diferentes casas comerciales; esto se debe en parte a que la gestión de los puntos de referencia inicial no se encuentran en sintonía entre los diferentes programas. En este caso hemos encontrado una serie de inconvenientes que hacen que se deba idear una estrategia de conversión de formatos para asegurar un buen funcionamiento de los modelos. El principal problema en cuestión es el de la incorrecta posición de los modelos IFC con respecto a las coordenadas acordadas con el cliente. No existiendo un punto de referencia entre el modelo arquitectónico y el IFC de otra disciplina resulta imposible posicionar correctamente los modelos y por lo tanto es imposible realizar un Clash Detection.

Esta nueva estrategia se basa en la creación de un modelo llamado Masterlink (Contenedor de varios modelos enlazados) para cada una de las disciplinas; el modelo Masterlink ha adquirido las coordenadas del modelo URS, por lo tanto es posible insertarlo en cualquier modelo de la disciplina arquitectónica con una referencia geográfica correcta.

A continuación se muestra el procedimiento utilizado en modo detallado:

1. Enlazar el modelo IFC en un proyecto nuevo de Revit; se crea automáticamente un modelo de Revit del modelo IFC enlazado.

2. Abrir el archivo RVT convertido

3. Insertar en el archivo RVT el modelo con los ejes estructurales coincidente con la posición de los modelos MEP y CIV; usando la posición Origin to Origin (este modelo lo aportan las sociedades que realizan los modelos MEP y CIV para aportar puntos de referencia en común entre las disciplinas)

4. Copy/Monitor de los ejes estructurales

5. Guardar y cerrar el modelo

6. Abrir el modelo Masterlink (modelo sin elementos modelados en su interior pero contenedor de todos los modelos de una disciplina) y enlazar el modelo proveniente del IFC, en este caso, cada uno aparece en distintas posiciones, se debe alinear al modelo Masterlink e ubicarlo en una posición correcta

7. Seleccionar el modelo enlazado y en sus propiedades en Shared Site, seleccionar "publish the current shared coordinates system to", de esta manera se guarda el modelo en esa posición. 


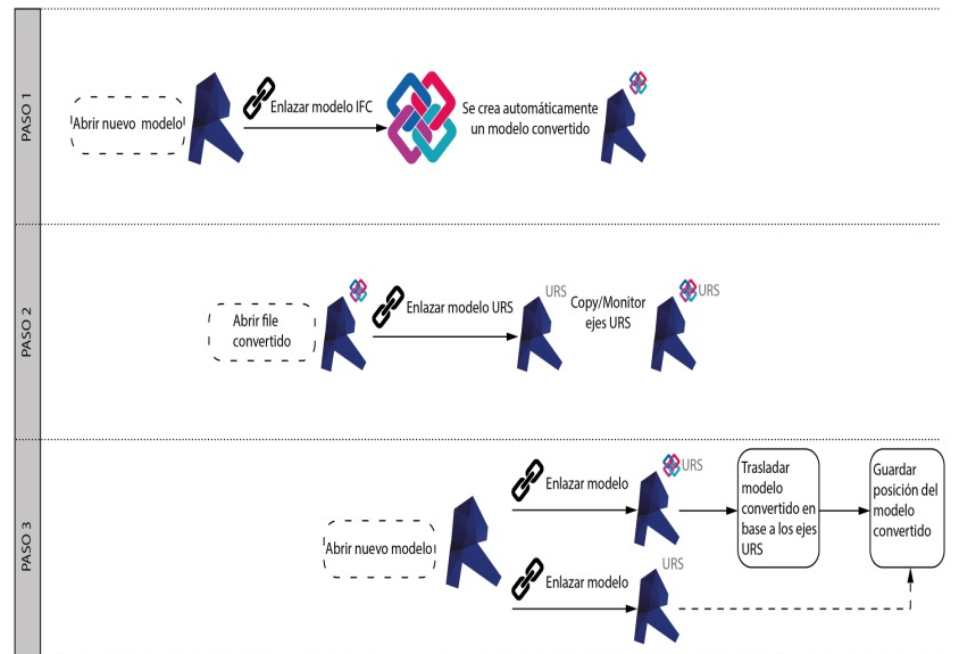

Fig 6. Proceso de creación de masterlink. 2016. Parallel Digital

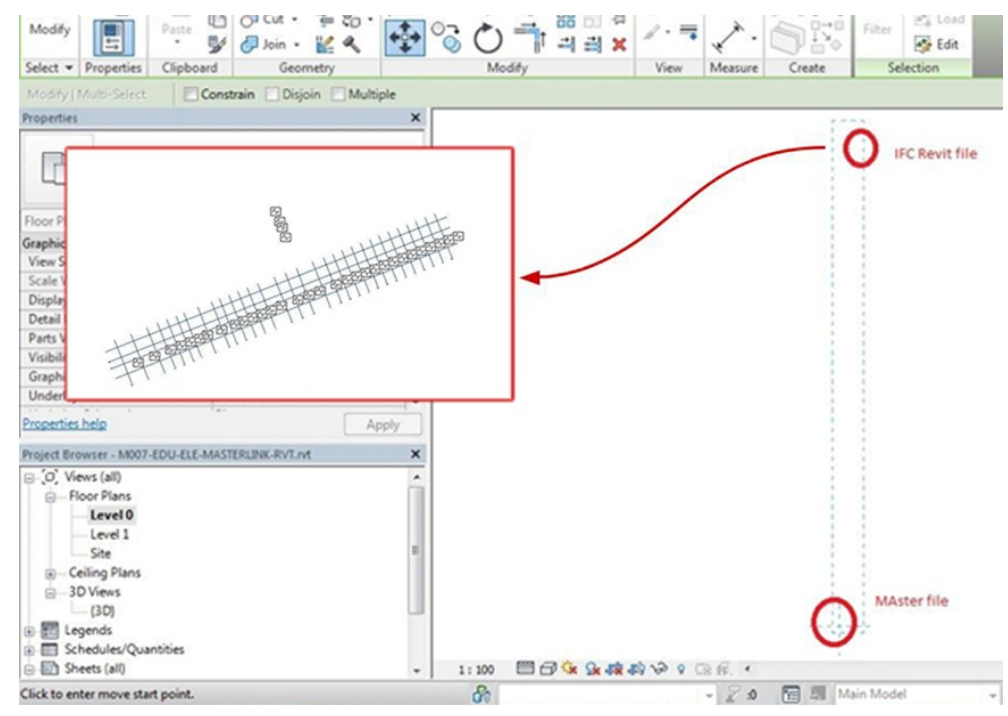

Fig 7. Proceso de creación de masterlink. 2016. Parallel Digital

Otro de los temas que se afrontan en el proyecto es el de la proyectación luminotécnica para la cual se necesita el uso del programa Dialux. Este programa se utiliza para analizar la iluminación artificial en espacios internos. En este caso el programa no es completamente compatible con Revit. El proyecto del metro se caracteriza por contener falsos techos abovedados y en algunos casos con doble curvatura. Revit no es capaz de exportar correctamente el modelo en formato STF, compatible con Dialux. EL metodo de exportación que permite mantener la volumetría correcta es el siguiente:

Revit $\rightarrow$ Export en formato Acis $\rightarrow$ Abrir en 3D Max $\rightarrow$ Exportar como 3ds 


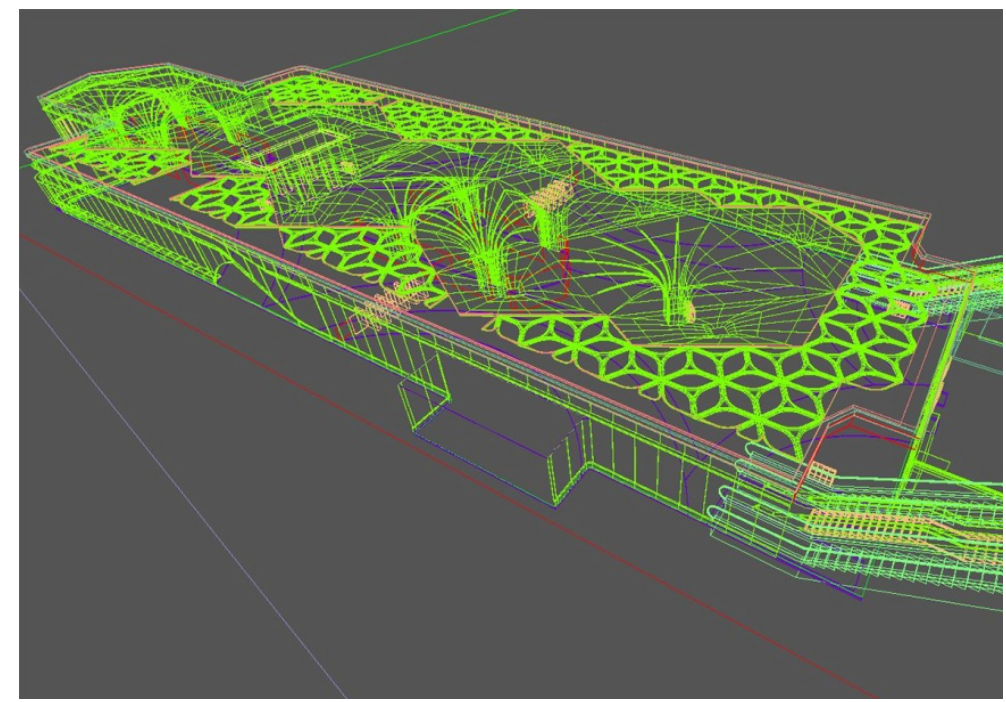

Fig 8. Exportación modelo 3ds. 2016. Parallel Digital

\section{CONCLUSIONES}

Después de analizar este proceso se llega a varias conclusiones y reflexiones:

1. Es absolutamente necesario iniciar cada proyecto con los objetivos bien claros y en base a ellos formular una estrategia, en el caso contrario se puede perder tiempo y dinero tanto por la parte de management como por la parte de modelado.

2. Al punto anterior le sigue la correcta implantación del trabajo desde un inicio. Es preferible tardar más tiempo desde un principio para organizar los equipos y recursos necesarios, digamos que forma parte de la filosofía BIM. En nuestro caso tuvimos que reformular varias veces las estrategias debido a que los objetivos iban cambiando y esto produjo ciertos retrasos en el envío de la información.

3. En esta experiencia hemos tenido la oportunidad de analizar con bastante detalle el funcionamiento de los modelos IFC. Nuestra percepción de este formato es que no funciona tan bien como en realidad debería. Al insertarlo o enlazarlo en Revit no funciona correctamente e incluso pierde la geometría del archivo de orígen. Consideramos que hasta que no mejore, desafortunadamente tendremos que trabajar con formatos completamente compatibles entre los softwares que usamos.

4. Otra de nuestras consideraciones es que todos los agentes intervinientes en el proceso BIM, incluidos los modeladores, tienen que contener una base de conocimientos BIM, de esta manera pueden comprender las exigencias y necesidades de todo el proceso y así obtener resultados de mayor calidad. 
5. Podemos decir que nuestra estrategia es vencedora porque gracias a un detallado BIM implementation plan y los documentos que lo acompañan hemos conseguido que cualquier tipo de sociedad de modelado BIM pueda llegar a realizar estas estaciones de metro en un tiempo limitado. Los documentos aportados han supuesto una gran cantidad de trabajo al equipo coordinador pero han permitido la fácil comprensión por parte de los receptores, simplificando de esta manera el workflow.

\section{REFERENCIAS}

[1] www.railway-technology.com/projects/doha-metro

[2] www.archidaily.com/549428/unstudio-appointed-to-create-identify-for-qatar-s-new-metronetwork

[3] Hardin Brad, Mccool Dave (2015). BIM and Construction Management

[4] David Shepered. BIM management handbook. no. 112-120

[5] Paul F.Aubin, Darryl McClelland (2015). BIM Collaboration with Autodesk Navisworks.no. 155 


\section{LA CODIFICACIÓN EN EL FLUJO DE TRABAJO: DE LA GESTIÓN AL PARÁMETRO EN LA ESTACIÓN FERROVIARIA DE TELDE}

\section{Céspedes Sánchez, Susana (1), Alonso Guinea, David (2), Santamarta Martínez, Jaime (3)}

(1) BIM Project Manager, Acciona Ingeniería, susana.cespedes.sanchez@acciona.com

(2) BIM Project Manager, Acciona Ingeniería, David.Alonso.Guinea@acciona.com

(3) Head of BIM, Acciona Ingeniería, jaime.santamarta.martinez@acciona.com

\section{RESUMEN}

Uno de los principales hitos del BIM en Acciona, es estandarizar homogéneamente la manera de trabajar en disciplinas tan distintas como edificación u obras lineales. Se ha buscado para ello generar recursos como el BEP, parámetros y estándares comunes.

En cada caso, se definen entre otros, los criterios de denominación de elementos y de parametrización, además de dónde y cómo se deberán aplicar cada uno de ellos.

Tomando como ejemplo el proyecto de la Estación Ferroviaria de Telde, seguir el flujo BIM ha supuesto un reto ya que los socios de la UTE no empleaban dicha metodología. Los objetivos se basaron en establecer criterios que relacionaran las diversas nomenclaturas de codificación buscando una trazabilidad entre elementos de una misma disciplina.

Se crearon dos clases de codificación, una primera de gestión (comunicaciones, CDE, archivos, organización de navegador o tablas de planificación) y una segunda de elementos del modelo (niveles, parámetros nuevos, familias y tipos, acabados).

Asimismo, las categorías de las tablas de planificación sirvieron para su uso en las tareas de organización, revisión y completado de la información. Además, agilizaron la realización de cambios de las nomenclaturas y códigos, lo que facilitó el control de calidad del proyecto.

Palabras clave: criterios, codificación, elementos, gestión, tablas

\section{ABSTRACT}

One of the key milestones of BIM in Acciona is to homogenously standardize the way projects must be developed, taking into account the big differences there are between disciplines as diverse as building and alignment projects. Therefore, resources such as BEP, parameters and common standards, have been generated.

In each case, the criteria of element naming and parameter assignment, as well as where and how each of them should be applied will be defined. 
Taking as an example Telde Railway Station project, it has been a challenge to follow BIM workflow, since the partners of the Joint Venture did not use this methodology. The goal was to establish criteria that related the various coding nomenclatures, so that traceability between elements of the same discipline could be achieved.

Two types of coding were created, one for management (communications, CDE, files, browser organization or planning schedules) and a second one for modelled elements (levels, new parameters, families and types, finishes).

In addition, categories of the content tables were used to organize, review and complete the information. They also made easier changes in the nomenclatures and codes, facilitating quality control of the project.

Keywords: criteria, coding, elements, management, schedules

\section{$1 \quad$ INTRODUCCIÓN}

La codificación es algo imprescindible en todas las fases y disciplinas pertenecientes al BIM, lo que implica que, para una eficaz organización del trabajo, todos los participantes del trabajo colaborativo la conozcan y apliquen. Desde las personas que gestionan y aparentemente están más alejadas del modelo, hasta los modeladores, cada uno en un rango de implicación, intentando que las codificaciones sigan criterios vinculados entre sí.

En este caso se trataba de un proyecto en UTE con otras dos empresas que no conocían la metodología BIM, por lo que se organizó el trabajo de acuerdo a esta premisa, lo que no implicó renunciar a la metodología BIM, se decidió planificar las tareas de acuerdo a las circunstancias y sacar el mayor partido posible. A pesar de ello, se obtuvieron ventajas y una experiencia que aportó conocimiento.

Los dos objetivos que se plantearon fueron:

- Primer objetivo, debían de cumplirlo todos los integrantes del equipo: la codificación, organización y gestión de toda la documentación, y lo mismo para las comunicaciones, es decir cumplir con los objetivos del CDE

- Segundo objetivo que sólo fue para Acciona Ingeniería: continuar codificando en el modelo, con criterios vinculados a la documentación, y llevar el BIM tan lejos como se pudiera, teniendo en cuenta que solo tenemos parte del proyecto asignado.

Dentro de las herramientas de modelado hay funcionalidades que son de gran ayuda para conseguir este segundo objetivo, por ejemplo las tablas de planificación.

Todo ello explicado y recogido en el BEP, del que hablaremos con respecto a estas cuestiones. 


\section{OBJETIVOS}

El proyecto tenía como características que se trataba de un intercambiador formado principalmente por una estación ferroviaria de tipología semienterrada, con andén enterrado y vestíbulo en superficie (fig. 1), de $180 \mathrm{~m}$ de longitud por $30 \mathrm{~m}$ de ancho libre y casi $9.000 \mathrm{~m}^{2}$ de superficie. Geométricamente había dos aspectos importantes: andenes inclinados y cubiertas a distinto nivel en cada una de sus 18 crujías, lo que hacía que modelar con Revit resultara algo imprescindible, ya que generar 18 secciones en cad y las posibles modificaciones posteriores, resultaban una inmensa pérdida de tiempo. Los beneficios del modelado se acentuaron al ser un proyecto de construcción de geometría complicada [1].

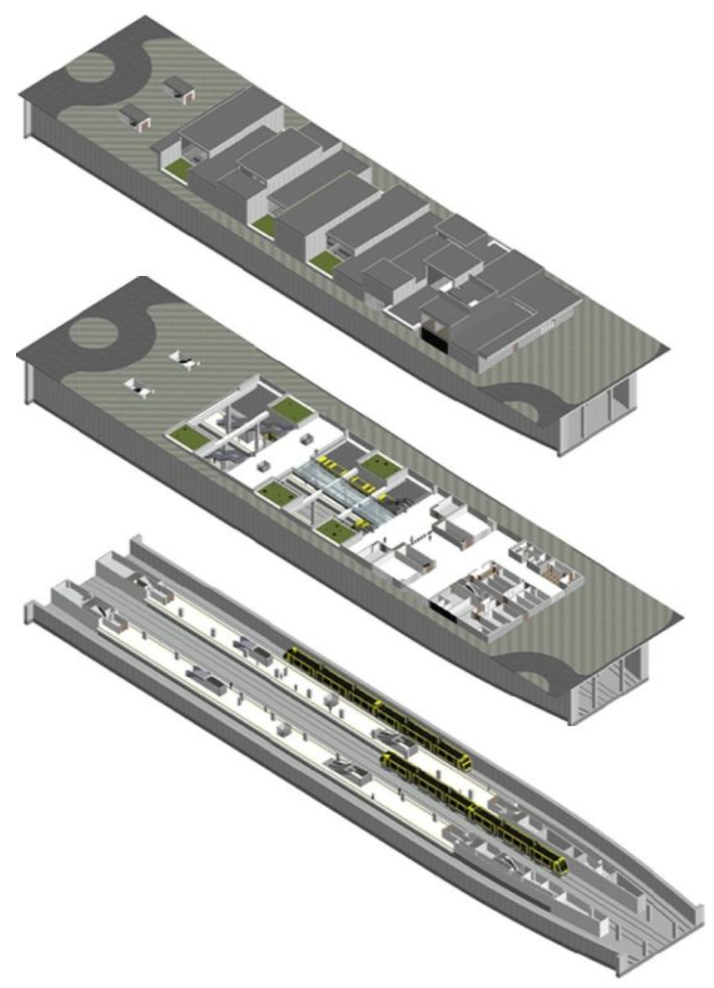

Fig 1. Tres plantas superpuestas de la Estación: andén, vestíbulo, cubierta. 2016. Acciona Ingeniería

Como punto de partida existían los retos de que el cliente no pedía BIM y que los socios no trabajaban según esta metodología, por lo que no estaba clara la relación con el resto de agentes. La primera labor fue concienciar de las cualidades y de los beneficios de la metodología BIM y ver donde se podía aplicar, de acuerdo al reparto de tareas.

El trabajo estaba dividido de la siguiente manera: Acciona se encargaba de la coordinación, la arquitectura, la geotecnia y la estructura. Las otras empresas de la UTE: tenían asignado el diseño inicial, las instalaciones, la urbanización y los viarios, medioambiente y coordinación del presupuesto. 
Como se ha comentado, el trabajo se planteó con dos objetivos, ambos para organizar y colaborar de manera eficiente: el primero para toda la UTE y el segundo sólo para Acciona Ingeniería. Por ello el BEP también se organizó en dos partes y fue un documento vivo durante todo el proceso. Como parte del equipo que iba a trabajar en este proyecto no tenía demasiada experiencia BIM, se decidió crear dos "carpetas compartidas":

- BEP_gestión-documentos

- BEP_modelo

en las que se introducían tablas Excel con las codificaciones por cada tema o elemento, con lo que más adelante se terminaría de dar forma al BEP. Esta idea era una forma de tener colaborativa la parte más funcional de este documento, de fácil consulta y evolución, con unos criterios de nomenclatura fijados inicialmente.

\section{$2.1 \quad$ Objetivo 1}

Como coordinadores del proyecto, se propuso un sistema de organización de la información en la nube, para hacer las funciones de entorno de datos común (CDE). De cara a gestionar los datos, se archivó, en este sistema la documentación y la información no gráfica y gráfica que no es el modelo.

Se establecieron cuatro fases principales: Trabajo (se verifica, revisa y aprueba) Compartido (se recibe la aprobación del cliente) Documentación para imprimir (se verifica) y $\underline{\text { Archivado }}$ [2].

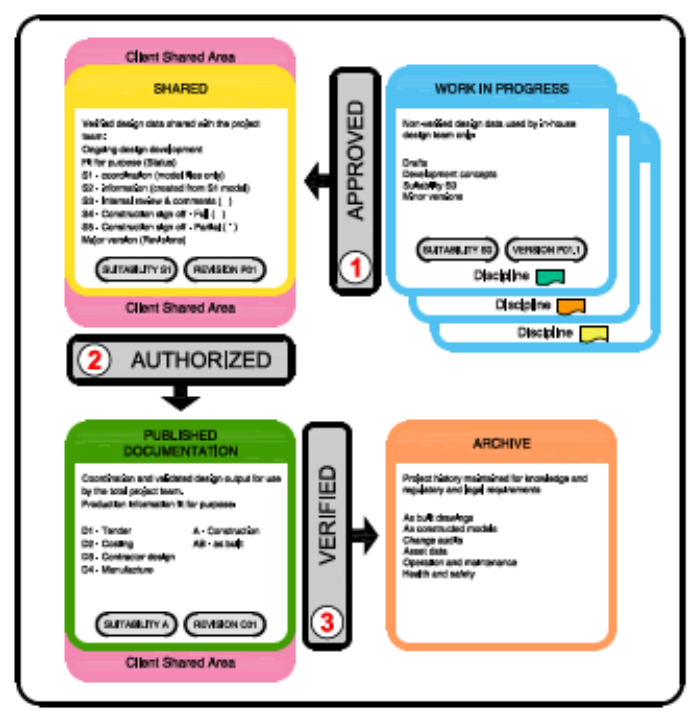

Fig. 2 Fases CDE .2014. BS PAS 1192-3:2014

La principal característica es que el CDE proporciona un medio colaborativo para compartir el trabajo. La información se guarda codificada y organizada con trazabilidad, se garantiza que la información es sólo generada una vez y es reusada por todo usuario que la necesite, 
cada archivo sólo lo puede modificar su autor conservando su propiedad, pero todos los datos son de libre acceso para todos, se indica la fase del archivo (en proceso, compartido, aprobado, verificado) de manera que todo está organizado y nada desaparece, reduciendo el tiempo de coordinar la información y consiguiendo gran control sobre las revisiones y versiones de la información[3].

El gestor documental utilizado permitía todos estos aspectos:

- Almacenaje y gestión de la información centralizada, mejorando la colaboración y el control de los documentos, las revisiones y versiones.

- Control de cambios para seguimiento de la trazabilidad de los documentos y controlar el acceso seguro a estos (fig. 4)

- Control de todas las actividades: creación, control y uso de documentación y emails.

- Acceso rápido y seguro a los documentos en función de los perfiles de acceso (coordinador, equipo, UTE, gerente, cliente...) con ubicación intuitiva.

Se utilizó el gestor Documental: Documentum, que es el que en ese momento estaba implantado de forma generalizada en la empresa, pero tiene el inconveniente de no visualizar archivos gráficos y menos aún modelos, por lo que se están buscando otras alternativas para un próximo proyecto BIM en UTE.

Este sistema también se aplicó a las comunicaciones, para que estas fueran más eficientes entre los diferentes agentes, realizándolas con la misma tipología de codificación y sin incluir adjuntos. Para ello desde CDE se escribe un correo electrónico como enlace, al seleccionar el archivo este genera un correo con un link, (fig. 3) de esta manera siempre se conectaba a la última versión, evitando errores de descoordinación y multiplicidad de archivos. Se consiguió implicar incluso al cliente, ya que debía aprobar la información del proyecto a través del CDE.

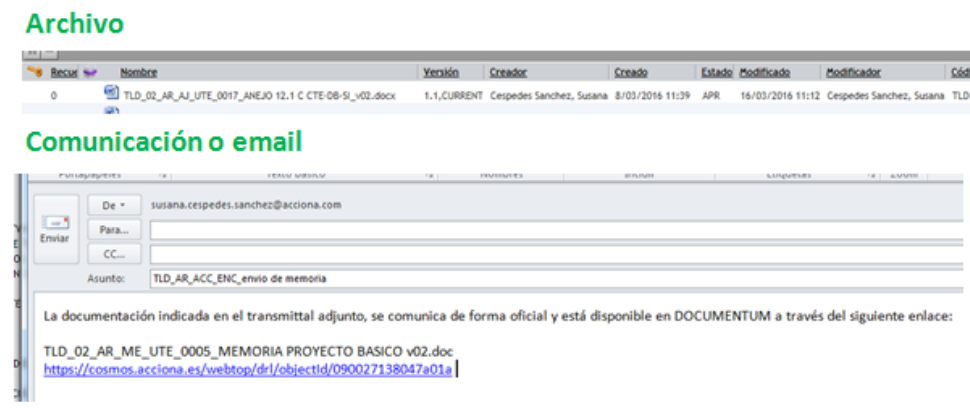

Fig. 3 Codificación de un archivo y una comunicación o email, 2016. Acciona Ingeniería 


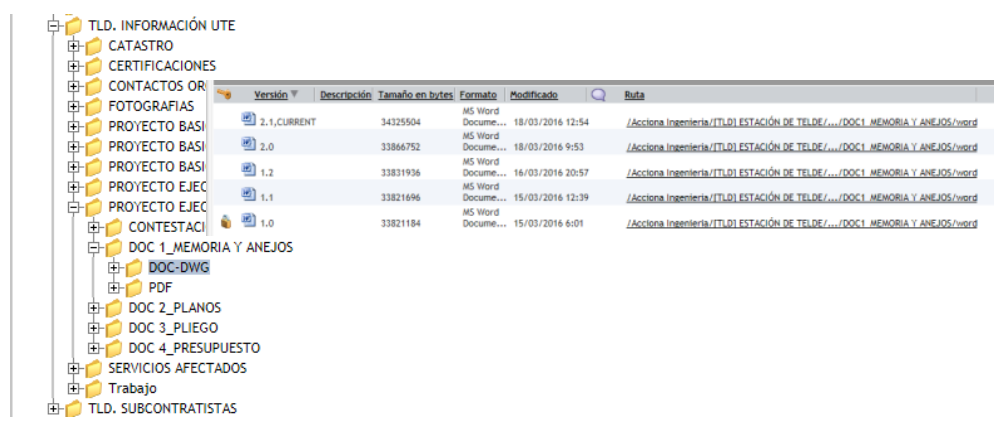

Fig. 4 Versiones de un documento 2016. Acciona Ingeniería

Los criterios para la codificación partían del sistema de Documentum aplicado en otra división de la empresa que no trabaja con BIM, un ejemplo de un documento seria:

$$
\text { TLD_02_AR_AJ_ACC_001_CTE-DBSI_v01 }
$$

- TLD: código de tres letras que identifica el proyecto, Telde en este caso

- 02: fase del proyecto en la que se encuentra, proyecto ejecución en este caso

- AR: disciplina del documento, dos letras: arquitectura en este caso

- AJ: tipo de documento, anejo en este caso

- 001: código que genera el propio gestor al introducir el archivo

- CTE-DBSI: descripción del documento, justificación a incendios en este caso

- v01: versión entregada de este documento, siendo v00 la primera, en esta caso es la segunda

Para las comunicaciones o emails, se emplea una codificación similar, mismos criterios pero adaptado a que es un elemento distinto, un ejemplo seria:

TLD_GD_ACC_UTE_códigos para emails

- TLD: código de tres letras que identifica el proyecto, Telde en este caso

- GD: disciplina del documento, dos letras: gestión documental en este caso

- ACC: clave del emisor, de tres letras, Acciona en este caso

- UTE: clave del receptor, de tres letras, UTE o socios en este caso

- códigos para emails, asunto del email 


\subsection{Objetivo 2}

El segundo objetivo consistió en realizar una cooperación avanzada, con un flujo activo de información y medidas interactivas [1] .Clasificación, organización y codificación de toda la parte técnica que nos correspondía, es decir el modelo con la arquitectura y las estructuras.

Se hizo una tabla Excel por cada uno de los aspectos comentados a continuación, indicando su nomenclatura, primero en una carpeta compartida y finalmente incluidas en el BEP:

- Subproyectos, con una letra inicial que distingue los que son de arquitectura (A_), estructuras (E_) o varios (sin letra). Creando vistas para controlarlos.

- Parámetros, seguían una serie de reglas, como: siempre en mayúscula, sin tildes, agrupándolos siempre en la misma zona, haciendo siempre parámetros compartidos (para evitar duplicidades y asegurar se pueden usar en todo caso). Se debía rellenar un Excel donde se indicaban todos los campos a rellenar y donde permitía analizar si no existía un parámetro reutilizable o realmente había que crearlo. (fig. 5)

- $\quad$ Niveles, para que se ordenen de mayor a menor y Rejillas, de izquierda a derecha

- Familias, TLD_MH_... (las iniciales del proyecto, el elemento, en este caso Muro de Hormigón)

- Tablas de planificación, (se explica en metodología)

- Marca de tipo, codificación necesaria para filtrar tablas y realizar tablas de acabados (comentado con más detalle en metodología)

- Código de montaje, no se incluyó código ya que no se exportaba a presto (comentado con más detalle en metodología)

- $\quad$ Navegador, tres iniciales por cada usuario. SCS..., por cada tipo de fase WIP (trabajo ) FP (planos definitivos)

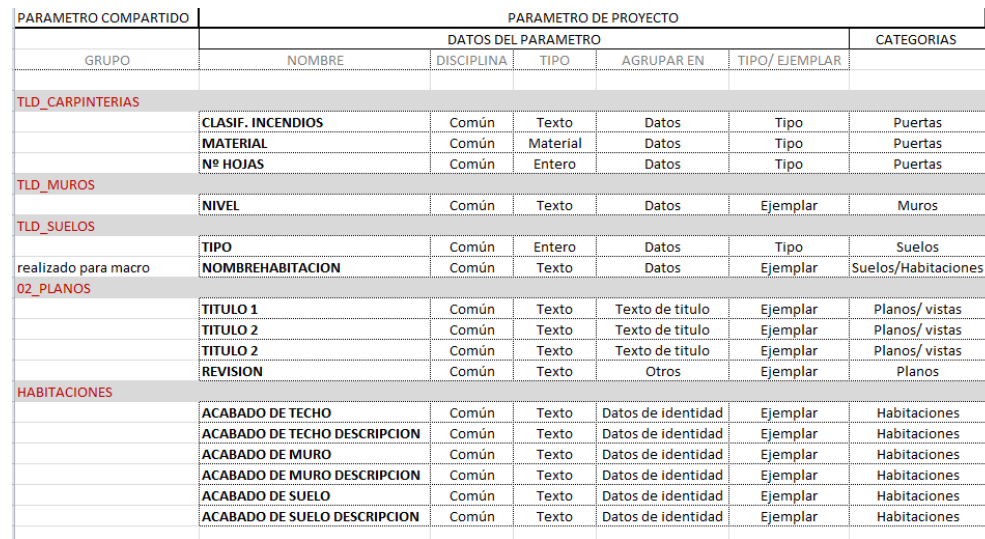

Fig. 5 Tabla de parámetros. 2016. Acciona Ingeniería 


\section{METODOLOGÍA}

Una vez el modelo empezaba a estar más completo, y con los criterios de codificaciones asignados, el control de toda esta información, se realizó con las tablas de planificación, que son una herramienta dinámica de trabajo y no solo una obtención inmutable de información, muy útiles para visualizar los distintos parámetros de cada elemento y sus codificaciones y chequear si están bien aplicados.

Las utilidades de éstas han sido varias:

- Correcciones y verificaciones, tanto de codificaciones como de otro tipo de información (alturas muros, clasificación a incendios en puertas...). Son herramientas muy eficaces para realizar modificaciones masivas al agrupar elementos en una misma línea.

- Realización y revisión de planos de acabados

- Realización de mediciones en Excel, que entregábamos al socio.

Se realizó un listado de las tablas sobre las que se iba a trabajar, codificando la nomenclatura de las tablas según su uso:

- tablas base o "key", ejemplos:(000_listas de planos, $001 \_$lista de vistas, 01)

- tablas de medición, ejemplo:(MED_ARQ_elementos, MED_STR_elementos)

- tablas para planos, ejemplo: FP_

- tablas para trabajo... ejemplo: WIP_STR

También se codificaron algunos parámetros que contenían las tablas. Se analizó las que eran necesarias y a qué categoría pertenecían, ya que según su categoría disponen de unos parámetros u otros. A partir de aquí, se veía qué parámetros nuevos se necesitaban y qué filtros, para que cada tabla tuviese toda la información que necesitábamos en cada caso.

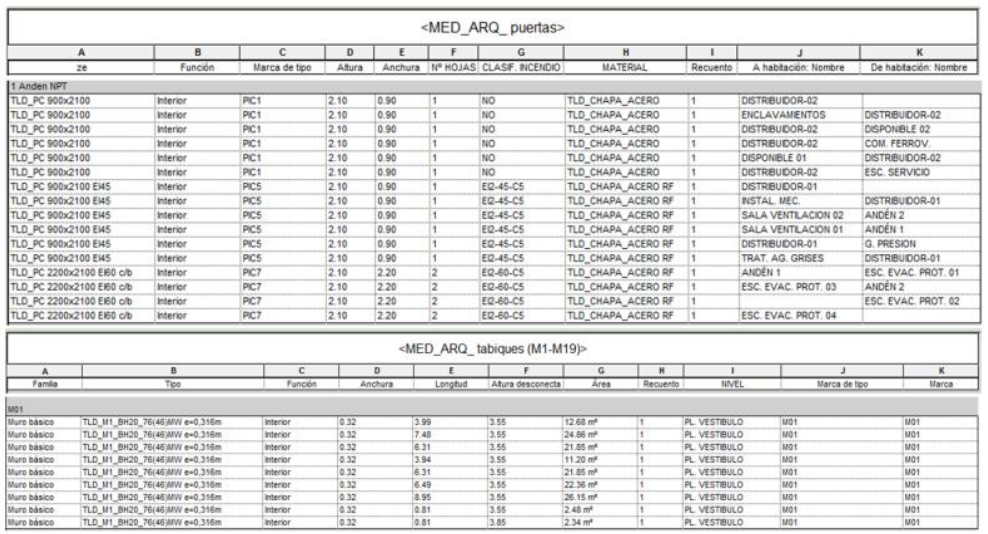

Fig. 6 Trabajo con tablas de planificación 2016. Acciona Ingeniería 
Por ejemplo, en puertas se tuvo que añadir más información para poder clasificarlas por número de hojas, por resistencia a incendios y por material y medirlas según los grupos creados. Para ello le añadimos parámetros nuevos.

El concepto es que las categorías de Revit no son equivalentes a las categorías de construcción, tratar de mantener esta relación es imposible: hay situaciones en las que un elemento constructivo requiere varias categorías de Revit y a la inversa, en que distintos elementos constructivos se encuentran en la misma categoría:

- Ciertos elementos constructivos, están formados por varias unidades de obra distintas y/o varias categorías revit distintas. Ejemplo $\rightarrow$ techos se necesitaron dos tablas (categoría techos: para falsos techos horizontales y categoría muros para tabicas o partes verticales para cambios de nivel).

- Por otra parte, varios elementos y/o unidades de obra están en una misma categoría Ejemplo $\rightarrow$ categoría: muros, elementos: revestimientos, tabiques, fachadas. Para poder solucionar esto se buscaron otros elementos de agrupación, como el parámetro de sistema marca de tipo, y se codificó adecuadamente, para hacer tres tablas de categoría muros, se aplicaron filtros:

- La de revestimientos tiene marcas de tipo que comienzan por R (R1: granito, R2: gres, R3: enfoscado...)

- La de tabiques por M (M01: bloque de hormigón de 12, M02: bloque de hormigón de 20, M03: pladur tipo...)

- La de muros de hormigón por $\mathrm{MH}$ (MH01: muro e:60cm, MH02: muro e:30cm...)

Las mediciones las unificaba el socio, que no trabaja con BIM y que además tenía una versión de presto antigua, que no reconocía la extensión del fichero de Presto generado a partir de Revit. Acciona Ingeniería se comprometió a enviar todas las mediciones de arquitectura en Excel, para ello se hicieron tablas de planificación o de cómputo de materiales de diversos temas: barandillas, fachadas (paneles hormigón prefabricado y paneles Viroc), muros (de hormigón y de bloque de hormigón), tabiques cartón-yeso puertas (todos los tipos: madera, chapa), falsos techos, cubiertas, suelos, revestimientos...Toda la medición se realizaba era a partir de tablas, la idea era que toda la medición de Acciona fuese realizada a partir del modelo, por lo que se modeló todo lo comprometido a medir

Pensando en tener cada medición completa, es decir para tener localizada cada una en su ubicación o en la habitación en la que se encuentra (así lo solicitaba el socio al ser la manera tradicional de presentar las mediciones) se vio que algunas tablas estaban incompletas ya que no tenían esa información. Algunas categorías disponen de esta opción, como las puertas, en cambio para suelos y techos hubo que realizar un parámetro nuevo asociado a una macro para solucionarlo, de esta manera la tabla de suelos y la de techos 
también incluían la habitación de cada medición, para evitar tener que ir informando uno a uno los elementos en el modelo.

La diversidad de tablas sirvió para revisar el proyecto, cambiando los filtros aplicados, se observaba que las casillas tuviesen la información ordenada, cuando no era así se detectaba el error y se corregía. Esas tablas llenas de información han sido exportadas a Excel y mandadas al socio para facilitarle su labor, ahorrándose medir.

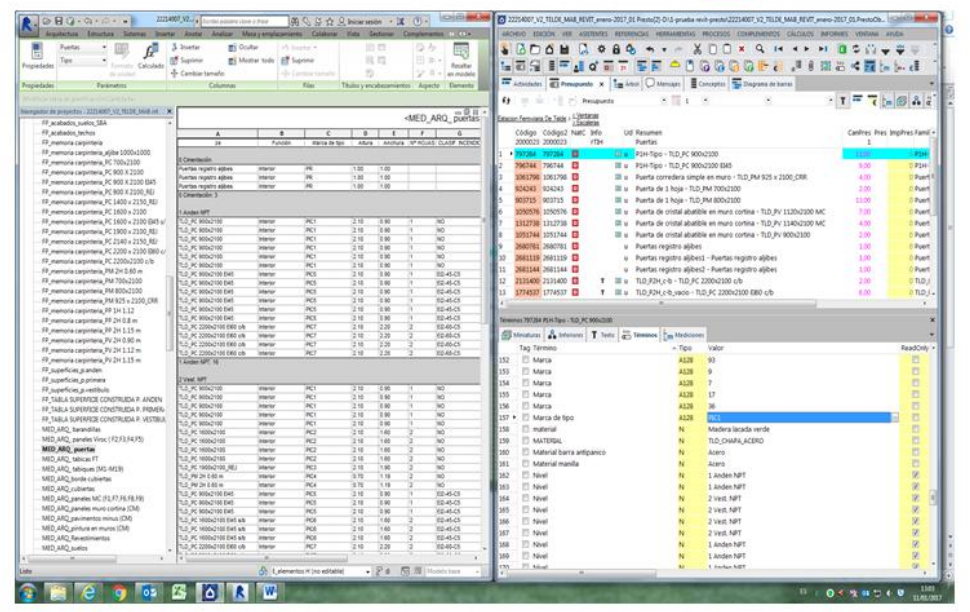

Fig 7. Comparación de resultados Revit-Presto.2016. Acciona Ingeniería

Para finalizar, como protocolo interno de calidad, para completar un proceso iniciado, y realizar unas lecciones aprendidas completas, Acciona Ingeniería decidió después de tener todas las tablas elaboradas, realizar la exportación de Revit a Presto, para chequear los resultados de las tablas de planificación con los Términos de Presto. La "marca de tipo" de Presto correspondía a la unidad de obra y a la medición de Revit. Gracias a la revisión de la medición en las tablas se tuvo la seguridad de que la medición final era correcta. (fig 7)

\section{CONCLUSIONES}

BIM implica estricta disciplina. Tanta información requiere estar completamente codificada (BEP) organizada (CDE) y revisada (tablas planificación). Siempre ha sido algo que garantizaba el éxito, pero con BIM es imprescindible.

Los aspectos importantes a tener en cuenta son:

- Codificar y documentar en el BEP: con visión global de la gestión de la información, se debe codificar de manera relacionada, por ello el método para su redacción, estará basado en dos aspectos que se relacionan entre ellos:

- Codificación. con criterios de nomenclaturas que sirvan para temas de gestión (carpetas en la nube, correos) e incluso el parámetro: tres iniciales para identificar proyecto, dos iniciales para identificar disciplina, tres iniciales para identificar emisor, dos números identifican versión.... 
- Realización de fichas que incluyen codificaciones de los aspectos más funcionales: archivos, emails, subproyectos, parámetros, niveles y rejillas, familias, tablas de planificación, marca de tipo, código de montaje. Los códigos que ayudaran al éxito de la exportación de las mediciones en Presto son códigos de montaje para identificar partidas y marcas de tipo para identificar y clasificar acabados y relacionar planos de acabados con mediciones.

- Gestionar a partir de un CDE apropiado (para documentos y para visualizar modelos, esto último es más difícil), creando un entorno de trabajo colaborativo adecuado: que alinea objetivos y comparte la información.

- Ayudarse con elementos de control o revisión como las tablas de planificación, en una tabla vemos todos los items codificados asociados a un elemento y permite comprobar su coherencia. Además tiene la virtud de servir para revisar, corregir y modificar toda la información del modelado, realizar acabados, sacar mediciones...

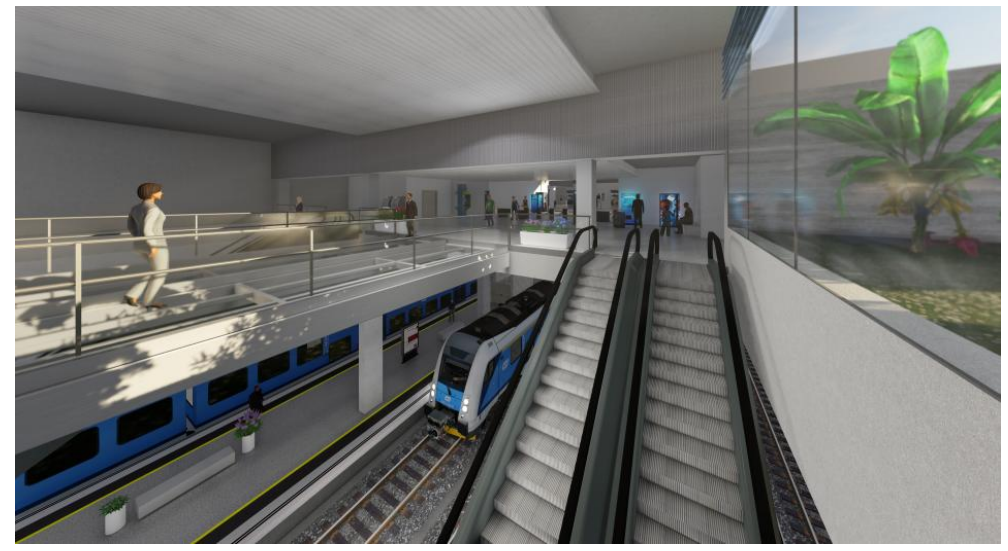

Fig. 8 Imagen del interior de la estación.2016. Acciona Ingeniería

\section{REFERENCIAS}

[1]. Guía de usuarios BIM. Doc 11. Gestión de un proyecto BIM

[2]. BS 1192:2007+A2:2010

[3]. PAS 1192-2:2013 


\section{INVENTORY BIM DE INFRAESTRUCTURAS DE LA UNIVERSIDAD DE SEVILLA}

\section{Gómez Rodríguez, Matías, Cortés Albalá, Isidro (1), Nieto Julián, Enrique (2)}

(1) Depto. de Expresión Gráfica e Ingeniería en la Edificación. ETSIE. Universidad de Sevilla. icortes@us.es

(2) Depto. de Expresión Gráfica e Ingeniería en la Edificación. ETSIE. Universidad de Sevilla. jenieto@us.es

\section{RESUMEN}

El sector AECO está inverso desde hace años en una reestructuración integral, una vez analizadas y asumidas por todos los agentes intervinientes las causas que motivaron la profunda crisis. En España, la construcción de nueva planta ha sufrido un importante estancamiento en los últimos años, con la excepción de las obras de reforma y el necesario mantenimiento del edificio, hechos que han provocado que ahora se apueste por el sostenimiento eficiente de las edificaciones, dirigiendo los recursos disponibles, tecnológicos y humanos, a la necesaria y adecuada gestión de las infraestructuras existentes.

La Universidad de Sevilla dispone de un inmenso parque de edificios e instalaciones que debe de mantener durante su ciclo de vida útil, aunque se encuentra con grandes dificultades para gestionarlos eficazmente. Con estos antecedentes, desde la Escuela Técnica Superior de Ingeniería de Edificación (ETSIE), se ha iniciado un protocolo de levantamiento de las infraestructuras del Campus de Reina Mercedes, empleando una metodología de trabajo sustentada en un modelo de información del edificio o BIM.

El caso expuesto se centra en el Edificio de Laboratorios de ETSIE, un edificio afectado por continuas readaptaciones, ya que fue diseñado inicialmente como aulario, y que no dispone de una documentación fiable del estado actual. El trabajo se inicia con un modelado 3D fidedigno de lo existente, a la vez se analiza los métodos de integración de procesos BIM en el levantamiento fiel del edificio. El procedimiento ha derivado en un modelo BIM "as-built" del edificio analizado, que se extenderá a todo el Campus Universitario Reina Mercedes con el fin de conformar un inventario de información de sus infraestructuras o "Inventory BIM".

El modelo BIM será base eficiente para las gestiones de mantenimiento y operaciones del edificio, dentro de la división del Facility Management, una disciplina destinada a la optimización de la explotación de inmuebles a lo largo de su vida útil.

Palabras clave: BIM, BIM As-built, Facility Management, Inventory BIM, Mantenimiento BIM

\section{ABSTRACT}

The AECO sector has been inverse for years in a comprehensive restructuring, once analyzed and assumed by all the intervening agents the causes that motivated the deep crisis. In Spain, the construction of new buildings has suffered a significant stagnation in recent years, with the exception of renovation works and the necessary maintenance of the 
building, so that now is committed to the efficient maintenance of buildings, directing the resources Available, both technological and human, to the necessary and adequate management of existing infrastructures.

The University of Seville has a huge park buildings and facilities must maintain during their lifecycle, although it is with great difficulty to manage them effectively. With this background, from the School of Building Engineering (ETSIE), has begun a protocol to lift the infrastructures of the Campus of Reina Mercedes, using a methodology of work based on a information model of the building or BIM.

The case is centered on the Laboratory Building of ETSIE, a building affected by continuous readaptations, since it was initially designed as a classroom, and does not have reliable documentation of the current state. The procedure has resulted in an "as-built" BIM model of the analyzed building, which will be extended to the entire Reina Mercedes University Campus in order to form an inventory of information on its infrastructures or "Inventory BIM".

The BIM model will be an efficient basis for the maintenance and operation of the building, within the Facility Management division, a discipline aimed at optimizing the operation of buildings.

Keywords: BIM, BIM As-built, Facility Management, Inventory BIM

\section{INTRODUCCIÓN}

Es indudable que el sector de la construcción es un componente muy significativo en la economía de un país, pero a pesar de ello, pueden resaltarse numerosos problemas en su desarrollo, al menos en lo que respecta a nuestro país, España. Entre estos problemas pueden destacarse: incumplimiento de los plazos, baja productividad, errores en los presupuestos, insuficiente calidad de los proyectos, altos índices de accidentes en comparación con otros sectores económicos, falta de gestiones adecuadas en mantenimiento de edificios, etc. Además, todo esto se suma a la crisis económica por la que estamos pasando, que popularmente es muy común atribuirla al declive de la denominada "burbuja inmobiliaria". Sin embargo, los orígenes de la deficiente situación de la construcción en España no son atribuibles únicamente a esta decadencia, o a la situación de crisis económica en la que se encuentra el país, sino que también tiene un componente estructural, sistémico, que arrastra desde mucho antes, en lo relativo al modelo productivo y competitivo en el que se basa. Dicho componente se refiere a la metodología de trabajo que se emplea en la construcción española, que desemboca en la generación de los problemas con los que se comenzaba el presente párrafo.

Building Information Modeling, conocido por sus siglas BIM, es una de las metodologías de trabajo que parecen llamadas a generar un cambio importante en la forma que actualmente se tiene de gestionar los proyectos en la construcción. Se trata de un incipiente modelo de proceso constructivo que puede resumirse como la generación de modelos de información tridimensionales tipo BIS [1], a partir de los cuales se gestiona tanto el diseño, como la 
construcción y el mantenimiento de los edificios, englobando todo el proceso constructivo y toda la vida útil del edificio, tal y como explica Begoña Fuentes en su libro Impacto del BIM en el proceso constructivo español [2]. Por consiguiente, este proceso, conforma un ciclo cerrado que comienza en el diseño del edificio (Fig. 1).

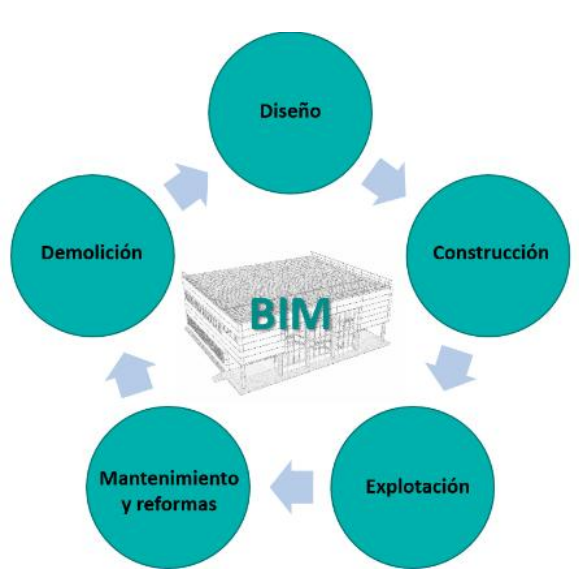

Fig. 1. Ciclo generado por la metodología BIM.

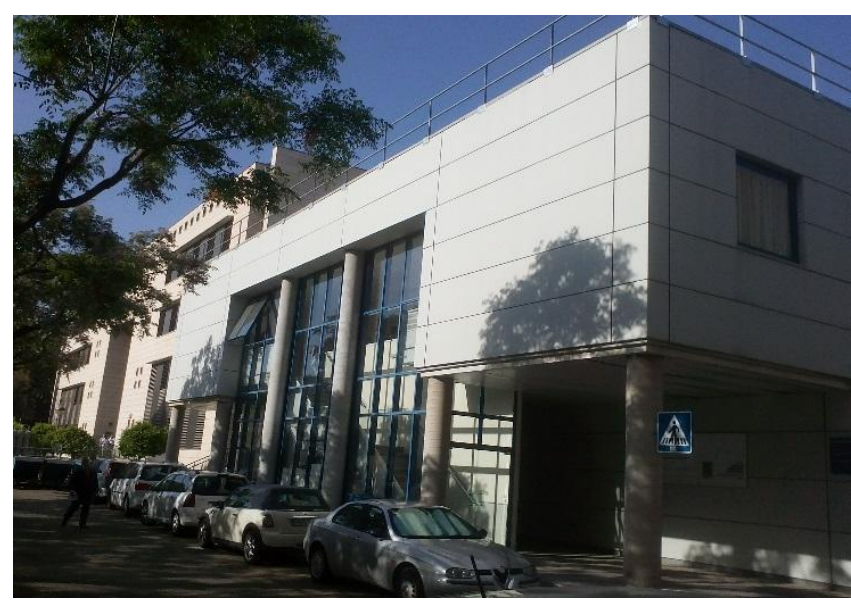

Fig. 2. Edificio de Laboratorios E.T.S.I.E. Fachada principal.

Si bien este sería el proceso normal, ¿qué sucede con los edificios ya construidos?, ¿podemos afrontar la vida útil del edificio, es decir su mantenimiento bajo el paraguas de esta metodología de trabajo?, es decir, cómo generamos un modelo BIM para gestionar el mantenimiento y explotación del edificio durante su vida útil, una vez construido y en uso. Esta idea ha sido la fuente de inspiración que ha generado la elaboración de esta investigación sobre la Integración de procesos BIM en el levantamiento de edificios existentes. Además, con este modelado se plantea la iniciativa de elaboración de un modelo BIM "as-built" de todo el complejo universitario, estableciendo dicha iniciativa como línea de desarrollo abierta, para que en posteriors etapas se siga desarrollando el repositorio de proyecto creado.

\section{ELECCIÓN DEL MODELO}

Debido al enfoque que se le ha pretendido dar al estudio, se ha elegido un edificio donde es clara la necesidad de aplicación de la disciplina conocida con el nombre de Facility Management, es decir, un edificio donde es necesario un mantenimiento adecuado y riguroso. Además, el edificio tipo que puede requerir dicha actuación debe tener una entidad suficiente para que tenga sentido la elaboración de una adecuada documentación de estado actual mediante generación de un modelo virtual de información BIM, de forma que sea rentable el importante esfuerzo económico, intelectual y de tiempo que ello supone. De ahí que se haya optado por el nombrado Edificio de Laboratorios de la Escuela Técnica Superior de Ingeniería de Edificación, propiedad de la Universidad de Sevilla. Éste, como todo edificio perteneciente a una institución de estas características, necesita contar con una correcta definición del estado actual del edificio y una impecable gestión y planificación de su 
mantenimiento, por lo que se ha considerado oportuno la elección del mismo como piloto de esta investigación. Con esta elección se pretende también enfatizar la responsabilidad que tiene la administración pública de liderar el desarrollo de este tipo de tecnologías como modelo de trabajo futuro para la correcta explotación y mantenimiento de edificios, que es una cuestión indispensable para que esta metodología comience a introducirse en el modelo de proceso constructivo actual.

\section{HIPÓTESIS DE PARTIDA}

Para abordar este proyecto se ha comenzado generando un caso hipotético en el que la E.T.S.I.E. pretendiese realizar una reforma en el edificio de estudio, con la intención de cambiar la imagen exterior del mismo y redistribuir las estancias interiores, para incorporación de nuevos usos. Para ello, sería necesaria la demolición de ciertos elementos del inmueble, tomándose en este caso como elementos a demoler: las placas de fachada, las particiones interiores, los solados y los falsos techos, así como la eliminación de las encimeras, los sanitarios y el resto de equipamientos especiales con los que cuenta el edificio. Esto genera la presunción de empleabilidad de la tecnología BIM como una herramienta adecuada para la elaboración de una definición y documentación de estado actual del edificio, de forma que pudiera darse solución a la reforma planteada y a la vez hacer posible una correcta gestión del mantenimiento y explotación del edificio.
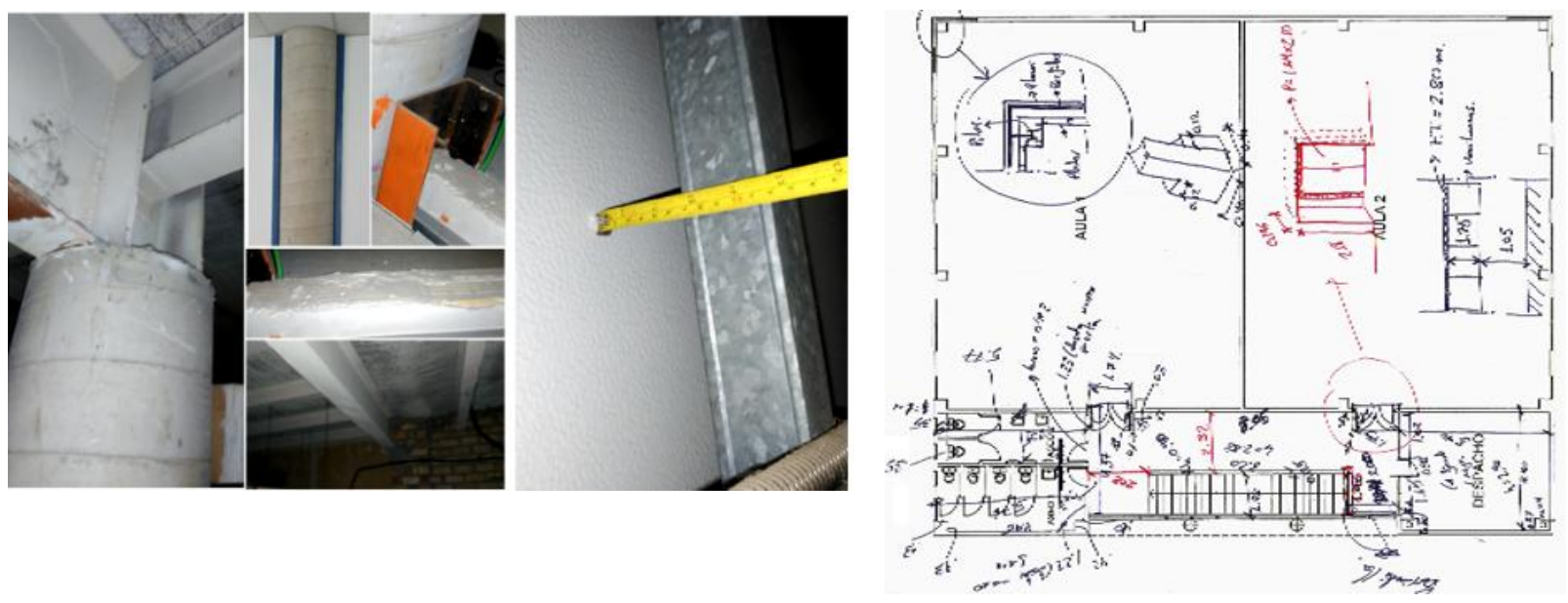

Fig. 3. Análisis, prospecciones visuales y catas.

Fig. 4. Croquis de anotaciones tras la medición

Además, se necesita generar una planimetría de estado actual formalizada del edificio, por lo que nos acogeremos a la hipótesis de que la metodología BIM permite y facilita dicha tarea. Finalmente, se desea poner a prueba también la extracción de mediciones y presupuestos a partir del modelo, estableciendo la conjetura de que es posible, para confirmarlo o desmentirlo con el desarrollo del proyecto. 


\section{OBJETIVOS}

Se pretende realizar un estudio pormenorizado y modelado BIM del Edificio de Laboratorios de la E.T.S.I.E. para la obtención de una información de estado actual fiable y precisa. Por consiguiente, hay que resaltar como objetivo principal el de obtener un modelo BIM que defina completa y rigurosamente el edificio, y que facilite el seguimiento del Facility Management en un edificio donde las gestiones de mantenimiento y explotación se consideran de vital importancia, debido al uso docente al que está destinado. Entre los objetivos específicos marcados encontramos:

- Establecer una metodología de trabajo para el estudio y análisis de edificios existentes y para la elaboración de sus modelos BIM de Estado Actual.

- Generación del propio modelo BIM de Estado Actual del edificio en cuestión, hasta un nivel de desarrollo LOD 300, de acuerdo con el documento Level of Development Specification [3], publicado en 2013 por el American Institute of Architects (AIA).

- Modelado del emplazamiento del edificio, mediante la creación de volúmenes de los edificios que componen el Campus Universitario Reina Mercedes, a nivel LOD 100, iniciando un modelo BIM "as-built" del complejo y promover esta iniciativa en la escuela.

- Elaboración de un efectivo sistema de gestión de información incluida en el modelo BIM.

- Obtención de la planimetría formalizada de estado actual del edificio en cuestión, del cual no se disponía de documentación fiable.

- Obtención de una medición y presupuesto de demolición a partir de la hipótesis de reforma implantada.

\section{METODOLOGÍA}

Se parte de la idea de crear una metodología de trabajo exportable a edificios de similares características. Por ello, se ha definido el proceso de trabajo a seguir para la elaboración del modelo BIM de Estado Actual del edificio en cuestión, permitiendo la extrapolación de esta metodología a otros posibles trabajos similares. El proceso constaría de varias fases, que se podrían concretar en las seis siguientes:

FASE 1: Análisis preliminar y recopilación de documentación. En esta fase se procederá a un primer estudio del edificio y a la recopilación de la información y documentación existente del mismo. Ésta es la forma de saber a qué nos enfrentamos y qué información habrá que sacar en un estudio pormenorizado posterior, para poder abordar el levantamiento del edificio. Por ello, en esta fase se analizarán: datos de partida, denominación y uso del inmueble, situación y emplazamiento, referencia catastral y demás datos del edificio.

FASE 2: Toma de datos y análisis constructivo del edificio. Esta fase consistirá en el análisis constructivo y toma de datos del edificio, obteniendo una definición completa del mismo a nivel constructivo, estructural y de acabados. Esta fase conlleva dos tareas: por un lado la medición del edificio y su entorno empleando equipos precisos (distanciómetro y escaner laser); y, por otro lado, una serie de prospecciones visuales y catas en el inmueble, 
analizándolo a partir de puntos estratégicos para realizar una definición constructiva y estructural previa al inicio del modelado.

FASE 3: Elaboración del modelo virtual del edificio. Para la realización de esta fase se atenderá a los consejos recogidos en el libro Integración transversal de materias de ingeniería de edificación. Vivienda colectiva [4], donde se expone el modelado de un edificio mediante la plataforma de modelado Allplan.

Se comenzará con la elección del software BIM, optando en este caso por la aplicación Allplan 2015, de Netmetschek. Hecho esto, se creará un nuevo repositorio de proyecto en la aplicación y se establecerá una correcta estructura de pisos, definiendo los planos proyectivos o planos estándares que se emplearían posteriormente para el modelado. Para ello se emplearán las cotas de nivel obtenidas en la Fase 2. A continuación se procederá a la organización del proyecto, definiendo las correspondientes reservas de archivos, tanto para el edificio en cuestión como para el resto de edificios del campus (Fig. 4). Tras la creación y organización del proyecto se procederá a definir el sistema de coordenadas y unidades de medida a emplear en el modelado, acorde con las especificaciones recogidas en el Documento 2 de las Guías uBIM: "Modelado de Estado Actual” [5].

\begin{tabular}{|c|l|}
\hline № de archivo & \multicolumn{1}{|c|}{ Contenido del archivo } \\
\hline $0-999$ & Edificio de Laboratorios de la ETSIE (Edificio a modelar) \\
\hline $0-99$ & Archivos auxiliares de trabajo (plantillas, leyendas, informes...) \\
$100-199$ & Planta Baja (Edif. Lab. ETSIE) \\
$200-299$ & Planta Primera (Edif. Lab. ETSIE) \\
$300-399$ & Cubierta (Edif. Lab. ETSIE) \\
$400-499$ & Cimentación (Edif. Lab. ETSIE) \\
$500-599$ & Alzados (Edif. Lab. ETSIE) \\
$600-699$ & Secciones (Edif. Lab. ETSIE) \\
\hline $1000-1999$ & Escuela Técnica Superior de Ingeniería de Edificación \\
\hline $2000-2999$ & Escuela Técnica Superior de Arquitectura \\
\hline $\mathbf{3 0 0 0 - 3 9 9 9}$ & Aulario compartido E.T.S.I.E. + E.T.S.A. \\
\hline $4000-4999$ & Pabellón polideportivo. \\
\hline $\mathbf{5 0 0 0 - 5 9 9 9}$ & Torre antiguo Pabellón de Córdoba. Expo 1929 \\
\hline $\mathbf{6 0 0 0 - 6 9 9 9}$ & Aparcamientos de la E.T.S.I.E. \\
\hline $\mathbf{7 0 0 0 - 7 9 9 9}$ & Centro de Investigación C.I.T.I.U.S. \\
\hline $\mathbf{8 0 0 0 - 8 9 9 9}$ & Aparcamientos C.I.T.I.U.S. \\
\hline
\end{tabular}

Fig. 4. Reservas de archivos en proyecto "Campus Reina Mercedes.

A partir de ahí, queda organizado y definido el proyecto en el que se trabajará, pero queda una cuestión imprescindible, que reside en la delimitación del nivel de precisión que se pretende obtener, así como las tolerancias dimensionales que pueden asumirse. Para ello se atenderá a lo especificado en la Guía uBIM n 2: "Modelado de Estado Actual", eligiendo como nivel de precisión el Nivel 3: Modelo de elementos de construcción. Este es el nivel máximo de precisión de un modelo de estado actual y para ello, la guía aporta una tabla con los contenidos que deben ser modelados, la cual se tendrá muy en cuenta en el desarrollo de esta fase. Por otro lado, hay que tener en cuenta que las estructuras de edificios antiguos están casi siempre deformadas, desplomadas o curvadas, o pueden tener cualquier otra inexactitud geométrica, observable también en el resto de elementos que conforma el edificio [6]. Por ello, es inoportuno luchar por una geometría absoluta en el modelado de un edificio existente no patrimonial, siendo necesario asumir algunas tolerancias. En este caso, al ser un edificio construido de menos 20 años, se tomarán como tolerancias dimensionales las recogidas en la guía: $10 \mathrm{~mm}$ en esquinas y aristas de elementos constructivos, $25 \mathrm{~mm}$ en superficies de muros o suelos, y $50 \mathrm{~mm}$ en estructuras viejas irregulares o cubiertas. 
Hecho esto, quedaría perfectamente organizado el repositorio creado, y los criterios a tener en cuenta para abordar el modelado, por lo que podemos iniciar el trabajo de construcción virtual del edificio. Se comenzará por realizar un modelado del emplazamiento donde se sitúa el edificio, para lo cual podrán emplearse los modelos tridimensionales de la Biblioteca de elementos 3D de Google: "3D Warehouse", en la cual se pueden obtener simples volúmenes tridimensionales de muchos edificios singulares, como ha sido nuestro caso. Con esto se obtiene el modelo de emplazamiento a nivel LOD 100 requerido por las Guías uBIM. En caso de no contar con los edificios deseados en la nombrada biblioteca, bastaría con levantar la geometría exterior básica de los edificios colindantes, y se cumpliría así el nivel LOD 100 (Fig. 5). Hecho esto, se procederá a la realización de la maqueta virtual del edificio elegido, teniendo en cuenta toda la información obtenida en las anteriores fases, y modelándolo tal y como se encuentra construido en la realidad, asegurándose de ello mediante los datos y fotos obtenidos en las visitas al edificio. En el caso que nos ocupa (procedimiento BIM), se generan elementos constructivos virtuales (muros, pilares, vigas, forjados, etc), los cuales permiten la incorporación de parámetros diversos, según los objetivos del trabajo a desarrollar, lo que convierte al modelo resultante en un contenedor de datos del edificio o "modelo de información del edificio" (Fig. 6).

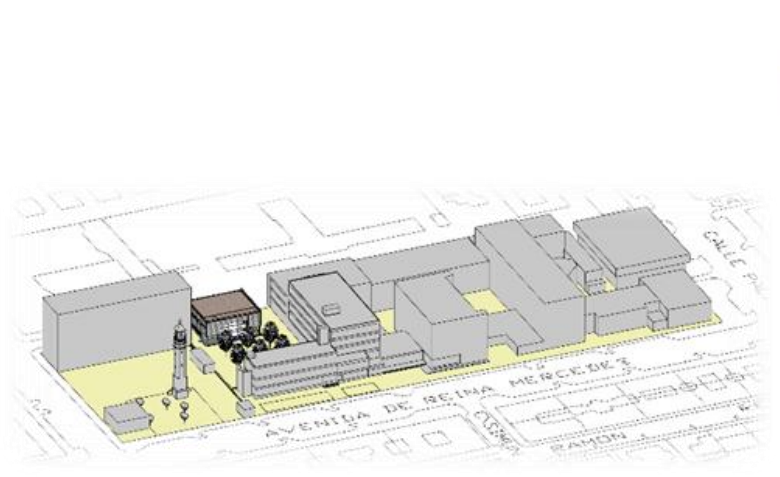

Fig. 5. Modelado del emplazamiento

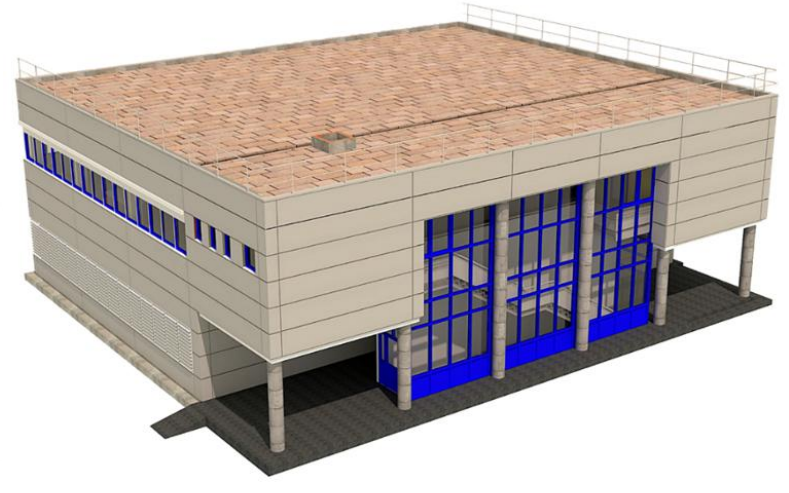

Fig. 6. Modelo BIM generado. Allplan 2015

Finalmente, para controlar y gestionar la información contenida en el modelo, así como su nivel de fiabilidad y algunas anotaciones de modelado, se elaborarán las fichas descriptivas de especificación BIM, algunas de las cuales que serán explicadas y mostradas en el apartado 6 de este documento.

FASE 4: Generación de planimetría de Estado Actual a partir del modelo. Esta fase está directamente relacionada con la anterior, puesto que durante la elaboración del modelo se tendrá que mostrar especial rigurosidad a la hora de definir los elementos que se vayan modelando, de forma que se permita la obtención de una documentación gráfica que responda a las prescripciones técnicas que un nivel de proyecto formalizado de estado actual debe cumplir para su correcta interpretación. Entiéndase como tal la descripción del modelo arquitectónico a una escala 1:50, y con utilización de correcta simbología y criterios de representación para permitir una descripción general del modelo. No obstante, en este trabajo se ha avanzado algo más al obtenerse detalles aclaratorios, de elementos destacados, a escala 1:20 (Fig. 7). 
FASE 5: Elaboración de medición y presupuesto a partir del modelo. Tras la hipótesis de reforma planteada, se desea obtener una medición y presupuesto de demolición de algunos elementos del edificio, esto se llevará a cabo en la presente fase, una vez completado el modelo BIM de Estado Actual. El proceso de obtención de mediciones y presupuestos a partir de un modelo BIM conlleva tres etapas o tareas. Por un lado se deben asignar partidas a los elementos del modelo, para lo cual se comenzará elaborando una base de precios con las partidas que nos compete, empleando en este caso el programa "Arquímedes", y obteniendo los precios a través del generador de precios de Cype. Dicha base de datos se empleará como catálogo en Allplan, asignando las partidas que se desean medir a los elementos correspondientes del modelo.

Una vez asignados los códigos de partida a lo que se desea medir, se procederá a la extracción de las mediciones de la maqueta virtual, lo cual se generará en este caso mediante un informe de medición (formato XCA). Por último, se importará el archivo XCA generado en la base de precios generada al principio, de forma que cada medición se vincula automáticamente con su correspondiente código de partida, obteniéndose el correspondiente presupuesto, en este caso de demolición.

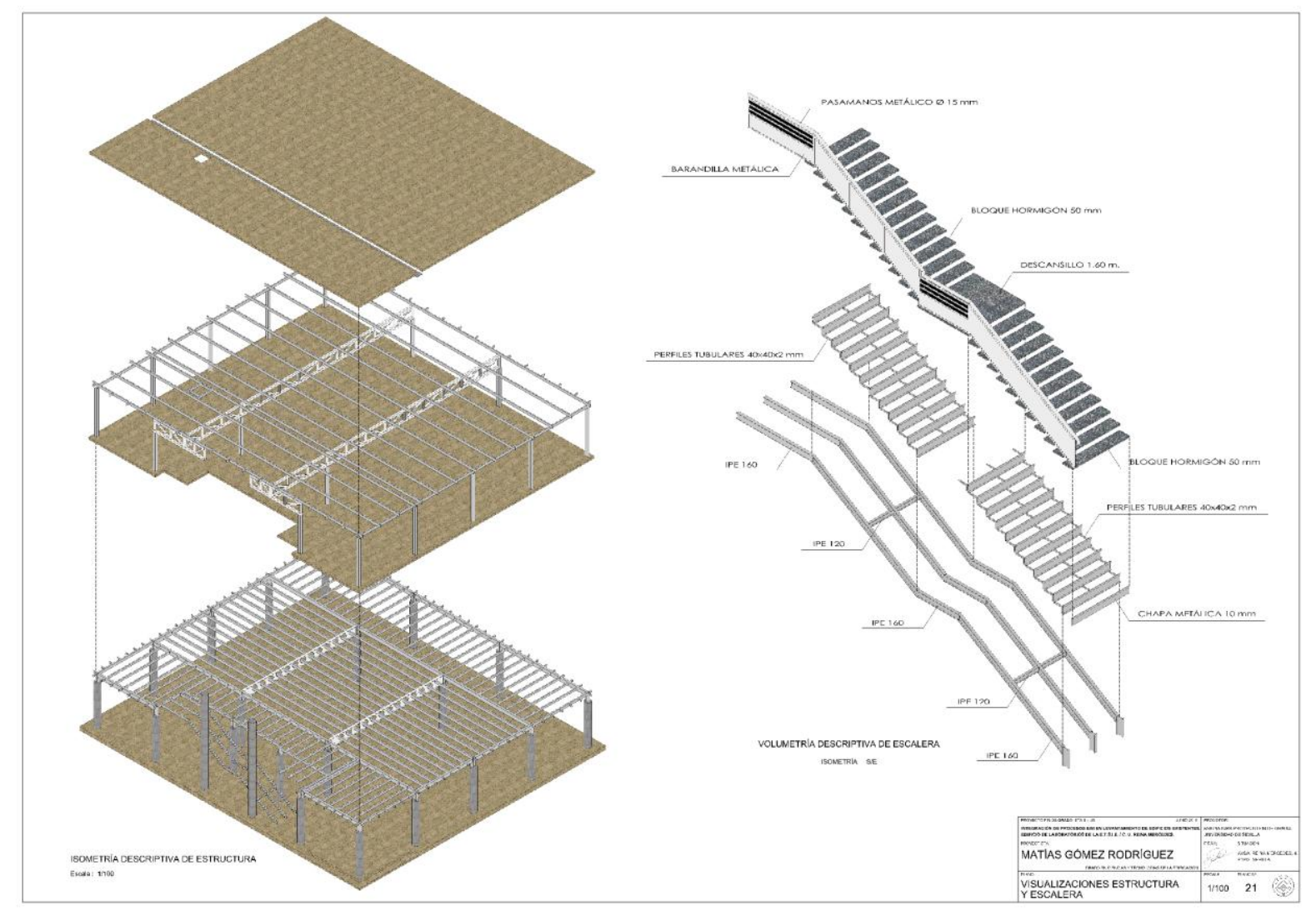

Fig. 7. Ejemplo de planimetría obtenida

Para esta última fase se empleará el software "Presto", y comprobar así su conectividad con Allplan (Fig. 8). 


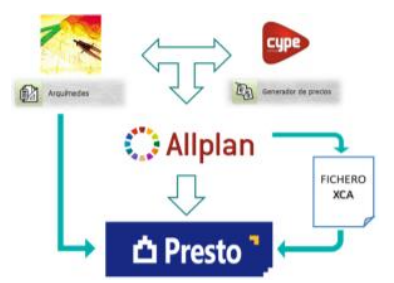

Fig. 8. Esquema del proceso de extracción de medición y presupuesto

FASE 6: Exportación del modelo a formatos de transferencia. Un vez finalizado el modelo BIM, es necesario exportarlo en formato de intercambio IFC, que es el estándar de intercambio de información normalizado para el traspaso de información del modelo en su proceso constructivo definido por esta metodología. En el caso expuesto, se ha obteniendo un archivo IFC para el modelo de emplazamiento, otro para el contenido arquitectónico (Architectural BIM) y otro con el contenido estructural del edificio (Structural BIM).

\section{FICHAS DESCRIPTIVAS DE ESPECIFICACIÓN BIM}

Un aspecto que se considera primordial en la realización de trabajos de este tipo es la creación de un sistema de control y gestión de la información contenida en el modelo BIM. Este sistema estará sustentado en Fichas Descriptivas de Especificación BIM, atendiendo a lo establecido en el Documento 3 de las Guías uBIM [5], "Diseño Arquitectónico", con la finalidad de describir los contenidos del modelo y explique la finalidad para la que se ha modelado, así como su grado de precisión y demás cuestiones que se estimen oportunas. Para nuestro caso, se ha ido un poco más allá de lo que establecen las Guías uBIM, generándose tanto la ficha descriptiva del modelo que requiere la guía, como otras fichas descriptivas para cada uno de los elementos o capítulos que lo componenten. De este modo, se ha procedido a la creación de plantillas para Fichas Descriptivas de Especificación $\mathrm{BIM}$, de forma que se cumplan los fundamentos teóricos recogidos en la citada Guía uBIM, y ampliándose con los parámetros y anotaciones que se han considerado oportunos. Además, se ha creado un repositorio para albergar todos los edificios que componen el Campus Universitario Reina Mercedes. Se pretende que las mismas puedan ser extrapoladas al abordaje de cualquier otro modelado BIM, ya sea de estado actual (existente) o de nuevo diseño de edificio.

\begin{tabular}{|c|c|c|c|c|}
\hline FICHA № & 1 & \multicolumn{3}{|c|}{ RESUMEN DE ESPECIFICACIÓN BIM. MODELO EMPLAZAMIENTC } \\
\hline \multicolumn{3}{|c|}{ TÍTULO / PROYECTO } & \multicolumn{2}{|c|}{ "CAMPUS REINA MERCEDES" } \\
\hline \multicolumn{3}{|c|}{ SOFTWARE BIM / VERSIÓN EMPLEADA } & \multicolumn{2}{|c|}{ ALLPLAN 2015} \\
\hline \multicolumn{3}{|c|}{ FINALIDAD DEL PROYECTO } & \multicolumn{2}{|c|}{$\begin{array}{l}\text { GESTIÓN DEL MANTENIMIENTOY } \\
\text { OPERACIONES DEL CAMPUS }\end{array}$} \\
\hline \multirow{3}{*}{\multicolumn{2}{|c|}{$\begin{array}{c}\text { EDIFICIO DE } \\
\text { LABORATORIOS } \\
\text { DE LA E.T.S.I.E. } \\
\text { (*FICHA NN22) }\end{array}$}} & NIVEL DE DESARROLLO & LOD 300 & \\
\hline & & RESERVA DE ARCHIVOS & $0-999$ & \\
\hline & & ÚLTIMA ACTUALIZACIÓN & $24 / 06 / 15$ & \\
\hline \multirow{3}{*}{\multicolumn{2}{|c|}{$\begin{array}{l}\text { EDIFICIO } \\
\text { PRINCIPAL } \\
\text { E.T.S.I.E. }\end{array}$}} & NIVEL DE DESARROLLOO & LOD 100 & \\
\hline & & RESERVA DE ARCHIVOS & $1000-1999$ & \\
\hline & & ÚLTIMA ACTUALZZACIÓN & $24 / 06 / 15$ & \\
\hline \multirow{3}{*}{\multicolumn{2}{|c|}{$\begin{array}{l}\text { EDIFICIO } \\
\text { PRINCIPAL } \\
\text { E.T.S.A. }\end{array}$}} & NIVEL DE DESARROLLO & LOD 100 & \\
\hline & & RESERVA DE ARCHIVOS & $2000-2999$ & \\
\hline & & ÚLTIMA ACTUALIZACIÓN & $24 / 06 / 15$ & \\
\hline \multirow{3}{*}{\multicolumn{2}{|c|}{$\begin{array}{l}\text { AULARIO } \\
\text { COMPARTIDO } \\
\text { E.T.S.I.E. + } \\
\text { E.T.S.A. }\end{array}$}} & NIVEL DE DESARROLLO & LOD 100 & \\
\hline & & RESERVA DE ARCHIVOS & $3000-3999$ & \\
\hline & & ÚLTIMAACTUALZZACIÓN & $24 / 06 / 15$ & \\
\hline
\end{tabular}

Fig. 9. Ficha Resumen de Especificación BIM

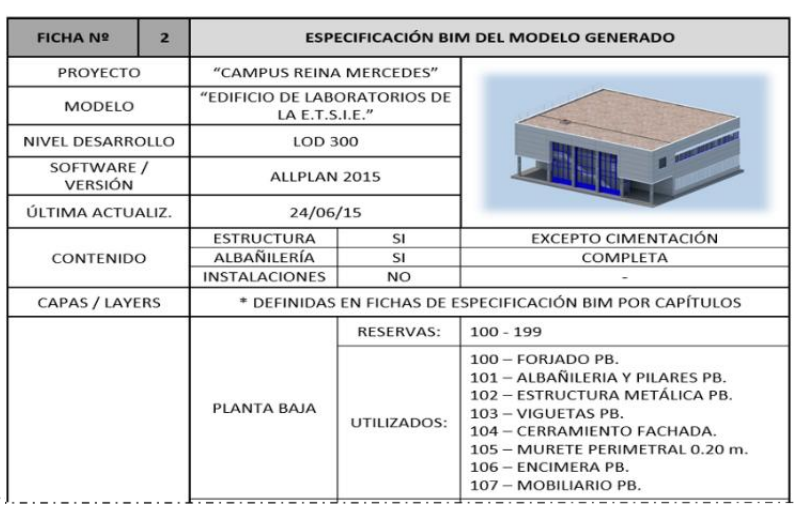

Fig. 10. Ficha de Especificación del modelo 
El resultado de ello ha sido, por un lado la ficha resumen referente al repositorio completo que ha sido generado como iniciativa de elaboración del Modelo BIM "As-built" del campus (Fig. 9), donde se define el nivel de desarrollo y la fecha de actualización de cada edificio que compone el complejo universitario. Por otro lado cabe destacar la Ficha de Especificación BIM del modelo generado (Fig. 10), con la información requerida por las guías uBIM. Y por último, se hace especial mención a la creación de las denominadas fichas de especificación BIM por capítulos, que gestionan más detalladamente la información contenida en cada uno de los capítulos o partes del edificio. En la Fig. 11 se puede observar un ejemplo del modelo de ficha creado para ello, concretamente la ficha referente a la estructura del edificio.

\begin{tabular}{|c|c|c|c|c|}
\hline FICHA NS & 7 & \multicolumn{2}{|c|}{ ESPECIFICACIÓN BIM POR CAPÍTULOS } & ESTRUCTURA \\
\hline \multicolumn{2}{|c|}{ PROYECTO } & "CAMPUS REINA MERCEDES" & ANIMACI & MODELO: \\
\hline \multicolumn{2}{|c|}{ MODELO } & $\begin{array}{l}\text { "EDIFICIO DE LABORATORIOS } \\
\text { DE LAE.T.S.I.E." }\end{array}$ & & \\
\hline \multicolumn{2}{|c|}{$\begin{array}{l}\text { CAPÍTULO / } \\
\text { ELEMENTO }\end{array}$} & $\frac{\text { PILARES, VIGAS, VIGUETAS Y }}{\text { CERCHAS }}$ & & \\
\hline \multicolumn{2}{|c|}{ NIVEL DESARROLLO } & LOD 300 & & \\
\hline \multicolumn{2}{|c|}{$\begin{array}{l}\text { SOFTWARE / } \\
\text { VERSIÓN }\end{array}$} & ALLPLAN 2015 & & \\
\hline \multicolumn{2}{|c|}{ ÚLTIMA ACTUALIZ. } & $24 / 06 / 15$ & & \\
\hline \multirow{3}{*}{\multicolumn{2}{|c|}{$\begin{array}{l}\text { ARCHIVOS DE } \\
\text { TRABAJO }\end{array}$}} & PLANTA BAJA & & \\
\hline & & PLANTA PRIMERA & & \\
\hline & & PLANTA CUBIERTA & & \\
\hline \multicolumn{2}{|c|}{$\begin{array}{c}\text { CAPAS / } \\
\text { LAYERS AUPLAN }\end{array}$} & \multicolumn{3}{|c|}{ AR_PI / AR_PI_H / AR_VI / AR_PAR } \\
\hline \multicolumn{2}{|c|}{$\begin{array}{l}\text { ASISTENTE DE } \\
\text { CREACIÓN_ALLPLAN }\end{array}$} & \multicolumn{3}{|c|}{$\begin{array}{l}\text { HERRAMIENTA "PILAR", HERRAMIENTA "VIGA" Y FUNCIÓN } \\
\text { "CONSTRUCCIÓN GENERAL EN MADERA-ACERO" }\end{array}$} \\
\hline \multicolumn{2}{|c|}{$\begin{array}{l}\text { CATEGORÍA DE } \\
\text { REFORMA ALLPLAN }\end{array}$} & \multicolumn{3}{|c|}{ ATRIBUTO “ELEMENTO EXISTENTE” } \\
\hline
\end{tabular}

Fig. 11. Ficha de Especificación por capítulo

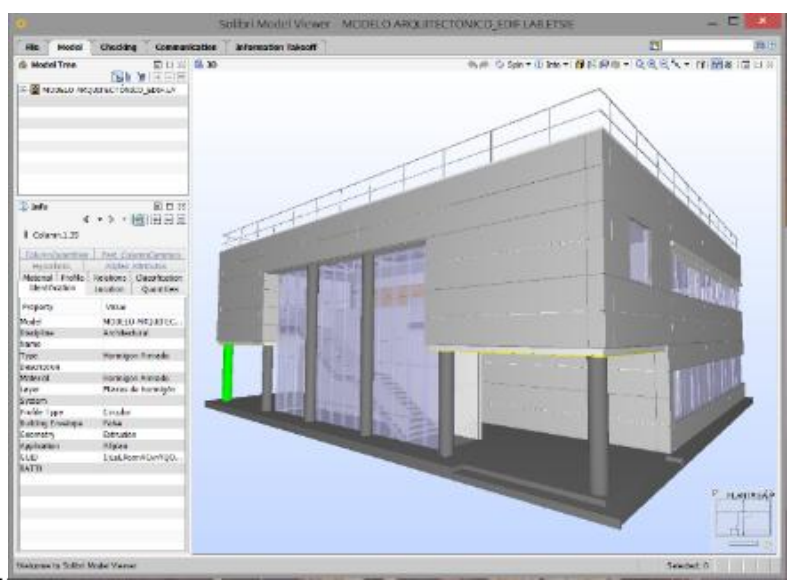

Fig. 12. Visualizaciones Architectural BIM. Format IFC

\section{RESULTADO}

Respecto de los resultados del trabajo hay que decir que se ha seguido rigurosamente con lo establecido previamente en la metodología planteada, obteniendo en cada fase los objetivos propuestos. Respecto de las fases 1 y 2 , referentes al estudio y análisis del edificio, hemos obtenido una completa memoria constructiva que recoge toda la información emanada de las distintas etapas de análisis. Un documento donde se explica de forma escrita la definición completa del edificio, desde su sustentación hasta sus instalaciones, pasando por su estructura, sistema de envolvente, revestimientos, acabados, etc.

Para el desarrollo de la Fase 3, considerada la más importante del proceso, se ha seguido rigurosamente lo planteado en la metodología, cumpliendo en todo momento los establecido en las Guías uBIM, referente al nivel de precisión del modelo, las tolerancias dimensionales, etc. Con ello se ha obtenido el modelo BIM que se buscaba, con toda la información de definición del edificio integrada en el mismo para definir el edificio tal y como se encuentra en la realidad. Este es el llamado modelo BIM de Estado Actual al que nos referíamos en los objetivos. Pero llegados a este punto surge una duda: ¿cómo se cuantifica y se gestiona esta información integrada en el modelo?, puesto que se debe crear un repositorio que pueda ser transferido a otros usuarios y que pueda ser entendido y utilizado por los mismos. 
Para dar respuesta a esto surgen las que hemos denominado como Fichas Descriptivas de Especificación BIM.

La Fase 4 hacía referencia a la extracción de la planimetría formal de estado actual a partir del modelo, por lo que, siguiendo con el proceso metodológico planteado, los resultados son más que evidentes. Se ha obtenido una planimetría completa a escala 1:50 y detalles constructivos a escala 1:20, generando así la deseada planimetría formal de estado actual, que se planteaba como objetivo. Por consiguiente, se obtienen planos de mobiliario, usos y superficies, alzados, planos de estructuras, planos de acabados, detalles constructivos y visualizaciones 3D del edificio, para aclaración de algunas partes peculiares, como son la fachada o la escalera principal. En la siguiente fase $\left(n^{\circ} 5\right)$, se ha obtenido la medición y presupuesto de demolición de la hipótesis de reforma planteada, con la posibilidad de exportar en diferentes formatos (PDF, XLS, BC3), y su interoperabilidad con aplicaciones de presupuestos.

Finalmente, el desarrollo de la Fase 6 pone fin al proceso de trabajo establecido en este trabajo para abordar el caso práctico planteado, dando paso a las correspondientes conclusiones del estudio. En esta última fase se obtienen los diversos archivos de transferencia en formato IFC (Architectural BIM, Structural BIM y Modelo de emplazamiento), además de un archivo .PDF-3D del edificio, creado para una mejor visualización del mismo. Además, se ha decidido realizar y conservar también el repositorio en formato PRJ, que es el formato nativo de Allplan. De esta forma se pretende hacer más sencilla la posterior utilización de este modelo para una segunda fase de la investigación, para seguir con la elaboración del modelo BIM "as-built" de todo el campus, que era otro de los objetivos del proyecto. Hay que resaltar que el archivo IFC ha sido abierto desde la aplicaciones BIM de Graphisoft, ArchiCAD 20, con una transferencia de datos totalas en lo referente a elementos paramétricos. La visualización del modelo $3 \mathrm{D}$ ha sido total, sin pérdida de la geometría generada desde el software nativo. En la actualidad se está gestionando las instalaciones del edificio desde el software ArchiCAD, en un nuevo Proyecto Fin de Grado enfocado al Facility Management sustentado en un modelo BIM

\section{CONCLUSIONES}

La tecnología BIM surge en principio como idea para el diseño de edificios de nueva planta, de forma que el modelo generado acompañe al edificio durante su construcción y después durante toda su vida útil. No obstante, con la realización de este trabajo se pretendía poner a prueba otra de las facetas que puede tener dicha metodología, consistente en la obtención de modelos BIM de edificios una vez construidos, para utilización durante su explotación. Como conclusión a esta empleabilidad de la tecnología BIM, es necesario afirmar que sólo será rentable cuando el edificio cuente con una entidad importante y donde las gestiones de Facility Management sean imprescindibles, ya que la obtención de un BIM de Estado Actual sin contar con una documentación de partida fiable que lo defina requiere un esfuerzo importante, tanto intelectual como económico, puesto que son notables las horas que se necesitan para su estudio, definición y modelado. 
Sin embargo, en lo que respecta al caso práctico abordado en este trabajo, tratándose de un edificio institucional y de uso docente, se considera satisfactoria la generación de un modelo BIM de Estado Actual, puesto que con ello se define y se documenta correctamente un edificio del que no se tenía constancia de información alguna, conteniéndose toda la información constructiva en un solo repositorio, y facilitando bastante las gestiones de mantenimiento y operaciones.

Con respecto a los cambios que esta metodología aportará al proceso constructivo español, podemos resaltar que es previsible la desaparición de los actuales niveles de proyecto (Proyecto Básico, de Ejecución y “As-built”), para ser sustituidos por los nuevos niveles LOD (100 - 500), u otros de similares contenidos adaptados al mercado español, que declaran el nivel de desarrollo y fiabilidad de un BIM.

Por último hay que enfatizar la incipiente necesidad de una mayor formación en esta metodología de trabajo de los profesionales del sector AEC, puesto que el nuevo modelo de proceso constructivo gira en torno a una tecnología más eficiente. Además, supone la asimilación de un proceso de trabajo multidisciplinar, con la implementación de nuevos perfiles profesionales como el BIM Director, BIM Manager, BIM coordinator, BIM Designer, BIM Modeller, etc.

\section{REFERENCIAS}

[1] BIS hace referencia a "Building Information Systems", es decir, Sistemas de Información de la Edificación, en los cuales se basa la metodología BIM.

[2] Fuentes Giner, B. (2014). Impacto de BIM en el proceso constructivo español, p. 142, 180. Valencia. EUBIM

[3] BIMforum \& AIA. (2013). Level of Development Specification.

[4] Cortés Albalá, Isidro et alii. (2009). Integración transversal de materias de ingeniería de edificación. Vivienda colectiva, p. 17-24. Sevilla. OCE, S.A.

[5] BuildingSMART Spanish Chapter. (2014). Capítulo 2. Modelado de Estado Actual. Guías de usuarios BIM. Iniciativa uBIM. España. BUILDING SMART.

[6] Julián, N., Moyano, J., Rico Delgado, F., \& Antón García, D. (2013). La necesidad de un modelo de información aplicado al patrimonio arquitectónico. In 1er Congreso Nacional BIM-EUBIM 2013, Valencia, 24 y 25 de mayo. 

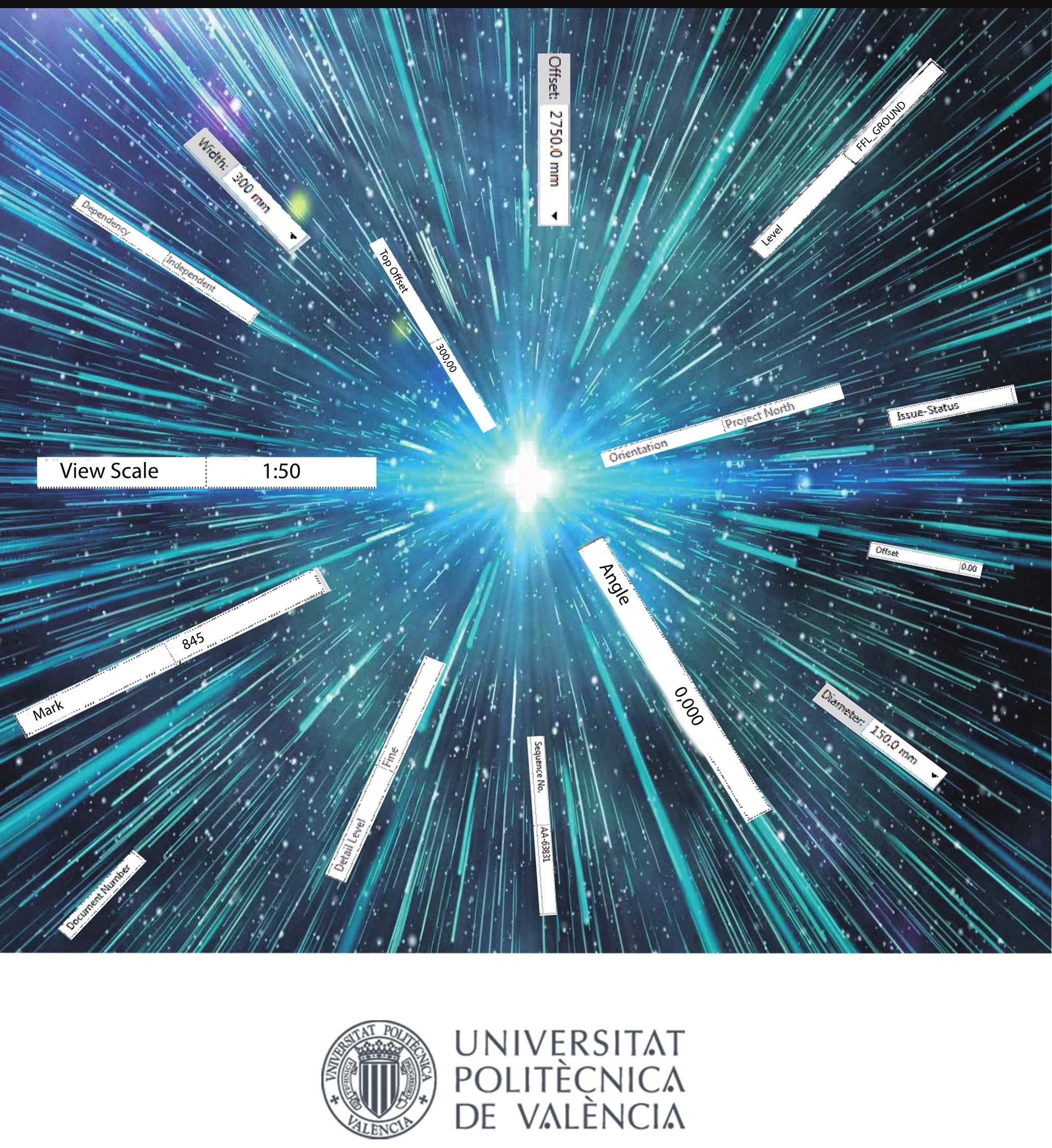